Rechte des Dritten schützt (s. beispielhaft den Fall 3 in: Eisentraut, Fälle zum Verwaltungsrecht, 2020). Ist der Verwaltungsakt aufgrund einer Norm rechtswidrig, die nicht dem Schutz der Rechte des klagenden Dritten dient, ist der Verwaltungsakt zwar rechtswidrig, aber die Klage dennoch unbegründet. ${ }^{1346}$ Teilweise werden Drittanfechtungsklagen deshalb auch nur aus dem Blickwinkel der drittschützenden Norm geprüft (dazu näher Rn. 548).

831 Hausarbeitswissen: Entsprechend zu den Ausführungen in der Klagebefugnis (s. Rn. 285) ist bei der Verbandsklage auch keine Verletzung subjektiver Rechte erforderlich. ${ }^{1347}$ Hintergrund ist das Europäische Unionsrecht, das den deutschen Gesetzgeber teilweise zu einer Abkehr von dem Prinzip der Verletztenklage gezwungen hat. ${ }^{1348}$

\title{
IV. Klausurrelevante Ermächtigungsgrundlagen und ihre Prüfung (Tobias Brings-Wiesen; Nikolas Eisentraut; Sebastian Eickenjäger; Felix Steengrafe; Sebastian Piecha; Mariamo Katharina Ilal)
}

Die Prüfung bestimmter Ermächtigungsgrundlagen muss in Prüfungssituationen regelmäßig beherrscht werden. Dazu zählen insbesondere die Ermächtigungsgrundlagen des Allgemeinen Verwaltungsrechts (Rn. 832ff.), des Polizeiund Ordnungsrechts (Rn. $1000 \mathrm{ff}$.), des Versammlungsrechts (Rn. 1141 ff.), des Bauordnungsrechts (Rn. 1222ff.), des Kommunalrechts (Rn. 1252ff.) sowie des Verwaltungsvollstreckungsrechts (Rn. 1292ff.).

\section{Ermächtigungsgrundlagen des Allgemeinen Verwaltungsrechts (Tobias Brings-Wiesen)}

832 Die Anfechtungsklage gemäß § 42 I Var. 1 VwGO ist das „schärfste Schwert“ des rechtsschutzbegehrenden Bürgers gegen einen Verwaltungsakt, der ihn in seinen subjektiven Rechten verletzt. Zum einen ist das Aufhebungsurteil des Gerichts unmittelbar rechtsgestaltend und beendet die Wirksamkeit eines Verwaltungsakts i.S.v. § 43 II VwVfG, ohne dass es eines erneuten Tätigwerdens der Verwaltung bedürfte (s. dazu Rn. 6). Zum anderen kann es in Rechtskraft erwachsen $^{1349}$ und somit im Regelfall endgültig für Rechtssicherheit und Rechtsfrieden sorgen. ${ }^{1350}$

1346 Hufen, Verwaltungsprozessrecht, 11. Aufl. 2019, § 25 Rn. 43. 1347 Hufen, Verwaltungsprozessrecht, 11. Aufl. 2019, § 25 Rn. 49.

1348 Näher Maurer/Waldhoff, Allgemeines Verwaltungsrecht, 19. Aufl. 2017, § 8 Rn. 16.

1349 S. zur Rechtskraft Schenke, Verwaltungsprozessrecht, 16. Aufl. 2019, Rn. 615 ff.; Würtenberger/Heckmann, Verwaltungsprozessrecht, 4. Aufl. 2018, Rn. $294 \mathrm{ff}$. 
Für Prüfungssituationen ist die Anfechtungsklage reizvoll, weil sie mit dem Verwaltungsakt die geläufigste Handlungsform zum Gegenstand hat. Sie erlaubt es dem Prüfer, in vielerlei Hinsicht verwaltungsrechtliches Grundverständnis abzufragen.

Da die maßgeblichen materiellen Vorgaben für Verwaltungshandeln sich ganz überwiegend aus dem sachnäheren Fachrecht ergeben, kennt das allgemeine Verwaltungsrecht selbst nur sehr wenige Ermächtigungsgrundlagen. Dies sollte jedoch keineswegs zu dem Trugschluss verleiten, diese seien nicht oder auch nur weniger prüfungsrelevant. Da in ihnen die vormals ungeschriebenen allgemeinen Grundsätze des Verwaltungsrechts eine Normierung gefunden haben, sind sie Ausgangspunkt eines Grundverständnisses für die systematischen Zusammenhänge des Verwaltungsrechts. Selbst soweit sie nicht unmittelbar anwendbar sind, können die in ihnen zum Ausdruck kommenden Wertungen im Rahmen der Prüfung von Spezialnormen des besonderen Verwaltungsrechts Orientierung bieten.

Vor diesem Hintergrund ist es elementar, die für Prüfungen mit Abstand relevantesten Konstellationen der Anfechtungsklagen im allgemeinen Verwaltungsrecht $\mathrm{zu}$ verinnerlichen. Die folgenden Ausführungen widmen sich daher dem gesamten Themenkomplex der behördlichen Aufhebung von Verwaltungsakten gemäß §§ 48 ff. VwVfG sowie - in der gebotenen Kürze - der Anfechtungsklage gegen die Zusicherung auf Erlass eines Verwaltungsakts mit Drittwirkung.

\section{a) Die behördliche Aufhebung eines Verwaltungsakts gemäß $\S 48 \mathrm{f}$. VwVfG}

Die Prüfung der Aufhebung von Verwaltungsakten gemäß §§ 48f. VwVfG ist einer 836 der Prüfungsklassiker. Ihr sollte daher in der Prüfungsvorbereitung besondere Aufmerksamkeit zuteilwerden. Die folgenden Ausführungen beschränken sich zwar expressis verbis auf die $\S \S 48 \mathrm{f}$. VwVfG. Sie behalten jedoch wegen der weit überwiegend bestehenden Wortgleichheit auch für die VwVfGe der Länder ihre Gültigkeit. ${ }^{1351}$

1350 Auch die Aufhebung eines Verwaltungsakts gemäß $\S \S 48 \mathrm{ff}$. VwVfG ist dann nur noch in begrenzten Ausnahmefällen denkbar, vgl. nur VGH Mannheim, Urt. v. 18.6.2008, Az.: 13 S 2809/ 07 = BeckRS 2008, 37311, Rn. 33ff.; s. auch J. Müller, in: Bader/Ronellenfitsch, VwVfG, 44. Ed., Stand: 1.1.2019, § 48 Rn. 37.

1351 Vgl. dazu nur die überschaubaren Hinweise auf abweichendes Landesrecht vor den Kommentierungen zu den §§ 48f. VwVfG bei Sachs, in: Stelkens/Bonk/Sachs, VwVfG, 9. Aufl. 2018. 

eines Verwaltungsakts i. S.v. § 43 II VwVfG (s. bereits Rn. 181). Davon abzugrenzen sind:

- die behördliche Aufhebung eines Verwaltungsakts am Ende eines Vorverfahrens ( $§ 72 \mathrm{VwGO}$ ), das sich ausschließlich nach den $\S \S 68 \mathrm{ff}$. VwGO richtet (s. dazu Rn. $301 \mathrm{ff}$ );

- (zumindest nach herrschender Meinung) die behördliche Aufhebung eines Verwaltungsakts in Folge des Wiederaufgreifens des Verfahrens gemäß $§ 51$ VwVfG (s. dazu $\S 3$ Rn. 120), sowie

- die gerichtliche Aufhebung eines Verwaltungsakts im Wege der Anfechtungsklage (§§ 42 I Var. 1, 113 I 1 VwGO) sowie der Verpflichtungsklage (§§ 42 I Var. 2, 113 V VwGO, in Form der Versagungsgegenklage).

838 Die behördliche Aufhebung gemäß $\S ~ 48 \mathrm{f}$. VwVfG wird wesentlich von zwei widerstreitenden Grundinteressen gelenkt, deren Ausgleich bereits der Gesetzgeber in der Ausformulierung der Vorschriften zu erreichen gesucht hat und die auch die Entscheidungen der Behörde über die Aufhebung im Einzelfall leiten: dem (schutzwürdigen) Vertrauen der Betroffenen auf den Bestand des aufzuhebenden Verwaltungsakts bzw. das objektive Interesse der Rechtssicherheit daran einerseits und dem öffentlichen Interesse an der Herstellung rechtmäßiger Zustände entsprechend dem Grundsatz der Gesetzmäßigkeit der Verwaltung andererseits (s. dazu $\S 1 \mathrm{Rn}$. 13). Diese gegenläufigen Interessen sind je nach Aufhebungskonstellation in Verbindung mit den gesetzlichen Vorgaben unter Berücksichtigung verschiedener Vorprägungen miteinander in Einklang zu bringen.

Behördliche Aufhebungen erfüllen alle Merkmale des § 35 S. 1 VwVfG (s. dazu Rn. 42 ff.) und sind daher selbst Verwaltungsakte. ${ }^{1352}$ Ihre Regelungswirkung besteht darin, die Wirksamkeit des vorangegangenen Verwaltungsakts zu beenden (§ 43 II VwVfG). Daraus folgt sowohl, dass sie den allgemeinen rechtlichen Vorgaben für Verwaltungsakte nach dem $\mathrm{VwVfG}$ zu genügen haben, als auch, dass bei Rechtsfehlern über den Widerspruch ( 68 I 1 VwGO) bzw. die Anfechtungsklage (§ 42 I Var. 1 VwGO) ihre (behördliche bzw. gerichtliche) Aufhebung ersucht werden kann. Kommt es dabei zu einer „Aufhebung der Aufhebung“, hat diese das Wiederaufleben der Wirksamkeit des ursprünglichen Verwaltungsakts ex tunc zur Folge. ${ }^{1353}$

1352 So auch Maurer/Waldhoff, Allgemeines Verwaltungsrecht, 19. Aufl. 2017, §11 Rn. 20; ausführlich Sachs, in: Stelkens/Bonk/Sachs, VwVfG, 9. Aufl. 2018, § 48 Rn. $242 \mathrm{ff.}$

1353 Maurer/Waldhoff, Allgemeines Verwaltungsrecht, 19. Aufl. 2017, § 11 Rn. 20; Detterbeck, Allgemeines Verwaltungsrecht, 17. Aufl. 2019, Rn. 738; Ipsen, Allgemeines Verwaltungsrecht, 11. Aufl. 2019, Rn. 722. 
Vor diesem Hintergrund kann die Erhebung einer Anfechtungsklage gegen 840 die Aufhebungsentscheidung einer Behörde in zwei Konstellationen dem Klagebegehren entsprechen: (1) Die Behörde hat sich eigeninitiativ für die Aufhebung eines Verwaltungsakts entschieden, was zulasten eines - insbesondere bislang begünstigten - Adressaten geht; (2) die Behörde hat sich eigeninitiativ oder auf Antrag für die Aufhebung eines Verwaltungsakts mit Drittwirkung entschieden, was zwar zugunsten eines zugleich aber zulasten eines anderen Betroffenen geht. In beiden Fällen wird es regelmäßig dem Wunsch der von der Aufhebungsentscheidung belasteten Personen entsprechen, schlicht die Aufhebung aus der Welt zu schaffen, damit der sie ursprünglich begünstigende Verwaltungsakt wiederauflebt. ${ }^{1354}$

Für ein besseres Verständnis der $\S \S 48 \mathrm{f}$. VwVfG und als „Checkliste“ für 841 die Vorüberlegungen in der Prüfung sollte berücksichtigt werden, dass die beiden Vorschriften grundsätzlich fünf Differenzierungsmerkmale enthalten, die die Prüfung an verschiedenen Stellen lenken.

- Die Grundunterscheidung zwischen Rücknahme und Widerruf wird anhand der Rechtswidrigkeit bzw. der Rechtmäßigkeit ihres Bezugsobjekts, dem aufzuhebenden Verwaltungsakt, getroffen. Zumindest ausdrücklich ${ }^{1355}$ steht für die Aufhebung eines rechtswidrigen Verwaltungsakts das Mittel der Rücknahme gemäß § 48 VwVfG, für die Aufhebung eines rechtmäßigen Verwaltungsakts das Mittel des Widerrufs gemäß § 49 VwVfG zur Verfügung.

- Das schutzwürdige Vertrauen der Betroffenen auf den Bestand eines aufzuhebenden Verwaltungsakts wiegt umso schwerer, je positiver die Auswirkungen dieses Verwaltungsakts für sie sind. Daher knüpft der Gesetzgeber sowohl die Rücknahme als auch den Widerruf begünstigender Verwaltungsakte zusätzlich an die Erfüllung besonderer Tatbestandsvoraussetzungen (§ 48 I 2, II bis IV, § 49 II, III VwVfG), während die Aufhebung belastender Verwaltungsakte im ordnungsgemäßen Ermessen der Behörden steht (§ 48 I 1, § 49 I VwVfG).

- Unter den begünstigenden Verwaltungsakten kommt denen, die eine einmalige oder laufende Geldleistung oder teilbare Sachleistung (zur Erfüllung eines bestimmten Zwecks) gewähren oder hierfür Voraussetzung sind, nochmals eine Sonderstellung zu. Da es bei ihnen materiell meist ausschließlich um fiskalische Interessen geht, hält der Gesetzgeber es für

1354 Von mindestens gleicher Prüfungsrelevanz sind indes die Konstellationen, in denen Betroffene (nach Eintritt der Bestandskraft) den Erlass einer behördlichen Aufhebungsentscheidung gemäß §§ $48 \mathrm{f}$. VwVfG begehren, s. dazu noch unter $\S 3$ Rn. $96 \mathrm{ff}$.

1355 S. zur Erweiterung des Anwendungsbereichs von $\S 49$ VwVfG über eine „teleologische Erweiterung“ des Tatbestands noch Rn. 948. 
leichter erträglich, ihre Wirkung aufrecht $\mathrm{zu}$ erhalten. Aus diesem Grund knüpft er ihre Rücknahme (§ 48 II, IV VwVfG) bzw. ihren Widerruf (mit Wirkung für die Vergangenheit $§ 49$ III VwVfG) im Interesse der Vertrauensschutzes an die Einhaltung besonders strikter Tatbestandsvoraussetzungen. Die sonstigen Verwaltungsakte können hingegen grundsätzlich unter weniger strengen Anforderungen aufgehoben werden.

- Ein Verwaltungsakt kann nur ausschnittsweise Anlass für eine Aufhebung bieten. Wie die gerichtliche Aufhebung im Rahmen der Anfechtungsklage (vgl. § 113 I 1 VwGO: „,soweit“) können auch Rücknahme und Widerruf nicht nur zur vollständigen, sondern auch zur bloß partiellen Aufhebung eines Verwaltungsakts führen (vgl. § 48 I 1, § 49 I, II 1, III 1 VwVfG: „ganz oder teilweise“). Die Rechtmäßigkeit dieses Vorgehens kann bereits auf Tatbestandsebene zu thematisieren sein (vgl. § 48 II 1 VwVfG: „soweit“), sie wird jedoch insbesondere im Rahmen der ordnungsgemäßen Ermessensausübung der Behörde relevant werden.

- Die Frage einer nur begrenzten Aufhebung stellt sich jedoch nicht nur in sachlicher, sondern insbesondere auch in zeitlicher Hinsicht. Die Gründe für die Aufhebung eines Verwaltungsakts bestehen in der überwiegenden Zahl der Fälle bereits lange vor der behördlichen Entscheidung darüber. Sie können bereits im Zeitpunkt seines Erlasses vorliegen oder erst später eintreten. Wird die Behörde ihrer erst später gewahr, stellt sich die wichtige Frage einer potentiellen Rückwirkung der Aufhebung (ex tunc). § 48 VwVfG verlangt bereits im Tatbestand nach einer zeitlichen Differenzierung (§ 48 II 1 VwVfG: „,soweit“; § 48 II 2 VwVfG: „wenn der Begünstigte gewährte Leistungen verbraucht oder eine Vermögensdisposition getroffen hat"), stellt die Entscheidung ansonsten aber ins Ermessen der Behörde (§ 48 I 1 VwVfG: „mit Wirkung für die Zukunft oder für die Vergangenheit"). § 49 VwVfG erlaubt einen Widerruf grundsätzlich nur mit Wirkung für die Zukunft (§ 49 I, II 1 VwVfG), nur in den Ausnahmefällen von Abs. 3 auch mit Wirkung für die Vergangenheit.

842 Bei aller hinlänglich bekannten Prüfungsrelevanz der $\S$ 48f. VwVfG sollte nie vergessen werden, dass ihre Anwendbarkeit ausgeschlossen sein kann. Dies kann bereits der Tatsache geschuldet sein, dass entsprechend § 2 VwVfG bestimmte Sachgebiete in Gänze aus dem Anwendungsbereich des VwVfG ausgenommen sind. ${ }^{1356}$ So gelten für Verfahren nach der Abgabenordnung (§ 2 II Nr. 1 VwVfG) die $\S \S 130,172$ ff. AO; für Verfahren nach dem Sozialgesetzbuch (§ 2 II

1356 Sachs, in: Stelkens/Bonk/Sachs, VwVfG, 9. Aufl. 2018, § 48 Rn. 3; Suerbaum, in: Mann/ Sennekamp/Uechtritz, VwVfG, 2. Aufl. 2019, § 48 Rn. $13 \mathrm{ff}$.

Tobias Brings-Wiesen 
Nr. 4 VwVfG) die $§ \S 44$ ff. SGBX. Fehlen in Folge dieser Ausnahme gesetzliche Vorgaben, kann gar ein Rückgriff auf allgemeine Grundsätze des Verwaltungsrechts erforderlich sein. ${ }^{1357}$ Eine Anwendbarkeit der $\S \S 48 \mathrm{f}$. VwVfG ist jedoch auch im Anwendungsbereich des VwVfG insoweit ausgeschlossen, als sie durch spezialgesetzliche Ermächtigungsgrundlagen überlagert werden. ${ }^{1358}$ Bereits im Studium bekannt sein sollten insbesondere: § 15 GastG, § 45 WaffG $^{1359}$, § 35 StAG und - angesichts der in den letzten Jahren gestiegenen Bedeutung des Migrationsrechts - auch die $\S \S 73 \mathrm{ff}$. AsylG und der $\S 52$ AufenthG. Diese Spezialnormen können die §§ 48f. VwVfG vollständig verdrängen, soweit sie beabsichtigen, die Möglichkeiten der Aufhebung eines Verwaltungsakts für einen bestimmten Sachbereich abschließend zu regeln. Bestehen hingegen Rechtslücken, können die $\S \S 48 \mathrm{f}$. VwVfG weiterhin subsidiär herangezogen werden. Das Verhältnis von Spezialvorschriften zu den $\S \S 48 \mathrm{f}$. VwVfG ist im Einzelfall im Wege der Auslegung zu ermitteln. ${ }^{1360}$

Bereits an dieser Stelle sei darauf verwiesen, dass in einer Klausur nicht außer $\mathbf{8 4 3}$ Acht gelassen werden sollte, dass die Aufhebung eines „Leistungsverwaltungsaktes“ (gemäß § 48 II bzw. § 49 III VwVfG) gerne mit der unmittelbaren Rückforderung einer (auf Grundlage des aufgehobenen Verwaltungsakts erteilten) Leistung gemäß § 49a VwVfG verbunden wird. Diese Erstattung wird in Prüfungen meist noch im Anschluss an die Aufhebung zu prüfen sein (s. dazu Rn. 989 ff.). Dies entspricht dem praktischen Vorgehen im Rahmen des Rechtsschutzbegehrens: Es bedarf zuerst der gerichtlichen „Aufhebung der Aufhebung“, um der Erstattung die zentrale Tatbestandsvoraussetzung $\mathrm{zu}$ entziehen (vgl. § 49a I 1 VwVfG) ${ }^{1361}$. Da der Aufgabenstellung in der Prüfung jedoch keine Grenzen gesetzt sind, besteht auch die Möglichkeit, die isolierte Prüfung des Erstattungsbescheids

1357 Sachs, in: Stelkens/Bonk/Sachs, VwVfG, 9. Aufl. 2018, § 48 Rn. 3.

1358 S. dazu am Beispiel des Gaststättenrechts die Fallbearbeitung bei Broscheit, JA 2016, 840 (841); am Beispiel des Gewerberechts die Fallbearbeitung bei Klafki, JURA 2018, 1019 (1020 f.). 1359 S. dazu die Fallbearbeitung bei Knappe/Thelen, JURA 2018, 829.

1360 So regelt bspw. der erwähnte $\S 52$ AufenthG nur den Widerruf von Aufenthaltstiteln, während die Rücknahme sich nach $\$ 48$ VwVfG richtet (vgl. nur die Allgemeine Verwaltungsvorschrift zum Aufenthaltsgesetz v. 26.10.2009, Zu § 52, Punkt 52.0.3); § 15 I GastG erfasst nur einen bestimmten Fall der Rücknahme und verlangt von der Behörde eine gebundene Entscheidung, während ansonsten eine Rücknahme über § 48 VwVfG möglich ist (vgl. nur Schönleiter, GastG, 2012, § 15 Rn. 1). Im Einzelfall mag das Verhältnis komplizierter sein, vgl. bspw. zu § 73 AsylG nur Bergmann, in: ders./Dienelt, Ausländerrecht, 12. Aufl. 2018, §73 AsylG Rn. 3, 21; s. dazu beispielhaft auch die Fallbearbeitung bei Knappe/Thelen, JURA 2018, 829 (834f.).

1361 In den Kategorien des Bereicherungsrechts gemäß §§ 812ff. BGB gedacht: Ohne „Aufhebung der Aufhebung“ besteht der Rechtsgrund für eine Leistung fort.

Tobias Brings-Wiesen 
$\mathrm{zu}$ verlangen, sodass in diesen Fällen eine umfängliche Inzidentprüfung der §§ 48f. VwVfG innerhalb des Tatbestands von § 49a VwVfG erfolgen muss.

\section{b) Rücknahme eines Verwaltungsakts nach § $48 \mathrm{VwVfG}$}

844 Die folgende Darstellung orientiert sich - wie die späteren Ausführungen zu den §§ 49 bis 51 VwVfG - weitgehend am Prüfungsschema der Vorschrift. Grundlegendere Ausführungen zum Verhältnis der Normen untereinander finden sich soweit sie nicht bereits erfolgt sind - an den für die Prüfung relevanten Stellen, um dort zu einem systematischen Verständnis für Struktur und Inhalt der Vorschriften beizutragen.

\section{Prüfungsschema zu § 48 VwVfG:}

I. Einheitliche Ermächtigungsgrundlage: § 48 I 1 VwVfG

II. Formelle Rechtmäßigkeit

1. Zuständigkeit (Beachte: $\S 48 \mathrm{~V}$ VwVfG)

2. Verfahren (Insbesondere: $\S 28$ I VwVfG)

3. Form (Beachte: actus contrarius-Gedanke)

III. Materielle Rechtmäßigkeit

1. Tatbestand

a) Vorliegens eines Verwaltungsakts (als Gegenstand der Aufhebung)

b) Rechtswidrigkeit des aufzuhebenden Verwaltungsakts (grds. im Zeitpunkt seines Erlasses)

c) Ggf. weitere tatbestandliche Voraussetzungen gemäß §48 II bis IV VwVfG im Falle des Vorliegens eines rechtswidrigen begünstigenden Verwaltungsakts gemäß § 48 I 2 VwVfG

aa) Ggf. weitere tatbestandliche Voraussetzungen gemäß $§ 48$ II VwVfG im Falle des Vorliegens eines Verwaltungsakts, der eine einmalige oder laufende Geldleistung oder teilbare Sachleistung gewährt oder hierfür Voraussetzung ist („Leistungsverwaltungsakt")

(1) Tatsächliches Vertrauen

(2) Schutzwürdigkeit dieses Vertrauens

(a) Ausschluss der Schutzwürdigkeit bei Vorliegen eines der Gründe in § 48 II 3 VwVfG

(b) Regelvermutung zugunsten einer Schutzwürdigkeit im Falle des Verbrauchs einer Leistung oder einer Vermögensdisposition (,Vertrauensbetätigung“) gemäß § 48 II 2 VwVfG 
(c) Abwägung des Vertrauens auf den Bestand des Verwaltungsakts mit dem öffentlichen Interesse an einer Rücknahme

bb) Kein Ausschluss der Rücknahme aufgrund von Verfristung gemäß $\S 48 \mathrm{IV}$ VwVfG

2. Rechtsfolge: Ordnungsgemäße Ermessensausübung gemäß § 48 I 1 VwVfG (Beachte: „ganz oder teilweise mit Wirkung für die Zukunft oder für die Vergangenheit")

\section{aa) Ermächtigungsgrundlage, § 48 I 1 VwVfG}

$\S 48$ I 1 VwVfG bildet die für Rücknahmen nach dem allgemeinen Verwaltungs- 846 recht einheitliche Ermächtigungsgrundlage. ${ }^{1362}$ In der Ausbildungsliteratur zur Fallbearbeitung werden verschiedene Varianten des Prüfungsaufbaus zur Ermächtigungsgrundlage vertreten. So erfolgt vielerorts bereits innerhalb dieses Gliederungspunktes eine ausführliche Prüfung der Rechtswidrigkeit des aufzuhebenden Verwaltungsakts. ${ }^{1363}$ Andernorts wird anfänglich global auf die $\S 48$ und/oder § 49 VwVfG als Ermächtigungsgrundlagen für die Aufhebung eines Verwaltungsakts rekurriert, während die weitere Präzisierung der Ermächtigungsgrundlage mit fortschreitender Prüfung erfolgt. ${ }^{1364}$ Um nicht vom gewohnten - und regelmäßig zu Recht erwarteten - Vorgehen zu diesem Prüfungspunkt (s. Rn. 574f.) abzuweichen, ist demgegenüber vorzugswürdig, auch innerhalb der $\S \S 48 \mathrm{f}$. VwVfG präzise eine (potentiell) einschlägige Ermächtigungsgrundlage zu identifizieren, deren Voraussetzungen - also u.a. die Rechtswidrigkeit bzw. Rechtmäßigkeit des aufzuhebenden Verwaltungsakts (s. dazu näher Rn. 865 ff.) sodann im Rahmen der materiellen Rechtmäßigkeit genauer zu prüfen sind. ${ }^{1365}$

1362 Suerbaum, in: Mann/Sennekamp/Uechtritz, VwVfG, 2. Aufl. 2019, § 48 Rn. 34; so auch Sachs, in: Stelkens/Bonk/Sachs, VwVfG, 9. Aufl. 2018, § 48 Rn. 37; Kastner, in: Fehling/Kastner/ Störmer, Verwaltungsrecht, 4. Aufl. 2016, § 48 VwVfG Rn. 11; Erichsen/Brügge, JURA 1999, 155 (156).

1363 So Ernst/Kämmerer, Fälle zum Allgemeinen Verwaltungsrecht, 3. Aufl. 2016, Fall 11, S. 158 (162f.); Kahl/Hilbert, JURA 2011, 948 (952ff.); Faßbender, JuS 2016, 538 (541f.). Teilweise erfolgt die Bestimmung der Ermächtigungsgrundlage auch am Anfang der Prüfung der materiellen Rechtmäßigkeit, Greim-Diroll, JURA 2018, 740 (743).

1364 So Martini, JuS 2003, 266 (267 f.); Funke/Waidhas, JA 2014, 439 (442); Broscheit, JA 2016, 840 (841); Klafki, JURA 2018, 1019 (1020 f.).

1365 So auch Klement, JuS 2010, 1088 (1090); Staufer/Steinebach, JURA 2012, 883 (887); Ingold, JuS 2014, 40 (41); Haltern/Manthey, JuS 2016, 344 (346); Kruse, ZJS 2017, 212 (214f.); Payandeh, ZJS 2017, 544 (550); Wormit, JURA 2018, 87; (89); Linke, JuS 2018, 259 (261); Edenharter, JuS 2018, 456 (458); Winter-Peter, JURA 2018, 508 (509f.); auch Pünder, JA 2004, 467 (469). 
Angesichts des differenzierten Meinungsbildes wird man jedoch jede Aufbauvariante für vertretbar erachten müssen. Wichtig ist, sich konsequent für einen Weg $\mathrm{zu}$ entscheiden und diese reine Aufbaufrage in der Prüfung nicht $\mathrm{zu}$ thematisieren. Ist indes das Verhältnis zu einer spezialgesetzlichen Ermächtigungsgrundlage zu erörtern (s. näher Rn. 842), ist die Ermächtigungsgrundlage notwendigerweise genau $\mathrm{zu}$ bestimmen. ${ }^{1366}$

847 Verfassungsrechtliche Bedenken bezüglich § 48 VwVfG bestehen grundsätzlich nicht. ${ }^{1367}$ In der Prüfung sollte daher auf diese Problematik nur dann eingegangen werden, wenn deutliche Hinweise im Sachverhalt den Schluss auf den Wunsch des Prüfenden erlauben, diese Problematisierung sehen $\mathrm{zu}$ wollen. ${ }^{1368}$

\section{bb) Formelle Rechtmäßigkeit}

848 Wie bereits dargelegt (s. Rn. 839) handelt es sich bei der Rücknahme selbst um einen Verwaltungsakt, der in einem neuen, selbstständigen Verwaltungsverfahren erlassen wird. ${ }^{1369}$ Aus diesem Grund gelten die allgemeinen rechtlichen Vorgaben für Verwaltungsakte nach dem VwVfG, inklusive der Vorschriften über Zuständigkeit, Verfahren und Form. Insofern kann an dieser Stelle auch grundsätzlich auf die allgemeinen Ausführungen zur formellen Rechtmäßigkeit verwiesen werden (s. dazu Rn. 579 ff.). Die folgenden Darstellungen konzentrieren sich auf die Ausnahmefälle und Besonderheiten der Prüfung der formellen Rechtmäßigkeit im Rahmen der $\S \S 48 f$. VwVfG ${ }^{1370}$.

\section{(1) Zuständigkeit}

849 Soweit das Fachrecht zur örtlichen Zuständigkeit schweigt, ist diese nach $\S 3$ VwVfG zu bestimmen. Nach Eintritt der Bestandskraft des zurückzunehmenden

1366 S. dazu die Fallbearbeitung bei Edenharter, JuS 2018, 456 (458).

1367 Vgl. dazu nur BVerwG, Beschl. v. 20.10.2006, Az.: 6 B 67.06 = juris, Rn. 4 ff., unter Verweis auf BVerfG, Urt. v. 24.5.2006, Az.: 2 BvR 669/04 = BVerfGE 116, 24 (54ff.), wo nur für Ausnahmekonstellationen eine Verfassungswidrigkeit für möglich gehalten wird, a.a. O., 59f. - S. aber auch die Meinung der Senatsminderheit, a.a. $0 ., 60 \mathrm{ff}$.

1368 S. dazu bspw. die Fallbearbeitung bei von Weschpfennig, JURA 2014, 1055 (1059).

1369 Vgl. nur BVerwG, Urt. v. 20.12.1999, Az.: 7 C 42.98 = BVerwGE 110, 226 (230 ff.); Ramsauer, in: Kopp/Ramsauer, VwVfG, 20. Aufl. 2019, § 48 Rn. 162.

1370 Da hinsichtlich $\S 49$ VwVfG praktisch keine nennenswerten Unterschiede gelten, können die Ausführungen seiner bezüglich bereits hier mitgedacht werden. 
Verwaltungsakts ${ }^{1371}$ sollte in der Prüfung auch auf den $\S 48$ V VwVfG rekurriert werden. Dieser stellt (fast) nur klar, ${ }^{1372}$ was bereits nach den anderweitig einschlägigen Vorschriften gilt: Nach Unanfechtbarkeit entscheidet über die Rücknahme des Verwaltungsakts die nach § 3 VwVfG zuständige Behörde und dies selbst dann, wenn der zurückzunehmende Verwaltungsakt von einer anderen Behörde erlassen wurde, sprich es zu einem Wechsel der örtlichen Zuständigkeit gekommen ist.

Examenswissen: Nur im Hinblick auf die Vorschrift des § 3 III VwVfG ist § 48 V VwVfG eine eigene rechtliche Wirkung zu entnehmen. Danach kann die bisher zuständige Behörde das Verwaltungsverfahren auch im Falle von Änderungen der die Zuständigkeit begründenden Umstände in dessen Lauf fortführen, wenn dies unter Wahrung der Interessen der Beteiligten der einfachen und zweckmäßigen Durchführung des Verfahrens dient und die nunmehr zuständige Behörde zustimmt. § 3 III VwVfG ist somit eigentlich beschränkt auf Änderungen in laufenden Verfahren. Angesichts der eindeutigen Verweisung wird man die Vorschrift jedoch auch auf das neue Rücknahmeverfahren entsprechend anzuwenden haben. ${ }^{1373}$

Für die sachliche Zuständigkeit ist keinesfalls auf § 48 V VwVfG abzustellen. Die Vorschrift regelt lediglich Fragen der örtlichen Zuständigkeit. ${ }^{1374}$ Dies ist indes verständlich. Dem VwVfG sind allgemein keine Vorgaben zur sachlichen Zuständigkeit zu entnehmen, weil „eine Einheitlichkeit der Vorschriften über die sachliche Zuständigkeit niemals bestanden hat und bei der Verschiedenartigkeit der Behördenorganisation auch nicht bestehen kann“1375. Maßgeblich sind für die Bestimmung der sachlichen Zuständigkeit auch im Falle der Rücknahme die Zuständigkeitsregeln des jeweils anzuwenden Fachrechts. ${ }^{1376}$

Hat eine unzuständige Behörde den zurückzunehmenden Verwaltungsakt erlassen, ist die Zuständigkeit für die Rücknahme gleichwohl nach dem jeweils einschlägigen Fachrecht bzw. den allgemeinen Vorgaben des Verwaltungsver-

1371 Und - in Anbetracht des klaren Wortlauts - auch nur dann, J. Müller, in: Bader/Ronellenfitsch, VwVfG, 44. Ed., Stand: 1.1.2019, § 48 Rn. 124.

1372 Ramsauer, in: Kopp/Ramsauer, VwVfG, 20. Aufl. 2019, § 48 Rn. 162; Suerbaum, in: Mann/ Sennekamp/Uechtritz, VwVfG, 2. Aufl. 2019, § 48 Rn. 217, 226.

1373 Ramsauer, in: Kopp/Ramsauer, VwVfG, 20. Aufl. 2019, § 48 Rn. 163; Sachs, in: Stelkens/ Bonk/Sachs, VwVfG, 9. Aufl. 2018, § 48 Rn. 256. A.A. J. Müller, in: Bader/Ronellenfitsch, VwVfG, 44. Ed., Stand: 1.1.2019, § 48 Rn. 124; Kastner, in: Fehling/Kastner/Störmer, Verwaltungsrecht, 4. Aufl. 2016, § 48 VwVfG Rn. 68.

1374 S. nur BVerwG, Urt. v. 20.12.1999, Az.: 7 C 42.98 = BVerwGE 110, 226 (230).

1375 BVerwG, Urt. v. 20.12.1999, Az.: 7 C 42.98 = BVerwGE 110, 226 (230), unter Rekurs auf den Musterentwurf eines Verwaltungsverfahrensgesetzes, 2. Aufl. 1968, S. 82.

1376 S. nur BVerwG, Urt. v. 20.12.1999, Az.: 7 C 42.98 = BVerwGE 110, 226 (230), mit dem zusätzlichen Hinweis, dass bei deren Unergiebigkeit allgemeine verwaltungsverfahrensrechtliche Grundsätze greifen. 
fahrensrechts zu bestimmen, sodass die Behörde zuständig ist, die zum Zeitpunkt der Rücknahmeentscheidung für den Erlass des aufzuhebenden Verwaltungsakts zuständig ist. ${ }^{1377}$

Nach alldem wird zwar im Ergebnis regelmäßig sowohl in örtlicher als auch in sachlicher Hinsicht die Behörde für die Rücknahme zuständig sein, die bereits den ursprünglichen Verwaltungsakt erlassen hat bzw. diejenige, die diesen hätte erlassen müssen. In der Prüfung sollte jedoch gleichwohl sauber dargelegt werden, warum dies so ist.

854 Während der Anhängigkeit eines Vorverfahrens (bis zum Eintritt der Bestandskraft des Widerspruchsbescheids) erstreckt sich die Zuständigkeit darüber hinaus auf die Widerspruchsbehörde. ${ }^{1378}$

\section{(2) Verfahren}

855 Für ein ordnungsgemäßes Verfahren ist unter den Bedingungen des § 28 VwVfG insbesondere eine Anhörung erforderlich. ${ }^{1379}$ Insbesondere im Falle der Rücknahme eines begünstigenden Verwaltungsakts wird in die aktuelle Rechtsstellung des durch den Verwaltungsakt Begünstigten als Beteiligter nach § 13 I Nr. 2 VwVfG eingegriffen. ${ }^{1380}$ Auch im Falle der Rücknahme eines belastenden Verwaltungsakts ist dies jedoch nicht per se ausgeschlossen. Im Falle der Rücknahme eines Verwaltungsakts mit Drittwirkung besteht die Pflicht zur Anhörung des Drittbetroffenen erst nach dessen Hinzuziehung gemäß $\S 13$ II VwVfG, auf die indes ein Anspruch bestehen kann. ${ }^{1381}$

\section{(3) Form}

856 Soweit dem Fachrecht keine speziellen Formvorgaben zu entnehmen sind, würde auch für den Verwaltungsakt der Rücknahme eigentlich der Grundsatz der Formfreiheit gemäß $\S 37$ II 1 VwVfG gelten (s. dazu Rn. 681). Aus der individu-

1377 Für einen Fall örtlicher Unzuständigkeit BVerwG, Beschl. v. 25.8.1995, Az.: 5 B $141.95=$ NVwZ-RR 1995, 538; für einen Fall sachlicher Unzuständigkeit BVerwG, Urt. v. 20.12.1999, Az.: 7 C 42.98 = BVerwGE 110, 226 (229ff.).

1378 S. dazu und zum Verhältnis zur Ausgangsbehörde allgemein Ramsauer, in: Kopp/Ramsauer, VwVfG, 20. Aufl. 2019, § 48 Rn. $164 \mathrm{ff}$.

1379 S. dazu anschaulich OVG Münster, Urt. v. 10.12.1984, Az.: 16 A 3086/83 = NVwZ 1985, 661 (662).

1380 Vgl. BVerwG, Urt. v. 14.10.1982, Az.: 3 C 46.81 = BVerwGE 66, 184 (186).

1381 Dazu jeweils m.w. N. Ramsauer, in: Kopp/Ramsauer, VwVfG, 20. Aufl. 2019, § 28 Rn. 22 f; Kallerhoff/Mayen, in: Stelkens/Bonk/Sachs, VwVfG, 9. Aufl. 2018, § 28 Rn. 33; Schwarz, in: Fehling/Kastner/Störmer, Verwaltungsrecht, 4. Aufl. 2016, § 28 VwVfG Rn. 21 f. 
alschutzorientierten Fortführung des actus contrarius-Gedankens kann sich jedoch ergeben, dass für die Rücknahme die Form einzuhalten ist, in der der zurückzunehmende Verwaltungsakt (entsprechend der für ihn geltenden Vorgaben) erteilt wurde. ${ }^{1382}$ Insofern ist die Entscheidung über die Rücknahme, insbesondere im Hinblick auf die ihr zugrundeliegenden Ermessenserwägungen, ${ }^{1383}$ auch gemäß § 39 VwVfG zu begründen (s. dazu Rn. 690 ff.). ${ }^{1384}$

\section{cc) Materielle Rechtmäßigkeit}

Während Ausführungen zur Ermächtigungsgrundlage und zur formellen Rechtmäßigkeit regelmäßig „reine Formsache“ sein werden bzw. nur allgemein bekannte Probleme aufgreifen, wird der Schwerpunkt der Prüfungen von Rücknahmen gemäß § 48 VwVfG praktisch immer auf der materiellen Rechtmäßigkeit liegen.

\section{(1) Überblick über die Prüfung des Tatbestands}

Die Tatbestandsprüfung fällt je nach Vorliegen der von $\S 48$ VwVfG besonders hervorgehobenen Charakteristika eines Verwaltungsakts unterschiedlich umfänglich aus. Stets festzustellen ist, dass sich die Entscheidung der Behörde auf einen rechtswidrigen Verwaltungsakt bezieht.

Ist dieser Verwaltungsakt belastend, ist die Tatbestandsprüfung $\mathrm{zu}$ beenden und abschließend gemäß § 48 I 1 VwVfG die ordnungsgemäße Ermessensausübung der Behörde bei der Entscheidung über die Rücknahme zu beurteilen.

Ist der Verwaltungsakt indes i.S.v. § 48 I 2 VwVfG begünstigend, sind die 860 zusätzlichen Tatbestandsvoraussetzungen der Abs. 2 bis $4 \mathrm{zu}$ prüfen. Innerhalb dieser wird indes nochmals unterschieden zwischen Verwaltungsakten, die eine einmalige oder laufende Geldleistung oder teilbare Sachleistung gewähren oder hierfür Voraussetzung sind (im Folgenden: „Leistungsverwaltungsakte“), und sonstigen Verwaltungsakten. Für beide ist ein möglicher Ausschluss der Rücknahme aufgrund von Verfristung gemäß § 48 IV VwVfG zu prüfen. Nur für die Erstgenannten sieht $\S 48$ II VwVfG darüber hinaus weitere besondere Tatbestandserwägungen vor.

1382 So i. E. auch Sachs, in: Stelkens/Bonk/Sachs, VwVfG, 9. Aufl. 2018, § 48 Rn. 242; Kastner, in: Fehling/Kastner/Störmer, Verwaltungsrecht, 4. Aufl. 2016, § 48 VwVfG Rn. 72; Ehlers/Kallerhoff, JURA 2009, 823 (834).

1383 Wobei das Begründungserfordernis im Falle von § 48 II 4 VwVfG reduziert sein kann, s. nur BVerwG, Urt. v. 16.6.1997, Az.: 3 C 22.96 = BVerwGE 105, 55 (57).

1384 Ramsauer, in: Kopp/Ramsauer, VwVfG, 20. Aufl. 2019, § 48 Rn. 171; Sachs, in: Stelkens/ Bonk/Sachs, VwVfG, 9. Aufl. 2018, § 48 Rn. 253. 


\section{(2) Tatbestandsmerkmal 1: Vorliegen eines Verwaltungsakts}

861 Bezugsobjekt der Rücknahme (zum Widerruf s. Rn. $941 \mathrm{ff}$.) ist ein Verwaltungsakt. Im Rahmen von Prüfungen wird diesem Tatbestandsmerkmal selten besondere Aufmerksamkeit zuteil. Dies ist in der weit überwiegenden Zahl der Sachverhalte auch vertretbar. Stets sollte jedoch zumindest in der gebotenen Kürze das Vorliegen der Merkmale des $§ 35$ VwVfG (s. Rn. 42ff.) und der Eintritt der rechtlichen Existenz eines Verwaltungsakts (s. Rn. 117 ff.) dargelegt werden (soweit dies bei verwaltungsprozessualer Einbettung noch nicht bei der Erläuterung der statthaften Klageart erfolgt ist, sodass entsprechend verwiesen werden könnte).

862 Examenswissen: Diese kurze Vergewisserung des Vorliegens eines Verwaltungsakts ist auch der Tatsache geschuldet, dass die Möglichkeit der Aufhebung von bloß „formellen Verwaltungsakten“ (s. dazu Rn. 21 ff.), „Nichtakten“ (s. dazu Rn. 20) und nichtigen Verwaltungsakten (s. dazu Rn. 19, 197 ff.) umstritten ist.

Besonders intensiv diskutiert wird die Anwendbarkeit von $\S 48 \mathrm{VwVfG}$ auf nichtige Verwaltungsakte.

Gegen eine Anwendung ${ }^{1385}$ wird insbesondere die Systematik des VwVfG ins Feld geführt. Die behördliche Aufhebung ziele auf die Beseitigung der Wirksamkeit, setze diese folglich voraus. Die Aufhebung eines nichtigen Verwaltungsakts gehe daher ins Leere. ${ }^{1386}$ Die Anwendung von $\S 48$ VwVfG würde die - in §43 II, III VwVfG angelegte - Unterscheidung zwischen bloßer Rechtswidrigkeit und Nichtigkeit verwischen. ${ }^{1387}$ Insbesondere sei für eine analoge Anwendung kein Raum, da angesichts der Möglichkeit behördlicher Feststellung gemäß § 44 V VwVfG bereits keine Regelungslücke bestehe. ${ }^{1388}$ Die nötige Klarheit wider den Rechtsschein eines nichtigen Verwaltungsakts könne auch über die speziell dafür vorgesehenen Rechtsbehelfe erreicht werden. ${ }^{1389}$ Da sich behördliche Nichtigkeitsfeststellung und Aufhebung sowohl nach den Voraussetzungen als auch nach den Rechtsfolgen unterschieden, könne keine Parallele zur gerichtlichen Aufhebung eines nichtigen Verwaltungsakts (s. dazu Rn. 197 ff.) gezogen werden. ${ }^{1390}$

1385 Detterbeck, Allgemeines Verwaltungsrecht, 17. Aufl. 2019, Rn. 684; Maurer/Waldhoff, Allgemeines Verwaltungsrecht, 19. Aufl. 2017, § 11 Rn. 7; Suerbaum, in: Mann/Sennekamp/Uechtritz, VwVfG, 2. Aufl. 2019, § 48 Rn. 40; Erichsen/Brügge, JURA 1999, 155 (156); Schladebach, VerwArch 2013, 188 (203f.); Mehde, JURA 2017, 783 (786).

1386 S. nur Maurer/Waldhoff, Allgemeines Verwaltungsrecht, 19. Aufl. 2017, § 11 Rn. 7. Im Interesse dogmatischer Konsistenz wird daher vermittelnd auch vertreten, dass § 48 VwVfG zwar anwendbar, die Aufhebung jedoch nur deklaratorischer Natur sei, J. Müller, in: Bader/Ronellenfitsch, VwVfG, 44. Ed., Stand: 1.1.2019, § 48 Rn. 8.

1387 Kastner, in: Fehling/Kastner/Störmer, Verwaltungsrecht, 4. Aufl. 2016, § 48 VwVfG Rn. 23. 1388 Schladebach, VerwArch 2013, 188 (203); wohl auch Detterbeck, Allgemeines Verwaltungsrecht, 17. Aufl. 2019, Rn. 684.

1389 Maurer/Waldhoff, Allgemeines Verwaltungsrecht, 19. Aufl. 2017, §11 Rn. 7; Kastner, in: Fehling/Kastner/Störmer, Verwaltungsrecht, 4. Aufl. 2016, § 48 VwVfG Rn. 23; Schladebach, VerwArch 2013, 188 (203f.).

1390 Maurer/Waldhoff, Allgemeines Verwaltungsrecht, 19. Aufl. 2017, §11 Rn. 7. Soweit demgegenüber die Möglichkeit einer Anfechtungsklage befürwortet wird, wird auch auf den dies indi-

Tobias Brings-Wiesen 
Die herrschende Meinung spricht sich demgegenüber für eine - zumindest analoge ${ }^{1391}$ Anwendung aus. ${ }^{1392}$ Dafür spreche - wie im Verwaltungsgerichtsprozess (s. Rn. 197 ff.) - der Grundsatz der Verfahrensökonomie: Durch die Möglichkeit der Aufhebung erübrige sich für die Behörde die schwierige - und oftmals umstrittene - Entscheidung, ob der Verwaltungsakt nichtig oder bloß rechtswidrig sei. ${ }^{1393}$ Sie sei somit vor allem in Grenz- und Zweifelsfällen vielfach der einfachere Weg. ${ }^{1394}$ Außerdem bestehe mangels Vergleichbarkeit von Feststellungs- und Aufhebungsentscheidung sehr wohl eine Regelungslücke und demnach ein Interesse an der Anwendbarkeit: Endgültig beseitigt werde der Rechtsschein erst durch Aufhebung des den Rechtsschein erzeugenden Aktes. ${ }^{1395}$ Demgegenüber sei die Unterscheidung von bloßer Rechtswidrigkeit und Nichtigkeit im Hinblick auf $\S 48$ VwVfG systematisch nicht zwingend: Weder schaffe § 43 II VwVfG einen untrennbaren Zusammenhang zwischen Aufhebung und Wirksamkeit, noch sei es dem Gesetzgeber per se untersagt, auch die Aufhebung eines unwirksamen Verwaltungsakts vorzusehen. ${ }^{1396}$ Bejaht man eine Anwendbarkeit, ist für den Fall, dass die Behörde oder ein Betroffener diesen Weg wählen, eine Prüfung der Nichtigkeit entbehrlich. ${ }^{1397}$ Es gelten die Voraussetzungen des $\S 48$ VwVfG. ${ }^{1398}$

Das Bundesverwaltungsgericht hat zuletzt zu erkennen gegeben, dass es die Argumentation, dass ein aufgrund von Erledigung bereits unwirksamer Verwaltungsakt zwar nicht mehr rechtsgestaltend aufgehoben, sehr wohl aber der mit ihm verbundene Rechtsschein durch eine Aufhebung beseitigt werden könnte, hinsichtlich aller Konstellationen der Unwirksamkeit für überzeugend hält. ${ }^{1399}$ Angesichts der fortbestehenden Kontroverse um diese Position ${ }^{1400}$ sollte in

zierenden Wortlaut von § 43 II 2 VwGO abgestellt, Detterbeck, Allgemeines Verwaltungsrecht, 17. Aufl. 2019, Rn. 684 (Fn. 315).

1391 Ramsauer, in: Kopp/Ramsauer, VwVfG, 20. Aufl. 2019, § 44 Rn. 70 ; § 48 Rn. 18, verneint eine unmittelbare Anwendung mit der Begründung, die Rücknahme sei gemäß §43 II VwVfG auf wirksame Verwaltungsakte bezogen; so wohl auch Ehlers/Kallerhoff, JURA 2009, 823 (825); dagegen jedoch Schenke, JuS 2016, 97 (100, Fn. 27).

1392 OVG Münster, Urt. v. 3.12.2009, Az.: 18 A 1787/06 = NVwZ-RR 2010, 411 (412); Peine/Siegel, Allgemeines Verwaltungsrecht, 12. Aufl. 2018, Rn. 603; Sachs, in: Stelkens/Bonk/Sachs, VwVfG, 9. Aufl. 2018, § 44 Rn. 199; § 48 Rn. 57 m.w. N. Zustimmend wohl auch BVerwG, Urt. v. 17.11.2016, Az.: 6 C 36.15 = BVerwGE 156, 283 (285, Rn. 12).

1393 So zu § 44 SGB X BSG, Urt. v. 23.02.1989, Az.: 11/7 RAr 103/87 = NVwZ 1989, 902 (903). 1394 Ramsauer, in: Kopp/Ramsauer, VwVfG, 20. Aufl. 2019, § 44 Rn. 70; § 48 Rn. 18; Schenke, JuS 2016, 97 (100).

1395 Ehlers/Kallerhoff, JURA 2009, 823 (25).

1396 Schenke, JuS 2016, 97 (101).

1397 Schenke, JuS 2016, 97 (103).

1398 S. aber zur wichtigen Frage eines Ermessens der Behörde im Falle der Nichtigkeit ausführlich Schenke, JuS 2016, 97 (102f.).

1399 BVerwG, Urt. v. 17.11.2016, Az.: 6 C 36.15 = BVerwGE 156, 283 (285, Rn. 12), im Zusammenhang mit dem Widerruf eines Verwaltungsakts nach dessen Erledigung „auf andere Weise“ durch Verzicht.

1400 Aus der Lehrbuchliteratur dagegen Maurer/Waldhoff, Allgemeines Verwaltungsrecht, 19. Aufl. 2017, § 11 Rn. 7; Detterbeck, Allgemeines Verwaltungsrecht, 17. Aufl. 2019, Rn. 684 (zum nichtigen Verwaltungsakt); Ruffert, in: Ehlers/Pünder, Allgemeines Verwaltungsrecht, 15. Aufl. 2016, § 24 Rn. 7; dafür Peine/Siegel, Allgemeines Verwaltungsrecht, 12. Aufl. 2018, Rn. 603. 
einer Klausur jedoch im Falle von bloß formellen Verwaltungsakten, Nichtakten und nichtigen Verwaltungsakten unbedingt auf das Problem eingegangen werden. In diesem Zusammenhang können dann auch tiefergehende Ausführungen zu Verwaltungsaktqualität und Wirksamkeit erforderlich werden.

863 Weitgehend bedeutungslos ${ }^{1401}$ ist demgegenüber die Frage seiner Bestandskraft, wie sich bereits am Wortlaut von $\S 48$ I 1 VwVfG (,auch nachdem er unanfechtbar geworden ist“) verdeutlicht. Dies eröffnet insbesondere die Möglichkeit der Betroffenen, die Aufhebung eines Verwaltungsakts auch über das Ende der Klagefrist hinaus zu beantragen. Die Anhängigkeit eines Widerspruchs- oder Gerichtsverfahrens steht einer Aufhebung gemäß §§ 48f. VwVfG grundsätzlich nicht im Wege, hat jedoch gemäß $\S 50 \mathrm{VwVfG}$ Auswirkungen auf deren materielle Rechtmäßigkeitsmaßstäbe (s. dazu Rn. 979 ff.). Die Rechtskraft aufgrund gerichtlicher Bestätigung eines Verwaltungsakts wird der Aufhebung hingegen regelmäßig entgegenstehen. ${ }^{1402}$

864 Objekt einer Rücknahme nach $\S 48$ VwVfG können auch Abhilfe- (§ 72 VwGO) oder Widerspruchsbescheide $(\S 73 \mathrm{VwGO})^{1403}$ sowie Aufhebungsbescheide gemäß §§ 48f. VwVfG selbst sein. Auf Genehmigungsfiktionen ist § $48 \mathrm{VwVfG}$ gemäß § 42a I 2 VwVfG entsprechend anwendbar.

\section{(3) Tatbestandsmerkmal 2: Rechtswidrigkeit des aufzuhebenden Verwaltungsakts}

865 Ein Schwerpunkt von Prüfungen am Maßstab von $\S 48 \mathrm{VwVfG}$ wird meist in der Inzidentprüfung der Rechtskonformität des aufzuhebenden Verwaltungsakts liegen. Dabei bestehen in der Sache keine Besonderheiten: Ein Verwaltungsakt ist rechtswidrig, wenn er nicht auf einer eigentlich erforderlichen Ermächtigungsgrundlage beruht oder in formeller ${ }^{1404}$ oder materieller Hinsicht gegen einschlägige Rechtsvorschriften (auch und insbesondere Unionsrecht ${ }^{1405}$ ) verstößt.

1401 Gestritten wird jedoch um die Fragen der Interessenabwägung gemäß § 48 II VwVfG und der Ermessensausübung im Falle der Rücknahme eines noch nicht bestandskräftigen Verwaltungsakts, s. dazu noch Rn. 925.

1402 S. nur J. Müller, in: Bader/Ronellenfitsch, VwVfG, 44. Ed., Stand: 1.1.2019, § 48 Rn. 37, m.w. N.

1403 S. dazu ausführlich Rn. $301 \mathrm{ff}$. Soweit ein Widerspruchsbescheid ergangen ist, so ist regelmäßig dessen Rechtswidrigkeit zu beurteilen, Ramsauer, in: Kopp/Ramsauer, VwVfG, 20. Aufl. 2019, § 48 Rn. 50.

1404 S. aber zu den (vor allem) formelle Rechtsfehler betreffenden $\S \S 45 \mathrm{ff}$. VwVfG noch Rn. 652. $1405 \mathrm{~S}$. zu den daraus resultierenden besonderen Konsequenzen noch Rn. $929 \mathrm{ff}$. 
Steht am Ende dieser Prüfung fest, dass der Verwaltungsakt rechtmäßig war, hätte er ausschließlich nach § 49 VwVfG widerrufen werden dürfen. ${ }^{1406}$

War er demgegenüber rechtswidrig, legt zwar der Wortlaut der §§ 48, 49866 VwVfG nahe, dass nur eine Rücknahme in Frage kommt. Die ganz herrschende Meinung hält jedoch auch den Widerruf eines rechtswidrigen Verwaltungsakts gemäß § 49 VwVfG für möglich (s. dazu Rn. 948).

Für die Prüfung bedeutet dies: Soweit sich aus einem Sachverhalt hinrei- 867 chende Anhaltspunkte für einen Widerruf ergeben, sollte die Bearbeitung mit $\S 49$ VwVfG beginnen. Unter dem Prüfungspunkt „Rechtmäßigkeit des Verwaltungsakts“ sollte dann - zumeist in der gebotenen Kürze - auf die Möglichkeit des Widerrufs rechtswidriger Verwaltungsakte eingegangen werden. In der Konsequenz kann dann die Entscheidung über die Rechtmäßigkeit (vorerst) dahinstehen. ${ }^{1407}$ Sollte jedoch sodann wegen Rechtswidrigkeit des Widerrufs oder schlicht ergänzend noch $\S 48$ VwVfG geprüft werden, ist zwingend eine Entscheidung zu treffen. Auch sollten Ausführungen dort nicht unterbleiben, wo sie je nach Sachverhaltsgestaltung ersichtlich erwartet werden. ${ }^{1408}$

Wie im Fall der Anfechtungsklage (\$§ 42 I Var. 1, 113 I 1 VwGO) ergibt sich aus 868 Wortlaut und Systematik der $\S \S 48 \mathrm{f}$. VwVfG, dass ein Verwaltungsakt auch nur teilweise aufgehoben werden kann.

Zuletzt gilt es in zeitlicher Hinsicht einige Besonderheiten $\mathrm{zu}$ beachten. 869 Maßgeblicher Beurteilungszeitpunkt der Rechtskonformität des aufzuhebenden Verwaltungsakts ${ }^{1409}$ ist der Zeitpunkt seines Erlasses. ${ }^{1410}$ Spätere Änderungen der Sach- und - insbesondere auch der - Rechtslage bleiben grundsätzlich unberücksichtigt. ${ }^{1411}$

1406 Maurer/Waldhoff, Allgemeines Verwaltungsrecht, 19. Aufl. 2017, § 11 Rn. 17. Es besteht indes unter bestimmten Voraussetzungen die Möglichkeit zur Auslegung der behördlichen Entscheidung.

1407 Detterbeck, Allgemeines Verwaltungsrecht, 17. Aufl. 2019, Rn. 685; Peine/Siegel, Allgemeines Verwaltungsrecht, 12. Aufl. 2018, Rn. 603; Manssen/Greim, JuS 2010, 429 (432).

1408 So zu Recht Faßbender, JuS 2016, 538 (Fn. 2).

1409 Anderes gilt im Falle der Aufhebung eines Widerspruchsbescheids nach §73 VwGO, Detterbeck, Allgemeines Verwaltungsrecht, 17. Aufl. 2019, § 10 Fn. 302.

1410 Maurer/Waldhoff, Allgemeines Verwaltungsrecht, 19. Aufl. 2017, § 11 Rn. 18; Detterbeck, Allgemeines Verwaltungsrecht, 17. Aufl. 2019, Rn. 680; Ramsauer, in: Kopp/Ramsauer, VwVfG, 20. Aufl. 2019, § 48 Rn. 57; Sachs, in: Stelkens/Bonk/Sachs, VwVfG, 9. Aufl. 2018, § 48 Rn. 49. 1411 Vgl. nur die Beispiele bei Ramsauer, in: Kopp/Ramsauer, VwVfG, 20. Aufl. 2019, § 48 Rn. $58 \mathrm{ff}$. 
870 Examenswissen: Prüfungsrelevant weil zum Teil stark umstritten sind indes die folgenden Ausnahmen:

Keine nachträgliche Änderung der Rechtslage liegt im Falle der gerichtlichen Nichtigerklärung einer Vorschrift wegen Unvereinbarkeit mit höherrangigem Recht (vgl. §§ 78, 95 III 1 BVerfGG; §§ 49, 61 III 1 VGHG NRW; § 47 V 2 Hs. 1 VwGO) vor. Die verschiedenen Gerichte treffen dabei jeweils eine allgemeinverbindliche Feststellungsentscheidung, keine rechtsgestaltende Aufhebungsentscheidung. Die Vorschriften waren objektiv bereits vorher rechtswidrig und damit nichtig. Daraus folgt, dass auch die auf den betroffenen Vorschriften beruhenden Verwaltungsakte mangels wirksamer Rechtsgrundlage als von Anfang $a n^{1412}$ rechtswidrig $^{1413} \mathrm{zu}$ erachten sind. ${ }^{1414}$ Gleiches gilt für die Konstellation, dass die einen ursprünglich rechtmäßigen Verwaltungsakt betreffenden Vorschriften vom Gesetzgeber mit Rückwirkung geändert werden. ${ }^{1415}$ Gleiches kann sich ergeben, wenn die nachträgliche Änderung einer Verwaltungsentscheidung mit Rückwirkung erfolgt. ${ }^{1416}$

Umstritten ist der Umgang mit ursprünglich rechtmäßigen, - aufgrund von Änderungen der Sach- oder Rechtslage - nachträglich rechtswidrig ${ }^{1417}$ gewordenen „Dauerverwaltungsakten“ (s. dazu Rn. 541). Das Bundesverwaltungsgericht geht in ständiger Rechtsprechung ${ }^{1418}$ davon aus, dass ihre Aufhebung für den Zeitraum $a b$ dem Eintritt der Rechtswidrigkeit als Rücknahme nach $\S 48$ VwVfG und nicht als Widerruf nach $\S 49$ VwVfG zu bewerten ist. Die Gegenmeinung ${ }^{1419}$ hält dem insbesondere das systematische Argument entgegen, dass Konstellationen nachträgli-

1412 Dies soll laut Ramsauer, in: Kopp/Ramsauer, VwVfG, 20. Aufl. 2018, § 48 Rn. 56, nicht gelten, wenn trotz Rechtswidrigkeit eine vorläufige Fortgeltung anerkannt bzw. angeordnet wird. Dies wird jedoch höchstens nach den Umständen der Entscheidung in Frage kommen können. 1413 S. zur Rechtswidrigkeit aufgrund fehlender oder mangelhafter Ermächtigungsgrundlage ausführlich Rn. $554 \mathrm{ff}$. Sie führt jedoch keineswegs automatisch zur Unwirksamkeit des Verwaltungsakts (wegen Erledigung oder Nichtigkeit), s. dazu ausführlich Rn. 185 sowie in § 6 Rn. 153. 1414 BVerwG, Urt. v. 25.10.2012, Az.: 2 C 59.11 = BVerwGE 145, 14 (16, Rn. 10); Detterbeck, Allgemeines Verwaltungsrecht, 17. Aufl. 2019, Rn. 683; Ramsauer, in: Kopp/Ramsauer, VwVfG, 20. Aufl. 2019, § 48 Rn. 56. S. zur weiteren Berücksichtigung der Nichtigkeit für die Rücknahmeentscheidung BVerwG, Urt. v. 24.2.2011, Az.. 2 C 50.09 = NVwZ 2011, 888 (889f.); dazu auch Detterbeck, a.a.O.

1415 Maurer/Waldhoff, Allgemeines Verwaltungsrecht, 19. Aufl. 2017, § 11 Rn. 19; Detterbeck, Allgemeines Verwaltungsrecht, 17. Aufl. 2019, Rn. 681; Ramsauer, in: Kopp/Ramsauer, VwVfG, 20. Aufl. 2019, § 48 Rn. 15a.

1416 Vgl. BVerwG, Urt. v. 16.11.1989, Az.: 2 C 43.87 = BVerwGE 84, 111 (113), dort durch gerichtliche Aufhebung eines Verwaltungsakts, was auch auf die Beurteilung eines in sachlichem Zusammenhang stehenden Verwaltungsakts zurückwirkte.

1417 Zum umgekehrten Fall des nachträglichen Rechtmäßigwerdens rechtswidriger Verwaltungsakte Schenke, NVwZ 2015, 1341.

1418 BVerwG, Urt. v. 2.11.1989, Az.: 2 C 43.87 = BVerwGE 84, 111 (113f.); Urt. v. 28.6.2012, Az.: 2 C 13.11 = BVerwGE 143, 230 (233, Rn. 15); anders aber für den Planfeststellungsbeschluss BVerwG, Urt. v. 29.4.2016, Az.: 4 A 2.15 = BVerwGE 155, 81 (86, Rn. 28). So auch mit ausführlicher Begründung Schenke, DVBl 1989, 433.

1419 S. nur Maurer/Waldhoff, Allgemeines Verwaltungsrecht, 19. Aufl. 2017, § 11 Rn. 19; Detterbeck, Allgemeines Verwaltungsrecht, 17. Aufl. 2019, Rn. 682; Ruffert, in: Ehlers/Pünder, Allgemeines Verwaltungsrecht, 15. Aufl. 2016, § 24 Rn. 6; Ehlers/Kallerhoff, JURA 2009, 823 (825).

Tobias Brings-Wiesen 
cher Veränderung der Sach- oder Rechtslage entsprechend § 49 II 1 Nr. 3, 4 VwVfG eindeutig der Aufhebung durch Widerruf zugewiesen sind.

Da auch formelle Rechtsfehler zur Rechtswidrigkeit des aufzuhebenden Verwaltungsakts führen können, ${ }^{1420}$ sind auch die Fehlerfolgenregelungen der $\S \S 45 \mathrm{f}$. VwVfG besonders zu berücksichtigen: Während weitestgehend Einigkeit ${ }^{1421}$ darüber besteht, dass ein ursprünglich rechtswidriger Verwaltungsakt rückwirkend rechtmäßig wird, wenn ein Verfahrens- oder Formfehler gemäß § 45 VwVfG (s. dazu Rn. 652ff.) durch Nachholung der entsprechenden Handlung nachträglich geheilt wird, ${ }^{1422}$ ist die Frage einer Rücknahme im Falle von Unbeachtlichkeit gemäß $§ 46$ VwVfG umstritten ${ }^{1423}$.

Umstritten ist auch der Umgang mit Konstellationen, in denen der Verwaltungsakt gemäß $\S 47 \mathrm{VwVfG}$ durch die Behörde bereits umgedeutet wurde bzw. noch werden kann. ${ }^{1424}$

\section{(4) Tatbestandsmerkmal 3: Belastender oder begünstigender Verwaltungsakt}

Handelt es sich um einen rechtswidrigen Verwaltungsakt, so ist eine Rücknahme nach $\S 48$ VwVfG möglich. Für die Klärung der Frage, welche weiteren Voraussetzungen erfüllt sein müssen, ist sodann zu prüfen, ob der zurückzunehmende Verwaltungsakt eine belastende oder begünstigende Wirkung hat. Was unter einem begünstigenden Verwaltungsakt zu verstehen ist, ist in § 48 I 2 VwVfG legaldefiniert als Verwaltungsakt, der ein Recht oder einen rechtlich erheblichen Vorteil begründet oder bestätigt hat. Handelt es sich um einen solchen begünstigenden Verwaltungsakt, kann seine Rücknahme nur unter den zusätzlichen Voraussetzungen der Abs. 2 bis 4 erfolgen. Andernfalls steht die Rücknahme entsprechend dem „Grundsatz der freien Rücknehmbarkeit“ gemäß §48 I 1 VwVfG im Ermessen der Behörde.

Für die Beantwortung der Frage, ob ein Verwaltungsakt ein Recht oder einen $\mathbf{8 7 2}$ rechtlich erheblichen Vorteil begründet oder bestätigt, ist die Wirkung des aufzuhebenden Verwaltungsakts an sich in den Fokus zu nehmen. Treffend formuliert Ramsauer, dass die Vorschrift Rechte im engeren Sinne und rechtlich geschützte Interessen, d.h. alle von der Rechtsordnung durch Sätze des öffentlichen Rechts als schutzwürdig anerkannten und rechtlich geschützten Vorteile,

1420 Ramsauer, in: Kopp/Ramsauer, VwVfG, 20. Aufl. 2019, § 48 Rn. 52.

1421 S. dazu nur Ramsauer, in: Kopp/Ramsauer, VwVfG, 20. Aufl. 2019, § 45 Rn. 14; Sachs, in: Stelkens/Bonk/Sachs, VwVfG, 9. Aufl. 2018, § 45 Rn. 21f., jeweils m.w. N.

1422 OVG Münster, Beschl. v. 23.6.1987, Az.: 13 B 826/87 = NVwZ 1988, 740 (741); Sachs, in: Stelkens/Bonk/Sachs, VwVfG, 9. Aufl. 2018, § 45 Rn. 21, 23; § 48 Rn. 56; Ehlers/Kallerhoff, JURA 2009, 823 (825).

1423 S. dazu m.w. N. nur Sachs, in: Stelkens/Bonk/Sachs, VwVfG, 9. Aufl. 2018, § 46 Rn. 12.

1424 Dafür Maurer/Waldhoff, Allgemeines Verwaltungsrecht, 19. Aufl. 2017, § 11 Rn. 16; Peuker, in: Knack/Henneke, VwVfG, 10. Aufl. 2014, § 48 Rn. 46; Ehlers/Kallerhoff, JURA 2009, 823 (825); a. A. aber Sachs, in: Stelkens/Bonk/Sachs, VwVfG, 9. Aufl. 2018, § 48 Rn. 58. 
die aus dem Verwaltungsakt erwuchsen, umfasse. ${ }^{1425}$ Diese müssen durch den Verwaltungsakt begründet, bestätigt oder festgestellt werden. Begünstigend ist ein Verwaltungsakt jedoch auch dann, wenn die Rechtsordnung an seinen an sich neutralen Regelungsinhalt begünstigende Rechtsfolgen knüpft. So wurde beispielsweise die Feststellung der Zivildienstunfähigkeit (§ 8 ZDG) als begünstigend gewertet, weil in der Folge die mit dem Zivildienst verbundenen gesetzlichen Pflichten entfielen. ${ }^{1426} \mathrm{Zu}$ verneinen ist eine Begünstigung hingegen, wenn sie wie im Falle der Umnummerierung von Grundstücken im öffentlichen Interesse liegt und höchstens reflexhaft tatsächliche Auswirkungen für die Betroffenen hat. ${ }^{1427}$

Teilweise wird für die Bestimmung einer Begünstigung oder Belastung auf die Wirkung der Aufhebung abgestellt, sodass die Aufhebung einer Belastung zulasten des Betroffenen nach den Maßstäben für begünstigende Verwaltungsakte behandelt werden soll. ${ }^{1428}$ Dieses Vorgehen wird indes von der herrschenden Meinung und der Rechtsprechung nicht geteilt. ${ }^{1429}$ Bei Verwaltungsakten, die zugleich belastend und begünstigend sind, kommt es vorrangig auf die Teilbarkeit an, ansonsten sind sie wie begünstigende Verwaltungsakte zu behandeln. ${ }^{1430}$ Bei Verwaltungsakten mit Drittwirkung kommt es stets auf die Perspektive des „Adressaten“ - d.h. die Person, für die ein Verwaltungsakt i.S.v. § 41 I 1, § 43 I 1 VwVfG bestimmt ist (s. dazu Rn. 107) - an. ${ }^{1431}$

874 Ein begünstigender Verwaltungsakt darf nur unter den Einschränkungen der Abs. 2 bis 4 zurückgenommen werden. Entgegen vereinzelt vertretener Ansicht ${ }^{1432}$ handelt es sich um weitere Tatbestandsvoraussetzungen deren Vorliegen gerichtlich voll überprüfbar ist und die je nach Vorliegen eine Rücknahme ausschließen. ${ }^{1433}$

1425 Ramsauer, in: Kopp/Ramsauer, VwVfG, 20. Aufl. 2019, § 48 Rn. 66; auch mit Negativbeispielen, a.a.O., Rn. 65.

1426 BVerwG, Urt. v. 25.6.1982, Az.: 8 C 122.81 = BVerwGE 66, 61 (62).

1427 OVG Münster, Beschl. v. 29.2.2012, Az.: 5 A 353/11 = NVwZ-RR 2012, 541 (541f.).

1428 S. nur Maurer/Waldhoff, Allgemeines Verwaltungsrecht, 19. Aufl. 2017, § 11 Rn. 13; Detterbeck, Allgemeines Verwaltungsrecht, 17. Aufl. 2019, Rn. 686f.

1429 S. dazu nur das Beispiel bei Ramsauer, in Kopp/Ramsauer, VwVfG, 20. Aufl. 2019, § 48 Rn. 69 m.w.N.

1430 Ramsauer, in: Kopp/Ramsauer, VwVfG, 20. Aufl. 2019, § 48 Rn. 72; Ehlers/Kallerhoff, JURA 2009, 823 (827).

1431 Vgl. dazu nur BVerwG, Urt. v. 9.5.2012 Az.: 6 C 3.11 = BVerwGE 143, 87 (106ff., Rn. 46 f.). a. A. dagegen m.w. N. Ehlers/Kallerhoff, JURA 2009, 823 (827).

1432 Peuker, in: Knack/Henneke, VwVfG, 10. Aufl. 2014, § 48 Rn. 66; Ziekow, VwVfG, 3. Aufl. 2013, $\S 48 \mathrm{Rn} .14$.

1433 OVG Münster, Urt. v. 25.11.1996, Az.: 25 A 1950/96 = NVwZ-RR 1997, 585 (585f.); Maurer/ Waldhoff, Allgemeines Verwaltungsrecht, 19. Aufl. 2017, §11 Rn. 29; Detterbeck, Allgemeines

Tobias Brings-Wiesen 
Handelt es sich hingegen um einen belastenden Verwaltungsakt, findet die Tatbestandsprüfung hier ihren Abschluss, sodass zum Ermessen (s. dazu Rn. $921 \mathrm{ff}$.) überzugehen ist.

\section{(5) Besondere Tatbestandsvoraussetzungen bei Rücknahme eines begünstigenden Verwaltungsakts, $\$ 48$ II bis IV VwVfG}

Handelt es sich um einen rechtswidrigen, aber begünstigenden Verwaltungsakt, 875 bedarf es der Prüfung der weiteren besonderen Tatbestandsvoraussetzungen des $§ 48$ II bis IV VwVfG.

Auch insofern bedarf es jedoch einer weiteren Differenzierung zwischen 876 zwei Kategorien begünstigender Verwaltungsakte. Während die in $\S 48$ IV VwVfG vorgesehene Fristenregelung auf beide Kategorien anzuwenden ist (s. dazu Rn. 905 ff.), sieht § 48 II VwVfG nur für Verwaltungsakte, die eine einmalige oder laufende Geldleistung oder teilbare Sachleistung gewähren oder hierfür Voraussetzung sind, näher ausdifferenzierte Tatbestandsvoraussetzungen zum Ausgleich der widerstreitenden Interessen vor. Für alle sonstigen Verwaltungsakte ist nach der Prüfung von § 48 IV VwVfG unmittelbar zum Ermessen überzugehen. ${ }^{1434}$

\section{(a) Leistungsverwaltungsakte, § 48 II VwVfG}

Für „Leitungsverwaltungsakte“ hat der Gesetzgeber in § 48 II VwVfG die Be- 877 rücksichtigung des schutzwürdigen Vertrauens bereits weitgehend tatbestandlich ausgestaltet. Gemäß § 48 II 1 VwVfG ist eine Rücknahme ausgeschlossen, soweit der Begünstigte auf den Bestand des Verwaltungsakts vertraut hat und sein Vertrauen unter Abwägung mit dem öffentlichen Interesse an einer Rücknahme schutzwürdig ist. Diese Abwägung wird wiederum vorgeprägt durch die die Schutzwürdigkeit konkretisierenden Vorgaben in § 48 II 2 und 3 VwVfG. ${ }^{1435}$

\section{Begriffsbestimmung}

Die Anwendbarkeit von § 48 II VwVfG setzt voraus, dass es sich um einen Leis- 878 tungsverwaltungsakt handelt. Wesentlich für die Abgrenzung zu Abs. 3 ist, dass aus dem Verwaltungsakt vorrangig eine finanzielle Belastung für die öffentliche Hand resultieren muss. ${ }^{1436}$ Der Gesetzgeber ging davon aus, dass die „sonstigen

Verwaltungsrecht, 17. Aufl. 2019, Rn. 703; Ramsauer, in: Kopp/Ramsauer, VwVfG, 20. Aufl. 2019, $\S 48$ Rn. 84, 127.

1434 S. zu den diesbezüglich geltenden Besonderheiten aber noch Rn. 928.

1435 Ramsauer, in: Kopp/Ramsauer, VwVfG, 20. Aufl. 2019, § 48 Rn. 94.

1436 Ramsauer, in: Kopp/Ramsauer, VwVfG, 20. Aufl. 2019, § 48 Rn. 88.

Tobias Brings-Wiesen 
Verwaltungsakte“ stärker staatsbezogen sind und es daher schwerer erträglich ist, einen rechtswidrigen Zustand aufrechtzuerhalten, als wenn es nur um fiskalische Interessen geht. ${ }^{1437}$

Ein Verwaltungsakt gewährt eine Leistung, wenn er eine Regelung enthält, die unmittelbar zu einer Vermehrung des Vermögens des Begünstigten führt. ${ }^{1438}$ Diese kann in der unmittelbaren Anspruchsbegründung, aber auch im Verzicht auf eine eigentlich bestehende Forderung, wie im Falle einer Steuerbefreiung, liegen ${ }^{1439}$. Sachleistungen umfassen zumindest alle körperlichen Gegenstände i.S.d. § 90 BGB, ${ }^{1440}$ selbst dann wenn nur der Gebrauch an ihnen überlassen wird $^{1441}$. Vor diesem Hintergrund ist auch die Teilbarkeit zu verstehen: Sie ist in sachlicher wie zeitlicher Hinsicht denkbar. ${ }^{1442}$

Es genügt indes auch, dass der Verwaltungsakt bloß Voraussetzung für eine einmalige oder laufende Geldleistung oder teilbare Sachleistung ist. Dies ist der Fall, wenn durch den Verwaltungsakt rechtliche Voraussetzungen festgestellt werden, die sich unmittelbar in Richtung einer Leistung auswirken, wie beispielsweise bei der Festsetzung des Besoldungsdienstalters. ${ }^{1443}$ Umstritten war dies lange Zeit für statusfeststellende Bescheide mit Tatbestandswirkung gegenüber allen anderen Behörden (wie im Rahmen des Staatsangehörigen- oder Asylrechts), die die Grundlage für die Gewährung weiterer Geld- oder Sachleistungen bilden. Hier scheint das Bundesverwaltungsgericht jedoch mittlerweile durchweg zwischen dem eigentlichen Statusbescheid und den an diesen anknüpfenden Bescheiden zu unterscheiden. ${ }^{1444}$

Alle anderen Verwaltungsakte, insbesondere solche die eine nicht monetäre Rechtsstellung gestalten oder feststellen ${ }^{1445}$ oder ein bestimmtes Verhalten erlauben (s. dazu Rn. 64), unterfallen § 48 III VwVfG. Dazu gehören beispielsweise die Feststellung der Asylberechtigung gemäß § 31 AsylG, die Gaststättenerlaubnis gemäß § 2 I GastG oder die Baugenehmigung auf Grundlage der einschlägigen landesbauordnungsrechtlichen Vorschriften.

1437 BT-Drucks. 7/910, S. 71. Darauf rekurrierend auch das BVerwG, Urt. v. 28.5.2015, Az.: 1 C 24.14 = BVerwGE 152, 164 (174, Rn. 29).

1438 Erichsen/Brügge, JURA 1999, 155 (158f.); Ehlers/Kallerhoff, JURA 2009, 823 (829). So für Geldleistungen BVerwG, Urt. v. 22.3.2017, Az.: 5 C 4.16 = BVerwGE 158, 258 (265, Rn. 23).

1439 S. zu weiteren Beispielen Ramsauer, in: Kopp/Ramsauer, VwVfG, 20. Aufl. 2019, § 48 Rn. 87. 1440 Suerbaum, in: Mann/Sennekamp/Uechtritz, VwVfG, 2. Aufl. 2019, § 48 Rn. 120.

1441 Ramsauer, in: Kopp/Ramsauer, VwVfG, 20. Aufl. 2019, § 48 Rn. 88.

1442 Sachs, in: Stelkens/Bonk/Sachs, VwVfG, 9. Aufl. 2018, § 48 Rn. 130.

1443 Ramsauer, in: Kopp/Ramsauer, VwVfG, 20. Aufl. 2019, § 48 Rn. 91.

1444 S. dazu nur BVerwG, Urt. v. 28.5.2015, Az.: 1 C 24.14 = BVerwGE 152, 164 (174f., Rn. 30) m.w. N.

1445 BVerwG, Urt. v. 28.5.2015, Az.: 1 C 24.14 = BVerwGE 152, 164 (174, Rn. 29). 


\section{Tatsächliches Vertrauen}

Als Grundvoraussetzung der sodann vorzunehmenden Abwägung gemäß § 48 II 1 VwVfG wird verlangt, dass auf Seiten des Begünstigten tatsächliches Vertrauen in den (Fort-)Bestand des Verwaltungsakts vorlag. Dies wird in Prüfungen selten ein Problem darstellen und höchstens dann von Interesse sein, wenn gegenteilig klar ersichtlich ist, dass der Betroffene eben nicht vertraut hat, beispielsweise weil er den Verwaltungsakt gar nicht kannte ${ }^{1446}$ oder bereits sicher von einer Aufhebung ausging ${ }^{1447}$. Wie $\S 48$ II 2 VwVfG verdeutlicht muss der Betroffene sein Vertrauen aber noch nicht „betätigt“ haben. ${ }^{1448}$

Besteht schon kein Vertrauen, kann die Prüfung von § 48 II VwVfG bereits an dieser Stelle beendet werden - es bedarf dann nur noch der Prüfung eines möglichen Rücknahmeausschlusses aufgrund von Verfristung gemäß § 48 IV VwVfG sowie der ordnungsgemäßen Ermessensausübung gemäß § 48 I 1 VwVfG.

\section{Ausschluss der Schutzwürdigkeit des Vertrauens gemäß § 48 II 3 VwVfG}

Soweit hingegen tatsächliches Vertrauen besteht, kann dessen Berücksichtigung $\mathbf{8 8 4}$ für die Abwägung gleichwohl gemäß $§ 48$ II 3 VwVfG von vornherein ausgeschlossen $^{1449}$ sein, wenn einer der dort genannten Tatbestände erfüllt ist.

Dies ist der Fall, wenn der Verwaltungsakt durch arglistige Täuschung, 885 Drohung oder Bestechung erwirkt wurde (Nr. 1). ${ }^{1450}$

Eine arglistige Täuschung liegt laut Bundesverwaltungsgericht vor, wenn $\mathbf{8 8 6}$ der Täuschende weiß und will, dass die Behörde durch insbesondere die Vorspiegelung falscher Tatsachen zum Erlass eines Verwaltungsakts veranlasst wird, den sie andernfalls nicht oder nicht mit diesem Inhalt erlassen hätte. ${ }^{1451}$ Er muss zumindest mit bedingtem Vorsatz tätig werden. ${ }^{1452}$ Sie kann durch gezielte An-

1446 Maurer/Waldhoff, Allgemeines Verwaltungsrecht, 19. Aufl. 2017, § 11 Rn. 35; Ramsauer, in: Kopp/Ramsauer, VwVfG, 20. Aufl. 2019, § 48 Rn. 97.

1447 Detterbeck, Allgemeines Verwaltungsrecht, 17. Aufl. 2019, Rn. 697.

1448 So zutreffend Ramsauer, in: Kopp/Ramsauer, VwVfG, 20. Aufl. 2019, § 48 Rn. 96; Ehlers/ Kallerhoff, JURA 2009, 823 (830); a. A. aber Sachs, in: Stelkens/Bonk/Sachs, VwVfG, 9. Aufl. 2018, $\S 48$ Rn. 136; J. Müller, in: Bader/Ronellenfitsch, VwVfG, 44. Ed., Stand: 1.1.2019, § 48 Rn. 56.

1449 So auch Detterbeck, Allgemeines Verwaltungsrecht, 17. Aufl. 2019, Rn. 698 (,ausnahmslos und ohne Wertungsmöglichkeit“); Peine/Siegel, Allgemeines Verwaltungsrecht, 12. Aufl. 2018, Rn. 731; Ramsauer, in Kopp/Ramsauer, VwVfG, 20. Aufl. 2019, § 48 Rn. 103; Sachs, in: Stelkens/ Bonk/Sachs, VwVfG, 9. Aufl. 2018, § 48 Rn. 148.

1450 Die Tatbestände in $\S 48$ II 3 Nr. 1 und 2 VwVfG sind verfassungsrechtlich nicht zu beanstanden, vgl. BVerfG, Beschl. v. 16.12.1981, Az.: 1 BvR 898/79 u. a. = BVerfGE 59, 128 (171).

1451 BVerwG, Urt. v. 22.3.2017, Az.: 5 C 4.16 = BVerwGE 158, 258 (265, Rn. 25); ähnlich bereits BVerwG, Urt. v. 9.9.2013, Az.: 1 C 6.03 = BVerwGE 119, 17 (22): „bewusste Täuschung“. 1452 Suerbaum, in: Mann/Sennekamp/Uechtritz, VwVfG, 2. Aufl. 2019, § 48 Rn. 134. 
gaben oder ein Verschweigen erfolgen. ${ }^{1453}$ Selbst beständige Zweifel auf Seiten der Behörde schließen eine Täuschung nicht aus. ${ }^{1454}$

Um eine Drohung handelt es sich, wenn einer Person ein zukünftiges Übel in Aussicht gestellt wird, um von ihr im Wege psychischen Zwangs eine bestimmte Handlung, Duldung oder Unterlassung zu erwirken. Hier kann eine Orientierung an den Begriffen des Strafrechts erfolgen, ${ }^{1455}$ die Verwirklichung eines Straftatbestands ist jedoch nicht erforderlich.

888 Um eine Bestechung handelt es sich insbesondere dann, wenn der Tatbestand des $\S 334$ I 1 StGB erfüllt ist. ${ }^{1456}$ Dies ist der Fall, wenn der Begünstigte einem für die zuständige Behörde tätigen Amtswalter einen Vorteil für diesen oder einen Dritten als Gegenleistung dafür gewährt (hat), dass jener eine Diensthandlung vorgenommen und dadurch seine Dienstpflichten verletzt hat. Eine Bestechung i.S.v. § 48 II 3 Nr. 1 VwVfG muss jedoch nicht zwingend diesen Straftatbestand erfüllen. Es genügt bereits eine Vorteilsgewährung i.S.v. § $333 \mathrm{StGB}^{1457}$ und jede andere versprochene oder erfolgte Vorteilsgewährung als Gegenleistung für einen entsprechenden verfahrenslenkenden Eingriff ${ }^{1458}$. Von Bedeutung sind insofern also nicht bloß Bestechungen von Amtswaltern, sondern auch von Zeugen. ${ }^{1459}$ Amtswalter müssen darüber hinaus die Rechtswidrigkeit des von ihnen erlassenen Verwaltungsakts nicht erkannt haben. ${ }^{1460}$

889 Der Begriff des Erwirkens verdeutlicht, dass die drei erfassten Handlungen für den Erlass des Verwaltungsakts zumindest objektiv mitursächlich gewesen sein müssen. ${ }^{1461}$ Wie bereits erwähnt müssen die Einwirkungen nicht zwingend gegenüber dem entscheidenden Amtswalter erfolgen. Bereits denklogisch verlangen alle Handlungen das Vorliegen von Vorsatz. Um ein Erwirken kann es sich auch dann handeln, wenn der Begünstigte die Handlungen nicht selbst vorge-

1453 Peuker, in: Knack/Henneke, VwVfG, 10. Aufl. 2014, § 48 Rn. 120.

1454 VGH Mannheim, Beschl. v. 9.5.1990, Az.: 13 S 2666/89 = NVwZ 1990, 1198 (1199)

1455 Kastner, in: Fehling/Kastner/Störmer, Verwaltungsrecht, 4. Aufl. 2016, § 48 VwVfG Rn. 46 1456 BVerwG, Urt. v. 22.3.2017, Az.: 5 C 4.16 = BVerwGE 158, 258 (265, Rn. 25).

1457 So zu Recht Ramsauer, in: Kopp/Ramsauer, VwVfG, 20. Aufl. 2019, § 48 Rn. 112; Kastner, in: Kastner/Fehling/Störmer, Verwaltungsrecht, 4. Aufl. 2016, § 48 VwVfG Rn. 46; Suerbaum, in: Mann/Sennekamp/Uechtritz, VwVfG, 2. Aufl. 2019, § 48 Rn. 134.

1458 J. Müller, in: Bader/Ronellenfitsch, VwVfG, 44. Ed., Stand: 1.1.2019, § 48 Rn. 70.

1459 BVerwG, Beschl.v. 27.10.2004, Az.: 4 B 74.04 = juris, Rn. 8.

1460 BVerwG, Beschl.v. 27.10.2004, Az.: 4 B 74.04 = juris, Rn. 8; Urt. v. 22.3.2017, Az.: 5 C $4.16=$ BVerwGE 158, 258 (265, Rn. 25).

1461 BVerwG, Beschl.v. 27.10.2004, Az.: 4 B 74.04 = juris, Rn. 8; Urt. v. 22.3.2017, Az.: 5 C $4.16=$ BVerwGE 158, 258 (265, Rn. 25).

Tobias Brings-Wiesen 
nommen, sondern im Wege der Anstiftung oder Beihilfe mit realisiert hat. ${ }^{1462}$ Das Handeln eines (gesetzlichen) Vertreters kann zugerechnet werden. ${ }^{1463}$

Darüber hinaus soll sich der Begünstigte nicht auf sein Vertrauen berufen können, wenn der den Verwaltungsakt durch Angaben erwirkt hat, die in wesentlicher Beziehung unrichtig oder unvollständig waren (Nr. 2).

Unrichtig sind Angaben, wenn sie schlicht nicht die objektive Tatsachenlage 891 wiedergeben. Unvollständig sind sie, wenn sie nicht dem von der Behörde erkennbar erwarteten Umfang entsprechen. ${ }^{1464}$ Entsprechende Erwartungen können bereits aus einer gesetzlichen Mitwirkungspflicht resultieren, sie können indes auch auf einen von der Behörde ausdrücklich geäußerten oder zumindest kontextual klar erkennbaren Willen zurückzuführen sein. ${ }^{1465}$ Wie hinsichtlich des Ausschlusstatbestands unter Nr. 1 wird verlangt, dass die Angaben für den Erlass des begünstigenden Verwaltungsakts mitursächlich waren. Demgegenüber ist ein Verschulden für die Anwendung des Ausschlusstatbestands unter Nr. 2 keine Voraussetzung. ${ }^{1466}$ Daher ist nicht von Bedeutung, ob der Begünstigte die Unrichtigkeit oder Unvollständigkeit kannte oder hätte kennen müssen. Wie sich auch der Gesetzesbegründung ergibt, ${ }^{1467}$ liegt der Vorschrift vielmehr die Idee einer Aufteilung von Risikosphären zugrunde. ${ }^{1468}$ So ist im Falle der Unvollstän-

1462 So bereits die Gesetzesmaterialien, BT-Drucks. 7/910, S. 70; Ramsauer, in: Kopp/Ramsauer, VwVfG, 20. Aufl. 2019, § 48 Rn. 111; Sachs, in: Stelkens/Bonk/Sachs, VwVfG, 9. Aufl. 2018, § 48 Rn. 151.

1463 BVerwG, Urt. v. 9.9.2003, Az.: 1 C 6.03 = BVerwGE 119, 17 (24): Verhalten eines Elternteils; Urt. v. 22.3.2017, Az.: 5 C 4.16 = BVerwGE 158, 258 (266, Rn. 28): Verhalten des Ehepartners. So auch Ramsauer, in: Kopp/Ramsauer, VwVfG, 20. Aufl. 2019, § 48 Rn. 114; Sachs, in: Stelkens/Bonk/ Sachs, VwVfG, 9. Aufl. 2018, § 48 Rn. 151.

1464 Ehlers/Kallerhoff, JURA 2009, 823 (830).

1465 Ehlers/Kallerhoff, JURA 2009, 823 (830). Vgl. zu einer Mitteilungspflicht auch BVerwG, Urt. v. 28.6.2012, Az.: 2 C 13.11 = BVerwGE 143, 230 (234, Rn. 18), hier indes hinsichtlich des Unterlassens der Mitteilung einer veränderten Sachlage, die zum Rechtswidrigwerden eines Dauerverwaltungsaktes geführt hat, und mangels „Erwirkens“ zu einer Berücksichtigung der Wertungen des § 48 II 3 Nr. 2 VwVfG im Rahmen der nach § 48 II 1 VwVfG erforderlichen Abwägung.

1466 BVerwG, Urt. v. 14.8.1986, Az.: 3 C 9.85 = BVerwGE 74, 357 (364); Urt. v. 20.10.1987, Az.: 9 C 255.86 = BVerwGE 78, 139 (142f.).

1467 BT-Drucks. 7/910, S. 70.

1468 Vgl. für ein besseres Verständnis des Konzepts den Sachverhalt bei BVerwG, Urt. v. 20.10. 1987, Az.: 9 C 255.86 = BVerwGE 78, 139 (142f.), für einen Fall, in dem eine Betroffene unbekannterweise unrichtige Urkunden einreichte. Hier handelt es sich insofern um ein gutes Beispiel dafür, warum ein Verschulden nicht verlangt werden kann, weil sonst die Risikoverteilung entgegen des gesetzgeberischen Willens zu stark zulasten der Behörde ginge. Dafür spricht in systematischer Hinsicht auch die Existenz von § 49a II 2 VwVfG, der gar nicht nötig wäre, wenn ein Verschulden bereits hier erfasst wäre, vgl. BVerwG, a.a.O. 
digkeit - wie bereits oben angedeutet - gegebenenfalls doch korrigierend nach Wertungsgesichtspunkten zu entscheiden, ob der Betroffene die Relevanz der Angaben erkennen konnte. ${ }^{1469}$ Die Angaben sind in wesentlicher Beziehung fehlerhaft, wenn sie für die Subsumtion unter den Tatbestand und eine gegebenenfalls erforderliche Ermessenserwägung relevant sind. ${ }^{1470}$

Zuletzt soll sich der Begünstigte nicht auf sein Vertrauen berufen können, wenn er die Rechtswidrigkeit des Verwaltungsakts kannte oder infolge grober Fahrlässigkeit nicht kannte (Nr. 3). Bezugspunkt der Kenntnis ist die Rechtswidrigkeit des Verwaltungsakts, nicht bloß die Kenntnis der Tatsachen, die diese Rechtswidrigkeit begründen. ${ }^{1471}$ Dementsprechend können die Voraussetzungen des Tatbestands auch erst zu einem späteren Zeitpunkt eintreten. ${ }^{1472}$ Wenige Schwierigkeiten wird regelmäßig die Feststellung der positiven Kenntnis der Rechtswidrigkeit bereiten. Sie wird jedoch zugleich entsprechend selten in Erscheinung treten. Relevanter sind die Konstellationen grob fahrlässiger Unkenntnis. Grobe Fahrlässigkeit liegt vor, wenn der Begünstigte die erforderliche Sorgfalt in besonders schwerem Maße verletzt hat. ${ }^{1473}$ Hinsichtlich der erforderlichen Sorgfalt gilt ein konkret-individueller Maßstab in Ansehen der konkret betroffenen Person ${ }^{1474}$ und der sonstigen Umstände des Sachverhalts. Insofern lässt sich grob abstufen: Fehlen besondere Anhaltspunkte im Sachverhalt, ist im Rahmen einer „Parallelwertung in der Laiensphäre“1475 auf das durchschnittliche Rechtsverständnis eines Normalbürgers abzustellen. ${ }^{1476}$ Da dieser grundsätzlich auf ein rechtmäßiges Handeln der Behörde vertrauen darf, wird man ihm nur im Falle offensichtlicher, sich aufdrängender Zweifel an der Rechtmäßigkeit die Pflicht auferlegen können, einen Verwaltungsakt unter Verwendung zusätzlicher Erkenntnismittel oder gar einer Erkundigung bei der Behörde zu überprüfen. ${ }^{1477}$

1469 S. dazu BVerwG, Urt. v. 6.6.1991, Az.: 3 C 46.86 = BVerwGE 88, 278 (285), unter Verweis BVerwG, Urt. v. 25.10.1978, Az.: 8 C 55.75 = BVerwGE 56, 354 (358), wo die Behörde den Mangel eines Antragsformulars gegen sich gelten lassen musste.

1470 Sachs, in: Stelkens/Bonk/Sachs, VwVfG, 9. Aufl. 2018, § 48 Rn. 154.

1471 Ramsauer, in: Kopp/Ramsauer, VwVfG, 20. Aufl. 2019, § 48 Rn. 122; Kastner, in: Fehling/ Kastner/Störmer, Verwaltungsrecht, 4. Aufl. 2016, § 48 VwVfG Rn. 48.

1472 Ramsauer, in: Kopp/Ramsauer, VwVfG, 20. Aufl. 2019, § 48 Rn. 121; Sachs, in: Stelkens/ Bonk/Sachs, VwVfG, 9. Aufl. 2018, § 48 Rn. 159.

1473 BVerwG, Urt. v. 17.2.1993, Az.: 11 C 47.92 = BVerwGE 92, 81 (84); so auch Ramsauer, in: Kopp/ Ramsauer, VwVfG, 20. Aufl. 2019, § 48 Rn. 124; Sachs, in: Stelkens/Bonk/Sachs, VwVfG, 9. Aufl. 2018, § 48 Rn. 161.

1474 So bereits die Gesetzesmaterialien, BT-Drucks. 7/910, S. 70.

1475 Ramsauer, in: Kopp/Ramsauer, VwVfG, 20. Aufl. 2019, § 48 Rn. 122.

1476 Sachs, in: Stelkens/Bonk/Sachs, VwVfG, 9. Aufl. 2018, § 48 Rn. 162.

1477 Vgl. OVG Lüneburg, Beschl.v. 31.3.2010, Az.: 4 LC 281/08 = NJW 2010, 2061 (2062).

Tobias Brings-Wiesen 
Die individuellen Kenntnisse und Fähigkeiten des Begünstigten (oder seines Vertreters ${ }^{1478}$ ) und die besonderen Umstände des Einzelfalls können jedoch die Sorgfaltsanforderungen erhöhen, so insbesondere im Falle von Unternehmen mit eigenen Rechtsabteilungen, Personen mit juristischer Vorbildung ${ }^{1479}$ oder auch Beamten ${ }^{1480}$. Es besteht jedoch auch in diesem Fall keine generelle, anlasslose Nachforschungspflicht. ${ }^{1481}$

Greift einer dieser drei Tatbestände, kann die Prüfung von § 48 II VwVfG an dieser Stelle beendet werden: Da der Begünstigte sich gemäß § 48 II 3 VwVfG nicht auf sein Vertrauen berufen kann, überwiegt gemäß § 48 II 1 VwVfG zwangsläufig das öffentliche Interesse an der Rücknahme des Verwaltungsakts. ${ }^{1482}$ Wiederum bedarf es dann nur noch der Prüfung eines möglichen Rücknahmeausschlusses aufgrund von Verfristung gemäß § 48 IV VwVfG sowie der ordnungsgemäßen Ermessensausübung gemäß § 48 I 1 VwVfG. Dabei sind jedoch sodann zwei Besonderheiten $\mathrm{zu}$ berücksichtigen: Sofern von einer Erwirkung des Verwaltungsakts durch arglistige Täuschung, Drohung oder Bestechung (§ 48 II 3 Nr. 1 VwVfG) ausgegangen wird, ist die Anwendung der Fristenregelung gemäß § 48 IV 2 VwVfG ausgeschlossen (s. dazu Rn. 906). Wird nur einer der Ausschlusstatbestände bejaht, bestimmt § 48 II 4 VwVfG, dass der Verwaltungsakt in der Regel mit Wirkung für die Vergangenheit zurückzunehmen ist (s. dazu Rn. 927).

\section{Regelvermutung des \$ 48 II 2 VwVfG}

Greift indes keiner der Ausschlusstatbestände, kann nun § 48 II 2 VwVfG umgekehrt zum Vorteil des Begünstigten wirken. Danach ist sein Vertrauen in der Regel schutzwürdig, wenn er die gewährte Leistung verbraucht oder eine Vermögensdisposition getroffen hat, die er nicht mehr oder nur unter unzumutbaren Nachteilen rückgängig machen kann. An dieser Stelle wird die Vertrauensbetätigung relevant. Bereits der Wortlaut (,in der Regel“) verdeutlicht, dass damit die nach § 48 II 1 VwVfG eigentlich erforderliche Abwägung keineswegs vorweggenommen wird. Sie wird jedoch entscheidend vorgeprägt (s. dazu Rn. 899).

1478 Ramsauer, in: Kopp/Ramsauer, VwVfG, 20. Aufl. 2019, § 48 Rn. 123.

1479 Ramsauer, in: Kopp/Ramsauer, VwVfG, 20. Aufl. 2019, § 48 Rn. 125.

1480 BVerwG, Urt.v. 13.11.1986, Az.: 2 C 29.84 = NVwZ 1987, 500, betr. einen Ruhestandsbeamten. 1481 Vgl. dazu im beihilferechtlichen Kontext BVerwG, Urt. v. 17.2.1993, Az.: 11 C $47.92=$ BVerwGE 92, 81 (84), allerdings noch zur alten Rechtslage, bevor mit der ersten einschlägigen Mitteilung der Kommission (ABl. EG Nr. C 318 v. 24.11.1983, S. 3) allgemein auf die Möglichkeit einer Rückforderung bei fehlender Notifikation gemäß dem - heutigen - Art. 108 III AEUV hingewiesen wurde. S. zu diesem Themenkomplex noch Rn. 935.

1482 So auch Ehlers/Kallerhoff, JURA 2009, 823 (830). 
Die gewährten Leistungen sind verbraucht, wenn sie sich bei wirtschaftlicher Betrachtung nicht mehr im Vermögen des Begünstigten befinden. Dabei sind laut Bundesverwaltungsgericht die zivilrechtlichen Grundsätze zum Umfang des Bereicherungsanspruchs nach $\S 818$ BGB heranzuziehen. ${ }^{1483}$ Entsprechend § 818 III BGB ist somit insbesondere eine mögliche Entreicherung zu prüfen, die jedoch dann nicht gegeben ist, wenn eine (Geld-)Leistung verwendet wurde, um Anschaffungen vorzunehmen, die sich wertmäßig noch im Vermögen des Begünstigten befinden ${ }^{1484}$ oder nur Ausgaben erspart wurden, die auch sonst bestanden hätten, ${ }^{1485}$ insbesondere im Falle der Schuldentilgung ${ }^{1486}$. Handelte es sich dagegen um (nur geringfügig gesteigerte ${ }^{1487}$ ) Ausgaben des täglichen Lebens, ${ }^{1488}$ denen insbesondere die Leistungsgewährung auch dienen soll, ${ }^{1489}$ ist von einer Entreicherung auszugehen.

896 Der Begriff der Vermögensdispositionen wird weit ausgelegt. Dazu gehören all jene Verhaltensweisen des Begünstigten, die im Vertrauen auf den begünstigenden Verwaltungsakt erfolgt sind und Auswirkungen auf seine Vermögenssituation haben. ${ }^{1490}$ Der Ursachenzusammenhang ist dabei von besonderer Bedeutung. ${ }^{1491}$ Dies ist insbesondere mit Blick auf $\S 48$ III VwVfG von Relevanz, für den sowohl hinsichtlich des Entschädigungsanspruchs ${ }^{1492}$ als auch hinsichtlich der Ermessensausübung (s. dazu Rn. 928) auf (die Wertungen des) § 48 II VwVfG zurückzugreifen ist. So kann beispielsweise im kostenpflichtigen Erstellenlassen von Bauplänen im Vertrauen auf eine Baugenehmigung ${ }^{1493}$ oder im Inverkehrbringen von BSE-belastetem Fleisch im Vertrauen auf eine Genusstauglichkeitsbescheinigung, weil sich der Hersteller möglichen Ersatzansprüchen seiner Abnehmer aussetzt, eine Vermögensdisposition liegen. ${ }^{1494}$ Hinzukommen muss jedoch, dass die Disposition nicht mehr oder nur unter unzumutbaren

1483 BVerwG, Urt. v. 28.1.1993, Az.: 2 C 15.91 = NVwZ-RR 1994, 32 (33).

1484 S. dazu BVerwG, Urt. v. 28.1.1993, Az.: 2 C 15.91 = NVwZ-RR 1994, 32 (33).

1485 VGH München, Beschl. v. 24.9.2002, Az.: 19 B 98.945 = BeckRS 2003, 20336.

1486 BVerwG, Urt. v. 28.1.1993, Az.: 2 C 15.91 = NVwZ-RR 1994, 32 (33).

1487 BVerwG, Urt. v. 28.1.1993, Az.: 2 C 15.91 = NVwZ-RR 1994, 32 (33).

1488 Ehlers/Kallerhoff, JURA 2009, 823 (831).

1489 Vgl. Maurer/Waldhoff, Allgemeines Verwaltungsrecht, 19. Aufl. 2017, § 11 Rn. 37: „Besoldungsbezüge, Renten, Stipendien“.

1490 Ramsauer, in: Kopp/Ramsauer, VwVfG, 20. Aufl. 2019, § 48 Rn. 109; OVG Münster, Urt. v. 9.5. 2011, Az.: 1 A 88/08 = BeckRS 2011, 51124 .

1491 OVG Münster, Urt. v. 9.5.2011, Az.: 1 A 88/08 = BeckRS 2011, 51124.

1492 BVerwG, Urt. v. 28.1.2010, Az.: 3 C 17.09 = BVerwGE 136, 43 (45f., Rn. 12).

1493 Ramsauer, in: Kopp/Ramsauer, VwVfG, 20. Aufl. 2019, § 48 Rn. 109.

1494 BVerwG, Urt. v. 28.1.2010, Az.: 3 C 17.09 = BVerwGE 136, 43 (46f., Rn. 16)

Tobias Brings-Wiesen 
Nachteilen rückgängig ${ }^{1495} \mathrm{zu}$ machen ist. Sie können bereits aus tatsächlichen Gründen irreversibel sein - so wie in den genannten Beispielen der Bauplan als Werkleistung nicht einfach wieder verschwinden, das Inverkehrbringen nicht ungeschehen gemacht werden kann. Denkbar ist aber auch, dass Rückabwicklungen von Rechts wegen unmöglich sind. ${ }^{1496}$ Die Unzumutbarkeit einer Rückabwicklung ist indes nach den individuellen Verhältnissen des Betroffenen zu beurteilen. ${ }^{1497}$

\section{Abschließende Abwägung zwischen schutzwürdigem Vertrauen und öf- fentlichem Interesse gemäß § 48 II 1 VwVfG}

Nach Abschluss der drei vorstehenden Prüfungspunkte darf die nach $\S 48$ II 1897 VwVfG erforderliche Abwägung als Ausgangspunkt dieses Prüfungsabschnitts nicht unterschlagen werden. Es ist zu prüfen, ob das Vertrauen des Begünstigten auf den Bestand des Verwaltungsakts unter Abwägung mit dem öffentlichen Interesse an einer Rücknahme schutzwürdig ist. Es muss „eine wertende Abwägung der Gesichtspunkte, die für eine Aufrechterhaltung des begünstigenden Hoheitsaktes sprechen, gegen das öffentliche Interesse an der Herstellung des an sich nach den maßgeblichen Rechtsvorschriften gebotenen Rechtszustandes“ erfolgen. ${ }^{1498}$

Auf Seiten der Behörde steht das dem Grundsatz der Gesetzmäßigkeit der 898 Verwaltung entspringende Interesse an der Wiederherstellung rechtmäßiger Zustände. Die dem einschlägigen Fachrecht zugrundeliegenden Regulierungsinteressen können dieses allgemeine Interesse im Einzelfall verstärken. Daneben tritt im Falle von Leistungsverwaltungsakten auch das fiskalische Interesse des Staates an der Vermeidung ungerechtfertigter Ausgaben ${ }^{1499}$ und deren Rückführung in den Haushalt ${ }^{1500}$. Handelt es sich um auf einem Dauerverwaltungsakt

1495 Detterbeck, Allgemeines Verwaltungsrecht, 17. Aufl. 2019, Rn. 700, plädiert im Interesse des Gleichlaufs darüber hinaus für eine entsprechende Anwendung der zivilrechtlichen Grundsätze des Bereicherungsrechts auch auf Vermögensdispositionen.

1496 OVG Münster, Urt. v. 9.5.2011, Az.: 1 A 88/08 = BeckRS 2011, 51124.

1497 J. Müller, in: Bader/Ronellenfitsch, VwVfG, 44. Ed., Stand: 1.1.2019, § 48 Rn. 67.

1498 Vgl. BVerwG, Urt.v. 31.8.2006, Az.: 7 C 16.05 = juris, Rn. 24; Urt. v. 19. 2. 2009, Az.: 8 C 4.08 = juris, Rn. 45; VGH München, Urt. v. 9.3.1999, Az.: 9 B 96.1786 = juris, Rn. 27; OVG Bautzen, Urt. v. 19.2.2008, Az.: 1 B 538/06 = juris, Rn. 24; Ramsauer, in: Kopp/Ramsauer, VwVfG, 20. Aufl. 2019, $\S 48$ Rn. 98.

1499 BVerwG, Beschl. v. 25.6.1986, Az.: 1 WB 166.84 = BVerwGE 83, 195 (199); Urt. v. 31.8.2006, Az.: 7 C 16.05 = juris, Rn. 25.

1500 Ramsauer, in: Kopp/Ramsauer, VwVfG, 20. Aufl. 2019, § 48 Rn. 99. 
beruhende, regelmäßig wiederkehrende Leistungen wird für die Zukunft häufig ein erhebliches fiskalisches Interesse daran bestehen, dass diese Leistungen nicht weitergezahlt werden. ${ }^{1501}$ Eine derartige Differenzierung in zeitlicher Hinsicht (Vergangenheit - Zukunft) ist ausweislich des Wortlauts („,soweit“) genauso möglich wie ein bloß sachlich anteiliger Vertrauensschutz.

Auf Seiten des Begünstigten sind alle im unmittelbaren Zusammenhang mit seinem Vertrauen auf den Bestand des Verwaltungsakts stehenden Erwägungen zu berücksichtigen. Vorrangig ist zu beachten, dass im Falle einer Vertrauensbetätigung gemäß $\S 48$ II 2 VwVfG das öffentliche Interesse an der Wiederherstellung gesetzmäßiger Verhältnisse nur noch in Ausnahmefällen überwiegen soll. ${ }^{1502}$ Zusätzlich sind die das Vertrauen erzeugenden oder vernichtenden Umstände in die Betrachtung einzubeziehen, soweit sie nicht bereits durch $\S 48$ II 2, 3 VwVfG Berücksichtigung gefunden haben: Ein Fehlen jeglicher Mitverantwortung des Begünstigten für die Fehlerhaftigkeit, eine besondere Förmlichkeit des Verfahrens oder ein besonders langer Zeitraum seit Erlass des Verwaltungsakts können für die Schutzwürdigkeit sprechen; ein Widerrufsvorbehalt oder eine aus sonstigen Gründen bestehende Erwartung der Aufhebung können dagegen sprechen. ${ }^{1503}$ Der Schutz des Vertrauens soll jedoch kein Selbstzweck sein, sondern gerade die dahinterstehenden materiellen Rechte des Begünstigten in den Blick nehmen. ${ }^{1504}$ Entsprechend sind auch die Folgen der Rücknahme und ihre Verhältnismäßigkeit im Hinblick auf die Rechtsgüter des Begünstigten zu berücksichtigen. ${ }^{1505} \mathrm{Zu}$ weit geht es jedoch, bereits im Tatbestand die schutzwürdigen Interessen aller Betroffenen zu berücksichtigen. ${ }^{1506}$ Dagegen spricht bereits der Wortlaut der Norm, der klar auf das Vertrauen des Begünstigten abstellt. Dies ist vielmehr eine Frage der ordnungsgemäßen Ermessensausübung (s. Rn. 927).

1501 BVerwG, Urt.v. 28.10.2004, Az.: 2 C 13.03 = NVwZ-RR 2005, 341 (342). Dieses muss aber nicht zwingend immer zur Rücknahme führen, vgl. die Umstände in BVerwG, Urt. v. 26.9.1991, Az.: 5 C 14.87 = NVwZ-RR 1992, 485 (486).

1502 Ramsauer, in: Kopp/Ramsauer, VwVfG, 20. Aufl. 2019, § 48 Rn. 103.

1503 J. Müller, in: Bader/Ronellenfitsch, VwVfG, 44. Ed., Stand: 1.1.2019, § 48 Rn. 60. S. dazu auch Peuker, in: Knack/Henneke, VwVfG, 10. Aufl. 2014, § 48 Rn. $111 \mathrm{ff}$.

1504 Vgl. VG Oldenburg, Urt. v. 23.5.2001, Az.: 2 A 790/99 = NVwZ 2002, 119 (121); J. Müller, in: Bader/Ronellenfitsch, VwVfG, 44. Ed., Stand: 1.1.2019, § 48 Rn. 60.

1505 Maurer/Waldhoff, Allgemeines Verwaltungsrecht, 19. Aufl. 2017, §11 Rn. 38. Vgl. auch BVerwG, Urt. v. 11.2.1982, Az.: 2 C 9.81 = BeckRS 1982, 31268995.

1506 So aber Ramsauer, in: Kopp/Ramsauer, VwVfG, 20. Aufl. 2019, § 48 Rn. 101; wohl auch Maurer/Waldhoff, Allgemeines Verwaltungsrecht, 19. Aufl. 2017, § 11 Rn. 38. 


\section{(b) Sonstige Verwaltungsakte}

Für die Rücknahme sonstiger Verwaltungsakte enthält §48 III VwVfG zwar 900 keine zusätzlichen Tatbestandsvoraussetzungen.

Die Norm enthält aber einen eigenen Entschädigungsanspruch zugunsten 901 des Betroffenen. Bereits diese Unterscheidung ist elementar: Wird die Rücknahmeentscheidung der Behörde geprüft, ist § 48 III VwVfG im Tatbestand unter keinen Umständen näher zu prüfen. Alles andere zeugte von fehlendem Systemverständnis. Sehr wohl Erwähnung finden kann er allerdings im Rahmen der Prüfung der ordnungsgemäßen Ermessensausübung, dies jedoch - wie noch zu zeigen sein wird (s. dazu Rn. 928) - nur in zweierlei Hinsicht: Das schutzwürdige Vertrauen des Begünstigten ist - nach richtiger Auffassung - unter Berücksichtigung der Wertungen, die in $§ 48 \mathrm{II}$ VwVfG ihren Ausdruck gefunden haben, ${ }^{1507}$ sowie unter Berücksichtigung der Möglichkeit, dieses im Wege des Entschädigungsanspruchs nach § 48 III VwVfG zu realisieren, in die Ermessensausübung einzubeziehen. ${ }^{1508}$

Der Entschädigungsanspruch an sich kommt ausweislich § 48 III 1 VwVfG 902 erst in Frage, wenn eine wirksame Rücknahmeentscheidung der Behörde vorliegt. Auch hieran zeigt sich noch einmal, dass zwischen beiden Fragestellungen zwingend zu trennen ist. Der Ausgleich des ihm entstandenen Vermögensnachteils erfolgt nur auf Antrag des Betroffenen und wird von der Behörde gemäß $\S 48$ III 4 VwVfG durch Verwaltungsakt festgesetzt. Kommt es also zu einer Ablehnung des Antrags, kann der Betroffene Festsetzung der Entschädigung im Wege des Widerspruchs (§ $68 \mathrm{II}$ VwGO) bzw. im Wege der Verpflichtungsklage (§ 42 I Var. 2 VwGO, in Form der Versagungsgegenklage) erzwingen. ${ }^{1509}$ Entsprechend ist er wegen der öffentlich-rechtlichen Natur des Entschädigungsanspruchs auf dem Verwaltungsrechtsweg geltend zu machen. ${ }^{1510}$

In der Prüfung sollte wie folgt vorgegangen werden: ${ }^{1511}$ Anspruchsgrundlage 903 ist $§ 48$ III 1 VwVfG. In formeller Hinsicht bedarf es gemäß § 48 III 1 VwVfG des Antrags bei der Behörde, die den Verwaltungsakt zurückgenommen hat. In materieller Hinsicht muss (1) ein rechtswidriger begünstigender Verwaltungsakt

1507 Unter Rekurs auf diese „Wertungen“ wird kenntlich, dass die Vorschrift keineswegs unmittelbar angewandt wird.

1508 S. dazu nur Ehlers/Kallerhoff, JURA 2009, 823 (832).

1509 Ramsauer, in: Kopp/Ramsauer, VwVfG, 20. Aufl. 2019, § 48 Rn. 144.

1510 Maurer/Waldhoff, Allgemeines Verwaltungsrecht, 19. Aufl. 2017, § 11 Rn. 52.

1511 S. dazu m.w. N. nur Maurer/Waldhoff, Allgemeines Verwaltungsrecht, 19. Aufl. 2017, § 11 Rn. $49 \mathrm{ff}$. 
i.S.v. § 48 I 2, III VwVfG (2) wirksam ${ }^{1512}$ zurückgenommen worden sein, wodurch (3) dem Antragssteller ein Vermögensnachteil entstanden ist, der (4) darauf zurückgeht, dass er auf den Bestand des Verwaltungsakts vertraut hat, soweit sein Vertrauen unter Abwägung mit dem öffentlichen Interesse schutzwürdig ist (was entgegen der Beschränkung des Verweises in § 48 III 2 VwVfG auf § 48 II 3 VwVfG jedoch unter entsprechender Berücksichtigung der Wertungen des § 48 II VwVfG insgesamt $\mathrm{zu}$ erfolgen hat ${ }^{1513}$ ). Zuletzt (5) darf der Anspruch insbesondere nicht gemäß § 48 III 5 VwVfG verfristet sein, wobei die Frist erst nach einem entsprechenden Hinweis der Behörde zu laufen beginnt.

904 Gerichtet ist der Anspruch auf den Ausgleich des durch die Rücknahme entstandenen Vertrauensschadens, wobei jedoch ein Mitverschulden des Betroffenen entsprechend reduzierend berücksichtigt werden kann ${ }^{1514}$.

\section{(c) Kein Ausschluss aufgrund von Verfristung gemäß § 48 IV VwVfG}

905 Gemäß § 48 IV 1 VwVfG kann die Rücknahme eines begünstigenden Verwaltungsakts $^{1515}$ ausnahmsweise ${ }^{1516}$ ausgeschlossen ${ }^{1517}$ sein, wenn die zuständige Behörde diese nicht innerhalb eines Jahres, nachdem sie von Tatsachen Kenntnis erlangt hat, welche die Rücknahme rechtfertigen, bekanntgibt ${ }^{1518}$. Die Vorschrift ist das letzte Glied der Kette von dem Vertrauensschutz des Begünstigten dienenden Vorgaben in $\S 48$ VwVfG. Sie kann spezialgesetzlich verdrängt oder ergänzt werden. ${ }^{1519}$ Gemäß $\S \S 49$ II 2, III 2 VwVfG gilt sie entsprechend für den Widerruf von begünstigenden Verwaltungsakten. Ihre Anwendung zwischen Verwaltungsträgern ist umstritten. ${ }^{1520}$

1512 Maßgeblich wird insbesondere eine etwaige Nichtigkeit sein, vgl. dazu OVG Münster, Urt. v. 12.7.2012, Az.: 10 A 1769/10 = NVwZ-RR 2012, 953 (954).

1513 S. nur BVerwG, Urt. v. 28.1.2010, Az.: 3 C 17.09 = BVerwGE 136, 43 (45f., Rn. 12).

1514 Ramsauer, in: Kopp/Ramsauer, VwVfG, 20. Aufl. 2019, § 48 Rn. 142.

1515 Der Ausschlusstatbestand gilt angesichts des klaren Wortlauts von § 48 I 2 VwVfG nicht für belastende Verwaltungsakte, Ramsauer, in: Kopp/Ramsauer, VwVfG, 20. Aufl. 2019, § 48 Rn. 150; Sachs, in: Stelkens/Bonk/Sachs, VwVfG, 9. Aufl. 2018, § 48 Rn. 199.

1516 Das zeitlich unbeschränkte Rücknahmerecht bleibt die Regel, während sein Ausschluss die Ausnahme bildet, Sachs, in: Stelkens/Bonk/Sachs, VwVfG, 9. Aufl. 2018, § 48 Rn. 203.

1517 Es handelt sich um eine Ausschlussfrist, Sachs, in: Stelkens/Bonk/Sachs, VwVfG, 9. Aufl. 2018, § 48 Rn. 204.

1518 Dies ist jedoch umstritten, dazu ausführlich Broscheit, DVBl 2017, 1274. Ebenso auf den Zeitpunkt der Bekanntgabe abstellend Ramsauer, in: Kopp/Ramsauer, VwVfG, 20. Aufl. 2019, § 48 Rn. 152; J. Müller, in: Bader/Ronellenfitsch, VwVfG, 44. Ed., Stand: 1.1.2019, § 48 Rn. 117.2.

1519 Sachs, in: Stelkens/Bonk/Sachs, VwVfG, 9. Aufl. 2018, § 48 Rn. 203.

1520 Gegen eine Anwendbarkeit Sachs, in: Stelkens/Bonk/Sachs, VwVfG, 9. Aufl. 2018, § 48 Rn. 202, m.w. N. auch zur Gegenansicht.

Tobias Brings-Wiesen 
Der Ausschlusstatbestand ist gemäß § 48 IV 2 VwVfG nicht anwendbar, 906 wenn der Begünstigte den Verwaltungsakt gemäß § 48 II 3 Nr. 1 VwVfG durch arglistige Täuschung, Drohung oder Bestechung erwirkt hat. Obgleich nicht klar ersichtlich gilt dies auch für Verwaltungsakte, die gemäß § 48 III VwVfG zurückzunehmen sind, ${ }^{1521}$ obwohl für sie die Ausschlusstatbestände des $§ 48$ II 3 VwVfG sonst höchstens im Rahmen des Ermessens Berücksichtigung finden (s. dazu Rn. 901). Diese Verwaltungsakte sind zeitlich unbeschränkt rücknehmbar. ${ }^{1522}$

Bei § 48 IV 1 VwVfG handelt es sich sodann um eine der meistdiskutier- 907 ten Vorschriften des allgemeinen Verwaltungsrechts. Die zahlreichen, über mehrere Jahrzehnte unter Auseinandersetzung mit verschiedenen Entwicklungen in der Rechtsprechung vertretenen Ansätze zu ihrer Auslegung können und sollen an dieser Stelle nicht umfassend - schon gar nicht unter Berücksichtigung all ihrer Nuancierungen - dargestellt werden. Wichtig ist jedoch, zumindest die drei zentralen Problemkomplexe und die sie betreffenden Grundpositionen richtig zu erfassen. Sie sind beständig wiederkehrende Probleme verwaltungsrechtlicher Prüfungen.

(1) Umstritten ist zunächst, was i.S.d. Vorschrift unter „Tatsachen [...], 908 welche die Rücknahme eines rechtswidrigen Verwaltungsakts rechtfertigen“, zu verstehen ist. Von diesem Verständnis hängt nicht nur der Fristbeginn ${ }^{1523}$, sondern maßgeblich bereits der Anwendungsbereich der Vorschrift ab. Um die Kontroverse um die Auslegung zu verstehen, ist es hilfreich, sich vorab vor Augen $\mathrm{zu}$ führen, dass der Erlass eines bereits ursprünglich rechtswidrigen Verwaltungsakts auf Fehler zurückzuführen sein kann, die zwei unterschiedlichen Fehlerkreisen entspringen: Entweder ist die Behörde bereits von einem unvollständigen oder falschen Sachverhalt ausgegangen oder sie hat bei umfassender und richtiger Erfassung der Faktenlage nur das einschlägige Recht falsch angewendet. Fehler aus beiden Kreisen können letztlich die Rechtswidrigkeit eines Verwaltungsakts begründen, ${ }^{1524}$ bei Letzteren handelt es sich jedoch um reine ${ }^{1525}$

1521 Vgl. nur BVerwG, Urt.v. 23.5.1995, Az.: 1 C 3.94 = BVerwGE 98, 298 (312); Sachs, in: Stelkens/ Bonk/Sachs, VwVfG, 9. Aufl. 2018, § 48 Rn. 209.

1522 Sachs, in: Stelkens/Bonk/Sachs, VwVfG, 9. Aufl. 2018, § 48 Rn. 201.

1523 Die Frist beginnt anders als bspw. nach $\S 45$ III SGB X nicht mit der Bekanntgabe des zurückzunehmenden Verwaltungsakts.

1524 So auch der Große Senat des BVerwG, Beschl. v. 19.12.1984, Az.: BVerwG Gr. Sen. 1 und 2.84 = BVerwGE 70, 356 (358).

1525 Hierin liegt der zentrale Unterschied. Auch das Zugrundelegen eines unvollständigen oder unrichtigen Sachverhalts führt im Ergebnis zu einer falschen Rechtsanwendung, deren Ursprung liegt jedoch in einer falschen Vorstellung von der Wirklichkeit und nicht in einer falschen Vorstellung vom Recht begründet. 
Rechtsanwendungsfehler. Umstritten ist nun, ob beide Fehlerkreise auch von $\S 48$ IV VwVfG erfasst werden.

909 So wird vertreten, dass mit „Tatsachen [...], welche die Rücknahme eines rechtswidrigen Verwaltungsakts rechtfertigen“, ausschließlich die tatsächlichen Umstände des dem Verwaltungsakt zugrundeliegenden Sachverhalts gemeint sind. Daraus werden sodann wiederum zwei unterschiedliche Schlussfolgerungen abgeleitet: Eine Ansicht ${ }^{1526}$ schließt daraus, dass erst später erkannte Rechtsanwendungsfehler für den Fristbeginn unerheblich sind. Ist der Sachverhalt zum Zeitpunkt der Entscheidung ${ }^{1527}$ ausermittelt, beginnt deren Lauf folglich bereits mit dem Erlass des Verwaltungsakts, ${ }^{1528}$ sodass eine danach eintretende positive Kenntnis der Behörde von ihrem Rechtsanwendungsfehler irrelevant sein soll. Eine andere Ansicht ${ }^{1529}$ schließt daraus hingegen, dass die Ausschlussfrist auf Rechtsanwendungsfehler schlicht nicht anwendbar ist, was wiederum eine unbefristete Rücknahme ermöglicht.

Die Gegenansicht, die insbesondere vom Bundesverwaltungsgericht ${ }^{1530}$ vertreten wird, wendet $\S 48$ IV VwVfG indes auch auf besagte reine Rechtsanwendungsfehler an, sprich „Fälle, in denen die Behörde bei voller Kenntnis des entscheidungserheblichen Sachverhalts unrichtig entschieden hat"1531 und dies nachträglich erkennt. Zwar verlangt die Norm nach „Tatsachen“, dieser Terminus soll jedoch in seinem sprachlichen Zusammenhang verstanden werden: Verlangt sind eben „Tatsachen“, die eine Rücknahme „rechtfertigen“. Wie dargelegt kann der Grund für eine Rücknahme jedoch auch in einem Rechtsanwendungsfehler liegen, ohne dass die Vorschrift näher zwischen beiden Fehlerkreisen unterscheiden würde. ${ }^{1532}$ Dies soll auch vor dem Hintergrund überzeugen, dass sich beide Kreise nicht nur schwer voneinander abgrenzen lassen, sondern bisweilen

1526 So noch BVerwG, Urt.v. 25. 6.1982, Az.: 8 C 122.81 = BVerwGE 66, 61 (63ff.); OVG Berlin, Urt.v. 29.10.1982, Az.: OVG 2 B 153/80 = NJW 1983, 2156.

1527 Der Anwendungsbereich der Vorschrift ist nicht beschränkt auf Fälle nachträglicher Kenntnisnahme, BVerwG, Urt. v. 25.6.1982, Az.: 8 C 122.81 = BVerwGE 66, 61 (63).

1528 Nicht aber bereits zu einem tatsächlich denkbaren früheren Zeitpunkt, da die Rücknahme denklogisch erst nach dem Erlass möglich wird, BVerwG, Urt. v. 25.6.1982, Az.: 8 C $122.81=$ BVerwGE 66, 61 (64f.).

1529 So noch VGH München, Urt. v. 20.5.1983, Az.: 23 B 81 A.1968 = DVBl 1983, 946 (947f.); OVG Münster, Urt. v. 24.7.1984, Az.: 13 A 1910/83 = NVwZ 1984, 734.

1530 Grundlegend Großer Senat des BVerwG, Beschl. v. 19.12.1984, Az.: BVerwG Gr. Sen. 1 und 2.84 = BVerwGE 70, 356 (357 ff.); zuletzt ausdrücklich aufrechterhalten in Beschl.v. 29. 8. 2014, Az.: 4 B 1.14 = juris, Rn. 4 ff. Zum Meinungsstand vor dem Beschluss des Großen Senats, a.a.O., s. Hendler, JuS 1985, 947 (947 ff.).

1531 BVerwG, Beschl. v. 19.12.1984, Az.: BVerwG Gr. Sen. 1 und 2.84 = BVerwGE 70, 356 (357). 1532 BVerwG, Beschl. v. 19.12.1984, Az.: BVerwG Gr. Sen. 1 und 2.84 = BVerwGE 70, 356 (358f.). 
ununterscheidbar überlagern. ${ }^{1533}$ In systematischer Hinsicht wird zusätzlich auf den Ausnahmetatbestand des §48 IV 2 VwVfG verwiesen, der durch die Inbezugnahme von § 48 II 3 Nr. 1 VwVfG auch Konstellationen der Drohung oder Bestechung erfasse, bei denen die Rechtswidrigkeit des Verwaltungsakts (regelmäßig) nur auf reinen Rechtsanwendungsfehlern beruht und der folglich deren Subsumtion unter § 48 IV 1 VwVfG voraussetze, um nicht mehrheitlich überflüssig zu sein. ${ }^{1534}$ Dies soll zuletzt auch der Telos der Norm bestätigen: Soll im Interesse der Gesetzmäßigkeit der Verwaltung die grundsätzliche Möglichkeit der Rücknahme bei Rechtswidrigkeit bestehen, ist nicht ersichtlich, warum die beiden Fehlerkreise unterschiedlich behandelt werden sollten. ${ }^{1535}$ Den beiden genannten Gegenansichten (s. dazu Rn. 909) gelinge es nicht auf die gleiche Art und Weise die widerstreitenden Interessen (Gesetzmäßigkeit der Verwaltung; Rechtssicherheit und Vertrauensschutz) in Ausgleich zu bringen. Angesichts all dessen ${ }^{1536}$ überzeugt die Position des Bundesverwaltungsgerichts. ${ }^{1537}$

(2) Daran anknüpfend stellt sich sodann die Frage, wann im Sinne der Vorschrift „Kenntnis“ vorliegt und somit die Jahresfrist zu laufen beginnt. Diesbezüglich werden im Wesentlichen zwei Positionen vertreten, die die Frist des $\S 48$ IV 1 VwVfG entweder im Sinne einer „Bearbeitungsfrist“ oder im Sinne einer „Entscheidungsfrist“ interpretieren.

Eine starke Ansicht in der Literatur erkennt eine Bearbeitungsfrist. ${ }^{1538}$ Der 912 Fristlauf soll in dem Moment beginnen, in dem die Behörde Kenntnis von der Tatsache erlangt, die die Rechtswidrigkeit des Verwaltungsakts und somit dessen Rücknehmbarkeit begründet. Insbesondere das Bundesverwaltungsgericht sieht in § 48 IV 1 VwVfG jedoch eine Entscheidungsfrist: Neben der Rechtswidrigkeit des Verwaltungsakts müssten die für die Rücknahme außerdem erhebli-

1533 BVerwG, Beschl.v. 19.12.1984, Az.: BVerwG Gr. Sen. 1 und 2.84 = BVerwGE 70, 356 (360 f.). 1534 BVerwG, Beschl. v. 19.12.1984, Az.: BVerwG Gr. Sen. 1 und 2.84 = BVerwGE 70, 356 (359). 1535 BVerwG, Beschl.v. 19.12.1984, Az.: BVerwG Gr. Sen. 1 und 2.84 = BVerwGE 70, 356 (359f.). 1536 Der Große Senat des BVerwG, Beschl. v. 19.12.1984, Az.: BVerwG Gr. Sen. 1 und $2.84=$ BVerwGE 70, 356 (361f.), findet zuletzt auch Bestätigung in den Gesetzesmaterialien, die jedoch mindestens wenig ergiebig scheinen, so auch Weides, DÖV 1985, 431 (433f.); noch kritischer Pieroth, NVwZ 1984, 681 (686); Kopp, DVBl 1985, 525 (525f.); Schoch, NVwZ 1985, 880 (883).

1537 A.A. aber u.a. Sachs, in: Stelkens/Bonk/Sachs, VwVfG, 9. Aufl. 2018, § 48 Rn. 223 ff.; J. Müller, in: Bader/Ronellenfitsch, VwVfG, 44. Ed., Stand: 1.1.2019, § 48 Rn. 110.1; Pieroth, NVwZ 1984, 681 (685f.); Kopp, DVBl 1985, 525 (525f.); Schoch, NVwZ 1985, 880 (883f.); Ehlers/ Kallerhoff, JURA 2009, 823 (834).

1538 Maurer/Waldhoff, Allgemeines Verwaltungsrecht, 19. Aufl. 2017, §11 Rn. 44; Detterbeck, Allgemeines Verwaltungsrecht, 17. Aufl. 2019, Rn. 713; Peine/Siegel, Allgemeines Verwaltungsrecht, 12. Aufl. 2018, Rn. 628; Suerbaum, in: Mann/Sennekamp/Uechtritz, VwVfG, 2. Aufl. 2019, $\S 48$ Rn. 196 f. m.w.N. 
chen Tatsachen, insbesondere die für die nach § 48 II VwVfG erforderliche Abwägung und die Ermessensausübung relevanten Umstände, vollständig bekannt sein. Die Frist beginne daher erst zu laufen, wenn die Behörde ohne weitere Sachaufklärung objektiv in der Lage sei, zu entscheiden. ${ }^{1539}$

Wortlaut und Genese der Vorschrift sind für die Beantwortung dieser Streitfrage unergiebig - sie lassen sich in beide Richtungen interpretieren. ${ }^{1540}$ Somit rückt insbesondere ihr Telos in den Vordergrund. Das Bundesverwaltungsgericht argumentiert, der Zweck der Vorschrift, mit Ablauf der Frist den Rücknahmefall unter Herstellung eines gesetzmäßigen Zustands abgeschlossen zu haben, könne nur unvollkommen erfüllt werden, wenn die Behörde bereits vor Entscheidungsreife gezwungen wäre, zu entscheiden. ${ }^{1541}$ Dem wird jedoch zu Recht entgegengehalten, dass bei Annahme einer „Entscheidungsfrist“ der gleichsam zu beachtende Zweck der Schaffung von Rechtssicherheit durch praktische Entwertung der Fristenregelung verfehlt wird. ${ }^{1542}$ Darüber hinaus wird auch nicht recht ersichtlich, warum die Behörde nach Entscheidungsreife noch ein ganzes Jahr Zeit haben sollte, nur um die Entscheidung bekanntzugeben. Dies erscheint noch weniger plausibel, wenn in systematischer Hinsicht andere dem Interesse der Rechtssicherheit dienende Fristen (vgl. nur $\S \S 70,74,75$ VwGO) in den Blick genommen werden, denen keine vergleichbare Gewichtung zugunsten des Interesses der Gesetzmäßigkeit der Verwaltung zugrunde liegt. ${ }^{1543}$

Davon entschieden abzugrenzen ist die Konstellation, dass eine Behörde von die Rücknahme rechtfertigenden Tatsachen Kenntnis erlangt, auf deren Grundlage sie eine Entscheidung über die Rücknahme trifft, bei der ihr dann ein Rechtsanwendungsfehler unterläuft. Auf diesem Wege kommt es nicht zu einem Neubeginn der Frist. ${ }^{1544}$

(3) Gleichsam umstritten ist zuletzt, wessen Kenntnis entscheidend ist. Ausdrücklich stellt die Norm nur auf die „Behörde“ ab. Bereits in systematischer

1539 BVerwG, Beschl.v. 19.12.1984, Az.: BVerwG Gr. Sen. 1 und 2.84 = BVerwGE 70, 356 (362f.); zuletzt ausdrücklich aufrechterhalten in Beschl. v. 10.1.2018, Az.: 3 B 59.16 = LKV 2018, 124 (125). Zustimmend Ziekow, VwVfG, 3. Aufl. 2013, § 48 Rn. 54. Der Gesetzgeber hat diese Interpretation hingenommen, vgl. BT-Drucks. 10/6283, S. 5; so auch BVerwG, Beschl.v. 5.5.1988, Az.: 7 B $8.88=$ NJW 1988, 2911 (2912).

1540 Satt vieler Stadie, DÖV 1992, 247 (250).

1541 BVerwG, Beschl. v. 19.12.1984, Az.: BVerwG Gr. Sen. 1 und 2.84 = BVerwGE 70, 356 (363f.). S. aber zur Lösung dieses Problems Stadie, DÖV 1992, 247 (250).

1542 S. nur Maurer/Waldhoff, Allgemeines Verwaltungsrecht, 19. Aufl. 2017, § 11 Rn. 44.

1543 S. nur Peuker, in: Knack/Henneke, VwVfG, 10. Aufl. 2014, § 48 Rn. 99; Stadie, DÖV 1992, 247 (251).

1544 Vgl. dazu BVerwG, Urt. v. 22.10.1987, Az.: 3 C 27.86 = NVwZ 1988, 349 (350); so auch Sachs, in: Stelkens/Bonk/Sachs, VwVfG, 9. Aufl. 2018, § 48 Rn. 227 m.w. N. 
Hinsicht kann dies nur die für die Rücknahme zuständige Behörde sein, sodass die Kenntnis anderer Behörden ${ }^{1545}$ ohne Bedeutung bleibt. Nur dies entspricht dem Zweck der Vorschrift, eben der zuständigen Behörde eine hinreichend lange Zeit für eine erneute Prüfung einzuräumen. ${ }^{1546}$

Umstritten ist jedoch, auf wessen Kenntnis es behördenintern ankommt. ${ }^{1547}$ Auch insofern hat das Bundesverwaltungsgericht eine rücknahmefreundliche Interpretation vertreten: Es komme nur darauf an, dass der nach der innerbehördlichen Geschäftsverteilung zur Rücknahme des Verwaltungsakts berufene Amtswalter oder ein sonst innerbehördlich zur rechtlichen Überprüfung des Verwaltungsakts berufener Amtswalter ${ }^{1548}$ die die Rücknahme des Verwaltungsakts rechtfertigenden Tatsachen feststelle. ${ }^{1549}$ Dafür spreche, dass eine „Behörde“ als rechtsorganisatorische Einheit nicht zu einer „Kenntnis“ fähig sei, es vielmehr stets auf das Wissen der für sie handelnden Amtswalter ankomme. ${ }^{1550}$

Die Gegenmeinung ${ }^{1551}$ will demgegenüber auf die Kenntnis der Organisationseinheit „Behörde“ abstellen. Dafür spreche bereits der Wortlaut, aus dem sich weder ergebe, dass ein anderer als der in § 1 IV VwVfG definierte Behördenbegriff zugrunde gelegt werde, noch dass es auf einen einzelnen Amtswalter ankommen könnte. ${ }^{1552}$ Überdies trete die Behörde im Verhältnis zum Bürger als Einheit auf und müsse innerhalb ihrer Organisationsverantwortung dafür sorgen, dass der

1545 Dies gilt auch für den Fall, dass der zurückzunehmende Verwaltungsakt von einer unzuständigen Behörde erlassen wurde, BVerwG, Urt. v. 20.12.1999, Az.: 7 C 42.98 = BVerwGE 110, 226 (234). S. aber zur Situation des zwischenzeitlichen Zuständigkeitswechsels Ramsauer, in: Kopp/ Ramsauer, VwVfG, 20. Aufl. 2019, § 48 Rn. 159.

1546 BVerwG, Urt.v. 20.12.1999, Az.: 7 C 42.98 = BVerwGE 110, 226 (234); Beschl.v. 10.1.2018, Az.: 3 B 59.16 = LKV 2018, 124 (125).

1547 Zu Recht weist Detterbeck, Allgemeines Verwaltungsrecht, 17. Aufl. 2019, Rn. 713, darauf hin, dass dieser dritte Problemkomplex der Sache nach weitgehend obsolet wird, wenn man der Ansicht folgt, dass es sich um eine „Entscheidungsfrist“ handelt.

1548 Ein einzelne Fachfragen begutachtender Mitarbeiter soll nicht genügen, BVerwG, Urt. v. 24.5.2012, Az.: 5 C 17.11 = BVerwGE 143, 161 (165f., Rn. 19).

1549 BVerwG, Beschl. v. 19.12.1984, Az.: BVerwG Gr. Sen. 1 und 2.84 = BVerwGE 70, 356 (364); Urt.v. 24.5. 2012, Az.: 5 C 17.11 = BVerwGE 143, 161 (165, Rn. 19f.).Vgl. auch BSG, Urt.v. 8. 2.1996, Az.: 13 RJ 35/94 = BeckRS 1996, 30759854.

1550 J. Müller, in: Bader/Ronellenfitsch, VwVfG, 44. Ed., Stand: 1.1.2019, § 48 Rn. 111; so auch Sachs, in: Stelkens/Bonk/Sachs, VwVfG, 9. Aufl. 2018, § 48 Rn. 214, der jedoch sodann zu einer anderen Lösung kommt.

1551 OVG Berlin, Urt. v. 29.10.1982, Az.: OVG 2 B 153/80 = NJW 1983, 2156 (2156f.); Ruffert, in: Ehlers/Pünder, Allgemeines Verwaltungsrecht, 15. Auf. 2016, § 24 Rn. 23; Pieroth, NVwZ 1984, 681 (684f.); Schoch, NVwZ 1985, 880 (885).

1552 Peuker, in: Knack/Henneke, VwVfG, 10. Aufl. 2014, § 48 Rn. 101; Schoch, NVwZ 1985, 880 (885). 
Informationsfluss funktioniere. ${ }^{1553}$ Der Bürger selbst könne die behördeninterne Zuständigkeitsverteilung nicht beurteilen und hätte selbst bei Befassung der zuständigen Behörde keine Rechtssicherheit. ${ }^{1554}$

Daneben sind zu Recht vermittelnde Ansichten getreten, die die Umstände des Einzelfalls in den Blick nehmen. ${ }^{1555}$ Diese blicken grundsätzlich auf die Behörde als rechtsorganisatorische Einheit, fokussieren jedoch im Sinne eines Organisationsverschuldens ${ }^{1556}$ sodann die behördeninternen Verhältnisse. Von Kenntnis der „Behörde“ ist ab dem Zeitpunkt auszugehen, zu dem im Falle eines ordnungsgemäßen Geschäftsgangs der zuständige Amtswalter durch Weitergabe der Informationen Kenntnis erlangt hätte. Davon wird beispielsweise dann nicht auszugehen sein, wenn nur ein sachlich völlig unzuständiger Amtswalter Kenntnis erlangt ${ }^{1557}$ oder die interne Weitergabe von Informationen aus datenschutzrechtlichen Gründen unzulässig ist ${ }^{1558}$. Nur diese Ansicht vermag es im Interesse des Zwecks der Vorschrift, der Behörde in vollständiger Kenntnis der eine Rücknahme potentiell rechtfertigenden Tatsachen noch einmal Zeit für eine Entscheidung zu geben, realistische Ergebnisse zu erzeugen: Zweifelsohne muss bereits sinnlogisch auf die Kenntnis eines Menschen abgestellt werden, dies kann indes nicht jede mit einem Verfahrensvorgang nicht vertraute Person sein. Ein von der internen Organisation abhängiger Informationsfluss innerhalb der Behörde kann nur dort erwartet werden, wo dafür hinreichender Anlass besteht und die rechtlichen Vorgaben ihn erlauben.

919 Es bedarf positiver Kenntnis, schuldhafte Unkenntnis genügt nicht. ${ }^{1559}$ Insofern genügt beispielsweise die bloße Aktenkundigkeit nicht, ${ }^{1560}$ vielmehr muss ein Bewusstsein für die Relevanz der Tatsachen bestehen.

1553 S. nur Maurer/Waldhoff, Allgemeines Verwaltungsrecht, 19. Aufl. 2017, § 11 Rn. 44.

1554 OVG Berlin, Urt. v. 29.10.1982, Az.: OVG 2 B 153/80 = NJW 1983, 2156 (2157); Peuker, in: Knack/Henneke, VwVfG, 10. Aufl. 2014, § 48 Rn. 101.

1555 Vgl. dazu jeweils m.w. N. - insbesondere aus der finanzgerichtlichen Rspr. - Ramsauer, in: Kopp/Ramsauer, VwVfG, 20. Aufl. 2019, § 48 Rn. 158; Kastner, in: Fehling/Kastner/Störmer, Verwaltungsrecht, 4. Aufl. 2016, § 48 VwVfG Rn. 65; Suerbaum, in: Mann/Sennekamp/Uechtritz, VwVfG, 2. Aufl. 2019, § 48 Rn. 205; ähnlich auch Sachs, in: Stelkens/Bonk/Sachs, VwVfG, 9. Aufl. 2018, § 48 Rn. $214 \mathrm{f}$.

1556 Ramsauer, in: Kopp/Ramsauer, VwVfG, 20. Aufl. 2019, § 48 Rn. 158; Suerbaum, in: Mann/ Sennekamp/Uechtritz, VwVfG, 2. Aufl. 2019, § 48 Rn. 205.

1557 Sachs, in: Stelkens/Bonk/Sachs, VwVfG, 9. Aufl. 2018, § 48 Rn. 215.

1558 Sachs, in: Stelkens/Bonk/Sachs, VwVfG, 9. Aufl. 2018, § 48 Rn. 215; Kastner, in: Fehling/ Kastner/Störmer, Verwaltungsrecht, 4. Aufl. 2016, § 48 VwVfG Rn. 65.

1559 BVerwG, Urt. v. 24.1.2001, Az.: 8 C 8.00 = BVerwGE 112, 360 (363).

1560 BVerwG, Urt. v. 24.1.2001, Az.: 8 C 8.00 = BVerwGE 112, 360 (363); so auch Ramsauer, in: Kopp/Ramsauer, VwVfG, 20. Aufl. 2019, § 48 Rn. 153. 
Für die Berechnung der Frist gilt $\S 31 \mathrm{VwVfG}$, der auch auf die Vorschriften 920 der $\S 187$ ff. BGB verweist. Die „Kenntnis“ der Behörde ist das gemäß § 187 I BGB für den Fristbeginn relevante Ereignis, dessen Ende sodann gemäß § 188 II Hs. 2 BGB zu bestimmen ist. ${ }^{1561}$

\section{(6) Rechtsfolge: Ermessen, § 48 I 1 VwVfG}

Die Entscheidung der Behörde über die Rücknahme eines Verwaltungsakts 921 steht gemäß § 48 I 1 VwVfG in ihrem Ermessen. (s. zum Ermessen ausführlich Rn. $729 \mathrm{ff} ., 739 \mathrm{ff}$.) Sie kann entscheiden, ob sie ihn überhaupt zurücknimmt (Entschließungsermessen), und falls ja, ob dies zum einen ganz oder teilweise, zum anderen mit Wirkung für die Zukunft oder für die Vergangenheit geschieht (Auswahlermessen). In zeitlicher Hinsicht ist der Behörde insbesondere die Möglichkeit geboten, sehr variabel auf Vertrauensschutzerwägungen zu reagieren, die sich erst nach dem Erlass ergeben.

Grundsätzlich gelten die allgemeinen Vorgaben betreffend Ermessensent- 922 scheidungen. Dabei sind im Zusammenhang mit § 48 VwVfG indes folgende Besonderheiten $\mathrm{zu}$ berücksichtigen, die sich je nach für die Rücknahme einschlägigem Absatz der Norm ergeben.

\section{(a) Im Falle eines belastenden Verwaltungsakts}

Im Falle der Rücknahme eines rechtswidrigen belastenden Verwaltungsakts stehen sich allgemein der Grundsatz der Gesetzmäßigkeit der Verwaltung und das Interesse der Schaffung von Rechtssicherheit und Rechtsfrieden durch eine einmal getroffene Entscheidung gegenüber. ${ }^{1562}$ Bereits die Tatsache, dass der Gesetzgeber ein solches Ermessen vorgesehen hat, verdeutlicht, dass allein die Rechtswidrigkeit nicht eine Rücknahme nach sich zieht. Vielmehr sollen beide Interessen grundsätzlich gleichberechtigt nebeneinanderstehen. ${ }^{1563}$

Gleichwohl ergibt sich laut Bundesverwaltungsgericht ein besonderes Be- 924 gründungserfordernis für die Annahme eines Überwiegens der materiellen Einzelfallgerechtigkeit. Dies ist keineswegs überraschend. Wie der Vertrauensschutz hat das mit ihm verwandte Interesse der Rechtssicherheit für sich

1561 S. für ein Berechnungsbeispiel Ramsauer, in: Kopp/Ramsauer, VwVfG, 20. Aufl. 2019, § 48 Rn. 152.

1562 Maurer/Waldhoff, Allgemeines Verwaltungsrecht, 19. Aufl. 2017, § 11 Rn. 72.

1563 BVerwG, Urt. v. 24. 2. 2011, Az.: 2 C 50.09 = NVwZ 2011, 888 (889, Rn. 11); Urt. v. 20.11.2018, Az.: 1 C 23.17 = NVwZ-RR 2019, 170 (172f., Rn. 26); auch bereits Beschl. v. 7.7.2004, Az.: 6 C $24.03=$ BVerwGE 121, 226 (229f.). 
genommen keine weitergehenden materiellen Gehalte, sprich: Für das Interesse der Rechtssicherheit spricht oftmals allein, dass es sich um „ein wesentliches Element der Rechtsstaatlichkeit und damit ein[es] Konstitutionsprinzip[s] des Grundgesetzes“ handelt. ${ }^{1564}$ Dieses gewichtet das Bundesverwaltungsgericht indes so stark, dass selbst ein Verwaltungsakt, der auf einer verfassungswidrigen Norm basiert, nicht ohne weiteres zurückgenommen werden darf. ${ }^{1565}$ Ausnahmsweise wird jedoch ein Anspruch auf Rücknahme - gar eines bestandskräftigen Verwaltungsakts - angenommen, wenn dessen Aufrechterhaltung „schlechthin unerträglich“ ist. ${ }^{1566}$ Dies geschieht vor dem Hintergrund der Annahme, dass bei einer allzu starken Abweichung von rechtlichen Vorgaben der mit der Rechtssicherheit in Verbindung stehende Rechtsfrieden nicht erreicht werden kann. ${ }^{1567} \mathrm{Ob}$ eine derartige Unerträglichkeit vorliegt, hängt von den Umständen des Einzelfalls und deren Abwägung gegeneinander ab. ${ }^{1568}$ Dies ist in der Rechtsprechung des Bundesverwaltungsgerichts insbesondere in vier anerkannten Fallgruppen denkbar ${ }^{1569}$ : (1) Bei Verstoß gegen den Grundsatz der Selbstbindung der Verwaltung gemäß Art. 3 I GG (s. dazu Rn. 772ff.), (2) bei Verstoß gegen die guten Sitten oder gegen Treu und Glauben, (3) im Falle einer offensichtlichen Rechtswidrigkeit des Verwaltungsakts ${ }^{1570}$ sowie (4) unter Berücksichtigung der Wertungen und Intentionen des dem Verwaltungsakt zugrundeliegenden Fachrechts ${ }^{1571}$ (da $\S 48$ VwVfG selbst keine materiellen Gesichtspunkte zu entnehmen sind). ${ }^{1572}$ Insofern ist die Behörde jedoch zugleich in sachlicher Hinsicht beschränkt: Ermessenserwägungen, die dem Fachrecht nicht zugrundeliegen, sind sachfremd. Zuletzt können auch im Falle eines belastenden Verwaltungsakts auf Seiten der Betroffenen Vertrauensschutzerwägungen (unter Berücksichtigung aller Umstände des Einzelfalls, s. dazu Rn. 899) für eine Aufrechterhaltung des Verwaltungsakts streiten.

1564 BVerwG, Beschl. v. 7.7.2004, Az.: 6 C 24.03 = BVerwGE 121, 226 (230).

1565 Vgl. BVerwG, Urt. v. 24.2.2011, Az.: 2 C 50.09 = NVwZ 2011, 888 (889, Rn. 14f.).

1566 BVerwG, Beschl.v. 7.7.2004, Az.: 6 C 24.03 = BVerwGE 121, 226 (230); Urt. v. 24.2.2011, Az.: 2 C 50.09 = NVwZ 2011, 888 (889, Rn. 11), jeweils m.w. N.

1567 Vgl. BVerwG, Urt. v. 27.1.1994, Az.: 2 C 12.92 = BVerwGE 95, 86 (92).

1568 BVerwG, Urt. v. 24. 2.2011, Az.: 2 C 50.09 = NVwZ 2011, 888 (889, Rn. 11).

1569 S. dazu die Fallbearbeitung bei Ludwigs, JURA 2009, 226 (230 f.).

1570 Vgl. dazu BVerwG, Urt. v. 17.1.2007, Az.: 6 C 32.06 = MMR 2007, 365 (366): Es kann auf die Maßstäbe zu §44 I VwVfG zurückgegriffen werden, ohne dass es jedoch einer besonderen Schwere bedürfte. So auch Ludwigs, NVwZ 2007, 549 (551); Ludwigs, JURA 2009, 226 (231).

1571 BVerwG, Beschl.v. 7.7.2004, Az.: 6 C 24.03 = BVerwGE 121, 226 (231); Urt. v. 24. 2.2011, Az.: 2 C 50.09 = NVwZ 2011, 888 (889, Rn. 16).

1572 S. nur BVerwG, Beschl. v. 7.7.2004, Az.: 6 C 24.03 = BVerwGE 121, 226 (231). 
Vor diesem Hintergrund besteht Streit um die Ermessensausübung vor 925 Eintritt der Bestandskraft eines Verwaltungsakts. Eine Ansicht geht für diesen Fall von einer Ermessensreduktion auf Null zugunsten einer Rücknahme aus. ${ }^{1573}$ Angesichts von Rechtswidrigkeit und noch bestehender Anfechtbarkeit bestehe schlicht kein abwägungsrelevantes Interesse am Fortbestand des Verwaltungsakts. ${ }^{1574}$ Auch bestehe wegen des vielfachen Ausschlusses des Vorverfahrens auf Grundlage von § 68 I 2 VwGO ein praktisches Bedürfnis dem Bürger einen strikten Rechtsanspruch zuzusprechen. ${ }^{1575}$ Die Gegenansicht ${ }^{1576}$ hält dem den klaren Wortlaut des §48 I 1 VwVfG, der Ermessen ausdrücklich auch für noch nicht bestandskräftige gewordene Verwaltungsakte vorsieht, entgegen. Darüber hinaus bestehe kein Bedürfnis nach einem Rechtsanspruch, da der Bürger sein Ziel selbst bei Ausschluss des Vorverfahrens noch mit der Anfechtungsklage erreichen könne. ${ }^{1577}$

\section{(b) Im Falle eines begünstigenden Verwaltungsakts}

Die Normstruktur von § 48 I 1 und 2 VwVfG verdeutlicht, dass der Behörde auch im Falle der Rücknahme von begünstigenden Verwaltungsakten ein Ermessen zusteht. ${ }^{1578}$ Im Hinblick auf die Besonderheiten der Ermessensausübung ist indes wiederum zwischen Leistungsverwaltungsakten und sonstigen Verwaltungsakten $\mathrm{zu}$ unterscheiden.

Handelt es sich um die Rücknahme eines begünstigenden Leistungsver- 927 waltungsaktes i.S.v. §48 II VwVfG ist zu berücksichtigen, dass wesentliche rechtliche Bewertungen bereits im Tatbestand, insbesondere im Rahmen der Abwägung zwischen dem schutzwürdigen Vertrauen auf den Bestand des Verwaltungsakts und dem öffentlichen Interesse an einer Rücknahme, vorzunehmen waren. Dies führt zwar grundsätzlich ${ }^{1579}$ nicht $\mathrm{zu}$ einer rechtlich zwingenden Engführung des Ermessensspielraums im Sinne eines „intendierten Ermessens“ (s. zu diesem Begriff ausführlich Rn. 732). Rein faktisch verdichtet die Systematik

1573 S. nur Detterbeck, Allgemeines Verwaltungsrecht, 17. Aufl. 2019, Rn. 692, m.w. N.; wohl auch Ramsauer, in: Kopp/Ramsauer, VwVfG, 20. Aufl. 2019, § 48 Rn. 80.

1574 Detterbeck, Allgemeines Verwaltungsrecht, 17. Aufl. 2019, Rn. 692.

1575 Detterbeck, Allgemeines Verwaltungsrecht, 17. Aufl. 2019, Rn. 692.

1576 S. nur Maurer/Waldhoff, Allgemeines Verwaltungsrecht, 19. Aufl. 2017, § 11 Rn. 74; Sachs, in: Stelkens/Bonk/Sachs, VwVfG, 9. Aufl. 2018, § 48 Rn. 48; Peuker, in: Knack/Henneke, VwVfG, 10. Aufl. 2014, § $48 \mathrm{Rn} .77$.

1577 Maurer/Waldhoff, Allgemeines Verwaltungsrecht, 19. Aufl. 2017, § 11 Rn. 74.

1578 Ramsauer, in: Kopp/Ramsauer, VwVfG, 20. Aufl. 2019, § 48 Rn. 127; Suerbaum, in: Mann/ Sennekamp/Uechtritz, VwVfG, 2. Aufl. 2019, § 48 Rn. 143.

1579 Eine Ausnahme bildet die sogleich zu thematisierende Vorschrift des § 48 II 4 VwVfG. 
der Vorschrift jedoch den verbleibenden Ermessensspielraum. Für ein besseres Verständnis ist zwischen verschiedenen Entwicklungen innerhalb einer Prüfung zu unterscheiden: ${ }^{1580}$

- Gelangt man im Rahmen von $\$ 48$ II 1 VwVfG zu dem Ergebnis, dass das schutzwürdige Vertrauen (insbesondere auf Grundlage der Regelvermutung des § 48 II 2 VwVfG) das öffentliche Interesse überwiegt, darf bereits aus diesem Grund nicht zurückgenommen werden. Die Frage der ordnungsgemäßen Ermessensausübung stellt sich überhaupt nicht. ${ }^{1581}$

- Ist das Vertrauen gemäß § 48 II 3 VwVfG ausgeschlossen, entfällt die Abwägung gemäß § 48 II 1 VwVfG. In der Folge begrenzt § 48 II 4 VwVfG auch die Ermessensausübung dahingehend, dass der Verwaltungsakt in der Regel mit Wirkung für die Vergangenheit zurückzunehmen ist. Damit wird zwar wörtlich verdeutlicht, dass noch Raum für Ermessen besteht. ${ }^{1582}$ Dieses ist jedoch bereits rechtlich stark beschränkt. Laut Bundesverwaltungsgericht müssen im Einzelfall besondere Gründe, gar außergewöhnliche Umstände vorliegen, wenn eine Rücknahme nur für die Zukunft angeordnet oder überhaupt von der Rücknahme abgesehen werden soll. ${ }^{1583}$ Derartige Fälle sind jedoch in der Praxis erwartungsgemäß selten. ${ }^{1584}$

- In allen übrigen Konstellationen ist man im Rahmen von § 48 II 1 VwVfG zu dem Ergebnis gelangt, dass das öffentliche Interesse das schutzwürdige Vertrauen (gegebenenfalls gar entgegen der Regelvermutung des § 48 II 2 VwVfG) überwiegt. Bei der sodann folgenden Prüfung der Ermessensausübung können bestimmte Ermessensfehler - wie ein Ermessensausfall ${ }^{1585}$ oder ein Ermessensmissbrauch aufgrund sachfremder Erwägungen - unproblematisch $\mathrm{zu}$ bejahen sein. Vorsicht ist jedoch geboten hinsichtlich des schutzwürdigen Vertrauens (und der damit unmittelbar zusammenhän-

1580 Zum Folgenden Suerbaum, in: Mann/Sennekamp/Uechtritz, VwVfG, 2. Aufl. 2019, § 48 Rn. 143 ff.; so auch Ramsauer, in: Kopp/Ramsauer, VwVfG, 20. Aufl. 2019, § 48 Rn. 127 ff.

1581 Sollte, weil dies verlangt ist, hilfsgutachtlich weiter geprüft werden, müsste im Rahmen des Ermessens konsequent auf das schutzwürdige Vertrauen verwiesen werden. Darüber hinaus wären - je nach gegebenem Anlass - die übrigen Ermessenserwägungen in die Prüfung einzubeziehen.

1582 S. dazu auch BVerwG, Urt. v. 9.9.2013, Az.: 1 C 6.03 = BVerwGE 119, 17 (22f., 25).

1583 BVerwG, Urt. v. 23.5.1996, Az.: 3 C 13.94 = juris, Rn. 51; Urt. v. 16.6.1997, Az.: 3 C $22.96=$ BVerwGE 105, 55 (57 f.); Urt. v. 22.3.2017, Az.: 5 C 4.16 = BVerwGE 158, 258 (270f., Rn. 40 f.).

1584 Ramsauer, in: Kopp/Ramsauer, VwVfG, 20. Aufl. 2019, § 48 Rn. 127c, nennt beispielhaft die Zurechnung des absprachewidrigen Verhaltens eines Vertreters (s. dazu indes auch BVerwG, Urt.v. 22.3.2017, Az.: 5 C 4.16 = BVerwGE 158, 258 [270f., Rn. $40 \mathrm{f}$.]) oder das Befinden in einer Zwangslage.

1585 Suerbaum, in: Mann/Sennekamp/Uechtritz, VwVfG, 2. Aufl. 2019, § 48 Rn. 149.

Tobias Brings-Wiesen 
genden rechtlichen Erwägungen, s. dazu Rn. 899): Dieses wurde bereits erschöpfend in der Abwägung gemäß § 48 II 1 VwVfG berücksichtigt, ohne dass es ihm allein gelungen wäre, das öffentliche Interesse $\mathrm{zu}$ überwiegen. ${ }^{1586}$ Gegen eine Rücknahme müssen daher andere, darüberhinausgehende Ermessenserwägungen sprechen, wie beispielsweise gleichheitsrechtliche Erwägungen gemäß Art. 3 I GG (insbesondere bei Konstellationen der Selbstbindung der Verwaltung ${ }^{1587}$ oder freiheitsrechtliche Aspekte unter besonderer Berücksichtigung von Verhältnismäßigkeitsgesichtspunkten (auch und insbesondere im Hinblick auf die Interessen Dritter).

Auch die Rücknahme eines sonstigen begünstigenden Verwaltungsakts ge- 928 mäß § 48 III VwVfG steht gemäß § 48 I 1 VwVfG im Ermessen der Behörde. Mangels Vorprägung durch Beurteilungen innerhalb des Tatbestands kann das Ermessen hier uneingeschränkt geprüft werden. Besonders umstritten ist jedoch die Frage, ob und inwieweit im Rahmen der Ermessensausübung auch Vertrauensschutzerwägungen zu berücksichtigen sind. ${ }^{1588}$ Dagegen könnte in systematischer Hinsicht sprechen, dass der Vertrauensschutz im Rahmen von § 48 III VwVfG nur durch den Ausgleichsanspruch in Form von Vermögensschutz, nicht aber in Form von Bestandsschutz zu gewähren sein soll. In diese Richtung deuten auch die Gesetzesmaterialien. ${ }^{1589}$ Die wohl herrschende Meinung ${ }^{1590}$ stellt jedoch zu Recht auf den Wortlaut ab, der ein Ermessen uneingeschränkt ermöglicht. Zudem wird geltend gemacht, dass eine völlige Ausblendung von Vertrauensschutzerwägungen vor dem Hintergrund des Rechtsstaatsprinzips verfassungsrechtlich unzulässig wäre - dies insbesondere in den Fällen, in denen ein immaterieller Schaden nicht im Wege des durch §48 III VwVfG gewährleisteten Vermögensschutzes kompensiert werden könnte. ${ }^{1591}$ Grundsätzlich sind damit Vertrauensschutzerwägungen auch in die Prüfung des Ermessens gemäß § 48 I 1, III VwVfG einzu-

1586 Kastner, in: Fehling/Kastner/Störmer, Verwaltungsrecht, 4. Aufl. 2016, § 48 VwVfG Rn. 53; Ehlers/Kallerhoff, JURA 2009, 823 (834).

1587 Suerbaum, in: Mann/Sennekamp/Uechtritz, VwVfG, 2. Aufl. 2019, § 48 Rn. 149; Ehlers/ Kallerhoff, JURA 2009, 823 (834).

1588 S. dazu mit Darstellung der unterschiedlichen Meinungen innerhalb des BVerwG Struzina/ Lindner, NVwZ 2016, 1295. Für eine Fallbearbeitung zu dieser Fragestellung von Weschpfennig, JURA 2014, 1055 (1064f.).

1589 So die Gesetzesmaterialien, BT-Drucks. 7/910, S. 71.

1590 Detterbeck, Allgemeines Verwaltungsrecht, 17. Aufl. 2019, Rn. 705; Ehlers/Kallerhoff, JURA 2009, 823 (832). So auch ohne nähere Begründung das BVerwG, Beschl. v 7.11.2000, Az.: 8 B 137.00 = NVwZ-RR 2001, 198 (199); Urt. v. 24.5.2012, Az.: 5 C 17.11 = BVerwGE 143, 161 (168f., Rn. $27 \mathrm{f}$.$) .$

1591 Ramsauer, in: Kopp/Ramsauer, VwVfG, 20. Aufl 2019, § 48 Rn. 137. 
beziehen. Nicht abschließend geklärt scheint indes, inwieweit dies zu erfolgen hat. So wird vertreten, dass die Möglichkeit des Ausgleichs von Vermögensnachteilen nur einen unter mehreren Gesichtspunkten darstelle. ${ }^{1592}$ Jedenfalls insoweit über diesen Anspruch keinerlei Vertrauensschutz effektuiert werden kann (wie beispielsweise in bereits genannten Fällen ausschließlich immaterieller Schäden), wird man Vertrauensschutzerwägungen im Rahmen des Ermessens berücksichtigen müssen. Dafür kann dann maßstabsbildend auf die in § 48 II 2, 3 VwVfG zum Ausdruck gekommenen Wertungen zurückgegriffen werden. ${ }^{1593}$

\section{(7) Rücknahme von Verwaltungsakten im unionsrechtlichen Kontext}

929 Zum Teil erhebliche Modifikationen der bislang dargestellten Grundsätze ergeben sich im Falle der Rücknahme von unionsrechtswidrigen Verwaltungsakten (s. zum Widerruf Rn. 978). ${ }^{1594}$ Insofern bietet § 48 VwVfG eines (s. zum unionrechtlichen Staatshaftungsanspruch $\S 11 \mathrm{Rn}$. 31ff.) der idealen Einfallstore für das Abrufen von Wissen und Systemverständnis zum Problemfeld der „Europäisierung des Verwaltungsrechts“1595. Besondere Praxis- wie Prüfungsrelevanz haben dabei die einen Empfänger begünstigenden unionsrechtswidrigen Beihilfenbewilligungsbescheide, die als „Leistungsverwaltungsakte“ gemäß §48 II VwVfG zurückzunehmen sind und für die beachtliche Sondermaßstäbe gelten (s. dazu Rn. 932ff.). Davon strikt zu unterscheiden ist die Rücknahme unionsrechtswidriger Verwaltungsakte im Übrigen (s. dazu Rn. 937ff.), die in der Prüfungspraxis zwar nur eine untergeordnete Rolle spielt, aber nicht minder kompliziert ist.

1592 Ramsauer, in: Kopp/Ramsauer, VwVfG, 20. Aufl. 2019, § 48 Rn. 137; wohl auch Peine/Siegel, Allgemeines Verwaltungsrecht, 12. Aufl. 2018, Rn. 621. A.A. aber wohl Sachs, in: Stelkens/Bonk/ Sachs, VwVfG, 9. Aufl. 2018, § 48 Rn. $180 \mathrm{ff}$.

1593 BVerwG, Beschl. v. 14.4.2010, Az.: 8 B 88.09 = juris, Rn. 9; Detterbeck, Allgemeines Verwaltungsrecht, 17. Aufl. 2019, Rn. 706; Ramsauer, in: Kopp/Ramsauer, VwVfG, 20. Aufl. 2019, § 48 Rn. 136 f.; Ehlers/Kallerhoff, JURA 2009, 823 (832).

1594 S. dazu ausführlich auch Maurer/Waldhoff, Allgemeines Verwaltungsrecht, 19. Aufl. 2017, $\S 11$ Rn. 53 ff.; Detterbeck, Allgemeines Verwaltungsrecht, 16. Aufl. 2018, Rn. 749ff.; Erbguth/ Guckelberger, Allgemeines Verwaltungsrecht, 9. Aufl. 2018, §16 Rn. $33 \mathrm{f}$.

1595 S. dazu im Überblick Voßkuhle/Schemmel, JuS 2019, 347; Kahl, NVwZ 2011, 449; ausführlich die Kommentierung von Stelkens, in: Stelkens/Bonk/Sachs, VwVfG, 9. Aufl. 2018, Europäisches Verwaltungsrecht, Europäisierung des Verwaltungsrechts und Internationales Verwaltungsrecht, passim.

Tobias Brings-Wiesen 
Im Interesse des besseren Verständnisses dieser durchaus komplexen Pro930 blematik ist im Folgenden vorab überblicksartig auf den Vollzug von Unionsrecht (s. Rn. 931) durch die deutsche Verwaltung sowie auf die Grundzüge des EU-Beihilfenrechts (s. Rn. 934) einzugehen.

\section{(a) Vollzug von Unionsrecht durch die Verwaltung}

Um die sogleich darzustellende Problematik zu erfassen, ist in der gebotenen 931 Kürze daran zu erinnern, wie Unionsrecht vollzogen wird. ${ }^{1596}$ Grundsätzlich ist zwischen dem unionseigenen (oder sog. „direkten“) und dem mitgliedstaatlichen (oder sog. „indirekten“) Vollzug zu unterscheiden, sprich dem Vollzug durch eigene Organe der Europäischen Union und dem Vollzug durch mitgliedstaatliche Institutionen. $\mathrm{Zu}$ einer ,unionsrechtlichen Überformung“1597 des deutschen Verwaltungsrechts kann es überhaupt nur kommen, wenn es sich um einen Fall mitgliedstaatlichen bzw. indirekten Vollzugs von Unionsrecht handelt. Im Rahmen der ihnen übertragenen Kompetenzen können die zuständigen Organe der Europäischen Union diesen Vollzug materiellen Unionsrechts durch die mitgliedstaatlichen Institutionen auch durch besondere verwaltungsorganisations- und -verfahrensrechtliche Vorgaben flankieren. Soweit derartige konkrete unionsrechtliche Vorgaben fehlen, gilt der Grundsatz der Verfahrensautonomie $^{1598}$ der Mitgliedstaaten ${ }^{1599}$, sodass die Vorschriften des mitgliedstaatlichen Verwaltungsrechts Anwendung finden. Der Vollzug von Unionsrecht hat dabei jedoch unter Beachtung des Grundsatzes der loyalen Zusammenarbeit gemäß Art. 4 III EUV, konkreter unter Beachtung von Äquivalenz- und Effektivitätsgrundsatz zu erfolgen. ${ }^{1600}$ Danach dürfen nationale Vorgaben für den Vollzug von Unionsrecht weder ungünstiger sein als bei rein nationalrechtlich determinierten Sachverhalten, noch dessen Verwirklichung praktisch unmöglich machen oder übermäßig erschweren. ${ }^{1601}$

1596 S. dazu im Überblick Maurer/Waldhoff, Allgemeines Verwaltungsrecht, 19. Aufl. 2017, § 2 Rn. 51ff.; § 22 Rn. 11; ausführlicher Ehlers, in: ders./Pünder, Allgemeines Verwaltungsrecht, 15. Aufl. 2016, § 5 Rn. $34 \mathrm{ff}$.

1597 So terminologisch Korte, JURA 2017, 656 (661).

1598 Dessen Anwendungsbereich indes nicht auf das „Verwaltungsverfahrensrecht“ nach deutschem Verständnis beschränkt ist, Ludwigs, NVwZ 2018, 1147 (1147f.).

1599 Dazu grundlegend - und zu der im Folgenden dargestellten Rspr. krit. - Krönke, Die Verfahrensautonomie der Mitgliedstaaten der Europäischen Union, 2013, passim; s. jüngst auch Ludwigs, NVwZ 2018, 1147.

1600 S. nur jüngst EuGH, Urt. v. 26.6.2019, Az.: C-407/18 - Addiko Bank, Rn. 46. So auch das BVerwG, Urt. v. 16.12.2010, Az.: 3 C 44.09 = BVerwGE 138, 322 (325f., Rn. 14).

1601 So in gebotener (terminologischer) Weite Ludwigs, NVwZ 2018, 1417 (1418).

Tobias Brings-Wiesen 


\section{(b) Besonderheiten bei der Rücknahme von begünstigenden EU-beihilfenrechtswidrigen Verwaltungsakten}

932 Vor besondere Herausforderungen stellt die Student`innen das überaus komplexe wie prüfungsrelevante Themenfeld der Rückabwicklung unionsrechtswidriger Beihilfen im Verhältnis zwischen Mitgliedstaat und Beihilfeempfänger. Diese Rückabwicklung erfolgt im Regelfall im mitgliedstaatlichen bzw. indirekten Vollzug, ohne dass auf besondere verwaltungsorganisations- und -verfahrensrechtliche Vorgaben zu rekurrieren wäre. ${ }^{1602}$ Rechtlicher Ausgangspunkt sind (bei Fehlen spezialgesetzlicher Vorschriften) die Vorschriften der §§ $48 \mathrm{ff}$. VwVfG, die jedoch unionsrechtlich stark überformt werden. Die Spannungslagen dieses Themenfeldes in ihren Nuancen zu erfassen, setzt ein Grundverständnis der zugrundeliegenden subventionsrechtlichen ${ }^{1603}$ Vorgaben voraus, auf die im Folgenden in der gebotenen Kürze ${ }^{1604}$ einzugehen ist.

Vorab ist zu berücksichtigen, dass eine Rückabwicklung unionsrechtswidriger Beihilfen keineswegs ausschließlich auf Grundlage der §§ $48 \mathrm{ff}$. VwVfG erfolgen muss. Obgleich derartige Sachverhaltskonstellationen in der juristischen Ausbildung mit Abstand die größte Aufmerksamkeit genießen dürften, hängt die Anwendbarkeit besagter Vorschriften - und in der Konsequenz der korrekte Prüfungsaufbau - maßgeblich von der Art der Gewähr der Beihilfe ab. ${ }^{1605}$ Ausgehend vom Grundsatz der Formenwahlfreiheit ${ }^{1606}$ kann die Verwaltung ihre Rechtsbeziehungen zu den Beihilfeempfängern einstufig oder zweistufig regeln und sich dabei der Formen des öffentlichen oder des privaten Rechts bedienen. ${ }^{1607}$ Eine Rückabwicklung über Verwaltungsakte auf Grundlage der $\S \S 48 \mathrm{ff}$. VwVfG ist daher regelmäßig nur dann möglich, wenn die Beihilfe selbst durch Verwal-

1602 Mangels umfassender oder auch nur sektorieller unionsrechtlicher Rücknahme- bzw. Widerrufsregelung ist dies selbst bei auf Grundlage von Unionsrecht gewährten und aus Unionsmitteln kofinanzierten Zuwendungen die Regel, BVerwG, Urt. v. 10.12.2003, Az.: 3 C 22.02 = NVwZRR 2004, 413 (413f.); VGH Mannheim, Urt. v. 22.5.2014, Az.: 10 S 1719/13 = juris, Rn. 27.

1603 „Subventionsrecht“ wird hier als Oberbegriff für die einschlägigen nationalen und unionalen Normen verwendet, so auch Korte, JURA 2017, 656.

1604 S. zur Schnittstelle des nationalen Subventions- und unionalen Beihilferechts ausführlich Ziekow, Öffentliches Wirtschaftsrecht, 4. Aufl. 2016, § 6, passim; Bungenberg/Motzkus, GewArch Beil. WiVerw 2/2013, 76; in einem auch für Anfänger^innen gut zugänglichen Überblick Ehlers, DVBl 2014, 1; zu den jüngsten Reformen Hilbert, JURA 2017, 1150.

1605 Finck/Gurlit, JURA 2011, 87 (89); Korte, JURA 2017, 656 (659ff.).

1606 BVerwG, Urt.v. 11.2.1993, Az.: 4 C 18.91 = BVerwGE 92, 56 (64); dazu ausführlich Detterbeck, Allgemeines Verwaltungsrecht, 17. Aufl. 2019, Rn. $903 \mathrm{ff}$.

1607 S. dazu Detterbeck, Allgemeines Verwaltungsrecht, 17. Aufl. 2019, Rn. 911 ff.; dazu auch die anschauliche Prüfung des BVerwG, Urt. v. 31.5.2012, Az.: 3 C 12.11 = NVwZ-RR 2012, 628 (629f., Rn. $14 \mathrm{ff}$.).

Tobias Brings-Wiesen 
tungsakt gewährt wurde. ${ }^{1608}$ Diese abgrenzende Prüfung kann je nach Aufgabenstellung an verschiedenen Stellen eines Gutachtens erforderlich werden. Steht fest, dass die Beihilfe im Wege eines Bewilligungsbescheids, der die Merkmale des $\S 35$ S. 1 VwVfG erfüllt, gewährt wurde, wird es sich (regelmäßig) auch um einen begünstigenden Verwaltungsakt i.S.v. § $48 \mathrm{I}_{2} \mathrm{VwVfG}^{1609}$ und in der Folge um einen Leistungsverwaltungsakt i.S.v. $§ 48$ II $1 \mathrm{VwVfG}^{1610}$ handeln. Dies macht eine Prüfung am Maßstab von § 48 I 2, II, IV VwVfG erforderlich (s. dazu Rn. 935 f.).

Examenswissen: Handelt es sich um einen öffentlich-rechtlichen Vertrag i.S.d. §§ $54 \mathrm{ff}$. VwVfG sind jedoch gleichsam Besonderheiten zu berücksichtigen, s. dazu noch § 5 Rn. 117, 124.

Erst in einer fortgeschrittenen Phase des juristischen Studiums steht zu erwarten, 934 dass innerhalb dieser Prüfung auch eine umfassendere Bewertung der Rechtslage am Maßstab des unionalen Beihilfenrechts zu leisten ist. Doch bereits um die Quellen der Unionsrechtswidrigkeit einer Beihilfegewähr präzise identifizieren und in der Folge deren Relevanz für die mitgliedstaatliche Aufhebungsentscheidung bestimmen zu können, bedarf es einer Grundkenntnis des unionalen Beihilfenrechts. Dabei ist maßgeblich zwischen materiellen und prozeduralen Vorgaben zu unterscheiden:

In materieller Hinsicht: Gemäß Art. 107 I AEUV sind staatliche oder aus staatlichen Mitteln gewährte Beihilfen gleich welcher Art, die durch die Begünstigung bestimmter Unternehmen oder Produktionszweige den Wettbewerb verfälschen oder zu verfälschen drohen, mit dem Binnenmarkt unvereinbar, soweit sie den Handel zwischen Mitgliedstaaten beeinträchtigen (und soweit in den Verträgen nichts anderes bestimmt ist). ${ }^{1611}$ Die Erfüllung dieser Voraussetzungen bedeutet indes noch nicht die Unionsrechtswidrigkeit einer Beihilfe. Das unionale Beihilfenrecht kennt diverse Ausnahmetatbestände: (1) Art. 107 II AEUV bestimmt, dass Beihilfen, die den dort identifizierten Zwecken dienen, bereits qua legem mit dem Binnenmarkt vereinbar sind. (2) Gemäß Art. 106 II AEUV sollen die Vorschriften der Verträge, insbesondere die Wettbewerbsregeln, für Unternehmen, die mit Dienstleistungen von allgemeinem wirtschaftlichem Interesse (DAWI) betraut sind, nicht gelten, soweit sie die Erfüllung der übertragenen DAWI (im

1608 Statt vieler Finck/Gurlit, JURA 2011, 87 (89), m.w. N., auch zur Gegenansicht.

1609 Der Bewilligungsbescheid begründet ein Recht, nämlich den Anspruch des Adressaten aus Auszahlung der bewilligten Beihilfe.

1610 Die vielfältigen Formen staatlicher Beihilfen, s. nur Cremer, in: Calliess/Ruffert, EUV/AEUV, 5. Aufl. 2016, Art. 107 AEUV Rn. 40 f., werden regelmäßig als Gewährung einer einmaligen oder laufenden Geldleistung gewertet werden können.

1611 Zum Beihilfenbegriff im Überblick Ehlers, DVBl 2014, 1 (2f.). 
Einzelfall) rechtlich oder tatsächlich verhindern. (3) Art. 107 III AEUV stellt die Entscheidung über die Binnenmarktvereinbarkeit von Beihilfen, die wieder anderen bestimmten Zwecken dienen, in das Ermessen der Kommission (z.T. unter Zusammenwirken mit dem Rat). (4) Aufgrund „außergewöhnlicher Umstände“ kann der Rat ${ }^{1612}$ (auf Antrag eines Mitgliedstaats) gemäß Art. 108 II Uabs. 3 AEUV im Einzelfall in Abweichung von Art. 107 AEUV oder von den nach Art. 109 AEUV erlassenen Verordnungen beschließen, dass eine Beihilfe als mit dem Binnenmarkt vereinbar gilt.

In prozeduraler Hinsicht: Nicht minder wichtig sind die prozeduralen Vorgaben des unionalen Beihilfenrechts. Sie dienen dem Zweck der Sicherung der Verfahrenshoheit der Kommission bei der Überwachung der Einhaltung der materiellen Vorgaben im Interesse der einheitlichen Durchsetzung der EU-Wettbewerbsordnung. Ihre Beurteilung der Vereinbarkeit von Beihilfemaßnahmen mit dem Binnenmarkt ist schlussendlich maßgeblich. ${ }^{1613}$ Um diese Prüfung effektiv zu ermöglichen, verlangt Art. 108 III 1 AEUV nicht nur, dass die Kommission von jeder beabsichtigten Einführung oder Umgestaltung von Beihilfen durch die Mitgliedstaaten unterrichtet wird (sog. Notifikationspflicht). Gemäß Art. 108 III 3 AEUV ist überdies festgelegt, dass die beabsichtigte Maßnahme nicht durchgeführt werden darf, bevor die Kommission nicht einen abschließenden Beschluss erlassen hat (sog. Durchführungsverbot). Ein diesen Vorgaben zuwiderlaufender Bewilligungsbescheid ist bereits formell unionsrechtswidrig.

Examenswissen: Das Beihilfeverfahren ist ausgefeilter als es Art. 108 AEUV auf den ersten Blick vermuten lässt. Dessen Einzelheiten regelt die auf Grundlage von Art. 109 AEUV erlassene Beihilfeverfahrensverordnung (BeihilfeVVO) ${ }^{1614}$. Darin sind drei verschiedene Wege der Initiierung einer vorbeugenden Prüfung der beabsichtigten Einführung oder Umgestaltung von Beihilfen (sog. „,neue Beihilfen“, Art. 1 lit. c) BeihilfeVVO) gemäß Art. 108 III AEUV vorgesehen:

(1) Der unionsrechtliche Normalfall ist die gemäß Art. 108 III 1 AEUV, Art. 2 BeihilfeVVO erforderliche Anmeldung durch die Mitgliedstaaten. Art. 109 Var. 3 AEUV ermächtigt ${ }^{1615}$ darüber

1612 Bei dreimonatiger Untätigkeit des Rates die Kommission, Art. 108 II Uabs. 4 AEUV.

1613 Dabei unterliegt sie der Kontrolle der Unionsgerichte, während die nationalen Gerichte bis zur endgültigen Entscheidung der Kommission nur über die Wahrung der Rechte der Einzelnen bei eventuellen Verstößen der mitgliedstaatlichen Behörden gegen Art. 108 III AEUV wachen, EuGH, Urt. v. 21.11.2013, Az.: C-284/12 - Deutsche Lufthansa, Rn. 28.

1614 Verordnung (EU) 2015/1589 des Rates vom 13. Juli 2015 über besondere Vorschriften für die Anwendung von Artikel 108 des Vertrags über die Arbeitsweise der Europäischen Union, ABl. EU Nr. L 248 v. 24.9. 2015 , S. 9.

1615 S. insofern auch die sog. „Ermächtigungsverordnung“, Verordnung (EU) 2015/1588 des Rates vom 13. Juli 2015 über die Anwendung der Artikel 107 und 108 des Vertrags über die Arbeitsweise der Europäischen Union auf bestimmte Gruppen horizontaler Beihilfen, ABl. EU Nr. L 248 v. 24.9.2015, S. 1. 
hinaus zum Erlass von Durchführungsverordnungen, die Beihilfen bestimmen, die von dem Verfahren nach Art. 108 III AEUV ausgenommen sind. Dem sind die zuständigen Organe durch Erlass der allgemeinen ${ }^{1616}$ De-minimis-Beihilfen-Verordnung ${ }^{1617}$ sowie der allgemeinen Gruppenfreistellungsverordnung ${ }^{1618}$ nachgekommen. ${ }^{1619}$

(2) Darüber hinaus kann jeder Beteiligte (vgl. die weite Legaldefinition in Art. 1 lit. h) BeihilfeVVO) gemäß Art. 24 II BeihilfeVVO eine förmliche Beschwerde einlegen, um die Kommission über mutmaßliche rechtswidrige Beihilfen zu informieren.

(3) Zuletzt kann die Kommission gemäß Art. 12 BeihilfeVVO auch von Amts wegen alle Auskünfte über mutmaßliche rechtswidrige Beihilfen prüfen.

Im unionsrechtlichen Normalfall der Anmeldung führt die Kommission innerhalb einer Frist von regelmäßig zwei Monaten (Art. 4 V BeihilfeVVO) eine vorläufige Prüfung durch, die mit einem positiven Beschluss i.S.v. Art. 4 II oder III BeihilfeVVO oder einem Beschluss über die Eröffnung des förmlichen Prüfverfahrens gemäß Art. 108 III 2 AEUV, Art. 4 IV BeihilfeVVO endet. Unterbleibt der Beschluss, gilt die Beihilfe als genehmigt und kann nach erneuter Notifikation durchgeführt werden (Art. 4 VI BeihilfeVVO). Das förmliche Prüfverfahren erfolgt auf Grundlage der Art. $6 \mathrm{ff}$. BeihilfeVVO. Es endet innerhalb von regelmäßig 18 Monaten (Art. 9 VI, VII BeihilfeVVO) wiederum mit einem Beschluss der Kommission (Art. 9 I BeihilfeVVO): Diese kann bereits das Vorliegen einer Beihilfe verneinen (Art. 9 II BeihilfeVVO), deren uneingeschränkte Vereinbarkeit mit dem Binnenmarkt beschließen (sog. „Positivbeschluss“, Art. 9 III BeihilfeVVO) oder diese unter Bedingungen und Auflagen stellen (sog. „mit Bedingungen und Auflagen verbundener Beschluss“, Art. 9 IV BeihilfeVVO). Ist die Beihilfe hingegen mit dem Binnenmarkt unvereinbar, so beschließt die Kommission, dass diese Beihilfe nicht eingeführt werden darf (sog. „Negativbeschluss“, Art. 108 II Uabs. 1 AEUV, Art. 9 V BeihilfeVVO). Wurde die Beihilfemaßnahme bereits durchgeführt, ergeht mit dem Negativbeschluss ein sog. „Rückforderungsbeschluss“ gemäß Art. 16 BeihilfeVVO, der auch Zinsen umfasst. Gemäß Art. 108 III 3 AEUV, Art. 3 BeihilfeVVO darf der be-

1616 Sonderregelungen gibt es bspw. im Agrarsektor, Verordnung (EU) Nr. 1408/2013 der Kommission vom 18. Dezember 2013 über die Anwendung der Artikel 107 und 108 des Vertrags über die Arbeitsweise der Europäischen Union auf De-minimis-Beihilfen im Agrarsektor, ABl. EU Nr. L 352 v. 24.12.2013, S. 9.

1617 Verordnung (EU) Nr. 1407/2013 der Kommission vom 18. Dezember 2013 über die Anwendung der Artikel 107 und 108 des Vertrags über die Arbeitsweise der Europäischen Union auf Deminimis-Beihilfen, ABl. EU Nr. L 352 v. 24.12.2013, S. 1. Eine Subsumtion unter die De-minimisVerordnung führt dazu, dass bereits der Beihilfentatbestand gemäß Art. 107 I AEUV nicht erfüllt ist, Koenig/Paul, in: Streinz, EUV/AEUV, 3. Aufl. 2018, Art. 109 AEUV Rn. 17.

1618 Verordnung (EU) Nr. 651/2014 der Kommission vom 17. Juni 2014 zur Feststellung der Vereinbarkeit bestimmter Gruppen von Beihilfen mit dem Binnenmarkt in Anwendung der Artikel 107 und 108 des Vertrags über die Arbeitsweise der Europäischen Union, ABl. EU Nr. L 187 v. 26.6. 2014, S. 1, zuletzt geändert durch Verordnung (EU) Nr. 2017/1084 der Kommission vom 14. Juni 2017 ABl. EU Nr. L 156 v. 20.6.2017, S. 1. Gemäß Art. 3 der Verordnung sind Beihilfen bei Erfüllen der Voraussetzungen auch mit dem Binnenmarkt vereinbar, Cremer, in: Calliess/Ruffert, EUV/AEUV, 5. Aufl. 2016, Art. 107 AEUV Rn. 66.

1619 Soweit Leistungen unter einen dieser Ausnahmetatbestände fallen, gelten die im Folgenden geschilderten Sondermaßstäbe nicht, vgl. die Fallbearbeitung bei Grupp/Stelkens, Nichts für viel Lärm, abrufbar unter: http://www.saarheim.de/Faelle/laerm-fall.htm (Bearbeitungsstand: 29.9.2019). 
treffende Mitgliedstaat die beabsichtigte Beihilfemaßnahme nicht durchführen, bevor die Kommission einen ihm günstigen Beschluss erlassen hat (oder die Maßnahme als genehmigt gilt); während des gesamten Prüfverfahrens besteht demnach ein Durchführungsverbot. Missachtet der Mitgliedstaat dieses Verbot, kann die Kommission gemäß Art. 13 BeihilfeVVO eine Anordnung zur Aussetzung oder einstweiligen Rückforderung der Beihilfe erlassen. In ihrer Funktion erfüllt die Kommission darüber hinaus entsprechend der BeihilfeVVO auch andere fortlaufende Aufgaben. ${ }^{1620}$

935 Vor diesem Hintergrund sind mehrere Konstellationen der Rückabwicklung von durch Verwaltungsakt bewilligten unionsrechtswidrigen Beihilfen denkbar. Die in der Ausbildung relevanteste Konstellation dürfte die Rückabwicklung nach Negativbeschluss der Kommission gemäß Art. 108 II Uabs. 1 AEUV, Art. 9 V BeihilfeVVO (in Verbindung mit einem Rückforderungsbeschluss gemäß Art. 16 BeihilfeVVO) sein. ${ }^{1621}$ Mit diesem Beschluss wird die materielle Unionsrechtswidrigkeit des Bewilligungsbescheides abschließend ${ }^{1622}$ festgestellt. Damit gehen im Falle der Begehr einer Rückabwicklung bereits sinnlogisch ein Verstoß gegen das Durchführungsverbot sowie regelmäßig eine Verletzung der Notifikationspflicht einher, sodass oftmals zugleich auch die formelle Unionsrechtswidrigkeit des Bescheids in Rede steht. Davon ausgehend sind im Rahmen der Prüfung von $\S 48$ I 1 und 2, II, IV VwVfG weiterhin ${ }^{1623}$ folgende Besonderheiten zu berücksichtigen:

- Im Rahmen der Prüfung der Verwaltungsaktqualität ist - spätestens ${ }^{1624}$ auf die Art der Beihilfengewähr einzugehen (s. dazu Rn. 933).

- Bei der Prüfung der Rechtswidrigkeit des zurückzunehmen Verwaltungsaktes haben Ausführungen zur formellen wie materiellen Unionsrechtswidrigkeit $\mathrm{zu}$ erfolgen. Dabei ist vorab $\mathrm{zu}$ berücksichtigen, dass

1620 Zum einen überprüft sie gemäß Art. 108 I AEUV fortlaufend die in den Mitgliedstaaten bestehenden Beihilferegelungen (und unterbreitet ggf. zweckdienliche Vorschläge zu deren Fortentwicklung; vgl. dazu auch die Art. $21 \mathrm{ff}$. BeihilfeVVO), zum anderen kontrolliert sie gemäß Art. 108 II Uabs. 1 Var. 2 AEUV (auch nach Beschwerde, Art. 24 II BeihilfeVVO) die missbräuchliche Anwendung gewährter Beihilfen.

1621 S. zu dieser Konstellation zentral EuGH, Urt. v. 20.3.1997, Az.: C-24/95 - Land RheinlandPfalz/Alcan Deutschland.

1622 Unbenommen ist es den verschiedenen Betroffenen, gegen den Beschluss Nichtigkeitsklage gemäß Art. 263 AEUV zu erheben, Cremer, in: Calliess/Ruffert, EUV/AEUV, 5. Aufl. 2016, Art. 108 AEUV Rn. 23.

1623 S. zur Subsumtion unter die Tatbestandsmerkmale „Verwaltungsakt“, „,begünstigender Verwaltungsakt“ und „Leistungsverwaltungsakt“ bereits Rn. 933.

1624 Vorstellbar ist, dass diesbezügliche Ausführungen je nach Aufgabenstellung bereits im Rahmen der Prüfung der Zulässigkeit einer Klage erfolgen müssen.

Tobias Brings-Wiesen 
grundsätzlich weder eine formelle ${ }^{1625}$ noch eine materielle ${ }^{1626}$ Unionsrechtswidrigkeit zu einer Nichtigkeit des Bescheids gemäß § $44 \mathrm{VwVfG}$ führt. ${ }^{1627}$ Bei einer Verletzung der Notifikationspflicht liegt ein Verfahrensfehler vor, bezüglich dessen sich die Frage stellt, ob er gemäß § 45 I Nr. 5, II VwVfG („Mitwirkung einer anderen Behörde“) durch Nachholung ${ }^{1628}$ geheilt werden kann. Dem steht jedoch insbesondere ${ }^{1629}$ das teleologische Argument entgegen, dass - wie im Falle eines späteren Positivbeschlusses der Kommission (s. dazu noch Rn. 936) - die Annahme einer Heilung die unmittelbare Wirkung dieser Vorschrift beeinträchtigen, ihre Missachtung begünstigen und somit ihre praktische Wirksamkeit nehmen würde. ${ }^{1630}$ Die materielle Unionsrechtswidrigkeit wird meist nicht gesondert zu prüfen sein: Mit Eintritt der Bestandskraft des Negativbeschlusses steht sie ohnehin fest. ${ }^{1631}$ Doch auch vorher steht es den mitgliedstaatlichen Institutionen aufgrund der ausschließlichen Kompetenz der Kommission nicht frei, vom Beschluss der Kommission abzuweichen. Die materielle Unionsrechtswidrigkeit kann daher im Rahmen der Prüfung zumeist ohne nähere Ausführungen unter Rekurs auf den Negativbeschluss vorausgesetzt werden. ${ }^{1632}$

- Die Unionsrechtswidrigkeit der Beihilfe wirkt sich insbesondere auf die Schutzwürdigkeit des Vertrauens des Beihilfeempfängers gemäß §48 II VwVfG aus. Der EuGH hat in der maßgeblichen Rechtssache „Land Rheinland-Pfalz/Alcan Deutschland“ geurteilt, dass berechtigtes Vertrauen auf die Ordnungsmäßigkeit einer Beihilfe nur dann bestehen kann, wenn diese unter Einhaltung des - mittlerweile - in Art. 108 AEUV vorgesehenen Verfahrens

1625 BVerwG, Urt.v. 16.12.2010, Az.: 3 C 44.09 = BVerwGE 138, 322 (326f., Rn. 16). So auch Kokott, DVBl 1993, 1235 (1237) (unter Rekurs auf § 44 III Nr. 4 VwVfG); Finck/Gurlit, JURA 2011, 87 (91) (unter Rekurs auf die zumeist fehlende Offensichtlichkeit).

1626 BVerwG, Beschl. v. 11.5.2000, Az.: 11 B 26.00 = NVwZ 2000, 1039 (1040).

1627 Der Streit um die Anwendbarkeit der Vorschrift auf nichtige Verwaltungsakte, s. dazu Rn. 862, ist mithin im Regelfall nicht zu diskutieren.

1628 So Finck/Gurlit, JURA 2011, 87 (91); Gurlit, ZJS 2011, 368 (370), die indes noch weiter gehen und in der schlichten „Positiventscheidung“ der Kommission den Anknüpfungspunkt für die Heilung sehen.

$1629 \mathrm{Zu}$ weiteren Argumenten s. Korte, JURA 2017, 656 (660).

1630 So i. E. auch Korte, JURA 2017, 656 (660). Vgl. aus der Rspr. des EuGH nur Urt. v. 12. 2. 2008, Az.: C-199/06 - CELF und ministre de la Culture und de la Communication, Rn. 40. Finck/Gurlit, JURA 2011, 87 (91), plädieren daher - unabhängig vom allgemeinen Streit um die zeitliche Dimension der Heilung (s. dazu bereits Rn. 862) - hier für eine bloße ex nunc-Wirkung.

1631 Detterbeck, Allgemeines Verwaltungsrecht, 17. Aufl. 2019, Rn. 753.

1632 Etwas anderes gilt insbesondere dann, wenn die Aufgabenstellung oder die Angaben im Sachverhalt die Prüfung erwarten lassen. 
gewährt wurde. ${ }^{1633}$ Aus der Verfahrenshoheit der Kommission resultieren mithin speziell für den beihilfenrechtlichen Kontext geltende Sondermaßstäbe. Weitgehend offen blieb dabei naturgemäß die Frage der Einordnung dieser Rechtsprechung in die Systematik von § 48 II VwVfG: Grundsätzlich denkbar ist bereits die Annahme eines Ausschlusses der Schutzwürdigkeit gemäß § 48 II 3 Nr. 3 VwVfG aufgrund grob fahrlässiger Unkenntnis der formellen und/oder materiellen Unionsrechtswidrigkeit des Verwaltungsaktes. Unter Berücksichtigung des konkret-individuellen Maßstabs wird im Hinblick auf die Einhaltung der formellen Vorgaben des Art. 108 III AEUV argumentiert, dass von einem sorgfältigen Durchschnittsbeihilfeempfänger regelmäßig zu erwarten sei, sich der ordnungsgemäßen Durchführung des Prüfverfahrens zu vergewissern. ${ }^{1634}$ Vorzugswürdig ist jedoch, in der Prüfung weiterhin die Umstände des Einzelfalls, wie Umfang und Marktrelevanz einer Beihilfe sowie Größe und Beihilfeerfahrenheit des empfangenden Unternehmens (mit oder ohne eigene Rechtsabteilung), zu berücksichtigen und nicht stets pauschal auf einen Ausschluss der Schutzwürdigkeit abzustellen. ${ }^{1635}$ Jedenfalls aber hat das Vertrauensschutzinteresse - selbst für den Fall, dass die Regelvermutung des § 48 II 2 VwVfG zugunsten des Beihilfeempfängers greift - in der Abwägung nach § 48 II 1 VwVfG wegen dem besonderen unionsrechtlichen Interesse an der effektiven Durchsetzung der unionalen Wettbewerbsordnung ${ }^{1636}$, das auf Seiten des öffentlichen Rücknahmeinteresses neben das Interesse an der Gesetzmäßigkeit der Verwaltung und das fiskalische Interesse tritt, in der Regel zurückzustehen. Auch im Falle einer überwiegenden Verantwortlichkeit ${ }^{1637}$ oder auch vorherigen Abstimmung $^{1638}$ mit der für die Bewilligung zuständigen Behörde soll deren rechtswidriges Verhalten kein schutzwürdiges Vertrauen begründen können, wenn die Vorgaben des Art. 108 III AEUV missachtet wurden. Die gleichsam unionsrechtlich geschützten Grundsätze von Rechtssicherheit und Vertrau-

1633 EuGH, Urt. v. 20.3.1997, Az.: C-24/95 - Land Rheinland-Pfalz/Alcan Deutschland, Rn. 25, $30 \mathrm{f}$.

1634 Für eine Nachforschungspflicht bereits der EuGH, Urt. v. 20.9.1990, Az.: C-5/89 - Kommission/Deutschland, Rn. 14; Urt. v. 20.3.1997, Az.: C-24/95 - Land Rheinland-Pfalz/Alcan Deutschland, Rn. 25; a.A. jedoch Detterbeck, Allgemeines Verwaltungsrecht, 17. Aufl. 2019, Rn. 754; Triantafyllou, NVwZ 1992, 436 (439).

1635 Suerbaum, in: Mann/Sennekamp/Uechtritz, VwVfG, 2. Aufl. 2019, § 48 Rn. 153.

1636 So bereits BVerwG, Urt. v. 17.2.1993, Az.: 11 C 47.92 = BVerwGE 92, 81 (86).

1637 EuGH, Urt. v. 20.3.1997, Az.: C-24/95 - Land Rheinland-Pfalz/Alcan Deutschland, Rn. $41 \mathrm{ff}$.; BVerwG, Urt. v. 23.4.1998, Az.: 3 C 15.97 = BVerwGE 106, 328 (338): Kein Verstoß gegen den Grundsatz von Treu und Glauben.

1638 BVerwG, Urt. v. 24.7.2014, Az.: 3 C 23.13 = NVwZ-RR 2015, 21 (22). 
ensschutz sollen laut EuGH lediglich bei Vorliegen - bis heute kaum näher bestimmter - „außergewöhnlicher Umstände“ überwiegen. ${ }^{1639}$

- In der Konsequenz kommt es sodann zu einem harten dogmatischen Bruch im Hinblick auf die Prüfung eines möglichen Ausschlusses der Rücknahme aufgrund von Verfristung gemäß § 48 IV VwVfG. Insofern verlangt der EuGH selbst für den Fall, dass die Jahresfrist des § 48 IV 1 VwVfG verstrichen ist, die Rücknahme des Bewilligungsbescheids. Die Anwendbarkeit von §48 IV VwVfG wird im Interesse der Effektivität des Unionsrechts schlicht ausgesetzt. $^{1640}$

- Zuletzt verlangt die Berücksichtigung der unionsrechtlichen Wertungen im Falle eines Negativbeschlusses der Kommission eine konsequente Reduktion des Rücknahmeermessens gemäß § 48 I 1 VwVfG auf Null. ${ }^{1641}$

- Zusätzlich steht die Unionsrechtswidrigkeit der Beihilfe später im Rahmen der Prüfung der Erstattung (s. dazu noch Rn. 989 ff.) dem Einwand der Entreicherung gemäß § 49a II i.V.m. §§ 812 ff. BGB entgegen.

Examenswissen: Die Unionsrechtswidrigkeit wirkt sich darüber hinaus (im Interesse des Effektivitätsgrundsatzes) auch vollstreckungs- und verwaltungsprozessrechtlich auf den Erstattungsbescheid aus: Verbunden mit einem Negativbeschluss gemäß Art. 108 II Uabs. 1 AEUV, Art. 9 I, V BeihilfeVVO ergeht gemäß Art. 16 I BeihilfeVVO grundsätzlich ein Rückforderungsbeschluss, infolgedessen der Mitgliedstaat alle notwendigen Maßnahmen zu ergreifen hat, um die Beihilfe vom Empfänger zurückzufordern. Gemäß Art. 16 III BeihilfeVVO „erfolgt die Rückforderung unverzüglich und nach den Verfahren des betreffenden Mitgliedstaats, sofern hierdurch die sofortige und tatsächliche Vollstreckung des Beschlusses der Kommission ermöglicht wird." Daraus folgt zunächst, dass die zuständige Behörde den Erstattungsbescheid für sofort vollziehbar zu erklären hat, und sodann, dass weder Behörden die Aussetzung der Vollziehung gemäß § 80 IV 1 VwGO anordnen, noch Gerichte die aufschiebende Wirkung eines Widerspruchs bzw. einer Anfechtungsklage gemäß § $80 \mathrm{~V} 1 \mathrm{VwGO}$ wiederherstellen dürfen. ${ }^{1642}$

Examenswissen: Davon strikt abzugrenzen sind Konstellationen bloß formell unionrechtswidriger Beihilfen. ${ }^{1643}$ Die mit ihnen verbundenen Rechtsprobleme unterscheiden sich danach, in welchem Stadium des Prüfverfahrens der Kommission ihre Rückabwicklung in Rede steht. ${ }^{1644}$

1639 EuGH, Urt. v. 11.3.2010, Az.: C-1/09 - CELF und Ministre de la Culture et de la Communication, Rn. 42f.; so auch Urt. v. 20.9.1990, Az.: C-5/89 - Kommission/Deutschland, Rn. 16.

1640 EuGH, Urt. v. 20.3.1997, Az.: C-24/95 - Land Rheinland-Pfalz/Alcan Deutschland, Rn. 31 ff.; BVerwG, Urt. v. 23.4.1998, Az.: 3 C 15.97 = BVerwGE 106, 328 (336ff.).

1641 EuGH, Urt. v. 20.3.1997, Az.: C-24/95 - Land Rheinland-Pfalz/Alcan Deutschland, Rn. 34; Detterbeck, Allgemeines Verwaltungsrecht, 17. Aufl. 2019, Rn. 756; Ruffert, in: Ehlers/Pünder, Allgemeines Verwaltungsrecht, 15. Aufl. 2016, § 24 Rn. 33.

1642 Detterbeck, Allgemeines Verwaltungsrecht, 17. Aufl. 2019, Rn. 758.

1643 Dazu auch Detterbeck, Allgemeines Verwaltungsrecht, 17. Aufl. 2019, Rn. 759 ff.; ausführlich auch zu anderen Konstellationen der Beihilfegewähr Finck/Gurlit, JURA 2011, 87.

1644 S. auch Korte, JURA 2017, 656 (662f.). 
In den verschiedenen Konstellationen sind im Rahmen der Prüfung von § 48 I 1 und 2, II, IV VwVfG wiederum beihilfenrechtlich bedingte Sondermaßstäbe zu berücksichtigen:

- Mit einem für den Mitgliedstaat günstigen Beschluss gemäß Art. 108 II Uabs. 1 AEUV stellt die Kommission abschließend fest, dass die Bewilligung einer Leistung - regelmäßig von Beginn an - mit dem materiellen Beihilfenrecht vereinbar gewesen ist. ${ }^{1645}$ Die nationalen Behörden sind dann nicht verpflichtet, die Beihilfegewähr aufgrund materieller Unionsrechtswidrigkeit unter Berücksichtigung der bereits geschilderten Modifikationen rückabzuwickeln. Der günstige Beschluss ändert indes nichts an einer bereits erfolgten Verletzung der formellen Vorgaben: Verstöße gegen die Notifikationspflicht gemäß Art. 108 III 1 AEUV und/ oder gegen das Durchführungsverbot gemäß Art. 108 III 3 AEUV werden dadurch nicht rückwirkend geheilt oder legitimiert. ${ }^{1646}$ Gleichwohl hat der EuGH entschieden, dass das Unionsrecht (auch außerhalb von Konstellationen „außergewöhnlicher Umstände“) nicht die Rückzahlung der gesamten rechtswidrigen Beihilfe verlangt. Begründet wird dies mit dem nur vorläufigen Charakter des Zwecks des Durchführungsverbots, den gemeinsamen Markt und andere Marktteilnehmer vor unzulässigen Wettbewerbsverzerrungen zu schützen. ${ }^{1647} \mathrm{Im}$ Interesse von dessen effektiver Durchsetzung verlangt der EuGH jedoch zumindest eine Abschöpfung der Zinsen, die der Beihilfeempfänger gezahlt hätte, wenn er sich den gewährten Beihilfebetrag bis zum Erlass des Beschlusses auf dem Markt hätte leihen müssen. ${ }^{1648}$ Wird der Beschluss der Kommission vor den Unionsgerichten angegriffen, kann sich der relevante Zeitraum bis zur endgültigen gerichtlichen Entscheidung ${ }^{1649}$ und gar darüber hinaus verlängern, ohne dass sich der Empfänger auf ein berechtigtes Vertrauen berufen könnte ${ }^{1650}$. Erfolgte die Beihilfegewähr unter Verletzung des Durchführungsverbots ausschließlich auf Grundlage eines Bewilligungsbescheids, hat die Rückabwicklung wie gewohnt auf Grundlage von § 48 I 1

1645 S. zu dieser Konstellation zentral EuGH, Urt.v. 12.2.2008, Az.: C-199/06 - CELF und Ministre de la Culture et de la Communication; Urt. v. 11.3.2010, Az.: C-1/09 - CELF und Ministre de la Culture et de la Communication. Dazu auch Detterbeck, Allgemeines Verwaltungsrecht, 17. Aufl. 2019, Rn. 762; Decker, in: Wolff/Decker, VwGO/VwVfG, 3. Aufl. 2012, § 48 VwVfG Rn. 54 ff.

1646 EuGH, Urt. v. 21.11.1991, Az.: C-354/90 - Fédération nationale du commerce extérieur des produits alimentaires u.a./Frankreich, Rn. 16; Urt.v. 12.2.2008, Az.: C-199/06 - CELF und ministre de la Culture und de la Communication, Rn. 40.

1647 EuGH, Urt. v. 12.2.2008, Az.: C-199/06 - CELF und Ministre de la Culture et de la Communication, Rn. 46 ff. Die Möglichkeit einer derartigen Anordnung nach nationalem Recht, schließt der EuGH zwar nicht aus, a.a.O., Rn. 53, sie wird indes bei Anwendung des Verhältnismäßigkeitsgrundsatzes hinter der bloßen Abschöpfung gezogener Vorteile zurückstehen, Finck/Gurlit, JURA 2011, 87 (92).

1648 EuGH, Urt. v. 12.2.2008, Az.: C-199/06 - CELF und Ministre de la Culture et de la Communication, Rn. 50 ff. Daran anknüpfend EuGH, Urt. v. 18.12.2008, Az.: C-384/07 - Wienstrom, Rn. 28 ff.; Urt. v. 5.3.2019, Az.: C-349/17 - Eesti Pagar, Rn. $131 \mathrm{ff}$.

1649 EuGH, Urt. v. 12.2.2008, Az.: C-199/06 - CELF und Ministre de la Culture et de la Communication, Rn. $56 \mathrm{ff}$.

1650 Der EuGH, Urt. v. 11.3.2010, Az.: C-1/09 - CELF und Ministre de la Culture et de la Communication, Rn. 41 ff., verneinte mangels Eintritts der Bestandskraft des Kommissionsbeschlusses gar für den Sonderfall des Aufeinanderfolgens von drei Nichtigkeitsklagen das Vorliegen „außergewöhnlicher Umstände“.

Tobias Brings-Wiesen 
und 2, II, IV und § 49a VwVfG zu erfolgen. ${ }^{1651}$ Dabei ist - neben den bereits dargelegten Besonderheiten betreffend die formelle Unionsrechtswidrigkeit (s. dazu Rn. 938) - zu berücksichtigen, dass eine Rücknahme des Bescheids entsprechend des bloß vorläufigen Sicherungszwecks des Durchführungsverbots ausschließlich mit Wirkung für die Vergangenheit und bis zum endgültigen Beschluss der Kommission erfolgt. In der Folge sind die Zinsvorteile als „bereits erbrachte Leistungen“ auf Grundlage von § 49a I 1 VwVfG zurückzufordern, wobei ein etwaiger Entreicherungseinwand gemäß § 49a II 2 VwVfG wiederum unionsrechtlich bedingt unbeachtet $\mathrm{zu}$ bleiben hat.

- Davon zu unterscheiden sind Konstellationen, in denen eine (zumindest vorläufige) Rückabwicklung während eines noch laufenden Prüfverfahrens begehrt wird. Wird eine Beihilfemaßnahme unter Verstoß gegen das Durchführungsverbot durchgeführt, haben die mitgliedstaatlichen Institutionen im Interesse des vorläufigen Sicherungszwecks des Art. 108 III AEUV Maßnahmen anzuordnen, die geeignet sind, die Rechtswidrigkeit der Durchführung zu beseitigen, damit der Empfänger in der bis zum Beschluss der Kommission noch zu verbleibenden Zeit nicht weiterhin frei über sie verfügen kann. ${ }^{1652}$ Auch insofern hat die Rückabwicklung auf Grundlage von § 48 I 1 und 2, II, IV und § 49a VwVfG zu erfolgen, wobei sich Rücknahme und Erstattung unter der auflösenden Bedingung eines günstigen Beschlusses der Kommission anbieten. ${ }^{1653}$ Vor Eröffnung des formellen Prüfverfahrens trifft sie dabei die Pflicht, die Voraussetzungen von Notifikationspflicht und Durchführungsverbot selbst zu prüfen; nach dessen Eröffnung sollen sie laut EuGH an den Beschluss der Kommission gebunden $\operatorname{sein}^{1654} .^{1655}$ Vor diesem Hintergrund liegt zumindest nahe, die bereits geschilderte weitgehende unionsrechtliche Überformung von § 48 I 1 und 2, II, IV und § 49a VwVfG auch in diesen Konstellationen anzunehmen - abschließend geklärt sind diese Fragen indes noch nicht. ${ }^{1656}$ Von einer strikten unionsrechtlichen Bindung wird man zumindest im Falle einer Anordnung der Kommission gemäß Art. 13 BeihilfeVVO auszugehen haben. ${ }^{1657}$

- Wettbewerber des Beihilfeempfängers ${ }^{1658}$ können sich in beiden Fällen im Wege von Anfechtungsklage und Vollzugsfolgenbeseitigungsklage gemäß § 113 I 1 und 2 VwGO (s. dazu näher Rn. 1387) gegen den Bewilligungsbescheid und die bereits erfolgte Durchführung der Beihilfemaßnahme wenden. ${ }^{1659}$ Art. 108 III 3 AEUV entfaltet nicht nur unmittelbare Wirkung, sondern zugunsten der Wettbewerber auch drittschützenden Charakter. ${ }^{1660}$

1651 BVerwG, Urt. v. 16.12.2010, Az.: 3 C 44.09 = BVerwGE 138, 322 (325f., Rn. 14f.); Finck/Gurlit, JURA 2011, 87 (91f.).

1652 EuGH, Urt. v. 11.3.2010, Az.: C-1/09 - CELF und Ministre de la Culture et de la Communication, Rn. 29f.; Urt. v. 21.11.2013, Az.: C-284/12 - Deutsche Lufthansa, Rn. 30 f.

1653 Detterbeck, Allgemeines Verwaltungsrecht, 17. Aufl. 2019, Rn. 761.

1654 S. dazu Martin-Ehlers, EuZW 2014, 247; Berrisch, EuZW 2014, 253; Rennert, DVBl 2014, 669. 1655 EuGH, Urt. v. 21.11.2013, Az.: C-284/12 - Deutsche Lufthansa, Rn. 33 ff. Keine derartige Bindung gilt indes im Falle eines Beschlusses der Kommission gemäß Art. 4 III BeihilfeVVO, BVerwG, Urt. v. 26.10.2016, Az.: 10 C 3.15 = EuZW 2017, 355 (357 ff., Rn. 18 ff.).

1656 Detterbeck, Allgemeines Verwaltungsrecht, 17. Aufl. 2019, Rn. 760.

1657 Detterbeck, Allgemeines Verwaltungsrecht, 17. Aufl. 2019, Rn. 761.

1658 S. zu beihilferechtlichen Konkurrentenklagen Rennert, EuZW 2011, 576.

1659 Detterbeck, Allgemeines Verwaltungsrecht, 17. Aufl. 2019, Rn. 760; Rennert, EuZW 2011, 576 (578). 


\section{(c) Die Rücknahme unionsrechtswidriger Verwaltungsakte im Übrigen}

937 Examenswissen: Wie bereits mehrfach angemerkt handelt es sich bei dem Voranstehenden um Sondermaßstäbe, die vom EuGH speziell für EU-beihilfenrechtlich relevante Sachverhalte statuiert und entsprechend von der deutschen Rechtsprechung rezipiert wurden. Auf den Regelfall der Rücknahme anderweitig unionsrechtswidriger Verwaltungsakte sind sie nicht übertragbar. Die mitgliedstaatlichen Institutionen sind aber bei Anwendung des §48 VwVfG in unionsrechtlich determinierten Sachverhalten weiterhin mindestens an die Grundsätze von Äquivalenz und Effektivität (als Ausprägungen des Grundsatzes der loyalen Zusammenarbeit gemäß Art. 4 III EUV, s. bereits Rn. 931) gebunden.

938 Dies hat in der Vergangenheit vermehrt zu der Frage geführt, ob eine mitgliedstaatliche Behörde wegen ihrer Bindung an den Effektivitätsgrundsatz die Pflicht treffen kann, eine bereits bestandskräftige Entscheidung zurückzunehmen, wenn sich durch ein späteres Urteil des EuGH deren Unionsrechtswidrigkeit offenbart. ${ }^{1661}$ Ausschlaggebend war der der Rechtssache „Kühne \& Heitz“ zugrundeliegende Sachverhalt ${ }^{1662}$ : Das niederländisches Unternehmen Kühne \& Heitz NV hatte von Dezember 1986 bis Dezember 1987 Geflügelteile in Drittstaaten exportiert und dafür gemäß EU-sekundärrechtlicher Vorgaben ursprünglich eine Ausfuhrerstattung erhalten. Bei einer nachträglichen Überprüfung dieses Vorgangs ordnete die zuständige niederländische Behörde die Geflügelteile einer neuen Tarifposition zu, die eine Erstattung nicht vorsah. In der Folge verlangte sie eine Rückzahlung in Höhe der Erstattung von Kühne \& Heitz NV, wogegen das Unternehmen erfolglos den Rechtsweg beschritt. Jahre später entschied der EuGH, dass die Zuordnung der Geflügelteile zur ursprünglichen Tarifposition korrekt war. ${ }^{1663}$ Das um Vorabentscheidung (gemäß Art. 267 AEUV) ersuchende niederländische Gericht erwog, unter den Umständen des Falles verpflichtet $\mathrm{zu}$ sein, einen bereits bestandskräftigen Bescheid zurückzunehmen, um die volle Wirksamkeit des Unionsrechts sicherzustellen. Eine derartige Verpflichtung verneinte der EuGH indes für den Regelfall: Unter Berücksichtigung des auch im Unionsrecht geltenden Grundsatzes der Rechtssicherheit seien mitgliedstaatliche Behörden grundsätzlich nicht verpflichtet, eine (nach Ablauf einer angemessenen Klagefrist oder Erschöpfung des Rechtswegs) bestandskräftige Verwaltungsentscheidung zurückzunehmen. ${ }^{1664}$ Vor diesem Hintergrund erachtete er in einem späteren Vorabentscheidungsverfahren insbesondere auch die deutsche Rechtslage für mit dem Effektivitätsgrundsatz vereinbar. ${ }^{1665}$ Wegen der besonderen Umstände des Falles „Kühne \&Heitz“ erkannte der EuGH jedoch ausnahmsweise auf eine Pflicht zur „Überprüfung“:

1660 BVerwG, Urt. v. 16.12.2010, Az.: 3 C 44.09 = BVerwGE 138, 322 (324f., Rn. 13); Urt. v. 26.10. 2016, Az.: 10 C 3.15 = EuZW 2017, 355 (356f., Rn. 13, 20).

1661 S. dazu auch die Fallbearbeitung bei Musil/Burchard, Klausurenkurs im Europarecht, 4. Aufl. 2016, Fall 14, S. 256.

1662 EuGH, Urt. v. 13.1.2004, Az.: C-453/00 - Kühne \& Heitz, Rn. $26 \mathrm{ff}$.

1663 EuGH, Urt. v. 5.10.1994, Az.: C-151/93 - Voogd Vleesimport en -export.

1664 EuGH, Urt.v. 13.1.2004, Az.: C-453/00 - Kühne \& Heitz, Rn. 24; zuletzt Urt. v. 20.12. 2017, Az.: C-492/16 - Incyte, Rn. 46. Darauf rekurrierend BVerwG, Urt. v. 22.10.2009, Az.: 1 C $26.08=$ BVerwGE 135, 137 (146, Rn. 20).

1665 EuGH, Urt. v. 19.9.2006, Az.: C-392/04 und C-422/04 - i-21 Germany und Arcor, Rn. $58 \mathrm{ff}$. 
- Die Behörde war nach nationalem Recht grundsätzlich befugt, die bestandskräftige Entscheidung zurückzunehmen.

- Die Entscheidung war infolge eines Urteils eines in letzter Instanz entscheidenden nationalen Gerichts bestandskräftig geworden, der nationale Rechtsweg mithin erschöpft gewesen.

- Dieses letztinstanzliche Urteil beruhte, wie eine nach seinem Erlass ergangene Entscheidung des Gerichtshofs zeigte, auf einer unrichtigen Auslegung des Unionsrechts, die erfolgt war, ohne dass der Gerichtshof um Vorabentscheidung ersucht wurde, obwohl der Tatbestand des Art. 267 III AEUV erfüllt war. ${ }^{1666}$

- Der Betroffene hatte sich, unmittelbar nachdem er Kenntnis von der besagten Entscheidung des Gerichtshofs erlangt hatte, an die Behörde gewandt. ${ }^{1667}$

An dieser Rechtsprechung hat der EuGH bis heute grundsätzlich festgehalten, ${ }^{1668}$ dabei jedoch zugleich immer wieder ihren Ausnahmecharakter demonstriert: Er verneinte ihre Anwendbarkeit mangels Erschöpfung des nationalen Rechtswegs ${ }^{1669}$ oder mangels gesetzlich vorgesehener Befugnis zur Durchbrechung der Vorgaben zur Gewährleistung von Rechtssicherheit ${ }^{1670}$. Zugleich hat der EuGH zaghaft andere „besondere Umstände“ erkannt, unter denen im Interesse der Sicherstellung der Unionsrechtmäßigkeit eine Verpflichtung der Überprüfung einer Verwaltungsentscheidung unter Durchbrechung ihrer Bestandskraft besteht: In „Byankov“ urteilte der EuGH, dass die Unmöglichkeit der erneuten Überprüfung eines offensichtlich rechtswidrigen bestandskräftigen Ausreiseverbots nach bulgarischem Recht wegen seines fundamentalen Widerspruchs zum Recht auf Freizügigkeit von Unionsbürgern gemäß Art. 21 I AEUV gegen den Effektivitätsgrundsatz verstößt. ${ }^{1671}$ In „Incyte“ schloß der EuGH insbesondere aus der Zielsetzung des zugrundeliegenden Sekundärrechts darauf, dass die Korrektur der bestandskräftig bestimmten, aber rechtswidrigen Laufzeit eines Patents möglich sein muss. ${ }^{1672}$ Obgleich der EuGH sich mit dem Rekurs auf mögliche „besondere Umstände“ eine Hintertür offenhält, zeigt sich unverkennbar der Ausnahmecharakter einer durch den Effektivitätsgrundsatz bedingten Verpflichtung zur Überprüfung eines Verwaltungsaktes unter Durchbrechung der Bestandskraft.

Liegt keine dieser Ausnahmekonstellationen vor, verlangt der Äquivalenzgrundsatz lediglich, dass bei Anwendung der nationalen Vorschriften nicht ohne sachliche Rechtfertigung zwischen unionsrechtlich und rein nationalrechtlich determinierten Sachverhalten unterschie-

1666 Dabei muss sich der Betroffene vor den nationalen Gerichten nicht auf Unionsrecht berufen haben, soweit diese verpflichtet sind, Unionsrecht von Amts wegen zu berücksichtigen, EuGH, Urt. v. 12.2.2008, Az.: C-2/06 - Kempter, Rn. 34ff. Die deutschen Verwaltungsgerichte trifft im Regelfall eine derartige Pflicht; s. aber zur besonderen Ausnahme hinsichtlich des Antrags auf Zulassung der Berufung gemäß §124a VwGO BVerwG, Urt. v. 22.10.2009, Az.: 1 C 15/08 = BVerwGE 135, 121 (133, Rn. 32).

1667 S. zur „Unmittelbarkeit“ näher EuGH, Urt. v. 12.2.2008, Az.: C-2/06 - Kempter, Rn. 54 ff. 1668 Zuletzt EuGH, Urt. v. 20.12.2017, Az.: C-492/16 - Incyte, Rn. 47.

1669 EuGH, Urt. v. 19.9. 2006, Az.: C-392/04 und C-422/04 - i-21 Germany und Arcor, Rn. 53; Urt.v. 4.10.2012, Az.: C-249/11 - Byankov, Rn. 51.

1670 Vgl. entsprechend zur Durchbrechung der Rechtskraft EuGH, Urt. v. 16.3.2006, Az.: C-234/ 04 - Kapferer, Rn. 23.

1671 EuGH, Urt. v. 4.10.2012, Az.: C-249/11 - Byankov, Rn. 77 ff.

1672 EuGH, Urt. v. 20.12.2017, Az.: C-492/16 - Incyte, Rn. 45 ff.

Tobias Brings-Wiesen 
den wird. ${ }^{1673}$ Dies bedeutet bei bestandskräftigen Verwaltungsakten insbesondere, dass auch im Falle ihrer Unionsrechtswidrigkeit nur bei Vorliegen einer der vom Bundesverwaltungsgericht etablierten Fallgruppen der Unerträglichkeit der Aufrechterhaltung der Bestandskraft eine Ermessensreduktion auf Null erfolgt (s. dazu Rn. 924).

940 Für die Prüfungspraxis bedeutet dies: Die Bewertung der Rücknahme unionsrechtswidriger Verwaltungsakte außerhalb des geschilderten beihilfenrechtlichen Kontexts erfolgt - auch wegen des Äquivalenzgrundsatzes - im Regelfall ohne besondere unionsrechtliche Überformung am Maßstab von $\S 48$ VwVfG. Besonderheiten werden sich dann höchstens im Rahmen der Prüfung der Rechtswidrigkeit des zurückzunehmenden Verwaltungsaktes ergeben, soweit diese unter Berücksichtigung unionalen Primär- oder Sekundärrechts zu erfolgen hat. ${ }^{1674}$ Anderes gilt in den wenigen geschilderten Ausnahmekonstellationen, die in der Prüfungspraxis zwar nur eine untergeordnete Rolle spielen dürften, aber wegen ihrer Feinheiten gleichwohl bekannt sein sollten: Die im Interesse des Effektivitätsgrundsatz erforderliche unionsrechtliche Überformung ist je nach Anwendungsfall des $\S 48$ VwVfG an verschiedenen Stellen der Prüfung denkbar. In der derzeit praktisch ${ }^{1675}$ allein relevanten Konstellation der Rücknahme eines belastenden Verwaltungsaktes gemäß § 48 I 1 VwVfG spielt sie sich ganz wesentlich im Rahmen der Prüfung des Ermessens als Frage einer unionsrechtlich bedingten Ermessensreduktion auf Null ab. Die den Rechtssachen „Bankyo“ und „Incyte“ zugrundeliegenden Sachverhaltskonstellationen lassen sich dabei bereits problemlos den vom Bundesverwaltungsgericht etablierten Fallgruppen zuordnen (Bankyo: „offensichtliche Rechtswidrigkeit“; Incyte: Berücksichtigung der Wertungen und Intentionen des zugrundeliegenden Fachrechts). Die besonderen Umstände der Rechtssache „Kühne \& Heitz“ sind demgegenüber als besondere unionsrechtliche Fallgruppe zu betrachten. ${ }^{1676}$ Weitere Ausnahmekonstellationen sollten in der Prüfung nur mit extremer Zurückhaltung überhaupt erwogen werden. Handelt es sich um eine dieser Ausnahmekonstellationen, ist abschließend auf den Streit einzugehen, ob der EuGH in diesen Fällen mit der Pflicht zur „Überprüfung“ tatsächlich eine Pflicht zur Rücknahme verbindet ${ }^{1677}$ oder lediglich ein Wiederaufgreifen des Verfahrens fordert ${ }^{1678}$. Von Letzterem wird man zumindest dann ausgehen müssen,

1673 Maurer/Waldhoff, Allgemeines Verwaltungsrecht, 19. Aufl. 2017, §11 Rn. 73. S. dazu die Prüfung des EuGH, Urt. v. 19.9.2006, Az.: C-392/04 und C-422/04 - i-21 Germany und Arcor, Rn. 62ff.; daran anknüpfend BVerwG, Urt. v. 17.1.2007, Az.: 6 C 32.06 = NVwZ 2007, 709 (711f., Rn. 16ff.); zust. Detterbeck, Allgemeines Verwaltungsrecht, 17. Aufl. 2019, Rn. 764. S. dazu auch die Fallbearbeitung bei Ludwigs, JURA 2009, 226 (232)

1674 S. zu den prüfungsrelevanten Grundfreiheiten Sauer, JuS 2017, 310. S. auch die Fallbearbeitung bei Staufer/Steinebach, JURA 2012, 883.

1675 Rücknahmen unionsrechtswidriger begünstigender Verwaltungsakte gemäß § 48 I 2, II bis IV VwVfG sind zwar theoretisch denkbar, spielten in der Praxis jedoch - wie die dargestellte Rechtsprechung zeigt - bislang (außerhalb des Subventionsrechts) keine Rolle.

1676 So auch Ludwigs, JURA 2009, 226 (229ff.), der abgrenzend auf die verschiedenen Konstellationen der Ermessensreduktion auf Null aufgrund nationalen und unionalen Rechts eingeht. 1677 So Maurer/Waldhoff, Allgemeines Verwaltungsrecht, 19. Aufl. 2017, § 11 Rn. 73; Ruffert, in: Ehlers/Pünder, Allgemeines Verwaltungsrecht, 15. Aufl. 2016, § 24 Rn. 17 f.; Frenz, DVBl 2004, 375; Kanitz/Wendel, EuZW 2008, 231 (235). Zumindest in bipolaren Rechtsverhältnissen Rennert, DVBl 2007, 401 (408); Ludwigs, JZ 2008, 466 (468f.).

1678 EuGH, Urt. v. 19.9.2006, Az.: C-392/04 und C-422/04 - i-21 Germany und Arcor, Rn. 52 (sehr deutlich: „,eventuell zurückzunehmen“); wohl auch das BVerwG, Urt.v. 22.10.2009, Az.:1 C 15/08 = 
wenn in multipolaren Rechtsverhältnissen die Belange betroffener Dritter zu berücksichtigen sind. ${ }^{1679}$ Sind diese Fragestellungen in die Prüfung eines Anspruchs auf Wiederaufgreifen des Verfahrens (s. dazu in $\S 3$ Rn. 98 ff.) eingebettet, hat dieser ultimativ am Maßstab von $\S 51$ V i.V.m. $\S 48$ I 1 VwVfG zu erfolgen, da nach der zutreffenden herrschenden Meinung ${ }^{1680}$ auch der Effektivitätsgrundsatz kein Abweichen vom Verständnis des Tatbestands der Änderung der Rechtslage gemäß § 51 I Nr. 1 VwVfG verlangt.

\section{dd) Literaturhinweise}

Lehrbeiträge: Britz/Richter, Die Aufhebung eines gemeinschaftsrechtswidrigen nicht begünstigenden Verwaltungsakts, JuS 2005, 198; Brügge/Erichsen, Die Rücknahme von Verwaltungsakten nach $\S 48$ VwVfG, JURA 1999, 155; Bungenberg/Motzkus, Die Praxis des Subventions- und Beihilfenrechts in Deutschland, GewArch Beil. WiVerw 2/2013, 76; Ehlers, Rechtsfragen des Subventionsrechts, DVBl 2014, 1; Ehlers/Kallerhoff, Die Rücknahme von Verwaltungsakten, JURA 2009, 823; Finck/Gurlit, Die Rückabwicklung formell unionsrechtswidriger Beihilfen, JURA 2011, 87; Hilbert, Die reformierte europäische Beihilfeaufsicht, JURA 2017, 1150; Korte, Grundlagen des Subventionsrechts, JURA 2017, 656; Krausnick, Grundfälle zu §§ 48, 49 VwVfG, JuS 2010, 594, 681 und 778; Martini, Die Aufhebung von Verwaltungsakten nach $\S 48$ ff. VwVfG, JA 2012, 762; JA 2013, 442; JA 2016, 830 und JA 2017, 838; Struzina/Lindner, Vertrauensschutz bei der Rücknahme von Verwaltungsakten nach § 48 III VwVfG, NVwZ 2016, 1295

Fallbearbeitungen: Broscheit, „Der findige Gaststättenbetreiber“, JA 2016, 840; Funke/Waidhas, „Subventioniertes Freibad“, JA 2014, 439; Gurlit, Übungsklausur: Gau-Wackenheimer Streit um Weinbau, ZJS 2011, 368; Kahl/Hilbert, Das nachträglich zerronnene Subventionsglück, JURA 2011, 948; Knappe/Tehlen, „Rocker ohne Knarre und Kutte“, JURA 2018, 829; Ludwigs, Jus vigilantibus scriptum, JURA 2009, 226; Musil/Burchard, Fall 14 - Bestandskraft als Europarechtsproblem, in: Klausurenkurs im Europarecht, 4. Aufl. 2016, S. 256; Peters, Der rechtswidrig gewährte Zuschuss, VR 2018, 62; Staufer/Steinebach, Recht auf Freizügigkeit und Hochschulzulassung, JURA 2012, 883; Vrhovac/Sprungmann,

BVerwGE 135, 121 (132f., Rn. 30, 33); Urt. v. 22.10.2009, Az.: 1 C 26/08 = BVerwGE 135, 137 (146f., Rn. 20, 23); so auch Britz/Richter, JuS 2005, 198 (199ff.); Krönke, Die Verfahrensautonomie der Mitgliedstaaten der Europäischen Union, 2013, S. 238.

1679 Detterbeck, Allgemeines Verwaltungsrecht, 17. Aufl. 2019, Rn. 765; Britz/Richter, JuS 2005, 198 (199); Ludwigs, DVBl 2008, 1164 (1169). Vgl. bereits EuGH, Urt. v. 13.1.2004, Az.: C-453/00 Kühne \& Heitz, Rn. 27.

1680 BVerwG, Urt.v. 22.10. 2009, Az.: 1 C 15/08 = BVerwGE 135, 121 (128, Rn. 21); Urt.v. 22.10. 2009, Az.: 1 C 26/08 = BVerwGE 135, 137 (143f., Rn. 16); Detterbeck, Allgemeines Verwaltungsrecht, 17. Aufl. 2019, Rn. 763; Britz/Richter, JuS 2005, 198 (201); Rennert, DVBl 2007, 400 (408); Kanitz/ Wendel, JuS 2008, 58 (63); Ludwigs, DVBl 2008, 1164 (1172). A.A. Lenze, VerwArch 2006, 49 (56 ff.). 
„Wash and go - auch am Heiligen Sonntag?“, JA 2018, 927; von Weschpfennig, „Doktor Ade“, JURA 2014, 1055

\section{c) Widerruf eines Verwaltungsakts nach $\S 49$ VwVfG}

941 Die folgende Darstellung zum Widerruf eines Verwaltungsakts gemäß § 49 VwVfG orientiert sich wiederum weitgehend am Prüfungsschema der Vorschrift, während sich grundlegendere Ausführungen an den für die Prüfung relevanten Stellen finden.

\section{Prüfungsschema zu § 49 VwVfG}

I. Ermächtigungsgrundlage: § 49 I, II oder III VwVfG (s. im Einzelnen Rn. 943)

II. Formelle Rechtmäßigkeit

1. Zuständigkeit (Beachte: $\S 49 \mathrm{~V} \mathrm{VwVfG)}$

2. Verfahren (Insbesondere: $\S 28 \mathrm{I} \mathrm{VwVfG}$ )

3. Form (Beachte: actus contrarius-Gedanke)

III. Materielle Rechtmäßigkeit

1. Tatbestand

a) Vorliegens eines Verwaltungsakts (als Gegenstand der Aufhebung)

b) Rechtmäßigkeit des aufzuhebenden Verwaltungsakts (im Zeitpunkt seines Erlasses) (Beachte: „Erst-recht-Schluss“ hinsichtlich rechtswidriger Verwaltungsakte)

c) Kein Ausschluss des Widerrufs, weil ein Verwaltungsakt gleichen Inhalts erneut erlassen werden müsste oder aus anderen Gründen ein Widerruf unzulässig ist (§ $49 \mathrm{I} \mathrm{VwVfG)}$

d) Ggf. weitere tatbestandliche Voraussetzungen gemäß § 49 II oder III VwVfG im Falle des Vorliegens eines rechtmäßigen begünstigenden Verwaltungsakts

aa) Tatbestandliche Voraussetzungen gemäß § 49 III VwVfG (als lex specialis)

(1) Vorliegen eines Verwaltungsakts, der eine einmalige oder laufende Geldleistung oder teilbare Sachleistung zur Erfüllung eines bestimmten Zwecks gewährt oder hierfür Voraussetzung ist (,Leistungsverwaltungsakt“)

(2) Vorliegen eines Widerrufsgrundes gemäß § 49 III 1 VwVfG

bb) Tatbestandliche Voraussetzungen gemäß § 49 II VwVfG

(1) Vorliegen eines sonstigen Verwaltungsakts

(2) Vorliegen eines Widerrufsgrundes gemäß § 49 II 1 VwVfG 
cc) Kein Ausschluss des Widerrufs aufgrund von Verfristung gemäß $\S 49$ II 2 bzw. III 2 i.V.m. § 48 IV VwVfG

2. Rechtsfolge: Ordnungsgemäße Ermessensausübung (Beachte: Zeitliche Ermessensbegrenzungen in § 49 I und II VwVfG [nur „mit Wirkung für die Zukunft“]; Ausnahme: Widerruf „mit Wirkung für die Vergangenheit“ gemäß § 49 III VwVfG)

\section{aa) Ermächtigungsgrundlage}

Anders als im Rahmen von $\S 48$ VwVfG besteht keine einheitliche Ermächti- 943 gungsgrundlage, sodass im Rahmen einer Prüfung jeweils auf den im Folgenden näher $\mathrm{zu}$ begutachtenden Absatz zu rekurrieren ist. Rechtmäßige belastende Verwaltungsakte sind gemäß § 49 I VwVfG zu widerrufen. Im Falle von rechtmäßigen begünstigenden Verwaltungsakten ist $\mathrm{zu}$ unterscheiden zwischen Verwaltungsakten, die eine einmalige oder laufende Geldleistung oder teilbare Sachleistung zur Erfüllung eines bestimmten Zwecks gewähren oder hierfür Voraussetzung sind und gemäß § 49 III VwVfG - auch mit Wirkung für die Vergangenheit - widerrufen werden können -, und sonstigen Verwaltungsakten, die gemäß § 49 II VwVfG widerrufen werden können. Wie im Rahmen von § 48 VwVfG (s. dazu Rn. 846) sollte eine dieser Ermächtigungsgrundlagen zu Beginn der Rechtmäßigkeitsprüfung präzise bestimmt, deren Voraussetzungen jedoch sodann erst im Rahmen der materiellen Rechtmäßigkeit ausführlich geprüft werden.

\section{bb) Formelle Rechtmäßigkeit}

Da auch der Widerruf eines Verwaltungsakts selbst ein Verwaltungsakt ist, 944 gelten die bereits zu § 48 VwVfG erfolgten Darstellungen entsprechend. ${ }^{1681} \S 49 \mathrm{~V}$ VwVfG entspricht dabei der Zuständigkeitsregelung des § 48 V VwVfG.

\section{cc) Materielle Rechtmäßigkeit}

Da auch der Widerruf im Ermessen der Behörde steht, ist im Rahmen der Prüfung 945 der materiellen Rechtmäßigkeit wiederum zwischen Tatbestand und Rechtsfolge zu unterteilen. Im Interesse der Darstellung werden diese Prüfungsebenen im Folgenden für die jeweiligen Absätze zusammen behandelt.

1681 S. zur besonderen Regelung des § 49 IV VwVfG nur Ramsauer, in: Kopp/Ramsauer, VwVfG, 20. Aufl. 2019, § 49 Rn. 75 ff. 
946

Wie im Rahmen von § 48 VwVfG und entsprechend der jeweils gewählten Ermächtigungsgrundlage sind im Tatbestand unterschiedliche Voraussetzungen zu prüfen.

\section{(1) Anwendungsbereich}

$947 \mathrm{Zu}$ Beginn ist wie bei $\S 48 \mathrm{VwVfG}$ die Anwendbarkeit der Vorschrift zu prüfen: Der Widerruf ist zumindest bei rein wörtlich-systematischer Betrachtung die Aufhebung eines rechtmäßigen Verwaltungsakts. Insofern kann auf die $\mathrm{zu} \S 48$ VwVfG erfolgten Darstellungen (s. dazu Rn. $865 \mathrm{ff}$.) entsprechend verwiesen werden.

948 Die wesentliche Besonderheit liegt jedoch darin, dass die Vorschrift nach herrschender Meinung über ihren klaren Wortlaut hinaus auch auf rechtswidrige Verwaltungsakte anwendbar ist. ${ }^{1682}$ Dies wird in teleologischer Hinsicht wesentlich auf einen „Erst-recht-Schluss“ gestützt: Wenn bereits ursprünglich rechtmäßige Verwaltungsakte nach $\S 49 \mathrm{VwVfG}$ widerrufen werden dürfen, müsse dies erst recht für Verwaltungsakte gelten, die bereits ursprünglich rechtswidrig gewesen sind und somit schon immer dem Grundsatz der Gesetzmäßigkeit der Verwaltung widersprochen haben.

\section{(2) Belastender oder begünstigender Verwaltungsakt}

949 Die Unterscheidung zwischen rechtmäßigen belastenden und begünstigenden Verwaltungsakten erfolgt wiederum nach der Legaldefinition in § 48 I 2 VwVfG. Handelt es sich um einen belastenden Verwaltungsakt, richtet sich der Widerruf nach § 49 I VwVfG. Für begünstigende Verwaltungsakte gilt § 49 II und III VwVfG.

\section{(a) Belastender Verwaltungsakt, § 49 I VwVfG}

950 Der Widerruf rechtmäßiger belastender Verwaltungsakte ist gemäß $§ 49$ I VwVfG ausgeschlossen, wenn ein Verwaltungsakt gleichen Inhalts erneut erlassen werden müsste oder aus anderen Gründen ein Widerruf unzulässig ist.

1682 S. dazu nur Ramsauer, in: Kopp/Ramsauer, VwVfG, 20. Aufl. 2019, § 49 Rn. 12 m.w. N.; dagegen aber bspw. Ehlers/Schröder, JURA 2010, 503 (506) m.w. N.; ausführlich zur Problematik Kiefer, NVwZ 2013, 1257; Struzina, DÖV 2017, 906, jeweils m.w. N. zu den versch. Ansichten und Argumenten. 
Neben den bereits dargestellten positiven Merkmalen handelt es sich um 951 zwei negative Tatbestandsmerkmale. ${ }^{1683}$ Dabei ist das erste Merkmal vor dem Hintergrund des Zwecks der §§ 48f. VwVfG selbsterklärend: Der Behörde soll über den Widerruf nicht ermöglicht werden, die rechtlichen Vorgaben zu umgehen, die für sie hinsichtlich des Erlasses des Verwaltungsakts gelten. ${ }^{1684}$ Es kommt im Wege einer hypothetischen Betrachtung darauf an, ob sie bei Aufhebung des Verwaltungsakts rechtlich verpflichtet wäre, diesen mit dem identischen Regelungsgehalt umgehend wieder zu erlassen. Dies ist der Fall, wenn die Behörde bei Erlass des ursprünglichen Verwaltungsakts gebunden war und weiterhin alle Tatbestandsvoraussetzungen vorliegen. ${ }^{1685}$ Davon wird man regelmäßig dann nicht ausgehen können, wenn eine gemäß § 36 I Var. 2 VwVfG beigefügte Auflage nicht erfüllt wurde oder sich die Sach- oder Rechtslage verändert hat. Stand die ursprüngliche Entscheidung hingegen im Ermessen der Behörde, wird nur eine Ermessensreduktion auf Null den Widerruf von vornherein sperren können. ${ }^{1686}$ Aus anderen Gründen kann ein Widerruf unzulässig sein, wenn ausdrückliche gesetzliche Bestimmungen, der Zweck des zugrundeliegenden Rechts, allgemeine Rechtsgrundsätze oder der Grundsatz der Selbstbindung der Verwaltung dem entgegenstehen. ${ }^{1687}$ Von diesen Beispielen dürfte insbesondere das letztgenannte wirkliche Prüfungsrelevanz haben.

Liegt keiner der Ausschlussgründe vor, steht die Entscheidung über den 952 Widerruf im Ermessen der Behörde, die darin lediglich in zeitlicher Hinsicht begrenzt ist: Wegen der in der Vergangenheit bestehenden Rechtmäßigkeit des Verwaltungsakts kann dessen Widerruf nur mit Wirkung für die Zukunft erfolgen. Wie im Rahmen von § 48 I 1 VwVfG können die verschiedenen Ermessenserwägungen des Einzelfalls uneingeschränkt Berücksichtigung finden. Dabei kann auch auf die § 49 II, III VwVfG zugrundeliegenden Wertungen abgestellt werden. Im Falle der nachträglichen Änderung der Sach- oder Rechtslage sprechen sowohl der Grundsatz der Gesetzmäßigkeit der Verwaltung als auch die Grundrechte des Belasteten regelmäßig für einen Widerruf eines Dauerverwaltungsaktes (mit

1683 Suerbaum, in: Mann/Sennekamp/Uechtritz, VwVfG, 2. Aufl. 2019, § 49 Rn. 60 ff.; wohl auch Kastner, in: Fehling/Kastner/Störmer, Verwaltungsrecht, 4. Aufl. 2016, § 49 VwVfG Rn. 20.

1684 Ramsauer, in: Kopp/Ramsauer, VwVfG, 20. Aufl. 2019, § 49 Rn. 21a.

1685 Maurer/Waldhoff, Allgemeines Verwaltungsrecht, 19. Aufl. 2017, § 11 Rn. 76.

1686 Ramsauer, in: Kopp/Ramsauer, VwVfG, 20. Aufl. 2019, § 49 Rn. 21b; Sachs, in: Stelkens/ Bonk/Sachs, VwVfG, 9. Aufl. 2018, § 49 Rn. 23; Suerbaum, in: Mann/Sennekamp/Uechtritz, VwVfG, 2. Aufl. 2019, § 49 Rn. 61.

1687 S. nur Ramsauer, in: Kopp/Ramsauer, VwVfG, 20. Aufl. 2019, § 49 Rn. 22. 
Wirkung für die Zukunft). ${ }^{1688}$ Etwas anderes kann dann gelten, wenn ein Antrag auf Wiederaufgreifen des Verfahrens gemäß $§ 51$ I Nr. 1 VwVfG innerhalb der vorgegebenen Frist versäumt wurde. ${ }^{1689}$

\section{(b) Begünstigender Verwaltungsakt}

953 Der Widerruf rechtmäßiger begünstigender Verwaltungsakte ist demgegenüber tatbestandlich stärker beschränkt: Zulässig ist er nur, soweit einer der in $\S 49$ II, III VwVfG normierten besonderen Widerrufsgründe vorliegt und der Widerruf nicht aufgrund von Verfristung gemäß § 49 II 2 bzw. § 49 III 2 i.V.m. § 48 IV VwVfG ausgeschlossen ist. Über den Wortlaut hinaus sind aus teleologisch-systematischen Erwägungen auch die in § 49 I VwVfG normierten Ausschlussgründe (s. dazu Rn. 951) zu berücksichtigen.

\section{Der Unterschied zwischen Abs. 2 und 3}

954 Der besondere Unterschied zwischen Abs. 2 und 3 liegt in der zeitlichen Ermessensbegrenzung: Während § 49 II VwVfG lediglich einen Widerruf mit Wirkung für die Zukunft zulässt, eröffnet § 49 III VwVfG die Möglichkeit, Leistungsverwaltungsakte (zur Begriffsbestimmung s. Rn. $878 \mathrm{ff}$.) unter den genannten Voraussetzungen auch mit Wirkung für die Vergangenheit zu widerrufen. Dabei kommt es jedoch nicht zu einer systematischen Trennung zwischen Leistungsund sonstigen Verwaltungsakten, sondern nur zu einer zeitlichen Erweiterung der Widerrufsmöglichkeit im Hinblick auf Leistungsverwaltungsakte. Dies bedeutet, dass der Widerruf von Leistungsverwaltungsakten, sofern er nur mit Wirkung für die Zukunft erfolgen soll, genauso auf die Widerrufsgründe des § 49 II VwVfG gestützt werden kann. ${ }^{1690}$ Da § 49 III 1 VwVfG spezieller ist, ist er jedoch zumindest vorrangig anzuwenden. ${ }^{1691}$

\section{Der Widerruf nach \$ 49 II VwVfG}

955 Ein Schwerpunkt der Prüfung des Widerrufs eines rechtmäßigen begünstigenden Verwaltungsakts wird regelmäßig auf den Widerrufsgründen des § 49 II 1 VwVfG liegen, auf die im Folgenden näher einzugehen sein wird. Darüber hinaus sind

1688 BVerwG, Urt. v. 17.8.2011, Az.: 6 C 9.10 = BVerwGE 140, 221 (243f., Rn. 55); Maurer/Waldhoff, Allgemeines Verwaltungsrecht, 19. Aufl. 2017, § 11 Rn. 77; Detterbeck, Allgemeines Verwaltungsrecht, 17. Aufl. 2019, Rn. 716.

1689 So zu Recht Detterbeck, Allgemeines Verwaltungsrecht, 17. Aufl. 2019, Rn. 716.

1690 Ramsauer, in: Kopp/Ramsauer, VwVfG, 20. Aufl. 2019, § 49 Rn. 62; Sachs, in: Stelkens/ Bonk/Sachs, VwVfG, 9. Aufl. 2018, § 49 Rn. 107.

1691 Detterbeck, Allgemeines Verwaltungsrecht, 17. Aufl. 2019, Rn. 726.

Tobias Brings-Wiesen 
tatbestandlich die Ausschlussgründe gemäß § 49 I VwVfG (dazu Rn. 951) und $\S 49$ II 2 i.V.m. § 48 IV VwVfG (dazu Rn. 905 ff.) zu berücksichtigen, bezüglich derer die bereits erfolgten Ausführungen entsprechend gelten. Abschließend ist die ordnungsgemäße Ermessensausübung der Behörde zu prüfen.

\section{Gesetzlich oder durch Vorbehalt zugelassener Widerruf, Abs. II 1 Nr. 1}

Gemäß § 49 II 1 Nr. 1 VwVfG kann ein rechtmäßiger begünstigender Verwal- 956 tungsakt widerrufen werden, wenn der Widerruf durch Rechtsvorschrift zugelassen oder im Verwaltungsakt vorbehalten ist.

Var. 1 dieses Widerrufsgrundes unterfallen alle Konstellationen, in denen die Möglichkeit eines Widerrufs bereits gesetzlich vorgesehen ist. Für die Prüfung ist jedoch zu differenzieren: Ist der Widerruf spezialgesetzlich bereits abschließend geregelt, hat $§ 49$ VwVfG keine Bedeutung mehr - die Prüfung erfolgt vielmehr am Maßstab der Spezialnorm. ${ }^{1692}$ Nur soweit diese Spezialnorm (ausdrücklich oder nach Auslegung) Lücken aufweist, kann § 49 VwVfG ergänzend herangezogen werden. ${ }^{1693}$

Var. 2 dieses Widerrufsgrundes hat aus verschiedenen Gründen eine größere Prüfungsrelevanz. ${ }^{1694}$ Ein Widerruf ist zulässig, wenn er auf einen dem Verwaltungsakt als Nebenbestimmung beigefügten Widerrufsvorbehalt i.S.v. § 36 II Nr. 3 VwVfG gestützt werden kann. Dieser Anknüpfung macht es - in jedem Fall $^{1695}$ - erforderlich, inzident die Rechtmäßigkeit des in Rede stehenden Widerrufsvorbehalts (s. dazu Rn. 233f.) umfassend zu prüfen. ${ }^{1696}$

Vor Eintritt der Bestandskraft schließt die Rechtswidrigkeit des Vorbehalts einen auf ihn gestützten Widerruf aus. ${ }^{1697}$ Nach Eintritt der Bestandskraft ist die Bewertung rechtswidriger Widerrufsvorbehalte umstritten.

1692 Ramsauer, in: Kopp/Ramsauer, VwVfG, 20. Aufl. 2019, § 49 Rn. 32; Sachs, in: Stelkens/ Bonk/Sachs, VwVfG, 9. Aufl. 2018, § 49 Rn. 44; Abel, in: Bader/Ronellenfitsch, VwVfG, 44. Ed., Stand: 1.7.2019, § 49 Rn. 30.

1693 Dies wird sogar umfassend geschehen müssen, wenn gesetzlich nur allgemein eine Widerrufbarkeit vorgesehen ist, Sachs, in: Stelkens/Bonk/Sachs, VwVfG, 9. Aufl. 2018, § 49 Rn. 45. 1694 S. dazu die Fallbearbeitung bei Winter-Peter, JURA 2018, 508.

1695 Je nach Entscheidung für oder gegen die Berücksichtigung der Rechtswidrigkeit auf Tatbestandsebene (s. dazu sogleich Rn. 959) kann jedoch die Verortung im Prüfungsaufbau (im Tatbestand oder im Ermessen) unterschiedlich ausfallen.

1696 Vgl. für Beispiele der Rechtswidrigkeit eines Widerrufsvorbehalts Sachs, in: Stelkens/Bonk/ Sachs, VwVfG, 9. Aufl. 2018, § 49 Rn. 41; Abel, in: Bader/Ronellenfitsch, VwVfG, 44. Ed., Stand: 7. 2019, § 49 Rn. 32.

1697 Dann wird man insbesondere im Vorgehen gegen den Widerruf auch ein Vorgehen gegen den Widerrufsvorbehalt erblicken können, Ramsauer, in: Kopp/Ramsauer, VwVfG, 20. Aufl. 2019, $\S 49$ Rn. 37a; Ehlers/Schröder, JURA 2010, 503 (509). 
Die herrschende Ansicht, die insbesondere auch vom Bundesverwaltungsgericht vertreten wird, ${ }^{1698}$ verlangt lediglich die Wirksamkeit ${ }^{1699}$ des Widerrufsvorbehaltes. Sie stellt maßgeblich darauf ab, dass dieser als Nebenbestimmung an der Bestandskraft des Verwaltungsakts teilhat. Habe der Begünstigte von den ihm eröffneten Rechtsschutzmöglichkeiten ${ }^{1700}$ keinen Gebrauch gemacht, müsse er sich die Bestandskraft auch insoweit entgegenhalten lassen. Damit soll die Rechtswidrigkeit jedoch nicht irrelevant sein. Anhänger dieser Ansicht sprechen sich mehrheitlich dafür aus, die Rechtswidrigkeit als Erwägung in die Ermessensentscheidung einzustellen. ${ }^{1701}$ Dabei wird ihr jedoch unterschiedliches Gewicht beigemessen. ${ }^{1702}$

Die Gegenansicht ${ }^{1703}$ plädiert indes für eine bereits tatbestandliche Berücksichtigung der Rechtswidrigkeit auch nach Eintritt der Bestandskraft. Dafür spreche nicht nur der gesetzgeberische Wille, ${ }^{1704}$ sondern auch der der Vorschrift zugrundeliegende Interessenausgleich: Vor dem Hintergrund des Grundsatzes der Gesetzmäßigkeit der Verwaltung sei die Aufhebung rechtmäßiger Verwaltungsakte prinzipiell nicht geboten. ${ }^{1705}$ Auch wenn das Entstehen subjektiven Vertrauens auf den Bestand des Verwaltungsakts durch Beifügung des Widerrufsvorbehalts verhindert sein mag, dürfe nicht außer Acht gelassen werden, dass

1698 BVerwG, Urt. v. 21.11.1986, Az.: 8 C 33.84 = NVwZ 1987, 498 (499); Urt. v. 22.11.2018, Az.: 7 C 11.17 = juris, Rn. 32. Zust. Ruffert, in: Ehlers/Pünder, Allgemeines Verwaltungsrecht, 15. Aufl. 2016, § 25 Rn. 7; Ehlers/Schröder, JURA 2010, 503 (509), jeweils m.w. N.

1699 Vor diesem Hintergrund bietet es sich in Prüfungen an, Anhaltspunkte für die mögliche Nichtigkeit eines Widerrufsvorbehalts einzubauen. Zur Nichtigkeit ausführlich in $§ 6$ Rn. $115 \mathrm{ff}$.; s. zur Nichtigkeit allein von Nebenbestimmungen auch den Fall 12 in Eisentraut, Fälle zum Verwaltungsrecht, 2020.

1700 S. zur isolierten Anfechtung von Nebenbestimmungen ausführlich Rn. $204 \mathrm{ff}$.

1701 A.A. hingegen Ziekow, VwVfG, 3. Aufl. 2013, § 49 Rn. 12, der auch eine Berücksichtigung im Rahmen der Ermessensausübung ablehnt.

1702 Jedenfalls bei „offensichtlicher Rechtswidrigkeit“, BVerwG, Beschl. v. 19.5.1994, Az.: 1 B 104.94 = NVwZ-RR 1994, 580; noch offengelassen in Urt. v. 12.1989, Az.: 3 C 30.87 = NJW 1991, 766 (767). Rechtswidrigkeit führt „in der Regel“ zur Ermessensfehlerhaftigkeit, Ehlers/Schröder, JURA 2010, 503 (509); noch weitgehender wohl Sachs, in: Stelkens/Bonk/Sachs, VwVfG, 9. Aufl. 2018, § 49 Rn. 40. Für eine offene Ermessensausübung indes Ramsauer, in: Kopp/Ramsauer, VwVfG, 20. Aufl. 2019, § 49 Rn. 37a.

1703 Maurer/Waldhoff, Allgemeines Verwaltungsrecht, 19. Aufl. 2017, § 11 Rn. 62; Peuker, in: Knack/Henneke, VwVfG, 10. Aufl. 2014, § 49 Rn. 52; Krausnick, JuS 2010, 778 (780); so auch, wenngleich weiter differenzierend Decker, in: Wolff/Decker, VwGO/VwVfG, 3. Aufl. 2012, § 49 Rn. 11. S. dazu auch die Fallbearbeitung bei Winter-Peter, JURA 2018, 508 (510).

1704 S. dazu bereits die Gesetzesmaterialien, BT-Drucks. 7/910, S. 72.

1705 Krausnick, JuS 2010, 778 (780); für den Widerruf rechtswidriger Verwaltungsakte daher anders Decker, in: Wolff/Decker, VwGO/VwVfG, 3. Aufl. 2012, § 49 Rn. 11. 
objektiv betrachtet ein rechtmäßiger Hauptverwaltungsakt besteht, der überdies selbst in Bestandskraft erwachsen ist. Angesichts dessen scheint es tatsächlich nicht plausibel, die Behörde aus eigenem Fehlverhalten auch noch Vorteile für die Zukunft ziehen zu lassen. ${ }^{1706}$

Insbesondere wenn hinsichtlich des Widerrufsvorbehalts keine rechtlichen $\mathbf{9 6 0}$ Bedenken bestehen, bedarf es darüber hinaus der Prüfung der für den Widerruf angeführten Gründe. Diese Gründe können im Vorbehalt selbst näher konkretisiert sein, sodass sie als Voraussetzungen des Widerrufs einzuhalten sind. ${ }^{1707}$ Ihre Konkretisierung kann jedoch auch bereits in dem den Widerrufsvorbehalt erlaubenden Gesetz erfolgt sein. Fehlen konkrete Vorgaben, sind diese durch Auslegung des den Widerrufsvorbehalt erlaubenden Gesetzes zu ermitteln. Der Widerruf muss dann durch sachliche Erwägungen gerechtfertigt sein, die den Zwecksetzungen des einschlägigen Fachrechts entsprechen. ${ }^{1708}$ Die letztgenannte Konstellation ist Bestandteil der Ermessensausübung der Behörde, sodass im Falle eines Verstoßes ein Ermessensfehler vorliegt. ${ }^{1709}$

\section{Unterbleiben der (fristgemäßen) Erfüllung einer Auflage, Abs. II 1 Nr. 2}

Gemäß § 49 II 1 Nr. 2 VwVfG kann ein rechtmäßiger begünstigender Verwal- 961 tungsakt widerrufen werden, wenn mit dem Verwaltungsakt eine Auflage verbunden ist und der Begünstigte diese nicht oder nicht innerhalb einer ihm gesetzten Frist erfüllt hat.

Auch hier macht es die Verknüpfung des Widerrufs mit der Auflage i.S.v. 962 $\S 36$ II Nr. 4 VwVfG - in jedem Fall ${ }^{1710}$ - erforderlich, inzident die Rechtmäßigkeit der in Rede stehenden Auflage (s. dazu ausführlich Rn. $218 \mathrm{ff}$.) umfassend zu prüfen. ${ }^{1711}$ Im Einzelfall kann vorab auch die Abgrenzung der mit dem Verwaltungsakt verbundenen ${ }^{1712}$ Auflage von einer beschränkenden Inhaltsbestim-

1706 So Maurer/Waldhoff, Allgemeines Verwaltungsrecht, 19. Aufl. 2017, § 11 Rn. 62.

1707 Suerbaum, in: Mann/Sennekamp/Uechtritz, VwVfG, 2. Aufl. 2019, § 49 Rn. 78 m.w. N. (auch aus der Rspr.).

1708 Ramsauer, in: Kopp/Ramsauer, VwVfG, 20. Aufl. 2019, § 49 Rn. 35. S. für ein anschauliches Beispiel Maurer/Waldhoff, Allgemeines Verwaltungsrecht, 19. Aufl. 2017, § 11 Rn. 63.

1709 So auch Detterbeck, Allgemeines Verwaltungsrecht, 17. Aufl. 2019, Rn. 719.

1710 Je nach Entscheidung für oder gegen die Berücksichtigung der Rechtswidrigkeit auf Tatbestandsebene kann jedoch auch hier die Verortung im Prüfungsaufbau unterschiedlich ausfallen.

1711 S. dazu die Fallbearbeitung bei Klement, JuS 2010, 1088.

1712 Es muss eine rechtliche, keine verkörperte Verbindung bestehen. So kann sich eine Auflage vorab auch aus einem öffentlich-rechtlichen Vertrag ergeben, indem sich die Behörde nur zum Erlass eines Verwaltungsakts verpflichtet, BVerwG, Urt. v. 10.12.2003, Az.: 3 C 22.02 = NVwZRR 2003, 413 (414f.). 
mung ${ }^{1713}$ und einer auflösenden Bedingung ${ }^{1714}$ erforderlich (s. dazu Rn. 222ff.). Wie hinsichtlich des Widerrufsvorbehaltes wird um die Frage der Berücksichtigung der Rechtswidrigkeit einer Auflage nach Eintritt der Bestandskraft gerungen. Insofern gelten die bereits dargestellten Überlegungen (s. dazu Rn. 959) entsprechend. Auch hier verlangt die herrschende Ansicht lediglich Wirksamkeit der Auflage. ${ }^{1715}$ Vielerorts wird jedoch, obgleich es sich eigentlich um eine Voraussetzung der (materiellen) Rechtmäßigkeit handelt (§37 I VwVfG; s. zur vergleichbaren Problematik im Rahmen der Verwaltungsvollstreckung Rn. 1329f.), die hinreichende Bestimmtheit der Auflage auch im Zusammenhang mit dem Widerruf verlangt. ${ }^{1716}$

963 Der Begünstigte darf dem in der Auflage enthaltenen Gebot oder Verbot (auch nur teilweise ${ }^{1717}$ ) nicht oder nicht innerhalb einer ihm gesetzten Frist nachgekommen sein. Ob dies der Fall ist, bedarf der Beurteilung im Einzelfall. Die aufschiebende Wirkung von Widerspruch und Anfechtungsklage gegen die Auflage führt dazu, dass ein Widerruf zumindest während des Verfahrens nicht möglich ist. ${ }^{1718}$ Das Bundesverwaltungsgericht hat angedeutet, die isolierte Aufhebung einer Auflage deren Nichterfüllung gleichstellen zu wollen. ${ }^{1719}$ Dies ist jedoch weder mit dem Wortlaut, noch mit Sinn und Zweck des § 49 II 1 Nr. 2 VwVfG in Einklang zu bringen. ${ }^{1720}$ Es genügt die objektive Nichterfüllung der Auflage, die Vorschrift verlangt kein Verschulden des Begünstigten. ${ }^{1721}$ Dieses ist jedoch im Rahmen der Ermessensausübung zu berücksichtigen. Dabei kann auch das

1713 Auch auf beschränkende Inhaltsbestimmungen ist die Vorschrift nach h.M. nicht anwendbar, s. nur Ramsauer, in: Kopp/Ramsauer, VwVfG, 20. Aufl. 2019, § 49 Rn. 38 m.w. N.

1714 Krausnick, JuS 2010, 778 (780f.).

1715 OVG Münster, Urt. v. 20.4.2012, Az.: 4 A 1055/09 = NVwZ-RR 2012, 671 (675); s. sonst nur Ramsauer, in: Kopp/Ramsauer, VwVfG, 20. Aufl. 2019, § 49 Rn. 38a m.w. N.

1716 Ruffert, in: Ehlers/Pünder, Allgemeines Verwaltungsrecht, 15. Aufl. 2016, § 25 Rn. 8; Abel, in: Bader/Ronellenfitsch, VwVfG, 44. Ed., Stand: 1.7.2019, § 49 Rn. 37; Suerbaum, in: Mann/Sennekamp/Uechtritz, VwVfG, 2. Aufl. 2019, § 49 Rn. 79; a. A. aber Ziekow, VwVfG, 3. Aufl. 2013, § 49 Rn. 14.

1717 Ehlers/Schröder, JURA 2010, 503 (510).

1718 S. dazu Sachs, in: Stelkens/Bonk/Sachs, VwVfG, 9. Aufl. 2018, § 49 Rn. 52.

1719 BVerwG, Urt. v. 12.3.1982, Az.: 8 C 23.80 = BVerwGE 65, 139 (141).

1720 Überzeugend m.w. N. nur Suerbaum, in: Mann/Sennekamp/Uechtritz, VwVfG, 2. Aufl. 2019, $\S 49$ Rn. $84 \mathrm{f}$.

1721 S. nur Peine/Siegel, Allgemeines Verwaltungsrecht, 12. Aufl. 2018, Rn. 638; Ruffert, in: Ehlers/Pünder, Allgemeines Verwaltungsrecht, 15. Aufl. 2016, § 25 Rn. 8; Sachs, in: Stelkens/ Bonk/Sachs, VwVfG, 9. Aufl. 2018, § 49 Rn. 50. Vgl. auch BVerwG, Urt. v. 6.9.1995, Az.: 4 B $198.95=$ NVwZ-RR 1996, 193.

Tobias Brings-Wiesen 
Handeln Dritter dem Verantwortungsbereich des Begünstigten zuzurechnen sein. ${ }^{1722}$

Die Anforderungen im Tatbestand werden im Einzelfall zumeist gut hand- 964 habbar sein. Im Fokus der Prüfung eines Widerrufs auf Grundlage von § 49 II 1 Nr. 2 VwVfG steht jedoch überwiegend die ordnungsgemäße Ermessensausübung der Behörde. In deren Rahmen bedarf es einer besonderen Berücksichtigung von Verhältnismäßigkeitserwägungen. ${ }^{1723}$ Folgende Gesichtspunkte können im Einzelfall mit unterschiedlichem Gewicht in die Prüfung eingestellt werden: das Maß an Verschulden des Begünstigten, ${ }^{1724}$ die Wesentlichkeit der durch die Auflage gesicherten Rechtspflicht ${ }^{1725}$ und der Grad der Abweichung vom Gewollten. ${ }^{1726}$ Je nach Lage des Sachverhalts kann es erforderlich bzw. angemessen sein, den Begünstigten vor dem Widerruf abzumahnen ${ }^{1727}$ oder die Auflage im Wege der Verwaltungsvollstreckung zwangsweise durchzusetzen ${ }^{1728}$.

\section{Nachträgliche Änderung der Sachlage, Abs. II 1 Nr. 3}

Gemäß § 49 II 1 Nr. 3 VwVfG kann ein rechtmäßiger begünstigender Verwal- 965 tungsakt widerrufen werden, wenn die Behörde auf Grund nachträglich eingetretener Tatsachen berechtigt wäre, den Verwaltungsakt nicht zu erlassen, und wenn ohne den Widerruf das öffentliche Interesse gefährdet würde. Beide Voraussetzungen müssen kumulativ erfüllt sein.

Hinsichtlich der ersten Voraussetzung ist zunächst $\mathrm{zu}$ fragen, ob i.S.d. 966 Vorschrift nachträglich Tatsachen eingetreten sind. ${ }^{1729}$ Verlangt ist eine Veränderung der Sachlage, auf der die gesamte rechtliche Bewertung basiert, deren

1722 OVG Münster, Urt. v. 2.5.1994, Az.: 8 A 3885/93 = NVwZ 1996, 610 (612); VGH Mannheim, Urt. v. 7.4.2011, Az.: 10 S 2545/09 = BeckRS 2011, 50482.

1723 So auch Maurer/Waldhoff, Allgemeines Verwaltungsrecht, 19. Aufl. 2017, §11 Rn. 64; Detterbeck, Allgemeines Verwaltungsrecht, 17. Aufl. 2019, Rn. 720.

1724 Ruffert, in: Ehlers/Pünder, Allgemeines Verwaltungsrecht, 15. Aufl. 2016, § 25 Rn. 8; Ehlers/ Schröder, JURA 2010, 503 (510).

1725 Maurer/Waldhoff, Allgemeines Verwaltungsrecht, 19. Aufl. 2017, §11 Rn. 64; Detterbeck, Allgemeines Verwaltungsrecht, 17. Aufl. 2019, Rn. 720.

1726 Sachs, in: Stelkens/Bonk/Sachs, VwVfG, 9. Aufl. 2018, § 49 Rn. 57.

1727 Ramsauer, in: Kopp/Ramsauer, VwVfG, 20. Aufl. 2019, § 49 Rn. 39; Sachs, in: Stelkens/ Bonk/Sachs, VwVfG, 9. Aufl. 2018, § 49 Rn. 56; vgl. auch BVerwG, Beschl.v. 6.9.1991, Az.: 1 B 97.91 = NVwZ 1992, 167 (167 f.); Kastner, in: Fehling/Kastner/Störmer, Verwaltungsrecht, 4. Aufl. 2016, § 49 VwVfG Rn. 34.

1728 Maurer/Waldhoff, Allgemeines Verwaltungsrecht, 19. Aufl. 2017, § 11 Rn. 64; Kastner, in: Fehling/Kastner/Störmer, Verwaltungsrecht, 4. Aufl. 2016, § 49 VwVfG Rn. 33; Ehlers/Schröder, JURA 2010, 503 (510); Krausnick, JuS 2010, 778 (781).

1729 Für bestimmte Verwaltungsakte kann eine Anwendbarkeit der Vorschrift ausgeschlossen sein, s. Ramsauer, in: Kopp/Ramsauer, VwVfG, 20. Aufl. 2019, § 49 Rn. 42.

Tobias Brings-Wiesen 
Ergebnis der konkrete Verwaltungsakt ist. Dabei können die entscheidungserheblichen Elemente je nach dem zugrundeliegenden Recht sowohl in einem Verhalten von Beteiligten oder Betroffenen als auch in äußeren Umständen liegen. ${ }^{1730}$ Die Tatsachen müssen nachträglich eintreten. Dem nicht gleichgestellt ist die Situation, dass die Behörde erst zu einem späteren Zeitpunkt von ihnen erfährt ${ }^{1731}$ oder diese erst später anders beurteilt ${ }^{1732}$. Dementsprechend ist auch eine Änderung der Rechtsprechung keine nachträglich eingetretene Tatsache. ${ }^{1733}$ Für all diese Konstellationen kommt vielmehr eine Rücknahme gemäß § 48 VwVfG in Frage. Die wissenschaftliche Neubewertung einer Sachlage kann hingegen von Bedeutung sein. ${ }^{1734}$

Im nächsten Schritt ist im Rahmen einer Inzidentprüfung zu klären, ob die nachträglich eingetretene Tatsache von einer derartigen rechtlichen Relevanz ist, dass die Behörde berechtigt wäre, den ursprünglichen Verwaltungsakt nicht zu erlassen. Dies ist der Fall, wenn eine entsprechend veränderte Sachlage im Zeitpunkt der ursprünglichen Entscheidung hypothetisch dazu geführt hätte, dass die Behörde den Erlass des Verwaltungsakts mangels Vorliegens von Tatbestandsvoraussetzungen oder im Rahmen einer fehlerfreien Ermessensausübung hätte ablehnen müssen bzw. können. ${ }^{1735}$

Zuletzt muss geklärt werden, ob ohne den Widerruf das öffentliche Interesse gefährdet würde. Im „öffentlichen Interesse“ steht der Schutz des Staates, der Allgemeinheit und wichtiger Gemeinschaftsgüter. ${ }^{1736} \mathrm{Ob}$ im konkreten Einzelfall wichtige Gemeinschaftsgüter in Rede stehen und welche dies sind, ist unter Berücksichtigung des Regelungsgehalts des Verwaltungsakts und dem ihm

1730 So ausdrücklich BVerwG, Urt. v. 11.12.1990, Az.: 6 C 33.88 = NVwZ 1991, 577 (578). S. für Beispiele nur Ramsauer, in: Kopp/Ramsauer, VwVfG, 20. Aufl. 2019, § 49 Rn. 44f.; Sachs, in: Sachs/Stelkens/Bonk/Sachs, VwVfG, 9. Aufl. 2018, § 49 Rn. 59 ff.

1731 BVerwG, Urt. v. 19.9.2018, Az.: 8 C 16.17 = juris, Rn. 21.

1732 BVerwG, Urt. v. 11.12.1990, Az.: 6 C 33.88 = NVwZ 1991, 577 (578).

1733 Detterbeck, Allgemeines Verwaltungsrecht, 17. Aufl. 2019, Rn. 721; Ramsauer, in: Kopp/ Ramsauer, VwVfG, 20. Aufl. 2019, § 49 Rn. 46.

1734 BVerwG, Beschl. v. 16.7.1982, Az.: 7 B 190.81 = NVwZ 1984, 102 (103); so auch Ruffert, in: Ehlers/Pünder, Allgemeines Verwaltungsrecht, 15. Aufl. 2016, § 25 Rn. 10; Ramsauer, in: Kopp/ Ramsauer, VwVfG, 20. Aufl. 2019, § 49 Rn. 45; Ehlers/Schröder, JURA 2010, 503 (510). Es muss sich jedoch um eine allgemein anerkannte Neubewertung handeln, vgl. BVerwG, Beschl. v. 27.5. 2015, Az.: 3 B 5.15 = NVwZ 2016, 323 (325, Rn. 12); Urt.v. 28.4. 2016, Az.: 4 A 2.15 = BVerwGE 155, 81 (88f.; Rn. 36).

1735 S. nur Suerbaum, in: Mann/Sennekamp/Uechtritz, VwVfG, 2. Aufl. 2019, § 49 Rn. 90 ff.

1736 BVerwG, Beschl. v. 16.7.1982, Az.: 7 B 190.81 = NVwZ 1984, 102 (103); Urt. v. 24.1.1992, Az.: 7 C 38.90 = NVwZ 1992, 565 (566); VGH Mannheim, Urt. v. 20.6.2013, Az.: 9 S 2883/11 = NVwZRR 2014, 43 (47), m. zahlr. w. N. 
zugrundeliegenden Fachrecht zu ermitteln. ${ }^{1737}$ Daraus ergibt sich, dass die für den Widerruf zuständige Behörde nur das „öffentliche Interesse“ zu berücksichtigen hat, dessen Wahrung Teil ihres Aufgabenbereichs ist. ${ }^{1738}$ Das bloße Interesse an der Wiederherstellung eines rechtmäßigen Zustands genügt nicht. ${ }^{1739}$ Auch bloße Individualinteressen sind grundsätzlich nicht berücksichtigungsfähig. ${ }^{1740}$ Ein so näher identifiziertes öffentliches Interesse muss gefährdet sein. Dies setzt bereits denklogisch voraus, dass die Gefährdung des öffentlichen Interesses eine Konsequenz der nachträglich eingetretenen Tatsachen ist, insofern also Kausalität besteht. ${ }^{1741}$ Für eine Gefährdung genügt nicht, dass der Widerruf schlicht im öffentlichen Interesse liegt. Anders als bei § 49 II 1 Nr. 5 VwVfG bedarf es aber auch keines „schweren Nachteils“. Erforderlich ist vielmehr, dass der Widerruf zur Beseitigung oder Verhinderung eines sonst drohenden Schadens geboten ist. ${ }^{1742}$ Dabei setzt die Vorschrift voraus, dass der Widerruf zumindest geeignet ist, die Gefährdung zu beenden. Diese Feststellung genügt jedoch an dieser Stelle auch. Es bedarf noch keiner Abwägung mit den widerstreitenden Interessen auf Seiten des Begünstigten. Fragen der Erforderlichkeit und Angemessenheit sind vielmehr Bestandteile der nachfolgenden Prüfung der Ermessensausübung. ${ }^{1743}$ Obwohl in § 49 II 1 Nr. 3 VwVfG nicht ausdrücklich ausgewiesen, soll darin auch Berücksichtigung finden, ob und inwiefern von der Begünstigung bereits Gebrauch gemacht wurde. ${ }^{1744}$

1737 Vgl. für Beispiele Sachs, in: Stelkens/Bonk/Sachs, VwVfG, 9. Aufl. 2018, § 49 Rn. 70; Abel, in: Bader/Ronellenfitsch, VwVfG, 44. Ed., Stand: 1.7.2019, § 49 Rn. 57.

1738 Peine/Siegel, Allgemeines Verwaltungsrecht, 12. Aufl. 2018, Rn. 640; Ramsauer, in: Kopp/ Ramsauer, VwVfG, 20. Aufl. 2019, § 49 Rn. 48; Sachs, in: Stelkens/Bonk/Sachs, VwVfG, 9. Aufl. 2018, § 49 Rn. 72.

1739 VGH Mannheim, Urt. v. 20.6.2013, Az.: 9 S 2883/11 = NVwZ-RR 2014, 43 (47).

1740 S. BVerwG, Urt. v. 29.10.1998, Az.: 4 C 9.97 = NVwZ 1999, 417 (419), wo das Gericht indes andeutete, dass der Sachverhalt im Falle einer Gesundheitsgefahr anders zu beurteilen sein könnte.

1741 Peine/Siegel, Allgemeines Verwaltungsrecht, 12. Aufl. 2018, Rn. 640; Sachs, in: Stelkens/ Bonk/Sachs, VwVfG, 9. Aufl. 2018, § 49 Rn. 71; Abel, in: Bader/Ronellenfitsch, VwVfG, 44. Ed., Stand: 1.7.2019, § 49 Rn. 58.

1742 So ausdrücklich das BVerwG, Urt. v. 24.1.1992, Az.: 7 C 38.90 = NVwZ 1992, 565 (565f.). 1743 Es erschließt sich insbesondere nicht, warum die vielerorts scheinbar als Tatbestandsmerkmal genannte „Erforderlichkeit“, s. nur Sachs, in: Stelkens/Bonk/Sachs, VwVfG, 9. Aufl. 2018, § 49 Rn. 70, m.w. N., bereits hins. der Bewertung am Maßstab von § 49 II 1 Nr. 3 VwVfG vorliegen müsste.

1744 Sachs, in: Stelkens/Bonk/Sachs, VwVfG, 9. Aufl. 2018, § 49 Rn. 73; Abel, in: Bader/Ronellenfitsch, VwVfG, 44. Ed., Stand:1.7.2019, § 49 Rn. 56; Suerbaum, in Mann/Sennekamp/Uechtritz, VwVfG, 2. Aufl. 2019, § 49 Rn. 96. 


\section{Nachträgliche Änderung von Rechtsvorschriften, Abs. II 1 Nr. 4}

969 Gemäß § 49 II 1 Nr. 4 VwVfG kann ein rechtmäßiger begünstigender Verwaltungsakt widerrufen werden, wenn die Behörde auf Grund einer geänderten Rechtsvorschrift berechtigt wäre, den Verwaltungsakt nicht zu erlassen, soweit der Begünstigte von der Vergünstigung noch keinen Gebrauch gemacht oder auf Grund des Verwaltungsakts noch keine Leistungen empfangen hat und wenn ohne den Widerruf das öffentliche Interesse gefährdet würde. ${ }^{1745}$

Für die Vorschrift gelten überwiegend die bereits zu § 49 II 1 Nr. 3 VwVfG erfolgten Ausführungen entsprechend. Der erste wesentliche Unterschied liegt in der Ursache für die Neubewertung des Verwaltungsakterlasses: Es muss zu einer Änderung des Rechts ${ }^{1746}$ gekommen sein. Wenngleich der Wortlaut eine „geänderte Rechtsvorschrift“ verlangt, ist weitergehend jede Änderung des für die Beurteilung des Verwaltungsakts relevanten materiellen Rechts ${ }^{1747}$, sprich auch der Neuerlass oder die Aufhebung von Vorschriften, von Bedeutung. ${ }^{1748}$ Grundsätzlich nicht $\mathrm{zu}$ berücksichtigen sind Änderungen von Verwaltungsvorschriften $^{1749}$ oder der Rechtsprechung ${ }^{1750}$. Rückwirkende Änderungen der Rechtslage können zur Rechtswidrigkeit des Verwaltungsakts zum Zeitpunkt seines Erlasses führen; die Nichtigerklärung einer Vorschrift ist rein deklaratorisch und erstreckt sich regelmäßig auf die Vergangenheit ${ }^{1751}$. Auf diese Konstellationen ist $\S 48$ VwVfG anwendbar (s. dazu Rn. 870).

971 Der zweite wesentliche Unterschied liegt darin, dass § 49 II 1 Nr. 4 VwVfG einen Widerruf nur erlaubt, soweit der Begünstigte von der Vergünstigung noch keinen Gebrauch gemacht oder auf Grund des Verwaltungsakts noch keine Leistungen empfangen hat. Ein „Gebrauchmachen“ verlangt laut Bundesver-

1745 S. dazu die Fallbearbeitung bei Pernice-Warnke, ZJS 2018, 590 (596f.).

1746 Es wird vertreten, den Begriff „Rechtsvorschriften“ von dem Begriff der „Rechtslage“ in $\S 51$ I Nr. 1 VwVfG (s. dazu noch in $\S 3$ Rn. 116) abzugrenzen, s. nur Sachs, in: Stelkens/Bonk/Sachs, VwVfG, 9. Aufl. 2018, § 49 Rn. 79; dies mutet angesichts der sprachlichen Abweichung zwar plausibel an, bislang lassen sich jedoch - soweit ersichtlich - weder Rechtsprechung, noch Literatur Abgrenzungskriterien entnehmen.

1747 S. dazu Ramsauer, in: Kopp/Ramsauer, VwVfG, 20. Aufl. 2019, § 49 Rn. 50.

1748 Detterbeck, Allgemeines Verwaltungsrecht, 17. Aufl. 2019, Rn. 722.

1749 BVerwG, Urt. v. 11.12.1990, Az.: 6 C 33.88 = NVwZ 1991, 577 (579). Zu berücksichtigen sind jedoch ausnahmsweise Verwaltungsvorschriften mit Außenwirkung, Ruffert, in: Ehlers/Pünder, Allgemeines Verwaltungsrecht, 15. Aufl. 2016, § 25 Rn. 12; Ehlers/Schröder, JURA 2010, 824 (825). 1750 A.A. aber zu Änderungen der Rspr. Abel, in: Bader/Ronellenfitsch, VwVfG, 44. Ed., Stand: 1.7.2019, § 49 Rn. 60 f.

1751 Dazu anschaulich m.w. N. Suerbaum, in: Mann/Sennekamp/Uechtritz, VwVfG, 2. Aufl. 2019, § 49 Rn. $103 \mathrm{f}$.

Tobias Brings-Wiesen 
waltungsgericht ein „Inswerksetzen“. ${ }^{1752}$ Aus dem Sachverhalt muss sich ergeben, dass der Begünstigte in irgendeiner Art und Weise auf Grundlage der in einem Verwaltungsakt enthaltenen Regelung ${ }^{1753}$ tätig geworden ist. Umstritten ist, wie intensiv der Zusammenhang zwischen „Vergünstigung“ und „Gebrauchmachen“ sein muss. Einigkeit besteht über die Einbeziehung unmittelbarer Umsetzungen von Regelungsinhalten, beispielsweise dem Bau eines Hauses auf Grundlage einer Baugenehmigung. Unterschiedlich bewertet werden hingegen lediglich mittelbare Umsetzungen, wie beispielsweise Vorbereitungshandlungen oder Investitionen im Vertrauen auf einen Verwaltungsakt. ${ }^{1754}$ Derartige Umsetzungen werden jedoch spätestens im Rahmen der Ermessensausübung zu berücksichtigen sein. ${ }^{1755}$ Bei Leistungen jedweder Art kommt es allein auf den Empfang an, diese muss endgültig in das Vermögen des Begünstigten übergehen ${ }^{1756}$. Nicht verlangt sind ein Verbrauch oder eine Vermögensdisposition. ${ }^{1757}$

\section{Zur Verhütung oder Beseitigung schwerer Nachteile für das Gemeinwohl,}

\section{Abs. II 1 Nr. 5}

Gemäß § 49 II 1 Nr. 5 VwVfG kann ein rechtmäßiger begünstigender Verwal- 972 tungsakt widerrufen werden, um schwere Nachteile für das Gemeinwohl zu verhüten oder zu beseitigen. Es handelt sich um eine Art Auffangklausel, die der Behörde in besonderen Ausnahmekonstellationen den Widerruf ermöglichen soll. Dabei ist sie jedoch - anders als der Wortlaut suggeriert - nicht auf die Berücksichtigung von Allgemeininteressen beschränkt, sondern lässt auch die Einbeziehung hochrangiger Individualrechtsgüter $\mathrm{zu}^{1758}$ Gleichwohl ist ihre Praxis- wie Prüfungsrelevanz gering. ${ }^{1759}$ Die Anforderungen, die an die Schwere

1752 BVerwG, Urt. v. 24.1.1992, Az.: 7 C 38.90 = NVwZ 1992, 565 (566).

1753 Auch bei feststellenden Verwaltungsakten wird man daher grundsätzlich von der Möglichkeit eines „Inswerksetzens“ ausgehen können, Sachs, in: Stelkens/Bonk/Sachs, VwVfG, 9. Aufl. 2018, § 49 Rn. 77; Abel, in: Bader/Ronellenfitsch, VwVfG, 44. Ed., Stand: 1.7.2019, § 49 Rn. 62.1.

1754 Dafür Peuker, in: Knack/Henneke, VwVfG, 10. Aufl. 2014, § 49 Rn. 69; Kastner, in: Fehling/ Kastner/Störmer, Verwaltungsrecht, 4. Aufl. 2016, § 49 VwVfG Rn. 43; Suerbaum, in: Mann/Sennekamp/Uechtritz, VwVfG, 2. Aufl. 2019, § 49 Rn. 106; z.T. auch Ramsauer, in: Kopp/Ramsauer, VwVfG, 20. Aufl. 2019, § 49 Rn. 52.

1755 Sachs, in: Stelkens/Bonk/Sachs, VwVfG, 9. Aufl. 2018, § 49 Rn. 77; Abel, in: Bader/Ronellenfitsch, VwVfG, 44. Ed., Stand: 1.7.2019, § 49 Rn. 62.

1756 Kastner, in: Fehling/Kastner/Störmer, Verwaltungsrecht, 4. Aufl. 2016, § 49 VwVfG Rn. 43. 1757 Ruffert, in: Ehlers/Pünder, Allgemeines Verwaltungsrecht, 15. Aufl. 2016, § 25 Rn. 13; Sachs, in: Stelkens/Bonk/Sachs, VwVfG, 9. Aufl. 2018, § 49 Rn. 75.

1758 BVerwG, Urt. v. 21.5.1997, Az.: 11 C 1.96 = BVerwGE 105, 6 (15).

1759 So auch Ehlers/Schröder, JURA 2010, 824 (826). 
des Nachteils für das Gemeinwohl zu stellen sind, sind hoch. ${ }^{1760}$ Dementsprechend sollte auch in der Prüfung nur sehr restriktiv mit dem Tatbestand umgegangen werden.

\section{Exkurs: Entschädigungsanspruch gemäß § 49 VI VwVfG}

973 Ähnlich dem § 48 III VwVfG enthält auch § 49 VI VwVfG einen Entschädigungsanspruch. Sofern ein begünstigender Verwaltungsakt in den Fällen des Abs. II 1 Nr. 3 bis 5 widerrufen wird, hat die Behörde den Betroffenen auf Antrag für den Vermögensnachteil zu entschädigen, den dieser dadurch erleidet, dass er auf den Bestand des Verwaltungsakts vertraut hat, soweit sein Vertrauen schutzwürdig ist. $\S 48$ III 3 bis 5 soll entsprechend gelten. Insofern kann weitgehend auf die Ausführungen $\mathrm{zu} \S 48$ III VwVfG verwiesen werden. Ein wesentlicher Unterschied besteht indes darin, dass für Streitigkeiten über die Entschädigung gemäß § 49 VI VwVfG der ordentliche Rechtsweg zu beschreiten ist.

\section{Der Widerruf nach \$ 49 III VwVfG}

$974 \S 49$ III VwVfG ${ }^{1761}$ gilt - wie § 48 II VwVfG - für Verwaltungsakte, die eine einmalige oder laufende Geldleistung oder teilbare Sachleistung gewähren oder hierfür Voraussetzung sind, sodass insofern auf die bereits erfolgten Darstellungen verwiesen werden kann („Leistungsverwaltungsakte“). ${ }^{1762}$ Hinzukommen muss jedoch, dass die Leistung ultimativ zur Erfüllung eines bestimmten Zwecks dient. Davon zwingend zu unterscheiden sind Leistungsverwaltungsakte, bei denen bereits der Erlass selbst den vom Gesetz avisierten Zweck verwirklicht dazu gehören beispielsweise allgemeine Dienstbezüge von Beamten oder auch die Grundleistungen im Rahmen von Sozialleistungen. ${ }^{1763}$ Diese Leistungen dienen keinem bestimmten Zweck, sondern der allgemeinen Lebensführung. Die konkrete Zweckbindung muss aus dem Bescheid selbst mit hinreichender Bestimmtheit und Deutlichkeit hervorgehen. ${ }^{1764}$

975 Die so bestimmte Leistung kann wegen zweier Gründe widerrufen werden: entweder weil die Leistung nicht, nicht alsbald nach der Erbringung oder nicht

1760 S. nur Abel, in: Bader/Ronellenfitsch,VwVfG, 44. Ed., Stand. 1.7.2019, § 49 Rn. 64 ff.; Ehlers/ Schröder, JURA 2010, 824 (826).

1761 S. zu diesen Konstellationen instruktiv Folnovic/Hellriegel, NVwZ 2016, 638.

1762 Ramsauer, in: Kopp/Ramsauer, VwVfG, 20. Aufl. 2019, § 49 Rn. 64. S. dazu Rn. 878 ff

1763 Sachs, in: Stelkens/Bonk/Sachs, VwVfG, 9. Aufl. 2018, § 49 Rn. 92; Suerbaum, in: Mann/ Sennekamp/Uechtritz, VwVfG, 2. Aufl. 2019, § 49 Rn. 128.

1764 OVG Münster, Urt. v. 13.6.2002, Az.: 12 A 693/99 = NVwZ-RR 2003, 803 (804); Ramsauer, in: Kopp/Ramsauer, VwVfG, 20. Aufl. 2019, § 49 Rn. 65; Sachs, in: Stelkens/Bonk/Sachs, VwVfG, 9. Aufl. 2018, § 49 Rn. $94 \mathrm{f}$. 
mehr für den in dem Verwaltungsakt bestimmten Zweck verwendet wird (Nr. 1) oder weil eine mit dem Verwaltungsakt verbundene Auflage nicht oder nicht innerhalb einer gesetzten Frist erfüllt wurde (Nr. 2) ${ }^{1765} \cdot{ }^{1766}$ Ein Verschulden des Begünstigten ist nicht von Belang. Die Vorschriften zielen nur darauf ab, die zweckentsprechende Leistungsverwendung sicherzustellen. Ein fehlendes Verschulden ist jedoch wiederum im Rahmen der Ermessensausübung zu berücksichtigen.

Auch hier sind tatbestandlich die Ausschlussgründe gemäß § 49 I VwVfG (dazu Rn. 951) und § 49 III 2 i.V.m. § 48 IV VwVfG (dazu Rn. 905 ff.) zu berücksichtigen, bezüglich derer die bereits erfolgten Ausführungen gleichsam entsprechend gelten.

Abschließend ist die ordnungsgemäße Ermessensausübung der Behörde zu prüfen: Gemäß §49 III 1 Hs. 1 VwVfG kann ein rechtmäßiger begünstigender Leistungsverwaltungsakt widerrufen werden. Anders als §49 I oder II VwVfG kennt § 49 III VwVfG auch keine Ermessensbegrenzung in zeitlicher Hinsicht: Der Widerruf ist grundsätzlich auch mit Wirkung für die Vergangenheit zulässig. Dies macht seinen besonderen Reiz aus. Die Vorschrift dient der Sicherung einer dem Zweck der Gewährung entsprechenden Verwendung öffentlicher Mittel und insofern den haushaltsrechtlichen Grundsätzen der Wirtschaftlichkeit und Sparsamkeit. ${ }^{1767}$ Entgegen des klaren Wortlauts hat das Bundesverwaltungsgericht wegen der Relevanz dieser Grundsätze im Falle des § 49 III 1 Nr. 1 VwVfG ein „intendiertes Ermessen“ angenommen, ${ }^{1768}$ sodass besondere Gründe für eine Abweichung vorliegen müssen.

\section{(3) Widerruf von Verwaltungsakten im unionsrechtlichen Kontext}

Auch im Falle des Widerrufs von nachträglich unionsrechtswidrig gewordenen 978

Verwaltungsakten ergeben sich Besonderheiten. ${ }^{1769}$ Besonderes Augenmerk fiel

1765 Zur Auflage gilt das zu § 49 II 1 Nr. 1 und 2 VwVfG Dargelegte entsprechend: Nach h.M. soll es nicht auf deren Wirksamkeit ankommen, s. dazu Rn. $956 \mathrm{ff}$.

1766 Vgl. dazu die Beispielsfälle bei Ehlers/Schröder, JURA 2010, 824 (826ff.); s. auch die Fallbearbeitungen bei Haltern/Manthey, JuS 2016, 344, sowie bei Ernst/Kämmerer, Fälle zum Allgemeinen Verwaltungsrecht, 3. Aufl. 2016, Fall 11, S. 158 (165f.).

1767 So treffend Ramsauer, in: Kopp/Ramsauer, VwVfG, 20. Aufl. 2019, § 49 Rn. 73.

1768 BVerwG, Urt. v. 16.6.1997, Az.: 3 C 22.96 = BVerwGE 105, 55 (57 f.); Urt. v. 26.2.2015, Az.: 3 C 8.14 = BVerwGE 151, 302 (307, Rn. 17).

1769 S. dazu auch Peine/Siegel, Allgemeines Verwaltungsrecht, 12. Aufl. 2018, Rn. 655; Erbguth/ Guckelberger, Allgemeines Verwaltungsrecht, 9. Aufl. 2018, § 16 Rn. 35.

Tobias Brings-Wiesen 
zuletzt auf das Urteil des EuGH in der Rechtssache „Stadt Papenburg“, ${ }^{1770}$ in dessen Folge die unionsrechtliche Überformung des § 49 II VwVfG diskutiert wurde. ${ }^{1771}$ Denkbar ist darüber hinaus auch, dass es zum Widerruf einer ursprünglich unionsrechtmäßig gewährten Beihilfe (s. dazu Rn. $937 \mathrm{ff}$.) auf Grundlage von § 49 VwVfG kommt. Dies kommt im Falle einer „missbräuchlichen Anwendung von Beihilfen“ i.S.v. Art. 1 lit. g) BeihilfeVVO in Frage, deren Kontrolle der Kommission gemäß Art. 108 II Uabs. 1 AEUV, Art. 20 BeihilfeVVO obliegt. Eine Verwendung von Beihilfen entgegen den Beschlüssen der Kommission gemäß Art. 4 III und Art. 9 III BeihilfeVVO findet ihre Entsprechung im Widerrufsgrund nach § 49 III 1 Nr. 1 Var. 2 VwVfG $^{1772}$; eine Verwendung von Beihilfen unter Verstoß gegen Auflagen zu einem Beschluss gemäß Art. 9 IV BeihilfeVVO findet ihre Entsprechung im Widerrufsgrund nach $\S 49$ III 1 Nr. 2 VwVfG ${ }^{1773}$. Erlässt die Kommission zum Abschluss eines (neuen) formellen Prüfverfahrens sodann einen Negativbeschluss gemäß Art. 20 i.V.m. Art. 9 V BeihilfeVVO ist von einer den bereits dargestellten Konstellationen entsprechenden unionsrechtlichen Überformung der Entscheidung über den Widerruf des Bewilligungsbescheids und die Erstattung der bereits erbrachten Leistungen auszugehen.

\section{dd) Literaturhinweise}

Lehrbeiträge: Brügge/Erichsen, Der Widerruf von Verwaltungsakten nach §49 VwVfG und der öffentlich-rechtliche Erstattungsanspruch nach § 49a VwVfG, JURA 1999, 496; Ehlers/Schröder, Der Widerruf von Verwaltungsakten (Teil I), JURA 2010, 503; Ehlers/Schröder, Der Widerruf von Verwaltungsakten (Teil II), JURA 2010, 824; Kiefer, Können rechtswidrige Verwaltungsakte widerrufen werden?, NVwZ 2013, 1257; Struzina, Die Prüfung von Rücknahme und Widerruf, DÖV 2017, 906 (s. darüber hinaus auch bereits unter Rn. 939)

Fallbearbeitungen: Edenharter, Fortgeschrittenenklausur - Öffentliches Recht: Allgemeines Verwaltungsrecht - Explosive Biogasanlage, JuS 2018, 456;

1770 EuGH, Urt. v. 14.1.2010, Az.: C-226/08 - Stadt Papenburg. S. dazu auch Hecker, Europäisierung der Widerrufsdogmatik? - Zum „Papenburg“-Urteil des Europäischen Gerichtshofs, in: Festschrift Peine, 2016, S. 663.

1771 S. dazu Suerbaum, in: Mann/Sennekamp/Uechtritz, VwVfG, 2. Aufl. 2019, § 49 Rn. 30 ff.; Ehlers/Schröder, JURA 2010, 824 (825f.); Kahl, NVwZ 2011, 449 (453).

1772 Es ist davon auszugehen, dass der der einschlägigen Ausnahmevorschrift des AEUV zugrundeliegende Zweck in der Folge als „bestimmter Zweck“ auch der Leistungsgewähr i.S.v. $\S 49$ III 1 Nr. 1 Var. 2 VwVfG zugrunde zu legen ist. Der subsidiär anwendbare § 49 II 1 Nr. 5 VwVfG würde zumindest unter normalen Umständen keinen Widerruf für die Vergangenheit legitimieren. 1773 So auch Korte, JURA 2017, 656 (663).

Tobias Brings-Wiesen 
Ernst/Kämmerer, Fall 11 - Für Subventionen keine Subventionen, in: Fälle zum Allgemeinen Verwaltungsrecht, 3. Aufl. 2016, S. 158; Faßbender, (Original-)Referendarexamensklausur - Öffentliches Recht: Allgemeines Verwaltungsrecht und Europarecht - Subvention für ökologische Landwirtschaft, JuS 2016, 538; GreimDiroll, Blumige Aussichten, JURA 2018, 740; Haltern/Manthey, (Original-)Referendarexamensklausur - Öffentliche Recht: Verwaltungsrecht - Rechtsnachfolge und Verwaltungsaktbefugnis im Subventionsrecht, JuS 2016, 344; Klafki, „Die reisende Kristallkugel“ Eine Tour d'Horizon durch das Gewerberecht, JURA 2018, 1019; Klement, Referendarexamensklausur - Öffentliches Recht: Allgemeines Verwaltungsrecht - Ellingers Traum aus Kindertagen, JuS 2018, 1088; Kühn, Politische Bildung auf dem Oktoberfest, JURA 2017, 1214; Manssen/Greim, Referendarexamensklausur - Öffentliches Recht: Rückforderung von Subventionen „Biofleisch, nein danke“, JuS 2010, 429; Payandeh, Übungsfall: Der fragwürdige Widerrufsvorbehalt, ZJS 2017, 544; Polzin/Doll, Der Gesichtsschleier in der Schule, JURA 2017, 1436; Winter-Peter, Widerruf einer Genehmigung, JURA 2018, 508; Wormit, Ein unheiliger Weihnachtsabend, JURA 2018, 87

\section{d) Rücknahme und Widerruf im Rechtsbehelfsverfahren gegen Verwaltungsakte mit Drittwirkung, §50 VwVfG}

Gemäß $\S 50$ VwVfG gelten $\S 48$ I 2, II bis IV sowie $\S 49$ II bis IV und VI nicht, 979 wenn ein begünstigender Verwaltungsakt, der von einem Dritten angefochten worden ist, während des Vorverfahrens oder während des verwaltungsgerichtlichen Verfahrens aufgehoben wird, soweit dadurch dem Widerspruch oder der Klage abgeholfen wird. Die Vorschrift hat zwar nun einen sehr begrenzten Anwendungsbereich, sollte allerdings wegen ihrer Komplexität nicht in der „Lernlücke“ verschwinden. ${ }^{1774}$

Der Anwendungsbereich von $\S 50$ VwVfG ist doppelt beschränkt: ${ }^{1775}$ In 980 sachlich-persönlicher Hinsicht gilt die Vorschrift nur im Falle der Erhebung eines Widerspruchs gemäß § 68 I 1 VwGO bzw. einer Anfechtungsklage gemäß $\S 42$ I Var. 1 VwGO gegen einen den Adressaten begünstigenden Verwaltungsakt

1774 S. dazu ausführlich Remmert, VerwArch 2000, 209; Horn, Die Aufhebung des der Drittanfechtung unterliegenden Verwaltungsakts, 1989; Klostermann, Die Aufhebung des Verwaltungsakts mit Doppelwirkung im Verwaltungsverfahren, 1992. S. auch Gassner, JuS 1997, 794.

1775 S. zum Anwendungsbereich näher Ramsauer, in: Kopp/Ramsauer, VwVfG, 20. Aufl. 2019, $\S 50$ Rn. 3f., 12. 
mit Drittwirkung ${ }^{1776}$ durch den belasteten Dritten. In zeitlicher Hinsicht gilt die Vorschrift sodann nur für die Dauer des jeweiligen Verfahrens.

Entgegen des leicht widersprüchlichen Wortlauts soll eine Aufhebung des durch den Dritten angegriffenen begünstigenden Verwaltungsakts während der Verfahren nicht ausgeschlossen sein. ${ }^{1777}$ Die Norm modifiziert auch nicht die Voraussetzungen einer Aufhebung innerhalb des laufenden Rechtsbehelfsverfahrens. ${ }^{1778}$ Auch Abhilfe- oder Widerspruchsbehörde können den Verwaltungsakt ohne jegliche Berücksichtigung von $\S \S 48 \mathrm{f}$. VwVfG im Vorverfahren aufheben. ${ }^{1779}$ Die Vorschrift bewirkt vielmehr eine Modifikation der Voraussetzungen, die die zuständige Behörde außerhalb eines laufenden Rechtsbehelfsverfahrens einzuhalten hat, wenn sie der widerspruchsbehördlichen oder gerichtlichen Entscheidung durch Aufhebung gemäß \$§ $48 \mathrm{f}$. VwVfG ${ }^{1780}$ vorgreifen will. Im Vorverfahren steht die Entscheidung der Widerspruchsbehörde über den Weg der Aufhebung in ihrem Ermessen. ${ }^{1781}$

Die Wirkung von $\S 50$ VwVfG greift nur bei Vorliegen der folgenden Voraussetzungen, die im Einzelnen in verschiedener Hinsicht strittig diskutiert werden, worauf an dieser Stelle jedoch nicht en detail eingegangen werden soll $^{1782}$ :

(1) Der Anwendungsbereich der Vorschrift muss überhaupt eröffnet sein. Dies ist nur dann der Fall, wenn es sich um einen Verwaltungsakt mit Drittwirkung handelt, gegen den der belastete Dritte einen Widerspruch gemäß § 68 I 1 VwGO bzw. eine Anfechtungsklage gemäß § 42 I Var. 1 VwGO erhoben hat.

(2) Das somit anhängig gewordene Rechtsbehelfsverfahren muss noch andauern.

1776 S. dazu ausführlich bereits Rn. 296f. S. auch die Darstellungen bei Sachs, in: Stelkens/ Bonk/Sachs, VwVfG, 9. Aufl. 2018, § 50 Rn. 8 ff.

1777 Detterbeck, Allgemeines Verwaltungsrecht, 17. Aufl. 2019, Rn. 744; Ramsauer, in: Kopp/ Ramsauer, VwVfG, 20. Aufl. 2019, §50 Rn. 6. S. zur dogmatischen Frage der Ermächtigungsgrundlage für den Widerruf rechtmäßiger begünstigender Verwaltungsakte Remmert, VerwArch 2000, 209 (211) m.w. Nw.

1778 Maurer/Waldhoff, Allgemeines Verwaltungsrecht, 19. Aufl. 2017, § 11 Rn. 95.

1779 Ramsauer, in: Kopp/Ramsauer, VwVfG, 19. Aufl. 2018, § 50 Rn. 10.

1780 Oder gegebenenfalls aufgrund entsprechender Vorschriften des Fachrechts, für die eine analoge Anwendung diskutiert wird, s. nur Ramsauer, in: Kopp/Ramsauer, VwVfG, 20. Aufl. 2019, $\S 50$ Rn. 5; Sachs, in: Stelkens/Bonk/Sachs, VwVfG, 9. Aufl. 2018, § 50 Rn. 1, jeweils m.w. N.

1781 BVerwG, Urt. v. 18.4.1996, Az.: 4 C 6.95 = BVerwGE 101, 64 (69f.); vgl. zust. nur Sachs, in: Stelkens/Bonk/Sachs, VwVfG, 9. Aufl. 2018, §50 Rn. 5 m.w. Nw. Dagegen jedoch ausführlich Cornils, Die Verwaltung 2000, 485.

1782 S. für eine gut zugängliche Darstellung einzelner Probleme Remmert, VerwArch 2000, 209. S. für einen Überblick über die zu den Erfolgsaussichten des Rechtsbehelfs existierenden Positionen nur Sachs, in: Stelkens/Bonk/Sachs, VwVfG, 9. Aufl. 2018, § 50 Rn. 99. 
(3) Der Rechtsbehelf muss zulässig sein. ${ }^{1783}$

(4) Umstritten ist insbesondere, ob und falls ja, inwiefern das anhängige 986 Rechtsbehelfsverfahren in der Sache erfolgreich sein muss. $\mathrm{Zu}$ dieser Frage existieren verschiedene nuancierende Positionen, wesentlich lassen sich jedoch drei Hauptansätze identifizieren. Eine Ansicht verzichtet völlig auf eine Prüfung der Erfolgsaussichten des Rechtsbehelfs in der Sache. ${ }^{1784}$ Eine vermittelnde Ansicht verlangt lediglich, dass der Rechtsbehelf nicht offensichtlich unbegrün$\operatorname{det}^{1785}$ sein darf. ${ }^{1786}$ Die letzte Ansicht fordert hingegen, dass der Rechtsbehelf begründet sein muss. ${ }^{1787}$ Unabhängig davon, welcher Meinung man folgt, wird man jedenfalls bei Zulässigkeit und Begründetheit eines Rechtsbehelfs konsequenterweise eine Ermessensreduktion auf Null im Hinblick auf die Aufhebungsentscheidung annehmen müssen. ${ }^{1788}$

(5) Die Aufhebung gemäß §§ 48f. VwVfG muss dem eingelegten Rechtsbehelf 987 tatsächlich „abhelfen“, sprich das Begehren des Verfahrensführers verwirklichen.

Liegen diese Voraussetzungen vor, entfällt für die Behörde im Rahmen der 988 Aufhebung gemäß §§ 48f. VwVfG zumindest die Notwendigkeit der Beachtung der Vorschriften, die tatbestandlich das schutzwürdige Vertrauen des Begünstigten absichern sollen. Ziel der Vorschrift ist es, eine (weitgehende) Annäherung an die materiellen Beurteilungsmaßstäbe im Rechtsbehelfsverfahren, in dem Vertrauensschutzerwägungen mangels Bestandskraft maximal eine untergeordnete Bedeutung haben, zu erwirken. Hat man das Vorliegen der Voraussetzungen

1783 Dies scheint heute der ganz h.M. zu entsprechen, s. nur BVerwG, Urt. v. 13.11.1997, Az.: 3 C 33.96 = BVerwGE 105, 354 (360 f.); Urt. v. 4.4. 2012, Az.: 8 C 9.11 = juris, Rn. 38. S. dazu überdies die Nachweise - auch zu vereinzelt vertretenen Gegenmeinungen - bei Suerbaum, in: Mann/ Sennekamp/Uechtritz, VwVfG, 2. Aufl. 2019, § 50 Rn. 22.

1784 So bspw. OVG Münster, Urt. v. 25.4.1988, Az.: 13 A 464/87 = NVwZ 1989, 72 (73); Falkenbach, in: Bader/Ronellenfitsch, VwVfG, 44. Ed., Stand:1.7.2019, § 50 Rn. 7; Ziekow, VwVfG, 3. Aufl. 2013, $\S 50$ Rn. 9; Krausnick, JuS 2010, 594 (598).

1785 Für das VGH München, Urt. v. 10.12.1996, Az.: 20 B 95.3349 = NVwZ 1997, 701 (703), ist dies dann der Fall, wenn Gründe für den Erfolg des Rechtsbehelfs zu sprechen vermögen, ohne dass es aus einer ex-post-Perspektive darauf ankommt, ob sich diese Gründe auch tatsächlich durchzusetzen vermögen.

1786 Peine/Siegel, Allgemeines Verwaltungsrecht, 12. Aufl. 2018, Rn. 658; Ehlers/Kallerhoff, JURA 2009, 823 (828).

1787 S. nur Sachs, in: Stelkens/Bonk/Sachs, VwVfG, 9. Aufl. 2018, § 50 Rn. 93, m.w. N.; wohl auch das BVerwG, Urt. v. 24.2.2000, Az.: 4 C 12.98 = BVerwGE 110, 355 (362).

1788 So das BVerwG, Urt. v. 8.11.2001, Az.: 4 C 18.00 = NVwZ 2002, 730 (732f.). A.A. aber Ramsauer, in: Kopp/Ramsauer, VwVfG, 20. Aufl. 2019, § 50 Rn. 24. 
des $\S 50$ VwVfG bejaht, kann daher im Folgenden eine Prüfung der Tatbestandsvoraussetzungen gemäß $§ 48$ I 2, II bis IV und § 49 II, III VwVfG unterbleiben. ${ }^{1789}$ Wurde es hingegen verneint, sind die $\S \S 48 \mathrm{f}$. VwVfG uneingeschränkt zu prüfen. Umstritten ist, ob darüber hinaus jeglicher Vertrauensschutz ausgeschlossen sein soll, also insbesondere auch die Pflicht der Behörde entfällt, Vertrauensschutzerwägungen im Rahmen der Ausübung ihres Ermessens zu berücksichtigen. ${ }^{1790}$ Dies wird jedoch nur dann überhaupt ein Problem sein, wenn mangels Erforderlichkeit von Begründetheit noch Raum für eine Ermessensausübung verbleibt. Hier zeigt sich wiederum die besondere dogmatische Komplexität der Vorschrift, deren Auslegung je nach Positionierung in bestimmten interdependenten Streitfragen differiert.

\section{e) Erstattung, § 49a VwVfG}

989 Gemäß § 49a VwVfG sind bereits erbrachte Leistungen zu erstatten, soweit ein Verwaltungsakt mit Wirkung für die Vergangenheit zurückgenommen oder widerrufen worden oder infolge Eintritts einer auflösenden Bedingung unwirksam geworden ist. Die Vorschrift ist eine besonders normierte Ausprägung (s. zum allgemeinen öffentlich-rechtlichen Erstattungsanspruch ausführlich unter $\S 5$ Rn. 189 ff.) des öffentlich-rechtlichen Erstattungsanspruchs zugunsten der Behörde und dient als Ermächtigungsgrundlage für die Rückforderung bestimmter rechtsgrundlos erbrachter Leistungen. Entsprechend bestimmt § 49a I 2 VwVfG ausdrücklich, dass die zu erstattende Leistung durch Verwaltungsakt festzusetzen ist. ${ }^{1791}$ Die Rückforderung basiert zwar zum Teil auf der Aufhebung eines Verwaltungsakts mit Wirkung für die Vergangenheit (§ 49a I 1 Var. 1 und 2 VwVfG), sie ist jedoch ein rechtlich davon zu unterscheidender Verwaltungsakt, dessen Aufhebung im Wege des Widerspruchs (§ 68 I 1 VwGO) bzw. der Anfechtungsklage (§ 42 I Var. 1 VwGO) eigenständig zu begehren ist.

990 In Prüfungen erfolgt die Rückforderung von Leistungen überwiegend in Verbindung mit der Aufhebungsentscheidung. Dies ist vor dem Hintergrund, dass die Rückforderung gemäß § 49a I 1 VwVfG u. a. nur im Falle der Aufhebung (Var. 1 und 2) zulässig ist, verständlich. Aus dem Sachverhalt wird sich regelmäßig klar ergeben, dass die Behörde es begehrt, zwei verschiedene Regelungen vorzunehmen. Davon ist im Wege der Auslegung selbst dann auszugehen, wenn diese in

1789 S. dafür ausführlich zu verschiedenen Positionen Sachs, in: Stelkens/Bonk/Sachs, VwVfG, 9. Aufl. 2018, § 50 Rn. $71 \mathrm{ff}$.

1790 S. dazu Ramsauer, in: Kopp/Ramsauer, VwVfG, 20. Aufl. 2019, § 50 Rn. 8.

1791 Es handelt sich um eine der seltenen ausdrücklichen Verwaltungsaktbefugnisse, s. dazu Rn. 760.

Tobias Brings-Wiesen 
einem Bescheid zusammengefasst sind. ${ }^{1792}$ Unter Umständen kann durch Auslegung gar einem bloßen Rückforderungsbescheid die vorgeschaltete Aufhebung eines Verwaltungsakts entnommen werden. Je nach Aufgabenstellung kann es zwar vereinzelt erforderlich sein, die Aufhebungsentscheidung der Behörde im Rahmen von § 49a I 1 VwVfG inzident umfassend zu prüfen. Da die Rückforderung jedoch nur von der Wirksamkeit der Aufhebung abhängig ist, wird sie in der überwiegenden Zahl der Fälle sinnvoll nur in unmittelbarer Kombination mit der Beurteilung der Wirksamkeit des einer Leistung zugrundeliegenden Verwaltungsakts zu prüfen sein. Dabei wird sie praktisch immer dessen Überprüfung nachfolgen. Die klassische Prüfungskonstellation ist die Erhebung zweier (in objektiver Klagehäufung gemäß §44 VwGO - s. dazu unter §1 Rn. 64, $231 \mathrm{ff}$., 252ff. - miteinander verbundener) Anfechtungsklagen gegen die Aufhebung eines Verwaltungsakts und die darauf beruhende Rückforderung bereits erbrachter Leistungen gemäß § 49a I 1 VwVfG. In diesem Fall sollte besonders darauf geachtet werden, dass im Zeitstress zum Ende der Prüfung die Rückforderung nicht unterschlagen wird.

\section{aa) Ermächtigungsgrundlage und formelle Rechtmäßigkeit}

Wie bereits dargelegt ist $\S 49$ a I 1 VwVfG Ermächtigungsgrundlage des Rück- 991 forderungsbescheids.

Da es sich bei dem Rückforderungsbescheid um einen Verwaltungsakt han- 992 delt, gelten wiederum die allgemeinen rechtlichen Vorgaben für Verwaltungsakte nach dem VwVfG. Daher kann auch an dieser Stelle grundsätzlich auf die allgemeinen Ausführungen zur formellen Rechtmäßigkeit verwiesen werden (s. dazu Rn. 579 ff.). Folgende Besonderheiten sind zu berücksichtigen: Die Zuständigkeit für die Rückforderung liegt nach herrschender Meinung entweder bei der Behörde, die auch für die Aufhebung des leistungsbegründenden Verwaltungsakts (Var. 1 und 2) zuständig gewesen ist, oder im Falle des Eintritts einer auflösenden Bedingung bei der Behörde, die den Hauptverwaltungsakt erlassen hat. ${ }^{1793}$ Da der Rückforderungsbescheid durch die Begründung einer Leistungspflicht in die Rechte des durch die Leistung Begünstigten eingreift, ist auch seiner bezüglich

1792 So auch Maurer/Waldhoff, Allgemeines Verwaltungsrecht, 19. Aufl 2017, § 11 Rn. 48. 1793 Sachs, in: Stelkens/Bonk/Sachs, VwVfG, 9. Aufl. 2018, § 49a Rn. 34; Kastner, in: Fehling/ Kastner/Störmer, Verwaltungsrecht, 4. Aufl. 2016, § 49a VwVfG Rn. 8; Suerbaum, in: Mann/Sennekamp/Uechtritz,VwVfG, 2. Aufl. 2019, § 49a Rn. 50; Peuker, in: Knack/Henneke, VwVfG, 10. Aufl. 2014, § 49a Rn. 28; Gröpl, VerwArch 1997, 23 (43f.). 
eine Anhörung gemäß § 28 I VwVfG erforderlich. Zuletzt ist zu beachten, dass der Rückforderungsbescheid gemäß § 49a I 2 VwVfG schriftlich ergehen muss.

\section{bb) Materielle Rechtmäßigkeit}

993 Die Rückforderung durch die Behörde auf Grundlage von § 49a VwVfG erfolgt rechtmäßig, soweit sie die folgenden Voraussetzungen erfüllt:: ${ }^{1794}$

(1) Ausdrücklich ist der Anwendungsbereich der Vorschrift auf drei Konstellationen beschränkt: die Rücknahme, den Widerruf oder die Erledigung eines Verwaltungsakts infolge Eintritts einer auflösenden Bedingung. Gemein ist den drei Konstellationen, dass die Unwirksamkeit mit Wirkung für die Vergangenheit eintreten muss. Soweit in einer Prüfung bereits vorab die Aufhebung eines Verwaltungsakts geprüft wurde, kann an dieser Stelle nach oben verwiesen werden. Dabei ist irrelevant, ob die Prüfung am Maßstab spezialgesetzlicher Aufhebungstatbestände oder der §§ 48f. VwVfG erfolgte. ${ }^{1795}$ Dies kann insbesondere auch dazu führen, dass die Prüfung mangels rechtmäßiger Aufhebung zumindest mit Wirkung für die Vergangenheit - sofort $\mathrm{zu}$ beenden ist. Eine analoge Anwendbarkeit der Vorschrift auf andere Konstellationen der Unwirksamkeit mit Wirkung für die Vergangenheit wird unter Rekurs auf den klaren Wortlaut und die Entstehungsgeschichte der Norm nahezu einheitlich abgelehnt. ${ }^{1796}$ Nichts anderes gilt grundsätzlich für Aufhebungen mit Wirkung für die Zukunft. ${ }^{1797}$ Zum Teil wird jedoch mit der Begründung, die Aufhebung mit Wirkung für die Zukunft lasse den Rechtsgrund für das Behalten der empfangenen Leistung entfallen, für eine analoge Anwendung plädiert. ${ }^{1798}$ Dies ist abzulehnen. ${ }^{1799}$ In all diesen Konstellationen ist die Behörde vielmehr auf den allgemeinen öffentlich-rechtlichen Erstattungsanspruch verwiesen. Soweit es nur zu einem anteiligen Entfall des Rechtsgrundes für eine Leistung kommt, ist die Erstattung darauf beschränkt. ${ }^{1800}$

1794 S. für einen Prüfungsaufbau auch Kastner, in: Fehling/Kastner/Störmer, Verwaltungsrecht, 4. Aufl. 2016, § 49a VwVfG Rn. 3.

1795 Ramsauer, in: Kopp/Ramsauer, VwVfG, 20. Aufl. 2019, § 49a Rn. 3.

1796 S. nur Ramsauer, in: Kopp/Ramsauer, VwVfG, 20. Aufl. 2019, § 49a Rn. 3f. m.w. N.

1797 Detterbeck, Allgemeines Verwaltungsrecht, 17. Aufl. 2019, Rn. 731; Ramsauer, in: Kopp/ Ramsauer, VwVfG, 20. Aufl. 2019, § 49a Rn. 8; Ehlers/Schröder, JURA 2010, 824 (831).

1798 Dafür Sachs, in: Stelkens/Bonk/Sachs, VwVfG, 9. Aufl. 2018, § 49a Rn. 9, 16, 19; Falkenbach, in: Bader/Ronellenfitsch, VwVfG, 44. Ed., Stand: 1.7.2019, § 49a Rn. 5 f.

1799 S. dazu mit überzeugender Begründung nur Folnovic/Hellriegel, NVwZ 2016, 638 (641 f). 1800 Maurer/Waldhoff, Allgemeines Verwaltungsrecht, 19. Aufl. 2017, § 11 Rn. 48.

Tobias Brings-Wiesen 
(2) Der Bescheid muss gegen den richtigen Adressaten, nämlich den 995 Schuldner des Erstattungsanspruchs, gerichtet sein. Dies ist regelmäßig die im ursprünglichen Verwaltungsakt als Empfänger der Leistung ausgewiesene Person. ${ }^{1801}$ Nur unter besonderen Umständen können von der Behörde auch Dritte in Anspruch genommen werden. ${ }^{1802}$

(3) Der Erstattungsanspruch der Behörde darf noch nicht verjährt sein. Dies 996 ist im Einklang mit der herrschenden Meinung nach §195 i.V.m. § 199 I BGB analog zu bestimmen. ${ }^{1803}$ Danach beträgt die regelmäßige Verjährungsfrist drei Jahre und beginnt mit dem Schluss des Jahres, in dem der Anspruch entstanden ist und der Gläubiger von den Anspruch begründenden Umständen Kenntnis erlangt hat oder ohne grobe Fahrlässigkeit hätte erlangen müssen. Eine Hemmung nach $\S \S 203 \mathrm{ff}$. BGB analog ist möglich. ${ }^{1804}$

(4) Die von der Behörde vorgenommene Festsetzung muss sich innerhalb des gesetzlich zulässigen Umfangs der Erstattung bewegen. Dies richtet sich nach § 49a II bis IV VwVfG. Hinsichtlich der erbrachten Leistung ordnet §49a II 1 VwVfG die entsprechende Geltung der Vorschriften des Bürgerlichen Gesetzbuchs über die Herausgabe einer ungerechtfertigten Bereicherung ( $\S \S 812 \mathrm{ff}$. BGB) an. Da der Rechtsgrund für die Erstattung jedoch abschließend in § 49a I 1 VwVfG geregelt ist, handelt es sich dabei nur um eine Rechtsfolgenverweisung auf die $\S \S 818 \mathrm{ff}$. BGB. $^{1805}$ Dies bedeutet insbesondere, ${ }^{1806}$ dass der Begünstigte sich gemäß $§ 818$ III BGB auf den Wegfall der Bereicherung berufen kann - dies allerdings gemäß (des als lex specialis zu § 819 I BGB anwendbaren ${ }^{1807}$ ) §49a II 2 VwVfG nur, soweit er nicht die Umstände kannte oder infolge grober Fahrlässigkeit nicht kannte, die zur Rücknahme, zum Widerruf oder zur Unwirksamkeit des Verwaltungsakts geführt haben. Anders als im Rahmen von $§ 48$ II 3 Nr. 3 VwVfG (s. dazu Rn. 892) soll sich die Kenntnis oder grob fahrlässige Unkenntnis hier nur

1801 Falkenbach, in: Bader/Ronellenfitsch, VwVfG, 44. Ed., Stand: 1.7.2019, § 49a Rn. 16; Ramsauer, in: Kopp/Ramsauer, VwVfG, 20. Aufl. 2019, § 49a Rn. 10.

1802 S. dazu Falkenbach, in: Bader/Ronellenfitsch, VwVfG, 44. Ed., Stand: 1.7.2019, § 49a Rn. 16 ff.; Ramsauer, in: Kopp/Ramsauer, VwVfG, 20. Aufl. 2019, § 49a Rn. 10a.

1803 Vgl. dazu - im subventionsrechtlichen Kontext - nur Scherer-Leydecker/Laboranowitsch, NVwZ 2017, 1837, m. ausf. Darstellung des aktuellen Streitstands; s. auch die überzeugende Begründung des BVerwG, Urt. v. 15.3.2017, Az.: 10 C 3.16 = BVerwGE 158, 199 (203f., Rn. 19).

1804 BVerwG, Urt. v. 15.3.2017, Az.: 10 C 3.16 = BVerwGE 158, 199 (206f., Rn. 24).

1805 Sachs, in: Stelkens/Bonk/Sachs, VwVfG, 9. Aufl. 2018, § 49a Rn. 42.

1806 Für eine anschauliche Darstellung der sonstigen Folgen Sachs, in: Stelkens/Bonk/Sachs, VwVfG, 9. Aufl. 2018, § 49a Rn. $43 \mathrm{ff}$.

1807 Maurer/Waldhoff, Allgemeines Verwaltungsrecht, 19. Aufl. 2017, § 11 Rn. 48. 
auf die tatsächlichen Voraussetzungen der die Aufhebung begründenden Rechtswidrigkeit beziehen, nicht indes auf die Rechtswidrigkeit selbst. ${ }^{1808}$

Bei der Entscheidung über die Rückforderung gewährt § 49a I 1 VwVfG der Behörde im Hinblick auf die erbrachte Leistung selbst kein Ermessen. Sie muss diese vielmehr zurückfordern. Die Forderung von Zinsen gemäß §49a III, IV VwVfG hingegen steht im Ermessen der Behörde.

\section{f) Die Zusicherung, § 38 VwVfG}

999 Besonderer Berücksichtigung bedarf auch die Möglichkeit einer Anfechtungsklage gemäß § 42 I Var. 1 VwGO gegen die Zusicherung auf Erlass eines Verwaltungsakts mit Drittwirkung gemäß $\S 38$ VwVfG. ${ }^{1809}$ Dabei handelt es sich um einen gesetzlich ausdrücklich normierten Unterfall der Zusage: Ausweislich der Legaldefinition in § 38 I 1 VwVfG handelt es sich um die behördliche Zusage, einen bestimmten Verwaltungsakt später zu erlassen oder zu unterlassen. Obgleich die Rechtsqualität der Zusicherung weiterhin lebhaft umstritten ist, geht zumindest die wohl herrschende Meinung davon aus, dass es sich bei ihr um einen Verwaltungsakt handelt. ${ }^{1810}$ Daraus folgt, dass in multipolaren Rechtsverhältnissen das Begehren eines belasteten Dritten bei Verletzung seiner Rechte durch die dem Begünstigten gegenüber ausgesprochene Zusicherung darauf gerichtet sein kann, diesen Verwaltungsakt aufheben zu lassen. Die Erhebung von Rechtsbehelfen ist erforderlich, um die - zumindest gemäß § 38 II VwVfG - unabhängig von einer etwaigen Rechtswidrigkeit eintretende Wirksamkeit der Zusicherung zu beenden und dem Begünstigten so die Anspruchsgrundlage für den Erlass eines Verwaltungsakts zu nehmen (s. dazu in $\S 3$ Rn. 71, 79). Im Rahmen der Prüfung der Begründetheit ist sodann zu berücksichtigen, dass $\S 38$ VwVfG einige Besonderheiten betreffend Wirksamkeits- und Rechtsmäßigkeitsvoraussetzungen der Zusicherung bereithält. ${ }^{1811} \mathrm{Da}$ - zumindest gemäß § 38 II VwVfG - die §§ $48 \mathrm{f}$. VwVfG entsprechend anwendbar sind, kann eine rechtswidrige Zusicherung auch gemäß § 48 VwVfG zurückgenommen werden. Kommt es schließlich zum Erlass

1808 BVerwG, Urt. v. 13.11.1997, Az.: 3 C 33.96 = BVerwGE 105, 354 (362).

1809 Maurer/Waldhoff, Allgemeines Verwaltungsrecht, 19. Aufl. 2017, § 9 Rn. 61. S. dazu Stelkens, in: Stelkens/Bonk/Sachs, VwVfG, 9. Aufl. 2018, § 38 Rn. 119ff.; für einen gut zugänglichen Überblick zu den Rechtsproblemen rund um die Zusicherung Hebeler/Schäfer, JURA 2010, 881; Kingler/Krebs, JuS 2010, 1059. S. dazu auch die Fallbearbeitung bei Pünder, JA 2004, 467.

1810 S. dazu nur Stelkens, in: Stelkens/Bonk/Sachs, VwVfG, 9. Aufl. 2018, § 38 Rn. 29 ff. m. zahlr. N. Da sich der Streit auf das Rechtsschutzbegehren auswirkt, wird er in einer Klausur regelmäßig $\mathrm{zu}$ entscheiden sein.

1811 S. dazu Kingler/Krebs, JuS 2010, 1059 (1060 ff.).

Tobias Brings-Wiesen 
des Verwaltungsakts auf Grundlage der Zusicherung, ist eine gegen diesen gerichtete Anfechtungsklage am Maßstab der Zusicherung und insofern unter Begutachtung ihrer Wirksamkeit zu prüfen. ${ }^{1812}$

\section{Literaturhinweise}

Lehrbeiträge: Guckelberger, Behördliche Zusicherungen und Zusagen, DÖV 2004, 357; Hebeler/Schäfer, „Versprechungen“ der Verwaltung - Zusagen, Zusicherungen und ähnliche behördliche Erklärungen, JURA 2010, 881; Kellner, Vertrauensschutz in kleiner Münze - Staatshaftungsrechtliche Aspekte der Zusicherung nach § 38 VwVfG, NVwZ 2013, 482; Kingler/Krebs, Die Zusicherung, § 38 VwVfG, JuS 2010, 1059

Fallbearbeitungen: Diederichsen, Referendarexamensklausur - Öffentliches Recht: Zoff um eine Zusage, JuS 2006, 60; Ernst/Kämmerer, Fall 10 - Ein dilettantischer Gastwirt, in: Fälle zum Allgemeinen Verwaltungsrecht, 3. Aufl. 2016, S. 139; Grupp/Stelkens, Wahlverwandtschaften, abrufbar unter: http://www.saarheim.de/ Faelle/wahlverwandtschaften-fall.htm (Bearbeitungsstand: 1.6.2018); Pünder, Die voreilige Subventionszusage, JA 2004, 467

Lehrvideos: Mayer/Breidenbach, Peer2Peer-Lehrvideo Rücknahme und Widerruf eines Verwaltungsakts, Teil 1 abrufbar unter https://youtu.be/y1QqFT_ YGGQ und Teil 2 abrufbar unter https://youtu.be/ojo0PLYW_Ik

\section{Ermächtigungsgrundlagen des Polizei- und Ordnungsrechts (Nikolas Eisentraut)}

Ein zentrales Anwendungsfeld für die Anfechtungsklage bietet das allgemeine 1000 Polizei- und Ordnungsrecht. Die Anfechtungsklage spielt im allgemeinen Polizei- und Ordnungsrecht deshalb eine bedeutende Rolle, weil die Polizei- und Ordnungsbehörden bei der Gefahrenabwehr häufig auf die Handlungsform des Verwaltungsakts zurückgreifen. ${ }^{1813}$

Aber Achtung: Nicht gegen jede polizei- oder ordnungsbehördliche Maß- 1001 nahme ist die Anfechtungsklage statthaft. Die Ermächtigungsgrundlagen der Polizei- und Ordnungsgesetze der Länder sprechen häufig nur von den durch die Polizei- oder Ordnungsbehörden zu ergreifenden „Maßnahmen“. ${ }^{1814}$ Nur dann,

1812 Stelkens, in: Stelkens/Bonk/Sachs, VwVfG, 9. Aufl. 2018, § 38 Rn. 122.

1813 Schenke, Polizei- und Ordnungsrecht, 10. Aufl. 2018, Rn. 482.

1814 Schenke, Polizei- und Ordnungsrecht, 10. Aufl. 2018, Rn. 482. 
wenn es sich bei der Maßnahme auch um einen Verwaltungsakt handelt, den der Kläger aufgehoben wissen will, ist die Anfechtungsklage statthaft.

1002

Auch bei Klausuren im Polizei- und Ordnungsrecht stellt sich daher regelmäßig unter dem Prüfungspunkt „Statthafte Klageart“ (s. dazu einleitend $\S 1$ Rn. 222ff.) die Frage, ob die zu prüfende Maßnahme als Verwaltungsakt zu qualifizieren ist (grundlegend zum Begriff des Verwaltungsakts Rn. $38 \mathrm{ff}$.).

1003 Nicht als Verwaltungsakt qualifiziert, sondern dem Realbereich des Handelns der Verwaltung (Realakt, s. dazu näher $§ 5$ Rn. 6 ff.) zugeordnet werden Warnungen (etwa die Gefährderansprache bzw. das Gefährderanschreiben ${ }^{1815}$ ), Datenerhebung und -verarbeitung, heimliche informationelle Eingriffe und die unmittelbare Ausführung von Maßnahmen, ${ }^{1816}$ aber auch polizeiliche Streifengänge, Beobachtungen und Ermahnungen. ${ }^{1817}$ Mangels Regelungswirkung sind gegen Realakte nur die Rechtsschutzformen der allgemeinen Leistungsklage (insbesondere in Form der Unterlassungsklage, s. zur allgemeinen Leistungsklage im Polizei- und Ordnungsrecht $\S 5$ Rn. 223ff.) sowie im Falle bereits erledigter Realakte die Feststellungsklage statthaft (s. zur Feststellungsklage im Polizei- und Ordnungsrecht $\S 6$ Rn. 181 ff.). ${ }^{1818}$

1004 In der Regel gelingt die Abgrenzung mittels einer sauberen Subsumtion unter die Tatbestandsmerkmale des Verwaltungsaktbegriffs. Insbesondere im Falle ausdrücklicher Anordnungen durch die handelnden Behörden kann der Regelungscharakter typischerweise bejaht werden. ${ }^{1819}$ Fehlt eine solche ausdrückliche Anordnung, ist die Qualifikation als Verwaltungsakt jedoch zweifelhaft, insbesondere, wenn es um Standardbefugnisse geht, die zu einem tatsächlichen Handeln ermächtigen. Dem entsprechend ist die Qualifikation als Verwaltungsakt für einige Standardmaßnahmen umstritten, sodass hier ein besonderes Problembewusstsein nicht schaden kann. Dies gilt insbesondere für den Gewahrsam, die Durchsuchung, die Sicherstellung sowie für die erkennungsdienstliche Behandlung. ${ }^{1820}$ Zwar ist die faktische Durchführung der Maßnahmen dem Realbereich des Verwaltungshandelns zuzuordnen; nach klassischer Sichtweise enthält die Durchführung aber zugleich die Regelung, dass der Betroffene die Maßnahme dulden muss. ${ }^{1821}$ Danach wären die Maßnahmen also

1815 Götz/Geis, Allgemeines Polizei- und Ordnungsrecht, 16. Aufl. 2017, § 12 Rn. 5; Schoch, in: Schoch, Besonderes Verwaltungsrecht, 2018, Kapitel 1 Rn. 229.

1816 Götz/Geis, Allgemeines Polizei- und Ordnungsrecht, 16. Aufl. 2017, § 12 Rn. 1.

1817 Schenke, Polizei- und Ordnungsrecht, 10. Aufl. 2018, Rn. 484.

1818 Schenke, Polizei- und Ordnungsrecht, 10. Aufl. 2018, Rn. 663 und 667.

1819 Möstl, JURA 2011, 811 (848).

1820 Götz/Geis, Allgemeines Polizei- und Ordnungsrecht, 16. Aufl. 2017, § 12 Rn. 9.

1821 Götz/Geis, Allgemeines Polizei- und Ordnungsrecht, 16. Aufl. 2017, § 12 Rn. 11.

Nikolas Eisentraut 
als Verwaltungsakt zu qualifizieren. ${ }^{1822}$ Nach wohl überwiegender Auffassung soll es sich hingegen um Realakte handeln, weil die klassische Sichtweise konstruiert und in der Praxis überflüssig sei. ${ }^{1823}$

Die Qualifikation der streitgegenständlichen Maßnahme als Verwaltungs- 1005 akt reicht noch nicht aus, um die Statthaftigkeit der Anfechtungsklage zu bejahen. Der Verwaltungsakt muss weiterhin wirksam sein (zu diesem Erfordernis näher Rn. 98 ff.). Im Polizei- und Ordnungsrecht kommt es jedoch nicht selten vor, dass sich der Verwaltungsakt bereits erledigt hat. Ist bereits Erledigung eingetreten, kann der Kläger nur noch die Feststellung der Rechtswidrigkeit der Ordnungsverfügung mittels der Fortsetzungsfeststellungsklage verfolgen (s. zur Fortsetzungsfeststellungsklage im Polizei- und Ordnungsrecht näher $\S 4$ Rn. 62 ff.).

Zudem wird für ordnungsbehördliche Verwaltungsakte häufig die sofortige 1006 Vollziehbarkeit angeordnet (§ 80 II 1 Nr. 4 VwGO) oder sie besteht bereits qua Gesetz für „unaufschiebbare Anordnungen und Maßnahmen von Polizeivollzugsbeamten“ (§ 80 II 1 Nr. 2 VwGO). In diesen Fällen wird der Antragsteller einstweiligen Rechtsschutz nach § 80 Abs. 5 VwGO begehren (s. zum Antrag nach $\S 80$ V VwGO im Polizei- und Ordnungsrecht näher § 8 Rn. 79f.).

Ebenfalls nicht als Verwaltungsakt zu qualifizieren sind die sog. Gefahren- 1007 abwehrverordnungen. Die Polizei- und Ordnungsgesetze der Länder sehen die Möglichkeit vor, dass abstrakte Gefahren mittels Gefahrenabwehrverordnungen abgewehrt werden können. Gefahrenabwehrverordnungen gelten jedoch nicht konkret-individuell, sondern generell-abstrakt, formulieren ihre Ge- und Verbote also für eine unbestimmte Zahl von Fällen und für eine unbestimmte Zahl von Personen. Soweit im Landesrecht davon Gebrauch gemacht wurde, kann die Rechtmäßigkeit einer solchen Verordnung mittels der verwaltungsgerichtlichen Normenkontrolle nach $\S 47$ I Nr. 2 VwGO überprüft werden (zum Normenkontrollverfahren im Polizei- und Ordnungsrecht näher $\S 7$ Rn. 106ff.). Ansonsten kann ihre Rechtmäßigkeit inzident im Rahmen des Angriffs eines Vollzugsakts zu überprüfen sein (s. näher Rn. 1035 und Rn. 1091) sowie mittels der Feststellungsklage (s. § 6 Rn. $26 \mathrm{ff}$.). ${ }^{1824}$

1822 So auch weiterhin Götz/Geis, Allgemeines Polizei- und Ordnungsrecht, 16. Aufl. 2017, § 12 Rn. 11.

1823 M.w.N. zu dieser Ansicht Götz/Geis, Allgemeines Polizei- und Ordnungsrecht, 16. Aufl. 2017, $\S 12$ Rn. 11.

1824 Siegel, in: Siegel/Waldhoff, Öffentliches Recht für Berlin, 2. Aufl. 2017, § 2 Rn. 273. 
Examenswissen: Öffentlich-rechtliche Verträge werden im Polizei- und Ordnungsrecht hingegen nur selten geschlossen (näher zum öffentlich-rechtlichen Vertrag als Handlungsinstrument der Verwaltung $\S 5$ Rn. 65 ff.). ${ }^{1825}$

\section{a) Einführung in das Polizei- und Ordnungsrecht}

1008 Der Begriff des Polizei- und Ordnungsrechts umfasst alle Rechtsgrundlagen, die die Gefahrenabwehr durch die Verwaltung regeln. ${ }^{1826}$ Gefahrenabwehr meint dabei klassischer Weise (s. aber sogleich noch Rn. 1024f.) die Abwehr konkreter Gefahren für die polizeilichen Schutzgüter. ${ }^{1827}$ Darüber hinaus können die Gefahrenabwehrbehörden zudem im Bereich abstrakter Gefahren tätig werden, indem sie Gefahrenabwehrverordnungen erlassen (dazu § 7 Rn. 107) und Gefahrenvorsorge betreiben. ${ }^{1828}$

1009 Hausarbeitswissen: Die Gefahrenabwehr wird als Staatsaufgabe qualifiziert. ${ }^{1829}$ Als „staatliche Kernaufgabe“ steht sie einer Privatisierung nur in engen Grenzen offen. ${ }^{1830}$

\section{aa) Die Unterscheidung zwischen allgemeinem und besonderem Polizei- und Ordnungsrecht}

1010 Innerhalb des Rechts der Gefahrenabwehr wird unterschieden zwischen allgemeinem und besonderem Ordnungsrecht. ${ }^{1831}$ Da der Bund im Bereich der Gefahrenabwehr nur einzelne, bereichsspezifische Gesetzgebungskompetenzen besitzt, ${ }^{1832}$ ist die Regelung des allgemeinen Polizei- und Ordnungsrechts der Gesetzgebungskompetenz der Länder zugewiesen (Art. 70 GG). ${ }^{1833}$ Ihrer Kom-

1825 Dazu Schenke, Polizei- und Ordnungsrecht, 10. Aufl. 2018, Rn. 656ff.

1826 Schenke, Polizei- und Ordnungsrecht, 10. Aufl. 2018, Rn. 20; Schoch, in: Schoch, Besonderes Verwaltungsrecht, 2018, Kapitel 1 Rn. 1; zur Geschichte des Polizei- und Ordnungsrechts Kingreen/Poscher, Polizei- und Ordnungsrecht mit Versammlungsrecht, 10. Aufl. 2018, § 1 Rn. $1 \mathrm{ff}$. 1827 Schoch, in: Schoch, Besonderes Verwaltungsrecht, 2018, Kapitel 1 Rn. 10; zur Gefahrenabwehr als staatliche Aufgabe Schoch, in: Schoch, Besonderes Verwaltungsrecht, 2018, Kapitel 1 Rn. 65 ff.; zur Gefahrenabwehr durch Private Schoch, in: Schoch, Besonderes Verwaltungsrecht, 2018, Kapitel 1 Rn. $130 \mathrm{ff}$.

1828 Kingreen/Poscher, Polizei- und Ordnungsrecht mit Versammlungsrecht, 10. Aufl. 2018, § 8 Rn. 19.

1829 Näher dazu Schoch, in: Schoch, Besonderes Verwaltungsrecht, 2018, Kapitel 1 Rn. 65 ff. 1830 Siegel, in: Siegel/Waldhoff, Öffentliches Recht für Berlin, 2. Aufl. 2017, § 2 Rn. 4.

1831 Schenke, Polizei- und Ordnungsrecht, 10. Aufl. 2018, Rn. 20.

1832 Schoch, in: Schoch, Besonderes Verwaltungsrecht, 2018, Kapitel 1 Rn. 87 f.; Aufzählung bei Kingreen/Poscher, Polizei- und Ordnungsrecht mit Versammlungsrecht, 10. Aufl. 2018, § 2 Rn. $34 \mathrm{f}$. 1833 Schenke, Polizei- und Ordnungsrecht, 10. Aufl. 2018, Rn. 23; Schoch, in: Schoch, Besonderes Verwaltungsrecht, 2018, Kapitel 1 Rn. 90.

Nikolas Eisentraut 
petenz entsprechend haben die Länder allgemeine Polizei- und Ordnungsgesetze erlassen.

Hausarbeitswissen: Eine Vereinheitlichung der Regelungen ist zuletzt wieder in die Diskussion geraten, als die Innenministerkonferenz im Juni 2017 die Erarbeitung eines neuen Musterpolizeigesetzes beschlossen hat. ${ }^{1834}$ Einem Musterpolizeigesetz käme aufgrund der weiterhin bestehenden Länderkompetenz jedoch nur eine nicht bindende „Vorbildwirkung“ $z u$.

Folgende allgemeine Polizei- und Ordnungsgesetze existieren in den Bundesländern: ${ }^{1835}$

\begin{tabular}{ll}
\hline Bundesland & Polizei- und Ordnungsgesetz \\
\hline Baden-Württemberg & Polizeigesetz (BWPolG) \\
\hline Bayern & $\begin{array}{l}\text { 1. Gesetz über die Aufgaben und Befugnisse der Bayerischen } \\
\text { Staatlichen Polizei (Polizeiaufgabengesetz - BayPAG) } \\
\text { 2. Gesetz über das Landesstrafrecht und das Verordnungsrecht auf } \\
\text { dem Gebiet der öffentlichen Sicherheit und Ordnung (BayLStVG) }\end{array}$ \\
\hline Berlin & $\begin{array}{l}\text { Allgemeines Gesetz zum Schutz der öffentlichen Sicherheit und } \\
\text { Ordnung (ASOG Bln) }\end{array}$ \\
\hline Brandenburg & $\begin{array}{l}\text { 1. Gesetz über Aufbau und Befugnisse der Ordnungsbehörden } \\
\text { (Ordnungsbehördengesetz - BbgOBG) }\end{array}$ \\
$\begin{array}{l}\text { 2. Gesetz über die Aufgaben, Befugnisse, Organisation und Zu- } \\
\text { ständigkeit der Polizei im Land Brandenburg (Polizeigesetz - Bbg- } \\
\text { PolG) }\end{array}$ \\
\hline Bremisches Polizeigesetz (BremPolG) \\
\hline Bremen & $\begin{array}{l}\text { 1. Gesetz zum Schutz der öffentlichen Sicherheit und Ordnung } \\
\text { (HambSOG) } \\
\text { 2. Gesetz über die Datenverarbeitung der Polizei (HambPolEDVG) }\end{array}$ \\
\hline Hessisches Gesetz über die öffentliche Sicherheit und Ordnung \\
(HSOG)
\end{tabular}

1834 Schoch, in: Schoch, Besonderes Verwaltungsrecht, 2018, Kapitel 1 Rn. 91; zur Thematik näher Kaiser/Struzina, Vereinheitlichung des Polizeirechts? - Vom Beruf unserer Zeit zur Mustergesetzgebung, ZG 2018, 111; generell zu Zentralisierungstendenzen Kingreen/Poscher, Polizeiund Ordnungsrecht mit Versammlungsrecht, 10. Aufl. 2018, §1 Rn. $33 \mathrm{ff}$.

1835 Näher zu den einzelnen Gesetzen Kingreen/Poscher, Polizei- und Ordnungsrecht mit Versammlungsrecht, 10. Aufl. 2018, § 3 Rn. 9 ff.

Nikolas Eisentraut 
Fortsetzung

\begin{tabular}{|c|c|}
\hline Bundesland & Polizei- und Ordnungsgesetz \\
\hline Nordrhein-Westfalen & $\begin{array}{l}\text { 1. Polizeigesetz (PolG NRW) } \\
\text { 2. Gesetz über die Organisation und die Zuständigkeit der Polizei } \\
\text { (Polizeiorganisationsgesetz - NWPOG) } \\
\text { 3. Gesetz über die Aufbau und Befugnisse der Ordnungsbehörden } \\
\text { (Ordnungsbehördengesetz - NWOBG) }\end{array}$ \\
\hline Rheinland-Pfalz & Polizei- und Ordnungsbehördengesetz (PhPfPOG) \\
\hline Saarland & Saarländisches Polizeigesetz (SPolG) \\
\hline Sachsen & $\begin{array}{l}\text { 1. Polizeigesetz des Freistaates Sachsen (SächsPolG) } \\
\text { 2. Gesetz über die Sächsische Sicherheitswacht (Sicherheitswacht- } \\
\text { gesetz - SächsSWG) }\end{array}$ \\
\hline Sachsen-Anhalt & $\begin{array}{l}\text { Gesetz über die öffentliche Sicherheit und Ordnung des Landes } \\
\text { Sachsen-Anhalt (SOG LSA) }\end{array}$ \\
\hline Schleswig-Holstein & $\begin{array}{l}\text { 1. Allgemeines Verwaltungsgesetz für das Land Schleswig-Holstein } \\
\text { (Landesverwaltungsgesetz - SchlHLVwG) } \\
\text { 2. Gesetz über die Organisation der Polizei in Schleswig-Holstein } \\
\text { (Polizeiorganisationsgesetz - SchlHPOG) }\end{array}$ \\
\hline Thüringen & $\begin{array}{l}\text { 1. Gesetz über die Aufgaben und Befugnisse der Polizei (Polizei- } \\
\text { aufgabengesetz - ThürPAG) } \\
\text { 2. Gesetz über die Aufgaben und Befugnisse der Ordnungsbehörden } \\
\text { (Ordnungsbehördengesetz - ThürOBG) } \\
\text { 3. Gesetz über die Organisation der Polizei des Landes Thüringen } \\
\text { (Polizeiorganisationsgesetz - ThürPOG) }\end{array}$ \\
\hline
\end{tabular}

Examenswissen: Die Polizei- und Ordnungsgesetze sind zuletzt in mehreren Ländern Gegenstand von Reformen gewesen, die insbesondere der Erweiterung der polizei- und ordnungsbehördlichen Befugnisse dienten (zur Gefahr einer „Entgrenzung“ des Polizeirechts s. Rn. 1025). In Bayern ist etwa erstmals der Begriff der „drohenden Gefahr“ (dazu noch Rn. 1116) eingeführt worden. ${ }^{1836}$ Auch in Brandenburg sind Befugnisse erweitert worden. ${ }^{1837}$ Gleiches gilt für Mecklenburg-Vorpommern, ${ }^{1838}$ Hessen, ${ }^{1839}$ Nordrhein-Westfalen, ${ }^{1840}$ Niedersachsen, ${ }^{1841}$ Sachsen-Anhalt ${ }^{1842}$ und

1836 Gegenstand der Auseinandersetzungen ist das Gesetz zur effektiveren Überwachung gefährlicher Personen, GVBl. 2017, 388; näher dazu Schmid/Wenner, BayVBl. 2019, 109; Weinrich, NVwZ 2018, 1680; Waechter, NVwZ 2018, 458; Möstl, BayVBl. 2018, 156; Müller, BayVBl. 2018, 109. 1837 Zwölftes Gesetz zur Änderung des Brandenburgischen Polizeigesetzes v. 1.4.2019, GVBl. I 2019, Nr. 3.

1838 Sechstes Gesetz zur Änderung des Sicherheits- und Ordnungsgesetzes v. 22.3.2018, GVBl. S. 114 .

1839 Art. 3 des Gesetzes zur Neuausrichtung des Verfassungsschutzes in Hessen. v. 25.6.2018, GVBl. S. 302.

\section{Nikolas Eisentraut}


Sachsen ${ }^{1843}$, wo u.a. Body-Cams (dazu Rn. 1048) sowie die automatische Erfassung von Autokennzeichnen (dazu Rn. 1048) eingeführt wurden; Eine Kennzeichnungspflicht für Polizisten (dazu Rn. 1026) wurde hingegen nicht eingeführt. ${ }^{1844}$

Neben diesen allgemeinen Gesetzen bestehen spezielle Vorschriften, die das 1013 Recht der Gefahrenabwehr nur für einen bestimmten Sektor regeln. Sie werden als besonderes Gefahrenabwehrrecht bezeichnet. ${ }^{1845}$ Die Unterscheidung spielt aufgrund des Vorrangs spezieller Ermächtigungsgrundlagen vor den Ermächtigungsgrundlagen des allgemeinen Polizei- und Ordnungsrechts eine noch unter „Ermächtigungsgrundlage“ (s. Rn. 1036) zu vertiefende Rolle.

Zum prüfungsrelevanten besonderen Gefahrenabwehrrecht zählt insbeson- 1014 dere das Versammlungsrecht (s. näher Rn. 1037 ff.) und das Bauordnungsrecht (s. näher Rn. 1042).

Examenswissen: Dem besonderen Gefahrenabwehrrecht wird darüber hinaus eine Vielzahl an Verwaltungsbereichen zugeordnet, die zwar in den Ausbildungsordnungen nicht zum Prüfungsgegenstand gemacht werden. Da in Prüfungsarbeiten aber auch unbekannte Normen eine Rolle spielen können (s. § 1 Rn. 19), ist es nicht schädlich, einen Überblick zu haben. Insbesondere dem Gewerberecht ${ }^{1846}$ kommt Bedeutung als besonderes Gefahrenabwehrrecht zu. Aber beispielsweise auch im Luftrecht spielt Gefahrenabwehr eine Rolle. ${ }^{1847}$

\section{bb) Die Unterscheidung zwischen Landes- und Bundesbehörden}

Das allgemeine Polizei- und Ordnungsrecht wird von den Polizei- und Ord- 1016 nungsbehörden der Länder vollzogen. ${ }^{1848}$ Auch die in Klausuren relevanten Bereiche des besonderen Polizei- und Ordnungsrechts wie das Versammlungs-

1840 Gesetz zur Stärkung der Sicherheit in Nordrhein-Westfalen - Sechstes Gesetz zur Änderung des Polizeigesetzes des Landes Nordrhein-Westfalen v. 13.12.2018, GV. NRW. S. 638; näher dazu Coelln/Pernice-Warnke/Pützer/Reisch, NWVBl. 2019, 89; Ullrich/Walter/Zimmermann, NWVBl. 2019, 98; Thiel, NWVBl. 2018, 50.

1841 Gesetz zur Änderung des Niedersächsischen Gesetzes über die öffentliche Sicherheit und Ordnung und anderer Gesetze v. 20.5.2019, GVBl. S. 88.

1842 Siebentes Gesetz zur Änderung des Gesetzes über die öffentliche Sicherheit und Ordnung des Landes Sachsen-Anhalt v. 18.10. 2018, GVBl. S. 376 (kein Onlineangebot).

1843 Gesetz zur Neustrukturierung des Polizeirechtes des Freistaates Sachsen v. 11. Mai 2019, SächsGVBl. S. 358.

1844 Bereits der Referentenentwurf war Gegenstand von Kritik, so u.a. in einer Stellungnahme von Amnesty International v. 8.11.2018.

1845 Schenke, Polizei- und Ordnungsrecht, 10. Aufl. 2018, Rn. 21.

1846 Näher dazu Schenke, Polizei- und Ordnungsrecht, 10. Aufl. 2018, Rn. 21.

1847 Dazu Kaienburg, JA 2019, 119.

1848 Schenke, Polizei- und Ordnungsrecht, 10. Aufl. 2018, Rn. 437; Kingreen/Poscher, Polizeiund Ordnungsrecht mit Versammlungsrecht, 10. Aufl. 2018, § 2 Rn. 33.

Nikolas Eisentraut 
und Bauordnungsrecht werden durch die Landesbehörden vollzogen. Dies gilt im Grundsatz auch dann, wenn es sich um Bundesrecht handelt (etwa das Versammlungsgesetz des Bundes), s. Art. 83 GG. ${ }^{1849} 12$ Bundesländer haben dafür das sog. Trennungssystem realisiert (s. näher Rn. 1066): Polizeibehörden ${ }^{1850}$ und Ordnungsbehörden ${ }^{1851}$ sind danach organisatorisch getrennt (sog. „Entpolizeilichung“1852). Während die Polizei Gefahrenabwehr „am Ort des Geschehens“ betreibt, ist die Tätigkeit der Ordnungsbehörden durch die Tätigkeit „am Schreibtisch“ gekennzeichnet. ${ }^{1853} 4$ Bundesländer (Baden-Württemberg, Bremen, Saarland und Sachsen) haben hingegen das sog. Einheitssystem realisiert (s. auch Rn. 1067): Hier sind die Polizeibehörden den Behörden der allgemeinen Landesverwaltung zugeordnet; Indes wird auch in diesen Ländern zwischen Polizeivollzugsdienst und allgemeinen Polizeibehörden unterschieden. ${ }^{1854}$

1017 Hausarbeitswissen: Daneben nehmen auch Bundesbehörden auf Grundlage der bereichsspezifischen Gesetzgebungskompetenzen des Bundes Aufgaben der Gefahrenabwehr wahr. Dazu zählt zunächst die Bundespolizei, die auf Grundlage des BPolG handelt. ${ }^{1855}$ Weiterhin nimmt das Bundeskriminalamt, das auf Grundlage des BKA-Gesetzes tätig wird, wichtige Aufgaben der Gefahrenabwehr im Bereich des internationalen Terrorismus wahr. ${ }^{1856}$ Auf europäischer Ebene entstehen darüber hinaus zunehmend Strukturen der Zusammenarbeit bei der (grenzüberschreitenden) Gefahrenabwehr. ${ }^{1857}$ Insgesamt lassen sich „Zentralisierungstendenzen“ beobachten, wonach Kompetenzen auf immer höhere Ebenen verlagert werden (sollen). ${ }^{1858}$ Eine absolute Grenze dieser

1849 Kingreen/Poscher, Polizei- und Ordnungsrecht mit Versammlungsrecht, 10. Aufl. 2018, § 2 Rn. 36.

1850 Einen Überblick über die Polizeibehörden der einzelnen Bundesländer findet sich bei Götz/ Geis, Allgemeines Polizei- und Ordnungsrecht, 16. Aufl. 2017, § 20 Rn. 8.

1851 Einen Überblick über die allgemeinen Behörden der Gefahrenabwehr der einzelnen Bundesländer findet sich bei Götz/Geis, Allgemeines Polizei- und Ordnungsrecht, 16. Aufl. 2017, § 20 Rn. 17; zum „Ordnungsrecht“ als selbstständiges Rechtsgebiet Peters/Rind, LKV 2017, 251.

1852 Schenke, Polizei- und Ordnungsrecht, 10. Aufl. 2018, Rn. 449.

1853 Kingreen/Poscher, Polizei- und Ordnungsrecht mit Versammlungsrecht, 10. Aufl. 2018, § 2 Rn. 25.

1854 Götz/Geis, Allgemeines Polizei- und Ordnungsrecht, 16. Aufl. 2017, § 20 Rn. 14; zum Einheitssystem auch näher Schenke, Polizei- und Ordnungsrecht, 10. Aufl. 2018, Rn. 447 f.

1855 Näher Schoch, in: Schoch, Besonderes Verwaltungsrecht, 2018, Kapitel 1 Rn. $94 \mathrm{ff}$.

1856 Näher Schoch, in: Schoch, Besonderes Verwaltungsrecht, 2018, Kapitel 1 Rn. $98 \mathrm{ff}$.; Rn. $102 \mathrm{ff}$. auch zu den weiteren Verwaltungskompetenzen des Bundes.

1857 Näher Schoch, in: Schoch, Besonderes Verwaltungsrecht, 2018, Kapitel 1 Rn. $155 \mathrm{ff}$;; Rn. $181 \mathrm{ff}$. auch zur Internationalisierung; zur „Europäisierungs- und Inernationalisierungstendenz" auch Kingreen/Poscher, Polizei- und Ordnungsrecht mit Versammlungsrecht, 10. Aufl. 2018, § 1 Rn. 35f.

1858 Kingreen/Poscher, Polizei- und Ordnungsrecht mit Versammlungsrecht, 10. Aufl. 2018, § 1 Rn. 33.

\section{Nikolas Eisentraut}


Zentralisierung wird im Verbot der Schaffung einer allgemeinen Bundespolizei gesehen. ${ }^{1859}$ Aufgrund der Klausurrelevanz konzentriert sich die folgende Darstellung jedoch auf die Gefahrenabwehr durch Landesbehörden nach den jeweiligen allgemeinen Polizei- und Ordnungsgesetzen.

\section{cc) Abgrenzung zum Recht der Strafverfolgung}

Die Gefahrenabwehr ist abzugrenzen von der Strafverfolgung. ${ }^{1860}$ Während das 1018 Gefahrenabwehrrecht präventiv auf die Verhinderung einer Gefahr ausgerichtet ist, regelt das Strafverfolgungsrecht das repressive, sich an eine bereits geschehene Straftat anschließende polizeiliche Handeln. ${ }^{1861}$ Der Unterscheidung kommt in der Klausur bereits bei der Frage der Eröffnung des Verwaltungsrechtswegs zentrale Bedeutung zu (s. §1 Rn. 218), denn die gerichtliche Kontrolle repressiver polizeilicher Maßnahmen ist nicht den Verwaltungsgerichten, sondern der ordentlichen Gerichtsbarkeit zugewiesen (§ 23 EGGVG). In der Klausur ist daher bereits bei der Frage der Eröffnung des Verwaltungsrechtswegs zu problematisieren, ob die streitgegenständliche Maßnahme repressiven (dann: abdrängende Sonderzuweisung an die ordentlichen Gerichte) oder präventiven Charakter (dann: keine abdrängende Sonderzuweisung) hat.

Eine besondere Problematik in diesem Kontext stellen die sog. „doppel- 1019 funktionalen Maßnahmen“\$1862 dar. Bei diesen Maßnahmen kommt es zu einer Überschneidung zwischen Gefahrenabwehr- und Strafverfolgungsmaßnahme.

Beispiel: Dies wäre etwa der Fall, wenn eine bei einem Straftäter durchgeführte Identitätsfeststellung sowohl auf die Verfolgung der bereits begangenen Straftat als auch auf die Abwehr künftiger Straftatbegehungen gerichtet wäre.

Mit der wohl überwiegenden Auffassung ist in einem solchen Fall auf den Schwerpunkt der Maßnahme abzustellen; falls ein solcher nicht erkennbar ist, soll dem Gefahrenabwehrrecht Vorrang einzuräumen sein. ${ }^{1863}$

1859 Kingreen/Poscher, Polizei- und Ordnungsrecht mit Versammlungsrecht, 10. Aufl. 2018, § 2 Rn. 40.

1860 Näher Kingreen/Poscher, Polizei- und Ordnungsrecht mit Versammlungsrecht, 10. Aufl. 2018, § 2 Rn. $5 \mathrm{ff}$.

1861 Schoch, in: Schoch, Besonderes Verwaltungsrecht, 2018, Kapitel 1 Rn. 15f.; „der Anfangsverdacht markiert den Beginn der Strafverfolgung (§ 152 II StPO)“, Schoch, in: Schoch, Besonderes Verwaltungsrecht, 2018, Kapitel 1 Rn. 20.

1862 Übergreifend zur Thematik doppelfunktionaler Maßnahmen in der öffentlich-rechtlichen Klausur Danne, JuS 2018, 434.

1863 Schoch, in: Schoch, Besonderes Verwaltungsrecht, 2018, Kapitel 1 Rn. 20; Kingreen/Poscher, Polizei- und Ordnungsrecht mit Versammlungsrecht, 10. Aufl. 2018, § 2 Rn. 14.

Nikolas Eisentraut 
1020 Examenswissen: Das Meinungsbild ist vielschichtig. Teilweise wird bei doppelfunktionalen Maßnahmen auch ein Nebeneinander beider Ermächtigungsgrundlagen und damit auch der Rechtswege (§ 17 II 1 GVG) für möglich gehalten; es genüge, wenn die Voraussetzungen einer Ermächtigungsgrundlage erfüllt seien. ${ }^{1864} \mathrm{Nach}$ a.A. müssen bei „echten“ doppelfunktionalen Maßnahmen (also solchen, die nicht in mehrere, jeweils für sich zu beurteilende Maßnahmen aufgespalten werden können ${ }^{1865}$ ) hingegen die Voraussetzungen beider Ermächtigungsgrundlagen vorliegen. ${ }^{1866}$

1021 Darüber hinaus ist die Unterscheidung deshalb wichtig, weil die Gesetzgebungskompetenz im Bereich der Strafverfolgung der konkurrierenden Gesetzgebungskompetenz und damit im Wesentlichen dem Bund zu gewiesen ist, Art. 74 I Nr. 1 GG. ${ }^{1867}$ In diesen Bereichen bleibt den Ländern daher nur dann noch eine Regelungsbefugnis, wenn der Bund keine abschließenden Regelungen getroffen hat (näher zu dieser Problematik im Bereich der Strafverfolgungsvorsorge Rn. 1027).

\section{dd) Abgrenzung zum Recht der Nachrichtendienste und des Verfassungsschutzes}

1022 Der präventiven Tätigkeit der Gefahrenabwehrbehörden vorgelagert ist die Tätigkeit der Nachrichtendienste und Verfassungsschutzbehörden, da sie insbesondere Informationen im Vorfeld konkreter Gefahrenlagen beschaffen. ${ }^{1868}$

1023 Hausarbeitswissen: Indes sind Tendenzen einer „Entgrenzung“ des Rechts der Nachrichtendienste erkennbar (zu diesem Begriff sogleich noch Rn. 1024f.), ${ }^{1869}$ die zu einer Ausdehnung des Rechts der Nachrichtendienste in Bereiche polizei- und ordnungsbehördlicher Befugnisse führt. Eine verfassungsrechtliche Grenze zwischen Nachrichtendiensten und Polizei- bzw. Ordnungsbehörden wird teilweise im sog. Trennungsgebot gesehen. ${ }^{1870}$

1864 M.w.N. zu dieser Ansicht Kingreen/Poscher, Polizei- und Ordnungsrecht mit Versammlungsrecht, 10. Aufl. 2018, § 2 Rn. 14.

1865 Näher Schoch, in: Schoch, Besonderes Verwaltungsrecht, 2018, Kapitel 1 Rn. 21.

1866 Schoch, in: Schoch, Besonderes Verwaltungsrecht, 2018, Kapitel 1 Rn. 21.

1867 S. auch Schoch, in: Schoch, Besonderes Verwaltungsrecht, 2018, Kapitel 1 Rn. 17.

1868 Näher zu den Nachrichtendiensten und zum Trennungsprinzip Schoch, in: Schoch, Besonderes Verwaltungsrecht, 2018, Kapitel 1 Rn. $30 \mathrm{ff}$; s. auch Kingreen/Poscher, Polizei- und Ordnungsrecht mit Versammlungsrecht, 10. Aufl. 2018, § 2 Rn. $15 \mathrm{ff}$.

1869 So sorgte zuletzt ein Referentenentwurf des Bundesinnenministeriums zur Harmonisierung des Verfassungsschutzrechts für Kontroversen, in dem eine Kompetenzausweitung des Bundesnachrichtendienstes vorgesehen war; der Entwurf wurde auf netzpolitik.org veröffentlicht.

1870 Dazu Schoch, in: Schoch, Besonderes Verwaltungsrecht, 2018, Kapitel 1 Rn. 31 f.

\section{Nikolas Eisentraut}




\section{ee) Gefahrenabwehr im weiteren Sinne: Gefahrenvorsorge vs. Strafverfolgungsvorsorge}

Gefahrenabwehr bildet den Ausgangspunkt jeden polizei- und ordnungsbehördlichen Handelns. ${ }^{1871}$ Dabei bildet die konkrete Gefahr die „traditionelle Eingriffsschwelle im Polizeirecht“"1872. Gefahrenabwehr findet jedoch teilweise bereits im Vorfeld konkreter Gefahren statt: mit der sog. Gefahrenvorsorge soll bereits das Eintreten einer konkreten Gefahrensituation verhindert werden. ${ }^{1873}$ Zur Gefahrenvorsorge zählen Maßnahmen zur Verhütung von Straftaten, wozu insbesondere Überwachungsmaßnahmen (sog. Gefahrerforschungseingriffe) zählen. Darüber hinaus können die im bayerischen Polizeirecht realisierten Eingriffstatbestände bei sog. „drohender Gefahr“ (dazu noch näher Rn. 1116) aber auch zu Präventivhaft führen.

Examenswissen: Diese voranschreitende „Entgrenzung“ des Gefahrenabwehrrechts bedarf unter rechtsstaatlichen Gesichtspunkten einer kritischen Begleitung. ${ }^{1874}$ Die Entgrenzung des Gefahrenabwehrrechts ist nur im Rahmen des rechtsstaatlichen Korsetts möglich, das sich aus Vorrang und Vorbehalt des Gesetzes speist. ${ }^{1875}$ Die Staatsaufgabe der Gewährleistung von Sicherheit (s. bereits Rn. 1009) bewegt sich deshalb stets in einer Spannungslage zu den verfassungsrechtlichen Grenzen eines staatlichen Zugriffs auf persönliche Freiheiten. ${ }^{1876}$ Über das einfache Recht hinaus berühren eingreifende Maßnahmen der Polizei- und Ordnungsbehörden neben der allgemeinen Handlungsfreiheit eine Vielzahl spezieller Grundrechte, die die Auslegung des einfachen Rechts beeinflussen und in verwaltungsrechtlichen Prüfungsarbeiten insbesondere im Rahmen der Verhältnismäßigkeit polizeilicher Maßnahmen eine Rolle spielen können.

Beispiele: Die Durchsuchung von Wohnraum berührt das Grundrecht auf die Unverletzlichkeit der Wohnung aus Art. 13 GG; Freiheitsentziehende Maßnahmen berühren das grundrechts-

1871 Kingreen/Poscher, Polizei- und Ordnungsrecht mit Versammlungsrecht, 10. Aufl. 2018, § 3 Rn. $11 \mathrm{f}$.

1872 Trurnit, JURA 2019, 258 (262).

1873 Schoch, in: Schoch, Besonderes Verwaltungsrecht, 2018, Kapitel 1 Rn. 11; Kingreen/Poscher, Polizei- und Ordnungsrecht mit Versammlungsrecht, 10. Aufl. 2018, §1 Rn. 32; BVerwG, Urt. v. 25.1.2012, Az.: 6 C 9.11 = BVerwGE 141, 329 = NVwZ 2012, 757; dazu Siegel, NVwZ 2012, 738 und Waldhoff, JuS 2013, 94.

1874 Zum Begriff der Entgrenzung grundlegend Thiel, Die „Entgrenzung“ der Gefahrenabwehr, 2011; m.w. N. Schoch, in: Schoch, Besonderes Verwaltungsrecht, 2018, Kapitel 1 Rn. 13; Baldus, Die Verw 47 (2014), 1; Gutachten des Wissenschaftlichen Dienstes des Bundestages WD 33000 226/18 v. 27.7.2018: „Ausweitung polizeilicher Befugnisse in Deutschland und Europa“.

1875 Schoch, in: Schoch, Besonderes Verwaltungsrecht, 2018, Kapitel 1 Rn. 187 f.; umfassend zu den rechtsstaatlichen und demokratischen Grundlagen der Polizeiarbeit Denninger, in: Lisken/ Denninger, Handbuch des Polizeirechts, 6. Aufl. 2018, B., Rn. $24 \mathrm{ff}$.

1876 Becker, NVwZ 2015, 1335. 
gleiche Recht aus Art. 104 GG; ${ }^{1877}$ Überwachungsmaßnahmen berühren das Recht auf informationelle Selbstbestimmung (Art. 2 I i. V.m. Art. 1 I GG), das Fernmeldegeheimnis aus Art. 10 GG und das Grundrecht auf Gewährleistung der Vertraulichkeit und Integrität informationstechnischer Systeme. ${ }^{1878}$

1026 Hausarbeitswissen: Darüber hinaus werden auch ganz konkrete Maßnahmen diskutiert, um die Rechtsstaatlichkeit polizeilichen Handelns sicherzustellen. Gegenstand fortwährenden Streits ist die Frage, ob Polizeivollzugsbeamte einer Kennzeichnungspflicht unterliegen sollten. ${ }^{1879}$ Der damit einhergehende Eingriff in das Recht der Polizisten auf informationelle Selbstbestimmung wird vom $B V e r w G$ als gerechtfertigt angesehen. ${ }^{1880}$ Auch die Nutzung von sozialen Netzwerken durch Polizeiund Ordnungsbehörden wird in Hinblick auf ihre Grenzen untersucht. ${ }^{1881}$

1027 Zum Bereich der vorbeugenden Bekämpfung von Straftaten wird einerseits die Verhütung von Straftaten gezählt, andererseits die sog. Strafverfolgungsvorsorge. ${ }^{1882}$ Die Verhütung zielt darauf $a b$, dass Straftaten schon gar nicht passieren; Die Vorsorge dient hingegen dazu, im Falle trotzdem passierender Straftaten die Strafverfolgung zu vereinfachen. ${ }^{1883}$ Während die Verhütung der Gefahrenabwehr zugerechnet wird und damit in die Länderkompetenz fällt, wird die Strafverfolgungsvorsorge der Bundeskompetenz nach Art. 74 I Nr. 1 GG zugerechnet. ${ }^{1884}$

Examenswissen: Dies führt im Einzelfall zu schwierigen Abgrenzungsfragen. So musste sich das BVerwG etwa mit der Frage auseinandersetzen, ob die landesgesetzlich angeordnete Videobeobachtung auf der Hamburger Reeperbahn als Maßnahme der Gefahrenvorsorge (Verhütung von Straftaten) oder als Strafverfolgungsvorsorge zu qualifizieren sei. Da die Videoüberwachung beide Varianten erfülle, handele es sich um eine doppelfunktionale Maßnahme. Indes ergebe sich aus der konkurrierenden Bundeskompetenz für die Strafverfolgungsvorsorge keine Sperrwirkung in Bereichen, in denen der Bund keine abschließende Regelung erlassen habe. ${ }^{1885}$

1877 Beispiele nach Siegel, in: Siegel/Waldhoff, Öffentliches Recht für Berlin, 2. Aufl. 2017, § 2 Rn. 10.

1878 Näher Becker, NVwZ 2015, 1335; Zu den Auswirkungen des BKAG-Urteils des BVerfG auf das allgemeine Persönlichkeitsrecht Dürr, JA 2019, 432.

1879 Dazu näher Guckelberger, DÖV 2018, 421 und Daimagüler, NVwZ 2018, 1530; Knaust, DVBl 2017, 876.

1880 So für die Kennzeichnungspflicht für Polizeivollzugsbeamte in Brandenburg BVerwG, Urt.v. 26.9.2019, Az.: BVerwG 2 C 32.18.

1881 Näher Milker, NVwZ 2018, 1751; Ingold, VerwArch 2017, 240.

1882 Näher dazu Schoch, in: Schoch, Besonderes Verwaltungsrecht, 2018, Kapitel 1 Rn. $23 \mathrm{ff}$. 1883 Kingreen/Poscher, Polizei- und Ordnungsrecht mit Versammlungsrecht, 10. Aufl. 2018, § 2 Rn. 4.

1884 Kingreen/Poscher, Polizei- und Ordnungsrecht mit Versammlungsrecht, 10. Aufl. 2018, § 2 Rn. 5.

1885 BVerwG, Urt. v. 25.1.2012, Az.: 6 C 9.11 = BVerwGE 141, 329 = NVwZ 2012, 757; dazu Siegel, NVwZ 2012, 738 und Waldhoff, JuS 2013, 94.

\section{Nikolas Eisentraut}




\section{b) Prüfungsstruktur im Überblick}

Die Prüfung der Rechtmäßigkeit einer Ordnungsverfügung im Rahmen der An- 1028 fechtungsklage richtet sich nach dem klassischen Prüfungsschema für Verwaltungsakte (s. bereits Rn. 518ff.). Ein erster Schwerpunkt liegt auf der Ermittlung der einschlägigen Ermächtigungsgrundlage (s. näher sogleich Rn. 1029). Im Rahmen der formellen Rechtmäßigkeit sind die Prüfungspunkte Zuständigkeit, Verfahren und Form zu behandeln (s. näher sogleich Rn. 1062ff.). Im Rahmen der materiellen Rechtmäßigkeit sind die materiellen Voraussetzungen der einschlägigen Ermächtigungsgrundlage zu prüfen und die Rechtsfolge der Ermächtigungsgrundlage zu thematisieren (s. näher sogleich Rn. 1079).

\section{c) Ermächtigungsgrundlage}

Aufgrund des Vorbehalts des Gesetzes erfordern in Grundrechte eingreifende 1029 Gefahrenabwehrmaßnahmen stets das Vorliegen einer Ermächtigungsgrundlage (näher zum Erfordernis einer Ermächtigungsgrundlage Rn. 554 ff.). ${ }^{1886}$ Es reicht also nicht, dass die Polizei- und Ordnungsbehörden generell für die Aufgabe der Gefahrenabwehr zuständig sind. ${ }^{1887}$ Die konkrete Maßnahme muss auch auf Grundlage und unter Einhaltung der Voraussetzungen der jeweils einschlägigen Ermächtigungsgrundlage (auch Befugnisnorm genannt) vorgenommen werden.

In polizeirechtlichen Klausuren besteht neben der prozessualen Einklei- 1030 dung eine zentrale Aufgabe darin, die in Betracht kommenden Ermächtigungsgrundlagen zu erkennen und ordnungsgemäß zu prüfen.

Bevor auf die Ermächtigungsgrundlagen der allgemeinen Polizei- und Ord- 1031 nungsgesetze eingegangen werden kann, ist zunächst zu untersuchen, ob es spezialgesetzliche Befugnisse gibt, die die Ermächtigungsgrundlagen des allgemeinen Polizei- und Ordnungsrechts verdrängen können. ${ }^{1888}$

Findet sich keine spezialgesetzliche Befugnis, können die Ermächtigungs- 1032 grundlagen der allgemeinen Polizei- und Ordnungsgesetze herangezogen werden. Auch hier muss wieder differenziert werden: Alle allgemeinen Polizei- und Ordnungsgesetze unterscheiden zwischen General- und Spezialermächtigun-

1886 Schenke, Polizei- und Ordnungsrecht, 10. Aufl. 2018, Rn. 36f.; Schoch, in: Schoch, Besonderes Verwaltungsrecht, 2018, Kapitel 1 Rn. $187 \mathrm{f}$; Kingreen/Poscher, Polizei- und Ordnungsrecht mit Versammlungsrecht, 10. Aufl. 2018, § 2 Rn. 43.

1887 Sog. Trennung von Aufgabe, Zuständigkeit und Befugnis, näher dazu Schenke, Polizei- und Ordnungsrecht, 10. Aufl. 2018, Rn. 36; Schoch, in: Schoch, Besonderes Verwaltungsrecht, 2018, Kapitel 1 Rn. 189f.; Siegel/Waldhoff, Öffentliches Recht für Berlin, 2. Aufl. 2017, § 2 Rn. $131 \mathrm{ff}$. 1888 Kingreen/Poscher, Polizei- und Ordnungsrecht mit Versammlungsrecht, 10. Aufl. 2018, § 3 Rn. 25. 
gen. ${ }^{1889}$ Zur Erfüllung bestimmter Aufgaben der Gefahrenabwehr (den sog. Standardmaßnahmen) wurden spezielle Ermächtigungsgrundlagen geschaffen (sog. Standardbefugnisse). Als Auffangtatbestand findet sich daneben eine Generalklausel, die subsidiär zur Anwendung kommen kann, falls keine der Standardbefugnisse einschlägig ist.

1033 Schließlich kann schon im Rahmen der Suche nach der tauglichen Ermächtigungsgrundlage berücksichtigt werden, ob die Norm auch die konkret handelnde Behörde ermächtigt. In Ländern mit Trennungsprinzip (näher dazu Rn. 1066) stellt sich regelmäßig die Frage, ob die Befugnisnorm für die Polizei oder die Befugnisnorm für die Ordnungsbehörde einschlägig ist. ${ }^{1890}$

1034 Dieses „Nebeneinander“ macht es in polizeirechtlichen Klausuren oftmals erforderlich, sich zunächst genau mit der Frage auseinanderzusetzen, welche Ermächtigungsgrundlage eigentlich die Richtige ist. ${ }^{1891}$

1035 Examenswissen: Ausnahmsweise kann sich die Ermächtigungsgrundlage auch in einer Gefahrenabwehrverordnung finden. Denn auch Verordnungen genügen dem Vorbehalt des Gesetzes (s. Rn. 561). In Klausuren wäre eine solche regelmäßig als Annex zum Sachverhalt abgedruckt. Es kann dann erforderlich sein, die Verordnung selbst auf ihre Rechtmäßigkeit zu untersuchen (dazu noch näher $\S 7$ Rn. 109 ff.).

\section{aa) Abgrenzung gegenüber Befugnissen des besonderen Gefahrenabwehrrechts}

1036 Bevor die Ermächtigungsgrundlagen des allgemeinen Polizei- und Ordnungsrechts in Betracht gezogen werden, ist zunächst die Frage aufzuwerfen, ob speziellere Normen deren Anwendbarkeit sperren (sog. Spezialbefugnisse) ${ }^{1892}$

\section{(1) Versammlungsrecht}

1037 Besondere Bedeutung kommt dabei zunächst den Ermächtigungsgrundlagen des Versammlungsrechts zu (näher zum Versammlungsrecht Rn. 1141ff.). Die Sperrwirkung des Versammlungsrechts gegenüber dem allgemeinen Polizei- und Ordnungsrecht nennt man „Polizeifestigkeit des Versammlungsrechts“ (s. dazu auch Rn. 1162ff.). Dies bedeutet, dass den versammlungsrechtlichen Eingriffsbefugnissen Vorrang vor denen des allgemeinen Polizei- und Ordnungs-

1889 Schenke, Polizei- und Ordnungsrecht, 10. Aufl. 2018, Rn. 38.

1890 Poscher/Rustenberg, JuS 2011, 888 (890f.).

1891 Siegel, in: Siegel/Waldhoff, Öffentliches Recht für Berlin, 2. Aufl. 2017, § 2 Rn. 134.

1892 Schoch, in: Schoch, Besonderes Verwaltungsrecht, 2018, Kapitel 1 Rn. 196.

Nikolas Eisentraut 
rechts zukommt und letztere „gesperrt“ sind. ${ }^{1893}$ Die genaue Reichweite der Sperrwirkung ist jedoch umstritten: Auch wenn die Ermächtigungsgrundlagen des allgemeinen Polizei- und Ordnungsrechts durch das Versammlungsrecht gesperrt werden, können dessen Vorschriften nämlich lückenfüllend heranzuziehen sein, beispielsweise für die Frage der Bestimmung des richtigen Adressaten. ${ }^{1894}$ Die Abgrenzung ist auch deshalb wichtig, weil das Versammlungsrecht höhere Anforderungen an Eingriffe stellt, als dies die allgemeinen Polizeigesetze tun. ${ }^{1895}$

Die h.M. hält die Regelungen des Versammlungsrechts nur dann für ab- 1038 schließend, wenn es um ,versammlungsspezifische Gefahren“ geht. ${ }^{1896}$ Im Einzelnen können drei Zeitpunkte unterschieden werden: 1. Maßnahmen im Vorfeld einer Versammlung, 2. Maßnahmen während einer Versammlung und 3. Maßnahmen nach der Versammlung.

1. Das VersG des Bundes enthält keine Regelungen für Vorfeldmaßnahmen. 1039 Die h.M. möchte daher den Rückgriff auf die allgemeinen Polizei- und Ordnungsgesetze erlauben, etwa um Personenkontrollen bei der Anreise zur Versammlung und Durchsuchungen sowie Beschlagnahmen $\mathrm{zu}$ ermöglichen; $\mathrm{Zu}$ Maßnahmen im Vorfeld einer Versammlung zählen auch die Meldeauflage und die Gefährderansprache (s. dazu die Rn. 1049, 1055, 1163 und $\S 5$ Rn. 224, 234). ${ }^{1897}$ Soweit mit den Maßnahmen jedoch versammlungsspezifische Gefahren abgewehrt werden sollen, gerät der Rückgriff auf das allgemeine Polizei- und Ordnungsrecht in Konflikt mit dem Zitiergebot des Art. 19 I 2 GG, da ein Eingriff in Art. 8 I GG in Rede steht. Soweit man dennoch mit der h.M. von der Anwendbarkeit der allgemeinen Polizei- und Ordnungsgesetze ausgeht, müssen diese zumindest verfassungskonform ausgelegt werden. ${ }^{1898}$

2. Während der Versammlung ist der Rückgriff auf das allgemeine Polizei- 1040 und Ordnungsrecht gesperrt. Indes sollen nach h.M. unter Rückgriff auf die Ermächtigungsgrundlagen des Versammlungsrechts sog. Minusmaßnahmen möglich sein. ${ }^{1899} \S 15$ III VersG des Bundes ermöglicht danach nicht nur Versammlungsauflösungen, sondern im Sinne einer Generalklausel sämtliche weniger eingriffsintensiven Maßnahmen. ${ }^{1900}$

1893 Bünnigmann, JuS 2016, 695.

1894 Schoch, in: Schoch, Besonderes Verwaltungsrecht, 2018, Kapitel 1 Rn. 222; Siegel, in: Siegel/Waldhoff, Öffentliches Recht für Berlin, 2. Aufl. 2017, § 2 Rn. 135.

1895 Schoch, in: Schoch, Besonderes Verwaltungsrecht, 2018, Kapitel 1 Rn. 210.

1896 Schoch, in: Schoch, Besonderes Verwaltungsrecht, 2018, Kapitel 1 Rn. 217.

1897 Schoch, in: Schoch, Besonderes Verwaltungsrecht, 2018, Kapitel 1 Rn. $218 \mathrm{ff}$.

1898 Bünnigmann, JuS 2016, 695 (697).

1899 Schoch, in: Schoch, Besonderes Verwaltungsrecht, 2018, Kapitel 1 Rn. 221.

1900 Schoch, in: Schoch, Besonderes Verwaltungsrecht, 2018, Kapitel 1 Rn. 221.

Nikolas Eisentraut 
3. Bei Maßnahmen nach der Versammlung greift die Sperrwirkung des Versammlungsrechts nicht mehr, der Anwendungsbereich des allgemeinen Polizei- und Ordnungsrechts ist also wieder eröffnet; Dabei ist es unerheblich, ob die Versammlung durch die Polizei aufgelöst wurde oder ob sich die Teilnehmer`innen nach Durchführung einfach wieder zerstreuen. ${ }^{1901}$

\section{(2) Bauordnungsrecht}

1042 Speziellere Ermächtigungsgrundlagen finden sich zudem im Bauordnungsrecht. Die in den Bauordnungen enthaltenen Ermächtigungsgrundlagen für Abrissverfügungen, Nutzungsuntersagungen und Stilllegungsverfügungen (näher dazu Rn. 1234 ff.) gehen den Ermächtigungsgrundlagen des allgemeinen Polizei- und Ordnungsrechts vor.

\section{(3) Weitere Rechtsbereiche}

1043 In vielen weiteren Rechtsbereichen gibt es Beispiele für Spezialermächtigungen. ${ }^{1902}$ Auch das Gewerberecht sperrt in bestimmten Teilen die Ermächtigungsgrundlagen des allgemeinen Polizei- und Ordnungsrechts. § 1 I GewO sperrt die Gesetzgebungskompetenz der Länder (Art. 74 I Nr. 11, 72 I GG) für die Frage des „ob“ einer gewerblichen Tätigkeit; Im Bereich der Ausübung des Gewerbes („wie“) kann jedoch Landesordnungsrecht zum Tragen kommen. ${ }^{1903}$ Die Untersagung eines ohne erforderliche Zulassung betriebenen Gewerbes erfolgt daher auf Grundlage des § 15 I 2 GewO; da die Norm die Frage betrifft, „ob“ ein Gewerbe ausgeübt werden darf, sperrt sie den Rückgriff auf das landesrechtliche Gefahrenabwehrrecht. ${ }^{1904}$ Gleiches gilt für § 35 I 1 GewO bei der Gewerbeuntersagung wegen Unzuverlässigkeit. Ein Rückgriff auf das allgemeine Polizei- und Ordnungsrecht kommt hingegen bei Maßnahmen in Betracht, die die Ausübung des Gewerbes betreffen sowie bei eiligen bzw. vorläufigen Maßnahmen. ${ }^{1905}$

1901 Schoch, in: Schoch, Besonderes Verwaltungsrecht, 2018, Kapitel 1 Rn. 223.

1902 S. etwa § 24 BImSchG; weitere Beispiele bei Schoch, in: Schoch, Besonderes Verwaltungsrecht, 2018, Kapitel 1 Rn. $200 \mathrm{ff}$.

1903 Korte, in: Schmidt/Wollenschläger, Kompendium Öffentliches Wirtschaftsrecht, 4. Aufl. 2016, § 9 Rn. 39.

1904 Schoch, in: Schoch, Besonderes Verwaltungsrecht, 2018, Kapitel 1 Rn. 200 m.w. N.

1905 Korte, in: Schmidt/Wollenschläger, Kompendium Öffentliches Wirtschaftsrecht, 4. Aufl. 2016, § 9 Rn. 39. 


\section{bb) Abgrenzung zwischen Generalklausel(n) und Standardbefugnissen}

Ist keine Ermächtigungsgrundlage des besonderen Gefahrenabwehrrechts ein- 1044 schlägig, kommen die Ermächtigungsgrundlagen der allgemeinen Polizei- und Ordnungsgesetze in Betracht. Auch innerhalb des allgemeinen Polizei- und Ordnungsrechts bestehen Spezialitätsverhältnisse. Die sog. Generalklausel darf als Auffangtatbestand nur dann als Ermächtigungsgrundlage herangezogen werden, wenn nicht eine spezialgesetzliche Standardbefugnis die Voraussetzungen für den Eingriff normiert. ${ }^{1906}$

\section{(1) Die Standardbefugnisse}

Der Begriff der Standardbefugnisse bezeichnet häufig vorkommende und $\mathbf{1 0 4 5}$ deshalb vom Gesetzgeber in den allgemeinen Polizei- und Ordnungsgesetzen speziell geregelte Gefahrenabwehrmaßnahmen. ${ }^{1907}$

Unterschieden werden kann zwischen Gefahrenabwehrmaßnahmen, die auf 1046 eine Person oder Sache einwirken und Maßnahmen zur Datenerhebung und verarbeitung, die einen Bezug zu Daten aufweisen. Die Gruppierung der Standardbefugnisse variiert jedoch von Lehrbuch zu Lehrbuch.

\section{(a) Gefahrenabwehrmaßnahmen, die auf eine Person oder Sache einwirken} Für folgende auf eine Person oder Sache einwirkende Maßnahmen sind 1047 spezifische Ermächtigungsgrundlagen in den allgemeinen Polizei- und Ordnungsgesetzen kodifiziert worden:

- Platzverweisungen, ${ }^{1908}$ Aufenthaltsverbote ${ }^{1909}$ und Wohnungsverweisungen $^{1910}$, Kontaktverbote und elektronische Aufenthaltsüberwachung ${ }^{1911}$

- Ingewahrsamnahme ${ }^{1912}$

1906 Schoch, in: Schoch, Besonderes Verwaltungsrecht, 2018, Kapitel 1 Rn. 225 f.

1907 Schoch, in: Schoch, Besonderes Verwaltungsrecht, 2018, Kapitel 1 Rn. 225 spricht von wiederkehrenden, typisierbaren Handlungsmustern der Gefahrenabwehrbehörden; Kingreen/ Poscher, Polizei- und Ordnungsrecht mit Versammlungsrecht, 10. Aufl. 2018, § 11 Rn. 1 sprechen von Spezialbefugnissen.

1908 Näher Kingreen/Poscher, Polizei- und Ordnungsrecht mit Versammlungsrecht, 10. Aufl. 2018, § 15.

1909 Näher Kingreen/Poscher, Polizei- und Ordnungsrecht mit Versammlungsrecht, 10. Aufl. 2018, § 15; Benrath, DVBl 2017, 868; Eine Falllösung zu einem Aufenthaltsverbot findet sich bei Bretthauer, JURA 2018, 409 sowie bei Marxsen, JURA 2019, 105.

1910 Näher Kingreen/Poscher, Polizei- und Ordnungsrecht mit Versammlungsrecht, 10. Aufl. 2018, § 15; Seibert/Kohal, JURA 2019, 15. 
Examenswissen: Die Präventivhaft für Fußballhooligans war zuletzt Gegenstand einer Entscheidung des EGMR. ${ }^{1913}$

\section{- Sicherstellung und Beschlagnahme von Sachen ${ }^{1914}$}

Examenswissen: In Bremen und Hamburg ist die polizeiliche Unterbringung von Flüchtlingen spezialgesetzlich geregelt worden, während sie in anderen Bundesländern nur auf Grundlage der Generalklausel erfolgen kann. ${ }^{1915}$

- Verwertung, Einziehung und Vernichtung ${ }^{1916}$

- Durchsuchungen und Untersuchungen von Personen und Sachen ${ }^{1917}$ und das Betreten und die Durchsuchung von Wohnungen ${ }^{1918}$

\section{(b) Datenerhebung und Datenverarbeitung}

1048 Unter dem „Cluster“ Datenerhebung und Datenverarbeitung lässt sich eine Vielzahl an weiteren Standardbefugnissen zusammenfassen:

- Befragungen ${ }^{1919}$

- Identitätsfeststellungen ${ }^{1920}$

Examenswissen: Ein aktuell viel diskutiertes Thema im Kontext von Identitätsfeststellungen ist das sog. „racial profiling“, wenn beispielsweise der Eindruck entsteht, eine Identitätsfeststellung werde nur aufgrund der Hautfarbe durchgeführt. Die Anknüpfung an ein Merkmal des

1911 Näher Schenke, Polizei- und Ordnungsrecht, 10. Aufl. 2018, Rn. 139 f.; Guckelberger, DVBl 2017, 1121.

1912 Näher Schenke, Polizei- und Ordnungsrecht, 10. Aufl. 2018, Rn. 141 ff.; Kingreen/Poscher, Polizei- und Ordnungsrecht mit Versammlungsrecht, 10. Aufl. 2018, § 16.

1913 EGMR, Urt. v. 22.10.2018, Az.: 35553/12, 36678/12, 36711/12 (S, V u. A / Dänemark) = NVwZ 2019, 135 mit. Anm. Hoffmann.

1914 Näher Schenke, Polizei- und Ordnungsrecht, 10. Aufl. 2018, Rn. 158ff.; Kingreen/Poscher, Polizei- und Ordnungsrecht mit Versammlungsrecht, 10. Aufl. 2018, § 18.

1915 Dazu näher Guckelberger/Kollmann/Schmidt, DVBl. 2016, 1088; eine Fallösung zur Unterbringung geflüchteter Menschen auf Grundlage der polizeilichen Generalklausel findet sich bei Fontana/Klein, JA 2017, 846.

1916 Näher Schenke, Polizei- und Ordnungsrecht, 10. Aufl. 2018, Rn. $165 \mathrm{ff}$.

1917 Näher Schenke, Polizei- und Ordnungsrecht, 10. Aufl. 2018, Rn. 147 ff.; Kingreen/Poscher, Polizei- und Ordnungsrecht mit Versammlungsrecht, 10. Aufl. 2018, § 17.

1918 Näher Schenke, Polizei- und Ordnungsrecht, 10. Aufl. 2018, Rn. 152ff.; Kingreen/Poscher, Polizei- und Ordnungsrecht mit Versammlungsrecht, 10. Aufl. 2018, § 17 Rn. $19 \mathrm{ff}$.

1919 Näher Kingreen/Poscher, Polizei- und Ordnungsrecht mit Versammlungsrecht, 10. Aufl. 2018, § 13 Rn. 1 ff.

1920 Näher Schenke, Polizei- und Ordnungsrecht, 10. Aufl. 2018, Rn. 119 ff.; Kingreen/Poscher, Polizei- und Ordnungsrecht mit Versammlungsrecht, 10. Aufl. 2018, § 13 Rn. 30 ff.

Nikolas Eisentraut 
Art. 3 III 1 GG ist zwar grundsätzlich verboten, eine Anknüpfung kann jedoch als Teil eines Motivbündels unter strengen Voraussetzungen gerechtfertigt sein. ${ }^{1921}$

Examenswissen: Mit dem „racial profiling“ im Zusammenhang steht auch die Identitätsfeststellung an sog. „gefährlichen Orten“, weil die Standardbefugnisse hierfür weder ein verdächtiges Verhalten der kontrollierten Person noch eine konkrete Gefahr erfordern - Anknüpfungspunkt für Kontrollen sind daher oftmals an Art. 3 III 1 GG zu messende Kriterien. ${ }^{1922}$ Damit im Zusammenhang steht wiederum die sog. Schleierfahndung, bei der Identitätsfeststellungen ohne konkrete Gefahr ermöglicht werden. ${ }^{1923}$

\section{- $\quad$ erkennungsdienstliche Maßnahmen ${ }^{1924}$}

Examenswissen: Nicht nur die Polizei- und Ordnungsgesetze der Länder, sondern auch die StPO sieht eine Befugnisnorm für erkennungsdienstliche Maßnahmen vor. § 81b Alt. 2StPO ermöglicht die erkennungsdienstliche Behandlung von „Beschuldigten“. Obwohl in der StPO geregelt, wird die Vorschrift dem Gefahrenabwehrrecht zugeordnet; Da sie aber zugleich der Strafverfolgungsvorsorge zugeordnet wird, durfte der Bund eine Regelung in der StPO treffen. ${ }^{1925}$ Die Vorschrift beschränkt den Anwendungsbereich entsprechender landesrechtlicher Standardbefugnisse, soweit es um „Beschuldigte“ geht. Der Beschuldigtenbegriff wurde zuletzt vom BVerwG sehr weit ausgelegt. ${ }^{1926}$

\section{- Vorladung $^{1927}$ \\ - Videoüberwachung ${ }^{1928}$}

Examenswissen: Im Kontext der Videoüberwachung spielen zurzeit sog. Body-Cams eine Rolle. Hierbei handelt es sich um von Polizeibeamten körpernah getragene Bild- und Tonaufzeichnungsgeräte. Immer mehr Länder schaffen Standardbefugnisse für den Einsatz solcher Bodycams. ${ }^{1929}$

1921 Dazu zuletzt OVG NRW, Urt.v. 7.8.2018, Az.: 5 A 294/16 = NVwZ 2018, 1497; Besprechung des Urteils von Hebeler, JA 2019, 237; eine Examensklausur zum Thema Racial Profiling findet sich bei Schneider/Olk, JURA 2018, 936.

1922 Kritisch Tomerius, DVBl 2017, 1399.

1923 Dazu Michl, DÖV 2018, 50.

1924 Näher Schenke, Polizei- und Ordnungsrecht, 10. Aufl. 2018, Rn. 125 ff.; Kingreen/Poscher, Polizei- und Ordnungsrecht mit Versammlungsrecht, 10. Aufl. 2018, § 13 Rn. 59 ff.

1925 Harnisch/Urbanek, DÖV 2018, 229 (229f.).

1926 BVerwG, Urt. v. 27.06.2018, Az. 6 C 39.16 = NJW 2018, 3194.

1927 Näher Schenke, Polizei- und Ordnungsrecht, 10. Aufl. 2018, Rn. 130 ff.; Kingreen/Poscher, Polizei- und Ordnungsrecht mit Versammlungsrecht, 10. Aufl. 2018, § 13 Rn. 76 ff.

1928 Näher Kingreen/Poscher, Polizei- und Ordnungsrecht mit Versammlungsrecht, 10. Aufl. 2018, § 13 Rn. 96 ff.; Ogorek, DÖV 2018, 688.

1929 Einen Überblick geben Köhler/Thielicke, NVwZ-Extra 13/2019, 1; s. auch Lachenmann, NVwZ 2017, 1424; Martini/Nink/Wenzel, NVwZ 2016, 1772; speziell zu §15c PolG NRW Arzt/ Schuster, DVBl 2018, 351. 
- Rasterfahndung ${ }^{1930}$ und weitere Verkehrskontrollen ${ }^{1931}$

Examenswissen: Zuletzt hat das BVerfG landesrechtliche Normen der Polizei- und Ordnungsgesetze zum Teil für verfassungswidrig erklärt, die automatische Kennzeichenerfassungen ermöglichten. ${ }^{1932}$

- Observationen ${ }^{1933}$

- verdeckte Datenerhebungen in oder aus Wohnungen ${ }^{1934}$

- Einsatz von verdeckten Ermittlern ${ }^{1935}$ und V-Leuten ${ }^{1936}$

- Datenerhebungen aus der Telekommunikation ${ }^{1937}$

- Online-Durchsuchungen ${ }^{1938}$

1049 Eine besondere Problematik stellt die Frage dar, ab wann der Gesetzgeber eine Gefahrenabwehrmaßnahme standardisieren muss und ein Rückgriff auf die Generalklausel deshalb unzulässig ist. Beispielsweise konnten bis 2007 Videoüberwachungen auf die allgemeinen Datenerhebungsklauseln gestützt werden; ein Urteil des BVerfG ${ }^{1939}$ hat jedoch dazu geführt, dass die Videoüberwachung nunmehr in allen Polizei- und Ordnungsgesetzen als Standardmaßnahme aufgenommen wurde. ${ }^{1940}$ Unter besonderen Umständen kann der Gesetzgeber also zur Schaffung einer Standardmaßnahme verpflichtet sein. ${ }^{1941}$

1930 Näher Schenke, Polizei- und Ordnungsrecht, 10. Aufl. 2018, Rn. $213 \mathrm{ff}$.

1931 Näher Kingreen/Poscher, Polizei- und Ordnungsrecht mit Versammlungsrecht, 10. Aufl. 2018, § 13 Rn. $14 \mathrm{ff}$.

1932 BVerfG, Beschluss v. 18.12.2018, Az.: 1 BvR 142/15 = NVwZ 2019, 381; dazu Roggan, NVwZ 2019, 344.

1933 Näher Kingreen/Poscher, Polizei- und Ordnungsrecht mit Versammlungsrecht, 10. Aufl. 2018, § 13 Rn. $105 \mathrm{ff}$.

1934 Näher Kingreen/Poscher, Polizei- und Ordnungsrecht mit Versammlungsrecht, 10. Aufl. 2018, § 13 Rn. $128 \mathrm{ff}$.

1935 Dazu Höhnerlein, NVwZ 2016, 511.

1936 Näher Schenke, Polizei- und Ordnungsrecht, 10. Aufl. 2018, Rn. $198 \mathrm{ff}$.

1937 Näher Kingreen/Poscher, Polizei- und Ordnungsrecht mit Versammlungsrecht, 10. Aufl. 2018, § 13 Rn. $137 \mathrm{ff}$.

1938 Näher Kingreen/Poscher, Polizei- und Ordnungsrecht mit Versammlungsrecht, 10. Aufl. 2018, § 13 Rn. $147 \mathrm{ff}$.

1939 BVerfG, Beschl. v. 23.2.2007, Az.: 1 BvR 2368/06 = DÖV 2007, 606.

1940 Siegel, in: Siegel/Waldhoff, Öffentliches Recht für Berlin, 2. Aufl. 2017, § 2 Rn. 138.

1941 Schoch, in: Schoch, Besonderes Verwaltungsrecht, 2018, Kapitel 1 Rn. 227.

Nikolas Eisentraut 
Beispiele: Ob die Landesgesetzgeber zur Schaffung von Standardbefugnissen verpflichtet sind, wird aktuell in Hinblick auf die sog. Meldeauflage, ${ }^{1942}$ die Gefährderansprache ${ }^{1943}$ und die Unterbringung von geflüchteten Menschen ${ }^{1944}$ diskutiert. Auch Gesichtserkennungssysteme, wie sie zuletzt am Berliner Bahnhof Südkreuz getestet wurden, sind in die Diskussion geraten. ${ }^{1945}$ Weiterhin wird die Schaffung von Standardbefugnissen für Body-Cams (s. Rn. 1048) diskutiert. ${ }^{1946}$ Schließlich kann sich die Frage auch bei auf die Generalklausel gestützten Stadionverboten für Hooligans stellen. ${ }^{1947}$

Der Gesetzgeber verfügt insoweit über eine Einschätzungsprärogative; eine Pflicht zur Standardisierung kann sich jedoch aus der Qualität des Grundrechtseingriffs ergeben: Je tiefgreifender eine Freiheitsbeeinträchtigung ist, desto eher bedarf es einer klar konturierten Eingriffsgrundlage (Bestimmtheitsgebot). 1948

Die Standardmaßnahmen genießen Vorrang vor der Generalklausel. Der 1050 Rückgriff auf die Generalklausel ist also immer dann gesperrt, wenn eine Maßnahme in den Anwendungsbereich einer Standardbefugnis fällt. Dafür ist auf das in der Standardbefugnis genannte Mittel abzustellen. ${ }^{1949}$ Erforderlich ist eine Auslegung, um die Reichweite der von der Standardbefugnis erfassten und damit für die Generalklausel gesperrten Sachverhalte zu ermitteln. ${ }^{1950}$

Examenswissen: Darüber hinaus wird diskutiert, ob die Sperrwirkung auch über den Anwendungsbereich einer Standardbefugnis hinaus zu erweitern ist, wenn eine Maßnahme, die auf die Generalklausel gestützt werden soll, von der Eingriffsintensität gleich oder höher als die der Standardmaßnahme ist. ${ }^{1951}$ Solange eine Maßnahme jedoch nicht typisiert werden muss (s. dazu Rn. 1049), spricht nichts gegen die Anwendung der Generalklausel. ${ }^{1952}$

1942 Die Meldeauflage wurde bisher nur in Rheinland-Pfalz standardisiert, während Meldeauflagen in anderen Bundesländern bisher auf die Generalklausel gestützt werden. Für eine Standardisierung Schoch, in: Schoch, Besonderes Verwaltungsrecht, 2018, Kapitel 1 Rn. 228.

1943 Die Forderung nach einer Standardisierung unterstützend Schoch, in: Schoch, Besonderes Verwaltungsrecht, 2018, Kapitel 1 Rn. 229.

1944 Offen lassend OVG Lüneburg, Beschl.v. 1.12.2015, Az.: 11 ME 230/15 = DVBl 2016, 116.

1945 Dazu näher Roggan, NVwZ 2019, 344 (346f.).

1946 Roggan, NVwZ 2019, 344 (346).

1947 Dazu näher Siegel, NJW 2013, 1035 (1037).

1948 Schoch, in: Schoch, Besonderes Verwaltungsrecht, 2018, Kapitel 1 Rn. 230.

1949 Kingreen/Poscher, Polizei- und Ordnungsrecht mit Versammlungsrecht, 10. Aufl. 2018, § 5 Rn. 14.

1950 Näher dazu Möstl, JURA 2011, 811 (842f.).

1951 Zum Streistand näher Roscher/Rustenberg, JuS 2011, 888 (892); s. auch Kingreen/Poscher, Polizei- und Ordnungsrecht mit Versammlungsrecht, 10. Aufl. 2018, § 5 Rn. $16 \mathrm{ff}$.

1952 In diesem Sinne auch Kingreen/Poscher, Polizei- und Ordnungsrecht mit Versammlungsrecht, 10. Aufl. 2018, § 5 Rn. 20. 


\section{(2) Die Generalklausel(n)}

1052 Ist weder eine Befugnis des besonderen Gefahrenabwehrrechts, noch eine Spezialbefugnis des Allgemeinen Polizei- und Ordnungsrechts einschlägig, ist der Weg zur Generalklausel frei. Die allgemeinen Polizei- und Ordnungsgesetze der Länder kennen mehrere generalklauselartige Eingriffsermächtigungen.

1053 Zentrale Bedeutung kommt der Generalklausel für Eingriffsmaßnahmen im Einzelfall zu. In allen Landesgesetzen findet sich eine Regelung, wonach die zuständige Behörde die notwendigen Maßnahmen treffen kann, um eine im einzelnen Falle bestehende Gefahr für die öffentliche Sicherheit (oder Ordnung) abzuwehren:

\begin{tabular}{|c|c|}
\hline Baden-Württemberg & § 3 i.V.m. § 1 I 1 PolG BW \\
\hline Bayern & Art. 11 BayPAG / Art. 7 II i. V. m. Art. 6 BayLStVG \\
\hline Berlin & § 17 I ASOG \\
\hline Brandenburg & $\S 10$ I BbgPolG / § 13 I BbgOBG \\
\hline Bremen & $\S 10$ I 1 BremPolG (ohne öffentliche Ordnung) \\
\hline Hamburg & $\S 3$ I HmbSOG \\
\hline Hessen & $\S 11$ HessSOG \\
\hline Mecklenburg-Vorpommern & $\S 13$ SOG MV \\
\hline Niedersachsen & $\S 11$ i.V.m. § 2 Nr. 1 lit. a NdsSOG \\
\hline Nordrhein-Westfalen & § 8 I PolG NW / § 14 I OBG NW \\
\hline Rheinland-Pfalz & $\S 9$ I 1 POG RP \\
\hline Saarland & $\S 8$ I PolG SL \\
\hline Sachsen & §3। SächsPolG \\
\hline Sachsen-Anhalt & $\S 13$ i.V.m. § 3 Nr. 3 lit. a SOG LSA \\
\hline Schleswig-Holstein & $\S 174$ LVwG SH (ohne öffentliche Ordnung) \\
\hline Thüringen & $\S 12$ I und 2 ThürPAG / § 5 I ThürOBG \\
\hline BUND & § 14 I und II 1 BPolG / § 38 BKAG \\
\hline
\end{tabular}

1054 Der Generalklausel kommt für das gesamte Gefahrenabwehrrecht eine zentrale Funktion als „Strukturierungsmodell“1953 $\mathrm{zu}$. Denn auch die überwiegenden Standard- und Spezialbefugnisse folgen in der Prüfungsstruktur der General-

1953 Schoch, in: Schoch, Besonderes Verwaltungsrecht, 2018, Kapitel 1 Rn. 240. 
klausel: Erforderlich ist regelmäßig, dass auf Tatbestandsseite eine Gefahr für eine Schutzgut vorliegt, woraufhin auf Rechtsfolgenseite Ermessen eröffnet wird. ${ }^{1954}$ Für Klausuren ist es daher unabdingbar, die Prüfungsstruktur der Generalklausel zu beherrschen. Diese wird - anders als die Standardbefugnisse deshalb auch vertieft dargestellt (s. sogleich Rn. 1081ff.).

Examenswissen: Ein aktuell besonders häufig diskutierter Anwendungsfall, bei dem gestützt auf die Generalklausel ein Verwaltungsakt ergeht, ist die sog. Meldeauflage. ${ }^{1955}$ Zuletzt ist zudem über die Zulässigkeit der Unterbringung von geflüchteten Menschen auf Grundlage der Generalklausel diskutiert worden. ${ }^{1956}$

Eine häufig diskutierte Frage ist, ob gegen Generalklauseln verfassungsrechtli- 1056 che Bedenken bestehen. Da die Generalklausel jedoch „in jahrzehntelanger Entwicklung durch Rechtsprechung und Lehre nach Inhalt, Zweck und Ausmaß hinreichend präzisiert, in ihrer Bedeutung geklärt und im juristischen Sprachgebrauch verfestigt“"1957 ist, wird sie als verfassungsmäßig angesehen. ${ }^{1958}$ Zweifel an der Verfassungsmäßigkeit des Tatbestandsmerkmals der „öffentlichen Ordnung“ stellen nicht die gesamte Generalklausel in Frage (näher noch zu diesem Tatbestandsmerkmal Rn. 1097 ff.). ${ }^{1959}$

Daneben enthalten die Polizeigesetze auch Generalklauseln für die Datenbzw. Informationserhebung und -verarbeitung. ${ }^{1960}$

Schließlich gibt es in den meisten Polizei- und Ordnungsgesetzen (mit Aus- 1058 nahme von Bayern) eine Generalklausel für die abstrakt-generelle Gefahrenabwehr mittels Erlasses von Rechtsverordnungen (s. näher zur Prüfung der Rechtmäßigkeit von Gefahrenabwehrverordnungen § 7 Rn. 109 ff.). ${ }^{1961}$

1954 Schoch, in: Schoch, Besonderes Verwaltungsrecht, 2018, Kapitel 1 Rn. 240.

1955 Näher zur Meldeauflage Benrath, DVBl 2017, 868; Siegel, NJW 2013, 1035 (1037 f.); Schucht, NVwZ 2011, 709; Falllösungen zur Meldeauflage finden sich bei Marxsen, JURA 2019, 105 und bei Schneider, ZJS 2008, 281.

1956 Näher Guckelberger/Kollmann/Schmidt, Polizeiliche Unterbringung von Flüchtlingen in privaten Immobilien, DVBl. 2016, 1088; eine Fallösung zur Unterbringung geflüchteter Menschen auf Grundlage der polizeilichen Generalklausel findet sich bei Fontana/Klein, JA 2017, 846.

1957 So BVerfG, Beschl. v. 23.5.1980, Az.: 2 BvR 854/79 = BVerfGE 54, 143 (144f.).

1958 Schoch, in: Schoch, Besonderes Verwaltungsrecht, 2018, Kapitel 1 Rn. 241; Schenke, Polizei- und Ordnungsrecht, 10. Aufl. 2018, Rn. 49.

1959 Kingreen/Poscher, Polizei- und Ordnungsrecht mit Versammlungsrecht, 10. Aufl. 2018, § 5 Rn. 5.

1960 Kingreen/Poscher, Polizei- und Ordnungsrecht mit Versammlungsrecht, 10. Aufl. 2018, § 5 Rn. 2 und näher $\S 12$.

1961 Schoch, in: Schoch, Besonderes Verwaltungsrecht, 2018, Kapitel 1 Rn. 232; Kingreen/Poscher, Polizei- und Ordnungsrecht mit Versammlungsrecht, 10. Aufl. 2018, § 23 Rn. 1.

Nikolas Eisentraut 
cc) Die zwangsweise Durchsetzung des allgemeinen Polizei- und Ordnungsrechts

1059 Eine Sonderkonstellation bilden Fälle, in denen es um die zwangsweise Durchsetzung von Maßnahmen der Polizei- und Ordnungsbehörden geht.

Beispiel: Ein Platzverweis wird vom Polizeibeamten ausgesprochen (= Verwaltungsakt). Der renitente $R$ bewegt sich jedoch nicht von der Stelle. Daraufhin wird er vom Polizeibeamten vom Platz getragen.

1060 Als Ermächtigungsgrundlage für die Vollstreckung von Maßnahmen kommen teilweise die Standardbefugnisse selbst in Betracht. So liegt es bei der Ingewahrsamnahme, der Durchsuchung und der Sicherstellung: Die Ermächtigungsgrundlagen enthalten hier zugleich die Ermächtigung zu ihrer faktischen Durchsetzung. ${ }^{1962}$

1061 In der Regel bedarf die Vollstreckung aber einer eigenen Ermächtigungsgrundlage (zur Abgrenzung von Verwaltungsvollstreckungsrecht und polizeirechtlichen Standardmaßnahmen näher Rn. 1300). In Betracht kommt einerseits die Ermächtigungsgrundlage für die sog. unmittelbare Ausführung, die in den Polizei- und Ordnungsgesetzen zu finden ist; Andererseits kann die Vollstreckung auch auf Grundlage des VwVG erfolgen (näher zur Abgrenzung Rn. 1350 ff.).

\section{d) Formelle Rechtmäßigkeit}

1062 Bevor die materiellen Voraussetzungen und die Rechtsfolge der Ermächtigungsgrundlage geprüft werden, ist der Verwaltungsakt zunächst auf seine formelle Rechtmäßigkeit zu untersuchen.

\section{aa) Zuständigkeit}

1063 Unter der Überschrift „Zuständigkeit“ ist zu klären, ob die im Sachverhalt handelnde Behörde sachlich, örtlich und instantiell zuständig war, den Verwaltungsakt zu erlassen. ${ }^{1963}$

Ein Verstoß gegen die Zuständigkeitsregelungen führt im Grundsatz zur Rechtswidrigkeit, kann aber auch zur Nichtigkeit des Verwaltungsakts führen (s. näher § 6 Rn. 127).

1962 Kingreen/Poscher, Polizei- und Ordnungsrecht mit Versammlungsrecht, 10. Aufl. 2018, § 27 Rn. 19.

1963 Peine/Siegel, Allgemeines Verwaltungsrecht, 12. Aufl. 2018, Rn. 470.

Nikolas Eisentraut 
Sollte im Sachverhalt vorgegeben sein, dass die zuständige Behörde gehandelt hat, muss auf diese Frage nicht näher eingegangen werden (s. § 1 Rn. 25); es kann jedoch ergänzend kurz festgestellt werden, wer diese Behörde ist.

Die Frage der Zuständigkeit ist im Ausgangspunkt nach den allgemeinen 1064 Grundsätzen des Verwaltungsorganisationsrechts zu lösen (s. Rn. 580 ff.). Im Polizei- und Ordnungsrecht ist bei der Bestimmung der zuständigen Behörde darüber hinaus Folgendes zu beachten.

\section{(1) Sachliche Zuständigkeit}

Zunächst ist zu untersuchen, ob die sachlich zuständige Behörde gehandelt hat. 1065 Die Behörde ist sachlich zuständig, wenn sie berechtigt ist, den Aufgabenbereich wahrzunehmen. Untersucht werden sollte dafür die Frage, ob die Ordnungsbehörden oder die Polizei sachlich zuständig sind. Teilweise ist in den Bundesländern das sog. Trennsystem, teilweise das sog. Einheitssystem realisiert worden:

Beim Trennungssystem wird zwischen Ordnungsbehörden und Polizei un- 1066 terschieden. Während die Ordnungsbehörden Gefahrenabwehr „,vom Schreibtisch aus“ betreiben, ist die Polizei „vor Ort“ tätig. ${ }^{1964}$ Teilweise wurden für Polizei und Ordnungsbehörden sogar jeweils eigene Gesetze erlassen (s. die Übersicht in Rn. 1012). In Bundesländern mit Trennungsprinzip ist daher zu untersuchen, ob die Polizei oder die Ordnungsbehörden sachlich zuständig sind. Während im Grundsatz die Ordnungsbehörden zuständig sind (Subsidiarität der Polizei gegenüber den Ordnungsbehörden), ${ }^{1965}$ kann aufgrund besonderer Regelung ausnahmsweise eine originäre oder Eilzuständigkeit der Polizei begründet sein. ${ }^{1966}$ An die Trennung anknüpfend muss im Einzelfall geprüft werden, ob die Ermächtigungsgrundlage die Zuständigkeit auf die Polizei oder die Ordnungsbehörden beschränkt oder ob beide Behörden parallel zuständig sind.

Beispiel: In Berlin darf die Ingewahrsamnahme von Personen nach $\S 30$ I ASOG Bln nur durch die Polizei vorgenommen werden.

1964 Siegel, in: Siegel/Waldhoff, Öffentliches Recht für Berlin, 2. Aufl. 2017, § 2 Rn. 28.

1965 Kingreen/Poscher, Polizei- und Ordnungsrecht mit Versammlungsrecht, 10. Aufl. 2018, § 3 Rn. 19.

1966 Für Berlin Siegel, in: Siegel/Waldhoff, Öffentliches Recht für Berlin, 2. Aufl. 2017, § 2 Rn. $29 \mathrm{ff}$. 
1067 In Bundesländern mit Einheitssystem erfolgt eine solche Trennung nicht. Innerhalb der Polizei wird aber auch in diesen Ländern zwischen den Polizeiverwaltungsbehörden und dem Polizeivollzugsdienst unterschieden. ${ }^{1967}$

1068 Weiterhin besteht nach den sog. Privatrechtsklauseln der Polizei- und Ordnungsgesetze eine Subsidiarität der Tätigkeit der Polizei- und Ordnungsbehörden gegenüber der ordentlichen Gerichtsbarkeit. ${ }^{1968}$ Die Privatrechtsklauseln ordnen dafür an, dass der Schutz privater Rechte nur dann den Polizei- und Ordnungsbehörden obliegt, wenn gerichtlicher Schutz nicht rechtzeitig zu erlangen ist und wenn ohne Hilfe durch die Polizei- oder Ordnungsbehörden eine Rechtsvereitelung drohte. ${ }^{1969}$ Auch wenn die Privatrechtsklausel teilweise dem Wortlaut nach nur auf die Polizei erstreckt wird, soll sie erst Recht für die Tätigkeit der Ordnungsbehörden gelten. ${ }^{1970}$ Die Privatrechtsklausel ist nur dann einschlägig, wenn es allein um den Schutz privater Rechte geht; die Klausel läuft daher bei den typischerweise betroffenen Rechtsgütern Leib, Leben, Freiheit, Ehre und Eigentum leer, weil Angriffe darauf auch straf- oder öffentlich-rechtlich sanktionsbewehrt sind (näher noch zu den Schutzgütern Rn. 1086 ff.). ${ }^{1971}$ Abzustellen sein soll jedoch auf die einfach-rechtliche Schutzstellung, nicht auf die Schutzfunktion der Grundrechte. ${ }^{1972}$

Beispiel: Leben und Gesundheit werden von $\$ \S 223,212,211$ StGB als Teil der objektiven Rechtsordnung geschützt (nicht hingegen: Art. 2 II 1 GG).

1069 Teilweise finden sich in den allgemeinen Polizei- und Ordnungsgesetzen die sachliche Zuständigkeit näher regelnde Bestimmungen:

1967 Siegel, in: Siegel/Waldhoff, Öffentliches Recht für Berlin, 2. Aufl. 2017, § 2 Rn. 28.

1968 S. Art. 2 II BayPAG; § 1 II BBgPolG; § 1 IV ASOG Bln; § 1 II BremPolG; § 2 II PolG BW; § 3 III SOG Hamburg; § 1 III SOG Hessen; § 1 III SOG MV; § 1 III SOG Nds; § 1 II PolG NW; § 1 III POG RP; § 1 III PolG Saarland; § 2 II PolG Sachsen; § 1 II SOG SA; § 162 II LVwG SH; § 2 II PAG Thüringen; $\S 2$ II OBG Thüringen; § 1 IV BPolG.

1969 Kingreen/Poscher, Polizei- und Ordnungsrecht mit Versammlungsrecht, 10. Aufl. 2018, § 3 Rn. 41.

1970 Näher zu den einzelnen Voraussetzungen Kingreen/Poscher, Polizei- und Ordnungsrecht mit Versammlungsrecht, 10. Aufl. 2018, § 3 Rn. $41 \mathrm{ff}$.

1971 Kingreen/Poscher, Polizei- und Ordnungsrecht mit Versammlungsrecht, 10. Aufl. 2018, § 3 Rn. 42.

1972 Kingreen/Poscher, Polizei- und Ordnungsrecht mit Versammlungsrecht, 10. Aufl. 2018, § 3 Rn. 42. 
Beispiel: In Berlin richtet sich die sachliche Zuständigkeit nach den $\S \S 2 f f$. ASOG i.V.m. dem Zuständigkeitskatalog für Ordnungsaufgaben. ${ }^{1973}$ In Schleswig-Holstein ergibt sich die sachliche Zuständigkeit aus $\S 165$ LVwG. ${ }^{1974}$

\section{(2) Instantielle Zuständigkeit}

Die instantielle Zuständigkeit fragt danach, welche Hierarchieebene der Verwal- 1070 tung zuständig ist. Dieser Instanzenzug wird zumeist in den jeweiligen Polizeiund Ordnungsgesetzen näher geregelt. Ein Verstoß führt zur Rechtswidrigkeit des Verwaltungsakts, nicht jedoch zur Nichtigkeit. ${ }^{1975}$

Die Binnendifferenzierung innerhalb der jeweiligen Behörde ist hingegen 1071 ohne Belang. ${ }^{1976}$ Auch kommt es nicht darauf an, welcher Amtswalter, konkret: welche ${ }^{\star}$ r Polizeivollzugsbeamt ${ }^{\star}$ in gehandelt hat, weil ihr Handeln der Behörde zugerechnet wird. ${ }^{1977}$

\section{(3) Örtliche Zuständigkeit}

Die örtliche Zuständigkeit richtet sich in den Ländern mit Einheitssystem (s. be- 1072 reits Rn. 1067) nach sog. Polizeibezirken, die darauf abstellen, in welchem Bezirk eine polizeiliche Aufgabe wahrzunehmen ist; gleiches gilt im Grundsatz für die Ordnungsbehörden in Ländern mit Trennsystem. ${ }^{1978}$

Soweit sich die örtliche Zuständigkeit nicht aus dem jeweils einschlägigen 1073 Landesgesetz ergibt, kann hilfsweise auf $\S 3$ VwVfG zurückgegriffen werden.

\section{bb) Verfahren}

Die Frage etwaiger Verfahrensfehler ist im Ausgangspunkt nach den allgemeinen 1074 Grundsätzen des Verwaltungsverfahrensrechts zu lösen (s. hierzu Rn. 621 ff.), soweit sich aus den Polizeigesetzen keine spezifischen Verfahrensanforderungen ergeben. ${ }^{1979}$

1973 Siegel, in: Siegel/Waldhoff, Öffentliches Recht für Berlin, 2. Aufl. 2017, § 2 Rn. 131.

1974 Becker/Brüning, Öffentliches Recht in Schleswig-Holstein, 2014, § 3 Rn. 59.

1975 Schenke, Polizei- und Ordnungsrecht, 10. Aufl. 2018, Rn. 454.

1976 Kingreen/Poscher, Polizei- und Ordnungsrecht mit Versammlungsrecht, 10. Aufl. 2018, § 2 Rn. $28 \mathrm{f}$.

1977 Kingreen/Poscher, Polizei- und Ordnungsrecht mit Versammlungsrecht, 10. Aufl. 2018, § 5 Rn. 6.

1978 Schenke, Polizei- und Ordnungsrecht, 10. Aufl. 2018, Rn. 459.

1979 Schenke, Polizei- und Ordnungsrecht, 10. Aufl. 2018, Rn. 490; Kingreen/Poscher, Polizeiund Ordnungsrecht mit Versammlungsrecht, 10. Aufl. 2018, § 6 Rn. 19. 

VwVfG erforderlich. Davon kann jedoch - für das Polizei- und Ordnungsrecht besonders relevant - im Falle von Gefahr im Verzug nach § 28 II Nr. 1 VwVfG abgewichen werden. Zudem ist sie nach § 28 III VwVfG entbehrlich, wenn ihr ein zwingendes öffentliches Interesse entgegensteht. Im Polizei- und Ordnungsrecht wird der Anhörung aus diesen Gründen keine große Bedeutung zugemessen. ${ }^{1980}$

1076 Spezifische Verfahrensanforderungen ergeben sich insbesondere im Bereich der Standardbefugnisse. ${ }^{1981}$

1077 Examenswissen: Bei Minderjährigen ergibt sich aufgrund der Regelung des §12 I VwVfG die Besonderheit, dass diesen die Handlungsfähigkeit im Verwaltungsverfahren fehlen kann (s. Rn. 641). Auf die Generalklausel gestützte Verwaltungsakte können dann nur wirksam gegenüber ihren gesetzlichen Vertretern bekannt gegeben werden. ${ }^{1982}$ Sind die gesetzlichen Vertreter nicht erreichbar, kann kein wirksamer Verwaltungsakt gegenüber dem Minderjährigen erlassen werden; in diesem Fall muss die Behörde ohne Grundverwaltungsakt im Wege der Verwaltungsvollstreckung vorgehen (näher zur Verwaltungsvollstreckung im Polizei- und Ordnungsrecht Rn. 1059 ff.). ${ }^{1983}$

\section{cc) Form}

1078 Auch die Frage etwaiger Formfehler ist im Ausgangspunkt nach den allgemeinen Grundsätzen des Verwaltungsverfahrensrechts $\mathrm{zu}$ lösen (s. hierzu näher Rn. 681ff.), soweit sich aus den Polizeigesetzen keine spezifischen Verfahrensanforderungen ergeben. ${ }^{1984}$ Teilweise müssen nach den Landesgesetzen Ordnungsverfügungen in Abweichung vom Regelfall des § 37 II 1 VwVfG schriftlich erlassen werden, soweit nicht Gefahr im Vollzug vorliegt (so in § 19 I BbgOBG und $\S 20$ I NWOBG). Schließlich kommt der Ausnahme vom Begründungserfordernis nach § 39 II Nr. 2 VwVfG im Polizei- und Ordnungsrecht Bedeutung zu. ${ }^{1985}$

1980 Kingreen/Poscher, Polizei- und Ordnungsrecht mit Versammlungsrecht, 10. Aufl. 2018, § 6 Rn. 21.

1981 Kingreen/Poscher, Polizei- und Ordnungsrecht mit Versammlungsrecht, 10. Aufl. 2018, § 6 Rn. 20.

1982 Kingreen/Poscher, Polizei- und Ordnungsrecht mit Versammlungsrecht, 10. Aufl. 2018, § 9 Rn. 5.

1983 Kingreen/Poscher, Polizei- und Ordnungsrecht mit Versammlungsrecht, 10. Aufl. 2018, § 9 Rn. 5.

1984 Schenke, Polizei- und Ordnungsrecht, 10. Aufl. 2018, Rn. 490.

1985 Kingreen/Poscher, Polizei- und Ordnungsrecht mit Versammlungsrecht, 10. Aufl. 2018, § 6 Rn. 22.

\section{Nikolas Eisentraut}




\section{e) Materielle Rechtmäßigkeit}

Im Anschluss an die formelle Rechtmäßigkeit ist in der materiellen Rechtmä- 1079 ßigkeit ist zu prüfen, ob die streitgegenständliche Maßnahme auch den materiellrechtlichen Anforderungen der Ermächtigungsgrundlage entspricht und ob sie von deren Rechtsfolge gedeckt ist. Unterschieden werden muss danach, ob eine Standardbefugnis oder die Generalklausel als Ermächtigungsgrundlage für einschlägig befunden wurde. Die Prüfung kann sodann entlang der für das Verwaltungsrecht typischen Einteilung in Tatbestand und Rechtsfolge erfolgen (s. zur Grundstruktur der Prüfung der materiellen Rechtmäßigkeit Rn. 526ff.; für vertiefende Ausführungen s. Rn. 712 ff.; ein Überblick über weitere Möglichkeiten, die Prüfung aufzubauen, findet sich in Rn. $803 \mathrm{ff}$.).

\section{aa) Die Standardbefugnisse}

In ihrer Grundstruktur erfolgt die Prüfung der Standardbefugnisse dem Prü- 1080 fungsablauf für die Generalklausel. Diese wird deshalb sogleich umfassend dargestellt und muss beherrscht werden. Im Vergleich zur Generalklausel werden Tatbestand und Rechtsfolge bei Standardmaßnahmen jedoch vielfach modifiziert. ${ }^{1986}$ Alle diese Spezialregelungen auswendig zu lernen, macht keinen Sinn; vielmehr muss die Grundstruktur beherrscht und der Umgang mit den Besonderheiten innerhalb der Grundstruktur erlernt werden. ${ }^{1987}$ Die folgende Darstellung konzentriert sich daher auf die Prüfung der Generalklausel. Für eine tiefergreifende Auseinandersetzung mit den einzelnen Standardmaßnahmen wird auf die in Rn. 1140 genannte Vertiefungsliteratur hingewiesen.

\section{bb) Die Generalklausel}

Ist weder eine Ermächtigungsgrundlage des besonderen Gefahrenabwehrrechts, 1081 noch eine Standardbefugnis taugliche Ermächtigungsgrundlage (s. zur Abgrenzung soeben Rn. 1036 und Rn. 1044) und wurde deshalb die Generalklausel als „Auffang-Ermächtigungsgrundlage“ für einschlägig befunden, muss im Anschluss an die formelle Rechtmäßigkeit geprüft werden, ob die Maßnahme auch deren materiell-rechtlichen Anforderungen entspricht.

Die Generalklausel folgt in allen Bundesländern einer vergleichbaren 1082 Prüfungsstruktur (s. bereits die Normenübersicht in Rn. 1053). Wichtig ist es

1986 Siegel/Waldhoff, Öffentliches Recht für Berlin, 2. Aufl. 2017, § 2 Rn. 144.

1987 Kingreen/Poscher, Polizei- und Ordnungsrecht mit Versammlungsrecht, 10. Aufl. 2018, § 11 Rn. 28. 
auch bei der Prüfung der Generalklausel (wie stets im Verwaltungsrecht) klar zwischen Tatbestand und Rechtsfolge zu trennen. Auf Tatbestandsseite sind die Tatbestandsmerkmale der Ermächtigungsgrundlage zu prüfen. Sind sie erfüllt, ist zu untersuchen, ob die von der Behörde gewählte Rechtsfolge von der Ermächtigungsgrundlage gedeckt ist.

\section{(1) Tatbestandsmerkmale}

1083 Die Generalklausel kennt in der Regel 4 Tatbestandsmerkmale. Neben der in Klausuren schon im Rahmen des Prüfungspunktes „Ermächtigungsgrundlage“ $\mathrm{zu}$ klärenden Frage der Subsidiarität (a) bedarf es des Vorliegens einer Gefahr (c) für eines der polizeilichen Schutzgüter der öffentlichen Sicherheit oder Ordnung (b) und der taugliche Adressat der Maßnahme muss in Anspruch genommen worden sein (d).

1084 Die unbestimmten Tatbestandsmerkmale (öffentliche Sicherheit und Ordnung, Gefahr) sind vollständig gerichtlich überprüfbar. Der Behörde ist insofern kein Beurteilungsspielraum eingeräumt (s. zum Begriff des Beurteilungsspielraums näher Rn. 735). ${ }^{1988}$

\section{(a) Subsidiarität}

1085 Zur Subsidiarität der Generalklausel gegenüber Befugnissen des besonderen Gefahrenabwehrrechts s. Rn. $1036 \mathrm{ff}$. sowie zu den Standardbefugnissen s. Rn. $1044 \mathrm{ff}$.

\section{(b) Öffentliche Sicherheit und Ordnung}

1086 Zunächst müsste das Schutzgut der öffentlichen Sicherheit oder Ordnung betroffen sein. ${ }^{1989}$ Gegenüber dem Schutzgut der öffentlichen Sicherheit ist das Schutzgut der öffentlichen Ordnung subsidiär, es ist also nur dann zu prüfen, wenn das Schutzgut der öffentlichen Sicherheit nicht betroffen ist. ${ }^{1990}$

Das Schutzgut der öffentlichen Sicherheit umfasst 3 Elemente, auch Teilschutzgüter ${ }^{1991}$ genannt:

1988 Schenke, Polizei- und Ordnungsrecht, 10. Aufl. 2018, Rn. 51f.

1989 In den Bundesländern Bremen und Schleswig-Holstein beschränkt sich der Tatbestand allein auf die öffentliche Sicherheit.

1990 Schoch, in: Schoch, Besonderes Verwaltungsrecht, 2018, Kapitel 1 Rn. 243.

1991 Kingreen/Poscher, Polizei- und Ordnungsrecht mit Versammlungsrecht, 10. Aufl. 2018, § 7 Rn. 2.

\section{Nikolas Eisentraut}


1. die Unverletzlichkeit der Rechtsordnung,

2. die Unversehrtheit der Rechtsgüter und Rechte des Einzelnen und

3. den Bestand und die Funktionsfähigkeit des Staates und seiner Einrichtungen.

Soweit sich im einschlägigen Landesrecht keine Legaldefinition findet, ${ }^{1992}$ muss diese Definition auswendig gelernt werden.

Bei der Subsumtion unter die einzelnen Teilschutzgüter kann es zu Über- 1088 schneidungen derart kommen, dass eine Gefahr für mehrere der genannten Elemente bejaht werden kann. ${ }^{1993}$ Gegenüber den anderen Teilschutzgütern ist die Unverletzlichkeit der Rechtsordnung deshalb vorrangig zu prüfen, während den anderen Elementen eine Reservefunktion zukommt. ${ }^{1994}$

(1.) Das Element der Unverletzlichkeit der Rechtsordnung umfasst die 1089 gesamte Rechtsordnung und ermöglicht es so, drohende Verletzungen geltenden Rechts zu verhindern. ${ }^{1995}$ Aufgrund der Verrechtlichung weiter Lebensbereiche kommt dem ersten Element zentrale Bedeutung zu. ${ }^{1996}$

Erfasst werden zunächst drohende Verstöße gegen formelle Gesetze. Eine 1090 typische Fallgruppe bildet das Straf- und Ordnungswidrigkeitenrecht. Die Verhinderung von Verstößen gegen das StGB und das OWiG lassen sich häufig nur unter Rückgriff auf die Generalklausel unterbinden, beispielsweise wenn ein rechtsextremistisches Konzert wegen Volksverhetzung (§130 StGB) untersagt wird. ${ }^{1997} \mathrm{Zu}$ den gesetzlichen Vorschriften zählen weiterhin die Bestimmungen des Verwaltungs- wie auch des Privatrechts. ${ }^{1998}$ Letztere werden zwar auch vom Element der Unversehrtheit der Rechtgüter und Rechte des Einzelnen erfasst. Soweit sie jedoch beiden Teilschutzgütern unterfallen, greift die Privatrechtsklausel nicht (s. zur Privatrechtsklausel Rn. 1068).

Weiterhin erfasst die Generalklausel auch Verstöße gegen untergesetzliche 1091 Normen wie Gefahrenabwehrverordnungen. ${ }^{1999}$ In Klausuren bietet das Teil-

1992 So in § 2 Nr. 2 BremPolG, § 3 Nr. 1 SOG LSA sowie § 54 Nr. 1 ThürOBG.

1993 Zur historischen Begründung Kingreen/Poscher, Polizei- und Ordnungsrecht mit Versammlungsrecht, 10. Aufl. 2018, § 7 Rn. 4.

1994 Kingreen/Poscher, Polizei- und Ordnungsrecht mit Versammlungsrecht, 10. Aufl. 2018, § 7 Rn. 6.

1995 Schoch, in: Schoch, Besonderes Verwaltungsrecht, 2018, Kapitel 1 Rn. 245.

1996 Götz/Geis, Allgemeines Polizei- und Ordnungsrecht, 16. Aufl. 2017, §4 Rn. 7; Schoch, in: Schoch, Besonderes Verwaltungsrecht, 2018, Kapitel 1 Rn. 244.

1997 OVG Bremen Beschl.v. 26.11. 2011, Az.: 1 B 309/11 = BeckRS 2011, 56338; weitere Beispiele bei Schoch, Besonderes Verwaltungsrecht, 2018, Kapitel 1 Rn. 247.

1998 Schoch, in: Schoch, Besonderes Verwaltungsrecht, 2018, Kapitel 1 Rn. 248 und 252.

1999 Schoch, in: Schoch, Besonderes Verwaltungsrecht, 2018, Kapitel 1 Rn. 249.

Nikolas Eisentraut 
schutzgut der Unverletzlichkeit der Rechtsordnung daher auch das typische „Einfallstor“ in der Anfechtungsklage für die Prüfung der Rechtmäßigkeit einer Gefahrenabwehrverordnung (zur Rechtmäßigkeitsprüfung einer Gefahrenabwehrverordnung s. näher $\S 7$ Rn. 109 ff.). ${ }^{2000}$

1092 Auch das EU-Recht nimmt am Schutz der objektiven Rechtsordnung teil, etwa wenn aufgrund von Straßenblockaden eine Beeinträchtigung der Warenverkehrsfreiheit (Art. 34 AEUV) droht. ${ }^{2001}$

(2) Vom Element der Unversehrtheit der Rechtsgüter und Rechte des

Einzelnen erfasst werden insbesondere das Leben, die Gesundheit und Freiheit, sowie das Eigentum und Persönlichkeitsrechte. ${ }^{2002}$ In der Regel werden diese Rechtsgüter auch von der objektiven Rechtsordnung geschützt, sodass das zweite Element keine Anwendung findet. Es kann jedoch in zwei Fallgruppen zur Anwendung kommen: Einerseits spielt die Unversehrtheit der Rechtsgüter und Rechte des Einzelnen eine Rolle bei Naturereignissen, da das objektive Recht nur menschliches Verhalten regeln kann. ${ }^{2003}$

1094 Zum anderen greift das Element der Unversehrtheit der Rechtsgüter und Rechte des Einzelnen bei Selbstgefährdungen, da die objektive Rechtsordnung den Einzelnen nicht vor sich selbst schützt. ${ }^{2004}$ Bei einer vom freien Willen getragenen Selbstgefährdung, die zugleich unbeteiligte Dritte nicht gefährdet, wird aber regelmäßig aufgrund des Selbstbestimmungsrechts aus Art. 2 I, 2 II 1 GG auch dieses Teilschutzgut nicht als gefährdet angesehen. ${ }^{2005}$ Entsprechendes gilt für die Selbsttötung, auch wenn die Behörden hier regelmäßig einschreiten werden. ${ }^{2006}$ Die Rechtmäßigkeit des polizeilichen Einschreitens im Falle eines Selbsttötungsversuchs ergibt sich daraus, dass der Beamte in der ex ante Betrachtung nicht weiß, inwieweit der Selbsttötungsversuch von einem freien Willensentschluss getragen ist. Die Verhinderung wird deshalb als Gefahrerforschungsein-

2000 Kingreen/Poscher, Polizei- und Ordnungsrecht mit Versammlungsrecht, 10. Aufl. 2018, § 27 Rn. $15 \mathrm{ff}$.

2001 Schoch, in: Schoch, Besonderes Verwaltungsrecht, 2018, Kapitel 1 Rn. 251.

2002 Schoch, in: Schoch, Besonderes Verwaltungsrecht, 2018, Kapitel 1 Rn. 253.

2003 Kingreen/Poscher, Polizei- und Ordnungsrecht mit Versammlungsrecht, 10. Aufl. 2018, § 7 Rn. 6 und 21.

2004 Kingreen/Poscher, Polizei- und Ordnungsrecht mit Versammlungsrecht, 10. Aufl. 2018, § 7 Rn. 23.

2005 Kingreen/Poscher, Polizei- und Ordnungsrecht mit Versammlungsrecht, 10. Aufl. 2018, § 7 Rn. 25.

2006 Kingreen/Poscher, Polizei- und Ordnungsrecht mit Versammlungsrecht, 10. Aufl. 2018, § 7 Rn. $27 \mathrm{f}$.

Nikolas Eisentraut 
griff bzw. als Einschreiten wegen einer Anscheinsgefahr (zu diesen Begriffen Rn. 1107 und Rn. 1112ff.) qualifiziert. ${ }^{2007}$

Da die Durchsetzung privater Rechte und Rechtsgüter zunächst den Zivilgerichten vorbehalten ist, ist deren Schutz mittels der Polizei- und Ordnungsgesetze nur subsidiär möglich (s. bereits Rn. 1068). Die Landespolizeigesetze enthalten dementsprechend sog. Subsidiaritätsklauseln. ${ }^{2008}$ Danach können die Gefahrenabwehrbehörden zum Schutz privater Rechte und Rechtsgüter nur dann einschreiten, wenn gerichtlicher Schutz nicht rechtzeitig zu erlangen ist und wenn ohne behördliche Hilfe die Verwirklichung des Rechts vereitelt oder wesentlich erschwert würde. ${ }^{2009}$ Darüber hinaus ist teilweise auch ein Antragserfordernis des Berechtigten normiert worden. ${ }^{2010}$

(3.) Unter das Teilschutzgut des Bestands des Staates und seiner Einrichtungen und Veranstaltungen fällt zunächst die territoriale Unversehrtheit und politische Unabhängigkeit der Bundesrepublik Deutschland. Weiterhin erfasst werden vom Einrichtungsbegriff die Organe, Behörden, Körperschaften, Stiftungen, Anstalten und vergleichbare Sachkomplexe wie die öffentlichen Hochschulen, Kammern, Rundfunkanstalten und Schwimmbäder. Schließlich schützt der Begriff der Veranstaltung ad hoc gebildete Handlungskomplexe wie Staatsempfänge, Tage der offenen Tür und militärische Manöver. ${ }^{2011}$ Wiederum greift vorrangig das Teilschutzgut der objektiven Rechtsordnung, wenn eine Verletzung der Rechtsordnung in Rede steht, so etwa beim Widerstand gegen Vollstreckungsbeamte nach $\S 113$ StGB oder der Störung öffentlicher Betriebe nach $\S 316 \mathrm{~b}$ StGB. ${ }^{2012}$ Seine Auffangfunktion kann das Element dort erfüllen, wo nicht zugleich eine Verletzung der objektiven Rechtsordnung droht. ${ }^{2013}$ Dies gilt wie-

2007 Kingreen/Poscher, Polizei- und Ordnungsrecht mit Versammlungsrecht, 10. Aufl. 2018, § 7 Rn. 28.

2008 Näher dazu Schoch, in: Schoch, Besonderes Verwaltungsrecht, 2018, Kapitel 1 Rn. $254 \mathrm{ff}$. 2009 So in § 2 II PolG BW; Art. 2 II BayPAG; § 1 Abs. 4 ASOG Bln; § 1 II BbgPolG, § 1 II BremPolG; $\S 3$ Abs. 3 HmbSOG; § 1 Abs. 3 HessSOG; § 1 Abs. 3 SOG MW; § 1 Abs. 3 NdsSOG; § 1 II PolG NW; § 1 Abs. 3 POG RP; § 1 Abs. 3 PolG SL; § 2 II SächsPolG; § 1 II SOG LSA; § 162 II LVwG SH; § 2 II ThürPAG; $\S 2$ II ThürOBG; s. auch § 1 Abs. 4 BPolG.

2010 § 2 II PolG BW; § 2 II SächsPolG; in der Lit. wird teilweise generell ein Antrag gefordert, Nachweise zu dieser Ansicht bei Schoch, in: Schoch, Besonderes Verwaltungsrecht, 2018, Kapitel 1 Rn. 254 Fn. 724.

2011 Kingreen/Poscher, Polizei- und Ordnungsrecht mit Versammlungsrecht, 10. Aufl. 2018, § 7 Rn. 30.

2012 Schenke, Polizei- und Ordnungsrecht, 10. Aufl. 2018, Rn. 60; Kingreen/Poscher, Polizeiund Ordnungsrecht mit Versammlungsrecht, 10. Aufl. 2018, § 7 Rn. $32 \mathrm{f}$.

2013 Kingreen/Poscher, Polizei- und Ordnungsrecht mit Versammlungsrecht, 10. Aufl. 2018, § 7 Rn. 34. 
derum bei Naturereignissen, etwa wenn ein Gewitter einen Staatsempfang gefährdet. ${ }^{2014}$ Bloße Beeinträchtigungen der Funktionsfähigkeit der staatlichen Einrichtungen sollen hingegen nicht genügen, soweit sie nicht zugleich die Rechtsordnung verletzen; scharfe Kritik an einer staatlichen Einrichtung, das Fotografieren polizeilicher Einsätze und die Warnung vor polizeilichen Geschwindigkeitskontrollen sollen daher nicht tatbestandsmäßig sein. ${ }^{2015}$

Schließlich erfüllen auch Gefährdungen der öffentlichen Ordnung den Tatbestand der Generalklausel. Das Tatbestandsmerkmal der öffentlichen Ordnung ist jedoch hoch umstritten. In Bremen und Schleswig-Holstein wurde deshalb auch auf dieses Tatbestandsmerkmal verzichtet. In den meisten Bundesländern wird am Tatbestandsmerkmal der öffentlichen Ordnung jedoch bis heute festgehalten. Soweit sich keine Legaldefinition im Gesetz findet, ist folgende Definition auswendig zu lernen: „Die öffentliche Ordnung umfasst die Gesamtheit der im Rahmen der verfassungsmäßigen Ordnung liegenden ungeschriebenen Regeln für das Verhalten des einzelnen in der Öffentlichkeit, deren Beachtung nach den jeweils herrschenden Anschauungen unerlässliche Voraussetzung eins geordneten staatsbürgerlichen Zusammenlebens ist.““2016

Als Gefahr für die öffentliche Ordnung wurde beispielsweise das Angebot von „DamenSchlamm-Catchen oben ohne ${ }^{\text {¿2017 }}$ angesehen.

1098 Problematisch am Tatbestandsmerkmal ist, dass auf „ungeschriebene Regeln“ abgestellt wird. Es geht also um außerrechtliche Sozialnormen. Wer bestimmt jedoch über die ,jeweils herrschende Anschauung“? In der Praxis wird dafür nicht etwa empirisch die Mehrheitsanschauung der Bevölkerung ermittelt; der unbestimmte Rechtsbegriff wird vielmehr von den Gerichten ausgelegt. ${ }^{2018}$ Zum vergleichbaren Fall des Tatbestandsmerkmals der Sittenwidrigkeit in § 33a GewO hat das VG Karlsruhe sehr anschaulich ausgeführt: „Gleichwohl bedarf es entgegen der Ansicht des Klägers nicht der Einholung eines demoskopischen Sachverständigengutachtens zur Ermittlung der vorherrschenden sozialethischen Überzeugungen. Abgesehen davon, dass demoskopische Umfragen, die einem solchen Gutachten zugrunde zu legen wären, schon wegen der Abhängigkeit des

2014 Weitere Beispiele bei Kingreen/Poscher, Polizei- und Ordnungsrecht mit Versammlungsrecht, 10. Aufl. 2018, § 7 Rn. 35.

2015 Str., s. näher Kingreen/Poscher, Polizei- und Ordnungsrecht mit Versammlungsrecht, 10. Aufl. 2018, § 7 Rn. 37 f.

2016 So legaldefiniert in $\S 3$ Nr. 2 SOG LSA und § 54 Nr. 2 OBG Thüringen.

2017 VGH München, Beschluss v. 9.12.1983, Az.: 22 CE 83 A/3074 = NVwZ 1984, 254.

2018 Kritisch dazu Kingreen/Poscher, Polizei- und Ordnungsrecht mit Versammlungsrecht, 10. Aufl. 2018, § 7 Rn. 44. 
Ergebnisses von der jeweiligen konkret gewählten Fragestellung und ihrer vielschichtig möglichen Interpretation durch die Befragten keine Gewähr für ein zutreffendes Meinungsbild bieten könnten, ist es - wie bei anderen unbestimmten Rechtsbegriffen auch - Aufgabe der Rechtsprechung, den Inhalt des unbestimmten Rechtsbegriffs der guten Sitten selbst festzustellen (...).“2019

Obwohl das Tatbestandsmerkmal deshalb ideologisch anfällig ist und mit 1099 dem vom Grundgesetz intendierten Minderheitenschutz in einer Spannungslage steht, ${ }^{2020}$ halten die Rechtsprechung und die überwiegende Literatur am Tatbestandsmerkmal der öffentlichen Ordnung fest. ${ }^{2021}$ Typischerweise wird das Tatbestandsmerkmal herangezogen, um Gefährdungen der Menschenwürde begegnen zu können. Indes zählt Art. 1 I GG genau genommen zur geschriebenen Rechtsordnung und unterfällt bereits dem Tatbestandsmerkmal der öffentlichen Sicherheit. Zudem kommt der öffentlichen Ordnung im Versammlungsrecht Bedeutung zu (s. näher Rn. 1182f.).

Hausarbeitswissen: Mit der öffentlichen Ordnung in engem Zusammenhang steht das Tatbestandsmerkmal der Sittenwidrigkeit, das im Gewerberecht eine bedeutende Rolle spielt. Auch hier stellen die Gerichte auf „außerrechtliche Sozialnormen“ ab. ${ }^{2022}$ Als sittenwidrig wurden durch die Gerichte insbesondere Peep-Shows ${ }^{2023}$ und Laserdrome-Spiele ${ }^{2024}$ angesehen.

\section{(c) Gefahr}

Gefahrenabwehr besteht klassischer Weise in der Abwehr von Gefahren für die 1101 polizeilichen Schutzgüter. ${ }^{2025}$ Dem Gefahrbegriff kommt daher im Polizei- und Ordnungsrecht zentrale Bedeutung zu. Für auf Grundlage der Generalklausel erlassene Verwaltungsakte verlangt diese deshalb, dass eine Gefahr für eines der vorstehend erörterten Schutzgüter vorliegen muss.

2019 VG Karlsruhe, Urt. v. 12.09.2013, Az.: 3 K 496/12, juris Rn. 36.

$2020 \mathrm{Zu}$ diesen Kritikpunkten Kingreen/Poscher, Polizei- und Ordnungsrecht mit Versammlungsrecht, 10. Aufl. 2018, § 7 Rn. $44 \mathrm{ff}$.

2021 Kingreen/Poscher, Polizei- und Ordnungsrecht mit Versammlungsrecht, 10. Aufl. 2018, § 7 Rn. 49 und 52.

2022 Dazu näher Öttinger, GewArch 2016, 365.

2023 BVerwG, Urt. v. 15.12.1981, Az.: 1 C 232.79 = BVerwGE 64, 274.

2024 BVerwG, Beschl. v. 24.10.2001, Az.: 6 C 3/01 = BVerwGE 115, 189.

2025 Schoch, in: Schoch, Besonderes Verwaltungsrecht, 2018, Kapitel 1 Rn. 10; zur Gefahrenabwehr als staatliche Aufgabe Schoch, in: Schoch, Besonderes Verwaltungsrecht, 2018, Kapitel 1 Rn. 65 ff.; zur Gefahrenabwehr durch Private Schoch, in: Schoch, Besonderes Verwaltungsrecht, 2018, Kapitel 1 Rn. 130 ff. 
1102

Soweit sich im jeweils einschlägigen Polizeigesetz keine Legaldefinition findet, ${ }^{2026}$ muss folgende Definition beherrscht werden: „Eine Gefahr ist ein Zustand, der bei ungehindertem Ablauf des zu erwartenden Geschehens mit hinreichender Wahrscheinlichkeit ein geschütztes Rechtsgut schädigen wird.“ Die Generalklausel erfordert das Bestehen einer solchen Gefahr im Einzelfall (sog. konkrete Gefahr).

1103 Vom Begriff der konkreten Gefahr zu unterscheiden ist der Begriff der sog. abstrakten Gefahr. Eine abstrakte Gefahr liegt dann vor, wenn ein Verhalten abstrahiert vom konkreten Einzelfall typischerweise zu einer Rechtsgutsgefährdung führt. ${ }^{2027}$ Eine abstrakte Gefahr ist erforderlich, wenn die Behörde eine Gefahrenabwehrverordnung erlassen will (s. zur Gefahrenabwehrverordnung auch $\S 7$ Rn. 107).

1104 Auf Grundlage der Definition können mehrere Aspekte problematisiert werden:

1105 Zunächst kann zu problematisieren sein, ob das Vorliegen der Voraussetzungen des Gefahrbegriffs nach objektiven oder subjektiven Gesichtspunkten zu beurteilen ist:

1106 Nach dem sog. objektiven Gefahrbegriff käme es auf die im Nachhinein zweifelsfrei festgestellte Situation an (Beurteilung „ex post“).

1107 Nach heute herrschender Meinung ist jedoch mit dem subjektiven Gefahrbegriff darauf abzustellen, ob der handelnde Beamte in der konkreten Situation vertretbar von einem Zustand ausgehen durfte, der die Voraussetzungen des Gefahrbegriffs erfüllt (sog. ex ante Beurteilung). ${ }^{2028}$ Dadurch kann der Gefahrbegriff auch dann erfüllt sein, wenn der Beamte nur ex ante von einer Gefahr ausgehen durfte, obwohl ex post gar keine Gefahr vorlag (sog. Anscheinsgefahr). ${ }^{2029}$

1108 Durfte der Beamte hingegen von keiner Gefahr ausgehen und tut dies trotzdem, wird von einer sog. Putativgefahr (oder auch Scheingefahr) gesprochen. ${ }^{2030}$ Sein Vorgehen war dann mangels Gefahr rechtswidrig.

2026 Legaldefiniert in $\S 2$ Nr. 3 a) BremPolG; $\S 2$ Nr. 1 a) Nds. SOG; $§ 3$ Nr. 3 a) SOG LSA; § 54 Nr. 3 a) ThürOBG.

2027 Schenke, Polizei- und Ordnungsrecht, 10. Aufl. 2018, Rn. 70; Kingreen/Poscher, Polizeiund Ordnungsrecht mit Versammlungsrecht, 10. Aufl. 2018, § 8 Rn. 9.

2028 Kingreen/Poscher, Polizei- und Ordnungsrecht mit Versammlungsrecht, 10. Aufl. 2018, § 8 Rn. 48.

2029 Kingreen/Poscher, Polizei- und Ordnungsrecht mit Versammlungsrecht, 10. Aufl. 2018, § 8 Rn. 49.

2030 Kingreen/Poscher, Polizei- und Ordnungsrecht mit Versammlungsrecht, 10. Aufl. 2018, § 8 Rn. 61. 
Weiterhin können die einzelnen Definitionsmerkmale zu problematisieren 1109 sein:

So setzt die Definition voraus, dass eine Schädigung eines Rechtsguts 1110 droht. Nicht ausreichend sind demnach bloße Belästigungen. ${ }^{2031}$ Als Belästigungen werden Einwirkungen auf ein Rechtsgut qualifiziert, die zwar nachteilig, unangenehm, lästig oder unerfreulich sind, aber nicht darüber hinausgehen. ${ }^{2032}$ Unaufdringliches Betteln im öffentlichen Raum wird beispielsweise nicht als Gefahr, sondern bloß als Belästigung qualifiziert. ${ }^{2033}$

Weiterhin kommt es nach der Definition darauf an, dass die Gefahrenlage 1111 hinreichend wahrscheinlich ist. ${ }^{2034}$ Es reicht also nicht aus, dass eine Vermutung ohne tatsächliche Anhaltspunkte im Raum steht. ${ }^{2035}$ Auch ein reines Risiko reicht noch nicht, bei dem alles gegen die Wahrscheinlichkeit einer Schädigung spricht, diese aber nicht 100\%ig ausgeschlossen werden kann. ${ }^{2036}$ Dabei können die Anforderungen daran, wie wahrscheinlich ein Schadenseintritt sein muss, durchaus variieren: Umso höherrangig das Rechtsgut und der ihm drohende Schaden, desto geringere Anforderungen sind an die Wahrscheinlichkeit zu stellen. $^{2037}$

Eine besonders problematische Kategorie ist der sog. Gefahrenverdacht.Von 1112 einem Gefahrenverdacht wird gesprochen, wenn zwar die Möglichkeit einer Gefahr besteht, weil bereits Anhaltspunkte darauf hindeuten, der Beamte aber letztlich im Ungewissen darüber ist, die Anhaltspunkte also noch nicht für die Bejahung der hinreichenden Wahrscheinlichkeit des Schadenseintritts genügen. $^{2038}$

Umstritten ist, welche Befugnisse den Polizei- und Ordnungsbehörden im Falle eines Gefahrenverdachts zustehen:

2031 Schenke, Polizei- und Ordnungsrecht, 10. Aufl. 2018, Rn. 74.

2032 Kingreen/Poscher, Polizei- und Ordnungsrecht mit Versammlungsrecht, 10. Aufl. 2018, § 8 Rn. 3.

2033 Kingreen/Poscher, Polizei- und Ordnungsrecht mit Versammlungsrecht, 10. Aufl. 2018, § 8 Rn. 4.

2034 Schenke, Polizei- und Ordnungsrecht, 10. Aufl. 2018, Rn. 77.

2035 Kingreen/Poscher, Polizei- und Ordnungsrecht mit Versammlungsrecht, 10. Aufl. 2018, § 8 Rn. 6.

2036 Näher Kingreen/Poscher, Polizei- und Ordnungsrecht mit Versammlungsrecht, 10. Aufl. 2018, § 8 Rn. 6.

2037 Schenke, Polizei- und Ordnungsrecht, 10. Aufl. 2018, Rn. 77.

2038 Kingreen/Poscher, Polizei- und Ordnungsrecht mit Versammlungsrecht, 10. Aufl. 2018, § 8 Rn. 51; zu den unterschiedlichen Verständnissen und den daraus resultierenden Missverständnissen des Begriffs des Gefahrenverdachts näher Schenke, JuS 2018, 505 (508).

Nikolas Eisentraut 
Unproblematisch ist die Befugnisreichweite, wenn die Zulässigkeit eines Einschreitens bei Gefahrverdacht spezialgesetzlich normiert ist: Bestimmte Standardmaßnahmen lassen bereits einen Gefahrenverdacht ausreichen, so bei der Durchsuchung von Personen, Sachen und Wohnungen und dem Aufenthaltsverbot. ${ }^{2039}$ Die Ermächtigungsgrundlagen sprechen dabei meist von „Tatsachen, die die Annahme eines bestimmten Geschehens rechtfertigen“. ${ }^{2040}$

Problematisch wird es da, wo eine Maßnahme bei einem Gefahrenverdacht nur auf eine Ermächtigungsgrundlage gestützt werden könnte, die in tatbestandlicher Hinsicht das Vorliegen einer konkreten Gefahr verlangt (so insbesondere die Generalklausel). Nur wenn der Gefahrenverdacht zugleich als konkrete Gefahr qualifiziert werden kann, wäre ein Einschreiten möglich.

Ein Teil der Literatur sieht den Gefahrenverdacht deshalb als Unterform der konkreten Gefahr an. ${ }^{2041}$ Dagegen spricht jedoch, dass bei einem Gefahrenverdacht über die hinreichende Wahrscheinlichkeit eines Schadenseintritts gerade Unklarheit besteht.

Nach einer weiteren Ansicht soll es hingegen möglich sein, im Einzelfall zu untersuchen, ob ein Schaden mit hinreichender Wahrscheinlichkeit droht - nur dann könne der Gefahrenverdacht auch als konkrete Gefahr qualifiziert werden. ${ }^{2042}$ Dafür müsste dann jedoch ausnahmsweise der objektive Gefahrbegriff zugrunde gelegt werden, weil aus der ex ante Perspektive ja gerade Ungewissheit darüber besteht, ob eine konkrete Gefahr vorliegt. ${ }^{2043}$

Nach a. A. soll das Recht der Polizei- und Ordnungsbehörden zu Eingriffen nach der Generalklausel auch dann bestehen, wenn keine konkrete Gefahr vorliegt, weil der Generalklausel eine stillschweigende Ermächtigung dazu zu entnehmen sei. ${ }^{2044}$ Beschränkt seien Maßnahmen aus Verhältnismäßigkeitsgesichtspunkten aber auf Gefahrerforschungseingriffe. ${ }^{2045}$ Bei Gefahrerforschungseingriffen handelt es sich um der weiteren Erforschung des Sachverhalts dienende Maßnahmen, um herauszufinden, ob eine konkrete Gefahr besteht oder nicht. ${ }^{2046}$

2039 Kingreen/Poscher, Polizei- und Ordnungsrecht mit Versammlungsrecht, 10. Aufl. 2018, § 8 Rn. 53.

2040 Näher zu den möglichen Spezialermächtigungen Schenke, JuS 2018, 505 (509).

2041 Kingreen/Poscher, Polizei- und Ordnungsrecht mit Versammlungsrecht, 10. Aufl. 2018, § 9 Rn. 24.

2042 Schenke, JuS 2018, 505 (510).

2043 Meyer, JURA 2017, 1259 (1265); Schenke, Polizei- und Ordnungsrecht, 10. Aufl. 2018, Rn. 88a.

2044 Götz/Geis, Allgemeines Polizei- und Ordnungsrecht, 16. Aufl. 2017, § 6 Rn. 31.

2045 Vgl. Schenke, JuS 2018, 505 (510).

2046 Schenke, Polizei- und Ordnungsrecht, 10. Aufl. 2018, Rn. 86.

Nikolas Eisentraut 
Richtigerweise sollten bei bloßem Gefahrenverdacht, bei dem eine konkrete Gefahrensituation fehlt, allein Gefahrerforschungseingriffe zulässig sein, die nicht in die Rechte des Betroffenen eingreifen und deshalb auch keiner Ermächtigungsgrundlage bedürfen. ${ }^{2047}$ Solange keine Ermächtigungsnormen in den Polizei- und Ordnungsgesetzen geschaffen wurden, die eingreifende Maßnahmen im Falle eines Gefahrenverdachts ermöglichen, ${ }^{2048}$ sind sie mangels Gefahr als rechtwidrig zu qualifizieren. Dafür sprechen die ganz zentralen Grundsätze des Vorrangs und Vorbehalts des Gesetzes. ${ }^{2049}$

Die Wahrscheinlichkeit ist jedenfalls dann hinreichend konkret, wenn eine

\section{Schädigung bereits eingetreten ist oder jedenfalls mit Sicherheit zu erwar-} ten ist. ${ }^{2050} \mathrm{Im}$ Bereich darunter variieren die Anforderungen an die Wahrscheinlichkeit in Abhängigkeit vom Rechtsgut: Je gewichtiger das Rechtsgut ist, umso geringer sind die Anforderungen an die hinreichende Wahrscheinlichkeit. ${ }^{2051}$

Hausarbeitswissen: Wie weit der Begriff der konkreten Gefahr in das Vorfeld der Tatbegehung reicht, ist zuletzt intensiv in die Diskussion geraten. Ausgangspunkt waren in Reaktion auf das BKAG-Urteil des BVerfG ${ }^{2052}$ vorgenommene Änderungen am Bayerischen Polizeiaufgabengesetz. ${ }^{2053}$ Mit der sog. „drohenden Gefahr" ${ }^{\text {“2054 }}$ wurde in $\S 11$ Abs. 3 PAG Bayern eine neue „Gefahrenkategorie“ eingeführt, mittels derer bereits die Entstehung einer Gefahr verhindert werden können soll. Unklar ist, ob es sich hierbei um einen Unterfall einer konkreten Gefahr handelt, bei der nur die Wahrscheinlichkeitsschwelle in Hinblick auf die zeitliche und sachliche Dimension gelockert wurde ${ }^{2055}$ oder ob es sich bei der drohenden Gefahr um eine Verlagerung der Eingriffsermächtigung in den einer Gefahr vorgelagerten Bereich handelt. Für Letzteres spricht, das es ansonsten gar keiner Normierung bedurft hätte. In seinem BKAG-Urteil hat das BVerfG jedenfalls nur Überwachungsmaßnahmen bei terroristischen Gefahren im Falle einer drohenden Gefahr für zulässig gehalten; insofern entspricht die

2047 Schenke, Polizei- und Ordnungsrecht, 10. Aufl. 2018, Rn. 88a.

2048 Zu dieser Forderung Schenke, JuS 2018, 505 (510).

2049 Schenke, Polizei- und Ordnungsrecht, 10. Aufl. 2018, Rn. 88a.

2050 Kingreen/Poscher, Polizei- und Ordnungsrecht mit Versammlungsrecht, 10. Aufl. 2018, § 8 Rn. 6.

2051 Kingreen/Poscher, Polizei- und Ordnungsrecht mit Versammlungsrecht, 10. Aufl. 2018, § 8 Rn. 6.

2052 BVerfG, Urt. v. 20.4.2016, Az.: 1 BvR 966/09 = BVerfGE 141, 220; dazu Kießling, VerwArch 2017, 282.

2053 Kingreen/Poscher, Polizei- und Ordnungsrecht mit Versammlungsrecht, 10. Aufl. 2018, § 8 Rn. 15.

2054 Umfassend zum Begriff Leisner-Egensperger, DÖV 2018, 677.

2055 So Kingreen/Poscher, Polizei- und Ordnungsrecht mit Versammlungsrecht, 10. Aufl. 2018, $\S 8$ Rn. 16. 
Kategorie der drohenden Gefahr der des Gefahrenverdachts. ${ }^{2056}$ Die weitergehenden Eingriffsbefugnisse nach der bayerischen Regelung werden deshalb für verfassungswidrig erachtet. ${ }^{2057}$

1117 Der Gefahrbegriff wird für die Standardmaßnahmen teilweise qualifiziert (sog. qualifizierte Gefahren), sodass über das Vorliegen einer konkreten Gefahr hinausgehende Voraussetzungen $\mathrm{zu}$ prüfen sind. ${ }^{2058}$ Die Normierung der Standardbefugnisse folgt insofern der Je-Desto-Formel: Je eingriffsintensiver eine polizeiliche Maßnahme ist, desto höher sind die Anforderungen an den Gefahrbegriff. ${ }^{2059}$ Die Begriffe der „Gefahr für Leib und Leben“, der „gemeinen Gefahr“ und der „erheblichen Gefahr“ zeigen an, dass ein besonderes Gewicht der drohenden Schädigung vorliegen muss. ${ }^{2060}$ Wenn eine besondere zeitliche Nähe verlangt wird, sprechen die Polizei- und Ordnungsgesetze von „gegenwärtiger Gefahr“, „unmittelbar bevorstehender Gefahr“ oder einer „Gefahr im Verzug“. 2061 Der Begriff der „dringenden Gefahr“ wird nicht einheitlich zwischen diesen Polen verortet. ${ }^{2062}$

\section{(d) Polizei- und Ordnungspflichtigkeit}

1118 Auch wenn sich dies nicht unmittelbar aus dem Wortlaut der Generalklausel ergibt, dürfen auf die Generalklausel gestützte Verwaltungsakte rechtmäßiger Weise nur an die sog. Polizei- bzw. Ordnungspflichtigen adressiert werden. ${ }^{2063}$ Dies wird für alle Maßnahmen nach den Polizei- und Ordnungsgesetzen in eigenständigen Normen angeordnet. ${ }^{2064}$

1119 Teilweise wird die Polizei- und Ordnungspflichtigkeit nicht der Prüfung der Tatbestandsmerkmale zugeordnet, sondern als eigener Prüfungspunkt zwi-

2056 Trurnit, JURA 2019, 258 (265); Weiterentwicklung nach Shirvani, DVBl 2018, 1393 (1395). 2057 Kingreen/Poscher, Polizei- und Ordnungsrecht mit Versammlungsrecht, 10. Aufl. 2018, § 8 Rn. 18; Shirvani, DVBl 2018, 1393; a. A. Holzner, DÖV 2018, 946.

2058 Schenke, Polizei- und Ordnungsrecht, 10. Aufl. 2018, Rn. 78.

2059 Trurnit, JURA 2019, 258 (263).

2060 Kingreen/Poscher, Polizei- und Ordnungsrecht mit Versammlungsrecht, 10. Aufl. 2018, § 8 Rn. 21.

2061 Kingreen/Poscher, Polizei- und Ordnungsrecht mit Versammlungsrecht, 10. Aufl. 2018, § 8 Rn. 21.

2062 Kingreen/Poscher, Polizei- und Ordnungsrecht mit Versammlungsrecht, 10. Aufl. 2018, § 8 Rn. 21.

2063 Kingreen/Poscher, Polizei- und Ordnungsrecht mit Versammlungsrecht, 10. Aufl. 2018, § 9 Rn. 1.

2064 S. bspw. für Berlin die $\S \S 13,14$ und 16 ASOG.

\section{Nikolas Eisentraut}


schen Tatbestand und Rechtsfolge geprüft. ${ }^{2065}$ Vorliegend wird die Prüfung, ob überhaupt ein Polizei- bzw. Ordnungspflichtiger in Anspruch genommen wurde, bereits als Aspekt der Tatbestandsmäßigkeit geprüft. Die Frage der richtigen Auswahl unter mehreren in Betracht kommenden Störern wird hingegen als Ermessensentscheidung der Rechtsfolgenseite zugeordnet.

In den Polizei- und Ordnungsgesetzen wird zwischen verschiedenen Polizei-/ 1120 Ordnungspflichtigen unterschieden:

(1.) dem Verhaltensstörer, (2.) dem Zustandsstörer und (3.) dem Nichtstörer.

(1.) Der Verhaltensstörer ist derjenige, dessen Handeln oder Unterlassen die $\mathbf{1 1 2 1}$ Gefahrenquelle darstellt (sog. Verhaltensverantwortlichkeit). ${ }^{2066}$ Bei der Verhaltensverantwortlichkeit kommt es weder darauf an, dass den Verhaltensstörer ein Verschulden trifft, noch darauf, ob der Störer einsichts- oder verschuldensfähig ist. $^{2067}$

Examenswissen: Für Kinder unter 14, teilweise auch unter 16 Jahren wird zudem eine sog. Zusatzverantwortlichkeit der aufsichtspflichtigen Personen angenommen, die neben die Verhaltensverantwortlichkeit tritt. ${ }^{2068}$

Wann ein Handeln oder Unterlassen für eine Gefahrenquelle ursächlich ist, wird 1123 im Polizei- und Ordnungsrecht nach der sog. Theorie der unmittelbaren Verursachung beurteilt. ${ }^{2069}$ Danach ist jedes Verhalten ursächlich, das die „Gefahrengrenze“ "überschreitet. ${ }^{2070}$ Dafür erforderlich ist letztlich eine Wertung, welcher Beitrag noch als unmittelbare Verursachung gelten soll. ${ }^{2071}$ In Prüfungsarbeiten ist daher unter Auswertung der Sachverhaltsangaben eine vertretbare und mit Argumenten untermauerte Lösung zu finden, ob ein Beitrag eine Verhaltensverantwortlichkeit begründen kann oder nicht.

2065 Allgemein für die Adressatenstellung Peine/Siegel, Allgemeines Verwaltungsrecht, 12. Aufl. 2018, Rn. 526, 528.

2066 Kingreen/Poscher, Polizei- und Ordnungsrecht mit Versammlungsrecht, 10. Aufl. 2018, § 9 Rn. 2.

2067 Kingreen/Poscher, Polizei- und Ordnungsrecht mit Versammlungsrecht, 10. Aufl. 2018, § 9 Rn. 5.

2068 Näher Schenke, Polizei- und Ordnungsrecht, 10. Aufl. 2018, Rn. 265 ff.; Kingreen/Poscher, Polizei- und Ordnungsrecht mit Versammlungsrecht, 10. Aufl. 2018, § 9 Rn. 5.

2069 Die aus dem Strafrecht bekannte Äquivalenztheorie findet keine Anwendung, s. näher Kingreen/Poscher, Polizei- und Ordnungsrecht mit Versammlungsrecht, 10. Aufl. 2018, § 9 Rn. 10 sowie auch Schenke, Polizei- und Ordnungsrecht, 10. Aufl. 2018, Rn. $241 \mathrm{ff}$.

2070 Kingreen/Poscher, Polizei- und Ordnungsrecht mit Versammlungsrecht, 10. Aufl. 2018, § 9 Rn. 15.

2071 Schenke, Polizei- und Ordnungsrecht, 10. Aufl. 2018, Rn. 243. 
Eine besondere und in Klausurlösungen als Standardproblem zu beherrschende Problematik stellt die Fallgruppe der sog. Zweckveranlasser dar. Zweckveranlasser ist derjenige, der das Verhalten eines Verhaltensstörers subjektiv oder objektiv bezweckt, anstatt selbst die Gefahrengrenze zu überschreiten. ${ }^{2072}$

Beispiel: Eine Schaufensterwerbung führt dazu, dass es zu Menschenansammlungen nicht nur auf dem Gehsteig, sondern auch auf der Straße kommt, sodass der Straßenverkehr behindert wird. Die Gefahrengrenze überschreiten die Passanten, die auf der Fahrbahn stehen. Fraglich ist jedoch, ob auch der das Schaufenster verantwortende Geschäftsinhaber polizeipflichtig ist.

Weiteres Beispiel: Auch der Veranstalter eines Fußballspiels kann als Zweckveranlasser polizeipflichtig sein, wenn es zu Ausschreitungen der Fans kommt. ${ }^{2073}$

1125 Die dogmatische Herleitung der Polizei- und Ordnungspflichtigkeit des Zweckveranlassers stellt die Literatur vor Herausforderungen. ${ }^{2074}$ Ob etwa objektive oder subjektive Kriterien zugrunde zu legen sind, ist umstritten, teilweise wird auch ein Nebeneinander der Theorien angenommen, weil beide Aspekte für die Frage der Zurechnung der Störereigenschaft von Belang sein könnten. ${ }^{2075}$ Teilweise wird die Figur für verzichtbar gehalten, soweit eine Inanspruchnahme als Nichtstörer in Betracht kommt (dazu sogleich Rn. 1128). ${ }^{2076}$ In Prüfungsarbeiten kommt es darauf an, unter Aufzeigung der in der Literatur zum Thema der Zweckveranlassung vertretenen Positionen zu einem vertretbaren Ergebnis $\mathrm{zu}$ gelangen, was wiederum eine gut begründete Wertung verlangt. ${ }^{2077}$

1126 (2.) Der Zustandsstörer ist derjenige, der für eine Sache verantwortlich ist, die die Gefahrenquelle darstellt (sog. Zustandsverantwortlichkeit). ${ }^{2078}$ Sowohl die tatsächliche Gewalt über eine Sache als auch das Eigentum daran können die Verantwortlichkeit begründen. ${ }^{2079}$ Die überwiegende Ansicht fordert auch für eine

2072 Kingreen/Poscher, Polizei- und Ordnungsrecht mit Versammlungsrecht, 10. Aufl. 2018, § 9 Rn. 27; Schoch, JURA 2009, 360.

2073 OVG Berlin-Brandenburg, Beschl. v. 27.9.2013, Az.: 1 S 245.13, juris Rn. 2, s. Kingreen/Poscher, Polizei- und Ordnungsrecht mit Versammlungsrecht, 10. Aufl. 2018, § 9 Rn. 28.

$2074 \mathrm{Zu}$ den Ansätzen Kingreen/Poscher, Polizei- und Ordnungsrecht mit Versammlungsrecht, 10. Aufl. 2018, § 9 Rn. 29.

2075 Näher Schenke, Polizei- und Ordnungsrecht, 10. Aufl. 2018, Rn. 244 f.

2076 In diese Richtung Kingreen/Poscher, Polizei- und Ordnungsrecht mit Versammlungsrecht, 10. Aufl. 2018, § 9 Rn. 31.

2077 Die Figur des Zweckveranlassers präsentieren in einer Falllösung zu einer Original-Examensklausur Hebeler/Spitzlei, JA 2019, 282 (285f.).

2078 Kingreen/Poscher, Polizei- und Ordnungsrecht mit Versammlungsrecht, 10. Aufl. 2018, § 8 Rn. 2.

2079 Schenke, Polizei- und Ordnungsrecht, 10. Aufl. 2018, Rn. 268.

\section{Nikolas Eisentraut}


Sache das Überschreiten der Gefahrengrenze i.S.d. Theorie der unmittelbaren Verursachung. ${ }^{2080}$

Gibt es mehrere Zustands- und womöglich auch Verhaltensstörer, muss 1127 in der Klausur zunächst nur festgestellt werden, dass die Behörde jedenfalls eine als Störer zu qualifizierende Person in Anspruch genommen hat. Ob diese Auswahl auch richtig war, ist eine Frage der Ermessensausübung der Behörde und daher auf Rechtsfolgenseite zu erörtern (s. näher Rn. 1139).

(3.) Sollte weder der Verhaltensstörer, noch der Zustandsstörer in Anspruch 1128 genommen werden können, so können Polizei- und Ordnungsbehörden die Gefahr selbst beseitigen. ${ }^{2081}$ Sollte dies nicht möglich sein, kann schließlich der sog. Nicht-Störer in Anspruch genommen werden. ${ }^{2082}$ Die Voraussetzungen für ein Vorgehen gegen den Nichtstörer (auch polizeilicher Notstand genannt) sind in allen Polizei- und Ordnungsgesetzen der Länder konkretisiert worden. ${ }^{2083}$

Eine besondere Problematik bildet die Frage der Rechtsnachfolge in Polizei- 1129 und Ordnungspflichten. Eine Rechtsnachfolge wird beispielsweise im Todesfall durch die Erbfolge ausgelöst. In diesem Fall stellt sich die Frage, ob die Polizeibzw. Ordnungspflichtigkeit auf den Rechtsnachfolger übergehen kann. Es geht also darum, ob ein polizei- bzw. ordnungsrechtliches Vorgehen gegen den Rechtsnachfolger neu eingeleitet werden muss oder ob es fortgeführt werden kann (indem beispielsweise ein bestandskräftiger Verwaltungsakt auch gegen den Rechtsnachfolger vollstreckt wird). ${ }^{2084}$ Die Diskussion wird durch die Vielzahl an in der Literatur eingeführten Differenzierungskriterien noch erschwert. ${ }^{2085}$ Für eine erfolgreiche Klausurbearbeitung sollte die Kenntnis der folgenden Grundzüge reichen, um zu einer vertretbaren Lösung zu gelangen:

2080 Schenke, Polizei- und Ordnungsrecht, 10. Aufl. 2018, Rn. 268; Kingreen/Poscher, Polizeiund Ordnungsrecht mit Versammlungsrecht, 10. Aufl. 2018, § 9 Rn. 45.

2081 Kingreen/Poscher, Polizei- und Ordnungsrecht mit Versammlungsrecht, 10. Aufl. 2018, § 8 Rn. 2.

2082 Kingreen/Poscher, Polizei- und Ordnungsrecht mit Versammlungsrecht, 10. Aufl. 2018, § 8 Rn. 2.

2083 § 9 BWPolG; Art. 10 bayPAG; Art. 9 III BayLStVG; § 16 ASOG Bln; § 7 BbgPolG; § 18 BbgOBG; $\S 7$ BremPolG; § 10 I HambSOG; § 9 HSOG; § 71 I SOG SOG M-V; § 8 Nds.SOG; § 6 PolG NRW; § 19 NWOBG; § 7 RhPfPOG; § 6 SPolG; § 7 SächsPolG; § 10 SOG LSA; § 220 I SchlHLVwG; § 10 ThürPAG; $\S 13$ ThürOBG; § 20 I BPolG.

2084 Kingreen/Poscher, Polizei- und Ordnungsrecht mit Versammlungsrecht, 10. Aufl. 2018, § 9 Rn. 54.

2085 Die Modifikationen ablehnend Kingreen/Poscher, Polizei- und Ordnungsrecht mit Versammlungsrecht, 10. Aufl. 2018, § 9 Rn. 56.

Nikolas Eisentraut 
Bei höchstpersönlichen Pflichten, also solchen, die allein vom Rechtsvorgänger erfüllt werden können, scheidet eine Rechtsnachfolge aus. ${ }^{2086}$

Ansonsten ist $\mathrm{zu}$ differenzieren, ob es um die Rechtsnachfolge in eine $\mathrm{Zu}$ stands- oder Verhaltensverantwortlichkeit geht und ob sich die Verantwortlichkeit bereits konkretisiert hat.

1131 Eine Rechtsnachfolge in eine abstrakte (noch nicht konkretisierte) Zustandsverantwortlichkeit gibt es nicht. Gegen einen neuen Besitzer ergeht einfach eine neue polizei- bzw. ordnungsbehördliche Maßnahme.

Beispiel: A erbt von B ein Grundstück, auf dem ein Baum steht, der auf das Nachbarhaus zu stürzen droht. Gegenüber B wurde jedoch bisher noch keine Verfügung erlassen, wonach B zum Fällen des Baumes verpflichtet würde. Die Ordnungsbehörde kann auf Grundlage der polizeilichen Generalklausel gegenüber A nunmehr eine solche Anordnung treffen.

1132 Die Rechtsnachfolge in eine bereits konkretisierte Zustandsverantwortlichkeit wurde bisher für möglich gehalten. Die Pflichtigkeit „klebt“ sozusagen an der Sache, nicht am Verantwortlichen. Diese Ansicht ist jedoch in die Kritik geraten; vermehrt wird eine gesetzliche Regelung der Überleitung gefordert. ${ }^{2087}$

Beispiel: Bereits zu B's Lebzeiten hat die Behörde eine Fäll-Verfügung erlassen. Als B verstirbt, geht nach traditioneller Sichtweise mit dem Erbfall auch die mit der Verfügung begründete Pflicht, den Baum zu fällen, von B auf den Erben A über.

1133 Eine Rechtsnachfolge in eine abstrakte Verhaltensverantwortlichkeit scheidet aus, wenn sich der Rechtsnachfolger durch eigenes Verhalten der Polizeipflichtigkeit aussetzt. Eine Rechtsnachfolge kommt hier nur bei sog. ,unfertigen Verpflichtungen“ in Betracht. ${ }^{2088}$

Beispiel (angelehnt an Kingreen/Poscher, Polizei- und Ordnungsrecht mit Versammlungsrecht, 10. Aufl. 2018, § 9 Rn. 51): Rockstar R spielt zur Nachtzeit regelmäßig und unter voller Verstärkung seine E-Gitarre. Damit gefährdet er die Gesundheit der Patienten im benachbarten Krankenhaus. Als $R$ verstirbt, setzt sein Sohn $S$ die Tätigkeit fort. Die Ordnungsbehörde kann nunmehr direkt gegenüber $S$ eine Ordnungsverfügung erlassen, die ihm das nächtliche Gitarrenspiel untersagt.

2086 Kingreen/Poscher, Polizei- und Ordnungsrecht mit Versammlungsrecht, 10. Aufl. 2018, § 9 Rn. 54.

2087 Siegel, in: Siegel/Waldhoff, Öffentliches Recht in Berlin, 2. Aufl. 2017, § 2 Rn. 115.

2088 Siegel, in: Siegel/Waldhoff, Öffentliches Recht in Berlin, 2. Aufl. 2017, § 2 Rn. 117.

Nikolas Eisentraut 
Die Rechtsnachfolge in eine konkretisierte Verhaltensverantwortlichkeit soll 1134 ohne Überleitungsregelung nicht zulässig sein. ${ }^{2089}$

Beispiel: Gegenüber R wird eine Ordnungsverfügung erlassen, bevor er verstirbt. Ohne Überleitungsvorschrift entfaltet die Ordnungsverfügung keine Wirkungen gegenüber $S$.

\section{(2) Rechtsfolge: Ermessen}

Die Generalklauseln der Polizei- und Ordnungsgesetze eröffnen der zuständi1135 gen Behörde auf Rechtsfolgenseite Ermessen („kann“) (s. allgemein zum Ermessen Rn. 729 ff.). ${ }^{2090}$ Die behördliche Maßnahme ist daher auf Ermessensfehler zu untersuchen.

Untersucht werden muss einerseits, ob die Behörde ihr Entschließungser- 1136 messen und andererseits, ob sie ihr Auswahlermessen fehlerfrei ausgeübt hat. Folgende Fragen sind im allgemeinen Polizei- und Ordnungsrecht in diesem Kontext typischerweise zu thematisieren:

Im Rahmen der Prüfung des Auswahlermessens kann zunächst zu untersuchen sein, ob die Ermächtigungsgrundlage überhaupt die von der Behörde ergriffene Maßnahme deckt. ${ }^{2091}$ Da die Generalklausel dazu ermächtigt, die „erforderlichen Maßnahmen“ zu ergreifen, ist zu untersuchen, ob die Behörde ihr Ermessen überschritten und in Bezug auf die jeweils streitgegenständliche Maßnahme unverhältnismäßig gehandelt hat. ${ }^{2092}$

Aufbauhinweis: Teilweise wird die Verhältnismäßigkeit auch außerhalb der 1138 Ermessensfehler geprüft, weil die Polizei- und Ordnungsgesetze Verhältnismäßigkeit und Ermessen in jeweils eigenständigen Regelungen thematisieren. Nach überzeugender Ansicht handelt es sich bei der Verhältnismäßigkeit indes um einen Aspekt der Ermessensüberschreitung. ${ }^{2093}$

In die Prüfung des Auswahlermessens auf Ermessensfehler fällt auch die 1139 Frage, ob die Behörde die Auswahl unter mehreren Störern rechtsfehlerfrei getroffen hat. Diese Frage ist nur dann aufzuwerfen, wenn auch mehrere taugliche Adressaten für die Maßnahme in Betracht kommen. ${ }^{2094}$ Die Auswahl richtet sich stets zunächst nach dem Effektivitätsgebot, sodass die Behörde grundsätzlich den

2089 Siegel, in: Siegel/Waldhoff, Öffentliches Recht in Berlin, 2. Aufl. 2017, § 2 Rn. 117.

2090 Kingreen/Poscher, Polizei- und Ordnungsrecht mit Versammlungsrecht, 10. Aufl. 2018, § 10 Rn. 34.

2091 Peine/Siegel, Allgemeines Verwaltungsrecht, 12. Aufl. 2018, Rn. 530.

2092 Zum Verhältnismäßigkeitsgrundsatz im Polizei- und Ordnungsrecht näher Kingreen/Poscher, Polizei- und Ordnungsrecht mit Versammlungsrecht, 10. Aufl. 2018, § 10 Rn. $15 \mathrm{ff}$.

2093 Peine/Siegel, Allgemeines Verwaltungsrecht, 12. Aufl. 2018, Rn. $535 \mathrm{f}$.

2094 Peine/Siegel, Allgemeines Verwaltungsrecht, 12. Aufl. 2018, Rn. 529.

Nikolas Eisentraut 
Störer heranziehen darf, durch den sich die Gefahrenbeseitigung am wirksamsten realisieren lässt. ${ }^{2095}$ Bei gleicher Effektivität ist hilfsweise auf den Verhältnismäßigkeitsgrundsatz abzustellen. 2096

\section{f) Literaturhinweise}

1140 Lehrbuchliteratur zum Polizei- und Ordnungsrecht: Kingreen/Poscher, Polizeiund Ordnungsrecht mit Versammlungsrecht, 10. Aufl. 2018; Schoch, Polizei- und Ordnungsrecht, in: Schoch, Besonderes Verwaltungsrecht, 2018; Schenke, Polizei- und Ordnungsrecht, 10. Aufl. 2018; Götz/Geis, Allgemeines Polizei- und Ordnungsrecht, 16. Aufl. 2017; Gusy, Polizei- und Ordnungsrecht, 10. Aufl. 2017; Lisken/Denninger, Handbuch des Polizeirechts, 6. Aufl. 2018

Lesenswerte Aufsätze: Poscher/Rusteberg, Die Klausur im Polizeirecht, JuS 2011, S. 888 ff., S. 984 ff., 1082ff.; Möstl, Standardmaßnahmen des Polizei- und Ordnungsrechts, JURA 2011, S. 840 ff.; Trurnit, JURA 2019, 258 - Eingriffsschwellen für polizeiliche Maßnahmen; Meyer, JURA 2017, 1259 - Subjektiver oder objektiver Gefahrbegriff, „Gefahrenverdacht“ und Vorfeldbefugnisse: Dauerbaustellen des Gefahrenabwehrrechts; Danne, JuS 2018, 434 - Doppelfunktionale Maßnahmen in der öffentlich-rechtlichen Klausur; Stückemann, JA 2015, 569 Die Rechtsnachfolge in die gefahrenabwehrrechtliche Verhalts- und Zustandsverantwortlichkeit

Falllösung: Fall 1 in: Eisentraut, Fälle zum Verwaltungsrecht, 2020

\section{Ermächtigungsgrundlagen des Versammlungsrechts (Sebastian Eickenjäger)}

1141 Das Versammlungsrecht ist eines der Kernrechtsgebiete des besonderen Verwaltungsrechts, in Studium und Examen stets klausurrelevant ${ }^{2097}$ und nicht zuletzt auch in der Praxis von erheblicher Bedeutung. In Theorie und Praxis stellen sich aktuell Herausforderungen z. B. im Hinblick auf Versammlungen im Rahmen von Großveranstaltungen (G 20), sog. „gemischten“ Veranstaltungen, ${ }^{2098}$

2095 Kingreen/Poscher, Polizei- und Ordnungsrecht mit Versammlungsrecht, 10. Aufl. 2018, § 9 Rn. 89.

2096 Kingreen/Poscher, Polizei- und Ordnungsrecht mit Versammlungsrecht, 10. Aufl. 2018, § 9 Rn. 90.

2097 S. hierzu die in Rn. 1221 angeführten Literaturhinweise.

2098 S. hierzu Petersen, DÖV 2019, 131.

Nikolas Eisentraut/Sebastian Eickenjäger 
Versammlungen im privaten Raum ${ }^{2099}$ (Fraport) sowie hinsichtlich neuer Protestformen (Protestcamps, ${ }^{2100}$ Blockupy Proteste, Flash- und Smartmobs, ${ }^{2101}$ virtuelle Versammlungen ${ }^{2102}$ etc.). $\mathrm{Zu}$ berücksichtigen ist zudem, dass die Versammlungsfreiheit aus Art. 8 GG in hohem Maße durch die Rechtsprechung des BVerfG geprägt wurde und zunehmend auch eine Überlagerung des nationalen Versammlungsrechts durch europäisches, internationales und transnationales Recht $^{2103} \mathrm{zu}$ beobachten ist. Seit die Länder durch die Föderalismusreform im Jahre 2006 die ausschließliche Gesetzgebungskompetenz im Bereich des Versammlungsrechts erlangt haben, sind zudem in Bayern, Niedersachsen, Sachsen, Sachsen-Anhalt und Schleswig-Holstein Landesversammlungsgesetze neben das Bundesversammlungsgesetz (VersammlG) getreten, die teilweise Eingriffsbefugnisse neu regeln. In den Ländern, die bisher kein eigenes Landesversammlungsgesetz erlassen haben, gilt das Versammlungsgesetz des Bundes (VersammlG) gemäß Art. 125a I 1 GG als Bundesrecht fort.

Die folgende Tabelle führt die Versammlungsgesetze des Bundes und der 1142 Länder auf:

\begin{tabular}{ll}
\hline Bund & $\begin{array}{l}\text { Gesetz über Versammlungen und Aufzüge (VersammIG) vom 15. November } \\
\text { 1978 (BGBl. I 1789), zuletzt geändert durch Art. } 2 \text { G vom 8. Dezember 2008 } \\
\text { (BGBl. I S. 2366) }\end{array}$ \\
\hline Bayern & Bayerisches Versammlungsgesetz (BayVersG) vom 22. Juli 2008 (GVBI. \\
& S. 421), ab 1. 10. 2008; zuletzt geändert durch § 1 ÄndG vom 23.11. 2015 \\
& (GVBI. S. 410) \\
\hline Niedersachsen & Niedersächsisches Versammlungsgesetz (NdsVersG) vom 7. Oktober 2010 \\
& ab 1.2.2011 (Nds. GVBI. S. 465, ber. S. 532) \\
\hline Sachsen & Gesetz über Versammlungen und Aufzüge im Freistaat Sachsen (Sächs- \\
& VersG) vom 25. Januar 2012 (SächsGVBI. S. 54); zuletzt geändert durch \\
& Art. 4 ÄndG vom 17.12.2013 (SächsGBI. S. 890)
\end{tabular}

2099 S. BVerfG, Urt. v. 22.2.2011, Az.: 1 BvR 699/06 = BVerfGE 128, 266 - Fraport sowie Scharlau, Schutz von Versammlungen auf privatem Grund, 2018.

2100 S. hierzu etwa Hartmann, NVwZ 2018, 200 und Friedrich, DÖV 2019, 55.

2101 S. hierzu Lenski, VerwArch 103 (2012), 539; Neumann, NVwZ 2011, 1171.

2102 S. hierzu etwa Kersten, JuS 2017, 193; Möhlen, MMR 2013, 221; Vogelsang, Kommunikationsformen des Internetzeitalters im Lichte der Kommunikationsfreiheiten des Grundgesetzes, 2017.

2103 S. hierzu Ripke, Europäische Versammlungsfreiheit, 2012; Eickenjäger/Fischer-Lescano, Transnationalisierung des Versammlungsrechts, in: Ridder/Breitbach/Deiseroth, Kommentar Versammlungsrecht, i.E. 
Sachsen-Anhalt Gesetz des Landes Sachsen-Anhalt über Versammlungen und Aufzüge (VersG LSA) vom 3. Dezember 2009 (GVBI. LSA S. 558), ab 12.12.2009

Schleswig-Holstein Versammlungsfreiheitsgesetz für das Land Schleswig-Holstein (VersFG SH) vom 18. Juni 2015 (GVOBI. Schlesw.-H. 135)

\section{a) Versammlungsrecht in der Klausurbearbeitung}

1143 In der Klausur wird es sich regelmäßig um Anfechtungssituationen im Hinblick auf Maßnahmen gegen (geplante) Versammlungen handeln. Da die Maßnahmen nach dem Versammlungsrecht typischerweise als Verwaltungsakte zu qualifizieren sind, ist damit im Grundsatz die Anfechtungsklage statthaft.

1144 In Abwandlung der Grundkonstellation der Anfechtungsklage treffen Studierende zudem auf die Konstellation, dass eine geplante Versammlung unmittelbar bevorsteht. Hier ist oftmals ein Antrag auf Eilrechtsschutz nach § 80 V VwGO, gerichtet auf die Wiederherstellung bzw. Anordnung der aufschiebenden Wirkung eines Rechtsbehelfs, gegen sofort vollziehbare Maßnahmen zu prüfen (zum Antrag nach § $80 \mathrm{~V}$ VwGO § 8).

1145 Außerdem ist in der Klausur häufig die Fortsetzungsfeststellungklage statthaft, etwa wenn es um bereits erledigte Maßnahmen im Rahmen einer Versammlung oder um eine Auflösung der Versammlung geht. Das erforderliche Fortsetzungsfeststellungsinteresse wird hierbei regelmäßig aufgrund schwerwiegender Eingriffe in Art. 8 GG, eines bestehenden Rehabilitationsinteresses oder aufgrund bestehender Wiederholungsgefahr gegeben sein (zur Fortsetzungsfeststellungsklage § 4).

1146 Die Feststellungsklage nach $\S 43$ I VwGO ist im Rahmen des Versammlungsrechts etwa bzgl. der Feststellung der Rechtswidrigkeit der Erhebung und Verarbeitung von Daten einschlägig. ${ }^{2104}$ An einem anfechtbaren Verwaltungsakt fehlt es auch bei den in Klausuren immer wieder relevanten Gefährderinnenansprachen (s. hierzu auch Rn. 224f. und 1003 (Polizeirecht)), mit denen einzelnen Personen empfohlen wird, von Veranstaltungen fernzubleiben und zugleich mitgeteilt wird, dass ihnen gegenüber ansonsten Maßnahmen nach dem Polizeioder Versammlungsrecht vorgenommen werden, soweit die Voraussetzungen hierfür vorliegen (zur Feststellungsklage näher § 6).

2104 S. BVerwG, Urt. v. 25.10.2017, Az.: 6 C 45.16 = BeckRS 2017, 138147, wo mit der Erhebung der Feststellungsklage u.a. die Feststellung der Rechtswidrigkeit der Anfertigung von Bildaufnahmen mittels des Einsatzes von Tornado-Kampfflugzeugen begehrt wurde. 
Examenswissen: Entsprechende Anschreiben oder Ansprachen enthalten hinweisende Elemente (Mitteilung des Kenntnisstandes der Behörde bezüglich der betreffenden Person), empfehlende Elemente (den Hinweis, bestimmte Dinge zu tun bzw. zu unterlassen) und auch warnende Elemente (es drohen bestimmte behördliche Maßnahmen, wenn die Person nicht wie empfohlen handelt), geben jedoch kein Tun, Dulden oder Unterlassen rechtsverbindlich auf. Da die Ansprachen damit nicht darauf gerichtet sind, eine verbindliche Rechtsfolge festzusetzen und es mithin an einer Regelung im Sinne des $\S 351$ VwVfG fehlt, sind sie nicht als Verwaltungsakt zu qualifizieren. Die statthafte Klageart wäre somit entweder die allgemeine Leistungsklage (wenn die Ansprache oder ein Anschreiben für gegenstandslos erklärt werden soll) oder die Feststellungsklage (wenn festgestellt werden soll, dass die Behörde nicht berechtigt war, eine entsprechende Ansprache vorzunehmen oder ein entsprechendes Schreiben aufzusetzen) (zur allgemeinen Leistungsklage näher §5).

Die genannten Klausurkonstellationen setzen jeweils voraus, dass die zentralen 1148 Eingriffsgrundlagen des Versammlungsrechts geprüft werden können. Im Folgenden werden daher die für die Fallbearbeitung wichtigsten Eingriffsgrundlagen vorgestellt. Hierbei werden zwei Unterscheidungen vorgenommen: Zum einen zwischen Ermächtigungsgrundlagen für Eingriffe in Versammlungen unter freiem Himmel und Versammlungen in geschlossenen Räumen und zum anderen zwischen den Eingriffsbefugnissen nach dem Bundesversammlungsgesetz (VersammlG) und den Landesversammlungsgesetzen.

\section{b) Ermächtigungsgrundlagen}

Bevor in der Klausur Eingriffsgrundlagen des Versammlungsrechts (hierzu unten dd) herangezogen werden, ist zunächst (zumindest gedanklich) zu prüfen, ob der Anwendungsbereich der Versammlungsgesetze des Bundes und der Länder überhaupt eröffnet ist. Dies kann verneint werden, wenn keine Versammlung im Sinne der jeweiligen Versammlungsgesetze vorliegt (aa), wenn das jeweilige Versammlungsgesetz nur auf öffentliche Versammlungen Anwendung findet, es sich jedoch um eine nichtöffentliche Versammlung handelt (bb), und zuletzt, wenn ausnahmsweise die Sperrwirkung des Versammlungsrechts (sogenannte Polizeirechtsfestigkeit des Versammlungsrechts, s. dazu auch Rn. 1037 ff.) nicht greift (cc).

\section{aa) Versammlungsbegriffe der Versammlungsgesetze}

Zunächst zu der Frage, wann eine Veranstaltung nach den der Versammlungs- 1150 gesetze jeweils zugrundeliegenden Versammlungsbegriffen als Versammlung zu qualifizieren ist: 
Versammlung vor. In der Literatur besteht deshalb Uneinigkeit bzgl. der Frage, ob zwischen dem Begriff des §1 VersammlG und dem des Art. 8 I GG zu unterscheiden oder von einem einheitlichen Versammlungsbegriff auszugehen ist. ${ }^{2105}$ Eine Unterscheidung ist jedenfalls dort vorzunehmen, wo der Schutzbereich des Art. 8 I GG und der Regelungsbereich des VersammlG auseinanderfallen. ${ }^{2106} \mathrm{Zu}$ beachten ist in diesem Zusammenhang zunächst, dass Art. 8 I GG die Versammlungsfreiheit dem Wortlaut nach als Bürgerrecht vorsieht, ${ }^{2107}$ nach §1 I VersammlG jedoch ,jedermann“ berechtigt ist. Außerdem schützt Art. 8 I GG öffentliche wie nichtöffentliche Versammlungen, während das VersammlG gemäß $\S 1$ I grds. nur öffentliche Versammlungen umfasst (s. hierzu Rn. 1157f.). Schließlich sind vom VersammlG auch unfriedliche Versammlungen umfasst, obwohl diese vom Schutzbereich des Art. 8 I GG ausgeschlossen sind. ${ }^{2108}$

Von diesen Unterschieden abgesehen ist auf den Versammlungsbegriff des Art. 8 I GG in der Ausprägung durch die Rechtsprechung des BVerfG abzustellen, wonach es sich bei Zusammenkünften mehrerer Personen zur gemeinschaftlichen, auf die Teilhabe an der öffentlichen Meinungsbildung gerichteten Erörterung oder Kundgebung um eine Versammlung handelt. ${ }^{2109}$ In der Literatur besteht im Hinblick auf diese Definition Uneinigkeit darüber, welche Mindestteilnehmer^innenzahl gegeben sein muss und welche materiellen Anforderungen an den Zweck einer Veranstaltung zu stellen sind.

1153 Bzgl. der erforderlichen Anzahl der Teilnehmer^innen geht die h.M. von einer Mindestanzahl von zwei Personen aus, während andere mindestens drei ${ }^{2110}$ oder - mit Verweis auf die Mindestpersonenzahl für die Gründung von Vereinen - sieben Personen fordern. ${ }^{2111}$

1154 Im Hinblick auf die Anforderungen an den Zweck einer Veranstaltung besteht Einigkeit darüber, dass bloße Ansammlungen mangels innerer Verbindung nicht von der Versammlungsfreiheit geschützt werden. Davon abgesehen werden ein enger und ein weiter Versammlungsbegriff vertreten. Der weite Versamm-

2105 Laut BVerwG entspricht der Versammlungsbegriff des Versammlungsgesetzes demjenigen des Grundgesetzes, Urt. v. 16.05.2007, Az.: 6 C 23/06 = BVerwGE 129, 42 [45]. Zu dem Streitstand s. Kniesel/Braun/Keller, Besonderes Polizei- und Ordnungsrecht, 1. Aufl. 2018, Rn. 174 ff. m.w. N. 2106 Kniesel/Braun/Keller, Besonderes Polizei- und Ordnungsrecht, 1. Aufl. 2018, Rn. 174.

2107 S. hierzu Fischer-Lescano, Deutschengrundrechte: Ein Anachronismus, 2019, i.E.

2108 Kniesel/Braun/Keller, Besonderes Polizei- und Ordnungsrecht, 1. Aufl. 2018, Rn. 175.

2109 S. zuletzt BVerfG, Beschl. v. 27.10.2016, Az.: 1 BvR 458/10 = BVerfGE 143, 161 (210).

2110 OLG Saarbrücken, Beschl. v. 15.09.1998, Az.: Ss Z 225-98 (106-98) = NStZ-RR 1999, 119. 2111 S. hierzu Kniesel/Braun/Keller, Besonderes Polizei- und Ordnungsrecht, 1. Aufl. 2018, Rn. 62. 
lungsbegriff will eine Öffnung zugunsten von unpolitischen und privaten Formen des sich-versammelns umfassen, so dass auch ausschließlich genussorientierte Sport- und Musikveranstaltungen umfasst wären, solange kollektive Öffentlichkeit besteht. ${ }^{2112}$ Der enge Versammlungsbegriff, zu dem wohl auch das BVerfG tendiert, ${ }^{2113}$ verlangt, dass über das bloße Sich-Versammeln hinaus eine Meinungskundgabe erfolgen muss, die das Ziel hat, auf die Öffentlichkeit einzuwirken. ${ }^{2114}$

Examenswissen: Der EGMR hat zuletzt ausdrücklich davon abgesehen, den Versammlungsbegriff (des Art. 11 I EMRK) zu definieren oder Kriterien zur Bestimmung festzulegen, um die Gefahr einer restriktiven Interpretation zu vermeiden. ${ }^{2115}$ Im Anschluss daran wird in der Literatur für einen offenen Versammlungsbegriff plädiert, der sich von formellen (insbesondere körperliche Anwesenheit oder Mindestteilnehmer`innenzahl) und materiellen (bestimmter Zweck der Meinungsbildung) Kriterien freimacht und das Vorliegen einer Versammlung bejaht, wenn die Möglichkeit besteht, dass die Versammlung der kommunikativen Entfaltung in der Öffentlichkeit dient und es sich um einen Beitrag zur demokratischen Öffentlichkeit handelt. ${ }^{2116}$

Die Versammlungsgesetze Bayerns, Niedersachsens, Sachsens und Schleswig- 1156 Holsteins haben den engen Versammlungsbegriff des BVerfG übernommen. ${ }^{2117}$ In $\S 2$ I VersFG SH wurde eine Mindestteilnehmer^innenzahl von drei Personen und in Art. 2 I BayVersG, § 2 NdsVersG sowie $§ 1$ III SächsVersG von zwei Personen bestimmt. § 1 VersG LSA ist wortgleich mit § 1 VersammlG, womit diesbezüglich auf die Ausführungen zum Bundesversammlungsgesetz verwiesen werden kann.

\section{bb) Öffentliche und nichtöffentliche Versammlungen}

Die Versammlungsgesetze des Bundes und der Länder beantworten die Frage, ob 1157 sie sowohl auf öffentliche als auch auf nichtöffentliche Versammlungen anwendbar sind oder nicht, ganz unterschiedlich.

Bzgl. des VersammlG - dessen Eingriffsbefugnisse nicht auf nichtöffentliche Versammlungen anzuwenden sind - geht eine Ansicht davon aus, dass die

2112 So etwa Depenheuer in: Maunz/Dürig, GG, Art. 8, 48. EL 2006, Rn. 47.

2113 Petersen, DÖV 2019, 131 (132), m.w.N.

2114 BVerwG, Urt. v. 25.10.2017, Az.: 6 C 46/16 = NJW 2018, 716 (719).

2115 EGMR, Urt. v. 15.11.2018, Az.: 29580/12, 36847/12, 11252/13, 12317/13, 43746/14 (Navalnyy/ Russland), Rn. 98.

2116 S. hierzu Eickenjäger/Fischer-Lescano, Transnationalisierung des Versammlungsrechts, in: Ridder/Breitbach/Deiseroth, Kommentar Versammlungsrecht, i.E.

2117 Enders, in: Dürig-Friedel/Enders, Versammlungsrecht, 2016, § 1 VersammlG, Rn. 51 ff., 62 ff., 69f., 77 f. Vgl. auch Kniesel, in: Dietel/Kintzel/Kniesel, Versammlungsgesetze, 17. Aufl. 2016, § 1 VersammlG, Rn. 17 ff.; Petersen, DÖV 2019, 131 (132). 
Bestimmungen des VersammlG analog anzuwenden sind. ${ }^{2118}$ Hierfür spreche insbesondere, dass es sinn- und systemwidrig wäre, wenn die nichtöffentliche Versammlung - die weniger gefährdet und gefährlich sei als die öffentliche Versammlung - auf der Grundlage des allgemeinen Polizei- und Ordnungsrechts leichter eingeschränkt werden dürfte als eine öffentliche auf der Grundlage des Versammlungsrechts. Eine andere Ansicht geht von der Anwendbarkeit des allgemeinen Polizei- und Ordnungsrechts aus mit der Maßgabe, dass eine „verfassungsorientierte Interpretation“ der Ermächtigungsgrundlagen des allgemeinen Polizei- und Ordnungsrechts vorzunehmen sei, im Rahmen derer der besonderen Bedeutung des Art. 8 GG Rechnung zu tragen sei. ${ }^{2119}$

1159 Für das BayVersG gilt, dass dieses ausdrücklich gemäß Art. 2 III BayVersG im Hinblick auf die hier relevanten Eingriffsbefugnisse nur auf öffentliche Versammlungen Anwendung findet. Die Versammlungsgesetze in Sachsen (SächsVersG) und Sachsen-Anhalt (VersG LSA) beschränken sich ebenfalls (wie das VersammlG) auf öffentliche Versammlungen. Da hier eine analoge Anwendung des jeweiligen Landesversammlungsgesetzes offensichtlich mangels planwidriger Regelungslücke ausscheidet, kann in Bayern, Sachsen und Sachsen-Anhalt gegenüber nichtöffentlichen Versammlungen auf die allgemeinen Befugnisse nach dem allgemeinen Polizei- und Ordnungsrecht zurückgegriffen werden. ${ }^{2120}$ Da auch nichtöffentliche Versammlungen in den Schutzbereich der Versammlungsfreiheit fallen, sind hierbei jedoch stets die strengen Anforderungen des Art. 8 GG zu berücksichtigen. Dies gilt insbesondere im Hinblick auf nichtöffentliche Versammlungen in geschlossenen Räumen, bei denen ein Einschreiten nur bei Verstößen gegen das Waffenverbot, den Friedlichkeitsgrundsatz und zum Schutz gleichgewichtiger Verfassungsgüter zulässig ist. ${ }^{2121}$

1160 Anders verhält es sich beim NdsVersG, das gleichermaßen auf öffentliche und nichtöffentliche Versammlungen Anwendung findet und deshalb grds. Sperrwirkung gegenüber dem allgemeinen Polizei- und Ordnungsrecht entfaltet. ${ }^{2122}$ Das VersFG SH gilt grds. genauso wie das NdsVersG gemäß $\S \S 1$ I und 2 III VersFG SH für öffentliche wie für nichtöffentliche Versammlungen.

1161 Folgende Tabelle stellt die vorherigen Ausführungen überblicksartig dar:

2118 S. etwa Rühl, NVwZ 1988, 577 (579, 581); Kingreen/Poscher, Polizei- und Ordnungsrecht, 10. Aufl. 2018, § 19 Rn. 16.

2119 S. BVerwG, Urt. v. 23.3.1999, Az.: 1 C 12/97 = NVwZ 1999, 991 (992); Kniesel/Poscher, in: Lisken/Denninger, Handbuch des Polizeirechts, 6. Aufl. 2018, K, Rn. $21 \mathrm{f}$.

2120 Kniesel, in: Dietel/Kintzel/Kniesel, Versammlungsgesetze, 17. Aufl. 2016, §1 VersammlG, Rn. 20, $27 \mathrm{f}$.

2121 Heinhold, in: Wöchtler/Heinhold/Merk, BayVersG, 1. Aufl. 2011, Art. 2, Rn. 36.

2122 Miller, in: Wefelmeier/Miller, NdsVersG, 1. Aufl. 2012, § 2, Rn. 4.

Sebastian Eickenjäger 


\begin{tabular}{ll}
\hline $\begin{array}{l}\text { Im Geltungsbereich der folgenden } \\
\text { Versammlungsgesetze ... }\end{array}$ & $\begin{array}{l}\text {... auf nichtöffentliche Versammlungen anwendbares } \\
\text { Recht. }\end{array}$ \\
\hline VersammlG & $\begin{array}{l}\text { E.A.: analoge Anwendung VersammlG } \\
\text { A.A.: verfassungskonform interpretierte Bestimmungen } \\
\text { des allgemeinen Polizeirechts }\end{array}$ \\
\hline BayVersG & Verfassungskonform interpretierte Bestimmungen \\
& BayPAG \\
\hline NdsVersG & NdsVersG \\
\hline SächsVersG & Verfassungskonform interpretierte Bestimmungen \\
\hline VersG LSA & SächsPolG \\
\hline VersFG SH & Verfassungskonform interpretierte Bestimmungen \\
\hline
\end{tabular}

\section{cc) Polizeirechtsfestigkeit des Versammlungsrechts}

Die Formel der Polizeirechtsfestigkeit des Versammlungsrechts (hierzu auch Rn. 1037 ff.) beschreibt die Abgrenzung des Versammlungsrechts (als lex specialis) vom allgemeinen Polizei- und Ordnungsrecht (als lex generali) und dient dem besonderen Schutz der in Art. 8 I GG garantierten Versammlungsfreiheit. ${ }^{2123}$ In Versammlungen soll grds. nur nach Maßgabe der strengen Vorgaben des Versammlungsrechts eingegriffen werden können. Zudem zeichnen sich die Steuerungskonzepte der Bundes- und Landesversammlungsgesetze dadurch aus, dass sie Veranstalter*innen und Leitung in hohem Maße die Verantwortung für die Einhaltung des gesetzlichen Rahmens der Versammlungsfreiheit übertragen. ${ }^{2124}$ Insofern dient die „Sperrwirkung“ des Versammlungsrechts auch der Sicherstellung der „Autonomie“ der Versammlung. Der Rückgriff auf das allgemeine Polizei- und Ordnungsrecht zur Einschränkung der Versammlungsfreiheit ist daher nur zulässig, wenn die Versammlungsgesetze selbst keine abschließenden Regelungen enthalten.

Im Vorfeld der Versammlung entfalten die Bestimmungen der Versamm- 1163 lungsgesetze gegenüber der Gesamtversammlung mangels Regelungslücke vollumfänglich Sperrwirkung. Ein Rückgriff auf das allgemeine Polizei- und Ordnungsrecht ist jedoch ausnahmsweise zulässig, soweit es sich um Maßnahmen

2123 Götz/Geis, Allgemeines Polizei- und Ordnungsrecht, 16. Aufl. 2017, § 23 Rn. 38.

2124 Kniesel/Poscher, in: Lisken/Denninger, Handbuch des Polizeirechts, 6. Aufl. 2018, K, Rn. 24. 
gegenüber einzelnen Teilnehmer`innen handelt. ${ }^{2125}$ Hierzu zählen etwa Gefährder^innenansprachen, Meldeauflagen, Personenkontrollen, Durchsuchungen, Beschlagnahmen sowie Teilnahmeuntersagungen. Das Bundesversammlungsgesetz sieht hierfür keine Ermächtigungsgrundlagen vor. Und da es der Versammlung (bzw. den Veranstalter`innen und der Leitung) auch an organisatorischen Möglichkeiten und der nötigen Infrastruktur fehlt, um selbst (d.h. autonom) im Hinblick auf anreisende Teilnehmer^innen für die Wahrung der öffentlichen Sicherheit und Ordnung zu sorgen, können die Behörden hier ausnahmsweise auf das allgemeine Polizei- und Ordnungsrecht zurückgreifen. ${ }^{2126} \mathrm{Zu}$ beachten ist jedoch, dass manche Landesversammlungsgesetze solche „Vorfeldmaßnahmen“ gegenüber einzelnen Teilnehmer^innen teilweise bereits gesetzlich geregelt haben (s. hierzu Rn. $1086 \mathrm{ff}$. und $1204 \mathrm{ff}$.).

1164 Während der Versammlung können die Behörden nach der h.M. vermittelt über § 15 I VersammlG bzw. § 13 I 2 VersammlG Eingriffe auf das allgemeine Polizei- und Ordnungsrecht stützen, wenn hierdurch die eingriffsintensive Auflösung vermieden werden kann. ${ }^{2127}$ Als so genannte „Minusmaßnahmen“ (hierzu Rn. 1218ff.) kommen etwa die Sicherstellung gefährlicher Gegenstände, der Austausch von Leiter ${ }^{\star}$ innen und Ordnerinnen, der Ausschluss von Teilnehmer^innen sowie das Verbot der Verwendung einzelner strafrechtlich relevanter Musikstücke oder Plakate in Betracht. Auch hier ist zu berücksichtigen, dass mittlerweile manche Landesversammlungsgesetze entsprechende Minusmaßnahmen ausdrücklich geregelt haben (hierzu Rn. $1186 \mathrm{ff}$. und $1204 \mathrm{ff}$.).

Die h.M. in der Literatur und Rechtsprechung geht zudem davon aus, dass entgegen der Sperrwirkung bzw. der Polizeirechtsfestigkeit des Versammlungsrechts - bzgl. „nicht versammlungsspezifischer Gefahren“ (etwa bau-, feuer-, oder gesundheitspolizeilicher Art) auf die Regelungen des allgemeinen Polizeirechts zurückgegriffen werden kann. ${ }^{2128}$

2125 BVerwG, Urt. v. 25.10.2017, Az.: 6 C 45.16 = BeckRS 2017, 138147, Rn. 16.

2126 Kniesel/Poscher, in: Lisken/Denninger, Handbuch des Polizeirechts, 6. Aufl. 2018, K, Rn. $36 \mathrm{f}$.

2127 Götz/Geis, Allgemeines Polizei- und Ordnungsrecht, 16. Aufl. 2017, § 23 Rn. 39. Hierzu kritisch: Kniesel/Poscher, in: Lisken/Denninger, Handbuch des Polizeirechts, 6. Aufl. 2018, K, Rn. $26 \mathrm{ff}$.

2128 S. etwa Enders, in: Dürig-Friedl/Enders, Versammlungsrecht, 1. Aufl. 2016, § 5 VersammlG, Rn. 4.; Götz/Geis, Allgemeines Polizei- und Ordnungsrecht, 16. Aufl. 2017, § 23 Rn. 39; Kniesel/ Braun/Keller, Besonderes Polizei- und Ordnungsrecht, 1. Aufl. 2018, Rn. 418ff.; kritisch hierzu Eickenjäger/Haerkötter/Vetter, in: Ridder/Breitbach/Deiseroth, Versammlungsrecht, i.E., § 5 VersammlG, Rn. 54 und Eickenjäger/Ewering/Kohlmeier, in: Ridder/Breitbach/Deiseroth, Versammlungsrecht, i. E., § 13 VersammlG, Rn. $20 \mathrm{ff}$. 
Examenswissen: In diesem Zusammenhang von Bedeutung ist insbesondere das Urteil des VGH 1166 Mannheim zur Auflösung eines in geschlossenen Räumen abgehaltenen Konzerts einer rechtsextremistischen Skinhead-Band auf der Grundlage der polizeilichen Generalklausel aus feuerpolizeilichen Gründen zur Abwehr konkreter Gefahren für Leben und Gesundheit der Versammlungsteilnehmer*innen. ${ }^{2129}$ Die Entscheidung steht stellvertretend für Eingriffe aufgrund des Polizei- und Ordnungsrechts - egal ob Verbot oder Auflösung - aufgrund nicht versammlungsspezifischer Gefahren.

Mit der Beendigung einer Versammlung und nach einer Auflösung der Ver1167 sammlung entfällt auch der Vorrang der Versammlungsgesetze. ${ }^{2130}$ Auflösungen können dann durch die Behörden etwa mit Platzverweisen nach Maßgabe des allgemeinen Polizei- und Ordnungsrechts durchgesetzt werden.

$\mathrm{Zu}$ beachten ist jedoch, dass auch bei Vorfeldmaßnahmen, Minusmaßnahmen und Maßnahmen gegenüber Teilnehmer*innen im Rahmen der Abreise von der Versammlung der Schutz aus Art. 8 I GG greift und etwaige Maßnahmen auf der Grundlage des allgemeinen Polizei- und Ordnungsrechts den verfassungsrechtlichen Anforderungen des Art. 8 I GG genügen müssen. In diesem Sinne darf z. B. die Anreise nicht durch Kontrollen unzumutbar erschwert und das Recht auf einen geordneten Abzug nach Beendigung oder Auflösung der Versammlung nicht beeinträchtigt werden. ${ }^{2131}$

\section{dd) Die einzelnen Ermächtigungsgrundlagen der Versammlungsgesetze}

Für die Beschränkung von Versammlungen unter freiem Himmel und in geschlossenen Räumen sehen die Versammlungsgesetze des Bundes und der Länder eine Reihe von Eingriffsbefugnissen vor. Die wichtigsten Eingriffsmöglichkeiten stellen dabei Verbote, Beschränkungen (Auflagen) und die Auflösung dar. Darüber hinaus von Relevanz sind insbesondere die Ermächtigungen zu Maßnahmen gegenüber einzelnen Teilnehmerinnen.

In den folgenden zwei Tabellen werden die zentralen Ermächtigungsgrund- $\mathbf{1 1 7 0}$ lagen bzgl. Versammlungen unter freiem Himmel und in geschlossenen Räumen aufgeführt. Unter „d) Materielle Rechtmäßigkeit“ (Rn. 1177) erfolgt sodann eine systematische Darstellung der Ermächtigungsgrundlagen im Hinblick auf ihre materiell-rechtlichen Voraussetzungen.

2129 VGH Mannheim, Urt. v. 12.7.2010, Az.: 1 S 349/10 = BeckRS 2010, 52002.

2130 Götz/Geis, Allgemeines Polizei- und Ordnungsrecht, 16. Aufl. 2017, § 23 Rn. 39.

$2131 \mathrm{Zu}$ den verfassungsrechtlichen Anforderungen bei Vorfeldmaßnahmen s. Götz/Geis, Allgemeines Polizei- und Ordnungsrecht, 16. Aufl. 2017, § 23 Rn. 22. Zu der „Nachwirkung von Art. 8 I GG s. Kniesel/Braun/Keller, Besonderes Polizei- und Ordnungsrecht, 1. Aufl. 2018, Rn. 418 ff. 
1171 Die wichtigsten Eingriffsbefugnisse (Beschränkungen, Verbot und Auflösung) zu Versammlungen unter freiem Himmel im Überblick:

\begin{tabular}{ll}
\hline Versammlungsgesetze & Maßnahmen \\
\hline VersammlG & Beschränkungen: § 15 I \\
& Verbot: § 15 I \\
& Auflösung: § 15 III \\
\hline BayVersG & Beschränkungen: Art. 15 I und IV \\
& Verbot: Art. 15 I \\
& Auflösung: Art. 14 IV \\
\hline NdsVersG & Beschränkungen: § 8 I und IV \\
& Verbot: § 8 II 1 und IV \\
& Auflösung: § 8 II \\
\hline SächsVersG & Beschränkungen: § 15 I \\
& Verbot: § 15 I \\
\hline VersG LSA & Auflösung: § 15 III \\
& Beschränkungen: § 13 I \\
& Verbot: § 13 I \\
\hline VersFG SH & Auflösung: § 13 IV \\
& Beschränkungen: § 13 I \\
& Verbot: § 13 I \\
\hline
\end{tabular}

1172 Die wichtigsten Eingriffsbefugnisse zu Versammlungen in geschlossenen Räumen im Überblick:

\begin{tabular}{ll}
\hline Versammlungsgesetz & Maßnahmen \\
\hline VersammlG & Verbot: § 5 \\
& Auflösung: § 13 \\
\hline BayVersG & Verbot: Art. 12 I \\
& Auflösung: Art. 12 II \\
& Beschränkungen: Art. 12 \\
\hline NdsVersG & Verbot: § 14 II 1 \\
& Auflösung: § 14 II 1 \\
& Beschränkungen: § 14 I \\
& Besondere Maßnahmen (gegenüber einzelnen Personen): § 15 \\
\hline SächsVersG & Verbot: § 4 \\
& Auflösung: § 13 \\
\hline VersG LSA & Verbot: § 4
\end{tabular}

\section{Sebastian Eickenjäger}


Fortsetzung

\begin{tabular}{ll}
\hline Versammlungsgesetz & Maßnahmen \\
\hline & Auflösung: § 11 \\
\hline VersFG SH & Verbot: § 20 I \\
& Auflösung: § 20 I \\
& Beschränkungen: § 20 I \\
& Maßnahmen gegenüber einzelnen Personen: § 9 I und II i. V. m. § 20 I \\
\hline
\end{tabular}

\section{c) Formelle Rechtmäßigkeit}

Die Prüfung der formellen Rechtmäßigkeit gliedert sich in die Prüfungspunkte 1173 Zuständigkeit, Verfahren und Form (zur Prüfung im Allgemeinen ausführlich Rn. 579 ff.). Folgende versammlungsrechtliche Besonderheiten bestehen:

\section{aa) Zuständigkeit}

Die Zuständigkeiten für die dargestellten Eingriffsbefugnisse ergeben sich aus $\mathbf{1 1 7 4}$ landesrechtlichen Bestimmungen und stellen sich danach in den einzelnen Bundesländern wie folgt dar:2132

\begin{tabular}{|c|c|c|}
\hline Bundesland & Landesrechtliche Bestimmungen & Zuständige Behörden \\
\hline $\begin{array}{l}\text { Baden-Würt- } \\
\text { temberg }\end{array}$ & $\begin{array}{l}\text { Verordnung des Innenministeriums } \\
\text { über Zuständigkeiten nach dem Ver- } \\
\text { sammlungsgesetz (VersGZuVO) v. } \\
\text { 25.5.1977 (GBI. 196), zuletzt geändert } \\
\text { durch Art. } 1 \text { ÄndVO vom 17.12.2008 } \\
\text { (GBI. } 2009 \text { S. 5) }\end{array}$ & $\begin{array}{l}\text { - } \text { gem. § } 1 \text { I die Kreispolizeibehörden } \\
\text { als untere Verwaltungsbehörden } \\
\text { (also nach § } 15 \text { I Nr. } 1 \text { VwG BW in } \\
\text { den Landkreisen die Landratsämter, } \\
\text { in den Stadtkreisen gem. § } 15 \text { I Nr. } 2 \\
\text { VwG BW die Gemeinden) } \\
\text { - bei Maßnahmen „der Polizei“ } \\
\text { (§§ } 9 \text { II, 12, 12a, 13 I, 18, } 19 \text { IV, 19a } \\
\text { VersammIG): Polizeivollzugsdienst }\end{array}$ \\
\hline Bayern & Art. 24 BayVersG & $\begin{array}{l}\text { - II S. 1: Kreisverwaltungsbehörden } \\
\text { (gem. Art. } 37 \text { I } 1 \text { LKrO das Land- } \\
\text { ratsamt bzw. nach Art. } 9 \text { I } 1 \mathrm{GO} \text { die } \\
\text { kreisfreie Gemeinde) } \\
\text { - II S. 2: ab Beginn der Versammlung } \\
\text { und in unaufschiebbaren Fällen }\end{array}$ \\
\hline
\end{tabular}

2132 S. hierzu ausführlich die Ausführungen unter „Landesrechtliche Zuständigkeits-, Verfahrens- und Kostenregelungen“ zu den einzelnen Bundesländern in: Ridder/Breitbach/Deiseroth, Versammlungsrecht, i.E. 
Fortsetzung

\begin{tabular}{|c|c|c|}
\hline Bundesland & Landesrechtliche Bestimmungen & Zuständige Behörden \\
\hline & & $\begin{array}{l}\text { kann auch die Polizei (Polizeivoll- } \\
\text { zugsdienst) Maßnahmen treffen }\end{array}$ \\
\hline Berlin & $\begin{array}{l}\text { Allgemeines Gesetz zum Schutz der } \\
\text { öffentlichen Sicherheit und Ordnung in } \\
\text { Berlin } \\
\text { (Allgemeines Sicherheits- und Ord- } \\
\text { nungsgesetz - ASOG Bln) in der Fas- } \\
\text { sung v. 11.10.2006 (GVBI. S. 930), } \\
\text { zuletzt geändert durch Art. } 5 \text { G zur } \\
\text { Umsetzung der Seveso-III-RL und zur } \\
\text { Änd. zuständigkeitsrechtlicher Vor- } \\
\text { schriften v. 16.3.2018 (GVBI. 186) }\end{array}$ & $\begin{array}{l}\text { - gem. § } 2 \text { IV } 1 \text { i. V.m. Nr. } 23 \text { II der } \\
\text { Anlage: Polizeipräsident*in Berlin }\end{array}$ \\
\hline Brandenburg & $\begin{array}{l}\text { Verordnung zur Übertragung der Zu- } \\
\text { ständigkeiten nach dem Versamm- } \\
\text { lungsgesetz (ZustVO VersamG), v. } \\
\text { 29.10.1991 (GVBl. S. 470), zuletzt } \\
\text { geändert durch Art. } 2 \text { G zur Ersetzung } \\
\text { von § } 16 \text { des VersammlungsG v. 26.10. } \\
2006 \text { (GVBI. I 114) }\end{array}$ & $\begin{array}{l}\text { - } \text { gem. § 1: Polizeipräsidium (in Pots- } \\
\text { dam) } \\
\text { - bei Maßnahmen „der Polizei“ } \\
\text { (§§ } 9 \text { II, 12, 12a, 13 I, 18, } 19 \text { IV, 19a } \\
\text { VersammIG): Polizeivollzugsdienst }\end{array}$ \\
\hline Bremen & $\begin{array}{l}\text { Verordnung über die Zuständigkeit der } \\
\text { Verwaltungsbehörden nach dem Ver- } \\
\text { sammlungsgesetz v. 9.2.1993 } \\
\text { (Brem.GBI. S. 63), zuletzt geändert } \\
\text { durch Nr. } 2.3 \text { i. V. m. Anl. } 3 \text { und Nr. } 2.4 \\
\text { i. V.m. Anl. } 4 \text { ÄndBek. V. 2.8.2016 } \\
\text { (Brem.GBI. S. 434) }\end{array}$ & $\begin{array}{l}\text { - } \text { gem. } \S 1 \text { I für Maßnahmen nach } \\
\S \S 14 \text { I, } 15 \text { I, } 17 \text { a III und IV, } 18 \text { II } \\
\text { VersammIG }{ }^{2133} \text { die Ortspolizeibe- } \\
\text { hörden (gem. } \S 65 \text { I Nr. 2, } 67 \text { II } \\
\text { BremPolG in der Stadtgemeinde } \\
\text { Bremen das Ordnungsamt und in } \\
\text { der Stadtgemeinde Bremerhaven } \\
\text { der Oberbürgermeister als Vertreter } \\
\text { des Magistrats) } \\
\text { - bei Maßnahmen „der Polizei“ } \\
\text { (§§ } 9 \text { II, 12, 12a, 13I, 18, } 19 \text { IV, 19a } \\
\text { VersammIG) sowie Maßnahmen }\end{array}$ \\
\hline
\end{tabular}

2133 Obwohl § 5 VersammlG hier nicht genannt wird, ist davon auszugehen, dass für Verbote nach $\S 5$ VersammlG ebenfalls die Ortspolizeibehörden zuständig sind. Es ist jedenfalls nicht nachvollziehbar, warum die Zuständigkeit für Verbote von Versammlungen in geschlossenen Räumen anders ausfallen soll als die Zuständigkeit für Verbote von Versammlungen unter freiem Himmel.

2134 So jedenfalls VG Bremen, Urt. v. 4.9. 2014, Az.: 5 K 1145/13; kritisch hierzu Fischer-Lescano, Zuständigkeits-, Kosten und Verfahrensregeln Bremen, in: Ridder/Breitbach/Deiseroth, Kommentar Versammlungsrecht, i.E.

\section{Sebastian Eickenjäger}


Fortsetzung

\begin{tabular}{|c|c|c|}
\hline Bundesland & Landesrechtliche Bestimmungen & Zuständige Behörden \\
\hline & & $\begin{array}{l}\text { nach } \S 15 \text { III und IV VersammlG }{ }^{2134} \text { : } \\
\text { Polizeivollzugsdienst }\end{array}$ \\
\hline Hamburg & $\begin{array}{l}\text { Anordnung über Zuständigkeiten im } \\
\text { Versammlungsrecht und öffentlichen } \\
\text { Vereinsrecht v. 10.12.1968 (Amtl. } \\
\text { Anz. 1968, 1513), zuletzt geändert } \\
\text { durch Artikel } 37 \text { der Anordnung v. } \\
\text { 26.10.2010 (Amtl. Anz. S. 2129, 2132) }\end{array}$ & $\begin{array}{l}\text { - } \text { gem. Nr. I Abs. } 1 \text { Nr. } 1 \text { die Behörde } \\
\text { für Inneres und Sport } \\
\text { - } \text { bei Maßnahmen „der Polizei“ } \\
\text { (§§ } 9 \text { II, 12, 12a, 13 I, 18, } 19 \text { IV, 19a } \\
\text { VersammIG): Polizeivollzugsdienst }\end{array}$ \\
\hline Hessen & $\begin{array}{l}\text { Verordnung zur Durchführung des } \\
\text { Hessischen Gesetzes über die öffentli- } \\
\text { che Sicherheit und Ordnung und des } \\
\text { Hessischen Freiwilligen-Polizeidienst- } \\
\text { Gesetzes (HSOG-DVO) vom 12.6.2007 } \\
\text { (GVBI. I S. 323), zuletzt geändert durch } \\
\text { Art. } 1 \text { Vierte ÄndVO v. } 23.10 .2012 \\
\text { (GVBI. S. 326) }\end{array}$ & $\begin{array}{l}\text { - } \text { gem. §11 Nr. 2: allgemeine Ord- } \\
\text { nungsbehörden } \\
\text { - } \text { Gemeinde mit weniger als } 7.500 \\
\text { Einwohner*innen: Kreisordnungs- } \\
\text { behörde (also die/der Landrät*in) } \\
\text { - } \text { bei Maßnahmen „der Polizei“ } \\
\text { (§§ } 9 \text { II, 12, 12a, 13 I, 18, 19 IV, 19a } \\
\text { VersammlG): Polizeivollzugsdienst }\end{array}$ \\
\hline $\begin{array}{l}\text { Mecklenburg- } \\
\text { Vorpommern }\end{array}$ & $\begin{array}{l}\text { Landesverordnung über die zuständi- } \\
\text { gen Behörden nach dem Versamm- } \\
\text { lungsgesetz (VersG-ZustVO) v. } 21.7 . \\
1994 \text { (GVOBI. M-V S. 804), zuletzt ge- } \\
\text { ändert durch Erste ÄndVO vom 19.1. } \\
2007 \text { (GVOBI. M-V S. 30) }\end{array}$ & $\begin{array}{l}\text { - } \text { gem. } § 2 \text { die Landrät*innen und die } \\
\text { Oberbürgermeister*innen der kreis- } \\
\text { freien Städte als Kreisordnungsbe- } \\
\text { hörden } \\
\text { — } \\
\text { bei Maßnahmen „der Polizei“ } \\
\text { (§§ } 9 \text { II, 12, 12a, 13I, 18, } 19 \text { IV, 19a } \\
\text { VersammIG): Polizeivollzugsdienst }\end{array}$ \\
\hline Niedersachsen & $\S 24$ NdsVersG & $\begin{array}{l}\text { - vor Versammlungsbeginn (I } 1 \mathrm{Nr} \text {. 1): } \\
\text { untere Versammlungsbehörde } \\
\text { (Landkreise, kreisfreien Städte, } \\
\text { großen selbständigen Städte und } \\
\text { selbständigen Gemeinden wahr, auf } \\
\text { dem Gebiet der Landeshauptstadt } \\
\text { Hannover die Polizeidirektion Han- } \\
\text { nover) } \\
\text { - nach Versammlungsbeginn (I } 1 \\
\text { Nr. 2): die Polizei (Polizeivollzugs- } \\
\text { dienst) }\end{array}$ \\
\hline $\begin{array}{l}\text { Nordrhein- } \\
\text { Westfalen }\end{array}$ & $\begin{array}{l}\text { Verordnung über Zuständigkeiten } \\
\text { nach dem Versammlungsgesetz v. 2.2. } \\
1987 \text { (GV. NRW. S. 62), zuletzt geändert } \\
\text { durch Verordnung v. 9.9.2014 (GV. } \\
\text { NRW. S. 500) }\end{array}$ & $\begin{array}{l}\text { - } \text { gem. § 1: Kreispolizeibehörden } \\
\text { (gem. gem. § } 2 \text { I POG NRW die Poli- } \\
\text { zeipräsidien der kreisfreien Städte } \\
\text { und die Landrät*innen, soweit das } \\
\text { Kreisgebiet zu einem Polizeibezirk } \\
\text { erklärt wurde) }\end{array}$ \\
\hline
\end{tabular}


Fortsetzung

\begin{tabular}{|c|c|c|}
\hline Bundesland & Landesrechtliche Bestimmungen & Zuständige Behörden \\
\hline $\begin{array}{l}\text { Rheinland- } \\
\text { Pfalz }\end{array}$ & $\begin{array}{l}\text { Landesverordnung über die Zustän- } \\
\text { digkeit der allgemeinen Ordnungsbe- } \\
\text { hörden in der Fassung v. } 31.10 .1978 \\
\text { (GVBl. S. 695), zuletzt geändert durch } \\
\text { Artikel } 9 \text { des Zweiten Landesgesetzes } \\
\text { zur Kommunal- und Verwaltungsreform } \\
\text { vom 28.9. } 2010 \text { (GVBl. } 2010 \text { S. } 280 \text { ) }\end{array}$ & $\begin{array}{l}\text { - } \text { gemäß } \S \S 1,2 \text { Nr. } 9 \text { die Kreisord- } \\
\text { nungsbehörde (in den Landkreisen } \\
\text { die Kreisverwaltungen und in kreis- } \\
\text { freien Städten die Stadtverwaltun- } \\
\text { gen); } \\
\text { - } \text { in der großen kreisangehörigen } \\
\text { Stadt: Stadtverwaltung ( } § 1 \mathrm{Nr.} 9 \mathrm{HS} \\
\text { 2) } \\
\text { - } \text { bei Maßnahmen „der Polizei“ } \\
\text { (§§ } 9 \text { II, 12, 12a, 13 I, 18, } 19 \text { IV, 19a } \\
\text { VersammIG): Polizeipräsidien }\end{array}$ \\
\hline Saarland & $\begin{array}{l}\text { Verordnung zur Übertragung und Än- } \\
\text { derung von Zuständigkeiten v. } 17.9 \text {. } \\
1991 \text { (Amtsblatt 1991, 1066), zuletzt } \\
\text { geändert durch das Gesetz v. } 21.11 \text {. } \\
2007 \text { (Amtsbl. S. 2393) }\end{array}$ & $\begin{array}{l}\text { - } \text { gem. } § 11 \text { : die Landkreise, der Re- } \\
\text { gionalverband Saarbrücken, die } \\
\text { Landeshauptstadt Saarbrücken und } \\
\text { die kreisfreien Städte } \\
\text { - } \text { bei Maßnahmen „der Polizei“ } \\
\text { (§§ } 9 \text { II, 12,12a, 13 I, 18, 19 IV, 19a } \\
\text { VersammlG): Polizeivollzugsdienst }\end{array}$ \\
\hline Sachsen & $\S 32$ SächsVersG & $\begin{array}{l}\text { - } \text { gem. Abs. 1: Kreispolizeibehörden } \\
\text { (nach § } 64 \text { I Nr. } 3 \text { SächsPolG die } \\
\text { Landratsämter und die Kreisfreien } \\
\text { Städte) } \\
\text { - für die in Abs. } 2 \text { genannten Maß- } \\
\text { nahmen: Polizeivollzugsdienst }\end{array}$ \\
\hline
\end{tabular}

\begin{tabular}{|c|c|c|}
\hline $\begin{array}{l}\text { Sachsen-An- } \\
\text { halt }\end{array}$ & $\begin{array}{l}\text { Verordnung über die Zuständigkeiten } \\
\text { auf verschiedenen Gebieten der Ge- } \\
\text { fahrenabwehr (ZustVO SOG) } \\
\text { vom 31.7.2002 (GVBI. LSA S. 328), } \\
\text { zuletzt geändert durch Art. } 3 \text { Zweite } \\
\text { Polizeistrukturreformrerordnung v. } \\
\text { 18.12.2018 (GVBI. LSA S. 443). }\end{array}$ & $\begin{array}{l}\text { - } \text { gem. } § 1 \text { I Nr. } 1 \text { Landkreise bzw. die } \\
\text { kreisfreie Stadt Dessau-Roßlau; in } \\
\text { Halle und Magdeburg: gem. § } 1 \text { I } \\
\text { Nr. } 2 \text { die Polizeidirektion } \\
\text { - } \text { bei Maßnahmen „der Polizei“ } \\
\text { (§§ } 11 \text { I, } 16 \text { Abs. 3, } 17 \text { IV, } 18 \text { I Ver- } \\
\text { sammIG LSA): Polizeivollzugsdienst }\end{array}$ \\
\hline $\begin{array}{l}\text { Schleswig- } \\
\text { Holstein }\end{array}$ & $\S 27$ VersFG SH & 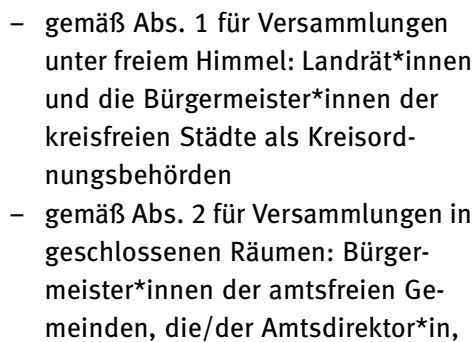 \\
\hline
\end{tabular}


Fortsetzung

\begin{tabular}{|c|c|c|}
\hline Bundesland & Landesrechtliche Bestimmungen & Zuständige Behörden \\
\hline & & $\begin{array}{l}\text { in ehrenamtlich verwalteten Ämtern } \\
\text { die/der Amtsvorsteher*in }\end{array}$ \\
\hline Thüringen & $\begin{array}{l}\text { Thüringer Verordnung zur Bestimmung } \\
\text { von Zuständigkeiten im Geschäftsbe- } \\
\text { reich des Innenministeriums v. } 15.4 \text {. } \\
2008 \text { (GVBl. 2008, 102), zuletzt geän- } \\
\text { dert durch Verordnung v. 8.10. } 2013 \\
\text { (GVBI. S. 311) }\end{array}$ & 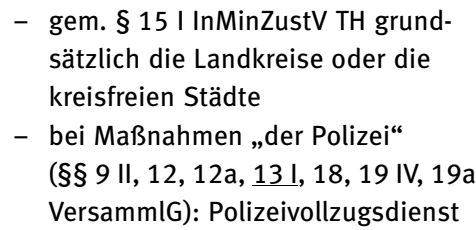 \\
\hline
\end{tabular}

\section{bb) Verfahren und Form}

Vor dem Erlass beschränkender Maßnahmen sind die Beteiligten anzuhören 1175 (§ 28 I VwVfG) soweit nicht ein Fall des § 28 II VwVfG (bei Maßnahmen im Rahmen von laufenden Versammlungen insbesondere Gefahr im Verzug gemäß § 28 II Nr. 1 VwVfG) vorliegt. Die Anhörung erfolgt oftmals im Rahmen eines sogenannten Kooperationsgesprächs, ${ }^{2135}$ dessen Durchführung in Landesversammlungsgesetze teilweise ausdrücklich geregelt ist (s. § 3 III VersFG SH, Art. 14 I 1 BayVersG sowie § 6 NdsVersG).

Beschränkungen nach § 15 I und II VersammlG sowie $\S \S 5$ und 13 VersammlG 1176 können grds. mündlich oder schriftlich ergehen (§ $37 \mathrm{II} \mathrm{VwVfG);} \mathrm{mündliche} \mathrm{Ver-}$ waltungsakte sind gemäß § 37 I 2 VwVfG schriftlich zu bestätigen, wenn hieran ein berechtigtes Interesse besteht und der_die Betroffene dies unverzüglich verlangt. Ein schriftlicher sowie ein schriftlich bestätigter Verwaltungsakt ist gemäß § 39 I 1 VwVfG mit einer Begründung zu versehen. Verfügungen nach § 13 VersammlG sind im Hinblick auf dessen Wortlaut (,unter Angabe eines Grundes“) auch dann zu begründen, wenn sie mündlich erfolgen. Diese Anforderungen sind aufgrund der höheren Eingriffsintensität eines präventiven Verbots analog auf mündliche Verbote nach $\S 5$ VersammlG zu übertragen. ${ }^{2136}$ Verfügungen sind zudem gemäß $\S 41 \mathrm{VwVfG}$ bekannt zu geben.

2135 Hettich, Versammlungsrecht in der Praxis, 2. Aufl. 2018, S. 222, Rn. 211.

2136 Eickenjäger/Haerkötter/Vetter, in: Ridder/Breitbach/Deiseroth, Kommentar Versammlungsrecht, i.E., § 5 VersammlG, Rn. 63. 


\section{d) Materielle Rechtmäßigkeit}

1177 Bei der Prüfung der Voraussetzungen der Ermächtigungsgrundlage ist wiederum danach zu differenzieren, ob es sich um eine Versammlung unter freiem Himmel oder in geschlossenen Räumen handelt.

\section{aa) Versammlungen unter freiem Himmel}

1178 Bei Versammlungen unter freiem Himmel muss weiter differenziert werden, ob das VersammlG des Bundes oder ein Landesversammlungsgesetz einschlägig ist.

\section{(1) VersammlG des Bundes}

1179 Für die Beschränkung von öffentlichen Versammlungen unter freiem Himmel sieht das VersammlG des Bundes verschiedene Eingriffsbefugnissen vor, von denen die wichtigsten die Verbote und Beschränkungen (Auflagen) nach §15 I VersammlG und die Auflösung nach § 15 III VersammlG darstellen. §15 I VersammlG bestimmt für das Verbot und die Erteilung von Auflagen, dass diese nur zulässig sind, wenn nach den zur Zeit des Erlasses der Verfügung erkennbaren Umständen die öffentliche Sicherheit oder Ordnung bei Durchführung der Versammlung oder des Aufzuges unmittelbar gefährdet ist. § 15 II VersammlG ermöglicht ein Verbot oder die Erteilung von Auflagen für Versammlungen an Orten, die als Gedenkstätten von historisch herausragender, überregionaler Bedeutung an die Opfer der menschenunwürdigen Behandlung unter der nationalsozialistischen Gewalt- und Willkürherrschaft erinnern. Die Auflösung nach § 15 III VersammlG ist zulässig, wenn Versammlungen nicht angemeldet sind, wenn von den Angaben der Anmeldung abgewichen oder den Auflagen zuwidergehandelt wird, oder wenn die Voraussetzungen zu einem Verbot gegeben sind.

1180 Gemäß Art. 8 II GG stehen Versammlungen unter freiem Himmel zwar unter einem allgemeinen Gesetzesvorbehalt. Das BVerfG verlangt seit der BrokdorfEntscheidung jedoch, dass aufgrund der grundlegenden Bedeutung der Versammlungsfreiheit für das Funktionieren der demokratischen Grundordnung die Auflösung und das Verbot nur zum Schutz gleichwertiger Rechtsgüter unter strikter Wahrung des Grundsatzes der Verhältnismäßigkeit und nur bei einer unmittelbaren, aus erkennbaren Umständen herleitbaren Gefährdung dieser Rechtsgüter erfolgen dürfen. ${ }^{2137}$

1181 Bzgl. der Anforderungen an beschränkende Maßnahmen ergibt sich aus der Rechtsprechung des BVerfG, dass eine Gefährdung der öffentlichen Sicherheit

2137 BVerfG, Beschl. v. 14.5.1985, Az.: 1 BvR 233, 341/81 = BVerfGE 69, 315 (348f., 353f.). 
grds. dann gegeben ist, wenn eine strafbare Verletzung der objektiven Rechtsordnung, der subjektiven Rechte und Rechtsgüter Dritter oder der Veranstaltungen des Staates und seiner Einrichtungen droht. ${ }^{2138}$ Die Rechtsgüter müssen dabei indes zum einen gleichwertig sein und zum anderen müssen die Versammlungsbehörden Maßnahmen auf das beschränken, was zum Schutze der Rechtsgüter erforderlich ist. ${ }^{2139}$

Dem Begriff der öffentlichen Ordnung kommt im Versammlungsrecht eine „Reservefunktion“ zu, um unvorhergesehenen und unerträglichen Störungen des öffentlichen Friedens begegnen zu können. ${ }^{2140}$ Öffentliche Ordnung meint dabei die Gesamtheit der ungeschriebenen Regeln, deren Befolgung nach den jeweils herrschenden sozialen und ethischen Anschauungen als unerlässliche Voraussetzung eines geordneten menschlichen Zusammenlebens innerhalb eines bestimmten Gebiets angesehen wird. ${ }^{2141} \mathrm{Zu}$ beachten ist, dass die öffentliche Ordnung regelmäßig nur zur Rechtfertigung von Auflagen herangezogen werden kann, da Verbote und Auflösungen im Wesentlichen nur zum Schutz elementarer Rechtsgüter in Betracht kommen. ${ }^{2142}$

Examenswissen: In der Praxis wurde die öffentliche Ordnung bisher insbesondere gegenüber rechtsextremen Versammlungen in Anschlag gebracht. ${ }^{2143}$ Das BVerfG ist dieser Rechtsprechung jedoch damit entgegengetreten, dass zur Abwehr von kommunikativen Angriffen auf Schutzgüter der Verfassung nur auf bereits geschaffene Strafrechtsnormen rekurriert werden darf und deshalb ein Rückgriff auf die in § 15 I VersammlG enthaltene Ermächtigung zum Schutz der öffentlichen Ordnung ausscheidet, soweit kein Straftatbestand erfüllt ist. ${ }^{2144}$ Die Versammlungsbehörden können gegenüber Versammlungen wegen einer Gefährdung der öffentlichen Ordnung deshalb nur dann einschreiten, wenn - über die Gefahr der Verwirklichung von Straftaten durch das Verbreiten nationalsozialistischen Gedankenguts hinaus - provokative oder aggressive Begleitumstände zu befürchten sind, von denen im konkreten Fall eine Einschüchterung der Bevölkerung sowie ein Klima der Gewaltdemonstration bzw. potentielle Gewaltbereitschaft

2138 S. Barczak, in: Ridder/Breitbach/Deiseroth, Versammlungsrecht, i.E., § 15 VersammlG, Rn. $95 \mathrm{ff}$.

2139 BVerfG, Beschl. v. 14.5.1985, Az.: 1 BvR 233, 341/81 = BVerfGE 69, 315 (348f., 353 f.).

2140 S. hierzu Barczak, in: Ridder/Breitbach/Deiseroth, Kommentar Versammlungsrecht, i.E., $\S 15$ VersammlG, Rn. 162.

2141 BVerfG, Beschl. v. 14.5.1985, Az.: 1 BvR 233, 341/81 = BVerfGE 69, 315 (352).

2142 BVerfG, Beschl. v. 14.5.1985, Az.: 1 BvR 233, 341/81 = BVerfGE 69, 315 (352f.).

2143 S. hierzu die Rspr. des OVG Münster, etwa die Beschl.v. 23.3.2001, Az.: 5 B 395/01 = NJW 2001, 2111; v. 12.4.2001, Az.: 5 B 492/01 = NJW 2001, 2113; v. 29.6. 2001, Az.: 5 B 832/01 = NJW 2001, 2986 und v. 02.3.2004, Az.: 5 B 392/04 = BeckRS 2004, 21977.

2144 S. hierzu die Beschl. des BVerfG v. 24.3.2001, Az.: 1 BvQ 13/01 = NJW 2001, 2069; v. 7.4. 2001, Az.: 1 BvQ 17/01 u. a. = NJW 2001, 2072; v. 12.4.2001, Az.: 1 BvQ 19/01 = NJW 2001, 2075; v. 1.5. 2001, Az.: 1 BvQ 22/01 = NJW 2001, 2076; v. 1.5.2001, Az.: 1 BvQ 21/01 = NJW 2001, 2078. 
ausgeht. ${ }^{2145}$ Dies kann beispielsweise dann der Fall sein, wenn Personen uniformiert, mit bestimmten Gegenständen (Landsknechtstrommeln, Fahnen, Fackeln etc.) oder in Marschordnung in paramilitärischer Art und Weise auftreten. ${ }^{2146}$

1184 Eine unmittelbare Gefährdung nach § 15 I und III VersammlG setzt laut BVerfG eine Sachlage voraus, die bei ungehindertem Geschehensablauf mit hoher Wahrscheinlichkeit zu einem Schaden für die der Versammlungsfreiheit entgegenstehenden Interessen führt. ${ }^{2147}$ Auch bei der Gefahrenprognose müssen die Versammlungsbehörden die Bedeutung der Versammlungsfreiheit berücksichtigen. Hieraus folgt, dass als Grundlage der Gefahrenprognose nur konkrete und nachvollziehbare tatsächliche Anhaltspunkte zugrunde gelegt werden können und bloße Vermutungen damit nicht ausreichen. ${ }^{2148}$

1185 Über die Befugnisse des § 15 I und III VersammlG hinaus sieht das VersammlG weitere Eingriffsmöglichkeiten vor. $\mathrm{Zu}$ nennen sind hier die Ermächtigung zur Durchsetzung des Schutzwaffen- und Vermummungsverbots nach § 17a IV VersammlG ${ }^{2149}$, zur Entsendung von Polizeibeamt*innen aus $\S 18$ I i.V.m. $\S 12$ VersammlG ${ }^{2150}$, zum Ausschluss von Teilnehmer^innen (bei Aufzügen) gemäß §§ 18 III und 19 IV VersammlG ${ }^{2151}$ und zur Vornahme von Bild- und Tonaufzeichnungen nach $\S \S 19$ a i.V.m. 12a VersammlG ${ }^{2152}$.

2145 BVerfG, Beschl.v. 23.6.2004, Az.:1 BvQ 19/04 = NJW 2004, 2814 (2815f.) und Beschl.v. 19.12. 2007, Az.: 1 BvR 2793/04 = NVwZ 2008, 671 (673f.).

2146 S. hierzu Barczak, in: Ridder/Breitbach/Deiseroth, Kommentar Versammlungsrecht, i. E., $\S 15$ VersammlG, Rn. 168. Vgl. auch BVerfG, Beschl.v. 24.3.2001, Az.: 1 BvQ 13/01 = NJW 2001, 2069 (2071). Laut BVerfG kann die öffentliche Ordnung auch verletzt sein, wenn ein rechtsextremer Aufzug an einem speziell der Erinnerung an das Unrecht des Nationalsozialismus und den Holocaust dienenden Gedenktag so durchgeführt werden soll, dass von seiner Art und Weise Provokationen ausgehen, die das sittliche Empfinden der Bürgerinnen und Bürger erheblich beeinträchtigen, Beschl. v. 26.1.2006, Az.: 1 BvQ 3/06 = NVwZ 2006, 585.

2147 BVerfG, Beschl. v. 19.12.2007, Az.: 1 BvR 2793/04 = NVwZ 2008, 671 (672).

2148 BVerfG, Beschl. v. 19.12.2007, Az.: 1 BvR 2793/04 = NVwZ 2008, 671 (672).

2149 Näher hierzu Kniesel/Braun/Keller, Besonderes Polizei- und Ordnungsrecht, 1. Aufl. 2018, Rn. $248 \mathrm{ff}$.

2150 Näher hierzu Kniesel/Braun/Keller, Besonderes Polizei- und Ordnungsrecht, 1. Aufl. 2018, Rn. $350 \mathrm{ff}$.

2151 Näher hierzu Kniesel/Braun/Keller, Besonderes Polizei- und Ordnungsrecht, 1. Aufl. 2018, Rn. 376 ff.; Kingreen/Poscher, Polizei- und Ordnungsrecht mit Versammlungsrecht, 10. Aufl. 2018, $\S 21, \mathrm{Rn} .7 \mathrm{ff}$.

2152 Näher hierzu Kingreen/Poscher, Polizei- und Ordnungsrecht mit Versammlungsrecht, 10. Aufl. 2018, § 20, Rn. 46 ff. und § 21 Rn. 5f.; Kniesel/Braun/Keller, Besonderes Polizei- und Ordnungsrecht, 1. Aufl. 2018, Rn. 358ff.; Götz/Geis, Allgemeines Polizei- und Ordnungsrecht, 16. Aufl. 2017, § 23 Rn. $30 \mathrm{ff}$.

\section{Sebastian Eickenjäger}




\section{(2) Landesversammlungsgesetze}

Das BayVersG regelt in Art. 15 entsprechend der Regelung in $\S 15$ VersammlG 1186 Beschränkung, Verbot und Auflösung von Versammlungen (Abs. 1 bis 4). In Art. 15 V BayVersG findet sich eine Ermächtigung zum Ausschluss von Störer*innen (vgl. § 18 VersammlG).

Die zentrale Eingriffsnorm im NdsVersG stellt $\S 8$ dar. Hier sind Beschrän- 1187 kung (Abs. 1 und 4), Verbot (Abs. 2S. 1 und Abs. 4) und Auflösung (Abs. 2) geregelt. Im Gegensatz zum VersammlG unterschiedet die Regelung in § 8 NdsVersG bzgl. der Eingriffsbefugnisse nicht nach dem Zeitpunkt (vor oder während der Versammlung), sondern nach der Schwere der Gefahr. ${ }^{2153}$

$\S 10$ NdsVersG sieht die Möglichkeit der Vornahme „besonderer Maßnahmen“ vor. Nach Abs. 1 S. 2 kann die Versammlungsbehörde Leiter^innen ablehnen oder den Einsatz von Ordner`innen untersagen. Abs. 2 ermöglicht ein Vorgehen gegen einzelne Teilnehmer*innen im Vorfeld und während der Versammlung; Abs. 3 ermächtigt zum Ausschluss von Teilnehmer*innen.

§ 15 SächsVersG entspricht im Hinblick auf Beschränkungen (Abs. 1), Verbot 1188 (Abs. 1) und Auflösung (Abs. 3) § 15 VersammlG. ${ }^{2154}$

§ 13 VersammlG LSA regelt Beschränkungen, Verbote und die Auflösung von 1189 Versammlungen. Im Unterschied zu § 15 I VersammlG sieht § 13 I VersammlG LSA vor, dass Verbote und Beschränkungen nur bei dem Vorliegen einer unmittelbaren Gefahr für die öffentliche Sicherheit möglich sind, die öffentliche Ordnung mithin nicht umfasst ist. Abs. 2 und 3 regeln Verbote und Beschränkungen im Hinblick auf Gedenkstätten und Gedenktage. Die Regelungen zur Auflösung in Abs. 4 und 5 entsprechen den Regelungen in $\S 15$ III und IV VersammlG.

Das VersFG SH sieht Eingriffsbefugnisse in den $\S \S 13$ bis 15 vor. Die zentrale Vorschrift ist $\S 13$ VersFG SH, welche Beschränkungen, das Verbot und die Auflösung regelt. Nach $\S 13$ I VersFG SH kann die zuständige Behörde die Durchführung einer Versammlung unter freiem Himmel beschränken oder verbieten, die Versammlung nach deren Beginn auch auflösen, wenn nach den zur Zeit des Erlasses der Maßnahmen erkennbaren Umständen die öffentliche Sicherheit bei Durchführung der Versammlung unmittelbar gefährdet ist. §13 IV regelt Beschränkungen, Verbote und die Auflösung im Hinblick auf Gedenkstätten. § 14 VersFG SH ermöglicht die Untersagung der Teilnahme einzelner Personen (Abs. 1)

2153 Enders, in: Dürig-Friedl/Enders, Versammlungsrecht, 1. Aufl. 2016, § 15 VersammlG, Rn. 204.

2154 Allein die Regelung zu Verboten oder Beschränkungen im Zusammenhang mit Gedenktagen oder Gedenkstätten (Abs. 2) weist Abweichungen zu § 15 VersammlG auf, indem hier eine Gleichsetzung „der nationalsozialistischen und der kommunistischen Gewaltherrschaft“ vorgenommen wird. S. hierzu Scheidler, NVwZ 2011, 924. 
bzw. den Ausschluss einzelner Teilnehmer^innen und §15 VersFG SH die Durchsuchung, Sicherstellung und Identitätsfeststellung.

\section{bb) Versammlungen in geschlossenen Räumen}

1191 Bei Versammlungen in geschlossenen Räumen besteht die Besonderheit, dass diese gemäß Art. 8 II GG schrankenlos gewährleistet sind. In der Praxis sind die Einschränkungsmöglichkeiten besonders bei so genannten Skinhead-Konzerten von Relevanz. ${ }^{2155}$

\section{(1) VersammlG des Bundes}

1192 Das VersammlG des Bundes sieht für Versammlungen in geschlossenen Räumen das Verbot nach § 5 und die Auflösung nach § 13 VersammlG vor. Maßgebliches Kriterium für die Abgrenzung zwischen Verbot und Auflösung ist der Beginn der Versammlung. Auf der Grundlage des $\S 5$ VersammlG können Versammlungen bis zum Beginn der konkreten Versammlung verboten werden. Nach Beginn kommt nur die Auflösung gemäß § 13 VersammlG in Betracht.

1193 Examenswissen: Laut zutreffender Ansicht des VGH Mannheim hat eine Versammlung begonnen, wenn sie der im Versammlungsgesetz vorgesehenen Ordnungsgewalt der Versammlungsleiter^innen unterliegt. ${ }^{2156}$ Eine Ausnahme bzgl. der strengen Abgrenzung zwischen Verbot und Auflösung im Hinblick auf den Beginn der Versammlung ergibt sich aus dem Verhältnis zwischen $\S 5$ Nr. 2 und § 13 I 1 Nr. 3 VersammlG. Laut § 13 I 1 Nr. 3 VersammlG kommt eine Auflösung in Betracht, wenn die Leitung Personen, die Waffen oder sonstige Gegenstände im Sinne von § 2 III mit sich führen, nicht sofort ausschließt und für die Durchführung des Ausschlusses sorgt. Gemäß $\S 5$ Nr. 2 VersammlG kommt ein Verbot nach Beginn einer Versammlung (!) in Betracht, wenn weiteren Teilnehmer^innen, die Waffen oder Gegenstände im Sinne des § 2 III VersammlG mit sich führen, der Zutritt gewährt wird. § 5 Nr. 2 VersammlG regelt danach den Fall, dass bewaffneten Teilnehmerinnen (aktiv) Zutritt gewährt wird und § 13 I 1 Nr. 3 VersammlG den Fall, dass sich bewaffnete Teilnehmer^innen mangels Kontrolle Zugang verschaffen.

\section{(a) $\$ \mathbf{5}$ - Verbot von Versammlungen in geschlossenen Räumen}

$1194 \S 5$ VersammlG regelt insgesamt vier Verbotstatbestände, aufgrund derer bzgl. versammlungsspezifischer Gefahren gegenüber Versammlungen in geschlossenen Räumen vorgegangen werden kann.

2155 S. hierzu etwa VGH Mannheim, Urt. v. 12.7.2010, Az.: 1 S 349/10 = BeckRS 2010, 52002. 2156 VGH Mannheim, Urt. v. 26.1.1998, Az.: 1 S 3280/96 = NVwZ 1998, 761 (763); so auch Enders, in: Dürig-Friedl/Enders, Versammlungsrecht, 1. Aufl. 2016, § 5 VersammlG, Rn. 7. 
§ 5 Nr. 1 VersammlG sieht die Möglichkeit des Verbots vor, wenn Veranstalter*innen unter die Vorschriften des $\S 1$ II Nr. 1 bis 4 fallen und im Falle der Nummer 4 das Verbot durch die zuständige Verwaltungsbehörde festgestellt worden ist. $§ 5 \mathrm{Nr} .1$ VersammlG knüpft damit an den Ausschluss von der Versammlungsfreiheit nach $\S 1$ II Nr. 1 bis 4 VersammlG an. Gleichzeitig bezieht sich $\S 5$ Nr. 1 VersammlG nur auf die Person des/der jeweils betreffenden Veranstalters ${ }^{\star}$ in. Im Einzelnen regelt $\S 5$ Nr. 1 VersammlG folgende Konstellationen:

- Nr. 1 i.V.m. § 1 II Nr. 1 VersammlG regelt die Möglichkeit eines Verbots für den Fall, dass jemand (als natürliche oder juristische Person) gemäß Art. 18 GG das Grundrecht der Versammlungsfreiheit verwirkt hat.

- Nr. 1 i.V.m. § 1 II Nr. 3 VersammlG ermöglicht ein Verbot gegenüber einer Partei, die nach Art. 21 II GG durch das BVerfG für verfassungswidrig erklärt worden ist.

- $\quad$ Für ein Verbot nach Nr. 1 i.V.m. § 1 II Nr. 2 VersammlG muss ebenfalls eine Feststellung der Verfassungswidrigkeit einer Partei gemäß Art. 21 II GG durch das BVerfG vorliegen; darüber hinaus ist hier jedoch auch ein Verbot gegenüber natürlichen Personen möglich.

- Laut Nr. 1 i.V.m. §1 II Nr. 4 VersammlG kann eine Versammlung verboten werden, wenn der/die Veranstalter*in eine gemäß Art. 9 II GG verbotene Vereinigung ist.

Ein Verbot kann daneben auf $§ 5$ Nr. 2 VersammlG gestützt werden, wenn be1196 waffneten Personen der Zutritt zur Versammlung gewährt wird.

§ 5 Nr. 3 VersammlG ermöglicht ein Verbot für den Fall, dass Tatsachen 1197 festgestellt sind, aus denen sich ergibt, dass Veranstalter*innen oder ihr Anhang einen gewalttätigen oder aufrührerischen Verlauf der Versammlung anstreben. Die Voraussetzungen „gewalttätig“ und „aufrührerisch“ stellen eine Konkretisierung des Friedlichkeitsgebots aus Art. 8 I GG dar. Zu berücksichtigen ist hierbei, dass laut BVerfG eine Versammlung nicht schon dann unfriedlich ist, wenn von einzelnen Teilen oder Teilnehmer*innen der Versammlung Gewalt ausgeht. ${ }^{2157}$ Ein Verbot kommt vielmehr nur dann in Betracht, wenn eine Demonstration im Ganzen einen gewalttätigen oder aufrührerischen Verlauf nimmt ${ }^{2158} \mathrm{bzw}$. von der Versammlung insgesamt ein aggressives Verhalten ausgeht.

Der Verbotstatbestand des $\mathbf{\S} \mathbf{5}$ Nr. 4 VersammlG setzt voraus, dass Tatsachen 1198 festgestellt sind, aus denen sich ergibt, dass der/die Veranstalter ${ }^{\star}$ in oder sein/ihr Anhang Ansichten vertreten oder Äußerungen dulden werden, die ein Verbrechen

2157 BVerfG, Beschl. v. 14.5.1985, Az.: 1 BvR 233, 341/81 = BVerfGE 69, 315 (359ff.). 2158 BVerfG, Beschl. v. 14.5.1985, Az.: 1 BvR 233, 341/81 = BVerfGE 69, 315 (361). 
oder ein von Amts wegen zu verfolgendes Vergehen zum Gegenstand haben. Er zeichnet sich dadurch aus, dass er nicht auf Beschränkungen der Versammlungsfreiheit verweist, die sich bereits aus dem GG selbst ergeben, sondern vielmehr an strafbares Verhalten ${ }^{2159}$ der Veranstalter ${ }^{\star}$ innen selbst bzw. des Anhanges anknüpft. ${ }^{2160}$

\section{(b) §13 - Auflösung von Versammlungen in geschlossenen Räumen}

$1199 \S 13$ VersammlG enthält - ebenso wie $\S 5$ VersammlG - insgesamt vier Tatbestände, die eine Auflösung von Versammlungen in geschlossenen Räumen ermöglichen:

1200 § 13 I 1 Nr. 1 VersammlG ermöglicht eine Auflösung, wenn - genauso wie bei einem Verbot nach $\S 5 \mathrm{Nr} .1$ VersammlG - im Hinblick auf Veranstalter^innen die Voraussetzungen des $\S 1$ II VersammlG erfüllt sind (hierzu Rn. 1195).

1201 § 13 I 1 Nr. 2 Alt. 1 VersammlG ist vergleichbar mit $\S 5$ Nr. 3 VersammlG und ermöglicht eine Auflösung, wenn die Versammlung einen gewalttätigen oder aufrührerischen Verlauf nimmt (hierzu Rn. 1197). ${ }^{2161}$ \& 13 I 1 Nr. 2 Alt. 2 VersammlG ermöglicht zudem eine Auflösung bei unmittelbarer Gefahr für Leben und Gesundheit der Teilnehmer^innen.

1202 § 13 I 1 Nr. 3 VersammlG ist vergleichbar mit § 5 Nr. 2 VersammlG und ermöglicht eine Auflösung für den Fall, dass die Leitung Personen, die Waffen oder sonstige Gegenstände im Sinne von § 2 III mit sich führen, nicht sofort ausschließt und für die Durchführung des Ausschlusses sorgt. Im Unterschied zu $§ 5 \mathrm{Nr}$. 3 VersammlG kommt es nicht darauf an, dass die Leitung bewaffneten Personen den Zutritt gewährt und selbst dafür verantwortlich ist, dass Waffen eingeführt werden. Es kommt vielmehr darauf an, ob die Leitung trotz der Kenntnis von bewaffneten Personen nicht für einen Ausschluss dieser sorgt. ${ }^{2162}$

$2159 \mathrm{Zu}$ einem Verbot führen können die folgenden Straftatbestände: $\S \S 80$ a, 81, 82, 90 a, 94, 95 , 105, 106, 111, 126, 130, 140, 240, 241, 353 d StGB.

$2160 \mathrm{Zu}$ den verfassungsrechtlichen Bedenken gegenüber dieses Tatbestands s. Eickenjäger/ Haerkötter/Vetter, in: Ridder/Breitbach/Deiseroth, Versammlungsrecht, i.E., § 5 VersammlG, Rn. $46 \mathrm{ff}$.

2161 Im Gegensatz zu $\S 5$ Nr. 3 VersammlG kommt es hier jedoch nicht darauf an, ob Veranstalter`innen oder deren Anhang einen gewalttätigen oder aufrührerischen Verlauf der Versammlung anstreben, sondern nur, ob tatsächlich die Versammlung einen entsprechenden Verlauf annimmt.

2162 S. Kniesel, in: Dietel/Kintzel/Kniesel, Versammlungsgesetze, 17. Aufl. 2016, § 13 VersammlG, Rn. 16; Eickenjäger/Ewering/Kohlmeier, in: Ridder/Breitbach/Deiseroth, Versammlungsrecht, i. E., § 13 VersammlG, Rn. 27. 
Auf der Grundlage des § 13 I 1 Nr. 4 VersammlG kommt eine Auflösung in 1203 Betracht, wenn durch den Verlauf der Versammlung gegen Strafgesetze verstoßen wird, die ein Verbrechen oder von Amts wegen zu verfolgendes Vergehen zum Gegenstand haben oder wenn in der Versammlung zu solchen Straftaten aufgefordert oder angereizt wird und die Leitung dies nicht unverzüglich unterbindet. Dieser Tatbestand geht über die Vorgaben des $\S 5$ Nr. 4 VersammlG hinaus und ist aufgrund seiner weiten Fassung in besonderem Maße im Lichte der verfassungsrechtlichen Vorgaben des Art. 8 GG zu betrachten. Im Hinblick auf die in Frage kommenden Straftaten sind in diesem Sinne einerseits Art. 8 I GG, der nur friedliche Versammlungen und Versammlungen ohne Waffen schützt und andererseits Art. 8 II GG, wonach Versammlungen in geschlossenen Räumen keinem Gesetzesvorbehalt unterliegen, zu berücksichtigen. ${ }^{2163}$ In diesem Sinne führt die Verwirklichung von Meinungsäußerungsdelikten einerseits nicht zur Unfriedlichkeit einer Versammlung, da es bei entsprechenden Straftaten an einer (physischen) Gefährlichkeit mangelt. Andererseits kann sich eine Auflösung nach §13 I 1 Nr. 4 VersammlG auf Meinungsäußerungsdelikte stützen, die auf den Schutz von Verfassungsgütern und Grundrechten Dritter (verfassungsimmanente Schranken) abzielen. Allerdings erscheint die Möglichkeit einer Auflösung aufgrund jeglicher Verfassungsgüter und Grundrechte Dritter im Hinblick auf die Bedeutung des schrankenlos gewährleisteten Rechts auf Versammlungsfreiheit in geschlossenen Räumen zu weitgehend. In der Literatur wird vor diesem Hintergrund argumentiert, dass nur Verstöße gegen Strafgesetze, die auf den Schutz der Art. 1 und Art. 20 GG ${ }^{2164}$ gerichtet sind, zu einer Auflösung berechtigen. Eine andere Ansicht spricht sich dafür aus, eine Beschränkung auf den Schutz des Art. 1 GG vorzunehmen. ${ }^{2165}$

\section{(2) Landesversammlungsgesetze}

Die Eingriffsgrundlagen für Versammlungen in geschlossenen Räumen sind auf $\mathbf{1 2 0 4}$ Landesebene ganz unterschiedlich ausgestaltet worden.

Die Regelungen in Sachsen und Sachsen-Anhalt zum Verbot und der Auf- 1205 lösung (§§ 4 und 13 SächsVersG und $\S \S 4$ und 11 VersammlG LSA) entsprechen den

2163 S. hierzu ausführlich Eickenjäger/Ewering/Kohlmeier, in: Ridder/Breitbach/Deiseroth, Kommentar Versammlungsrecht, i.E., § 13 VersammlG, Rn. $28 \mathrm{ff}$.

2164 So Kniesel/Poscher, in: Lisken/Denninger, Handbuch des Polizeirechts, 6. Aufl. 2018, K, Rn. 131-133.

2165 So Eickenjäger/Ewering/Kohlmeier, in: Ridder/Breitbach/Deiseroth, Versammlungsrecht, i.E., $\S 13$ VersammlG, Rn. $30 \mathrm{f}$. 
Regelungen des VersammlG. Insofern kann auf die Ausführungen zu §§ 5 und 13 VersammlG verwiesen werden.

1206

In Bayern sind die Eingriffsbefugnisse für Versammlungen in geschlossenen Räumen zusammenfassend in Art. 12 BayVersG geregelt. Art. 12 I BayVersG regelt das Verbot und Art. 12 II BayVersG die Auflösung. Die Verbots- und Auflösungstatbestände entsprechen weitgehend denen der $\S \S 5$ und 13 VersammlG. ${ }^{2166} \mathrm{Im}$ Gegensatz zum VersammlG ist in Art. 12 I und II BayVersG jeweils ausdrücklich die Möglichkeit vorgesehen, anstatt eines Verbots oder (nach Beginn der Versammlung) einer Auflösung sonstige Beschränkungen (insbesondere sogenannte „Minusmaßnahmen“) vorzunehmen. Art. 12 II 2 BayVersG bestimmt in diesem Sinne ausdrücklich für die Auflösung, dass diese in den Fällen von Satz 1 Nr. 2 bis 4 nur zulässig ist, wenn andere Maßnahmen der zuständigen Behörde, insbesondere eine Unterbrechung, nicht ausreichen. Insofern ist die Auflösung subsidiär gegenüber den Minusmaßnahmen.

Das NdsVersG fasst das Verbot und die Auflösung einer Versammlung in geschlossenen Räumen in § 14 II 1 NdsVersG zusammen. Im Gegensatz zu §§ 5 und 13 VersammlG gilt bzgl. beider Maßnahmen, dass diese verfügt werden können, wenn die Friedlichkeit der Versammlung unmittelbar gefährdet ist und die Gefahr nicht anders abgewehrt werden kann. § 14 NdsVersG orientiert sich mithin an Art. 8 II GG, wonach Versammlungen in geschlossenen Räumen ohne Gesetzesvorbehalt gewährleistet sind. § 14 I NdsVersG sieht zudem vor, dass die zuständige Behörde eine Versammlung in geschlossenen Räumen beschränken kann, also sogenannte „Minusmaßnahmen“ verfügen kann, wenn ihre Friedlichkeit unmittelbar gefährdet ist. Laut Abs. 2 S. 1 sind Verbote und Auflösungen ausdrücklich nur dann zulässig, wenn eine vorliegende Gefahr nicht anders, insbesondere durch Maßnahmen nach Abs. 1, abgewehrt werden kann. Über § 14 NdsVersG hinaus regelt $\S 15$ NdsVersG so genannte „,besondere Maßnahmen“, die gegenüber einzelnen Personen erlassen werden können.

1208 Auch das VersFG SH fasst in §20 I das Verbot und die Auflösung in einer Norm zusammen. Die zuständige Behörde kann danach eine Versammlung in geschlossenen Räumen verbieten, oder nach Beginn der Versammlung auflösen, wenn nach den zur Zeit des Erlasses der Maßnahmen erkennbaren Umständen eine unmittelbare Gefahr (1.) eines unfriedlichen Verlaufs der Versammlung, (2.) für Leben oder Gesundheit von Personen oder (3.) dafür besteht, dass in der Versammlung Äußerungen erfolgen, die ein Verbrechen oder ein von Amts wegen

$2166 \mathrm{Zu}$ den Unterschieden s. Haerkötter/Kohlmeier, in: Ridder/Breitbach/Deiseroth, Versammlungsrecht, i.E., Art. 12 BayVersG, Rn. 2ff. sowie Heinhold, in: Wächtler/Heinhold/Merk, BayVersG, 1. Aufl. 2011, Art. 12. 
zu verfolgendes Vergehen darstellen. Neben dem Verbot und der Auflösung besteht unter denselben Voraussetzungen nach Abs. 1 die Möglichkeit, die Versammlung zu beschränken, d.h. so genannte „Minusmaßnahmen“ zu erlassen. Verbote und Auflösungen sind nach Abs. 2 subsidiär gegenüber Beschränkungen und demnach nur zulässig, wenn entsprechende Maßnahmen nicht ausreichen.

Neben den in $\S 20$ VersFG SH genannten Maßnahmen kommen nach $\S 9$ I und II i.V.m. § 20 I VersFG SH Maßnahmen gegenüber einzelnen Versammlungsteilnehmer*innen in Betracht. § 9 VersFG SH verweist hierzu auf Maßnahmen nach dem LVwG, d.h. dem allgemeinen Polizeirecht, sieht über den Verweis in II auf § 20 VersFG SH für deren Anwendung jedoch vor, dass zusätzlich das Vorliegen einer Gefahr im Sinne von $\S 20$ I VersFG SH gegeben sein muss. Insofern handelt es sich bei dem Verweis auf $\S 20$ I VersFG SH um eine qualifizierte Rechtsgrundverweisung.

\section{cc) Adressat*innen und Pflichtigkeit im Versammlungsrecht}

Als Adressat ${ }^{\star}$ innen von Maßnahmen im Zusammenhang von Versammlungen 1209 kommen Teilnehmer^innen, Leiter*innen und Veranstalter*innen in Betracht.

Examenswissen: Veranstalter`innen sind diejenigen Personen, die zu der Versammlung einladen und für das Zustandekommen, Inhalt, Ausgestaltung und Durchführung der Versammlung zuständig sind. ${ }^{2167}$ Die Leiter`innen sind für die Organisation und Ordnung der laufenden Versammlung zuständig und bestimmen über Eröffnung, Unterbrechung und Beendigung der Versammlung. ${ }^{2168}$ Teilnehmer`innen sind alle Personen, die sich aktiv im Rahmen einer Versammlung beteiligen oder nur zuhören, nicht jedoch zufällig anwesende Passant*innen oder etwa unbeteiligtes Ausschankpersonal. ${ }^{2169}$

Soweit die Versammlungsgesetze des Bundes und der Länder selbst keine Stö- 1211 rer`innenbestimmungen enthalten, sind die entsprechenden Bestimmungen des allgemeinen Polizeirechts (hierzu Rn. 1118ff.) heranzuziehen. ${ }^{2170}$

Vor der Versammlung sind Veranstalter*innen die richtigen Adressat*innen 1212 von Verbotsverfügungen oder Auflagen. Adressat*innen von Auflösungsverfügungen und nachträglichen bzw. während der Versammlung verfügten Beschränkungen sind die Leiter^innen und alle Teilnehmenden. (Potentielle) Teil-

2167 Kniesel/Braun/Keller, Besonderes Polizei- und Ordnungsrecht, 1. Aufl. 2018, Rn. 197. 2168 Kniesel/Braun/Keller, Besonderes Polizei- und Ordnungsrecht, 1. Aufl. 2018, Rn. 199. 2169 Kniesel/Braun/Keller, Besonderes Polizei- und Ordnungsrecht, 1. Aufl. 2018, Rn. 203 ff. 2170 Kniesel/Braun/Keller, Besonderes Polizei- und Ordnungsrecht, 1. Aufl. 2018, Rn. 428. 
nehmer`innen können vor der Versammlung Adressat*innen sein, wenn es sich um sogenannte Vorfeldmaßnahmen und dabei insbesondere um Teilnahmeuntersagungen ${ }^{2171}$ handelt. Gegen externe Störer ${ }^{\star}$ innen, $d$. h. solche Personen, die Versammlungen stören, nicht aber selbst an einer (Gegen)Versammlung teilnehmen, kann nach Maßgabe des allgemeinen Polizeirechts vorgegangen werden. ${ }^{2172}$

Soweit es zu Störungen durch Dritte kommt, ist unter den Voraussetzungen des polizeilichen Notstandes auch eine Inanspruchnahme von Nichtstörer`innen möglich. Der polizeiliche Notstand ist mittlerweile teilweise in den neuen Landesversammlungsgesetzen ausdrücklich geregelt:

- Niedersachsen: § 8 III NdsVersG (Versammlungen unter freiem Himmel) und $\S 14$ III NdsVersG (Versammlungen in geschlossenen Räumen)

- Schleswig-Holstein: § 13 II VersFG SH (Versammlungen unter freiem Himmel) und § 20 III VersFG SH (Versammlungen in geschlossenen Räumen)

1214 Wo es keine entsprechenden Regelungen gibt, sind die sich aus der Rspr. des BVerfG ergebenden Vorgaben zu berücksichtigen. Danach besteht grds. die dahingehende Schutzpflicht des Staates, die Durchführung einer rechtmäßigen Versammlung gegenüber Störungen durch Nichtteilnehmer^innen unter allen Umständen und unter Heranziehung aller zur Verfügung stehenden Mittel und Ressourcen sicherzustellen. ${ }^{2173}$ Behördliche Maßnahmen sind zudem primär gegen die Störer`innen zu richten. ${ }^{2174}$ Von diesem Grundsatz darf nur abgewichen werden, „wenn gravierende irreparable Schäden an den Rechtsgütern Leben und Gesundheit drohen, wenn die Polizei tatsächlich der Gewalt nicht mehr Herr werden und die Entwicklung der Gewalt durch eigene Mittel nicht mehr steuern oder begrenzen kann (echter polizeilicher Notstand), oder wenn die Polizei in eine Gewalteskalation hineingezogen wird, die durch Gefahren für Leben und Gesundheit höchsten Ausmaßes für Versammlungsteilnehmer, Polizei, Unbeteiligte und Störer führen, dann steht es im Ermessen der Polizei, den Nicht-Störer in Anspruch zu nehmen (unechter polizeilicher Notstand)،“2175 Die Darlegungsund Beweislast für das Vorliegen von Gründen für ein Vorgehen gegen Nichtstörer^innen auf der Grundlage des polizeilichen Notstands liegt bei der Behörde;

2171 Näher hierzu Kniesel/Braun/Keller, Besonderes Polizei- und Ordnungsrecht, 1. Aufl. 2018, Rn. $326 \mathrm{ff}$.

2172 VGH Mannheim, Urt. v. 12.02.1990, Az.: 1 S 1646/89 = NVwZ-RR 1990, 602 (603f.).

2173 St. Rspr. BVerfG. S. zuletzt etwa BVerfG, Beschl. v. 11.9.2015, Az.: 1 BvR 2211/15; BVerfG, Beschl. v. 20.12.2012, Az.: 1 BvR 2794/10 = NVwZ 2013, 570 (571).

2174 BVerfG, Beschl. v. 20.12.2012, Az.: 1 BvR 2794/10 = NVwZ 2013, 570 (571).

2175 Rühl, NVwZ 1988, 577 (584).

Sebastian Eickenjäger 
diese muss detailliert und substantiiert darlegen, welche Maßnahmen und Anstrengungen (insbesondere im Hinblick auf das Ersuchen um Amtshilfe) unternommen wurden, um die sichere Durchführung der Versammlung sicherzustellen. ${ }^{2176}$

\section{dd) Rechtsfolge: Ermessen}

Im Hinblick auf die zuvor dargestellten versammlungsrechtlichen Ermächti- 1215 gungsgrundlagen steht den zuständigen Behörden auf der Rechtsfolgenseite ein Ermessen zu (s. zum Ermessen Rn. 729ff.). Mithin sind die entsprechenden Maßnahmen auf Ermessensfehler hin zu untersuchen (s. zur Ermessensprüfung Rn. 744 ff.).

Bzgl. des Verhältnisses der genannten Maßnahmen untereinander gilt, dass 1216 Verbote und die Auflösung nur zulässig sind, wenn zuvor alle sinnvoll anwendbaren milderen Mittel, insbesondere die Erteilung von Auflagen (etwa nach § 15 I VersammlG), ausgeschöpft wurden, um friedliche Demonstrationen zu ermöglichen. $^{2177}$

Gemäß § 13 I 2 VersammlG, Art. 12 II 2 BayVersG, § 13 I 2 SächsVersG, § 11 I 21217 VersG LSA gilt zudem für Versammlungen in geschlossenen Räumen ausdrücklich, dass eine Auflösung - im Sinne des Verhältnismäßigkeitsgrundsatzes - nur zulässig ist, wenn andere polizeiliche Maßnahmen, insbesondere eine Unterbrechung der Versammlung nicht ausreichen. Gemäß §§ 13 II und 20 II VersFG SH setzten (sowohl bei Versammlungen in geschlossenen Räumen als auch bei Versammlungen unter freiem Himmel) Verbote oder Auflösungen voraus, dass Beschränkungen nicht ausreichen.

Das BVerwG geht davon aus, dass neben dem Verbot oder der Auflösung der 1218 Erlass so genannter „Minusmaßnahmen“ zulässig und im Hinblick auf den Verhältnismäßigkeitsgrundsatz u.U. geboten ist. ${ }^{2178}$ Die zuständigen Behörden müssten im Rahmen der ihnen zustehenden Befugnisse ein milderes und angesichts der konkreten Sachlage angemesseneres Mittel zur Abwehr der von der Versammlung ausgehenden unmittelbaren Gefahren - wie z. B. die Sicherstellung eines beleidigenden Spruchbandes oder das Verbot von Musikstücken oder

2176 BVerfG, Beschl. v. 11.9.2015, Az.: 1 BvR 2211/15; BVerfG, Beschl. v. 20.12.2012, Az.: 1 BvR 2794/10 = NVwZ 2013, 570 (571).; BVerfG, Beschl.v. 10.5.2006, Az.: 1 BvQ 14/06, NVwZ 2006, 1049 (1049f.).

2177 BVerfG, Beschl. v. 14.5.1985, Az.: 1 BvR 233, 341/81 = BVerfGE 69, 315 (353).

2178 S. BVerwG, Urt. v. 8.9.1981, Az.: 1 C 88.77 = BVerwGE 64, 55 (58). S. auch BVerwG, Beschl.v. 14.01.1987, Az.: 1 B 219/86 = NVwZ 1988, 250; BVerwG, Beschl.v. 23.8.1991, Az.: 1 B 77/91 = BeckRS 1991, 31230188. 
Bands, wenn durch das Spielen der Stücke oder dem Auftritt einer Band zu erwarten ist, dass hierdurch Straftatbestände erfüllt werden - als mildere Maßnahme gegenüber der Auflösung einsetzen. ${ }^{2179}$

$1219 \mathrm{Zu}$ beachten ist hierbei, dass mehrere Landesversammlungsgesetze entsprechende Minusmaßnahmen ausdrücklich geregelt haben (hierzu Rn. 1186ff. und $1204 \mathrm{ff}$.).

1220 Examenswissen: In der Literatur wird dem Ansatz der Rspr. mit dem systematischen Argument entgegengetreten, dass es sich bei entsprechenden Maßnahmen um Aliud- und nicht um Minusmaßnahmen handelt und die Anwendung von Minusmaßnahmen das im VersammlG angelegte Konzept der versammlungsrechtlichen Selbstverantwortung (Grundsatz der Autonomie der Versammlung) unterminiere. ${ }^{2180}$ Hierfür wird angeführt, dass einerseits Behörden mit Auflagen unmittelbaren Gefahren begegnen könnten und andererseits Veranstalter^innen die Obliegenheit hätten, die Einhaltung der gesetzlichen und behördlichen Vorgaben sicherzustellen sowie mit den ihnen an die Hand gegebenen Mitteln die Teilnehmer^innen zu rechtskonformen Verhalten anzuhalten. ${ }^{2181}$ Soweit die Veranstalter^innen ihrer Obliegenheit nicht nachkämen oder sich zu einem Vorgehen gegenüber störenden Teilnehmer`innen nicht der Unterstützung der Ordnungsbehörden bedienen würden, stünde den Behörden nach der Konzeption des VersammlG das Mittel der Auflösung zur Verfügung. ${ }^{2182}$ Aufgrund des Grundsatzes der Autonomie der Versammlung dürften „Minusmaßnahmen“ danach nur angeregt, nicht aber unmittelbar angeordnet werden. ${ }^{2183}$

\section{e) Literaturhinweise}

1221 Lehrbücher: Götz/Geis, Allgemeines Polizei- und Ordnungsrecht, 16. Aufl. 2017, $\S 23$; Kingreen/Poscher, Polizei- und Ordnungsrecht mit Versammlungsrecht, 10. Aufl. 2018, §§ 19-22; Kniesel/Braun/Keller, Besonderes Polizei- und Ordnungsrecht, 1. Aufl. 2018, 1. Kapitel; Schenke, Polizei- und Ordnungsrecht, 10. Aufl. 2018, Rn. $360 \mathrm{ff}$.

2179 S. BVerwG, Urt. v. 8.9.1981, Az.: 1 C 88.77 = BVerwGE 64, 55 (58).

2180 Kniesel/Poscher, in: Lisken/Denninger, Handbuch des Polizeirechts, 6. Aufl. 2018, K, Rn. $24 \mathrm{ff}$; Wittmann, in: Ridder/Breitbach/Deiseroth, Kommentar Versammlungsrecht, i. E., § 15 VersammlG, Rn. $39 \mathrm{ff}$.

2181 Kniesel/Poscher, in: Lisken/Denninger, Handbuch des Polizeirechts, 6. Aufl. 2018, K, Rn. $24 \mathrm{ff}$; Wittmann, in: Ridder/Breitbach/Deiseroth, Kommentar Versammlungsrecht, i. E., § 15 VersammlG, Rn. $39 \mathrm{ff}$.

2182 Kniesel/Poscher, in: Lisken/Denninger, Handbuch des Polizeirechts, 6. Aufl. 2018, K, Rn. 24ff.; Wittmann, in: Ridder/Breitbach/Deiseroth, Versammlungsrecht, i. E., § 15 VersammlG, Rn. $39 \mathrm{ff}$.

2183 So Friedl, in: Friedl/Enders, Versammlungsrecht, 1. Aufl. 2016, § 13 VersammlG, Rn. 15 und 17; Eickenjäger/Ewering/Kohlmeier, in: Ridder/Breitbach/Deiseroth, Versammlungsrecht, i.E., $\S 13$ VersammlG, Rn. $32 \mathrm{ff}$.

Sebastian Eickenjäger 
Aktuelle Beiträge aus der Ausbildungsliteratur: Bünnigmann, Polizeifestigkeit im Versammlungsrecht, JuS 2016, 695; Gröpl/Leinenbach, Examensschwerpunkte des Versammlungsrechts, JA 2018, 8

Aktuelle Fallbesprechungen: Buchholtz, Streit um missglückte „Hagida“Demo, JuS 2018, 889; Herrmann, Ärger am Bahndamm, JuS 2017, 1093; Lassahn, Unerwünschte Gesellschaft, JuS 2016, 730; Marxsen/Lehners, Camp in Gipfelnähe, JuS 2018, 701; Schmitz, Versammlungsfreiheit und Gegendemonstration, JuS 2017, 753; Spilker/Wenzel, Pro-Asyl-Demonstration mit Hindernissen, JuS 2016, 337

\section{Ermächtigungsgrundlagen des Bauordnungsrechts (Felix Steengrafe)}

Die Anfechtung eines Verwaltungsakts kann im öffentlichen Baurecht entweder durch den Vorhabenträger, in Form der Anfechtung einer Nebenbestimmung oder einer belastenden, bauordnungsrechtlichen Anordnung, oder durch einen Dritten erfolgen.

In Betracht kommt zunächst die Anfechtung von Nebenbestimmungen zur

Baugenehmigung. Die Erteilung der Baugenehmigung ist - sofern deren tatbestandliche Voraussetzungen vorliegen - eine gebundene Entscheidung, auf die ein Rechtsanspruch besteht (s. § 3 Rn. 155). Auch für die Frage der Zulässigkeit von Nebenbestimmungen ist diese rechtliche Einordnung beachtlich. Nebenbestimmungen sind bei einer gebundenen Entscheidung nur zulässig, wenn diese durch eine Rechtsvorschrift zugelassen werden oder wenn die Nebenbestimmung sicherstellen soll, dass die gesetzlichen Voraussetzungen der Baugenehmigung erfüllt werden, § 36 I VwVfG. Die Erteilung einer Baugenehmigung mit einer Nebenbestimmung ist gegenüber der Versagung das mildere Mittel und damit entsprechend des Grundsatzes der Verhältnismäßigkeit erforderlich. Hinsichtlich der isolierten Anfechtbarkeit von Nebenbestimmungen wird an dieser Stelle auf die Ausführungen in Rn. $249 \mathrm{ff}$. verwiesen.

In der zweiten Konstellation ficht der Adressat eine bauordnungsrechtliche Verfügung an.

Die Baugenehmigung bzw. das Anzeigeverfahren soll präventiv Verstöße gegen das Baurecht verhindern (präventive Kontrolle). Bauordnungsverfügungen sollen hingegen im Rahmen oder nach der Realisierung des Bauvorhabens auftretende bzw. bestehende Verstöße gegen das Baurecht beseitigen (repressive Kontrolle). ${ }^{2184}$

2184 Kahl/Dubber, ZJS 2015, 558 (558); Stollmann/Beaucamp, Öffentliches Baurecht, 11. Aufl. 2017, § 19, Rn. 1; Oldiges/Brinktrine, in: Steiner/Brinktrine, Besonderes Verwaltungsrecht, 9. Aufl. 2018, § 3, Rn. 298. 
Als bauordnungsrechtliche Verfügungen kommen die Stilllegungs- oder Beseitigungsverfügung oder die Nutzungsuntersagung in Betracht. Für die einzelnen Voraussetzungen der bauordnungsrechtlichen Anordnungen wird an dieser Stelle auf Rn. $1234 \mathrm{ff}$. verwiesen.

1226 Eine Baugenehmigung begünstigt den Bauherren, kann jedoch zugleich auch einen Dritten belasten und ist damit ein Verwaltungsakt mit Doppelwirkung. ${ }^{2185}$ In Betracht kommt daher auch die Anfechtung der Baugenehmigung durch einen Nachbarn. Bei der Anfechtungsklage eines Nachbarn ist insbesondere die Klagebefugnis nach $\S 42$ II VwGO - aufgrund der fehlenden Adressateneigenschaft - problematisch. Die Klagebefugnis eines Dritten erfordert nach der Schutznormtheorie die Möglichkeit der Verletzung einer nachbarschützenden Vorschrift. Ausgangspunkt ist damit die Bestimmung einer möglicherweise verletzten Rechtsnorm. Der nachbarschützende Charakter von Rechtsnormen ergibt sich aus deren Auslegung, vor allem nach deren Wortlaut sowie Sinn und Zweck. ${ }^{2186}$ Nach der Feststellung der nachbarschützenden Wirkung der Rechtsnorm ist zu prüfen, ob der Kläger in dem von der Rechtsnorm besonders geschützten Personenkreis umfasst ist. Nach dem materiellen Nachbarbegriff ist „Nachbar“ in diesem Sinne jede Person, die sich im Einwirkungsbereich des Vorhabens langfristig oder ständig aufhält. ${ }^{2187}$ Das Bauplanungsrecht ist grundstücksbezogen. Ein bauplanungsrechtlicher Nachbarschutz steht damit nur dem Grundstückseigentümer oder Inhaber vergleichbarer dinglicher Rechte und nicht obligatorisch Berechtigten zu. ${ }^{2188}$

\section{a) Einführung in das Baurecht}

1227 Das öffentliche Baurecht umfasst alle Rechtsvorschriften über die Zulässigkeit, Grenzen, Ordnung sowie Förderung der Nutzung von Boden, insbesondere hinsichtlich der Errichtung, Nutzung, Veränderung sowie Beseitigung von baulichen Anlagen. ${ }^{2189}$

2185 Wolf, NVwZ 2013, 247 (247); Erbguth/Mann/Schubert, Besonderes Verwaltungsrecht, 12 Aufl. 2015, Rn. 1322; Sperlich, JA 2017, 38 (38).

2186 Erbguth/Mann/Schubert, Besonderes Verwaltungsrecht, 12. Aufl. 2015, Rn. 1329; Stollmann/Beaucamp, Öffentliches Baurecht, 11 Aufl. 2017, § 21, Rn. 31.

2187 Erbguth/Mann/Schubert, Besonderes Verwaltungsrecht, 12 Aufl. 2015, Rn. 1334; Muckel/ Ogorek, Öffentliches Baurecht, 3. Aufl. 2018, § 10, Rn. 16.

2188 BVerwG, Beschl.v. 11.7.1989, Az.: 4 B 33/89, Rn. 4 = NJW 1989, 2766 (2766); VGH München, Beschl. v. 9.5.2017, Az.: 9 CS 16.1241, Rn. 19; VGH München, Beschl.v. 2.9.2016, Az.: 9 CS 16.1138, Rn. 16; VGH Mannheim, Beschl.v. 27.6.2006, Az.: 8 S 997/06, Rn. 2.

2189 Stollmann/Beaucamp, Öffentliches Baurecht, 11. Aufl. 2017, §1, Rn. 1.

Felix Steengrafe 


\section{aa) Unterscheidung zwischen Bauplanungs- und Bauordnungsrecht}

Im öffentlichen Baurecht ist zwischen dem Bauplanungs- und Bauordnungsrecht 1228 zu unterscheiden. Das Bauplanungsrecht umfasst insbesondere die Zulässigkeit von Vorhaben nach den Regelungen des BauGB sowie die Vorschriften über die Bauleitplanung und setzt sich aus dem BauGB und auf diesem Gesetz erlassenen Verordnungen (Baunutzungsverordnung, Wertermittlungsverordnung und Planzeichenverordnung) zusammen. Die Bauleitplanung ist wiederum in den Flächennutzungsplan sowie den Bebauungsplan zu unterscheiden. Der Flächennutzungsplan im Sinne des $\S \S 5$ BauGB ff. ist der vorbereitende Bauleitplan, während der Bebauungsplan gemäß $\S \S 8$ BauGB ff. verbindlich ist. Während das Bauplanungsrecht flächenbezogen ist und damit einem Interessenausgleich zwischen öffentlichen und privaten Interessen dient, ist das Bauordnungsrecht objektbezogen und damit primär der Gefahrenabwehr zuzuordnen. ${ }^{2190}$ Das Bauordnungsrecht regelt die Voraussetzungen sowie das Verfahren zur Erteilung einer Baugenehmigung oder für den Erlass bauordnungsrechtlicher Verfügungen. Eine wesentliche bauordnungsrechtliche Anforderung in der Form des Verunstaltungsverbotes liegt in der Gestaltung des Vorhabens. ${ }^{2191}$ Die Rechtsgrundlagen des Bauordnungsrechts finden sich in den Bauordnungen der Bundesländer. Alle 16 Bundesländer haben eine eigene Bauordnung erlassen. Als Orientierungspunkt für die Bundesländer wurde die Musterbauordnung (im Folgenden MBauO) erarbeitet, die selbst jedoch kein Gesetz ist. Die Bauordnungen der Bundesländer orientieren sich in vielen Punkten an der MBauO. Aus Gründen der Übersichtlichkeit wird im Folgenden auf die Vorschriften der MBauO verwiesen, wobei jeweils auf die besonders relevanten landesrechtlichen Normen hingewiesen wird.

\section{bb) Verfassungsrechtliche Anknüpfungspunkte des öffentlichen Baurechts}

Der Bund verfügt gemäß Art. 74 I Nr. 18 GG über die konkurrierende Gesetz- 1229

gebungskompetenz für das Bodenrecht. Als Bestandteil der konkurrierenden Gesetzgebungskompetenz haben die Länder nach Art. 72 I GG „die Befugnis zur Gesetzgebung solange und soweit der Bund von seiner Gesetzgebungszuständigkeit nicht durch Gesetz Gebrauch gemacht hat.“ Das BauGB ist eine ab-

2190 Erbguth/Mann/Schubert, Besonderes Verwaltungsrecht, 12. Aufl. 2015, Rn. 795 ff.; Battis, Öffentliches Baurecht und Raumordungsrecht, 7. Aufl. 2017, Rn. $3 \mathrm{f}$.

2191 BVerwG, Beschl.v. 27.6.1991, Az.: 4 B 138/90, Rn. 6 = NVwZ 1991, 983 (984); BVerwG, Urt. v. 11.10.2007, Az.: 4 C 8/06, Rn. 10 ff.; Schröer, NZBau 2008, 759 (760); Erbguth/Mann/Schubert, Besonderes Verwaltungsrecht, 12. Aufl. 2015, Rn. 802; Muckel/Ogorek, Öffentliches Baurecht, 3. Aufl. 2018, § 9, Rn. 91.

Felix Steengrafe 
schließende Entscheidung des Gesetzgebers, weshalb keine Befugnis der Bundesländer zur Gesetzgebung im Bereich des Bauplanungsrechts besteht. ${ }^{2192}$

1230

Art. 28 II 1 GG gewährleistet den Gemeinden „,alle Angelegenheiten der örtlichen Gemeinschaft im Rahmen der Gesetze in eigener Verantwortung zu regeln“, was das Recht der Bauleitplanung umfasst. ${ }^{2193}$ Einfachgesetzlich spiegelt sich die Planungshoheit in § 2 I 1 BauGB wider, ${ }^{2194}$ nach dem die Gemeinden Bauleitpläne in eigener Verantwortung aufstellen. Ebenfalls durch Art. 28 II 1 GG als Ausdruck der Planungshoheit verfassungsrechtlich abgesichert ist das Recht der Gemeinde auf Beteiligung an Planungen von anderen Hoheitsträgern, sofern sich diese für die Gemeinde auswirken können. ${ }^{2195}$ Als Beispiel für eine solche Beteiligung ist $§ 9$ ROG anzuführen.

1231 Ebenfalls zum Schutz der kommunalen Planungshoheit sieht $\S 36$ BauGB die Regelung zum gemeindlichen Einvernehmen vor. ${ }^{2196}$ Nach § 36 I 1 BauGB wird über „die Zulässigkeit von Vorhaben nach den $\S \S 31,33$ bis 35 im bauaufsichtlichen Verfahren von der Baugenehmigungsbehörde im Einvernehmen mit der Gemeinde entschieden.“ Das gemeindliche Einvernehmen darf gemäß $\S 36$ II 1 BauGB nur aus den sich aus den $\S \S 31$, 33, 34 und 35 ergebenden Gründen versagt werden. Wird das gemeindliche Einvernehmen nicht binnen zwei Monaten nach Eingang des Ersuchens verweigert, gilt dieses gemäß § 36 II BauGB als erteilt. Die Berechnung der Frist erfolgt nach $\S \S 187$ I, 188 II BGB. ${ }^{2197}$ Ein rechtswidrig versagtes Einvernehmen der Gemeinde kann nach § 36 II 3 BauGB ersetzt werden.

1232 Das Bauordnungsrecht bezieht sich aufgrund seines Objektbezuges in erster Linie auf die Sicherheit sowie Gestaltung des Einzelvorhabens und ist Bestandteil des Polizei- und Ordnungsrechts, weshalb nach Art. 70 I GG eine Gesetzge-

2192 Erbguth/Mann/Schubert, Besonderes Verwaltungsrecht, 12. Aufl. 2015, Rn. $807 \mathrm{f}$. 2193 Krüper/Herbolsheimer, ZJS 2016, 546 (546f.); Krüper, ZJS 2010, 582 (582); Stollmann/ Beaucamp, Öffentliches Baurecht, 11. Aufl. 2017, § 2, Rn. 15 f.; Muckel/Ogorek, Öffentliches Baurecht, 3. Aufl. 2018, § 4, Rn. 1; Jeromin, in: Kröninger/Aschke/Jeromin, BauGB, 4. Aufl. 2018, § 2, Rn. 1.

2194 Stollmann/Beaucamp, Öffentliches Baurecht, 11. Aufl. 2017, § 2, Rn. 17; Muckel/Ogorek, Öffentliches Baurecht, 3. Aufl. 2018, § 4, Rn. 1; Jeromin, in: Kröninger/Aschke/Jeromin, BauGB, 4. Aufl. 2018, § 2, Rn. 1.

2195 Erbguth/Mann/Schubert, Besonderes Verwaltungsrecht, 12. Aufl. 2015, Rn. 812; Stollmann/ Beaucamp, Öffentliches Baurecht, 11. Aufl. 2017, § 2, Rn. 19.

2196 Hofmeister, in: Spannowsky/Uechtritz, BauGB, 3. Aufl. 2018, § 36, Rn. 1; Jeromin, in: Kröninger/Aschke/Jeromin, BauGB, 4. Aufl. 2018, § 36, Rn. 1.

2197 Hofmeister, in: Spannowsky/Uechtritz, 3. Aufl. 2018, § 36, Rn. 26; Jeromin, in: Kröninger/ Aschke/Jeromin, BauGB, 4. Aufl. 2018, § 36, Rn. 7.

Felix Steengrafe 
bungskompetenz der Länder besteht. ${ }^{2198}$ Diese Kompetenz drückt sich in den 16 Bauordnungen der Länder aus.

Für das öffentliche Baurecht ist Art. 14 GG von wesentlicher Bedeutung. 1233 Art. 14 I 1 GG schützt verfassungsrechtlich das Eigentum, was das Recht der Nutzung des Eigentums nach der eigenen Vorstellung umfasst. ${ }^{2199}$ Inhalt und Schranken der Eigentumsfreiheit bestimmen (einfache) Gesetze. ${ }^{2200}$ Ein Grundstück darf im Rahmen der Gesetze bebaut werden. Ein Anspruch auf Erteilung einer Baugenehmigung besteht, wenn öffentlich-rechtliche Vorschriften dem nicht entgegenstehen. Darüber hinaus kann zugunsten einer Bebauung ein Bestandsschutz eintreten. Ein unbeschränktes Baurecht besteht hingegen nicht. ${ }^{2201}$

Hausarbeitswissen: Es ist umstritten, ob sich diese sog. Baufreiheit aus Art. $14 G^{2202}$ oder aus verwaltungsrechtlichen Vorschriften ${ }^{2203}$ ergibt.

\section{b) Die Beseitigungsverfügung}

Eine Beseitigungsverfügung ist aufgrund ihrer erheblichen Folgen nur die ulti- 1234 ma ratio um einen baurechtskonformen Zustand wiederherzustellen. ${ }^{2204}$ Die Beseitigung eines Bauwerkes kann teilweise oder vollständig angeordnet werden.

\section{aa) Ermächtigungsgrundlagen}

$\S 80 \mathrm{MBauO}$ normiert die Ermächtigungsgrundlage für eine Beseitigungsverfügung. In den Ländern finden sich die Ermächtigungsgrundlagen in den folgenden Normen:

2198 BVerwG, Urt. v. 11.10.2007, Az.: 4 C 8/06, Rn. 10; Dirnberger, in: Spannowsky/Uechtritz, 3. Aufl. 2018, § 1, Rn. 2; Oldiges/Brinktrine, in: Steiner/Brinktrine, Besonderes Verwaltungsrecht, 9. Aufl. 2018, § 3, Rn. 14; Stollmann/Beaucamp, Öffentliches Baurecht, 11. Aufl. 2017, § 2, Rn. 25. 2199 Jarass, in: Jarass/Pieroth, GG, 15. Aufl. 2018, Art. 14, Rn. 16.

2200 BVerfG, Urt. v. 6.12.2016, 1 BvR 2821/11, 1 BvR 321/12, 1 BvR 1456/12 = NJW 2017, 217 (221); BVerfG, Beschl.v. 15.1.1969, 1 BvL 3/66; BVerwG, Urt. v. 18. 8.1960, I C 42/59 = NJW 1961, 793 (793); Jarass, in: Jarass/Pieroth, GG, 15. Aufl. 2018, Art. 14, Rn. 5.

2201 Stollmann/Beaucamp, Öffentliches Baurecht, 11. Aufl. 2017, § 2, Rn. 3 ff.; Erbguth/Mann/ Schubert, Besonderes Verwaltungsrecht, 12. Aufl. 2015, Rn. 816 ff.; Art. 14 GG bejahend: Jarass, in: Jarass/Pieroth, GG, 15. Aufl. 2018, Art. 14, Rn. 20.

2202 VGH Mannheim, Beschl. v. 22.1.1996, Az.: 8 S 2964/95, Rn. 3.

2203 Lege, ZJS 2012, 44 (45).

2204 Kahl/Dubber, ZJS 2015, 558 (561). 


\begin{tabular}{|c|c|}
\hline Baden-Württemberg & $\S 65$ LBO BW \\
\hline Bayern & Art. 76 BayBO \\
\hline Berlin & $\S 80$ BauO Bln \\
\hline Brandenburg & $\S 80 \mathrm{BbgBO}$ \\
\hline Bremen & $\S 79$ BremLBO \\
\hline Hamburg & $\S 76 \mathrm{HmbBO}$ \\
\hline Hessen & $\S 82 \mathrm{HBO}$ \\
\hline Mecklenburg-Vorpommern & $\S 80 \mathrm{LBO} \mathrm{MV}$ \\
\hline Niedersachsen & $\S 79$ NBauO \\
\hline Nordrhein-Westfalen & $\S 82 \mathrm{BauO} N R W$ \\
\hline Rheinland-Pfalz & $\S 81 \mathrm{f}$. LBO RP \\
\hline Saarland & $\S 82$ LBO Saar \\
\hline Sachsen & $\S \S 80$ SächsBO \\
\hline Sachsen-Anhalt & $\S 79$ BauO LSA \\
\hline Schleswig-Holstein & $\S 59 \mathrm{LBO}$ SH \\
\hline Thüringen & $\S 79$ ThürBO \\
\hline
\end{tabular}

\section{bb) Formelle Rechtmäßigkeit}

1235 Für ein bauordnungsrechtliches Einschreiten müssen - wie bei jedem Verwaltungsakt - die formellen Anforderungen in der Gestalt der sich aus dem Bauordnungsrecht ergebenden Zuständigkeit, des Verfahrens, insbesondere der Anhörung nach $\S 28$ VwVfG bei einer Bauordnungsverfügung als belastenden Verwaltungsakt, und der Form gewahrt werden (s. Rn. 579ff.). Bei einem schriftlichen Verwaltungsakt sind die Anforderungen des § 39 VwVfG zu berücksichtigen.

\section{cc) Materielle Rechtmäßigkeit}

1236 Ein genehmigungspflichtiges Vorhaben darf nur abgerissen werden, wenn dieses formell und materiell illegal ist. Diese Voraussetzungen müssen kumulativ vorliegen. ${ }^{2205}$ Formelle Illegalität bedeutet, dass die erforderliche Baugenehmi-

2205 VG Münster, Urt. v. 19.6.2018, Az.: 2 K 6704/17, Rn. 33; Kersten, in: Schoch, Besonderes Felix Steengrafe 
gung nicht vorliegt oder das Bauwerk wesentlich von der Genehmigung abweicht. ${ }^{2206}$ Materiell illegal ist ein Bauwerk, wenn dieses nicht mit den öffentlichrechtlichen Anforderungen vereinbar ist. ${ }^{2207}$

Sofern ein Bauwerk nicht mit den öffentlich-rechtlichen Vorgaben vereinbar 1237 und damit materiell illegal ist, dieses aber durch eine Baugenehmigung gedeckt und somit formell legal ist, darf eine Beseitigungsverfügung nicht ergehen. Vor einer solchen Verfügung müsste die Baugenehmigung bestandskräftig aufgehoben werden (zu Rücknahme und Widerruf näher Rn. $836 \mathrm{ff}$. ). ${ }^{2208}$ Im Falle eines vereinfachten Genehmigungsverfahrens kann sich die Legalisierungswirkung der Baugenehmigung nicht auf die im vereinfachten Genehmigungsverfahren ungeprüften Bereiche erstrecken, weshalb die vorherige Aufhebung der Baugenehmigung in diesem Einzelfall nicht erforderlich ist. ${ }^{2209}$ Einer Beseitigungsverfügung steht der passive Bestandsschutz als Ausdruck von Art. 14 I GG entgegen. War die Errichtung des Bauwerkes materiell rechtmäßig, schützt der passive Bestandsschutz vor einer Veränderung der Sach- und Rechtslage. ${ }^{2210}$ Diese Rechtsauffassung ist allerdings nicht unumstritten. Ebenfalls nicht unumstritten ist die Konstellation, in der die materielle Rechtmäßigkeit für einen Zeitraum nach der Errichtung und vor der ordnungsrechtlichen Verfügung eingetreten ist. ${ }^{2211}$ Bei genehmigungsfreien Vorhaben ist mangels erforderlicher Baugenehmigung naturgemäß nur auf die materielle Illegalität abzustellen.

Verwaltungsrecht, 2018, Kap. 3, Rn. 449; Kahl/Dubber, ZJS 2015, 558 (561); Lindner, JuS 2014, 118 (120).

2206 Kahl/Dubber, ZJS 2015, 558 (561); Lindner, JuS 2014, 118 (119); Oldiges/Brinktrine, in: Steiner/Brinktrine, Besonderes Verwaltungsrecht, 9. Aufl. 2018, § 3, Rn. 331; Battis, Öffentliches Baurecht und Raumordungsrecht, 7. Aufl. 2017, Rn. 599.

2207 OVG Greifswald, Beschl.v. 2.11.1993, 3 M 89/93 = NVwZ 1995, 608 (608); Oldiges/Brinktrine, in: Steiner/Brinktrine, Besonderes Verwaltungsrecht, 9. Aufl. 2018, § 3, Rn. 331; Battis, Öffentliches Baurecht und Raumordungsrecht, 7. Aufl. 2017, Rn. 599.

2208 Lindner, JuS 2014, 118 (121); Oldiges/Brinktrine, in: Steiner/Brinktrine, Besonderes Verwaltungsrecht, 9. Aufl. 2018, § 3, Rn. 335; Erbguth/Mann/Schubert, Besonderes Verwaltungsrecht, 12. Aufl. 2015, Rn. 1305.

2209 OVG Berlin-Brandenburg, Beschl. v. 23.6.2010, Az.: 2 S 99/09 = NVwZ-RR 2010, 794 (795); Lindner, JuS 2014, 118 (121).

2210 Battis, Öffentliches Baurecht und Raumordungsrecht, 7. Aufl. 2017, Rn. 601; Kersten, in: Schoch, Besonderes Verwaltungsrecht, 2018, Kap. 3, Rn. 450.

2211 VG Münster, Urt. v. 19.6.2018, Az.: 2 K 6704/17, Rn. 70; Battis, Öffentliches Baurecht und Raumordungsrecht, 7. Aufl. 2017, Rn. 601; Kersten, in: Schoch, Besonderes Verwaltungsrecht, 2018, Kap. 3, Rn. 450; Mit einem Überblick: Kahl/Dubber, ZJS 2015, 558 (563).

Felix Steengrafe 
Adressaten einer bauordnungsrechtlichen Verfügung können entweder der Handlungs- oder Zustandsstörer sein (s. Rn. 1121ff.). Bei der Auswahl des Störers ist die Effektivität der Gefahrenabwehr zu berücksichtigen. ${ }^{2212}$

Examenswissen: Eine Ordnungsverfügung kann auch gegenüber einem Rechtsnachfolger wirken. Maßgeblich ist hierbei das Landesrecht. ${ }^{2213}$ Sofern das Landesrecht keine Regelung enthält, stellt sich die Frage, ob mit der Verfügung eine höchstpersönliche Pflicht eintrat. In der Regel dürfte die Ordnungsverfügung allerdings sachbezogen und damit nicht höchstpersönlich sein. Auch ein Gesamtrechtsnachfolger wird damit durch die Verfügung verpflichtet. ${ }^{2214}$

\section{dd) Ermessen}

1239 Die Beseitigungsverfügung steht im pflichtgemäßen Ermessen der Bauverwaltung. Das Ermessen erstreckt sich auf das Erschließungsermessen („ob“) und das Auswahlermessen (,wie). Das Auswahlermessen erstreckt sich sowohl auf die Maßnahme als auch auf den Adressaten. ${ }^{2215}$ Bei der Auswahl ist die Effektivität der Gefahrenabwehr zu berücksichtigen. Nach der Rechtsprechung ist im Regelfall eine Ordnungsverfügung zu erlassen, um einen baurechtskonformen Zustand wiederherzustellen. Nur in Ausnahmefällen soll die Bauverwaltung von einer Beseitigungsverfügung absehen. ${ }^{2216}$

1240 Bestehen mehrere formell und materiell illegale Bauwerke ist grundsätzlich der allgemeine Gleichheitssatz des Art. 3 I GG anzuwenden. ${ }^{2217}$ Trotz des Gleichheitssatzes ist nicht erforderlich, dass die Bauverwaltung gegen alle illegalen Bauwerke zeitgleich vorgeht. Bei sachlichen Gründen darf sich die Verwaltung auf die Abarbeitung von Einzelfällen festlegen. Sachliche Gründe in diesem Sinne können das Gefahrenpotenzial einzelner Bauwerke, Größe oder Lage der Bauwerke oder die Kapazitätsgrenze der Baubehörde sein. ${ }^{2218}$ Eine Ungleichbehandlung kann einer Beseitigungsverfügung nur dann erfolgreich entgegengehalten werden, wenn kein sachlicher Grund für das abschnittsweise Vorgehen besteht. ${ }^{2219}$

2212 Erbguth/Mann/Schubert, Besonderes Verwaltungsrecht, 12. Aufl. 2015, Rn. 1313.

2213 Erbguth/Mann/Schubert, Besonderes Verwaltungsrecht, 12. Aufl. 2015, Rn. 1313.

2214 Stollmann/Beaucamp, Öffentliches Baurecht, 11. Aufl. 2017, § 19, Rn. 46 f.

$2215 \mathrm{Kahl} /$ Dubber, ZJS 2015, 558 (564).

2216 Kersten, in: Schoch, Besonderes Verwaltungsrecht, 2018, Kap. 3, Rn. 446; Kahl/Dubber, ZJS 2015, 558 (564).

2217 Kahl/Dubber, ZJS 2015, 558 (565); Stollmann/Beaucamp, Öffentliches Baurecht, 11. Aufl. 2017, § 19, Rn. 35; Kersten, in: Schoch, Besonderes Verwaltungsrecht, 2018, Kap. 3, Rn. 454.

2218 Kahl/Dubber, ZJS 2015, 558 (565).

2219 Kahl/Dubber, ZJS 2015, 558 (565).

Felix Steengrafe 
Bei Kenntnis der Bauverwaltung von einer rechtswidrigen Bebauung über 1241 einen längeren Zeitraum, kann beim Adressaten einer späteren Ordnungsverfügung die Vorstellung entstanden sein, dass sich die Verwaltung mit der Bebauung abgefunden habe. In einem solchen Fall stellt sich die Frage nach der Schutzwürdigkeit dieser Vorstellung. Nahm die Behörde die rechtswidrige Bebauung einfach hin (sog. faktische Duldung), begründet dies keinen Vertrauenstatbestand für die zukünftige Akzeptanz der rechtswidrigen Bebauung. Dies gilt selbst in den Fällen, in denen die faktische Duldung über einen langen Zeitraum bestand. ${ }^{2220}$ Ein Vertrauenstatbestand kann sich aus einer sog. aktiven Duldung ergeben. Für die Annahme dieser Form der Duldung muss die Behörde in unmissverständlicher Art und Weise erklären, ob, für welchen Zeitraum und in welchem Rahmen die Duldung des baurechtswidrigen Zustandes erfolgen soll. Eine solche Erklärung kann im Einzelfall einer bauaufsichtlichen Verfügung entgegengehalten werden. ${ }^{2221}$

Ein Ermessensfehler kann in der Gestalt der Ermessensüberschreitung 1242 durch eine unverhältnismäßige Entscheidung vorliegen. Die bauordnungsrechtlichen Verfügungen müssen - wie alle staatlichen Maßnahmen - verhältnismäßig sein, weshalb die Verhältnismäßigkeit zu prüfen ist. Der legitime Zweck ist die Schaffung von baurechtskonformen Zuständen. In der Regel ist die Beseitigungsverfügung zur Förderung des Ziels geeignet. Nicht erforderlich ist eine solche Verfügung, wenn durch ein milderes aber gleich effektives Mittel der baurechtskonforme Zustand hergestellt werden kann. Aufgrund des erheblichen Substanzeingriffes stellt die Beseitigung den gravierendsten Eingriff in das Eigentum dar. ${ }^{2222}$ Eine Nutzungsuntersagung oder eine Genehmigung mit erheblichen Nebenbestimmungen sowie ein Teilabriss sind in vielen Fällen ein milderes Mittel, dessen gleiche Effektivität im Einzelfall zu betrachten ist. ${ }^{2223}$ Bei der Angemessenheit ist zwischen der Schwere des Eingriffs und der Bedeutung des verfolgten Zieles abzuwägen. ${ }^{222}$ Trotz des erheblichen Eingriffs mit dem hohen wirtschaftlichen Schaden und den Folgen für den Adressaten stehen diese Er-

2220 OVG Münster, Urt. v. 24.2.2016, Az.: 7 A 1623/14 = NVwZ-RR 2016, 851 (853); OVG Münster, Urt. v. 22.8. 2005, 10 A 4694/03 = NJOZ 2005, 5183 (5190); Sommer, JA 2017, 567 (568).

2221 OVG Münster, Beschl. v. 16.3.2007, Az.: 7 B 134/07, Rn. 29 = NVwZ-RR 2007, 661 (662); OVG Münster, Urt. v. 22.8.2005, Az.: 10 A 4694/03, Rn. 95 ff. = NJOZ 2005, 5183 (5190); OVG Berlin, Urt.v. 14.5.1982, Az.: 2 B 57/79, Rn. 23 = NJW 1983, 777 (778); Sommer, JA 2017, 567 (568).

$2222 \mathrm{Kahl} /$ Dubber, ZJS 2015, 558 (565).

2223 Kahl/Dubber, ZJS 2015, 558 (565); Kersten, in: Schoch, Besonderes Verwaltungsrecht, 2018, Kap. 3, Rn. 453.

2224 Kahl/Dubber, ZJS 2015, 558 (565).

Felix Steengrafe 
wägungen nicht per se einer Beseitigungsverfügung entgegen, andernfalls würden baurechtswidrige Bauwerke privilegiert werden. ${ }^{2225}$

\section{c) Die Nutzungsuntersagung}

1243 Anders als bei der Beseitigungsverfügung zielt die Nutzungsuntersagung nicht auf eine Substanzbeeinträchtigung, sondern auf ein Unterlassen ab.

\section{aa) Ermächtigungsgrundlagen}

$1244 \S 80$ S. 2 MBauO ermächtigt eine Nutzung zu untersagen, wenn eine Anlage im Widerspruch zu öffentlich-rechtlichen Vorschriften genutzt wird. In den Ländern finden sich die Ermächtigungsgrundlagen in den folgenden Normen:

\begin{tabular}{|c|c|}
\hline Baden-Württemberg & $\S 65$ LBO BW \\
\hline Bayern & Art. 76 BayBO \\
\hline Berlin & $\S 80$ BauO Bln \\
\hline Brandenburg & $\S 80 \mathrm{BbgBO}$ \\
\hline Bremen & $\S 79$ BremLBO \\
\hline Hamburg & $\S 76 \mathrm{HmbBO}$ \\
\hline Hessen & $\S 82 \mathrm{HBO}$ \\
\hline Mecklenburg-Vorpommern & $\S 80 \mathrm{LBO} \mathrm{MV}$ \\
\hline Niedersachsen & $\S 79$ NBauO \\
\hline Nordrhein-Westfalen & $\S 82 \mathrm{BauO} N R W$ \\
\hline Rheinland-Pfalz & $\S 81 \mathrm{f}$. LBO RP \\
\hline Saarland & $\S 82$ LBO Saar \\
\hline Sachsen & $\S \S 80$ SächsBO \\
\hline Sachsen-Anhalt & $\S 79 \mathrm{BauO}$ LSA \\
\hline Schleswig-Holstein & $\S 59$ LBO SH \\
\hline Thüringen & $\S 79$ ThürBO \\
\hline
\end{tabular}

2225 OVG Berlin, Beschl. v. 27.11.2001, Az.: 2 N 27/01 = LKV 2002, 184 (185); Kahl/Dubber, ZJS 2015, 558 (565); Stollmann/Beaucamp, Öffentliches Baurecht, 11. Aufl. 2017, § 19, Rn. 34.

Felix Steengrafe 


\section{bb) Formelle Rechtmäßigkeit}

Die formellen Anforderungen an den Erlass einer Nutzungsuntersagung weichen 1245 nicht von den obigen Anforderungen ab (s. Rn. 1235).

\section{cc) Materielle Rechtmäßigkeit}

Bei der Nutzungsuntersagung steht die Nutzung des Bauwerkes nicht im Einklang 1246 mit den öffentlich-rechtlichen Vorgaben. Umstritten ist, ob für den Erlass einer Nutzungsuntersagung die formelle Illegalität ausreichend ist. Teilweise wird auch eine materielle Illegalität gefordert. Begründet wird diese weitgehende Forderung mit der Beeinträchtigung des Eigentums. ${ }^{2226}$ Für eine ausreichende formelle Illegalität spricht die geringe Eigentumsbeeinträchtigung. ${ }^{2227}$ Die Intensität ist wesentlich geringer als bei einer Beseitigungsverfügung. Besteht sowohl eine formelle als auch materielle Illegalität ist nach beiden Auffassungen eine Nutzungsuntersagung materiell rechtmäßig. Die Frage der Erforderlichkeit der materiellen Illegalität wirkt sich damit nur in den Fällen auf das Ergebnis aus, in denen eine formelle, aber keine materielle Illegalität besteht. Der Bestandsschutz endet bei einer Nutzungsänderung. ${ }^{2228}$ Die Bauverwaltung muss im Rahmen ihrer pflichtgemäßen Ermessensausübung - sofern ausschließlich eine formelle Illegalität gefordert werden sollte - eine mögliche (offensichtliche) materielle Rechtmäßigkeit berücksichtigen. ${ }^{2229}$ Ansonsten kann an dieser Stelle auf die vorherigen Ausführungen zum Ermessen bei der Beseitigungsverfügung verwiesen werden (s. Rn. 1239ff.).

\section{d) Die Stillegungsverfügung}

Anders als die Beseitigungsverfügung oder die Nutzungsuntersagung bezieht sich 1247 die Stilllegungsverfügung zeitlich auf die Errichtungsphase des Bauwerkes.

2226 VGH Mannheim, Beschl. v. 22.1.1996, Az.: 8 S 2964/95, Rn. 3.

2227 VGH München, Urt. v. 5.12.2005, 1 B 03.2608 = NVwZ-RR 2006, 754 (755); OVG Bautzen, Beschl.v. 25.6.2001, Az.: B 67/01 = LKV 2002, 180 (180); Kahl/Dubber, ZJS 2015, 558 (567); Kersten, in: Schoch, Besonderes Verwaltungsrecht, 2018, Kap. 3, Rn. 446.

2228 BVerfG, Beschl. v. 15.12.1995, Az.: 1 BvR 1713/92 = NVwZ-RR 1996, 483 (483); BVerwG, Beschl. v. 9.9.2002, Az.: 4 B 52/02; BVerwG, Beschl. v. 27.2.1993, 4 B 5/93, Rn. 3.

2229 VGH München, Urt. v. 5.12. 2005, Az.: 1 B 03.2608 = NVwZ-RR 2006, 754 (755); OVG Bautzen, Beschl. v. 25.6.2001, Az.: 1 B 67/01 = LKV 2002, 180 (180); Kahl/Dubber, ZJS 2015, 558 (568).

Felix Steengrafe 


\section{aa) Ermächtigungsgrundlagen}

1248 Die Ermächtigungsgrundlage für die Anordnung des Einstellens von Arbeiten ergibt sich aus $\S 79$ MBauO. In den Ländern finden sich die Ermächtigungsgrundlagen in den folgenden Normen:

\begin{tabular}{|c|c|}
\hline Baden-Württemberg & $\S 64$ LBO BW \\
\hline Bayern & Art. 75 BayBO \\
\hline Berlin & $\S 79$ BauO Bln \\
\hline Brandenburg & $\S 79 \mathrm{BbgBO}$ \\
\hline Bremen & $\S 78$ BremLBO \\
\hline Hamburg & $\S 75 \mathrm{HmbBO}$ \\
\hline Hessen & $\S 81 \mathrm{HBO}$ \\
\hline Mecklenburg-Vorpommern & $\S 79$ LBO MV \\
\hline Niedersachsen & $\S 79$ NBauO \\
\hline Nordrhein-Westfalen & $\S 81 \mathrm{BauO} N R W$ \\
\hline Rheinland-Pfalz & $\S 80$ LBO RP \\
\hline Saarland & $\S 81$ LBO Saar \\
\hline Sachsen & $\S \S 79$ SächsBO \\
\hline Sachsen-Anhalt & $\S 78$ BauO LSA \\
\hline Schleswig-Holstein & $\S 59 \mathrm{LBO}$ SH \\
\hline Thüringen & $\S 78$ ThürBO \\
\hline
\end{tabular}

\section{bb) Formelle Rechtmäßigkeit}

1249 Bezüglich der formellen Anforderungen kann auf die vorherigen Ausführungen verwiesen werden (s. Rn. 1235).

\section{cc) Materielle Rechtmäßigkeit}

1250 Das Einstellen von Arbeiten kann angeordnet werden, wenn Anlagen im Widerspruch zu öffentlich-rechtlichen Vorschriften errichtet, geändert oder beseitigt 
werden. Ausreichend ist die formelle Illegalität. ${ }^{2230}$ Die Legalisierungswirkung einer (materiell illegalen) Baugenehmigung steht einer Stilllegungsverfügung entgegen (s. Rn. 1237). ${ }^{2231}$ Bei genehmigungsfreien Vorhaben ist ausschließlich auf die materielle Illegalität abzustellen. ${ }^{2232}$ Auch für diese Verfügung steht der Bauverwaltung ein Ermessensspielraum zu. Für die Anforderungen an die pflichtgemäße Ermessensausübung wird auf die vorherigen Ausführungen verwiesen (s. Rn. 1239ff.).

\section{e) Literaturhinweise}

Lehrbücher: Battis, Öffentliches Baurecht und Raumordnungsrecht, 7. Aufl., 2017; 1251 Muckel/Ogorek, Öffentliches Baurecht, 3. Aufl. 2018; Stollmann/Beaucamp, Öffentliches Baurecht, 11. Aufl. 2017

Aufsätze: Schröer, Das Spannungsverhältnis zwischen bauordnungsrechtlichem Verunstaltungsverbot und bauplanungsrechtlichem Genehmigungsanspruch, NZBau 2008, 759; Krüper, Das Einvernehmen der Gemeinde nach § 36 BauGB - Materiell-, verfahrens- und prozessrechtliche Aspekte, ZJS 2010, 582; Krüper/Herbolsheimer, Die Veränderungssperre im Kontext gemeindlicher Planungshoheit, ZJS 2016, 546; Kahl/Dubber, Die repressive Bauaufsicht, ZJS 2015, 558; Wolf, Drittschutz im Bauplanungsrecht - Zur Weiterentwicklung eines stagnierenden Prozesses, NVwZ 2013, 247; Sperlich, Ein Meilenstein des Verwaltungsrechts: 40 Jahre „Schweinemästerfall“ - zur nachbarschützenden Wirkung des Rücksichtnahmegebotes, JA 2017, 38; Lindner, Formelle und materielle Illegalität bei bauordnungsrechtlichen Eingriffen - Zur dogmatischen Struktur von Baubeseitigungsanordnung und Nutzungsuntersagung, JuS 2014, 118; Sommer, Zur behördlichen Duldung im öffentlichen Baurecht, JA 2017, 567; Lege, Art. 14 für Fortgeschrittene - 45 Fragen zum Eigentum, die Sie nicht überall finden. Unter besonderer Berücksichtigung des Baurechts, ZJS 2012, 44

\section{Ermächtigungsgrundlagen des Kommunalrechts (Sebastian Piecha)}

Die Anfechtungsklage ist im besonderen Verwaltungsrecht eine häufige Konstel- 1252 lation in Prüfungsarbeiten. Sie spielt daher auch im Bereich des Kommunalrechts eine Rolle, wenngleich Fallgestaltungen im Bereich der Leistungs- und Feststel-

2230 Kahl/Dubber, ZJS 2015, 558 (568); Kersten, in: Schoch, Besonderes Verwaltungsrecht, 2018, Kap. 3, Rn. 445; Stollman/Beaucamp, Öffentliches Baurecht, 11. Aufl. 2017, § 19, Rn. 14.

$2231 \mathrm{Kahl} /$ Dubber, ZJS 2015, 558 (568).

2232 Kahl/Dubber, ZJS 2015, 558 (568).

Felix Steengrafe/Sebastian Piecha 
lungsklage hier eine noch größere Relevanz aufweisen (s. dazu § 5 Rn. $235 \mathrm{ff}$. und $\S 6$ Rn. $186 \mathrm{ff}$.$) .$

1253 Voraussetzung ist stets das Vorliegen eines Verwaltungsakts (dazu Rn. $38 \mathrm{ff}$.). Im Kommunalrecht kommen dabei mehrere Konstellationen in Betracht: Zunächst könnte sich ein Bürger gegen einen Verwaltungsakt der Kommune wehren. Dann ist inzident, also innerhalb der Prüfung der Ermächtigungsgrundlage des Verwaltungsakts möglicherweise das nach den Regelungen des jeweiligen Kommunalrechts ordnungsgemäße Zustandekommen der als Ermächtigungsgrundlage dienenden Satzung oder Verordnung zu prüfen. Diese Konstellation wird an gegebener Stelle erwähnt. Es erscheint jedoch insbesondere denkbar, dass die Kommune selbst Adressatin eines Verwaltungsakts ist, etwa wenn die Aufsichtsbehörde Maßnahmen gegen sie ergreift. Diese Konstellation wird ausführlich im Folgenden erläutert (s. Rn. 1271ff.). Schließlich scheint es auch möglich, dass ein Verwaltungsakt an ein Rats- bzw. Kreistagsmitglied gerichtet wird. Ob und warum es sich hierbei um einen Verwaltungsakt handelt, muss dann ebenfalls geprüft werden. Dies wird im Folgenden ebenfalls erörtert (s. ebenfalls Rn. 1271ff.).

1254 Bei den letzten beiden soeben genannten Konstellationen ist im Einzelfall teilweise sehr umstritten, ob es sich bei der Maßnahme um einen Verwaltungsakt handelt oder nicht. Hierbei sind dann die Voraussetzungen des § 35 S. 1 VwVfG schon im Rahmen der statthaften Klageart genau zu untersuchen (s. Rn. 38 ff.). Wann und wo die strittigen Punkte liegen, wird in diesem Abschnitt diskutiert.

\section{a) Einführung in das Kommunalrecht}

1255 Bevor jedoch die relevanten Ermächtigungsgrundlagen und Konstellation der Anfechtungsklage im Kommunalrecht beschrieben werden, wird im Folgenden nun zunächst ein einführender Überblick über die wesentlichen Grundlagen des Kommunalrechts gegeben, um dieses Rechtsgebiet für die Klausur- und Hausarbeitspraxis einordnen zu können.

\section{aa) Begriff des Kommunalrechts}

1256 Auch das Kommunalrecht hält zahlreiche Fallgestaltungen bereit, die Gegenstand einer Klausur sein können. ${ }^{2233}$ Dabei ist in den Anfangssemestern eine

2233 Die Prüfungsordnungen definieren das Kommunalrecht ausdrücklich als Teil des besonderen Verwaltungsrechts zu Pflichtfachstoff für die Erste Prüfung, etwa $§ 11$ II Nr. 13 lit. b) JAG NRW, § 18 II Nr. 5 lit. c) JAPO Bayern; auch für die Zweite juristische Staatsprüfung werden die Inhalte des Kommunalrechts als Pflichtfachstoff in den meisten Bundesländern als bekannt 
isolierte Kommunalrechts-Abschlussklausur durchaus häufiger als in Fortgeschrittenenübungen oder gar Examensklausuren der ersten oder zweiten (Staats-) Prüfung. In den beiden letzteren Konstellationen werden kommunalrechtliche Aufgabenstellungen oft und gern mit solchen aus anderen Gebieten des besonderen Verwaltungsrechts, etwa dem Polizei- und Ordnungsrecht oder dem Baurecht verbunden. Eine auf den ersten Blick rein kommunalrechtliche und überschaubare Aufgabe kann so leicht im Schwierigkeitsgrad erhöht werden.

Unter dem Begriff „Kommunalrecht“ versteht man die Rechtssätze, die die 1257 Rechtsstellung der Kommunen innerhalb des Staates, die Grundordnung sowie Organisation der Kommune sowie ihre Aufgaben, Instrumente und Finanzen regeln (Innenrecht der Kommune). ${ }^{2234}$ Dabei spielt im Kommunalrecht auch das Verhältnis zu ihren Bürgern bzw. Einwohnern (Außenrecht) eine Rolle. Ähnlich dem Staatsrecht für die Grundordnung des Staates und das Verhältnis zu den dort lebenden Menschen regelt das Kommunalrecht Entsprechendes auf der untersten Ebene staatlicher Verwaltung, den Kommunen. Es wird daher auch von Kommunalverfassung gesprochen, da die Regelungen grundlegende Bestimmungen zur Ordnung der Kommunen festlegen. Im Wesentlichen ist der Begriff jedoch ein Synonym zu dem des Kommunalrechts. Der Begriff Kommune ist dabei der Oberbegriff insbesondere für die Gebietskörperschaften der Städte und Gemeinden sowie für Gemeindeverbände wie die (Land-)Kreise. ${ }^{2235}$

Das Kommunalrecht ist nicht bundeseinheitlich geregelt, seine Ausgestaltung obliegt den einzelnen Ländern (dazu Rn. 1268), die hierfür die Gesetzgebungskompetenz (Art. 70 I GG) haben. ${ }^{2236}$ Bundesrechtlich enthält das GG lediglich zwei, wesentlich grundlegende, übergeordnete Vorgaben: Art. 28 I 2 GG legt fest, dass in Gemeinden, Städten und Kreisen eine nach den Grundsätzen der allgemeinen, unmittelbaren, freien, gleichen und geheimen Wahl hervorgegangene Volksvertretung besteht. Ferner gewährleistet Art. 28 II 1, 2 GG die kommunale Selbstverwaltungsgarantie (dazu Rn. 1259ff.). Landesverfassungsrechtlich ist diese Selbstverwaltungsgarantie meist noch einmal festgeschrieben, wenngleich sich

vorausgesetzt und können daher Prüfungsgegenstand sein, vgl. § 52 I Nr. 1 JAG NRW und § 58 II Nr. 1 JAPO Bayern.

2234 Vgl. Burgi, Kommunalrecht, 6. Aufl. 2019, § 1 Rn. 10.

2235 Mit Ausnahme des Grundgesetzes und des Landesrechts Nordrhein-Westfalen, in welchem die KrO NRW grundsätzlich die Bezeichnung „Kreis“ festlegt, haben alle Flächenländer die Bezeichnung „Landkreis“ gewählt. Im Folgenden wird daher die Bezeichnung „Landkreis“ verwendet sowie der Begriff „Kommune“, wenn sowohl Gemeinden als auch Gemeindeverbände genannt sind.

2236 Vgl. Gern/Brüning, Deutsches Kommunalrecht, 4. Aufl. 2019, Rn. 52 m.w. N.; zu den Möglichkeiten der Mischverwaltung und weiteren kommunalrechtlichen Bezügen s. ebendort, Rn. $53 \mathrm{ff}$. 
die inhaltliche Ausgestaltung jeweils teilweise stark unterscheidet und über die im GG festgelegten Garantien hinausgehen kann. ${ }^{2237}$ Die Gewährleistung aus dem Grundgesetz bildet insoweit die inhaltliche Mindestgarantie. ${ }^{2238}$

\section{bb) Die kommunale Selbstverwaltungsgarantie}

1259 Die kommunale Selbstverwaltungsgarantie (Art. 28 II GG bzw. ggf. die jeweilige Landesverfassungsbestimmung) umfasst im Wesentlichen zweierlei:

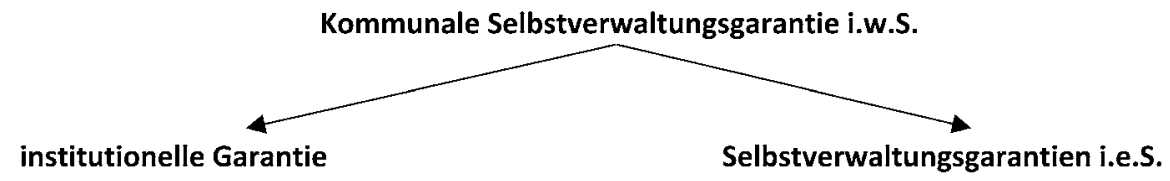

1260

Die institutionelle Garantie bedeutet, dass gewährleistet ist, dass es die Einrichtung (Institution) Kommune überhaupt als solche geben muss. ${ }^{2239}$ Dies meint jedoch nur allgemein die Einrichtung von Kommunen, nicht den Bestand einer einzelnen Kommune. 2240

Die Selbstverwaltungsgarantie i.e.S. bedeutet, dass den Kommunen ein eigener Aufgabenbereich zugesprochen wird, innerhalb dessen sie sich eigenverantwortlich organisieren können bzw. müssen sowie die damit verbundenen Aufgaben auch wahrnehmen. ${ }^{2241}$ Grundsätzlich besitzen die Städte und Gemeinden danach die Allzuständigkeit für alle Aufgaben der örtlichen Gemeinschaft, d.h. die alleinige und umfassende Zuständigkeit für die öffentliche Verwaltung, sofern Gesetze nichts anderes bestimmen. ${ }^{2242}$ Für Gemeindeverbän-

2237 Art. 71 I VerfBW, Art. 11 II 2 BayVerf., Art. 97 I 1 BbgVerf., Art. 1442 BremVerf., Art. 4 II 1 HmbVerf., Art. 137 III 1 HV, Art. 72 I Verf. M-V, Art. 78 VerfNRW, Art. 57 I NdsVerf., Art. 49 I VerfRP, Art. 118 SVerf, Art. 82 II SächsVerf, Art. 87 VerfLSA, Art. 54 VerfSH, Art. 91 I ThürVerf.; dazu ausführlich Burgi, Kommunalrecht, 6. Aufl. 2019, § 7 Rn. $5 \mathrm{ff}$; Ritgen, NVwZ 2018, $114 \mathrm{ff}$.

2238 Burgi, Kommunalrecht, 6. Aufl. 2019, § 6 Rn. 2; vgl. dazu zuletzt BVerfG, Urt. v. 21.11.2017, Az.: 2 BvR 2177/16 = BVerfGE 147, 185.

2239 BVerfG, Beschl. v. 23.11.1988, Az. 2 BvR 1619, 1628/83 = BVerfGE 79, 127 (143) - Rastede. 2240 BVerfG, Beschl. v. 27.11.1978, Az. 2 BvR 165/75 = BVerfGE 50, 50; Beschl. v. 18.10.1994, Az. 2 BvR 611/91 = LKV 1995, 187.

2241 Vgl. Gern/Brüning, Deutsches Kommunalrecht, 4. Aufl. 2019, Rn. 99.

2242 Vgl. etwa § 2 GO NRW; grundlegend: BVerfG, Beschl.v. 23.11.1988, Az. 2 BvR 1619, 1628/83= BVerfGE 79, 127 (143) - Rastede. 
de, insbesondere Landkreise, gilt Entsprechendes für alle Aufgaben der überörtlichen Gemeinschaft. ${ }^{2243}$

Hausarbeitswissen: Aufgaben der örtlichen bzw. überörtlichen Gemeinschaft bilden den Grundstock der Selbstverwaltung in den Kommunen. Wie sich diese Aufgaben jedoch bestimmen und herleiten, ist durchaus nicht unumstritten. Das BVerfG verweist in ständiger Rechtsprechung darauf, dass dies auch die Kompetenz umfasst, bislang unbesetzte Aufgaben in ihrem Bereich an sich zu ziehen. ${ }^{224}$ Zum einen müssen sie einen spezifisch örtlichen Bezug aufweisen. Zum anderen können es auch Aufgaben sein, die historisch den Kommunen zuwachsen und seit jeher eine kommunale Aufgabe gewesen sind. Schließlich war zeitweise auch in der Diskussion, dass sich einiges aus der finanziellen Leistungsfähigkeit der Kommunen ableite..$^{2245}$

Daraus ergibt sich im Wesentlichen, dass eine Kommune aus der Selbstverwal- 1263 tungsgarantie bestimmte Gemeindehoheiten ableiten kann, die ihr zustehen: ${ }^{2246}$

\section{- Inhaltliche Bestimmung der Aufgabenerledigung}

Die Kommune hat die Befugnis selbst zu bestimmen, wie sie ihre Aufgaben erledigt.

\section{- Subjektsgarantie}

Die Kommunen als solches haben Subjektsqualität, müssen also im Verwaltungsbau als selbstständige Gebietskörperschaften vorgesehen sein. Das schützt jedoch nicht den Bestand einzelner Kommunen, sondern nur die Institution „Kommune“ an sich. ${ }^{2247}$

\section{- Organisationshoheit}

Die Kommune kann ihre innere Organisation sowie die Wahl der Organisationsform zur Erfüllung der ihr obliegenden Aufgaben eigenverantwortlich bestimmen. Hierzu gehört etwa die Gliederung nach Abteilungen, Wahl der Rechtsform bei wirtschaftlichem Tätigwerden, Organisation der Ratsarbeit. Dabei wird diese durch die zahlreichen materiell-rechtlichen Vorgaben eingeschränkt.

2243 Vgl. etwa $\S 3 \mathrm{KrO}$ NRW.

2244 BVerfG, Beschl. v. 23.11.1988, Az. 2 BvR 1619, 1628/83 = BVerfGE 79, 127 (147) - Rastede. 2245 Kritisch Gern/Brüning, Deutsches Kommunalrecht, 4. Aufl. 2019, Rn. 83.

2246 Vgl. zum Ganzen Burgi, Kommunalrecht, 6. Aufl. 2019, § 6 Rn. 22ff.; Gern/Brüning, Deutsches Kommunalrecht, 4. Aufl. 2019, Rn. 99 ff.; Brüning, Jura 2015, 952 ff.; Magen, JuS 2006, 404 ff. 2247 BVerfG, Beschl. v. 12.5.1992, Az. 2 BvR 470, 650, 707/90 = BVerfGE 86, 90 (107). 


\section{- Kooperationshoheit}

Der Kommune steht es frei, mit anderen Kommunen oder Privaten zusammenzuarbeiten. Beeinträchtigt wird dies bei Zwangseingliederungen in eine Verwaltungsgemeinschaft, der pflichtigen Zuweisung von Aufgaben an einen Zweckverband oder die Pflicht zur Mitwirkung in einer ArGe (,Jobcenter“) $)^{2248}$.

\section{- Personalhoheit}

Die Kommune hat die Hoheit, über ihr Personal selbst zu entscheiden. Die beinhaltet die Auswahl, Einstellung und Ausgestaltung der Dienstverhältnisse sowie Zuweisung der Aufgaben. Sie hat Dienstherreneigenschaft und kann auch Beamte einstellen. Die Vorgaben des Beamten- oder Arbeitsrechts sind dabei einschränkend und rechtfertigungsbedürftig.

\section{- Finanzhoheit}

Die Kommune hat die Hoheit über ihre Finanzen und ihren Haushalt. Sie stellt eigenverantwortlich ihren Haushalt auf und verwaltet ihr Budget.

\section{- Freiheit der Wirtschaftsbetätigung}

Die Kommune hat das Recht zur Wahrnehmung von Aufgaben durch wirtschaftliche Betätigung.

\section{- Planungshoheit}

Die Kommune hat in ihrem Wirkungskreis die Hoheit, planerische Entscheidungen selbstständig zu fällen, etwa Bebauungspläne aufzustellen. Dies wird durch gesetzgeberische Vorgaben und mögliche überörtliche Planungen eingeschränkt.

\section{- Satzungshoheit}

Die Kommune hat die Hoheit, sich selbst eine Satzung zu geben und dort das Nähere zu regeln sowie die Hoheit, Satzungen im Rahmen ihres eigenen Wirkungskreises, oder wenn fachgesetzlich vorgesehen, zu bestimmen.

1264 Die kommunale Selbstverwaltungsgarantie kann man zwar inhaltlich als das „Grundrecht der Kommune“ verstehen, weil es den Gemeinden subjektive Rechte verleiht. Gleichwohl ist es dogmatisch gesehen kein Grundrecht, sondern eine 
rein institutionelle Garantie. ${ }^{2249}$ Diese Garantie kennt mehrere Schutzrichtungen und Verpflichtete: Zum einen müssen sowohl Bund als auch die Länder sie gewährleisten und achten, zum anderen müssen auch die Kommunen selbst diese (insbesondere gegenseitig) berücksichtigen, etwa wenn diese sich wirtschaftlich betätigen oder Planungsentscheidungen treffen, die Nachbargemeinden berühren können. ${ }^{2250}$ Schließlich müssen die Gemeinden sich auch selbst an die Selbstverwaltungsgarantie halten, indem sie Maßnahmen vermeiden, welche auf die Aushöhlung oder Abschaffung der Selbstverwaltung innerhalb einer Kommune hinauslaufen, indem etwa nicht sämtliche Aufgaben der Leistungsverwaltung privatisieren. Ausdrücklich nicht verpflichtet sind hingegen Private, denn das sieht Art. 28 II GG weder ausdrücklich noch im Wege einer unmittelbaren Drittwirkung für diese vor.

Auf die Selbstverwaltungsgarantie kommt es etwa bei Eingriffen durch die $\mathbf{1 2 6 5}$ Aufsichtsbehörde oder durch den Gesetzgeber an. Die Kommune kann dieses Recht vor den Verwaltungsgerichten oder auch im Rahmen der Kommunalverfassungsbeschwerde nach Art. 93 I Nr. 4b GG gerichtlich geltend machen. Insoweit ist der Begriff für Anfänger auch deshalb irreführend, da es dort nicht um die Geltendmachung eines Grundrechts, sondern einer institutionellen Garantie geht. Eingriffe in die kommunale Selbstverwaltungsgarantie können nur durch Gesetz erfolgen, denn sie ist nach Art. 28 II GG ausschließlich „im Rahmen der Gesetze“ gewährleistet. Das Recht der kommunalen Selbstverwaltung besteht somit nicht in unbegrenztem Umfang.

Eingriffe in die Selbstverwaltungsgarantie können durch sachliche Gründe des Gemeinwohls gerechtfertigt sein. Dies gilt jedoch nicht für jene, die den absolut geschützten Kernbereich oder Wesensgehalt berühren. Nach Rechtsprechung des BVerfG wird die kommunale Selbstverwaltungsgarantie nur dann gewährleistet, wenn die Kommune Gelegenheit zu kraftvoller Betätigung habe und nicht bloß ein Schattendasein führe. ${ }^{2251}$

Hausarbeitswissen: Was zum Kernbereich kommunaler Selbstverwaltung überhaupt gehört und wie dieser bestimmt wird, ist durchaus umstritten. ${ }^{2252}$ Die Rechtsprechung geht von einem historisch gewachsenen Kern des Selbstverwaltungsrechts aus (sog. Substanzmethode). ${ }^{2253}$ Teilweise wird in

2249 Dazu etwa BVerfG, Beschl. v. 23.11.1988, Az. 2 BvR 1619, 1628/83 = BVerfGE 79, 127 (143) Rastede; ausführlich Burgi, Kommunalrecht, 6. Aufl. 2019, § 6 Rn. 4; Gern/Brüning, Deutsches Kommunalrecht, 4. Aufl. 2019, Rn. 70 ff.

2250 Burgi, Kommunalrecht, 6. Aufl. 2019, § 6 Rn. 9 ff.; dort auch im Folgenden.

2251 BVerfG, Beschl. v. 23.11.1988, Az. 2 BvR 1619, 1628/83 = BVerfGE 79, 127 (143) - Rastede. 2252 Ausführlich Gern/Brüning, Deutsches Kommunalrecht, 4. Aufl. 2019, Rn. $119 \mathrm{ff}$.

2253 BVerfG, Beschl.v. 24.6.1969, Az. 2 BvR 446/64 = BVerfGE 26, 228 (238); BVerfG, Beschl.v. 7.2. 1992, Az. 2 BvL 24/84 = BVerfGE 83, 363 (381). 
der Literatur der Kernbereich danach bestimmt, was nach einem Eingriff in die Selbstverwaltungsgarantie noch übrig bleibt und inwieweit dies dem typischen Erscheinungsbild einer Kommune dann noch gerecht würde (sog. Substraktionsmethode). ${ }^{2254}$ Schließlich wird bei der Funktionalmethode noch ergänzend berücksichtigt, dass die kommunale Selbstverwaltung in das politische Gemeinwesen mit eigenen Aufgaben eingegliedert sei und ihr auch aus dem GG, etwa aus Art. 28 II GG spezifische Funktionen zugeordnet seien, die sie beibehalten müsse. ${ }^{2255}$

\section{cc) Landesrechtliche Ausgestaltung des Kommunalrechts}

1268 Den Ländern obliegt die Ausgestaltung des Kommunalrechts im Rahmen ihrer Gesetzgebungskompetenz. Man spricht bei den Regelungen, da sie die innere und äußere Verfassung der Kommunen zum Gegenstand haben, auch von „Kommunalverfassungsrecht“ (s. Rn. 1257). Grob unterschieden werden im Wesentlichen (Flächen-)Länder, ${ }^{2256}$ in denen es jeweils eigene Regelwerke für Gemeinden und Landkreise gibt und Länder, die sowohl für Gemeinden bzw. Städte als auch Landkreise geltende, gemeinsame Kommunalverfassungsgesetze vorweisen.

1269 Eine besondere Stellung nehmen die Stadtstaaten Berlin, Bremen und Hamburg ein, bei denen jeweils die Landesverfassung und weitere Landesgesetze die kommunale Ordnung festlegen. In Hamburg und Berlin besteht dabei gar eine Einheit zwischen Land und Stadt, wobei in Berlin und Hamburg etwa die Bezirksämter vergleichbare Funktionen wie in Flächenländern die Kommunen wahrnehmen. ${ }^{2257}$ Das Land Bremen besteht aus zwei Kommunen (Städte Bremen und Bremerhaven), wobei die Landesinstitutionen teilweise gleichzeitig als Organe der Stadt Bremen dienen (Art. 148 BremVerf), soweit die Stadt dies bestimmt, wohingegen die Stadt Bremerhaven jedoch weitgehend autonom selbstverwaltet wird. 2258

1270 Die Rechtsgrundlagen des Kommunal(verfassungs)rechts in den Ländern stellen sich wie folgt dar: ${ }^{2259}$

2254 BVerwG, Urt. v. 22.11. 957, Az. VII C 69/57= BVerwGE 6, 19 (25); Beschl. v. 20.5.1958, Az. I C 193.57 = BVerwGE 6, 342 (345f.).

2255 BayVerfGH, Entsch. v. 29. 8.1997, Az. 8-VII-96 u.a. = NVwZ-RR 1998, 82 (85).

2256 Als solche bezeichnet man alle Länder mit Ausnahme der „Stadtstaaten“ Berlin, Bremen und Hamburg.

2257 Dazu ausführlich Holland, in: Siegel/Waldhoff, Öffentliches Recht in Berlin, 2. Aufl. 2017, $\S 1$ F.; Art. 106 VI 3 GG geht (insbesondere für die Städte Hamburg und Berlin) davon aus, dass in einem Land nicht zwingend Gemeinden bestehen müssen.

2258 Dazu ausführlich Fischer-Lescano/Sperlich, Landesrecht Bremen: Studienbuch, 2018, §§ 2, 3.

2259 Vgl. im Einzelnen Gern/Brüning, Deutsches Kommunalrecht, 4. Aufl. 2019, Rn. 60; 197 ff. 


\begin{tabular}{ll}
\hline Land & Rechtsgrundlagen des Kommunalrechts (,Kommunalverfassung“) \\
\hline Baden-Württemberg & $\begin{array}{l}\text { Gemeindeordnung (GemO BW) } \\
\text { Landkreisordnung (LKrO BW) }\end{array}$ \\
\hline Bayern & $\begin{array}{l}\text { Gemeindeordnung (BayGO) } \\
\text { Landkreisordnung (BayLKrO) }\end{array}$ \\
\hline Berlin & $\begin{array}{l}\text { Verfassung von Berlin (BlnVerf) } \\
\text { Allgemeines Zuständigkeitengesetz (AZG) }\end{array}$ \\
\hline Brandenburg & Kommunalverfassung (BbgKVerf) \\
\hline Bremen & Verfassung für die Stadt Bremerhaven (VerfBrhv) \\
& Verfassung der Freien Hansestadt Bremen (VerfBrem) \\
\hline Hamburg & Verfassung der Freien und Hansestadt Hamburg (HmbVerf) \\
\hline Bezirksverwaltungsgesetz (BezVG) \\
\hline Hessen & Gemeindeordnung (HGO) \\
\hline Landkreisordnung (HKO) \\
\hline Mecklenburg-Vorpommern & Kommunalverfassung (KV M-V) \\
\hline Niedersachsen & Kommunalverfassungsgesetz (NKomVG) \\
\hline Nordrhein-Westfalen & Gemeindeordnung (GO NRW) \\
\hline Kreisordnung (KrO NRW) \\
\hline Sacheinland-Pfalz & Gemeindeordnung (GemO RP) \\
\hline Landkreisordnung (LKO RP)
\end{tabular}

\section{b) Die Anfechtungsklage im Kommunalrecht}

Es besteht im Kommunalrecht die Besonderheit, dass oft schon umstritten ist, ob die Anfechtungsklage in einer bestimmten Situation überhaupt statthaft ist oder nicht. Für die Darstellung in diesem Werk wird grundsätzlich die herrschende Literatur- bzw. Rechtsprechungsmeinung gewählt und an geeigneter Stelle dann auf diesen Streit eingegangen. 
Bei den Anfechtungssituationen kann dabei insbesondere zwischen zwei Arten unterschieden werden: Dabei kommt insbesondere die Kommune selbst als Adressatin von Verwaltungsakten nach $§ 35$ S. 1 VwVfG (zum Begriff des Verwaltungsakts ausführlich Rn. $38 \mathrm{ff}$.) in Betracht. Auch ist es möglich, dass ein Rats- oder Kreistagsmitglied in seiner Eigenschaft als Bürger Adressat eines Verwaltungsakts wird.

1272 Dabei muss stets zunächst eine Anfechtungssituation i.S.v. §42 I VwGO vorliegen, d.h. es muss der betreffende Verwaltungsakt mit dem Ziel der Aufhebung vor Gericht angegriffen werden. Dabei kommt es in kommunalrechtlichen Fragestellungen insbesondere auf eine saubere Subsumtion des Verwaltungsaktbegriffs (s. dazu näher in Rn. $38 \mathrm{ff}$.) an. In kommunalrechtlichen Sachverhalten dürften dabei i.d.R. die Merkmale „Außenwirkung“ sowie „Regelungswirkung“ problematisch sein:

1273 Herauszuarbeiten ist dann stets, ob tatsächlich ein Verwaltungsakt vorliegt oder nicht, denn danach richtet sich, ob mit der Anfechtungsklage die richtige Klageart gewählt wurde.

\section{aa) Maßnahmen der Kommunalaufsicht}

1274 Dabei sind hier im Wesentlichen Maßnahmen der Kommunalaufsicht problematisch. Die Aufsicht ist das notwendige Gegenstück zur Selbstverwaltungsgarantie. ${ }^{2260}$ Es soll ihre Erfüllung gesetzlicher Pflichten bzw. die Koordination innerhalb der staatlichen Grenzen gewährleisten und ihre Verwaltungstätigkeit schützen. ${ }^{2261}$ Man unterscheidet zwischen präventiver und repressiver Aufsicht: Die präventive Aufsicht erfolgt im Vorhinein etwa durch Anzeige- oder Vorlagepflichten gegenüber der Aufsichtsbehörde und Genehmigungsvorbehalte durch die Aufsichtsbehörde. Die repressive Aufsicht erfolgt im Nachhinein der kommunalen Maßnahme und beinhaltet i.d.R. inzident die Rechtmäßigkeitsprüfung der jeweiligen kommunalen Maßnahme (z. B. Beschluss des Rates). Dabei steht der Aufsichtsbehörde ein Entschließungs- (Ob) und Ausübungsermessen (Wie) in Bezug auf ihr Tätigwerden zu.

1275 Ob die Außenwirkung vorliegt, richtet sich nach dem jeweiligen Typ der wahrgenommenen Aufgabe: Eine Außenwirkung besteht regelmäßig, wenn es

2260 Etwa BVerfG, Urt. v. 23.1.1957, Az. 2 BvF 3/56 = BVerfGE 6, 104 (118); Beschl. v. 21.6.1988, Az. 2 BvR 602/83, 2 BvR 974/83 = BVerfGE 78, 331 (341).

2261 Burgi, Kommunalrecht, 6. Aufl. 2019, § 8 Rn. 27; Gern/Brüning, Deutsches Kommunalrecht, 4. Aufl. 2019, Rn. 303. 
sich um freiwillige oder pflichtige Selbstverwaltungsaufgaben handelt. Bei staatlichen Aufgaben dürfte diese Außenwirkung jedoch grundsätzlich fehlen. Bei Aufgaben, die im Wege der Organleihe wahrgenommen werden, ist dies im Einzelfall zu prüfen.

Hausarbeits-/Examenswissen: Dabei kommt es auch darauf an, ob das jeweilige Kommunalrecht eher dem dualistischen oder monistischen Modell folgt: ${ }^{2262}$ Nach dem dualistischen Modell ${ }^{2263}$ unterscheidet man klassische Selbstverwaltungsaufgaben und staatliche Aufgaben, die den Kommunen insbesondere als Auftragsangelegenheiten übertragen wurden. Das monistische Modell $^{2264}$ folgt einem einheitlichen Begriff für öffentliche Aufgaben, die grundsätzlich allein und in eigener Verantwortung von den Kommunen wahrgenommen werden, sofern die Gesetze nichts anderes bestimmen. Aber auch dieses Modell kennt die Unterscheidung von Aufgaben nach Selbstverwaltungs- und staatlichen (Weisungs-)Aufgaben.

Die Reichweite der Kommunalaufsicht ist dabei unterschiedlich. Sie lässt sich 1277 grundlegend in zwei Kategorien einteilen:

\section{(1) Rechtsaufsicht}

Es erfolgt ausschließlich eine Kontrolle der Rechtmäßigkeit des kommunalen Handelns.

\section{(2) Fachaufsicht bzw. Sonderaufsicht}

Das kommunale Handeln wird sowohl hinsichtlich seiner Rechtmäßigkeit sowie Zweckmäßigkeit kontrolliert.

Maßnahmen der Rechtsaufsicht sind unter bestimmten Voraussetzungen 1278 Verwaltungsakte und daher ggf. im Wege der Anfechtungsklage angreifbar (s. Rn. 1284), da sie in Selbstverwaltungsangelegenheiten i.d. R. zumindest Außen- bzw. Regelungswirkung aufweisen. Maßnahmen der Fach- oder Sonderaufsicht sind mangels Außenwirkung regelmäßig keine Verwaltungsalkte. Die Kommune wird dabei als verlängerter Arm des Staates tätig, womit auch keine subjektive Rechtsposition berührt wird..$^{2265}$

Eine Aufsichtsbehörde hat dann je nach landesrechtlicher Ausgestaltung eine Vielzahl von Möglichkeiten, einer Kommune mit Maßnahmen zu begegnen:

2262 Dazu etwa: Gern/Brüning, Deutsches Kommunalrecht, 4. Aufl. 2019, Rn. 265; Röhl, in: Schoch, Besonderes Verwaltungsrecht, 15. Aufl. 2013, Rn. $61 \mathrm{ff}$.

2263 Bayern, Niedersachsen, Rheinland-Pfalz, Saarland, Sachsen-Anhalt, Thüringen.

2264 Baden-Württemberg, Brandenburg, Hessen, Mecklenburg-Vorpommern, Nordrhein-Westfalen, Sachsen, Schleswig-Holstein.

2265 Vgl. etwa BVerwG, Urt. v. 16.3.1995, Az. 4 C 3/94 = NVwZ 1995, 899 (900). 


\section{- Informations-/Unterrichtungsrechte}

Die Aufsichtsbehörde ist umfassend über einzelne kommunale Selbstverwaltungsangelegenheiten zu informieren, wobei ihr hinsichtlich der Wahl der Mittel ein Ermessen zusteht (Akteneinsicht, Besichtigung etc.). Hierbei handelt es sich regelmäßig nicht um einen Verwaltungsakt, da hier die Regelungswirkung fehlt.

\section{- Beanstandungs-/Aufhebungsrechte}

Die Aufsichtsbehörde kann gefasste Beschlüsse, Anordnungen usw. beanstanden und gibt der Kommune somit die Möglichkeit zur Selbstkorrektur. Auch kann sie Handlungen aufheben oder rückgängig machen. Bei letzterem handelt es sich regelmäßig um Verwaltungsakte.

\section{- Anordnungs-/Anweisungsrechte}

Ist die Kommune zur Handlung verpflichtet und unterlässt diese, so kann die Aufsichtsbehörde diese Handlung anordnen bzw. anweisen. Bei Aufgaben im Selbstverwaltungsbereich ist dies ein Verwaltungsakt, gegen den die Anfechtungsklage statthaft wäre.

\section{- Ersatzvornahme}

Kommt die Kommune einer Beanstandung oder Anordnung nicht nach, so kann die Aufsichtsbehörde die geforderte Handlung selbst vornehmen oder einen Dritten hiermit beauftragen. Dies ist ebenfalls ein beklagbarer Verwaltungsakt. Dieser besitzt sogar ggf. eine Doppelnatur, da er auch gegen Bürger wirken kann, etwa wenn eine Satzung oder Verwaltungsakt ersatzweise erlassen wird.

\section{- Bestellung von Beauftragten}

Teilweise ${ }^{2266}$ wird die Bestellung eines Beauftragten ermöglicht, wenn die Kommune ihren Aufgaben in erheblichem Maße nicht oder nicht richtig nachkommt (etwa bzgl. des Haushalts). Dies stellt ebenfalls einen Verwaltungsakt dar.

\section{- Auflösung des Rates}

Als allerletztes Mittel, wenn keine Aufsichtsmaßnahme erfolgreich war, sehen einige Kommunalverfassungsgesetze auch die Auflösung des Rates unter engen Voraussetzungen vor. ${ }^{2267}$ 


\section{- Amtsenthebung des Bürgermeisters}

Schließlich kann in einigen Ländern ${ }^{2268}$ auch der Bürgermeister vorzeitig des Amtes enthoben werden.

\section{(1) Ermächtigungsgrundlagen}

Die Rechtsgrundlagen für die Maßnahmen der Kommunalaufsicht finden sich $\mathbf{1 2 8 0}$ hier:

\begin{tabular}{|c|c|}
\hline Land & Kommunalaufsicht \\
\hline Baden-Württemberg & $\begin{array}{l}\S \S 118 \mathrm{ff} . \text { Gem0 BW } \\
\S 51 \text { LKrO BW i.V.m. } \S \S 118 \mathrm{ff} . \text { GemO BW }\end{array}$ \\
\hline Bayern & $\begin{array}{l}\text { Art. } 108 \text { ff. BayGO } \\
\text { Art. } 94 \text { ff. BayLKrO }\end{array}$ \\
\hline Brandenburg & $\S \S 108 \mathrm{ff}$. BbgKVerf \\
\hline Bremen & $\begin{array}{l}\S \S 74 \mathrm{ff} . \text { VerfBrhv } \\
\text { Art. } 147 \text { VerfBrem }\end{array}$ \\
\hline Hessen & $\begin{array}{l}\S \S 135 \text { ff. HGO } \\
\S 54 \text { I HKO i. V. m. §§ } 135 \text { ff. HGO }\end{array}$ \\
\hline Mecklenburg-Vorpommern & $\S \S 78 \mathrm{ff} ., 123 \mathrm{KV} \mathrm{M}-\mathrm{V}$ \\
\hline Niedersachsen & $\S \S 170 \mathrm{ff}$. NKomVG \\
\hline Nordrhein-Westfalen & $\begin{array}{l}\S \S 119 \mathrm{ff} . \mathrm{GO} \text { NRW } \\
\S \S 57 \mathrm{KrO} \text { NRW i.V.m. §§ } 119 \mathrm{ff} . \mathrm{GO} \text { NRW }\end{array}$ \\
\hline Rheinland-Pfalz & $\begin{array}{l}\S \S 117 \mathrm{ff} . \text { GemO RP } \\
\S \S 60 \mathrm{ff} . \text { LKO RP }\end{array}$ \\
\hline Saarland & $\S \S 127 \mathrm{ff} . \mathrm{KSVG}$ \\
\hline Sachsen & $\begin{array}{l}\S \S 111 \text { ff. SächsGem0 } \\
\S 65 \text { SächsLKrO i.V. m. §§ } 111 \text { ff. SächsGem0 }\end{array}$ \\
\hline Sachsen-Anhalt & $\S \S 143 \mathrm{ff}$. KVG LSA \\
\hline Schleswig-Holstein & $\begin{array}{l}\S \S 120 \mathrm{ff} . \mathrm{GO} \mathrm{S}-\mathrm{H} \\
\S \S 59 \mathrm{ff} . \mathrm{KrO} \mathrm{S}-\mathrm{H}\end{array}$ \\
\hline Thüringen & $\S \S 116 \mathrm{ff}$. ThürKO \\
\hline
\end{tabular}

$2268 \S 128$ GO BW, § 118 SächsGemO, § 153 KVG LSA. 
1281 Bei der Klagebefugnis nach $\S 42$ II VwGO ist dann die Möglichkeit der Verletzung der kommunalen Selbstverwaltungsgarantie aus Art. 28 II GG (bzw. Landesverfassung) zu erwähnen. Dies gilt jedoch nicht, wenn es sich um staatliche Auftragsangelegenheiten handelt, denn dann ist die Selbstverwaltungsgarantie regelmäßig nicht betroffen. Es ist dann anhand der Schutznormtheorie zu untersuchen, ob sich die Kommune ausnahmsweise hierauf berufen kann. Bei Pflichtaufgaben nach Weisung im monistischen System kann sich die Klagebefugnis aus der landesrechtlich normierten kommunalen Selbstverwaltungsgarantie ergeben. ${ }^{2269}$

\section{(2) Formelle Rechtmäßigkeit}

1282 Bei der formellen Rechtmäßigkeit der Aufsichtsmaßnahme sind die Zuständigkeit, das Aufsichtsverfahren (Anhörung, Ablauf usw.) sowie mögliche Formvorschriften (etwa Schriftform) zu erörtern, die je nach Land unterschiedlich sein können.

1283 Die Zuständigkeit für die Aufsicht ist landesrechtlich höchst unterschiedlich geregelt, die in der Regel von der Größe oder Selbstständigkeit der Kommune abhängt: Meist nimmt diese Aufgabe bei kreisangehörigen Gemeinden jedoch der Landkreis und bei kreisfreien Städten eine staatliche Behörde (z. B. in NRW: Bezirksregierung) wahr. ${ }^{2270}$ Es kann jedoch auch sein, dass Fachgesetze aus dem besonderen Verwaltungsrecht eine spezielle Aufsichtsstruktur oder die Zuständigkeit für einzelne Bereiche besonderen Behörden zuweisen. Hier ist unbedingt auf die jeweiligen Gegebenheiten des Landes zu achten. Die in Rn. 1280 erwähnten Regelungen des Kommunal(verfassungs)rechts geben im Regelfall den genauen Rahmen für diese Verfahren vor. Gemein ist dem, dass unterschiedliche Maßnahmen (Aufhebung) etwa nur dann zulässig sind, wenn vorher eine andere Maßnahme (Beanstandung) erfolgt ist.

\section{(3) Materielle Rechtmäßigkeit}

1284 Im Rahmen der materiellen Rechtmäßigkeit sind sodann die inhaltlichen Voraussetzungen der Norm für die Kommunalaufsichtsmaßnahme zu prüfen. Regelmäßig wird eine Voraussetzung für ein Eingreifen sein, dass die Kommune rechtswidrig gehandelt hat, ob das Ermessen korrekt ausgeübt wurde und die Kommune hierdurch in ihren Selbstverwaltungsrechten verletzt wurde (subjektive

2269 Zum Ganzen: Burgi, Kommunalrecht, 6. Aufl. 2019, § 9 Rn. $13 \mathrm{ff}$.

2270 Übersicht bei Gern/Brüning, Deutsches Kommunalrecht, 4. Aufl. 2019, Rn. $308 \mathrm{ff}$.

Sebastian Piecha 
Rechtsverletzung). Dabei muss i.d.R. inzident die Maßnahme der Kommune geprüft werden. Das kann zu einem verschachtelten Aufbau führen und ermöglicht dem Aufgabensteller eine unterschiedliche Differenzierung des Schwierigkeitsgrades.

Vorschriften hinsichtlich des Ablaufs oder der Rechtmäßigkeit einer Rats-/ 1285 Kreistagssitzung können hier auch inzident zu prüfen sein. Folgende Normen sind dabei auf ihre Einhaltung zu prüfen:

\begin{tabular}{|c|c|}
\hline Land & Ablauf der Rats-/Kreistagssitzung \\
\hline Baden-Württemberg & $\begin{array}{l}\S \S 34 \mathrm{ff} . \text { GemO BW } \\
\S \S 29 \mathrm{ff} . \text { LKrO BW }\end{array}$ \\
\hline Bayern & $\begin{array}{l}\text { Art. } 45 \text { ff. BayGO } \\
\text { Art. } 40 \text { ff. BayLKrO }\end{array}$ \\
\hline Berlin & Art. $42 \mathrm{ff}$. BlnVerf \\
\hline Brandenburg & $\S \S 34 \mathrm{ff}$. BbgKVerf \\
\hline Bremen & $\begin{array}{l}\S \S 30 \mathrm{ff.} \text { VerfBrhv } \\
\text { Art. } 88 \mathrm{ff} . \text { VerfBrem }\end{array}$ \\
\hline Hamburg & Art. $19 \mathrm{ff.}$. VerfHH \\
\hline Hessen & $\begin{array}{l}\S \S 52 \text { ff. HGO } \\
\S \S 32 \text { ff. HKO i.V.m. HGO }\end{array}$ \\
\hline Mecklenburg-Vorpommern & $\S \S 29$ ff. KV M-V \\
\hline Niedersachsen & $\S \S 59$ ff. NKomVG \\
\hline Nordrhein-Westfalen & $\begin{array}{l}\S \S 47 \mathrm{ff} . \mathrm{GO} N \mathrm{NRW} \\
\S \S 32 \mathrm{ff} . \mathrm{KrO} \text { NRW }\end{array}$ \\
\hline Rheinland-Pfalz & $\begin{array}{l}\S \S 34 \mathrm{ff} . \text { GemO RP } \\
\S \S 27 \mathrm{ff} . \text { LKO RP }\end{array}$ \\
\hline Saarland & $\S \S 40 \mathrm{ff} . \mathrm{KSVG}$ \\
\hline Sachsen & $\begin{array}{l}\S \S 36 \mathrm{ff} . \text { SächsGem0 } \\
\S \S 32 \mathrm{ff} . \text { SächsLKrO }\end{array}$ \\
\hline Sachsen-Anhalt & $\S \S 52 \mathrm{ff}$. KVG LSA \\
\hline Schleswig-Holstein & $\begin{array}{l}\S \S 34 \mathrm{ff.} \mathrm{GO} \mathrm{S-H} \\
\S \S 29 \mathrm{ff} . \mathrm{KrO} \mathrm{S}-\mathrm{H}\end{array}$ \\
\hline Thüringen & $\S \S 35 \mathrm{ff}$. ThürKO \\
\hline
\end{tabular}


1286 Ob ein Ratsbeschluss rechtmäßig war, kann anhand des folgenden groben Prüfungsschemas erörtert werden, wobei jeweils die landesrechtlichen Besonderheiten zu beachten sind:

\section{Rechtmäßigkeit eines Ratsbeschlusses ${ }^{2271}$}

A. Formelle Rechtmäßigkeit

I. Zuständigkeit

1. Verbandskompetenz der Kommune

2. Organkompetenz des Rates/Kreistages

II. Verfahren und Form

1. Ordnungsgemäße Einberufung der Sitzung

2. Festsetzung der Tagesordnung

3. Rechtzeitige Bekanntmachung der Tagesordnung

4. Form- und fristgerechte Einladung

5. Beschlussfähigkeit der Sitzung

6. Ordnungsgemäße Sitzungsleitung

7. Öffentlichkeit der Ratssitzung

8. Ordnungsgemäße Abstimmung

a) Mehrheitserfordernisse

b) Modalitäten (geheim/offen)

c) Berechnung des Abstimmungsergebnisses

9. Kein Verstoß gegen Mitwirkungsverbote

a) Vor- oder Nachteil für Ratsmitglied, Angehörige oder juristische Person, bei der es beschäftigt ist

b) Unmittelbarkeit des Vor- oder Nachteils (kein Hinzutreten weiterer Umstände durch die betreffende Entscheidung selbst hervorgerufen)

c) Kein Ausschlussgrund

10. Kein Verstoß gegen das freie Mandat

III. Rechtsfolge formeller Fehler (Nichtigkeit, wenn keine Ausnahme)

1. Bloßer Geschäftsordnungs-Verstoß

2. Mangelnde Entscheidungserheblichkeit bei Verstoß gegen Mitwirkungsverbot

3. Unbeachtlichkeit wegen Fristablauf

B. Materielle Rechtmäßigkeit

I. Spezialgesetzliche Voraussetzungen

2271 Bätge, Kommunalrecht NRW, 5. Aufl. 2019, Rn. 253. 
II. Kein Verstoß gegen höherrangiges Recht

III. Allgemeine Rechtmäßigkeitsvoraussetzungen

IV. Keine Ermessensfehler, sofern Ermessen eröffnet

Auch die Verhältnismäßigkeit der Maßnahme ist zu prüfen, insbesondere kommt 1287 eine schwerwiegendere Maßnahme (z. B. Auflösung des Rates) erst dann in Betracht, wenn mildere Aufsichtsmaßnahmen (z.B. Beanstandung) erfolglos blieben. ${ }^{2272}$

\section{bb) Maßnahmen der Kommune gegen Einzelne}

Neben den Kommunalaufsichtsmaßnahmen kommen noch Maßnahmen gegen 1288 Einzelne in Betracht. Dabei sind insbesondere Konstellationen möglich, bei denen ein Ehrenamtler bzw. Rats-/Kreistagsmitglied Adressat des Verwaltungsakts ist. In den folgenden beiden Konstellationen muss auch schon im Rahmen der statthaften Klageart erörtert werden, weshalb es sich bei der jeweiligen Maßnahme überhaupt um einen Verwaltungsakt handelt.

\section{(1) Vertretungsverbote Ehrenamtlicher}

Ein häufiger Fall ist hier die Prüfung eines Vertretungsverbotes. In den meisten 1289 Kommunalverfassungsgesetzen sind nämlich umfassende Vertretungsverbote vorgesehen, die die Vertretung Ehrenamtlicher von Ansprüchen gegen die Kommune verbieten. ${ }^{2273}$ Stellen Rat oder Kreistag dann fest, dass ein solches Vertretungsverbot gegen einen Einzelnen (Ehrenamtlicher, Rats-/Kreistagsmitglied) besteht, so handelt es sich hierbei regelmäßig um einen mit der Anfechtungsklage anzugreifenden Verwaltungsakt i.S.v. § 35 S. 1 VwVfG.

\section{(2) Sanktionen gegen Ratsmitglieder}

Ein weiterer Fall im Kommunalrecht ist die Verhängung eines Ordnungsgeldes. 1290 Wird gegen ein Ratsmitglied oder einen Bürger ein Ordnungsgeld verhängt, so verlässt dies den innerorganisatorischen Bereich und es handelt sich um einen Verwaltungsakt i.S.v. § 35 S. 1 VwVfG gegen die natürliche Person, da dieser Außenwirkung entfaltet, die auch eine verbindliche Rechtsfolge (Ordnungsgeld-

2272 S. etwa Rennert, JuS 2008, 119 (120).

2273 §17 III GemO BW; Art.50 BayGO; §23 i.V. m. §20, §33 II BbgKVerf; §26 GO; §26 KV M-V; §42 NKomVG; §32 i.V.m. §43 II GO NRW; §21 GemO RP; § 26 II KSVG; §19 III SächsGemO; §32 III 2 KVG LSA; §23 i.V.m. §32 III GO SH. 
festsetzung ${ }^{2274}$ ) trifft. $^{2275}$ Im Übrigen sind solche Feststellungen des Rates eine rein innerorganisatorische Maßnahme, gegen die im Rahmen eines Kommunalverfassungsstreits geltend gemacht werden muss. Die Festsetzung ist nur dann rechtmäßig, wenn eine Verletzung des Kommunalrechts durch das Ratsmitglied erfolgt ist. Inzident ist diese Verletzung (etwa der Verschwiegenheitspflicht) durch das Ratsmitglied dann zu prüfen.

\section{c) Literaturhinweise}

1291 Lehrbuchliteratur zum Kommunalrecht: Burgi, Kommunalrecht, 6. Aufl. 2019; Ehlers/Fehling/Pünder (Hrsg.), Besonderes Verwaltungsrecht, Band III, 3. Aufl. 2013 (§ 64: Brüning, Kommunalverfassung, § 65: T. I. Schmidt: Kommunale Zusammenarbeit); Geis, Kommunalrecht, 4. Aufl. 2016; Gern/Brüning, Deutsches Kommunalrecht, 4. Aufl. 2019; Röhl, Kommunalrecht, in: Schoch, (Hrsg.), Besonderes Verwaltungsrecht, 15. Aufl. 2013; Schmidt, Kommunalrecht, 2. Aufl. 2014; Wolff/Bachof/Stober/Kluth, Verwaltungsrecht, Band II, 7. Aufl. 2010 (§§ 97-98); Lissack, Bayerisches Kommunalrecht, 4. Aufl. 2019

Landesspezifische Darstellungen des Kommunalrechts: Birkenfeld, Kommunalrecht Hessen, 6. Aufl. 2016; Pautsch, Kommunalrecht Niedersachsen, 2014; Bätge, Kommunalrecht Nordrhein-Westfalen, 5. Aufl. 2019; Ipsen, Niedersächsisches Kommunalrecht, 4. Aufl. 2011; Nauheim-Skrobek/Schmitz/Schmorleiz, Kommunalrecht Rheinland-Pfalz, 2. Aufl. 2017; Faßbender/König/Musall, Sächsisches Kommunalrecht, 2019

Aufsätze zum Kommunalrecht: Brüning, Die Verfassungsgarantie der kommunalen Selbstverwaltung aus Art. 28 II GG, Jura 2015, 592; Geis/Madeja, Kommunales Wirtschafts- und Finanzrecht (Teil I: JA 2013, 248; Teil II: JA 2013, 321); Knemeyer, Staatsaufsicht über die Kommunen, JuS 2000, 521; Lenski, Der öffentliche Raum als kommunale Einrichtung, JuS 2012, 984; Magen, Die Garantie kommunaler Selbstverwaltung, JuS 2006, 404; Otto, Der Kommunalverfassungsstreit in der Fallbearbeitung, ZJS 2015, 382; Pielow/Groneberg, Die deutschen Landkreise, JuS 2014, 794; Rennert, Die Klausur im Kommunalrecht (Teil 1: JuS 2008, 29; Teil 2: JuS 2008, 119; Teil 3: JuS 2008, 211); Schmitz, Der Öffentlichkeitsgrundsatz in der Kommunalverwaltung - Der Ausschluss der Öffentlichkeit in Grundstücksangelegenheiten im Gemeinderat, JuS 2017, 31; Starke, Grundfälle zur Kommunalverfassungsbeschwerde, JuS 2008, 319; Voßkuhle/Kaufhold,

2274 Z. B. § 29 III GO NRW.

2275 Vgl. OVG Münster, Beschl. v. 23.12.2009, Az. 15 A 2126/09 = DÖV 2010, 325; Bätge, Kommunalrecht NRW, 5. Aufl. 2019, Rn. 229. 
Grundwissen - Öffentliches Recht: Die verfassungsrechtliche Garantie der kommunalen Selbstverwaltung, JuS 2017, 728

Fallbearbeitungen: Bäcker, Fortgeschrittenenhausarbeit - Öffentliches Recht: Kommunalrecht - Zeichenkontingent im Amtsblatt, JuS 2018, 784; Bickenbach, Fortgeschrittenen-Hausarbeit - Öffentliches Recht: Städtisches Messezentrum, JuS 2006, 1091; v. Coelln, (Original-)Referendarexamensklausur Öffentliches Recht: Streit um die Entschädigung des Bürgermeisters, JuS 2008, 351; Everts, Assessorexamensklausur - Öffentliches Recht: Zulässigkeit einer kommunalen Bürgerbefragung, JuS 2004, 899; Ferreau, Fortgeschrittenenklausur - Öffentliches Recht: Staatsorganisations-, Kommunal-, Verwaltungsprozessrecht - Disharmonie im Kommunalwahlkampf, JuS 2017, 758; Janson/Blenk, Referendarexamensklausur - Öffentliches Recht: Verfassungsrecht und Kommunalrecht - Kein Geld mehr für die Gemeinderatsfraktion?, JuS 2018, 461; Jürgensen/Laude, Referendarexamensklausur - Öffentliches Recht: Allgemeines Verwaltungsrecht und Kommunalrecht - Grenzenlose Kommunalwirtschaft, JuS 2018, 635; Meickmann, Fortgeschrittenenklausur - Öffentliches Recht: Verwaltungsrecht - Die verschwiegene Bürgermeisterin, JuS 2017, 663; Sauer, Referendarexamensklausur - Öffentliches Recht: Zulassung zu einem Volksfest, JuS 2004, 1085; Towfigh/Schönfeldt, Eine Stadt in Aufruhr, JA 2018, 521; Winkler, Gelbengrün GmbH, JA 2004, 144; Wollenschläger/Lippstreu, Referendarexamensklausur - Öffentliches Recht: Zweitwohnungsteuer, JuS 2008, 529; Bätge, (Original-)Referendarexamensklausur - Öffentliches Recht: Verwaltungsrecht und Kommunalrecht - Sanktionen gegen ein Ratsmitglied, JuS 2018, 562

\section{Ermächtigungsgrundlagen des Verwaltungsvollstreckungsrechts (Mariamo Katharina Ilal)}

Das Verwaltungsvollstreckungsrecht ist bei Prüfern ${ }^{2276}$ vor allem als Einkleidung gefahrenabwehrrechtlicher Fallkonstellationen beliebt. Dies liegt einerseits daran, dass viele dieser Fallkonstellationen ohne weiteres um eine kostenrechtliche Ebene angereichert werden können. Andererseits liegt dies auch an der Affinität des Vollstreckungsrechts für Inzidenzprüfungen. Diese verlangen von den Bearbeiterinnen und Bearbeitern ein stark strukturiertes und sauberes Arbeiten anhand der verschiedenen Ebenen. Nicht selten stellt bereits das Erkennen einer vollstreckungsrechtlichen Konstellation einen ersten Fallstrick dar. Zudem

2276 Aus Gründen der besseren Lesbarkeit wird im Text an mehreren Stellen verallgemeinernd das generische Maskulinum verwendet. Diese Formulierungen umfassen gleichermaßen weibliche und männliche Personen; alle sind damit selbstverständlich gleichberechtigt angesprochen. 
lassen sich vollstreckungsrechtliche Klausurfälle meist ohne großen Aufwand um eine ganze Bandbreite verwaltungsprozessualer Fragestellungen erweitern.

Der folgende Beitrag möchte einen Überblick über die in Anfechtungskonstellationen relevanten Ermächtigungsgrundlagen des Verwaltungsvollstreckungsrechts geben. ${ }^{2277}$ Dafür wird nach einer Einführung (Rn. 1293ff.) das Verwaltungsvollstreckungsrecht in typischen Klausurkonstellationen verortet (Rn. 1299ff.). Dem schließen sich Ausführungen zur Rechtmäßigkeitsprüfung von Vollstreckungsmaßnahmen im gestreckten Vollstreckungsverfahren nach § 6 I VwVG (Rn. 1317 ff.), mittels sofortigem Vollzug nach § 6 II VwVG (Rn. 1345ff.) und zur kostenrechtlichen Sekundärebene (Rn. 1366ff.) an.

\section{a) Überblick und Einführung in das Verwaltungsvollstreckungsrecht}

1293 „Verwaltungsvollstreckung ist die zwangsweise Durchsetzung öffentlich-rechtlicher Verpflichtungen des Bürgers [...] durch die Behörde in einem verwaltungseigenen Verfahren.“'2278 Das Verwaltungsvollstreckungsrecht umschreibt die Gesamtheit der Rechtssätze, die die Rechtsdurchsetzung öffentlich-rechtlicher Pflichten durch die Verwaltung betreffen. Im weiteren Sinne umfasst der Begriff aber auch die der Vollstreckung nachgelagerte Sekundärebene, auf welcher es um Fragen der Kostenverteilung und Entschädigungsansprüche geht.

\section{aa) Das Recht zur Selbsttitulierung und Selbstvollstreckung}

1294 Während Private für die Rechtsdurchsetzung auf die Inanspruchnahme staatlicher Institutionen, namentlich Gerichte und staatliche Vollstreckungsorgane, angewiesen sind, bedarf es für die Vollstreckung öffentlich-rechtlicher Pflichten durch die Verwaltung keiner vorherigen gerichtlichen Titulierung. Anders als der Bürger wird die Verwaltung also nicht auf die Gerichte verwiesen, wenn sie Recht durchsetzen möchte. Vielmehr besitzt sie das Recht zur Selbsttitulierung und Selbstvollstreckung. ${ }^{2279}$ Erlässt eine Behörde einen Verwaltungsakt, der dem Adressaten ein Ge- oder Verbot auferlegt, so schafft sie sich dadurch

\footnotetext{
$2277 \mathrm{Zu}$ den in Feststellungskonstellationen relevanten Ermächtigungsgrundlagen des Verwaltungsvollstreckungsrechts s. § 6 Rn. $193 \mathrm{ff}$.

2278 Maurer/Waldhoff, Allgemeines Verwaltungsrecht, 19. Aufl. 2017, § 20 Rn. 1.

2279 Kingreen/Poscher, Polizei- und Ordnungsrecht, 10. Aufl. 2018, § 24 Rn. 36; Voßkuhle/ Wischmeyer, JuS 2016, 698 (699); ausführlich Lemke, Verwaltungsvollstreckungsrecht des Bundes und der Länder, 1997, S. $43 \mathrm{ff}$.
} 
gleichzeitig einen Vollstreckungstitel. Durch seine Titelfunktion ist der Verwaltungsakt „Zentralbegriff des Verwaltungsvollstreckungsrechts“2280. Kommt der Adressat der auferlegten Verpflichtung nicht nach, so kann die Behörde die Erfüllung der Verpflichtung unter den jeweiligen vollstreckungsrechtlichen Voraussetzungen (d.h. insbesondere unabhängig von der Rechtmäßigkeit des Verwaltungsakts, dazu sogleich unter Rn. 1327) selbst erzwingen.

\begin{abstract}
Beispiele: Ein Zwangsgeld wird zur Durchsetzung einer Wohnungsverweisung mit zehntätigem Rückkehrverbot verhängt. ${ }^{2281}$ Ein Dritter wird von der Behörde beauftragt, eine baurechtliche Gefahrenquelle zu beseitigen, nachdem der Adressat der ursprünglichen Verfügung seiner Pflicht nicht nachgekommen ist. ${ }^{2282}$ Ein im Halteverbot parkendes Fahrzeug wird durch einen beauftragten Dritten abgeschleppt. ${ }^{2283}$ Die Polizei setzt Wasserwerfer ein, um den Platzverweis gegenüber Teilnehmern einer aufgelösten Versammlung durchzusetzen. ${ }^{2284}$
\end{abstract}

\title{
bb) Normativer Rahmen
}

Das Verwaltungsvollstreckungsrecht kennt eine Vielzahl von spezialgesetzlichen Regelungen. ${ }^{2285}$ Den grundlegenden normativen Rahmen auf Bundesebene bilden aber das VwVG ${ }^{2286}$ und - soweit das Zwangsmittel des unmittelbaren Zwangs betroffen ist - das $\mathbf{U Z \mathbf { Z } \mathbf { w } ^ { 2 2 8 7 }}{ }^{\mathbf{2}}$. Sie gelten unmittelbar nur für die Verwaltungsvollstreckung durch Bundesbehörden (bzw. im Falle des UZwG für Vollzugsbeamte des Bundes). Auf Landesebene existieren verschiedene Regelungsansätze ${ }^{2288}$ : In Brandenburg beispielsweise gilt ein eigenes VwVG Bbg. In Berlin wiederum verweist § 8 VwVfG Bln dynamisch auf das VwVG des Bundes. Wieder anders ist es in Niedersachsen: Dort gilt zwar ein landeseigenes VwVG Nds. Jedoch finden sich die Regelungen zur Vollstreckung von Handlungs-, Duldungs- und Unterlassungspflichten im niedersächsischen Sicherheits- und Ordnungsgesetz.

2280 Baumeister, in: Schenke/Graulich/Ruthig, Sicherheitsrecht des Bundes, VwVG, 2. Aufl. 2019, Vorb. §§ 6-18 Rn. 18; Maurer/Waldhoff, Allgemeines Verwaltungsrecht, 19. Aufl. 2017, § 20 Rn. 2.

2281 OVG Münster, Urt. v. 9. 2.2012, Az.: 5 A 2152/10 = JuS 2012, 1151 (Anm. Walfhoff).

2282 BVerwG, Urt. v. 13.4.1984 - 4 C 31/81 = NJW 1984, 2591; BVerwG, Urt. v. 25.89.2008 - 7 C 5/ $08=$ NVwZ 2009, 122.

2283 BVerwG, Urt. v. 25.5.2018, Az.: 3 C 25/16 = NJW 2018, 2910.

2284 BVerfG, Beschl. v. 7.12.1998, Az.: 1 BvR 831/89 = NVwZ 1999, 290.

2285 Beispielsweise $\S \S 57 \mathrm{ff}$. AufenthG, §§ $34 \mathrm{ff}$. AsylG, §§ $249 \mathrm{ff}$. AO.

2286 v. 27.4.1953 (BGBl. I S. 15), zuletzt geändert durch Art. 1 des Gesetzes vom 30.6. 2017 (BGBl. I S. 1770).

2287 v. 10.3.1961 (BGBl. I, S. 165), zuletzt geändert durch Art. 4 des Gesetzes vom 24.5.2016 (BGBl. I S. 1217).

2288 Detaillierter Überblick über die verschiedenen Regelungsansätze der Länder bei Troidl, in: Engelhardt/App/Schlatmann, VwVG VwZG, 11. Aufl. 2017, Einf. Rn. 3. 
Die folgenden Ausführungen beziehen sich auf das VwVG des Bundes. Auf einige landesrechtliche Spezifika wird hingewiesen. Im Übrigen ist das grundlegende Prüfungsprogramm für vollstreckungsrechtliche Konstellationen auf Bundes- und Landesebene inhaltlich weitgehend parallel ausgestaltet.

\section{cc) Verwaltungszwang}

1296 Spricht man über Verwaltungsvollstreckung, so ist zwischen der Vollstreckung wegen Geldforderungen einerseits und der Erzwingung von Handlungen, Duldungen und Unterlassungen andererseits zu unterscheiden. Ersteres wird auch Beitreibung genannt. Letzteres wird unter dem Begriff des Verwaltungszwangs zusammengefasst. Diese Unterscheidung lässt sich auch anhand der Systematik des VwVG nachvollziehen: $\S \S 1-5 b$ VwVG regeln die Beitreibung, $\S \S 6-18$ VwVG den Verwaltungszwang. Der dritte Abschnitt des Gesetzes regelt die Kostenverteilung, §§ 19f. VwVG.

Wie auch in der juristischen Ausbildung liegt der Fokus dieses Beitrags auf dem Verwaltungszwang und den sich daran anschließenden Kostenfragen. ${ }^{2289}$

\section{dd) Pflichtiger}

1297 Gegen wen die Verwaltungsvollstreckung durchgeführt werden kann, ist im VwVG nicht ausdrücklich geregelt. Dies ist zunächst der durch den Verwaltungsakt Verpflichtete. ${ }^{2290}$ In Fällen des sofortigen Vollzugs (dazu unter Rn. $1345 \mathrm{ff}$.) ist dies derjenige, gegen den eine Grundverfügung hätte ergehen können. Bei objektbezogenen Verwaltungsakten kann Verpflichteter auch der Rechtsnachfolger sein. Die Durchsetzung einer baurechtlichen oder naturschutzrechtlichen Beseitigungsanordnung kann daher auch gegenüber einem neuen Grundstückseigentümer erfolgen. Bei mehreren in Betracht kommenden Pflichtigen muss die Behörde ihr Auswahlermessen ordnungsgemäß betätigen.

1298 Examenswissen: Der Verwaltungszwang gegen Behörden ist grundsätzlich unzulässig, § 17 VwVG. Dies ist Ausdruck des zwischenbehördlichen koordinationsrechtlichen Verhältnisses. Das Gesetz geht davon aus, dass die Behörde ein besonderes Ansehen genießt, aufgrund dessen es eines Verwaltungszwangs gegen sie grundsätzlich gar nicht bedarf. Vielmehr könne von der Behörde erwartet werden, dass sie ihren Verpflichtungen auch ohne die Anwendung von Zwangsmitteln

2289 Übersichtlich zur Vollstreckung wegen Geldforderungen Maurer/Waldhoff, Allgemeines Verwaltungsrecht, 19. Aufl. 2017, § 20 Rn. 9 ff.

2290 Baumeister, in: Schenke/Graulich/Ruthig, Sicherheitsrecht des Bundes, VwVG, 2. Aufl. 2019, Vorb. $\S \S 6-18$ Rn. $26 \mathrm{f}$. 
nachkommt. ${ }^{2291}$ Der Verwaltungszwang gegen Behörden ist daher nur zulässig, wenn er spezialgesetzlich zugelassen ist.

\section{b) Das Verwaltungsvollstreckungsrecht in der Klausur}

Typischer Ausgangspunkt einer vollstreckungsrechtlich eingekleideten Klausur ist die kostenrechtliche Sekundärebene (s. Rn. $1366 \mathrm{ff}$.). Die Prüfung eines Kostenbescheids setzt fundierte Kenntnisse der Verwaltungsvollstreckungsmaßnahmen und ihrer Rechtmäßigkeitsvoraussetzungen nach § 6 I und § 6 II VwVG voraus, auf die deshalb gesondert in Rn. $1317 \mathrm{ff}$. und Rn. $1345 \mathrm{ff}$. eingegangen wird.

Bevor jedoch die für das Verwaltungsvollstreckungsrecht typischen Ermächtigungsgrundlagen (Rn. 1302ff.), Zwangsmittel (Rn. 1306ff.) und Rechtsschutzkonstellationen (Rn. 1311ff.) im Überblick dargestellt werden, muss zunächst auf eine der häufigsten Fehlerquellen eingegangen werden: Die Verkennung vollstreckungsrechtlicher Konstellationen.

\section{aa) Erkennen einer vollstreckungsrechtlichen Konstellation, insbesondere Abgrenzung zu polizeirechtlichen Standardmaßnahmen}

Eine der größten Fehlerquellen in Klausurbearbeitungen ist das Verkennen vollstreckungsrechtlicher Konstellationen. Dies führt meist dazu, dass die Bearbeiterinnen und Bearbeiter versuchen, den Fall über die polizei- und ordnungsrechtlichen Generalklauseln zu lösen. Auslöser dieser Fehlerquelle ist, dass es nicht selten Parallelitäten zu den polizeirechtlichen Standardmaßnahmen gibt (s. dazu näher Rn. 1045ff.). Auch diese beinhalten teilweise Vollzugselemente, sodass hier die Abgrenzung zum Vollstreckungsrecht von besonderer Bedeutung ist.

Dabei ist zwischen Standardmaßnahmen mit Vollzugselement und Standardmaßnahmen ohne Vollzugselement zu differenzieren. ${ }^{2292}$

Erstere umfassen neben dem Ge- oder Verbot auch eine Befugnis zur Ausführung der Maßnahme durch die Polizei. Der Vollzug der Verfügung ist hier Teil der Standardmaßnahme. Beispiele für Standardmaßnahmen mit Vollzugselement sind das Festhalten zur Prüfung der Identität, die erkennungsdienstliche Behandlung, die Durchsuchung von Personen, Sachen und Wohnungen und die Inge-

2291 Deusch/Burr, in: Bader/Ronellenfitsch, VwVG, 43. Ed., Stand: 1.4.2019, § 17 Rn. 1.

2292 Hierzu auch Muckel, JA 2012, 272 (274); Poscher/Rusteberg, JuS 2012, 26 (27f.); teilweise findet sich auch die Bezeichnung „Standardmaßnahme mit/ohne Ausführungsermächtigung“, vgl. Baumeister, in: Schenke/Graulich/Ruthig, Sicherheitsrecht des Bundes, VwVG, 2. Aufl. 2019, Vorb. §§ 6-18 Rn. 14. 
wahrsamnahme. ${ }^{2293}$ Eines Rückgriffs auf das Verwaltungsvollstreckungsrecht bedarf es in diesen Fällen nicht. Etwas anderes gilt aber dann, wenn das polizeiliche Handeln „überschießende vollstreckungsrechtliche Elemente“ beinhaltet. Das ist dann der Fall, wenn die Polizei über das standardisierte Verfahren hinaus Zwang anwenden muss. Tritt also eine Polizistin die Wohnungstür zum Zwecke der Wohnungsdurchsuchung ein und muss eine andere Polizistin den wütenden Mieter festhalten, damit die Wohnungsdurchsuchung stattfinden kann, so müssen beide Maßnahmen anhand der vollstreckungsrechtlichen Ermächtigungsgrundlagen bewertet werden.

Bei Standardmaßnahmen ohne Vollzugselement stellt die Durchführung der Grundverfügung stets eine Vollstreckungsmaßnahme dar. Dies ist beispielsweise bei der Vorladung oder dem Platzverweis der Fall. ${ }^{2294}$

1301 Examenswissen (Die Abgrenzung von Standardmaßnahme und Vollstreckungsmaßnahme bei der Sicherstellung): Es ist umstritten, ob im Rahmen einer Sicherstellung die Ansichnahme des Gegenstandes noch von der polizeigesetzlichen Ermächtigungsgrundlage (Standardmaßnahme) gedeckt ist oder nach Vollstreckungsrecht zu bewerten ist. ${ }^{2295}$ Sieht man in der Ermächtigungsgrundlage zur Sicherstellung allein die Befugnis zum Erlass eines Verwaltungsakts, der auf die Herausgabe einer Sache gerichtet ist, so bedürfte es für die Ansichnahme der Sache eines Rückgriffs auf das Vollstreckungsrecht. ${ }^{2296}$ Andererseits wird vertreten, dass die Ermächtigungsgrundlage zur Sicherstellung bereits die Ansichnahme der Sache als Vollzugselement beinhaltet. ${ }^{2297}$ Muss die Herausgabe der Sache aber durch Anwendung von Zwang vollzogen werden, so handelt es sich um ein „überschießendes Element“, sodass jedenfalls in diesen Fällen Einigkeit über den vollstreckungsrechtlichen Charakter der Maßnahme besteht.

\section{bb) Überblick über die typischen Ermächtigungsgrundlagen im Verwaltungsvollstreckungsrecht}

1302 Das VwVG geht in § 6 I VwVG als Regelfall davon aus, dass der Verwaltungszwang auf der Grundlage eines vollziehbaren Verwaltungsakts erfolgt. Der Zwangsmittelanwendung gehen dabei regelmäßig noch zwei Verfahrensschritte voraus: die Androhung und die Festsetzung. Aus dieser Mehraktigkeit gewinnt die

2293 Beispiele aus: Mosbacher, in: Engelhardt/App/Schlatmann, VwVG VwZG, 11. Aufl. 2017, Vorb. §§ 6-18 Rn. 1a.

2294 Beispiele aus: Mosbacher, in: Engelhardt/App/Schlatmann, VwVG VwZG, 11. Aufl. 2017, Vorb. §§ 6-18 Rn. 1a.

2295 Muckel, JA 2012, 272 (274).

2296 Gusy, Polizei- und Ordnungsrecht, 10. Aufl. 2017, Rn. 286.

2297 Graulich, in: Lisken/Denninger, Handbuch des Polizeirechts, 6. Aufl. 2018, E Rn. 643; Kingreen/Poscher, Polizei- und Ordnungsrecht, 10. Aufl. 2018, § 18 Rn. 1, 15; W.-R. Schenke, in: Schenke/Graulich/Ruthig, Sicherheitsrecht des Bundes, BPolG, 2. Aufl. 2018, §47 Rn. 6; Wehr, in: Wehr, NK-BPolG, § 47 Rn. 2. 
Literatur den Namen „gestrecktes Verfahren“2298, welcher auch in diesem Beitrag Verwendung finden soll.

Examenswissen (Verwaltungszwang nach § 6 I VwVG auf Grundlage eines öffentlich-rechtlichen 1303 Vertrages): Auch ein öffentlich-rechtlicher Vertrag kann Vollstreckungsgrundlage sein (zum öffentlich-rechtlichen Vertrag s. ausführlich $\S 5$ Rn. 65 ff.). Dafür muss es sich zunächst um einen subordinationsrechtlichen Vertrag handeln ( 54 S. 2 VwVfG). Darüber hinaus muss sich der vertragsschließende Bürger der sofortigen Vollstreckung unterworfen haben (§ 61 I VwVfG). Sind diese Voraussetzungen erfüllt, so tritt in diesen Fällen im Rahmen des § 6 I VwVG der öffentliche Vertrag an die Stelle des dort genannten Verwaltungsakts.

Verwaltungszwang kann in dringenden Fällen auch ohne vorausgehenden Verwaltungsakt angewendet werden. Wenngleich es also nicht um den „Vollzug“ eines Verwaltungsakts geht, wird in diesen Fällen vom sog. sofortigen Vollzug ${ }^{2299}$ gesprochen. Ermächtigungsgrundlage ist \$ 6 II VwVG. Teilweise findet sich auch die

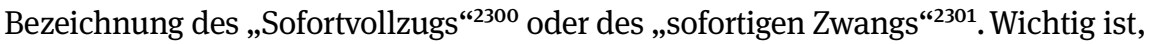
dass - unabhängig von dem in diesem Bereich anzutreffenden „besonders undurchsichtigen Begriffswirrwarr“2302 - die vollstreckungsrechtliche Problematik des sofortigen Vollzugs nicht mit der Anordnung der sofortigen Vollziehbarkeit i.S.d. $\S 80$ II 1 Nr. 4 VwGO verwechselt wird. Das eine lässt die aufschiebende Wirkung von Rechtsbehelfen, die gegen einen Verwaltungsakt eingelegt werden können, entfallen. Das andere bezeichnet die sofortige zwangsweise Durchsetzung einer Rechtspflicht.

Wie bereits eingangs angemerkt, nehmen vollstreckungsrechtlich eingeklei1305 dete Klausuren nicht selten ihren Ausgangspunkt auf der Kostenebene. Hierbei geht es um die Frage, wer die Kosten für eine Vollstreckungsmaßnahme zu tragen hat. Ermächtigungsgrundlage für die Kostenerhebung ist § 19 I VwVG.

\section{cc) Überblick über die Zwangsmittel}

$\S 9$ VwVG normiert die Mittel, mit denen der Verwaltungszwang angewendet wer- 1306 den kann, abschließend (sog. numerus clausus der Zwangsmittel). Als Zwangsmittel

2298 S. nur Kingreen/Poscher, Polizei- und Ordnungsrecht, 10. Aufl. 2018, § 24 Rn. 21; Muckel, JA 2012, 272 (275); Schweikert, Der Rechtswidrigkeitszusammenhang, 2013, S. 42.

2299 S. nur Kingreen/Poscher, Polizei- und Ordnungsrecht, 10. Aufl. 2018, § 24 Rn. 37; Maurer/ Waldhoff, Allgemeines Verwaltungsrecht, 19. Aufl. 2017, § 20 Rn. 25; Muckel, JA 2012, 354 (355). 2300 Baumeister, in: Schenke/Graulich/Ruthig, Sicherheitsrecht des Bundes, VwVG, 2. Aufl. 2019, Vorb. $\S \S 6-18$ Rn. 5.

2301 Schweikert, Der Rechtswidrigkeitszusammenhang, 2013, S. 47.

2302 Mosbacher, in: Engelhardt/App/Schlatmann, VwVG VwZG, 11. Aufl. 2017, § 6 Rn. 22. 
kommt je nach Fallkonstellation die Ersatzvornahme (§ 10 VwVG), das Zwangsgeld (§ 11 VwVG) oder der unmittelbare Zwang (§ 12 VwVG) in Betracht.

Bei der Ersatzvornahme wird ein beauftragter Dritter anstelle des Pflichtigen tätig. ${ }^{2303}$ Voraussetzung ist, dass die $\mathrm{zu}$ erzwingende Handlung eine vertretbare ist, d.h. dass sie nicht höchstpersönlich vorgenommen werden muss. Da Duldungs- und Unterlassungspflichten stets allein durch den Verpflichteten erfüllbar und damit höchstpersönlicher Natur sind, kommt die Ersatzvornahme als Zwangsmittel nur bei positiven Handlungspflichten in Betracht. Typisches Beispiel für vertretbare Handlungen ist die Beseitigung baurechtlicher Gefahrenquellen oder das Wegfahren eines Fahrzeugs aus dem Halteverbot.

$1308 \quad$ Mit dem Zwangsgeld soll der Betroffene durch die in Aussicht gestellte finanzielle Einbuße dazu gebracht werden, dem Grundverwaltungsakt Folge zu leisten. Nach § 11 I 1 VwVG geht das Gesetz davon aus, dass das Zwangsgeld regelmäßig bei unvertretbaren Pflichten verhängt werden kann. Typisches Beispiel dafür ist die Zwangsgeldverhängung für die Erzwingung von Auskünften oder Erklärungen. ${ }^{2304}$ Auch die Erzwingung von Duldungs- und Unterlassungspflichten (beispielsweise eine Wohnungsverweisung mit Rückkehrverbot) ist in diesem Zusammenhang zu nennen, § 11 II VwVG. Das Zwangsgeld kann nach § 11 I 2 VwVG aber auch bei vertretbaren Handlungen verhängt werden. Voraussetzung ist, dass die Ersatzvornahme untunlich ist. Als Regelbeispiel nennt das Gesetz die finanzielle Überforderung des Pflichtigen in Bezug auf die Kosten der Ersatzvornahme. Damit soll das Risiko verringert werden, dass die Kosten der Ersatzvornahme im Nachhinein nicht beigetrieben werden können. Der Rekurs auf das Zwangsgeld bietet dann den Vorteil, dass das Zwangsgeld die Höhe der Kosten der Ersatzvornahme nicht unbedingt erreichen muss, der Betroffene aber dennoch durch Inaussichtstellung finanzieller Einbußen (und ggf. der Ersatzzwanghaft) zur Rechtstreue angehalten wird.

1309 Examenswissen (Ersatzzwangshaft nach § 16 VwVG): Die Ersatzzwangshaft ist kein selbständiges Zwangsmittel, sondern ein Surrogat für das Zwangsgeld, wenn dessen Beitreibung uneinbringlich ist. Sie soll denjenigen Pflichtigen, dem gegenüber die Inaussichtstellung finanzieller Einbußen (regelmäßig mangels Zahlungsfähigkeit) kein ausreichendes Beugemittel darstellt, durch den

2303 Nicht von § 10 VwVG umfasst ist die Selbstvornahme durch die Vollzugsbehörde. Anders ist dies auf landesrechtlicher Ebene: Die meisten Länder sehen sowohl in der Beauftragung eines Dritten als auch in der Selbstvornahme durch die Behörde eine Ersatzvornahme (z. B. § 25 VwVG BW; Überblick bei Mosbacher, in: Engelhardt/App/Schlatmann, VwVG VwZG, 11. Aufl. 2017, § 10 Rn. 2, 17). Auf Bundesebene hingegen stellt die Selbstvornahme einen Unterfall des unmittelbaren Zwangs dar, s. § 12 Var. 2. VwVG.

2304 Beispiele aus App, JuS 2004, 7786 (789).

Mariamo Katharina Ilal 
Eingriff in die persönliche Freiheit zur Befolgung seiner Rechtspflicht bewegen. ${ }^{2305}$ Die Zwangshaft bedarf der richterlichen Anordnung.

Unmittelbarer Zwang ist die Einwirkung auf Personen oder Sachen durch 1310 körperliche Gewalt, ihre Hilfsmittel oder Waffen (so die Legaldefinition des § 2 I UZwG) sowie die behördliche Selbstvornahme. Aufgrund des Verhältnismäßigkeitsprinzips ist der unmittelbare Zwang „das an letzter Stelle stehende Zwangsmittel“2306. Wegen dieses Grundsatzes der Subsidiarität ist der unmittelbare Zwang nur zulässig, wenn Ersatzvornahme und Zwangsgeld nicht zum Ziel führen oder sie untunlich sind. ${ }^{2307}$ Ersteres ist der Fall, wenn Ersatzvornahme und Zwangsgeld entweder bereits erfolglos angewendet worden sind oder aber bereits vor ihrer Anwendung feststeht, dass sie erfolglos sein werden. ${ }^{2308}$ Nicht ausreichend ist die vermutliche Uneinbringlichkeit eines Zwangsgeldes aufgrund bescheidener Einkommensverhältnisse des Pflichtigen. ${ }^{2309}$ Ersatzvornahme und Zwangsgeld sind untunlich, wenn ihr Einsatz zwar Erfolg versprechend ist, der unmittelbare Zwang sich aber im konkreten Fall als wirksamer darstellt.. ${ }^{2310}$ Liegt unmittelbarer Zwang in der Form der Einwirkung auf Personen oder Sachen durch körperliche Gewalt, ihre Hilfsmittel oder Waffen vor, so müssen zusätzlich die Voraussetzungen des UZwG beachtet werden.

\section{dd) Typische Rechtsschutzkonstellationen}

Für die Bearbeitung einer verwaltungsvollstreckungsrechtlichen Klausur ist es 1311 essentiell, die verschiedenen rechtlichen Ebenen eines Sachverhalts zu erfassen und auseinanderzuhalten. Nicht selten müssen die Bearbeiterinnen und Bearbeiter in umfangreiche Inzidenzprüfungen einsteigen. Von ihnen wird verlangt, trotz der vielen Verschachtelungen den Überblick zu behalten und das rechtlich Relevante an den jeweils richtigen Stellen einzuordnen und darzustellen.

2305 Lemke, Verwaltungsvollstreckungsrecht des Bundes und der Länder, 1997, S. 276.

2306 Wacke, JZ 1962, 138 zitiert nach Mosbacher, in: Engelhardt/App/Schlatmann, VwVG VwZG, 11. Aufl. 2017, § 12 Rn. 7.

2307 Anderes gilt freilich, wenn Spezialgesetze den unmittelbaren Zwang als einziges Zwangsmittel bestimmen, z. B. §58 AufenthG.

2308 OVG Berlin-Brandenburg, Beschl. v. 5.6.2014, Az.: OVG 3 S 71.13.

2309 OVG Berlin-Brandenburg, Beschl. v. 23.8.2013, Az.: OVG 3 S 41.13.

2310 Dies ist beispielsweise der Fall, wenn die Vollzugbehörde einen Gegenstand, den der Pflichtige herausgeben muss, bei dem Pflichtigen findet. Hier könnte auch das Zwangsgeld zum Erfolg führen, jedoch ist es effizienter dem unwilligen Pflichtigen die Sache wegzunehmen, Beispiel aus Lemke, Verwaltungsvollstreckungsrecht des Bundes und der Länder, 1997, S. 290. 
Die erste Ebene betrifft die Grundverfügung. Soweit sie nicht unanfechtbar ist, sind gegen sie Widerspruch und Anfechtungsklage statthafte Rechtsbehelfe. Kommt den eingelegten Rechtsbehelfen aufschiebende Wirkung zu, so ist die Behörde aufgrund des Suspensiveffekts grundsätzlich daran gehindert, den Verwaltungsakt zu vollstrecken (zum Suspensiveffekt s. § 8 Rn. $4 \mathrm{ff}$.). Gleiches gilt im Falle eines erfolgreichen Antrags nach $\S 80 \mathrm{~V} 1 \mathrm{VwGO}$ (s. § 8 Rn. 1ff.). Einen Einblick in die typischen Ermächtigungsgrundlagen, die auf dieser Ebene eine Rolle spielen, finden sich in den Beiträgen zum allgemeinen Verwaltungsrecht (s. Rn. 832 ff.), Polizeirecht (s. Rn. 1000 ff.) und Versammlungsrecht (s. Rn. 1141 ff.) und Bauordnungsrecht (s. Rn. 1222ff.). Der Fokus dieses Beitrags liegt auf den anderen beiden Ebenen.

Zunächst ist dies die Ebene der Vollstreckungsmaßnahme. ${ }^{2311}$ Will der Kläger unmittelbar gegen eine Vollstreckungsmaßnahme vorgehen, so gilt es in der Klausur zunächst den statthaften Rechtsbehelf zu ermitteln und sodann in der Begründetheit in die Prüfung der Rechtmäßigkeit der Vollstreckungsmaßnahme einzusteigen (zu den Voraussetzungen sogleich unter Rn. $1317 \mathrm{ff}$. und Rn. $1345 \mathrm{ff}$.).

Handelt es sich um eine Maßnahme im gestreckten Verfahren, so ist entscheidend gegen welche Vollstreckungsmaßnahme sich der Kläger wendet: Gegen Androhung (vgl. § $18 \mathrm{I}$ VwVG) und Festsetzung sind Widerspruch und Anfechtungsklage statthafte Rechtsbehelfe. Da diesen Rechtsbehelfen gegen Maßnahmen in der Verwaltungsvollstreckung aufgrund von § 80 II 1 Nr. 3, S. 2 VwGO i.V.m. landesrechtlichen Vorschriften ${ }^{2312}$ regelmäßig keine aufschiebende Wirkung zukommt, kann hier auch einmal eine Rechtsschutzkonstellation nach $\S 80 \mathrm{~V} 1$ Fall 1 VwGO in Betracht kommen (Näheres hierzu in § 8). Die Anwendung der Zwangsmittel Ersatzvornahme und unmittelbarer Zwang ist indes ein Realakt, sodass hier die Feststellungsklage (u.U. in Verbindung mit Leistungsklage auf Rückgängigmachung der Vollzugsfolgen) statthafter Rechtsbehelf ist (näheres hierzu in $\S 6$ Rn. 193ff.). ${ }^{2313}$ Geht es dem Betroffenen um die Abwendung einer bevorstehen Zwangsmittelanwendung, so ist die vorbeugende Unterlassungsklage - hier aufgrund der Eilbedürftigkeit in Form des Antrags nach § 123 VwGO (Näheres hierzu in § 10) - statthaft.

2311 Ausführlich Lemke, Verwaltungsvollstreckungsrecht des Bundes und der Länder, 1997, S. $445 \mathrm{ff}$.

2312 Beispielsweise § 4 AGVwGO Berlin.

2313 Die Zwangsmittelanwendung im Falle eines Zwangsgeldes besteht in der Beitreibung des Zwangsgeld nach §§ 1-5b VwVG. Zu den Rechtsschutzkonstellationen in diesen Fällen s. Deusch/ Burr, in: Bader/Ronellenfitsch, VwVG, 43. Ed., Stand: 1.4.2019, § 5 Rn. 6 ff.; Maurer/Waldhoff, Allgemeines Verwaltungsrecht, 19. Aufl. 2017, § 20 Rn. 11. 
Für Maßnahmen des sofortigen Vollzugs ordnet § $18 \mathrm{II}$ VwVG - obschon es 1315 sich um Realakte handelt ${ }^{2314}$ - Widerspruch und Anfechtungsklage als statthafte Rechtsbehelfe an.

Die dritte Ebene stellt die sog. Kostenebene dar. Es ist weitaus typischer, dass 1316 eine Klausur ihren Ausgangspunkt auf der Kostenebene nimmt als dass sie direkt auf Ebene der Vollstreckungsmaßnahme ansetzt. Statthafter Rechtsbehelf gegen einen Kostenbescheid sind Widerspruch und Anfechtungsklage. Die Rechtmäßigkeit des Kostenbescheids setzt die Rechtmäßigkeit der Maßnahme, für die die Kosten erhoben werden, voraus (Näheres dazu unter Rn. 1366ff.). Dies ist Einfallstor für die inzidente Überprüfung der Vollstreckungsmaßnahme nach § 6 I oder § 6 II VwVG. Deren Rechtmäßigkeitsvoraussetzungen sollen nun im Einzelnen unter Rn. 1317 ff. für das gestreckte Verfahren und Rn. 1345 ff. für den sofortigen Vollzug dargestellt werden.

\section{c) Gestrecktes Verfahren, § 6 I VwVG}

Den Regelfall des Verwaltungszwangs stellt das sog. gestreckte Verfahren nach 1317 § 6 I VwVG dar. Demnach kann ein Verwaltungsakt, der auf die Herausgabe einer Sache oder auf die Vornahme einer Handlung oder auf Duldung oder Unterlassung gerichtet ist, mit den in §9 VwVG genannten Zwangsmitteln durchgesetzt werden, wenn er unanfechtbar ist oder wenn sein sofortiger Vollzug angeordnet oder wenn dem Rechtmittel keine aufschiebende Wirkung beigelegt ist.

Der Anwendung von Verwaltungszwang auf Grundlage eines vollziehbaren 1318 Verwaltungsakts gehen spezielle vollstreckungsrechtliche Verfahrensschritte voraus: Zunächst ist das von der Vollstreckungsbehörde ausgewählte Zwangsmittel anzudrohen, $\S 13$ VwVG. Dadurch soll der Adressat der Grundverfügung zur Rechtstreue angehalten werden, während gleichzeitig durch die Festlegung auf ein bestimmtes Zwangsmittel auch eine Warnung, was im Falle der Zuwiderhandlung an Konsequenzen droht, ergeht. ${ }^{2315}$ Wird die Verpflichtung innerhalb der Frist, die in der Androhung bestimmt ist, nicht erfüllt, so setzt die Vollzugsbehörde das Zwangsmittel fest, § $14 \mathrm{I}$ VwVG. ${ }^{2316}$ Die Festsetzung soll

2314 So die herrschende Meinung, s. nur Deusch/Burr, in: Bader/Ronellenfitsch, VwVG, 43. Ed., Stand: 1.4.2019, § 18 Rn. 9.

2315 Deusch/Burr, in: Bader/Ronellenfitsch, VwVG, 43. Ed., Stand: 1.4.2019, § 13 Rn. 1

2316 Viele landesrechtlichen Vollstreckungsvorschriften hingegen kennen die Festsetzung als Verfahrensstufe nicht, Überblick bei Troidl, in: Engelhardt/App/Schlatmann, VwVG VwZG, 11. Aufl. 2017, § 14 Rn. 7. 
dem Pflichtigen als letzte Warnung vor der Zwangsmittelanwendung dienen. ${ }^{2317}$ Erst dann kann das Zwangsmittel auch angewendet werden, § 15 VwVG.

Für die Klausurbearbeitung folgt aus eben dieser Mehraktigkeit des gestreckten Verfahrens nicht selten ein Aufbauproblem. Denn es bestehen regelmäßig gleich drei mögliche „Angriffspunkte“ im Rechtsschutzverfahren (Androhung, Festsetzung und Anwendung), die in ihren Voraussetzungen freilich ähnlich, in der Klausur jedoch dennoch auseinander zu halten sind.

1320

Androhung und Festsetzung sind Verwaltungsakte. Will der Betroffene gegen sie vorgehen, so sind Widerspruch und Anfechtungsklage statthafte Rechtsbehelfe, vgl. § 18 I VwVG. Bei der Zwangsmittelanwendung handelt es sich indes um einen Realakt, gegen den Rechtsschutz im Rahmen der Feststellungsklage gewährt wird. Diesen Unterschieden in der prozessualen Verarbeitung der verschiedenen Vollstreckungsmaßnahmen wird in diesem Beitrag dadurch Rechnung getragen, dass Rechtmäßigkeitsvoraussetzungen von Androhung und Festsetzung im Lehrbuchkapitel der Anfechtungsklage, der Zwangsmittelanwendung indes im Kapitel der Feststellungsklage (s. § 5 Rn. 193ff.) dargestellt werden.

1321 Die Rechtmäßigkeit von Androhung und Festsetzung ist in dem typischen verwaltungsrechtlichen Grundmuster Ermächtigungsgrundlage - formelle Rechtmäßigkeit - materielle Rechtmäßigkeit zu prüfen. Auf allen drei Stufen finden sich Voraussetzungen, die beiden Vollstreckungsvoraussetzungen gemein sind. Sie werden im Folgenden unter Rn. $1322 \mathrm{ff}$. auch gemeinsam dargestellt. Dem schließen sich Ausführungen zu Rechtmäßigkeitsvoraussetzungen an, die spezifisch für die Androhung (Rn. 1337 ff.) bzw. Festsetzung gelten (Rn. 1342ff.).

\section{aa) Gemeinsame Rechtmäßigkeitsvoraussetzungen von Androhung und Festsetzung}

1322 Androhung und Festsetzung müssen wie jedes verwaltungsrechtliche Eingriffshandeln auf einer Ermächtigungsgrundlage beruhen (s. Rn. $554 \mathrm{ff}$.) sowie bestimmten formellen und materiellen Voraussetzungen Genüge tun.

\section{(1) Ermächtigungsgrundlage}

1323 Ermächtigungsgrundlage von Androhung und Festsetzung ist § 6 I VwVG. Optional kann auch das jeweilige Zwangsmittel (§§ 9 lit. x, 10-12 VwVG) und die

2317 Instruktiv zu den Rechtswirkungen der Festsetzung BVerwG, Beschl.v. 21.8.1996-4 B 100/ $96=$ NVwZ 1997, 381.

Mariamo Katharina Ilal 
Verfahrensstufe (für die Androhung $§ 13$ VwVG, für die Festsetzung $§ 14$ VwVG) mit hinzu zitiert werden.

\section{(2) Formelle Rechtmäßigkeit}

Nach § 7 VwVG ist zuständige Vollzugsbehörde diejenige, die den zu vollziehen- 1324 den Verwaltungsakt erlassen hat (Grundsatz der Selbstvollstreckung durch die Ausgangsbehörde). ${ }^{2318} \mathrm{Da}$ Androhung und Festsetzung „Maßnahmen in der Verwaltungsvollstreckung“ sind, ist die Anhörung des Betroffenen nach § 28 II Nr. 5 VwVfG entbehrlich. ${ }^{2319}$

\section{(3) Materielle Rechtmäßigkeit: Allgemeine Vollstreckungsvoraussetzungen}

Die materielle Rechtmäßigkeit von Androhung und Festsetzung hängt zunächst vom Vorliegen der allgemeinen Vollstreckungsvoraussetzungen ab. Dafür muss den Vollstreckungsmaßnahmen ein wirksamer, bestimmter und vollstreckbarer Grundverwaltungsakt zugrunde liegen (Rn. $1326 \mathrm{ff}$.). Die Vollstreckungsbehörde muss das richtige Zwangsmittel gewählt haben (Rn. 1333). Es dürfen keine Vollstreckungshindernisse vorliegen (Rn. 1334) und die Maßnahme muss ermessensfehlerfrei und insbesondere verhältnismäßig sein (Rn. 1335f.).

\section{(a) Wirksamer, bestimmter und vollstreckbarer Grundverwaltungsakt}

Grundlage für den Verwaltungszwang nach §6 I VwVG ist ein wirksamer, be- 1326 stimmter und vollstreckbarer Grundverwaltungsakt. ${ }^{2320}$ Dabei sei vorausgeschickt, dass nur befehlende Verwaltungsakte, nicht aber feststellende oder rechtsgestaltende Verwaltungsakte überhaupt vollstreckungsfähig sind (vgl. Wortlaut § 6 I VwVG: „Verwaltungsakt, der auf die Herausgabe einer Sache oder

2318 Abweichendes kann sich teilweise aus den landesrechtlichen Vorschriften ergeben, so beispielsweise die Zuständigkeitserweiterung in § 8 I S. 3 VwVfG Bln.

2319 Für den Spezialfall der Festsetzung eines Zwangsgeldes vertritt eine Mindermeinung, dass die Festsetzung im Vorfeld der Beitreibung des Zwangsgeldes (§§ 1-5a VwVG) ergeht und deshalb eine Maßnahme vor (und eben nicht in) der Verwaltungsvollstreckung sei. Deshalb sei in diesen Fällen eine Anhörung eben doch erforderlich. Dem ist jedoch zu entgegen, dass dies zu einer künstlichen Aufspaltung eines einheitlichen Vollstreckungsvorgangs führte. Es ist nicht ersichtlich, weshalb die Androhung eines Zwangsgeldes eine Maßnahme im Vollstreckungsverfahren sein sollte, während die darauffolgende Festsetzung sodann als Maßnahme vor dem Vollstreckungsverfahren behandelt wird.

2320 Die Begriffe des Grundverwaltungsakts und der Grundverfügung werden in diesem Beitrag synonym verwendet. 
auf die Vornahme einer Handlung oder auf Duldung oder Unterlassung gerichtet ist").

\section{(aa) Wirksamkeit des Grundverwaltungsakts}

1327 Voraussetzung ist zunächst, dass ein wirksamer Grundverwaltungsakt vorliegt. Dies bestimmt sich nach den allgemeinen Vorschriften \$§ 43, 44 VwVfG (Näheres hierzu unter Rn. $98 \mathrm{ff}$.). Auf die Rechtmäßigkeit des Verwaltungsakts kommt es (soweit die Rechtswidrigkeit nicht zur Nichtigkeit führt) hingegen nicht an. Nicht selten firmiert dieser Grundsatz unter dem Schlagwort des fehlenden Rechtswidrigkeitszusammenhangs ${ }^{2321}$. Dahinter verbirgt sich der ,tragende Grundsatz des Verwaltungsvollstreckungsrechts, dass die Wirksamkeit und nicht die Rechtmäßigkeit vorausgegangener Verwaltungsakte Bedingung für die Rechtmäßigkeit der folgenden Akte und letztlich der Anwendung des Zwangsmittels ist““2322. Der fehlende Rechtswidrigkeitszusammenhang zwischen Grundverfügung und Vollstreckungsmaßnahme ist Ausdruck der Titelfunktion des Verwaltungsakts.

1328 Examenswissen (Vertiefende Herleitung des fehlenden Rechtswidrigkeitszusammenhangs): Bei unanfechtbaren Verwaltungsakten ergibt sich der fehlende Rechtswidrigkeitszusammenhang bereits aus der materieller Bestandskraft: Solange die Grundverfügung wirksam ist, kommt es für die Beurteilung der Rechtmäßigkeit der Vollstreckungsmaßnahme auf die Rechtmäßigkeit der Grundverfügung nicht an. ${ }^{2323}$ Hin und wieder finden sich in der Ausbildungsliteratur Verweise darauf, dass die Frage des Rechtswidrigkeitszusammenhangs bei Vollstreckungsmaßnahmen aufgrund sofort vollziehbarer Verwaltungsakte angesichts des Grundsatzes der Gesetzmäßigkeit der Verwaltung streitig sei. ${ }^{2324}$ Jedoch finden sich heute kaum $^{2325}$ noch Stimmen, die einen sol-

2321 Schweikert, Der Rechtswidrigkeitszusammenhang, 2013; Voßkuhle/Wischmeyer, JuS 2016, 698 (700).

2322 So das OVG Lüneburg hier zitiert durch BVerfG, Beschl. v. 7.12.1998 - 1 BvR 831/89 = NVwZ 1999, 290 (292).

2323 Deusch/Burr, in: Bader/Ronellenfitsch, VwVG, 43. Ed., Stand: 1.4.2019, § 6 Rn. 20; Muckel, JA 2012, 272 (277).

2324 Streitübersicht bei Poscher/Rusteberg, JuS 2012, 26 (28); Auslöser des Streits ist, dass bei sauberer Differenzierung zwischen der Vollstreckung unanfechtbarer und sofortig vollziehbarer Grundverfügungen die Titelfunktion streng genommen nur für erstere Fallgruppe zur Begründung des fehlenden Rechtswidrigkeitszusammenhangs herangezogen werden kann und sich deshalb eigenständig mit dem Grundsatz der Gesetzmäßigkeit der Verwaltung für die zweite Fallgruppe auseinander gesetzt werden muss. Diese dogmatisch sehr interessante Frage hat indes keinen Raum in der Klausurbearbeitung, weshalb in diesem Beitrag lediglich auf die ausführliche Diskussion bei Schweikert, Der Rechtswidrigkeitszusammenhang, 2013, S. 100, $140 \mathrm{ff}$. hingewiesen wird.

2325 So noch Schoch, in: Schoch, Besonderes Verwaltungsrecht, 2018, Kap. 1 Rn. 916.

Mariamo Katharina Ilal 
chen Rechtswidrigkeitszusammenhang für Fälle sofort vollziehbarer Verwaltungsakte fordern. Vielmehr ist auch hier die ganz herrschende Meinung, dass die Rechtmäßigkeit des sofort vollziehbaren Grundverwaltungsakts keine Rechtmäßigkeitsvoraussetzung für die Vollstreckungsmaßnahme ist. ${ }^{2326}$ Auch das BVerfG hat diese Rechtsauffassung als ,verfassungsrechtlich unbedenklich“2327 bestätigt. In der Klausur sollte dieser Meinungsstreit daher nicht geführt und höchstens mit einem Satz angedeutet werden.

Der Einwand der Gesetzmäßigkeit der Verwaltung bleibt indes auch von der herrschenden Meinung nicht gänzlich ungehört. Vollzieht eine Behörde „sehenden Auges“ einen rechtswidrigen Grundverwaltungsakt, so kann dies im Einzelfall zur Unverhältnismäßigkeit und damit zur Rechtswidrigkeit der Vollzugsmaßnahme führen (Näheres Rn. 1336). Das ändert aber nichts daran, dass im Prüfungspunkt Grundverwaltungsakt auch in diesen Fällen allein dessen Wirksamkeit ausschlaggebend ist. Sollte es in der Klausur einmal um den Vollzug trotz erkannter Rechtswidrigkeit gehen, so ist diese Problematik daher nicht unter „Wirksamkeit des Grundverwaltungsaktes“, sondern an späterer Stelle im Rahmen der Verhältnismäßigkeit zu diskutieren.

\section{(bb) Bestimmtheit des Grundverwaltungsakts}

Damit der Adressat der Verfügung erkennen kann, was von ihm verlangt wird und sein Verhalten daran anpassen kann, muss der Inhalt des erlassenen Grundverwaltungsaktes „vollständig, klar und unzweideutig erkennbar sein““2328. Der der Vollstreckungsmaßnahme zugrunde liegende Grundverwaltungsakt muss deshalb bestimmt sein, vgl. § 37 I VwVfG.

Examenswissen (Prüfung der Bestimmtheit als Ausnahme vom sonst fehlenden Rechtswidrigkeitszusammenhang): Die Unbestimmtheit des zu vollziehenden Verwaltungsakts führt dazu, dass dieser - obwohl lediglich rechtswidrig - nicht vollstreckbar ist. Es bietet sich daher an, das Bestimmtheitserfordernis systematisch als Ausnahme zum sonst geltenden Grundsatz des fehlenden Rechtswidrigkeitszusammenhangs zu begreifen. So wird es auch in der Rechtsprechung gesehen: „Insoweit erfährt der tragende Grundsatz des Verwaltungsvollstreckungsrechts, dass es für die Beurteilung einer Vollstreckungsmaßnahme auf die Rechtmäßigkeit der Grundverfügung nicht ankommt, eine Ausnahme. Die Unbestimmtheit der Grundverfügung infiziert eine zu ihrer Durchsetzung ergehende Vollstreckungsmaßnahme“2329.

2326 Stellvertretend für alle Poscher/Rusteberg, JuS 2012, 26 (28); ebenso der Konsens in der Rechtsprechung: BVerfG, Beschl. v. 7.12.1998, Az.: 1 BvR 831/89 = NVwZ 1999, 290 (292); OVG Lüneburg, Beschl.v. 23.4.2009, Az.: 11 ME 478/08; OVG Münster, Urt. v. 9.2.2012, Az.: 5 A 2152/10 = JuS 2012, 1151 (Anm. Waldhoff).

2327 BVerfG, Beschl. v. 7.12.1998, Az.: 1 BvR 831/89 = NVwZ 1999, 290 (292).

2328 Deusch/Burr, in: Bader/Ronellenfitsch, VwVG, 43. Ed., Stand: 1.4.2019, Vorb § 6 Rn. 10.

2329 VGH Mannheim, Urt. v. 10.1.2013, Az.: 8 S 2919/11 = NVwZ-RR 2013, 451 (452): In diesem Fall hatte die Behörde dem Adressaten ohne weitere Präzisierung aufgegeben, innerhalb einer bestimmten Frist die Außenwände seines Hauses ,in einem landschaftlich unauffälligen Farbton zu gestalten“ und nachdem der Adressat das Haus grün angestrichen hatte (und die Verfügung in Bestandskraft gewachsen war) ein Zwangsgeld angedroht. Das Gericht gab der dagegen gerichteten Anfechtungsklage mangels bestimmten Grundverwaltungsakts statt. 


\section{(cc) Vollstreckbarkeit des Grundverwaltungsakts}

1331 Der Verwaltungszwang ist nur zulässig, wenn der Grundverwaltungsakt unanfechtbar oder sofort vollziehbar ist. Die Unanfechtbarkeit tritt mit Ablauf der Rechtsbehelfsfristen ( $\S \S 70,73$ VwGO) ohne Einlegung eines Rechtsbehelfs oder aber mit einer rechtkräftigen ablehnenden Entscheidung über den eingelegten Rechtsbehelf ein. Ein Verwaltungsakt ist sofort vollziehbar, wenn Widerspruch und Anfechtungsklage keine aufschiebende Wirkung haben, vgl. § 80 I 1 VwGO. Die aufschiebende Wirkung kann dabei gesetzlich (§ 80 II 1 Nr. 1-3, S.2 VwGO) oder aber qua behördlicher Anordnung (sog. Anordnung der sofortigen Vollziehbarkeit, § 80 II 1 Nr. 4 VwGO) entfallen (Näheres hierzu in § 8 Rn. 14 ff.).

1332 Examenswissen (Abschleppfälle I): Nicht selten sind Abschleppmaßnahmen Ausgangspunkt vollstreckungsrechtlicher Klausurkonstellationen. Häufig geht es hier um den Wechsel vom gestreckten Verfahren in den sofortigen Vollzug (dazu später unter Rn. 1355). Einstiegstor ist aber die Erkenntnis, dass Verkehrszeichen Allgemeinverfügungen ( $\$ 35 \mathrm{~S} .2 \mathrm{VwVfG}$ ) sind, die wirksam werden, sobald sie so aufgestellt sind, dass sie „ein durchschnittlicher Kraftfahrer bei Einhaltung der nach § 1 StVO erforderlichen Sorgfalt schon mit einem raschen und beiläufigen Blick erfassen kann““2330 (s. hierzu auch Rn. 85, 165). Nach § 80 II 1 Nr. 2 VwGO analog sind sie auch sofort vollziehbar (s. auch § 8 Rn. 17). ${ }^{2331}$

\section{(b) Richtiges Zwangsmittel}

1333 Die Vollzugsbehörde muss das richtige Zwangsmittel gewählt haben (zu den Unterschieden und Voraussetzungen s. oben Rn. 1306ff.). Bei mehreren in Betracht kommenden Zwangsmitteln muss sie ihr Ermessen ordnungsgemäß ausüben. $^{2332}$

\section{(c) Keine Vollstreckungshindernisse}

1334 Vollstreckungshindernisse stehen einer Vollstreckungsmaßnahme entgegen. Sie sind im VwVG nur in Ansätzen geregelt. Allein die Zweckerreichung ist ausdrücklich in $\S 15$ III VwVG normiert. Dies ist beispielsweise der Fall, wenn der Pflichtige zwischenzeitlich seiner Verpflichtung nachgekommen ist. Die Vollstreckung ist dann einzustellen. Gleiches gilt im Falle des Zweckfortfalls wegen Veränderung der tatsächlichen Umstände oder einer neuen Rechtslage ${ }^{2333}$, der

2330 BVerwG, Urt. v. 25.5.2018, Az.: 3 C 25/16 = NJW 2018, 2910.

2331 Schoch, in: Schoch/Schneider/Bier, VwGO, 36. EL Februar 2019, § 80 Rn. 150 f.

2332 Dieser Punkt kann freilich auch erst im Rahmen des Ermessens geprüft werden.

2333 Das Haus, das Gegenstand einer Abrissverfügung war, weil es sich nach alter Rechtslage im Landschaftsschutzgebiet befunden hat, befindet sich nach einer Gesetzesänderung nicht mehr im 
Unmöglichkeit der Zweckerreichung ${ }^{2334}$ oder des durch die Vollzugsbehörde erklärten Vollstreckungsverzichts.

\section{(d) Ermessen, insbesondere Verhältnismäßigkeit}

Die Anwendung des Verwaltungszwangs liegt im Ermessen der Vollzugsbehörde, 1335 welches jedoch gerichtlich auf Ermessensfehler hin überprüfbar ist, § 114 VwGO (Näheres zum Ermessen allgemein unter Rn. 729 ff., 739 ff.). Fehler können sowohl auf Ebene des Entschließungsermessens als auch des Auswahlermessens (bei mehreren Pflichtigen oder mehreren möglichen Zwangsmitteln) bestehen. Insbesondere der in § 9 II VwVG einfach-rechtlich konkretisierte Verhältnismäßigkeitsgrundsatz ist ein wichtiges Korrektiv, an dem sich die Vollstreckungsmaßnahme messen lassen muss.

Examenswissen (Unverhältnismäßigkeit der Vollstreckungsmaßnahme bei erkannter Rechtswidrigkeit der Grundverfügung) ${ }^{2335}$ : Wie bereits an früherer Stelle angedeutet (s. Rn. 1328), kann die Rechtswidrigkeit einer Grundverfügung im Ausnahmefall doch einmal auf die Rechtmäßigkeit der Vollstreckungsmaßnahme durchschlagen. Dies ist dann der Fall, wenn die Behörde einen Grundverwaltungsakt in Kenntnis ihrer Rechtswidrigkeit vollzieht und damit ,sehenden Auges Unrecht vollstreckt“2336. Teilweise findet sich diese Problematik unter dem Schlagwort der „rechtsmissbräuchlichen oder sittenwidrigen Vollstreckung““2337. Eine solche Vollstreckungsmaßnahme ist unverhältnismäßig und damit rechtswidrig. In diesen Fällen muss in der Fallbearbeitung doch einmal ausnahmsweise inzident die Rechtswidrigkeit der Grundverfügung geprüft werden. Dies allein reicht für das Durchschlagen der Rechtswidrigkeit auf die Vollstreckungsebene jedoch noch nicht aus. Hinzukommen muss auf behördlicher Seite ein subjektives Element, auf welches im Sachverhalt hingewiesen werden muss.

\section{bb) Besondere Rechtmäßigkeitsvoraussetzungen der Androhung}

Zwangsmittel müssen im gestreckten Verfahren schriftlich angedroht werden. Die

Androhung ist ein von der Grundverfügung getrennter Verwaltungsakt, der dieser zeitlich nachgehen kann (sog. selbstständige Androhung). Die Androhung kann aber auch mit der Grundverfügung verbunden werden, § 13 II 1 VwVG; sie soll mit ihr verbunden werden, wenn den Rechtsbehelfen gegen die Grundverfügung

Landschaftsschutzgebiet, Beispiel aus: Troidl, in: Engelhardt/App/Schlatmann, VwVG VwZG, 11. Aufl. 2017, § 15 Rn. 9.

2334 Das Haus, das Objekt einer Abrissverfügung war, brennt ab.

2335 Ausführlich Schweikert, Der Rechtswidrigkeitszusammenhang, 2013, S. $196 \mathrm{f}$.

2336 Kingreen/Poscher, Polizei- und Ordnungsrecht, 10. Aufl. 2018, § 24 Rn. 33; Muckel, JA 2012, 272 (277).

2337 Sadler, VwVG VwZG, 9. Aufl. 2014, § 18 Rn. 6; Schweikert, Der Rechtswidrigkeitszusammenhang, 2013, S. 196. 
keine aufschiebende Wirkung zukommt, § 13 II 2 VwVG (sog. unselbstständige Androhung).

1338 Examenswissen (Einwendungen gegen die Grundverfügung im Rahmen der Anfechtung der Zwangsmittelandrohung): Ist die Androhung mit dem Grundverwaltungsakt verbunden (sog. unselbstständige Androhung, §13 II 2 VwVG), so erstreckt sich der Rechtsbehelf gegen die Zwangsmittelandrohung nach § 18 I 2 VwVG auch auf den Grundverwaltungsakt. Es kommt also zu einer gerichtlichen Überprüfung aller möglichen Einwendungen in einem Rechtsschutzverfahren. Prozessual wird dies über die objektive Klagehäufung nach § 44 VwGO erreicht (hierzu $\S 1$ Rn. 251). Freilich steht es dem Betroffenen frei, seinen Rechtsbehelf ausdrücklich auf die Zwangsmittelandrohung zu beschränken. Hat der Betroffene bereits einen Rechtsbehelf gegen den Grundverwaltungsakt eingelegt, so wird dieser durch die spätere Einlegung eines Rechtsbehelfs gegen die Zwangsmittelandrohung nicht berührt. ${ }^{2338}$ Es handelt sich dann um zwei selbstständige Rechtsschutzverfahren.

Ist die Androhung nicht mit dem Grundverwaltungsakt verbunden (sog. selbständige Androhung) und ist dieser unanfechtbar geworden, so sind Einwendungen des Betroffenen, die die Rechtmäßigkeit des Grundverwaltungsaktes betreffen, präkludiert. Der Betroffene kann in diesen Fällen lediglich geltend machen, durch die Androhung selbst in seinen Rechten verletzt zu sein, vgl. $\S 18$ I 3 VwVG. Dies umfasst beispielsweise Einwendungen gegen die Länge der Fristbemessung oder das Fehlen eines wirksamen Grundverwaltungsakts.

\section{(1) Besonderheiten innerhalb der formellen Rechtmäßigkeit}

1339 Die Androhung bedarf zu ihrer Rechtmäßigkeit der Schriftform, § 13 I 1 VwVG. Dies ist innerhalb der formellen Rechtmäßigkeit der Androhung zu prüfen.

\section{(2) Besonderheiten innerhalb der materiellen Rechtmäßigkeit}

1340 In materieller Hinsicht müssen neben den allgemeinen Vollstreckungsvoraussetzungen (oben Rn. 1325ff.) die Voraussetzungen des § $13 \mathrm{VwVG}$ geprüft werden. So muss für die Erfüllung der Verpflichtung eine angemessene Frist bestimmt werden, § 13 I 2 VwVG. Für Duldungs- und Unterlassungspflichten ist eine Fristsetzung regelmäßig entbehrlich, weil deren Erfüllung kein zeitbezogenes Tätigwerden des Adressaten voraussetzt. Nach § 13 III VwVG muss sich die Androhung auf ein bestimmtes Zwangsmittel beziehen. Die gleichzeitige Androhung mehrerer

2338 Deusch/Burr, in: Bader/Ronellenfitsch, VwVG, 43. Ed., Stand: 1.4.2019, VwVG, § 18 Rn. 5. 
möglicher Zwangsmittel ist nach § 13 III 2 VwVG unzulässig (Kumulationsverbot). ${ }^{2339}$

Entscheidet sich die Vollstreckungsbehörde für die Ersatzvornahme, so ist in der Androhung der Kostenbetrag vorläufig zu veranschlagen, § 13 IV 1 VwVG. Entscheidet sich die Vollstreckungsbehörde für das Zwangsgeld, so ist dieses in einer bestimmten Höhe anzudrohen, § 13 V VwVG.

Examenswissen (Androhung „für jeden Fall der Zuwiderhandlung“ gegen ein Verbot zulässig?): Es ist umstritten, ob eine Androhung für ,jeden Fall der Zuwiderhandlung“ gegen ein Verbot ergehen darf. Sieht man darin die Androhung eines Zwangsmittels für jede einzelne Zuwiderhandlung, so lässt sich vertreten, dass eine solche Androhung ,für jeden Fall der Zuwiderhandlung“ zulässig ist. Der Schutzzweck des Kumulationsverbots greife hier nicht ein, denn der Betroffene könne erkennen, was ihm drohe. ${ }^{2340}$ Andere wiederum verneinen die Zulässigkeit einer solchen Androhung, denn darin liege eine gleichzeitige Androhung mehrerer Zwangsmittel ,auf Vorrat“. ${ }^{2341}$ Zulässig sei dies nur, wenn das Gesetz eine solche Androhung „für jeden Fall der Zuwiderhandlung“" vorsehe. Entsprechende gesetzliche Vorgaben finden sich z. B. in § 17 FinDAG, $\S 332$ III 2 AO oder manchen landesrechtlichen Vollstreckungsgesetzen ${ }^{2342}$. Wo eine solche gesetzliche Grundlage fehle, würde eine Androhung „für jeden Fall der Zuwiderhandlung“ gegen den verfassungsrechtlichen Grundsatz des Vorbehalts des Gesetzes verstoßen.

\section{cc) Besondere Rechtmäßigkeitsvoraussetzungen der Festsetzung}

Innerhalb der materiellen Rechtmäßigkeit sind neben den allgemeinen Vollstre- 1342 ckungsvoraussetzung (oben Rn. $1325 \mathrm{ff}$.) folgende Voraussetzungen zu prüfen: Der Festsetzung muss eine wirksame, vollstreckbare Androhung vorausgehen. Auch hier gilt der tragende Grundsatz des Verwaltungsvollstreckungsrechts: Die Rechtmäßigkeit der Festsetzung hängt allein von der Wirksamkeit und Vollstreckbarkeit der Androhung ab, nicht aber von deren Rechtmäßigkeit. ${ }^{2343}$ In der Klausur sind an dieser Stelle daher nur die Wirksamkeitsvoraussetzungen der Androhung (keine Nichtigkeit nach § 44 VwVfG sowie ordnungsgemäße Zustel-

2339 Manche landesrechtlichen Vorschriften lassen hingegen die Androhung mehrerer Zwangsmittel zu, Übersicht bei Troidl, in: Engelhardt/App/Schlatmann, VwVG VwZG, 11. Aufl. 2017, § 13 Rn. 17.

2340 Troidl, in: Engelhardt/App/Schlatmann, VwVG VwZG, 11. Aufl. 2017, §13 Rn. 4.

2341 Deusch/Burr, in: Bader/Ronellenfitsch, VwVG, 43. Ed., Stand: 1.4. 2019, VwVG, § 13 Rn. 22 ff; Sadler, VwVG VwZG, 9. Aufl. 2014, § 13 Rn. 87; BVerwG, Gerichtsbescheid v. 26.6.1997-1 A 10/95 = NVwZ 1998, 393; OVG Berlin-Brandenburg, Beschl.v. 8.6.2011, Az.: OVG 1 B 31/08 = BeckRS 2011, 51745 .

2342 Beispielsweise § 17 VI 2 VwVG Bremen; § 57 III 2 VwVG NRW, § 63 III 2 VwVG RheinlandPfalz.

2343 VGH Kassel, Beschl. v. 4.10.1995, Az.: 4 TG 2043/95 = NVwZ-RR 1996, 715; Troidl, in: Engelhardt/App/Schlatmann, VwVG VwZG, 11. Aufl. 2017, § 14 Rn. 1. 
lung nach $\S 13$ VII VwVG i.V.m. VwZG) zu prüfen. Auf die unter Rn. 1337 ff. dargestellten Rechtmäßigkeitsvoraussetzungen der Androhung kommt es nicht an.

Darüber hinaus darf die Festsetzung erst nach Ablauf der in der Androhung benannten Frist ergehen. Sodann ist zu prüfen, ob sich die Festsetzung im Rahmen der zeitlich vorausgegangenen Androhung bewegt. So darf beispielsweise im Falle eines angedrohten Zwangsgeldes i.H.v. $500 €$ dieses später nicht i.H.v. $750 €$ festgesetzt werden.

1344 Examenswissen (Festsetzung von Zwangsgeld bei Unmöglichkeit eines weiteren Verstoßes gegen die Unterlassungsverfügung?): „Eines der umstrittensten Probleme des Verwaltungsvollstreckungsrechts “2344 betrifft die Frage, ob eine Behörde ein Zwangsgeld auch dann festsetzen darf, wenn zwar gegen die Unterlassungsverfügung verstoßen wurde, ein weiterer Verstoß jedoch nicht (mehr) möglich ist. Regelmäßig wird diese Streitfrage innerhalb der Verhältnismäßigkeit der Festsetzung verortet.

Als Beispielsfall sei folgende Konstellation skizziert: ${ }^{2345}$ Gegen den B ergeht eine sofort vollziehbare Wohnungsverweisung mit einem Rückkehrverbot für zehn Tage unter gleichzeitiger Androhung eines Zwangsgelds i.H.v. $500 €$ für den Fall der Zuwiderhandlung. Drei Tage vor Ablauf des Rückkehrverbots hält sich B verbotswidrig in der Wohnung auf. Einen Monat später setzt die Behörde ein Zwangsgeld von $500 €$ fest. Ist die Zwangsgeldfestsetzung rechtmäßig?

Problematisch ist hier allein die Tatsache, dass B zwar gegen das Verbot verstoßen hat, jedoch zum Zeitpunkt der Festsetzung ein weiterer Verstoß unmöglich war, da das Rückkehrverbot zeitlich befristet war.

Nach einer Ansicht ist eine Zwangsgeldfestsetzung in diesem Falle unzulässig. Denn wenn gegen ein Verbot nicht mehr verstoßen werden könne, so könne der Festsetzung auch keine Beugewirkung zukommen. ${ }^{2346}$ Es ginge dann nicht mehr darum, den Pflichtigen zur Rechtstreue anzuhalten, sondern seinen vorherigen Rechtsbruch abzustrafen. Ein solcher Strafcharakter sei dem Verwaltungsvollstreckungsrecht jedoch fremd, weshalb eine Zwangsgeldfestsetzung in diesen Fällen rechtswidrig sei.

Eine andere Ansicht stellt die Festsetzung in einen weiteren Zusammenhang mit der ihr vorausgegangen Androhung. ${ }^{2347}$ Wäre dem Betroffenen im Zeitpunkt der Androhung klar, dass im Falle der Zuwiderhandlung gegen das Unterlassungsgebot ein Zwangsgeld gar nicht festgesetzt werden könne, so würde die Androhung ihrer Beugewirkung verlustig gehen. Gerade bei zeitlich eng begrenzten Verboten wie im Falle eines zehntätigen Rückkehrverbots würde die Androhung von Zwangsgeld nicht mehr geeignet sein, den Betroffenen zur Rechtstreue anzu-

2344 App, JuS 2004, 786 (791).

2345 So der Ausgangsfall in OVG Münster, Urt. v. 9.2.2012, Az.: 5 A 2151/10.

2346 OVG Lüneburg, Beschl. v. 23.4.2009, Az.: 11 ME 478/08; Dünchheim, NVwZ 1996, 117.

2347 OVG Münster, Urt. v. 9.2.2012, Az.: 5 A 2151/10; App, JuS 2004, 786 (791); Baumeister, in: Schenke/Graulich/Ruthig, Sicherheitsrecht des Bundes, VwVG, 2. Aufl. 2019, § 15 Rn. 16; Graulich, in: Lisken/Denninger, Handbuch des Polizeirechts, 6. Aufl. 2018, E Rn. 912 ff.; Muckel, JA 2012, 272 (278). Teilweise wird die Problematik auch innerhalb der Vollstreckungshindernisse (insbesondere unter der Zweckerreichung bzw. des Zweckfortfalls) diskutiert, s. Lemke, Verwaltungsvollstreckungsrecht des Bundes und der Länder, 1997, S. $232 \mathrm{ff}$. 
mahnen und ihm Konsequenzen für den Fall der Zuwiderhandlung in Aussicht stellen. Dies hätte zur Folge, dass zur effektiven Durchsetzung des Verwaltungsakts nicht mehr das Zwangsgeld, sondern nur noch die Anwendung unmittelbaren Zwangs zum Ziel führte. Dies wiederum verkehre aber das vom Gesetzgeber vorgezeichnete Subsidiaritätsverhältnis des unmittelbaren Zwangs zu den anderen Zwangsmitteln in sein Gegenteil, vgl. \&12 VwVG. Der nachträglichen Zwangsgeldfestsetzung käme daher aufgrund ihres Zusammenwirkens mit der Androhung eine „fortbestehende mittelbare Beugefunktion ${ }^{\text {“2348 }} \mathrm{zu}$. Ohne die daraus folgende nachträgliche Festsetzungsbefugnis könne der Betroffene nahezu risikolos gegen Unterlassungspflichten verstoßen. Dies zeigt sich insbesondere dann, wenn der Betroffene durch den Verstoß Fakten schafft und dadurch die Fortgeltung der Unterlassungspflicht selbst beendet (z.B. pflichtwidriger Abriss eines denkmalgeschützten Hauses oder verbotswidrige Fällung eines Baumes). ${ }^{2349}$

\section{d) Sofortiger Vollzug, § 6 II VwVG}

Nach § 6 II VwVG kann Verwaltungszwang auch ohne vorausgehenden Verwal- 1345 tungsakt angewendet werden, wenn der sofortige Vollzug zur Verhinderung einer rechtswidrigen Tat, die einen Straf- oder Bußgeldtatbestand verwirklicht oder zur Abwendung einer drohenden Gefahr notwendig ist und die Behörde hierbei innerhalb ihrer gesetzlichen Befugnisse handelt. Der sofortige Vollzug findet vor allem im Gefahrenabwehrrecht Anwendung, denn hier besteht nicht selten ein zeitlicher Handlungsdruck für die Behörde, dem das mehraktige gestreckte Verfahren nicht angemessen Rechnung tragen kann.

Beispiel: Ein Baum auf dem Grundstück des S droht jeden Augenblick auf die Straße zu stürzen. Die Behörde lässt ihn durch einen beauftragten Dritten fällen. ${ }^{2350}$

Für den sofortigen Vollzug nicht untypisch ist auch, dass der Verpflichtete nicht 1346 rechtzeitig ermittelt oder erreicht werden kann, sodass ihm gegenüber gar kein Grundverwaltungsakt ergehen kann.

Beispiel: Die Behörde lässt einen Verstorbenen, dessen bestattungspflichtige Angehörige zunächst nicht bekannt sind, durch ein Bestattungsunternehmen beisetzen. ${ }^{2351}$

Die Anwendung von Zwangsmitteln im sofortigen Vollzug ist ein Realakt. Pro- 1347 zessual wird der sofortige Vollzug aber wie ein Verwaltungsakt behandelt, denn

2348 OVG Münster, Urt. v. 9.2.2012, Az.: 5 A 2152/10, Rn. 38.

2349 Beispiele aus OVG Münster, Urt. v. 9.2.2012, Az.: 5 A 2152/10, Rn. 35.

2350 Beispiel aus Muckel, JA 2012, 355 (347).

2351 Beispiel aus Sadler, VwVG VwZG, 9. Aufl. 2014, § 6 Rn. 337. 
$\S 18$ II VwVG ordnet als Rechtsbehelfe Widerspruch und Anfechtungsklage an. ${ }^{2352}$

1348 Auch der sofortige Vollzug ist in dem für das Verwaltungsrecht typischen Dreischritt Ermächtigungsgrundlage - formelle Rechtmäßigkeit - materielle Rechtmäßigkeit zu prüfen.

\section{aa) Ermächtigungsgrundlage}

1349 Ermächtigungsgrundlage für den sofortigen Vollzug ist § 6 II VwVG. Optional kann auch hier das jeweils einschlägige Zwangsmittel mitzitiert werden (§§ 9 I lit. x, $10-12 \mathrm{VwVG}$ ).

1350 An dieser Stelle kann in der Fallbearbeitung die Abgrenzung zwischen sofortigem Vollzug und der polizeirechtlichen unmittelbaren Ausführung verlangt werden. Die unmittelbare Ausführung ist in mehreren Bundesländern im Sicherheits- und Ordnungsgesetz normiert und erlaubt der Polizei eine Maßnahme selbst oder durch einen Beauftragten unmittelbar auszuführen, wenn der Zweck der Maßnahme durch Inanspruchnahme der Verantwortlichen nicht oder nicht rechtzeitig erreicht werden kann. ${ }^{2353}$ Die Ähnlichkeit beider Institute basiert auf der Dringlichkeit, mit der die jeweilige Maßnahme auszuführen ist. Wenig verwunderlich ist es daher, dass der sofortige Vollzug und die unmittelbare Ausführung in ihren Rechtsmäßigkeitsvoraussetzungen nahezu deckungsgleich sind. ${ }^{2354}$ Dennoch darf nicht übersehen werden, dass der sofortige Vollzug Verwaltungsvollstreckungsrecht, die unmittelbare Ausführung hingegen materielles Polizeirecht ist.

1351 Deshalb ist in Ländern, die beide Institute vorsehen, das eine vom anderen abzugrenzen. ${ }^{2355}$ Teilweise wird diese Abgrenzung über den Vorrang der unmittelbaren Ausführung vorgenommen. ${ }^{2356}$ Eine andere Ansicht tritt diesem lex specialis-Verhältnis mit Verweis auf die Unterschiedlichkeit der Regelungsgebiete

2352 Sadler, VwVG VwZG, 9. Aufl. 2014, § 6 Rn. 279, § 18 Rn. 12; da regelmäßig keine Rechtsbehelfsbelehrung erfolgt ist, gilt die Jahresfrist nach $\S 58$ II VwGO.

2353 Baden-Württemberg: § 8 PolG; Bayern: Art. 9 PAG; Berlin: § 15 ASOG; Hamburg: § 7 SOG; Hessen: § 8 HSOG; Rheinland-Pfalz: § 6 POG; Sachsen: § 6 PolG; Sachsen-Anhalt: § 9 SOG; Thüringen: § 9 PAG.

2354 Poscher/Rusteberg, JuS 2012, 26 (29).

2355 Ausführlich Lemke, Verwaltungsvollstreckungsrecht des Bundes und der Länder, 1997, S. $200 \mathrm{ff}$.

2356 Kaniess, LKV 2013, 401; Kingreen/Poscher, Polizei- und Ordnungsrecht, 10. Aufl. 2018, § 24 Rn. 43; Muckel, JA 2012, 272, (275); Poscher/Rusteberg, JuS 2012, 26 (29); Schoch, in: Schoch, Besonderes Verwaltungsrecht, 2018, Kap. 1 Rn. 936.

Mariamo Katharina Ilal 
(einerseits Vollstreckungsrecht, andererseits Polizeirecht) entgegen. ${ }^{2357}$ Während das Vollstreckungsrecht davon ausgehe, dass es bei dem Verpflichteten zu einer Willensbeugung kommt, solle die unmittelbare Ausführung darauf aufbauen, dass der Verantwortliche an sich seiner Pflicht nachkommen möchte und die Behörde lediglich anstelle seiner tätig wird, ohne dass es einer Willensbeugung bedarf. Ist der Verantwortliche nicht vor Ort und sein tatsächlicher Wille nicht ermittelbar, so soll nach dieser Ansicht auf die mutmaßliche Willensbeugung abzustellen sein. Wird der (mutmaßliche) Wille des Verpflichteten durch die Maßnahme gebeugt, handele es sich um eine Maßnahme nach § 6 II VwVG; andernfalls sei die landesrechtliche Vorschrift zur unmittelbaren Ausführung einschlägig.

In der Klausur wird von den Bearbeiterinnen und Bearbeitern verlangt, dass sie das Abgrenzungsproblem erkennen (freilich nur, wenn das jeweilige Landesrecht neben dem sofortigen Vollzug auch die unmittelbare Ausführung normiert), sich je nach Argumentationslinie für das eine oder das andere Institut entscheiden und dieses dann in seinen Voraussetzungen konsequent durchprüfen.

\section{bb) Formelle Rechtmäßigkeit}

Nach $§ 7$ VwVG gilt der Grundsatz der Selbstvollstreckung durch die Ausgangs-

behörde. Da im Falle des sofortigen Vollzugs regelmäßig kein Grundverwaltungsakt erlassen wurde, ist $\S 7 \mathrm{VwVG}$ dahingehend zu modifizieren, dass diejenige Behörde zuständig ist, die einen entsprechenden Grundverwaltungsakt hätte erlassen können. Da der sofortige Vollzug ein Realakt ist, bedarf es schon nach § 28 I VwVfG keiner Anhörung.

\section{cc) Materielle Rechtmäßigkeit}

Der Wortlaut des § 6 II VwVG geht davon aus, dass dem sofortigen Vollzug kein 1354 Grundverwaltungsakt vorausgeht. Dennoch gibt es Konstellationen, in denen ein Zwangsmittel trotz vorhandener Grundverfügung sofort und mithin ohne Durchlaufen des gestreckten Verfahrens angewendet wird (s. Rn. 1355). Der sofortige Vollzug setzt einen Dringlichkeitstatbestand voraus (s. Rn. 1357 ff.). Zudem muss die hypothetische Grundverfügung rechtmäßig sein, die Behörde also innerhalb ihrer gesetzlichen Befugnisse handeln (s. Rn. 1361). Darüber hinaus muss das

2357 Schenke, Polizei- und Ordnungsrecht, 10. Aufl. 2018, Rn. 564; VG Berlin, Urt. v. 19.6.2013, Az.: 14 K 34.13. 
richtige Zwangsmittel gewählt worden sein (Rn. 1362ff.) und die Maßnahme ermessensfehlerfrei und insbesondere verhältnismäßig sein (Rn. 1365).

\section{(1) Ohne vorausgehenden Verwaltungsakt}

1355 Wie bereits angedeutet, geht der Wortlaut des § 6 II VwVG davon aus, dass der sofortige Vollzug ohne vorausgehenden Verwaltungsakt ergeht. Dem Gesetzgeber standen hierbei Fallkonstellationen vor Augen, in denen der Verpflichtete nicht (rechtzeitig) ermittelbar oder erreichbar ist und deshalb der Handlungsdruck der Behörde ausgelöst wird. Es sei an das oben genannte Beispiel (s. Rn. 1346) des zu bestattenden Verstorbenen gedacht, dessen Angehörige zunächst nicht bekannt sind.

Indes gibt es auch Fallkonstellationen, in denen „der Grundverwaltungsakt zwar bereits erlassen wurde, aber die weiteren Voraussetzungen des gestuften Vollstreckungsverfahrens wegen plötzlich auftretender Eilbedürftigkeit nicht eingehalten werden können“2358. Hier kann das oben genannte Beispiel des umsturzgefährdeten Baumes (s. Rn. 1345) unter leichter Modifikation bemüht werden: ${ }^{2359}$ Der Baum auf dem Grundstück des S droht langsam auf die Straße zu kippen. Die Behörde gibt dem S daher unter Anordnung der sofortigen Vollziehbarkeit und unter Androhung eines Zwangsgeldes auf, den Baum innerhalb von 2 Wochen $\mathrm{zu}$ fällen. Noch vor Fristablauf weht ein starker Orkan über die Stadt, welcher den Baum fast vollständig entwurzelt. Er droht nun jeden Augenblick auf die Straße zu kippen. Die Behörde lässt ihn durch einen Dritten fällen. In einem solchen Fall besteht ein dringlicher Handlungsdruck, dem das mehraktige gestreckte Verfahren nicht gerecht wird. Im Sinne einer effektiven Gefahrenabwehr muss es der Vollzugsbehörde möglich sein, die Verpflichtung trotz vorausgehenden Verwaltungsakts sofort zu vollziehen. Ein solcher Übergang vom gestreckten Verfahren in den sofortigen Vollzug ist nach § 6 II VwVG analog möglich (sog. abgekürztes Verfahren). ${ }^{2360}$ Freilich muss sich die Vollstreckungsmaßnahme dann auch an den Rechtmäßigkeitsvoraussetzungen des sofortigen Vollzuges

2358 Deusch/Burr, in: Bader/Ronellenfitsch, VwVG, 43. Ed., Stand: 1.4. 2019, § 6 Rn. 25.

2359 Beispiel aus Muckel, JA 2012, 355, (358).

2360 Alternative Bezeichnungen und Herleitungen in Maurer/Waldhoff, Allgemeines Verwaltungsrecht, 19. Aufl. 2017, § 20 Rn. 27: „verkürztes Verfahren“, in Schweikert, Der Rechtswidrigkeitszusammenhang, 2013, S. 49: „abgekürztes Verfahren“, in Lemke, Verwaltungsvollstreckungsrecht des Bundes und der Länder, 1997, S. 125: „erleichtertes Verfahren“. 
messen lassen. Insbesondere muss hier die Grundverfügung (anders als im gestreckten Verfahren) rechtmäßig sein (dazu sogleich unter Rn. 1361). ${ }^{2361}$

Examenswissen (Abschleppfälle II): Auch die Abschleppfälle laufen häufig - sofern sie sich nach Vollstreckungsrecht richten - über § 6 II VwVG in analoger Anwendung. Denn regelmäßig wird ein Abschleppvorgang dadurch ausgelöst, dass ein Fahrzeug in einem durch ein Verkehrsschild ausgewiesenem Halteverbot steht. Soweit das Schild sichtbar aufgestellt ist, liegt eine wirksame Grundverfügung vor, die nach § 80 II 1 Nr. 2 VwGO analog sofort vollziehbar ist (dazu bereits oben Rn. 1332). Dennoch bietet sich ein Vorgehen im gestreckten Verfahren meist nicht an, beispielsweise weil das Fahrzeug eine Feuerwehreinfahrt blockiert oder den Straßenverkehr oder anstehende Baumarbeiten behindert und deshalb umgehend entfernt werden muss. Auch hier wird daher häufig trotz vorhandener Grundverfügung nicht im gestreckten Verfahren, sondern unter den Voraussetzungen des § 6 II VwVG analog vollstreckt.

\section{(2) Dringlichkeitstatbestand}

Die Voraussetzung der Dringlichkeit erklärt sich vor dem bereits angesprochenen zeitlichen Hintergrund des sofortigen Vollzugs. Er umfasst Fallkonstellationen, aber eben auch nur solche Fallkonstellationen, in denen die mit dem gestreckten Verfahren einhergehende zeitliche Verzögerung zur Durchsetzung der Rechtspflicht nicht in Kauf genommen werden kann.

Nach $\S 6$ II Fall 1 VwVG muss der sofortige Vollzug zur Verhinderung einer rechtswidrigen Tat, die einen Straf- oder Bußgeldtatbestand verwirklicht, notwendig sein. Maßgeblich ist, dass die Verwirklichung des objektiven Tatbestandes unmittelbar und mit an Sicherheit grenzender Wahrscheinlichkeit bevorsteht. Ein schuldhaftes Handeln ist nicht erforderlich.

Nach § 6 II Fall 2 VwVG muss der sofortige Vollzug zur Abwendung einer 1359 drohenden Gefahr notwendig sein. „Unter Gefahr ist eine Sachlage zu verstehen, die bei ungehindertem Ablauf des Geschehens mit hinreichender Wahrscheinlichkeit zu einem Schaden für die Schutzgüter der öffentlichen Sicherheit oder

2361 Lemke, Verwaltungsvollstreckungsrecht des Bundes und der Länder, 1997, S. 223f.; anders Schweikert, die bereits die analoge Anwendbarkeit des § 6 II VwVG auf Fallkonstellationen mit ergangener Grundverfügung in Frage stellt: Schweikert, Der Rechtswidrigkeitszusammenhang, 2013, S. 193 f. Interessanterweise schweigt die Ausbildungsliteratur zur Frage, ob das abgekürzte Verfahren einen Rechtswidrigkeitszusammenhang voraussetzt oder nicht. Vertiefende Ausführungen sind daher auf rechtswissenschaftlicher Ebene von großem Interesse, sollten jedoch nicht Eingang in eine Fallbearbeitung finden. Vielmehr lässt sich sehr gut vertreten, dass eine analoge Anwendung des § 6 II VwVG auch eine analoge Anwendung all seiner Rechtmäßigkeitsvoraussetzungen (inklusive der Rechtmäßigkeit der Grundverfügung) nach sich zieht, sodass die Erforderlichkeit eines Rechtswidrigkeitszusammenhangs zu bejahen ist. Diese Herangehensweise bringt zudem den Vorteil, dass durch die nun folgende inzidente Prüfung der Grundverfügung keine Punkte vergeben werden. 
Ordnung führen würde.“2362 Dies ist jedenfalls dann nicht der Fall, wenn der Erlass einer Ordnungsverfügung gegen den der Behörde bekannten Ordnungspflichtigen unter Anordnung der sofortigen Vollziehung und gleichzeitiger Androhung der Ersatzvornahme zwar zu kurzfristigen Verzögerungen führte, diese aber die Wirksamkeit der erforderlichen Maßnahme weder aufheben noch wesentlich beeinträchtigen würde. ${ }^{2363}$ Die Vollzugsbehörde ist also dazu angehalten, das vom Gesetz vorgegebene Regel-Ausnahme-Verhältnis zwischen § 6 I und § 6 II VwVG ernst zu nehmen. Justiziabel wird dies durch das Dringlichkeitserfordernis, welches gerichtlich voll überprüfbar ist. Der Vollzugsbehörde kommt insofern kein Beurteilungsspielraum zu.

1360 Wie im materiellen Polizeirecht bedeutet Gefahr i.S.d. § 6 II VwVG nicht allein die objektiv vorliegende Gefahr bei ex post-Betrachtung (ausführlich zum Gefahrbegriff unter Rn. $1101 \mathrm{ff}$.). Auch die sog. Anscheinsgefahr, also eine Gefahrenlage, die zwar nicht objektiv vorliegt, aber aus der ex-ante-Sicht eines Betrachters, der die „Sorgfalt, Klugheit und Besonnenheit eines typischen Beamten an den Tag legt“2364 gegeben ist, berechtigt die Behörde zum Einschreiten nach § 6 II VwVG. ${ }^{2365}$ Gleiches gilt für den Gefahrenverdacht: Auch hier darf die Behörde Maßnahmen zur Gefahrenerforschung nach § 6 II VwVG vornehmen. ${ }^{2366}$ Die Frage, ob die Anscheinsgefahr oder der Gefahrenverdacht von dem Verpflichteten in zurechenbarer Weise gesetzt worden ist, spielt für die Frage der Rechtmäßigkeit der Vollzugsmaßnahme keine Rolle. Anderes gilt auf Kostenebene (hierzu sogleich unter Rn. 1382). Von Anscheinsgefahr und Gefahrenverdacht ist freilich die Scheingefahr zu unterscheiden (s. auch Rn. 1108). ${ }^{2367}$ Hierbei liegt weder objektiv eine Gefahrenlage vor, noch würde ein Betrachter mit den Fähigkeiten eines ty-

2362 Deusch/Burr, in: Bader/Ronellenfitsch, VwVG, 43. Ed., Stand: 1.4. 2019, § 6 Rn. 23.

2363 OVG Münster, Beschl.v. 9.4.2008 - 11 A 1386/05 = NVwZ-RR 2008, 437: Im vorliegenden Fall ließ die Behörde einen nicht akut einsturzgefährdeten Wetterschacht auf dem Grundstück der Betroffenen im Wege der Ersatzvornahme im sofortigen Vollzug sichern. Dass der Wetterschacht sicherungsbedürftig war, wenngleich keine akute Gefahr eines Einsturzes bestand, hatte die Behörde erkannt. Das Gericht gab der Klage der Betroffenen gegen den daraufhin ergangenen Kostenbescheid statt und urteilte, dass der sofortige Vollzug in diesem Fall nicht dringlich gewesen ist. Die Behörde hätte vielmehr Zeit gehabt, der Betroffenen durch sofort vollziehbaren Verwaltungsakt aufzugeben, den Schacht zu sichern und gleichzeitig die Ersatzvornahme anzudrohen. Die damit einhergehende zeitliche Verzögerung hätte die Wirksamkeit der zu vollziehenden Pflicht nicht beeinträchtigt, da der Schacht nicht akut einsturzgefährdet war.

2364 Kingreen/Poscher, Polizei- und Ordnungsrecht, 10. Aufl. 2018, § 8 Rn. 48.

2365 Sadler, VwVG VwZG, 9. Aufl. 2014, § 6 Rn. 315.

2366 Sadler, VwVG VwZG, 9. Aufl. 2014, § 6 Rn. 316.

2367 Kingreen/Poscher, Polizei- und Ordnungsrecht, 10. Aufl. 2018, § 8 Rn. 63; Sadler, VwVG VwZG, 9. Aufl. 2014, § 6 Rn. 322. 
pischen Beamten von einer solchen ausgehen. Eine dagegen gerichtete Maßnahme ist mangels Dringlichkeit rechtswidrig und kann ggf. zu Folgeansprüchen des Betroffenen gegen die Vollzugsbehörde führen.

\section{(3) Rechtmäßigkeit der hypothetischen Grundverfügung}

Ausweislich des Wortlauts von § 6 II VwVG muss die Vollzugsbehörde innerhalb ihrer gesetzlichen Befugnisse handeln. Dies tut sie nur dann, wenn die hypothetisch zu erlassene Grundverfügung rechtmäßig ist. Anders als im gestreckten Verfahren gibt es im sofortigen Vollzug also einen Rechtswidrigkeitszusammenhang: Ist die hypothetische Grundverfügung rechtswidrig, so ist es auch die entsprechende Vollzugsmaßnahme. Mangels vorausgehendem Grundverwaltungsakt gibt es auch keine Titelfunktion, die zum Entfall des Rechtswidrigkeitszusammenhangs führen könnte. Diese Rechtmäßigkeitsvoraussetzung des sofortigen Vollzugs dient in der Fallbearbeitung häufig als Einstiegstor in eine nicht selten umfangreiche Inzidentprüfung der hypothetischen Grundverfügung. Die Prüfung erfolgt im bekannten Dreischritt Ermächtigungsgrundlage - formelle Rechtmäßigkeit - materielle Rechtmäßigkeit. Dabei gilt es, den Überblick über den Aufbau zu behalten und dem Korrektor oder der Korrektorin zu zeigen, dass man die Ebenen auseinanderhalten kann.

\section{(4) Zwangsmittel}

Die Behörde muss das richtige Zwangsmittel gewählt haben. Während § 6 II VwVG diesbezüglich keine Einschränkungen vorsieht, kommen in der Praxis als Zwangsmittel nur die Ersatzvornahme und der unmittelbare Zwang in Betracht. ${ }^{2368}$ Dies liegt daran, dass der sofortige Vollzug auf die unmittelbare Herbeiführung des Erfolges gerichtet ist, das Zwangsgeld und dessen Beitreibung jedoch durch seine Beugewirkung auf ein Tätigwerden des Verpflichteten abzielt.

Unter Umständen müssen an dieser Stelle besondere Voraussetzungen des Zwangsmittels geprüft werden. Beispielsweise muss der Einsatz von Schusswaffen, Explosivmitteln und Wasserwerfern - auch wenn er im sofortigen Vollzug geschieht - angedroht werden, vgl. § 13 UZwG. ${ }^{2369}$

2368 Deusch/Burr, in: Bader/Ronellenfitsch,VwVG, 43. Ed., Stand:1.4. 2019, § 6 Rn. 26; Erichsen/ Rauschenberg, JURA 1998, 31 (41); Sadler, VwVG VwZG, 9. Aufl. 2014, § 6 Rn. 301.

2369 Ausführlich zum Schusswaffengebrauch Graulich, in: Lisken/Denninger, Handbuch des Polizeirechts, 6. Aufl. 2018, E Rn. $916 \mathrm{ff}$. 
1364 Examenswissen (Zulässigkeit des finalen Rettungsschusses): Die Frage nach der Zulässigkeit des finalen Rettungsschusses als Fall einer Anwendung unmittelbaren Zwangs ist umstritten. ${ }^{2370}$ Der finale Rettungsschuss ist ein Schuss, der mit an Sicherheit grenzender Wahrscheinlichkeit tödlich wirken wird.

Uneinigkeit besteht bereits hinsichtlich seiner verfassungsrechtlichen Zulässigkeit. Ankerpunkte der verfassungsrechtlichen Diskussion sind dabei die Menschenwürde aus Art. 1 I GG, das Verbot der Todesstrafe nach Art. 102 GG sowie die Wesensgehaltgarantie gem. § 19 II GG in Bezug auf das Recht aus Leben aus Art. 2 II 1 GG. Diskussionswürdig ist auch die Zulässigkeit des finalen Rettungsschuss mit Blick auf Art. 2 EMRK. Geht man - wie die wohl herrschende Meinung - von der verfassungsrechtlichen Zulässigkeit des finalen Rettungsschusses aus, so stellt sich die Folgefrage über die Notwendigkeit einer expliziten gesetzlichen Grundlage. Mittlerweise ist der finale Rettungsschuss in fast allen Bundesländern normiert. Eine entsprechende Ermächtigungsgrundlage fehlt jedoch in Berlin, Mecklenburg-Vorpommern und Schleswig-Holstein sowie auf Bundesebene. Hier dürfen Schusswaffen nur eingesetzt werden, um Personen angriffs- oder fluchtunfähig zu machen. Teilweise wird vertreten, dass die Tötung eines Angreifers die schwerwiegendste Form der „Angriffsunfähigkeit“ darstelle und der finale Rettungsschuss deshalb auch ohne explizite gesetzliche Regelung zulässig sei. ${ }^{2371}$ Dem wird jedoch entgegengehalten, dass die in Rede stehenden Gesetze Art. 2 II 1 GG nicht als durch eben jenes Gesetz eingeschränktes Grundrecht nennen und somit ein Verstoß gegen das Zitiergebot nach Art. 19 I 2 GG vorläge. Zudem setze die „Angriffs- und Fluchtunfähigkeit“ eine lebende Person voraus. ${ }^{2372}$ Auch würde die Subsumtion des finalen Rettungsschuss unter die Ermächtigungsgrundlagen zur „Angriffs- und Fluchtunfähigkeit“ dem verfassungsrechtlichen Grundsatz des Vorbehalts des Gesetzes nicht Genüge tun. ${ }^{2373}$ Nach letztgenannter Ansicht ist der finale Rettungsschuss in Ländern ohne explizite Regelung sowie auf Bundesebene unzulässig. Dies lässt freilich die Möglichkeit des Entfalls der strafrechtlichen Verantwortlichkeit des Beamten nach §§ 32, 34 StGB unberührt. ${ }^{2374}$

\section{(5) Ermessen, insbesondere Verhältnismäßigkeit}

1365 Auch die Zwangsmittelanwendung im Rahmen des sofortigen Vollzuges darf keine Ermessensfehler enthalten. Insbesondere muss sie verhältnismäßig sein. Steht beispielsweise ein Auto verbotswidrig im Halteverbot, liegt an der Frontscheibe aber ein gut sichtbarer Hinweis mit Namen und Handynummer des

2370 Ausführlich Graulich, in: Lisken/Denninger, Handbuch des Polizeirechts, 6. Aufl. 2018, E Rn. $950 \mathrm{ff}$.

2371 Zum Meinungsstand und für weitere Nachweise wird auf Thiel, in: Möstl/Kugelmann, Polizei- und Ordnungsrecht NRW, 11. Ed., Stand: 1.11.2018, § 63 Rn. 13 verwiesen.

2372 Schenke, Polizei- und Ordnungsrecht, 10. Aufl. 2018, Rn. 561; ähnlich Graulich, in: Lisken/ Denninger, Handbuch des Polizeirechts, 6. Aufl. 2018, E Rn. 971; Ruthig, in: Schenke/Graulich/ Ruthig, Sicherheitsrecht des Bundes, UZwG, 2. Aufl. 2019, § 12 Rn. 6.

2373 Schenke, Polizei- und Ordnungsrecht, 10. Aufl. 2018, Rn. 561.

2374 Dies gilt jedenfalls, soweit man dem Hoheitsträger ein Notwehrrecht zubilligt; detailliert zum Streitstand Erb, in: MüKO-StGB, 3. Aufl. 2017, § 32 Rn. 186ff.

\section{Mariamo Katharina Ilal}


Fahrers, so muss die Vollzugsbehörde jedenfalls versuchen, den Fahrer zu kontaktieren, bevor sie das Auto abschleppen lässt. ${ }^{2375}$

\section{e) Sekundärebene, insbesondere Kosten}

Regelmäßig ist nicht die Vollstreckungsmaßnahme selbst, sondern der daraufhin 1366 ergehende Kostenbescheid Ausgangspunkt der Fallbearbeitung. Die Frage, wer die Kosten für die erfolgte Vollstreckungsmaßnahme zu tragen hat, ist auf der sog. Sekundärebene ${ }^{2376}$ verankert. Für die Fallbearbeitung ist entscheidend, dass die Ebenen Grundverfügung - Vollstreckungsmaßnahme - Kosten innerhalb des Aufbaus und der Prüfung strikt auseinandergehalten werden. Darin besteht meist schon die erste Hürde einer vollstreckungsrechtlich eingekleideten Klausur.

Neben den Kostenansprüchen der Behörde gegen den Pflichtigen umfasst 1367 die Sekundärebene auch die ggf. bestehenden Entschädigungsansprüche des Pflichtigen oder Dritter gegen die Vollzugsbehörde. Diese stellen die „Kehrseite der Kostenansprüche“ ${ }^{2377}$ dar und werden ausführlich in $\S 5$ Rn. 153 ff. dargestellt.

Kostenansprüche der Vollzugsbehörde sind das „Surrogat für die dem Verantwortlichen eigentlich obliegende Pflicht zur Gefahrenbeseitigung auf eigene Rechnung“2378. Die wichtigsten Kosten sind die bei der Durchführung der Vollstreckung entstandenen Kosten (sog. Auslagen, vgl. §344 AO). Dies sind insbesondere Aufwendungen, die die Behörde gegenüber Dritten getätigt hat. ${ }^{2379}$ Die Kosten werden durch schriftlichen Verwaltungsakt in Form eines Kostenbescheids geltend gemacht. Dieser kann dann wiederum im Wege der Beitreibung nach $\S \S 1-5 b$ VwVG vollstreckt werden.

Gegen den Kostenbescheid sind Widerspruch und Anfechtungsklage statthafte Rechtsbehelfe.

Examenswissen (Aufschiebende Wirkung der Rechtsbehelfe gegen den Kostenbescheid?): Mitunter wird diskutiert, ob Rechtsbehelfe gegen den Kostenbescheid nach erfolgter Verwaltungsvollstreckung aufschiebende Wirkung haben. Dem Wortlaut nach unterfallen sie § 80 II 1 Nr. 1 VwGO (Anforderungen von öffentlichen Abgaben und Kosten), sodass von einem Entfall der aufschiebenden Wirkung qua Gesetz auszugehen wäre. Sinn und Zweck des § 80 II 1 Nr. 1 VwGO ist

2375 Beispiel aus Erichsen/Rauschenberg, JURA 1998, 31 (41); anderes kann freilich wiederum gelten, wenn das Auto die Feuerwehrzufahrt zu einem brennenden Haus blockiert. Es muss wie immer eine Einzelfallbetrachtung vorgenommen werden.

2376 Je nachdem, wie die vorausgehenden Ebenen gezählt werden, findet sich auch der Begriff der „Tertiärebene“, vgl. Voßkuhle/Wischmeyer, JuS 2016, 698 (700).

2377 Poscher/Rusteberg, JuS 2012, 26 (32).

2378 Werner, JA 2000, 902 (908).

2379 Poscher/Rusteberg, JuS 2012, 26 (30).

Mariamo Katharina Ilal 
die Sicherung einer ordnungsgemäßen Haushaltsführung und eines stetigen Finanzmittelflusses an die Verwaltung. Die ihr zufließenden Mittel sollen für die Verwaltung kalkulierbar sein. Wann die Verwaltung im Wege des Verwaltungszwangs vorgehen muss, ist jedoch nicht vorhersehbar. Das Gleiche gilt für die dadurch entstehenden Kostenansprüche, weshalb sie für die Verwaltung sowieso nicht kalkulierbar sind und damit auch nicht die ratio der Haushaltssicherung treffen. Deshalb ist $\S 80$ II 1 Nr. 1 VwGO nach herrschender Meinung dahingehend teleologisch zu reduzieren, dass Kostenansprüche infolge von Vollstreckungsmaßnahmen nicht unter den Tatbestand fallen. ${ }^{2380}$ Auch unter $\S 80$ II S. 2 VwGO i.V.m. den landesrechtlichen Vorschriften, die die aufschiebende Wirkung für Maßnahmen in der Verwaltungsvollstreckung entfallen lassen, können die kostenrechtlichen Verfügungen nicht subsumiert werden. Denn es handelt sich hier um Maßnahmen die nach und nicht in der Verwaltungsvollstreckung ergehen. Somit haben Rechtsbehelfe gegen die Kostenbescheide regelmäßig aufschiebende Wirkung. Etwas anderes gilt freilich, wenn die Behörde die sofortige Vollziehbarkeit nach § 80 II 1 Nr. 4 VwGO anordnet.

\section{aa) Ermächtigungsgrundlage}

1371 Für die Erhebung von Kosten für durchgeführte Vollstreckungsmaßnahmen bedarf es einer gesetzlichen Grundlage. In der Klausur wird hier regelmäßig auf § 19 I VwVG abzustellen sein. ${ }^{2381}$ Danach können für Amtshandlungen nach dem VwVG (mithin Vollstreckungsmaßnahmen) Kosten erhoben werden. Das Gesetz enthält hier auch die Befugnis zur Geltendmachung der Kosten im Wege des Verwaltungsakts (vgl. § 19 I VwVG: werden erhoben), sodass sich die Vollzugsbehörde nicht auf den Klageweg verweisen lassen muss. ${ }^{2382}$

1372 Auch innerhalb der Ermächtigungsgrundlage des Kostenbescheids kann die oben besprochene Abgrenzung von unmittelbarer Ausführung und sofortigem Vollzug relevant werden (s. Rn. 1350 ff.). Hier setzt sich die Parallelität beider Institute fort. So ist für den Kostenbescheid nach sofortigem Vollzug auf § 19 I VwVG abzustellen, während die landesrechtlichen Polizeigesetze eigene Ermächtigungsgrundlagen für die Kostenerhebung nach der unmittelbaren Ausführung vorsehen. ${ }^{2383}$

1373 Examenswissen (Parallelität zu den polizeirechtlichen Kostenerhebungsnormen): Zu beachten ist in diesem Zusammenhang, dass vor allem auch die landesrechtlichen Sicherheits- und Ordnungsgesetze die Verwaltung zur Erhebung von Kosten für verschiedene Maßnahmen (bei-

2380 Gersdorf, in: Posser/Wolff VwGO, 49. Ed., Stand:1.7.2018, § 80 Rn. 54.1; Schoch, in: Schoch/ Schneider/Bier, VwGO, 36. EL Februar 2019, § 80 Rn. 144 m.w. N.

2381 Freilich sind auch hier spezialgesetzliche Ermächtigungsgrundlagen wie z.B. §§ 66, 67 AufenthG zu beachten.

2382 Näheres bei Muckel, JA 2012, 355 (360).

2383 Baden-Württemberg: § 8 II PolG; Bayern: Art. 9 II PAG; Berlin: § 15 II ASOG; Hamburg: § 7 III SOG; Hessen: § 8 II HSOG; Rheinland-Pfalz: § 6 II POG; Sachsen: § 6 II PolG; Sachsen-Anhalt: § 9 II SOG; Thüringen: §9 PAG II. 
spielsweise Kosten der unmittelbaren Ausführung; Sicherstellungs- und Verwahrungskosten) befugen. ${ }^{2384}$ Diese Normen gehören freilich nicht zum Verwaltungsvollstreckungsrecht, jedoch ist es aufgrund ihres parallel gelagerten Prüfungsprogramms sinnvoll, sie sich im Zusammenhang mit den vollstreckungsrechtlichen Kostengesetzen zu erschließen.

\section{bb) Formelle Rechtmäßigkeit}

In formeller Hinsicht gelten die üblichen Anforderungen. Überwiegend wird die 1374 Kostenerhebung als Annexkompetenz des Vollzuges gesehen, sodass danach die Vollzugsbehörde auch die für den Kostenbescheid zuständige Behörde ist, vgl. § 7 VwVG. ${ }^{2385}$ Zudem ist der Adressat des Verwaltungsakts nach § 28 I VwVfG anzuhören. Da die Kostenerhebung keine Maßnahme in der Verwaltungsvollstreckung ist, ist die Anhörung auch nicht nach § 28 II Nr. 5 VwVfG entbehrlich.

\section{cc) Materielle Rechtmäßigkeit}

In materieller Hinsicht muss der Kostenerhebung eine rechtmäßige Vollstre1375 ckungsmaßnahme zugrunde liegen (Rn. 1376) und an den richtigen Kostenschuldner (Rn. 1379) in richtiger Höhe (Rn. 1380 f.) gerichtet sein. Darüber hinaus gilt auch hier der Verhältnismäßigkeitsgrundsatz (Rn. 1382ff.).

\section{(1) Rechtmäßige Vollstreckungsmaßnahme}

Kosten können nur für rechtmäßige Vollstreckungsmaßnahmen erhoben wer1376 den (vgl. Amtshandlungen nach diesem Gesetz in § $19 \mathrm{I} \mathrm{VwVG).} \mathrm{Für} \mathrm{rechtswidriges}$ Verhalten muss die Behörde die Kosten selbst tragen. ${ }^{2386}$ Was als „rechtsstaatliche Selbstverständlichkeit““2387 aufgefasst werden kann, bedarf inhaltlich in der Klausur einer eingehenden Erläuterung und ist regelmäßig Einfallstor in die Prüfung der Vollstreckungsmaßnahme. Hier kommt es also darauf an, die Vollstreckungsmaßnahme anhand des § 6 I oder II VwVG inzident zu prüfen. Für die inhaltlichen Ausführungen wird auf die Rn. $1317 \mathrm{ff}$. und Rn. $1345 \mathrm{ff}$. verwiesen.

Examenswissen (Keine Kostenerhebung nach rechtswidriger Vollstreckung): Kommt ein Kostenanspruch mangels rechtmäßiger Vollstreckungsmaßnahme aus § 19 I VwVG nicht in Betracht, so scheiden auch Ansprüche aus öffentlich-rechtlicher Geschäftsführung ohne Auftrag (Näheres dazu in $\S 11$ Rn. 50 ff.) sowie der öffentlich-rechtliche Erstattungsanspruch (Näheres dazu in

2384 Beispielsweise $\S \$ 15$ II, 41 III ASOG Berlin.

2385 Muckel, JA 2012, 355 (360); Sadler, VwVG VwZG, 9. Aufl. 2014, § 7 Rn. 1.

2386 Poscher/Rusteberg, JuS 2012, 26 (31); Sadler, VwVG VwZG, 9. Aufl. 2014, § 19 Rn. 8.

2387 Muckel, JA 2012, 355 (360). 
$\S 5$ Rn. 189ff.) aus. Die vollstreckungsrechtliche Kostenerhebungsnorm ist insofern abschließend. ${ }^{2388}$

1378 Examenswissen (Ist die Rechtmäßigkeit der Grundverfügung Rechtmäßigkeitsvoraussetzung für den Kostenbescheid?): Die Frage nach dem Rechtswidrigkeitszusammenhang, die bereits auf Ebene der Überprüfung der Rechtmäßigkeit der Vollstreckungsmaßnahme behandelt wurde (s. Rn. 1328), findet sich auch auf Kostenebene wieder. ${ }^{2389}$

Es sei daran erinnert, dass die Rechtmäßigkeit der Grundverfügung für die Rechtmäßigkeit von Vollstreckungsmaßnahmen im gestreckten Verfahren keine Rolle spielt (zum insofern fehlenden Rechtswidrigkeitszusammenhang s. oben Rn. 1327). Auf Kostenebene besteht ebenfalls jedenfalls dann kein Rechtswidrigkeitszusammenhang, wenn die Kostenerhebung auf dem Vollzug eines bestandskräftigen Verwaltungsakts basiert. Für den Fall des Vollzugs eines sofort vollziehbaren Verwaltungsakts wird vereinzelt vertreten, dass in diesen Fällen der Kostenbescheid von der Rechtmäßigkeit des Verwaltungsakts abhängt. ${ }^{2390}$ Dem tritt jedoch die herrschende Meinung mit Bezug auf die Titelfunktion des Verwaltungsakts entgegen. ${ }^{2391}$ In diesen Fällen sei gesondert gegen die Grundverfügung im Wege der Anfechtungsklage vorzugehen. Dies sei auch immer noch möglich, denn weder der Vollzug noch der Kostenbescheid führen zur Erledigung des Grundverwaltungsakts. ${ }^{2392}$ Ist diese Anfechtungsklage begründet, so wird das Gericht nach § 113 I 2 VwGO (bei einem entsprechend vom Kläger zu stellenden Antrag) auch den Kostenbescheid aufheben. ${ }^{2393}$ Geht der Kläger aber isoliert gegen den Kostenbescheid vor, so kann er Einwendungen gegen die Grundverfügung nicht geltend machen.

Anderes gilt freilich für den sofortigen Vollzug. Hier ist die Rechtmäßigkeit der hypothetischen Grundverfügung ja aber auch bereits Rechtmäßigkeitsvoraussetzung der Vollstreckungsmaßnahme, welche wiederum Rechtmäßigkeitsvoraussetzung des Kostenbescheids ist.

\section{(2) Richtiger Kostenschuldner}

1379 Richtiger Kostenschuldner ist der Vollstreckungsschuldner. Bei mehreren in Betracht kommenden Schuldnern hat die Behörde nach pflichtgemäßem Ermessen auszuwählen.

2388 OVG Münster, Beschl. v. 9.4.2008 - 11 A 1386/05 = NVwZ-RR 2008, 437; Kingreen/Poscher, Polizei- und Ordnungsrecht, 10. Aufl. 2018, § 25 Rn. 10.

2389 Details bei Poscher/Rusteberg, JuS 2012, 26 (31) sowie Voßkuhle/Wischmeyer, JuS 2016, 689 (700).

2390 Enders, NVwZ 2009, 958 (959).

2391 Lemke, Verwaltungsvollstreckungsrecht des Bundes und der Länder, 1997, S. 446; Poscher/ Rusteberg, JuS 2012, 26 (31); BVerwG, Urt. v. 25.9.2008 - 7 C 5/08 = NVwZ 2009, 122.

2392 BVerwG, Urt. v. 25.9.2008 - 7 C 5/08 = NVwZ 2009, 122.

2393 Poscher/Rusteberg, JuS 2012, 26 (32); Voßkuhle/Wischmeyer, JuS 2016, 689 (700).

\section{Mariamo Katharina Ilal}




\section{(3) Richtige Höhe}

Die erhobenen Kosten dürfen den gesetzlich vorgegeben Rahmen nicht über- 1380 steigen. Bei der Kostenerhebung nach erfolgter Ersatzvornahme ist es unschädlich, wenn die erhobenen Kosten die in der Androhung aufgeführten Kosten übersteigen, s. § 13 IV VwVG (sog. Recht zur Nachforderung).

Examenswissen: In diesen Fällen ist der Pflichtige jedoch über die Kostenüberschreitung, sofern sie wesentlich ist, zu unterrichten. Eine unterlassene Unterrichtung führt zwar nicht zur Rechtswidrigkeit der Kostenerhebung, kann jedoch ggf. Amtshaftungsansprüche auslösen. ${ }^{2394}$

\section{(4) Verhältnismäßigkeit}

Die Kostenforderung muss verhältnismäßig sein.

Von besonderer Klausurrelevanz ist in diesem Punkt die Kostenerhebung gegenüber einem Anscheins- oder Verdachtsstörer. Wie bereits unter Rn. 1360 besprochen, können Vollstreckungsmaßnahmen auch dann rechtmäßig sein, wenn zwar objektiv keine Gefahrenlage vorliegt, aber ein Fall der Anscheinsgefahr oder des Gefahrverdachts gegeben ist. Für die Rechtmäßigkeit der Vollstreckungsmaßname spielt es keine Rolle, ob der Anscheins- oder Verdachtsstörer den Rechtsschein einer Gefahr zurechenbar verursacht hat. Entscheidend ist im Sinne einer effektiven Gefahrenabwehr allein die ex-ante-Betrachtung. Anders ist dies aber auf der nachgelagerten Kostenebene. Es geht hier nicht mehr um die Abwendung einer (Anscheins-)Gefahr, sondern um die Verteilung der Kostenlast für das Tätigwerden der Vollzugsbehörde. Das Argument der effektiven Gefahrenabwehr, das eine ex-ante-Betrachtung auf Vollzugsebene stützt, überzeugt in dieser Situation, in der die Gefahr bereits abgewehrt ist, nicht. Auf Kostenebene gilt daher eine ex-post-Betrachtung und zwar dergestalt, dass sie in Fällen der Anscheinsgefahr oder des Gefahrverdachts die Kostenlast nach dem Zurechnungsprinzip verteilt. ${ }^{2395}$

Hat also der Kostenschuldner, den Anschein der Gefahr bzw. den Gefahrverdacht in zurechenbarer Weise verursacht, so muss er auch für die Kosten aufkommen.

2394 BVerwG, Urt. v. 13.4.1984 - 4 C 31/81 = NJW 1984, 2591; Troidl, in: Engelhardt/App/ Schlatmann, VwVG VwZG, 11. Aufl. 2017, § 13 Rn. 6.

2395 OVG Hamburg, Urt. v. 24.9.1985, Az.: Bf VI 3/85 = NJW 1986, 2005; VGH Mannheim, Urt. v. 17.3. 2011 - 1 S 2513/10; Ob es darüber hinaus auch auf ein Vertretenmüssen ankommt, ist streitig: bejahend Stammberger, in: Engelhardt/App/Schlatmann VwVG VwZG, 11. Aufl. 2017, § 19 Rn. 5, verneinend VG Berlin, Urt. v. 28.11.1990 -1 A 154/89. 
Beispiel nach VG Berlin, Urt. v. 28.11.1990 - 1 A 154/89: Nachdem der Mieter auf mehrmaliges Klingeln der Polizei nicht reagierte, sich aber aufgrund zutreffender Angaben eines Nachbarn noch kurze Zeit vorher in der Wohnung die Lichtverhältnisse geändert hatten, vermutet die Polizei einen Unglücksfall und tritt die Wohnungstür ein. Im Nachhinein stellt sich heraus, dass der sich tatsächlich im Urlaub befindliche Mieter eine Zeitschaltuhr installiert hatte. Dies rechnete ihm das Gericht als zurechenbare Setzung des Gefahrverdachts an.

Fehlt ein solcher Zurechnungszusammenhang, so ist die Kostenforderung unverhältnismäßig.

Beispiel nach OVG Berlin, Beschl. v. 28.11.2001 - 1 N 45/00: Nachdem ein Nachbar der Polizei mitgeteilt hatte, dass der Mieter einer anliegenden Wohnung konkrete Suizidgedanken geäußert hatte und dieser auf ein Klingeln der Polizei nicht reagierte, tritt diese die Wohnungstür ein. Nachträglich kann nicht geklärt werden, ob der Mieter, der sich zum Zeitpunkt des Eintretens nicht in der Wohnung befunden hatte, dem Nachbarn gegenüber tatsächlich Suizidgedanken geäußert hatte. Die Unaufklärbarkeit ging zulasten der Polizei, sodass das Gericht zugunsten des Mieters annahm, er habe den Gefahrverdacht nicht zurechenbar verursacht.

Beispiel nach OVG Hamburg, NJW 1986, 2005: Nachdem angeblich ein herumstreunender junger Löwe von einem Anwohner gesichtet worden war, kommt es zu einem Polizeieinsatz. Später stellt sich heraus, dass der Löwe tatsächlich an der Leine seines Besitzers für nur wenige Minuten ausgeführt worden und später zurück in dessen Wohnung verbracht worden war. Das Gericht verneinte auch hier einen Zurechnungszusammenhang.

1383 Examenswissen (Abschleppfälle III): Auch in Abschleppfällen (s. bereits Rn. 1332 und Rn. 1356) kann die Verhältnismäßigkeit der Kostenforderung in Frage stehen. Hier geht es vor allem um Fälle, in denen ein Fahrzeug aus einer nachträglich eingerichteten Halteverbotszone abgeschleppt wird und die Kosten später vom Halter verlangt werden. ${ }^{2396}$ Auf Vollstreckungsebene ist zunächst wichtig zu erkennen, dass ein nachträglich per Verkehrsschild eingerichtetes Halteverbot eine Allgemeinverfügung ist, die - sofern das Verkehrsschild ordnungsgemäß aufgestellt ist - auch abwesenden Haltern gegenüber wirksam wird und sofort vollziehbar ist. Liegt ein Dringlichkeitstatbestand vor, so kann die Behörde auch in den sofortigen Vollzug nach § 6 II VwVG analog wechseln. Das Abschleppen des Fahrzeugs ist insbesondere dann verhältnismäßig, wenn die Behörde vorher versucht hat, den Halter zu kontaktieren, dies aber fruchtlos geblieben ist (z. B. weil der Halter im Urlaub war). Eine solche Abschleppmaßnahme kann also auch dann rechtmäßig sein, wenn zum Zeitpunkt des Parkens noch kein Halteverbot bestand, ein solches aber später eingerichtet wurde. Fraglich ist dann aber, ob die Kosten für die Abschleppmaßnahme vom Halter verlangt werden können. Das BVerwG geht in diesen Fällen davon aus, dass ein Verkehrsteilnehmer zwar „stets mit Situationen rechnen [muss], die eine kurzfristige Änderung der bestehenden Verkehrsregelungen erforderlich machen“2397 und damit nicht uneingeschränkt darauf vertrauen darf, dass ein ursprünglich ordnungsgemäß abgestelltes Fahrzeug dies auch bleibt. Ihn trifft daher eine Obliegenheit, in regelmäßigen Abständen nach dem abgestellten Fahrzeug zu sehen (oder ggf. einen Dritten damit zu beauftragen). Daraus leitet das Gericht eine

2396 So die Ausgangssituation in BVerwG, Urt. 24.5.2018 - 3 C 25/16 = NJW 2018, 2910.

2397 BVerwG, Urt. v. 24.05.2018, Az.: 3 C 25/16, Rn. 22 = NJW 2018, 2910 (2911).

\section{Mariamo Katharina Ilal}


„Mindestvorlaufzeit von drei vollen Tagen“2398 zugunsten des Halters ab, denn „nur ein solcher Vorlauf deckt auch eine typische Wochenendabwesenheit ab“2339. Daraus ergibt sich, dass „eine Kostenpflicht [...] erst für eine Abschleppmaßnahme am vierten Tag nach Aufstellung der Halteverbotsschilder den Anforderungen des Verhältnismäßigkeitsgrundsatzes““2400 entspricht.

\section{(5) Verjährung}

$\mathrm{Zu}$ guter Letzt kann in der Klausur auch einmal die Verjährung der Kostenforde- $\mathbf{1 3 8 4}$ rung relevant werden. Da § 19 I VwVG auch auf § 346 II AO verweist, gilt für die Kostenforderung die einjährige Festsetzungsfrist nach § 346 II 1 AO. Sie beginnt mit Ablauf des Kalenderjahrs, in dem die Kosten entstanden sind, § 346 II 2 AO. Anhaltspunkte für den Ablauf der Frist müssen sich jedoch aus dem Sachverhalt ergeben; ebenso kann wohl erwartet werden, dass - sofern zur Prüfung keine AO zugelassen ist - die relevante Norm im Sachverhalt abgedruckt wird. Regelmäßig wird dieser Punkt jedoch derart problemarm sein, dass er auch übergangen werden kann.

\section{dd) Überblick über die Entschädigungsansprüche}

Ebenfalls Gegenstand der Sekundärebene sind die ggf. bestehenden Ansprüche 1385 des durch den Verwaltungsvollzug Betroffenen gegen die Vollzugsbehörde (dazu bereits kurz in Rn. 1367; ausführlich zu den öffentlich-rechtlichen Ersatzleistungen $\S 5 \mathrm{Rn}$. $153 \mathrm{ff}$. sowie $\S 11){ }^{2401}$ Als Entschädigungsansprüche kommen für rechtswidriges Vollstreckungshandeln der allgemeine Amtshaftungsanspruch (§ 11 Rn. 2ff.) bzw. der allgemeine Aufopferungsanspruch in Betracht (§ 11 Rn. $61 \mathrm{ff}$.). ${ }^{2402}$ Ein Anspruch auf Entschädigung des Sonderopfers besteht auch bei einer rechtmäßigen, aber übermäßigen Inanspruchnahme (es sei an das Beispiel des Nichtstörers gedacht; Näheres auch in $\S 11$ Rn. $61 \mathrm{ff}$.). ${ }^{2403}$ Diese Ansprüche gelten in analoger Anwendung auch für den Anscheins- und Verdachtsstörer, sofern er den Anschein bzw. den Gefahrverdacht nicht zurechenbar gesetzt hat.

2398 BVerwG, Urt. v. 24.5.2018, Az.: 3 C 25/16, Rn. 24 = NJW 2018, 2910 (2911).

2399 BVerwG, Urt. v. 24.5.2018, Az.: 3 C 25/16, Rn. 28 = NJW 2018, 2910 (2912).

2400 BVerwG, Urt. v. 24.5.2018, Az.: 3 C 25/16, Rn. 31 = NJW 2018, 2910 (2912).

2401 Übersichtliche Darstellung bei Poscher/Rusteberg, JuS 2012, 26 (32).

2402 Für Entschädigungen nach rechtswidrigem Polizeihandeln normieren die landesrechtlichen Gesetze diesen Anspruch teilweise explizit, beispielsweise in §59 II ASOG Berlin.

2403 Auch insofern ist der Aufopferungsanspruch häufig spezialgesetzlich kodifiziert, beispielsweise in §59 I ASOG Berlin. 


\section{f) Literaturhinweise}

1386 Kingreen/Poscher, Polizei- und Ordnungsrecht, 10. Aufl. 2018, § 24; Lemke, Verwaltungsvollstreckungsrecht des Bundes und der Länder, 1997; Maurer/Waldhoff, Allgemeines Verwaltungsrecht, 19. Aufl. 2017, § 20; Muckel, Verwaltungsvollstreckung in der Klausur, JA 2012, 272ff. und 355 ff.; Poscher/Rusteberg, Die Klausur im Polizeirecht, JuS 2012, 26; Voßkuhle/Wischmeyer, Grundwissen - Öffentliches Recht: Verwaltungsvollstreckung, JuS 2016, 698

\section{Der Vollzugsfolgenbeseitigungsanspruch (Jana Himstedt)}

1387 Eine besondere Klausurkonstellation stellt es dar, wenn der Kläger nicht nur die Aufhebung eines Verwaltungsakts begehrt, sondern zugleich auch die Beseitigung der durch dessen Vollzug eingetretenen Folgen. Materiell-rechtlich lässt sich das letztere Klageziel auf den Folgenbeseitigungsanspruch stützen (sog. Vollzugsfolgenbeseitigungsanspruch, s. § 5 Rn. 174). Dessen prozessuale Durchsetzung erfordert nicht die Erhebung einer gesonderten Leistungsklage, sondern kann mithilfe eines Annexantrags nach § 113 I 2, 3 VwG0 direkt im Zuge der Anfechtungsklage erfolgen. § 113 I 2, 3 VwGO gewährt insofern eine spezielle objektive Klagehäufung ( $\$ 44 \mathrm{VwGO}$, s. zur objektiven Klagehäufung näher $\S 1$ Rn. $231 \mathrm{ff}.)^{2404}$, die eine vereinfachte Geltendmachung der Folgenbeseitigung gemeinsam mit dem Primärrechtsschutz (Anfechtung) ermöglichen soll.

Examenswissen: Die Statthaftigkeit eines solchen Antrags erfordert, dass die in § 113 I 2, 3 VwGO genannten Kriterien vorliegen, insbesondere also die Möglichkeit der Folgenbeseitigung und die Spruchreife der Sache. Einer Wiederherstellung des status quo ante dürfen mithin keine unüberwindbaren rechtlichen oder tatsächlichen Hindernisse entgegenstehen (Unmöglichkeit); auch darf ihr „Ob“ oder „Wie“ nicht im behördlichen Ermessen stehen und keine weitere Sachverhaltsaufklärung notwendig sein (fehlende Spruchreife)..$^{2405}$

Konsequenz für die Begründetheitsprüfung in solchen Konstellationen ist, dass diese einem zweistufigen Aufbau folgen muss: So wird sie zunächst hinsichtlich des Aufhebungsantrags (gerichtlicher Prüfungsmaßstab: § 113 I 1 VwGO) und sodann hinsichtlich des Annexantrags (Prüfungsmaßstab: § 113 I 2, 3 VwGO) vorgenommen. Für den Erfolg des Annexantrags müssen die materiell-rechtlichen Voraussetzungen des Folgenbeseitigungsanspruchs gegeben sein (s. §5 Rn. 176ff.), sofern keine vorrangige spezialgesetzliche Anspruchsgrundlage

2404 Riese in: Schoch/Schneider/Bier, VwGO, 36. EL Februar 2019 § 113 Rn. 81.

2405 Riese in: Schoch/Schneider/Bier, VwGO, 36. EL Februar 2019, § 113 Rn. 86, 89.

Mariamo Katharina Ilal/Jana Himstedt 